\title{
The Thermal Stability of the Naphthalene Sulfonic Acids Under Geothermal Conditions
}

\author{
By \\ Lucjan Sajkowski
}

\begin{abstract}
A thesis
submitted to the Victoria University of Wellington in partial fulfilment of the requirements for the degree of Doctor of Philosophy
\end{abstract}

School of Geography, Environment and Earth Sciences

Victoria University of Wellington

Wellington, New Zealand 


\section{Abstract}

A primary goal of this thesis was to obtain kinetic data on the breakdown and isomerisation reactions of naphthalene disulfonate (NDS) and naphthalene sulfonate (NSA) compounds under geothermal conditions. A secondary aim of this study was to investigate NDS/NSA isomerisation transformations as well as to study their kinetics and identify products of thermal disproportionation. Because of their apparent thermal stability, naphthalene disulfonate solutions have been frequently injected into active geothermal reservoirs and their subsequent detection ("recovery") in nearby wells/bore holes used as an indicator of well connectivity and local permeability. The results obtained in this thesis will enable a more insightful interpretation of field injection results and fluid flow in active geothermal reservoirs.

The studies presented in this thesis were designed to determine the thermal stability of aqueous NDS and NSA at high temperatures from 100 to $400^{\circ} \mathrm{C}$ in pure water and different salt solutions (i.e. $\mathrm{NaCl}+/-\mathrm{Na}_{2} \mathrm{SO}_{4}$ and $\mathrm{Na}_{2} \mathrm{~S}$ ) at saturated vapour pressure. The stabilities and isomerisation transformations of NDS and NSA were also studied in the presence of solid materials (i.e. quartz, greywacke, pumice) which may occur in the host geological environment of hydrothermal/geothermal reservoirs in the Earth's crust. Dilute aqueous solutions of NDS and NSA were contained in sealed silica glass ampoules (purged of atmospheric oxygen) and placed in stainless steel pressure vessels and heated for varying times to the desired high temperatures. Additional experiments were also conducted in which dilute NDS and NSA solutions were pumped from a de-oxygenated reservoir container through a flow-through autoclave containing different rock and mineral phases at temperatures up $400^{\circ} \mathrm{C}$. The resulting NDS and NSA isomers were then analysed using HPLC and GC-MS methodologies.

The 1,5-naphthalene disulfonate isomer (1,5-NDS) was found to be the least stable at $\mathrm{pH}_{\mathrm{t}}=3-8$ and readily transformed to 1 -naphthalene sulfonate (1-NSA) at $\mathrm{t} \geq 200^{\circ} \mathrm{C}$. The 2NSA was found to be the most stable isomer but disappeared at $t \geq 300^{\circ}$. The experimental data indicated that the stabilities of all the NDS and NSA studied as a function of temperature, $\mathrm{pH}$ and salt $(\mathrm{NaCl})$ concentration were in the sequence: $1,5-\mathrm{NDS}<1,6-\mathrm{NDS}<2,6-\mathrm{NDS} \approx 2,7-$ NDS < 2-NSA. The presence of dissolved salts was shown to slow down the decomposition rates.

Results from flow-through autoclave experiments suggest that between 100 and $250^{\circ} \mathrm{C}$, the stabilities of 2,6-NDS, 2,7-NDS, 1,5-NDS and 1,6-NDS are mainly controlled by solution $\mathrm{pH}$, while at $\mathrm{t} \geq 300^{\circ} \mathrm{C}$, temperature is the main stability controlling factor. Additionally, no adsorption of NDS/NSA on the surface of minerals was observed. 
A new high-performance liquid chromatography (HPLC) method combined with solidphase extraction (SPE) was developed to enable detection of NDS/NSA breakdown products at $\mathrm{t} \geq 300^{\circ} \mathrm{C}$. In hydrothermal solutions at temperatures greater than $300^{\circ} \mathrm{C}$, all the naphthalene sulfonate isomers become unstable with the formation naphthalene (NAP) and the two naphthol isomers, 1-naphthol (1-NAP) and 2-naphthol (2-NAP), as confirmed by both the new HPLC/SPE method and GC-MS (gas chromatography-mass spectroscopy). In addition, 1chloronaphthalene was also detected (using GC-MS) as a high temperature reaction product NDS/NSA disproportionation in $0.05 \mathrm{~m} \mathrm{NaCl}$ solutions.

The results of the experiments carried out during this thesis indicate that the stabilities the naphthalene mono- and disulfonates are a function of temperature, $\mathrm{pH}$ and salt concentration. The naphthalene sulfonates transform to different isomers and the kinetics of these isomerisation reactions have been determined. At temperatures $\geq 300^{\circ} \mathrm{C}$, the NDS and NSA compounds disproportionate to the naphthalene "backbone" molecule as well as to the two stable naphthols and 1-chloronaphthalene (in chloride containing solutions). The application of naphthalene sulfonates to determine well connectivity and local permeabilities in active geothermal reservoirs is thus rather more complicated than previously appreciated. An understanding of the various isomer transformations and their kinetics is required. Furthermore, naphthalene sulfonates injected into high temperature geothermal reservoirs are unstable and breakdown to naphthalene, naphthols and probable halogenated naphthalene compounds, none of which have been considered in the interpretation of NDS/NSA recovery data in active geothermal reservoirs. The thermal stabilities of NAP, 1- and 2-NAP and 1-chloronaphthalene indicate that these compounds may also be employed as connectivity tracers in high temperature $\left(\mathrm{t} \geq 300^{\circ} \mathrm{C}\right)$ systems. 


\section{Acknowledgements}

This $\mathrm{PhD}$ was supported by a Victoria University of Wellington PhD Scholarship. The research expenses and additional funding support was provided by the Mercury NZ Ltd. and the Geothermal Resources NZ programme at GNS Science.

I am deeply grateful to my supervisor Professor Terry Seward, who patiently read all lines of this thesis. He has guided me through this project and introduced to me the subtleties of scientific writing and encouraged me to carry on through these years. I would also like to thank my supervisor Dr Bruce Mountain for giving me the opportunity to be part of an incredible project and to work with many wonderful people. Thanks Bruce, for what I learned from you about experimental geochemistry.

This research would have been impossible without the help and understanding of the excellent staff of the NZGAL (New Zealand Geothermal Analytical Laboratory) and the scientists and technical staff at the Wairakei Research Centre.

Thank you, Andy, for all you have done for me and your generosity. You showed me New Zealand and made me feel at home here. Andy, thank you for your endless support!

My acknowledgement would be incomplete without thanking the biggest source of my strength, my parents and my sister. They supported my choice to come to New Zealand and to do a PhD even though it meant the world was between us. Thank you for the countless Skype sessions and the thousands of photographs and videos capturing the moments I missed while I was overseas. Some extra thanks to my grandparents for unlimited supply of polish teas, chocolates and newspapers. Some special words of gratitude go to my friends who have always been keeping in touch with me. It really meant a lot to me.

Lastly, thanks to my life partner, Kewa, who supported me mentally and was the one who was there for me during the thesis. 


\section{Table of contents}

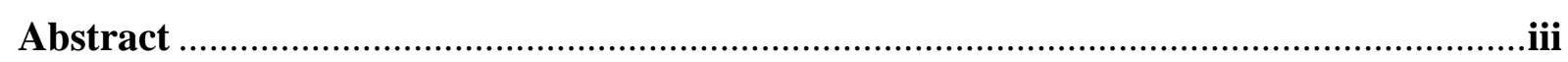

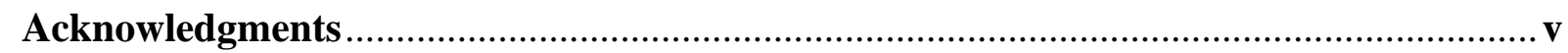

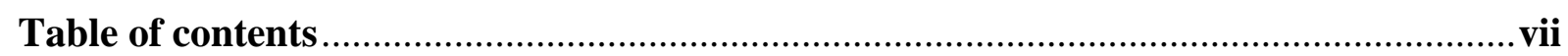

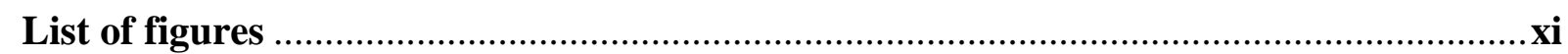

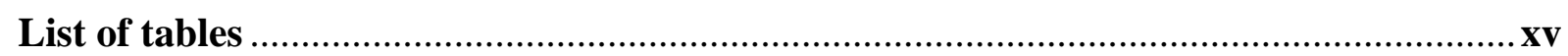

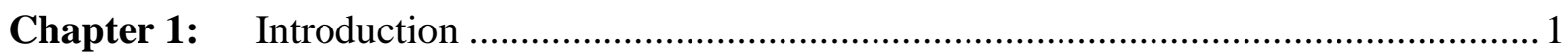

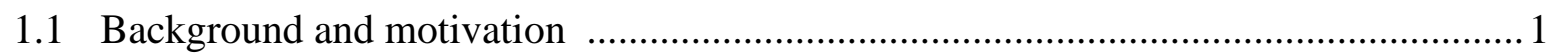

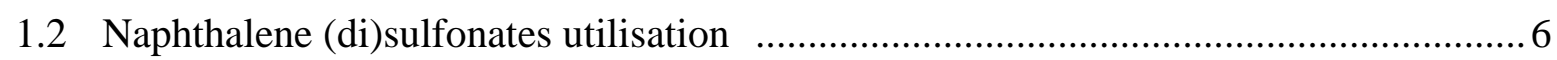

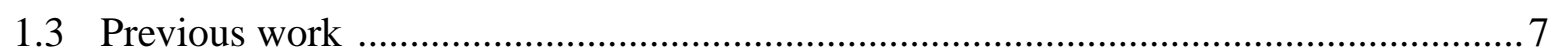

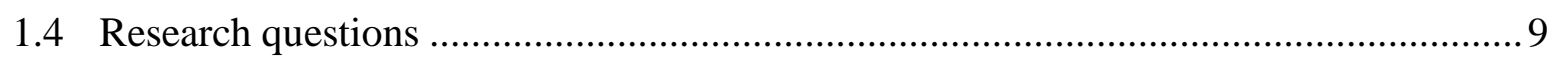

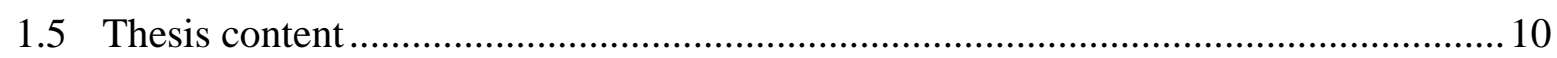

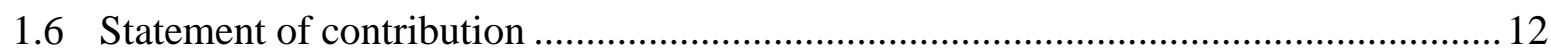

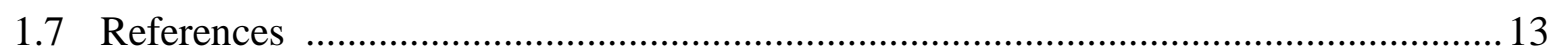

Chapter 2: The stability of 1,5-naphthalene disulfonate (1,5-NDS) and 2-naphthalene sulfonate (2-NSA) as a function of $\mathrm{pH}$ and salinity under geothermal conditions................... 19

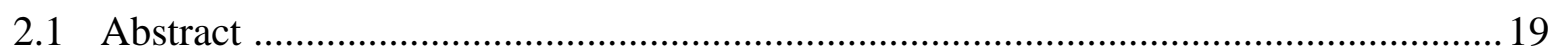

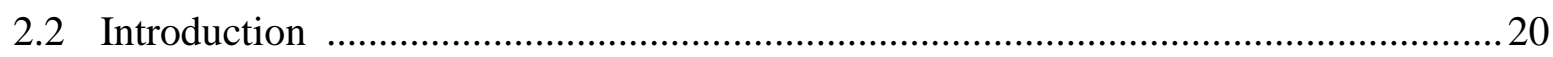

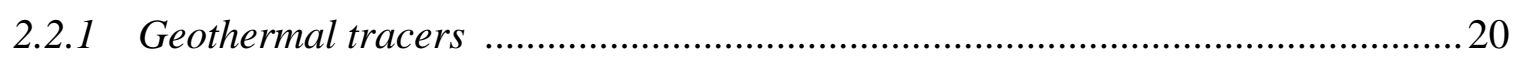

2.2.2 Thermal stability of the naphthalene sulfonates - previous studies ......................22

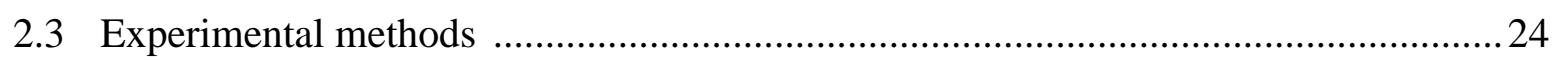

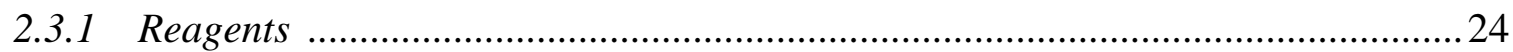

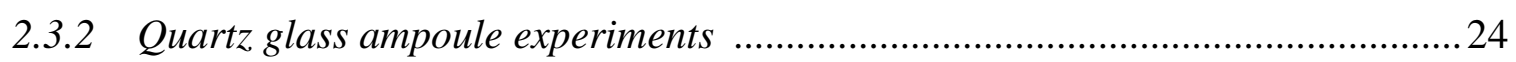

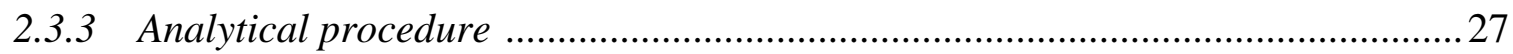

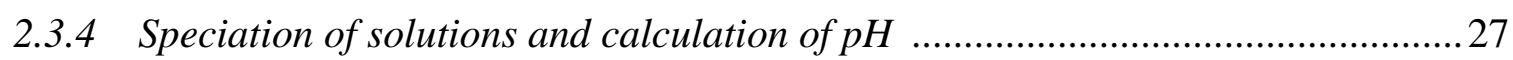

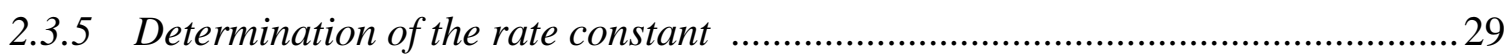

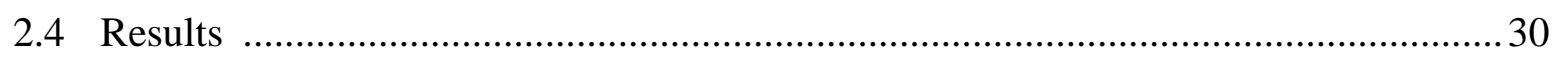

2.4.1 Set 1: 1,5-NDS stability in $\mathrm{NaCl}, \mathrm{Na}_{2} \mathrm{SO}_{4}, \mathrm{Na}_{2} \mathrm{~S}$ solutions and $\mathrm{FeS}_{2}$....................30

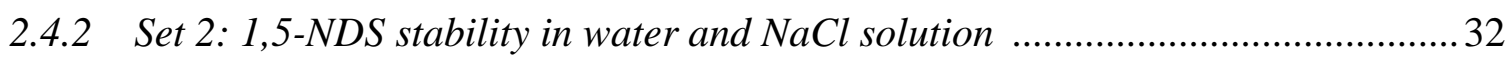

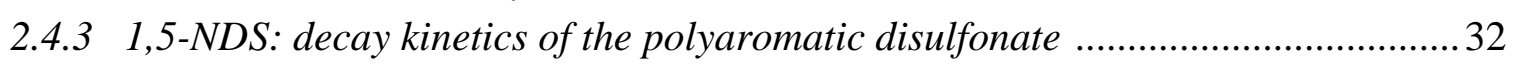

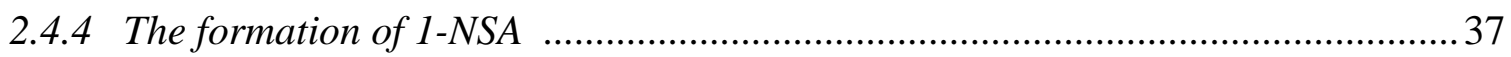

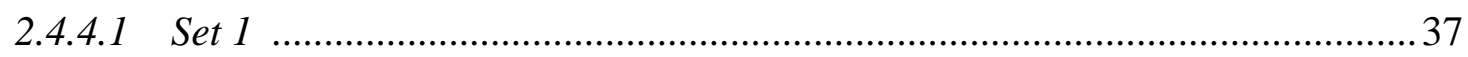

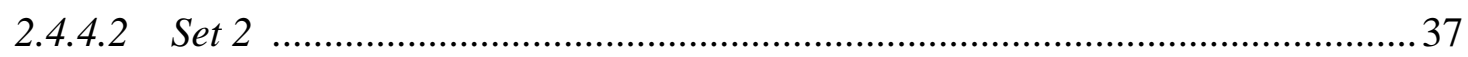

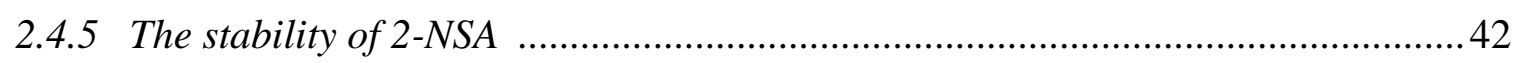

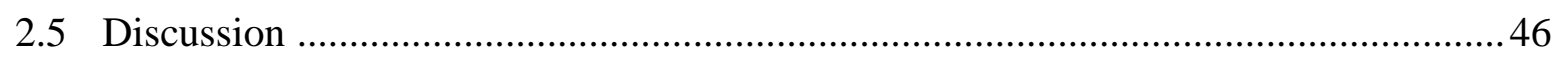

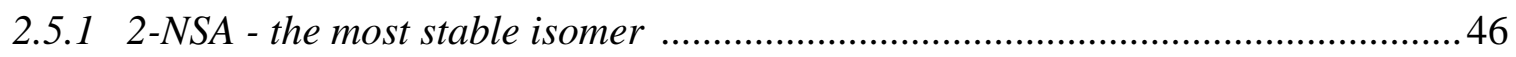

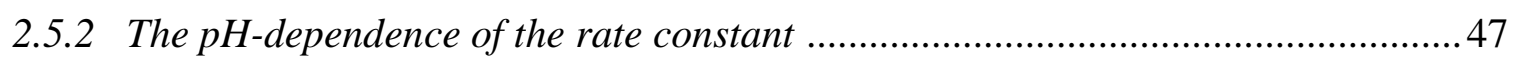

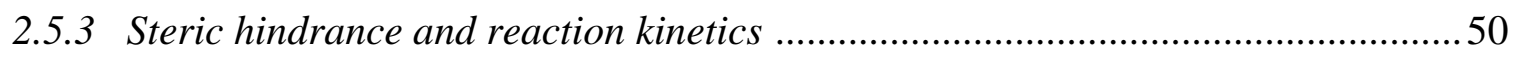

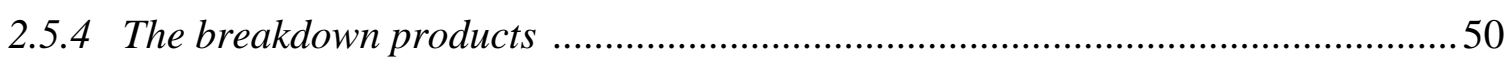


2.5.6 Examples of the fate of 1,5-NDS as a function of $\mathrm{pH}$, ionic strength and

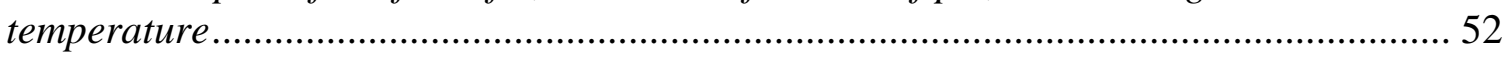

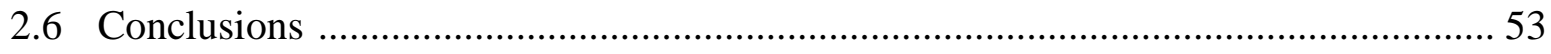

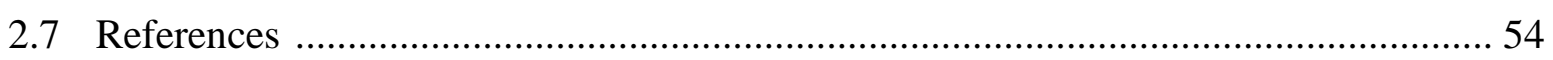

Chapter 3: Naphthalene sulfonate and disulfonate (2-NSA, 2,6-NDS, 2,7-NDS, 1,5-NDS and 1,6-NDS) breakdown kinetics at elevated temperature in the presence of greywacke .... 59

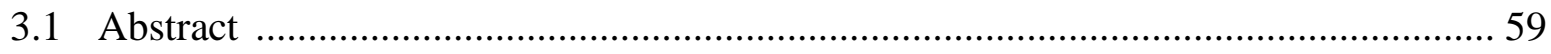

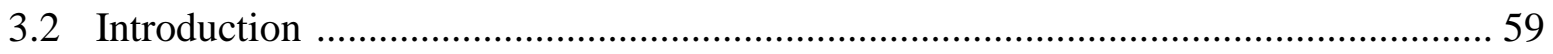

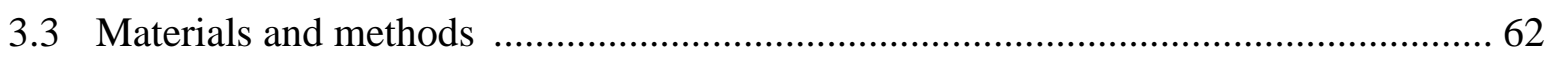

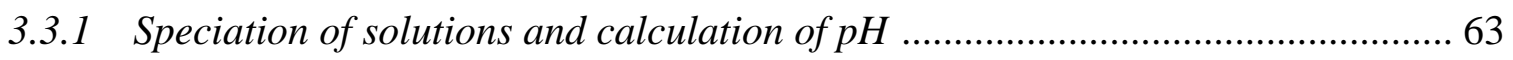

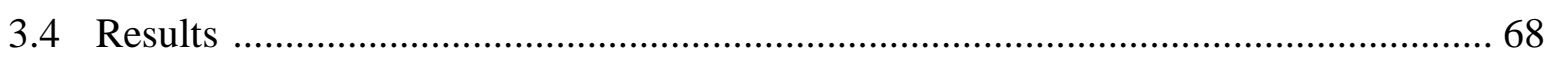

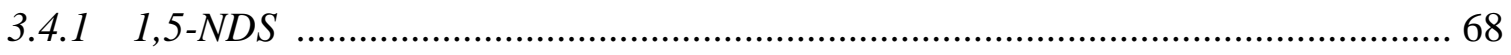

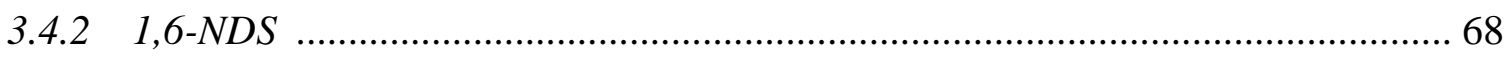

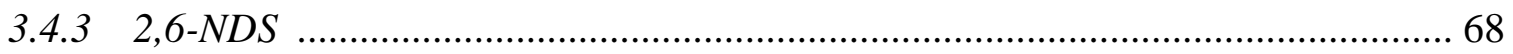

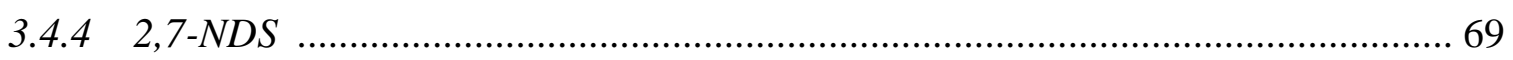

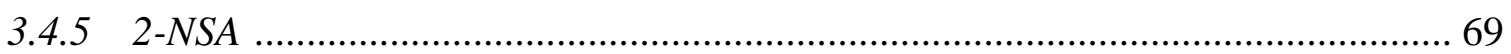

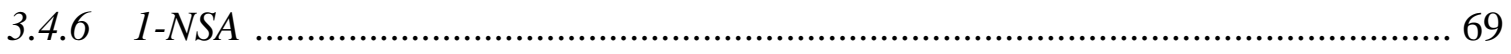

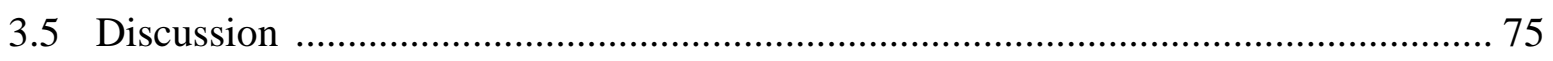

3.5.1 The naphthalene disulfonate decomposition ……................................................ 75

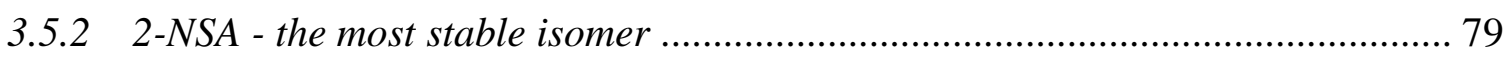

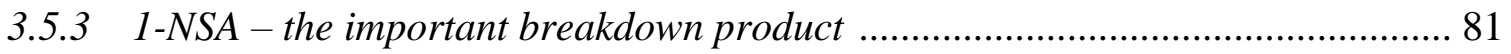

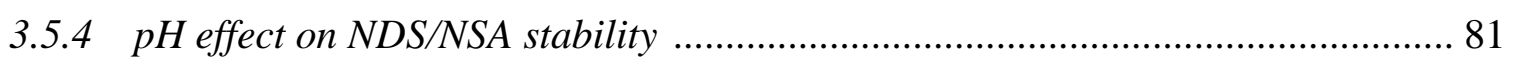

3.5.5 Examples of the fate of NDS as a function of $\mathrm{pH}$, ionic strength and temperature

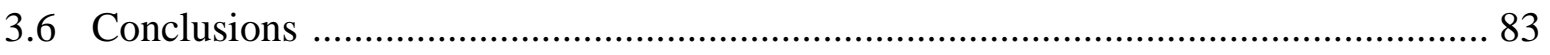

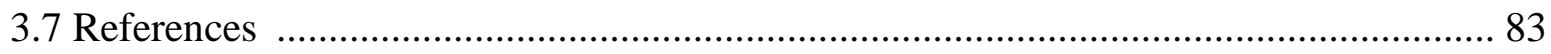

Chapter 4: A flow-through autoclave study of trace naphthalene disulfonate compounds in presence of solid materials at conditions relevant to active geothermal reservoirs ................ 87

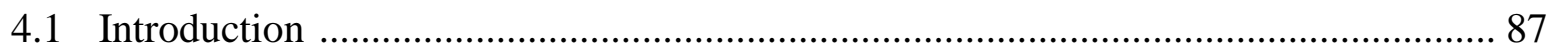

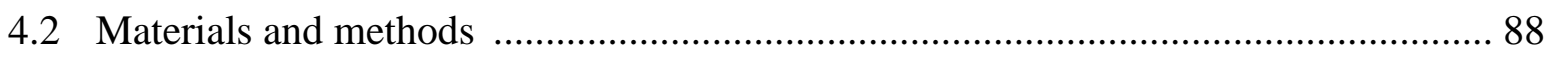

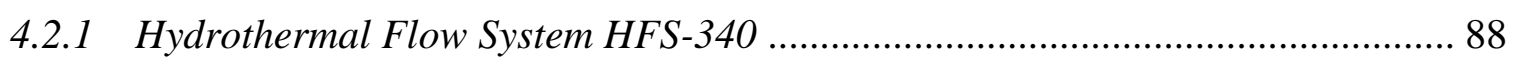

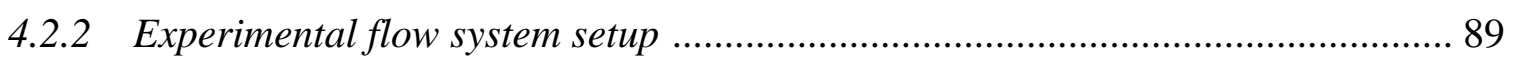

4.2.3 High performance liquid chromatography ....................................................... 91

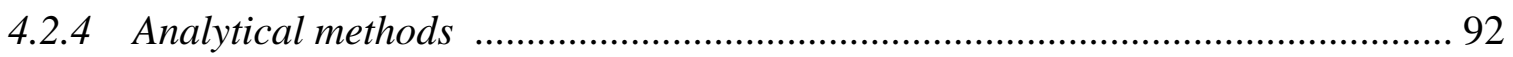

4.2.5 Estimation of $\mathrm{pH}$ at elevated temperatures ................................................... 92

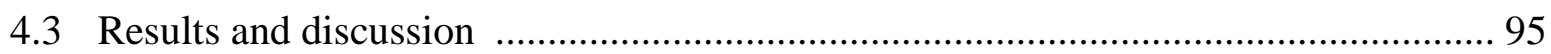

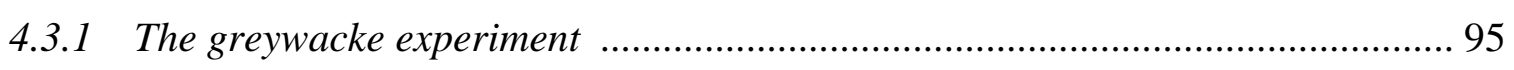

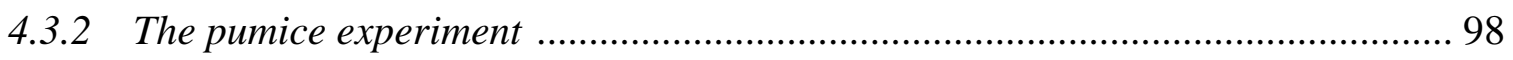

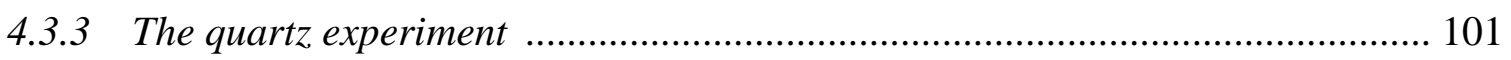

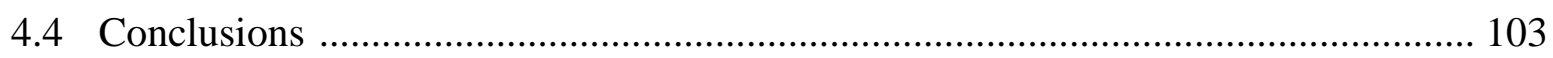


Chapter 5: Quantitative analysis of naphthalene, 1-naphthol and 2-naphthol at nanomol levels in geothermal fluids using solid-phase extraction with high performance liquid chromatography - fluorescence detection

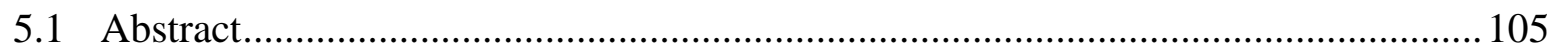

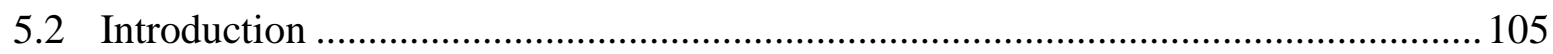

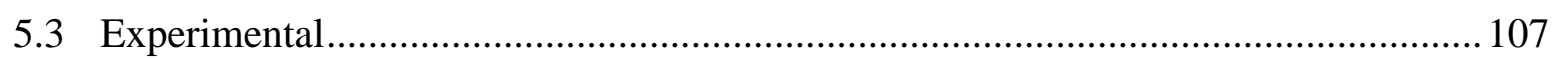

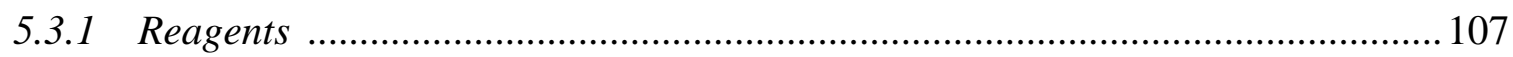

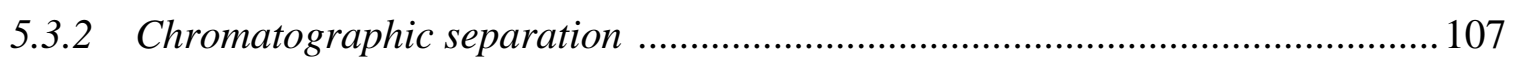

5.3.3 Standard preparation and calibration procedure .............................................. 108

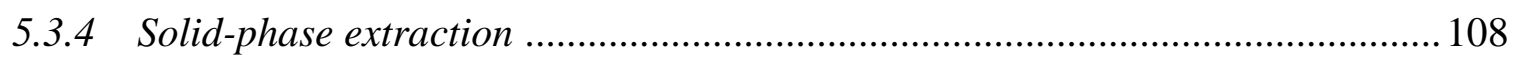

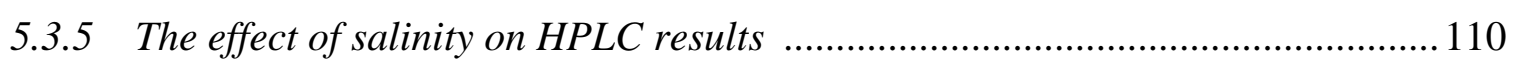

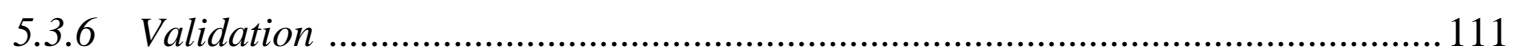

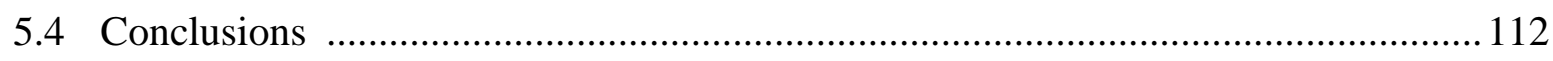

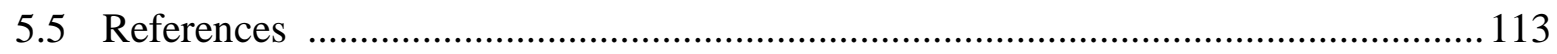

Chapter 6: Reaction pathways of 1,6-NDS and 1,5-NDS: decomposition in aqueous solutions at elevated temperatures to $300^{\circ} \mathrm{C}$ and the formation of naphthalene, naphthols and

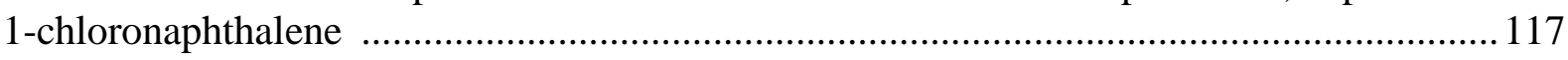

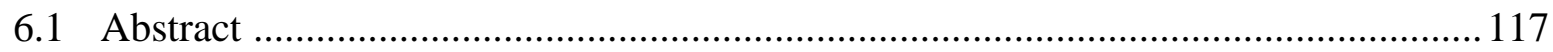

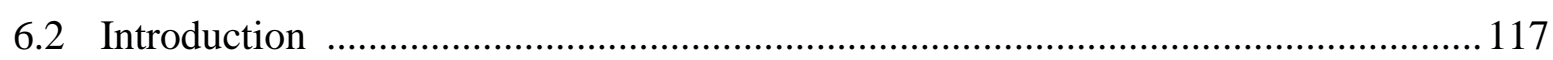

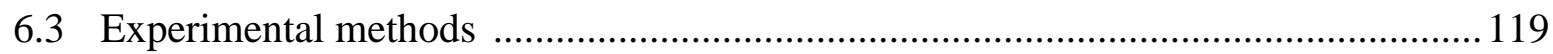

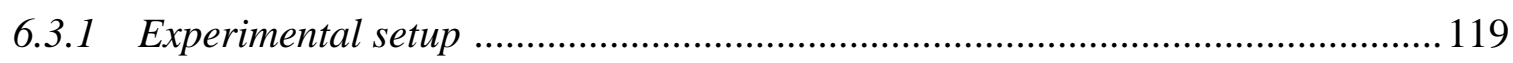

6.3.2 High-performance liquid chromatography ...................................................... 120

6.3.3 Gas chromatography - mass spectrometry ................................................... 120

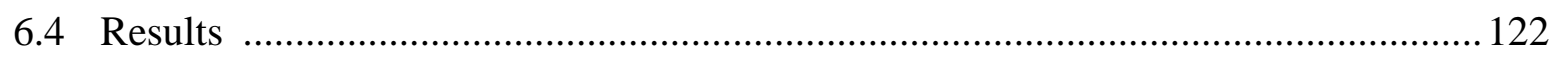

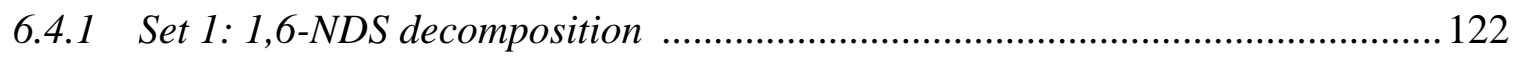

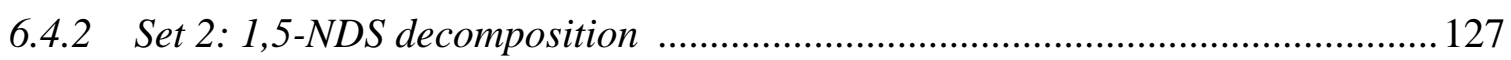

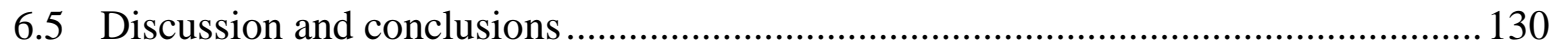

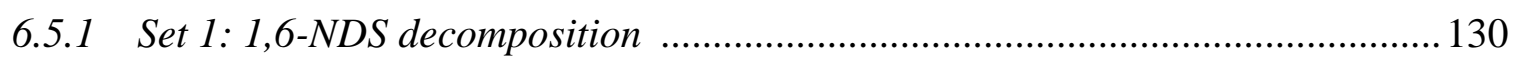

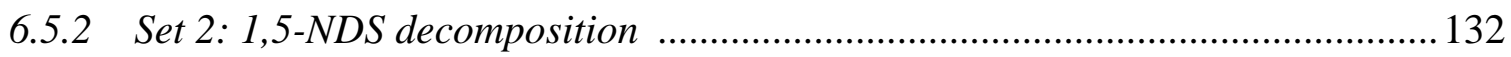

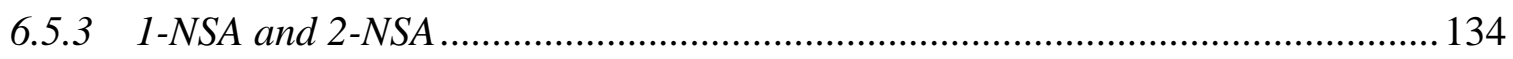

6.5.4 Naphthalene: the most stable breakdown product ............................................ 135

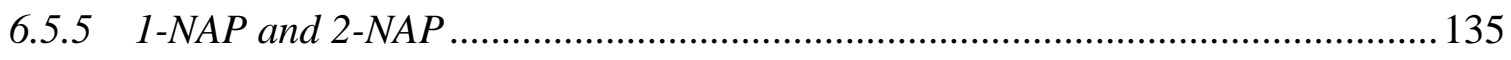

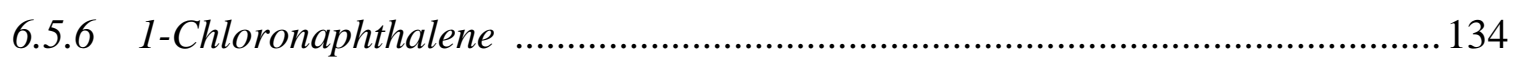

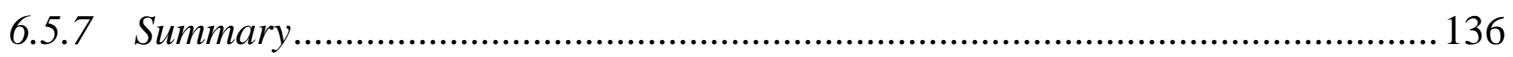

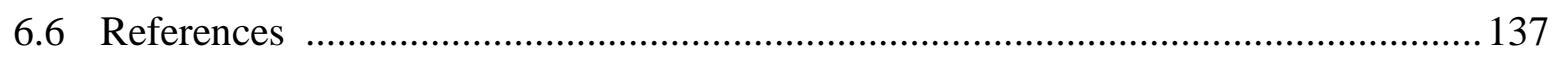

Chapter 7: Thermal stability of naphthalene disulfonates and naphthalene sulfonates under

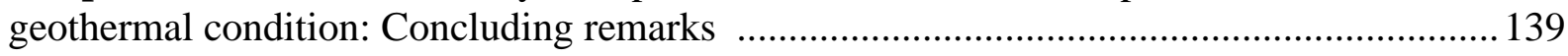

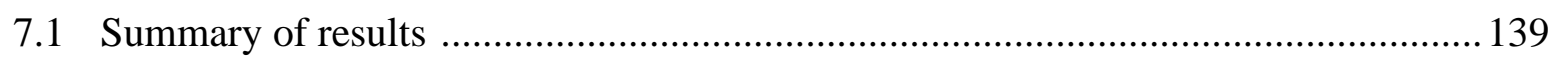

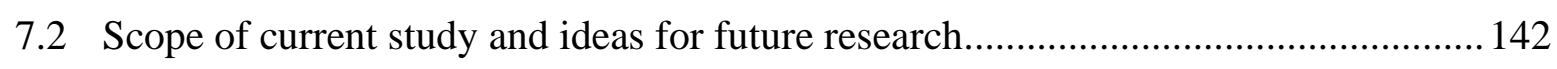

7.2.1 Complementary experiments with varied salt concentration and $\mathrm{pH}$................ 142 
7.2.2 Influence of NDS/NSA interactions on their thermal stability ........................... 142

7.2.3 NDS/NSA breakdown products long-term experiments ..................................... 142

7.2.4 Naphthalene detection in steam phase of active geothermal reservoirs ............ 143

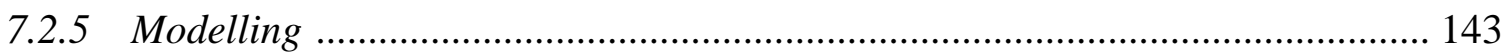

7.2.6 Naphthalene solubility at $\geq 200^{\circ} \mathrm{C}$ in aqueous fluids ................................... 143

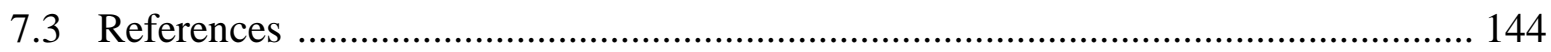

\section{Appendix}

A Ancillary projects ...................................................................................................................... 147

A.1 Long term storage conditions ............................................................................... 147

A.2 The adsorption of naphthalene sulfonates under geothermal conditions ......... 149

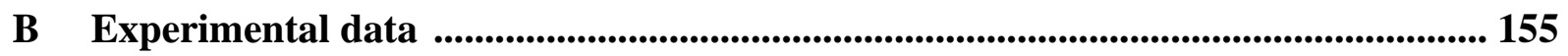

B.1 Supplementary material Chapter 2, Set 1, 1,5-NDS ..................................... 155

B.2 Supplementary material Chapter 2, Set 1, 1-NSA .............................................. 156

B.3 Supplementary material Chapter 2, Set 2, 1,5-NDS .......................................... 157

B.4 Supplementary material Chapter 2, Set 2, 2-NSA .......................................... 165

B.5 Supplementary material Chapter 2, Set 2, 1-NSA ........................................... 174

B.6 Supplementary material Chapter 3, 1,5-NDS (Set 1 and Set 2) .......................... 184

B.7 Supplementary material Chapter 3, 1,6-NDS (Set 1 and Set 2) ......................... 185

B.8 Supplementary material Chapter 3, 2,6-NDS (Set 1 and Set 2) ........................... 186

B.9 Supplementary material Chapter 3, 2,7-NDS (Set 1 and Set 2) .......................... 188

B.10 Supplementary material Chapter 3, 1-NSA (Set 1 and Set 2) ........................... 189

B.11 Supplementary material Chapter 3, 2-NSA (Set 1 and Set 2) ........................... 191

B.12 Supplementary material Chapter 4, greywacke experiment ............................. 193

B.13 Supplementary material Chapter 4, pumice experiment .................................... 196

B.14 Supplementary material Chapter 4, quartz experiment ...................................... 199

B.15 Supplementary material to Chapter 6 ........................................................... 202

B.16 Supplementary material to Chapter 7 ................................................................. 203 


\section{List of figures}

Figure 1.1: Geothermal power production diagram ..................................................... 1

Figure 1.2: Electrophilic aromatic substitution in the naphthalene ....................................5

Figure 1.3: Chemical structures of the polyaromatic sulfonates used in this study ................. 6

Figure 1.4: Concentration of six naphthalene sulfonic acids versus temperature at three

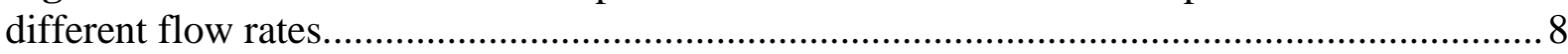

Figure 2.1: Chemical structures of the polyaromatic sulfonates addressed in this study.......21

Figure 2.2: Normalised fluorescence (proportional to concentration) of six naphthalene sulfonic acids versus temperature at three different flow rates

Figure 2.3: Concentrations of 1,5-NDS after heating at 250,270 and $300^{\circ} \mathrm{C} \mathrm{C}$, at equilibrium saturated vapour pressure in $\mathrm{Na}_{2} \mathrm{SO}_{4}$ and $\mathrm{NaCl}$ solutions

Figure 2.4: Concentrations of 1,5-NDS after heating at 200 and $300^{\circ} \mathrm{C}$, at equilibrium saturated vapour pressure and distilled water.

Figure 2.5: Concentrations of $1,5-\mathrm{NDS}$ after heating at 200 and $300^{\circ} \mathrm{C}$, at equilibrium saturated vapour pressure and $\mathrm{NaCl}$

Figure 2.6: Arrhenius plots of lnk (for 1,5-NDS) versus 1/T ( $\mathrm{T}$ in Kelvin) between 200 and $330^{\circ} \mathrm{C}$ at the equilibrium saturated vapour pressure and plots of half-life vs. temperature based upon the Arrhenius decay data

Figure 2.7: Molal concentrations of 1-NSA versus time in days after heating at 250, 270 and $300^{\circ} \mathrm{C}$ and equilibrium saturated vapour pressure $\left(\mathrm{Na}_{2} \mathrm{SO}_{4}, \mathrm{NaCl}\right)$

Figure 2.8: Molal concentrations of 1-NSA (water and $\mathrm{NaCl}$ solution) versus time/day after heating at $200^{\circ} \mathrm{C}$

Figure 2.9: Molal concentrations of 1-NSA (water and $\mathrm{NaCl}$ solution) versus time/day after heating at $300^{\circ} \mathrm{C}$

Figure 2.10: Concentrations of 2-NSA in distilled water after heating at 200 and $300^{\circ} \mathrm{C}$ and at the equilibrium saturated vapour pressure

Figure 2.11: Concentrations of 2-NSA in $\mathrm{NaCl}$ solution after heating at 200 and $300^{\circ} \mathrm{C}$ and at the equilibrium saturated vapour pressure

Figure 2.12: Electrophilic aromatic substitution in the naphthalene

Figure 2.13: Rate constant $\mathrm{k} / \mathrm{day}^{-1}$ versus $\mathrm{pH}_{\mathrm{t}}$ for the decay of $1,5-\mathrm{NDS}$ and 2-NSA at different temperatures and in different salt

Figure 2.14: The steric hindrance in 1,5-NDS

Figure 2.15: Percentage concentration (wt. \%) of 1,5-NDS, 1-NSA and naphthalene/naphthol over exposure time (day).

Figure 3.1: Chemical names and structures for the six polyaromatic sulfonates considered in this study.....

Figure 3.2: Concentrations of 1,5-NDS after heating at 200, 225, 250, 270, 300 and $330^{\circ} \mathrm{C}$ and at equilibrium saturated vapour pressure.

Figure 3.3: Concentrations of 1,6-NDS after heating at 200, 225, 250, 270, 300 and $330^{\circ} \mathrm{C}$ and at equilibrium saturated vapour pressure

Figure 3.4: Concentrations of 2,6-NDS after heating at 200, 225, 250, 270, 300 and $330^{\circ} \mathrm{C}$

and at equilibrium saturated vapour pressure 
Figure 3.5: Concentrations of 2,7-NDS after heating at 200, 225, 250, 270, 300 and $330^{\circ} \mathrm{C}$ and at equilibrium saturated vapour pressure

Figure 3.6: Concentrations of 2-NSA after heating at 200, 225, 250, 270, 300 and $330^{\circ} \mathrm{C}$ and at equilibrium saturated vapour pressure

Figure 3.7: Molal concentrations of 1-NSA versus time/day after heating at 250, 270, 300 and $330^{\circ} \mathrm{C}$ and at equilibrium saturated vapour pressure

Figure 3.8: Arrhenius plots of $\ln (\mathrm{k})$ vs. $1 / \mathrm{T}$ ( $\mathrm{T}$ in Kelvin) between $200^{\circ} \mathrm{C}$ and $330^{\circ} \mathrm{C}$ for $1,5-$

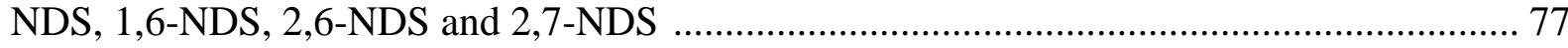

Figure 3.9: Plots of half-life vs. temperature based upon the Arrhenius decay data ............. 78

Figure 3.10: Electrophilic aromatic substitution in the naphthalene ................................... 79

Figure 3.11: Arrhenius plots of $\ln (\mathrm{k})$ vs. $1 / \mathrm{T}$ ( $\mathrm{T}$ in Kelvin) between 200 and $270^{\circ} \mathrm{C}$ and between 250 and $300^{\circ} \mathrm{C}$ for 2-NSA formation

Figure 3.12: Concentrations, wt. $\%$, of NDS/NSA after exposure to $260^{\circ} \mathrm{C}$ and at equilibrium saturated vapour pressure for 448 days

Figure 4.1: Schematic diagram of the high temperature and pressure hydrothermal flow simulator

Figure 4.2: Pressure-temperature path for the greywacke, the pumice and the quartz experiments

Figure 4.3: Six naphthalene sulfonates peaks in a HPLC chromatogram

Figure 4.4a: The concentration in mol kg-1 of 2,6-NDS, 2,7-NDS, 1,5-NDS, 1,6-NDS, 1-

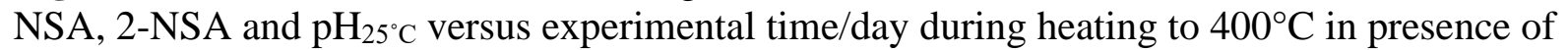
the greywacke .

Figure 4.4b: The concentrations of 2,6-NDS, 2,7-NDS, 1,5-NDS, 1,6-NDS, 1-NSA, 2-NSA and $\mathrm{Na}, \mathrm{SO}_{4}$ ions and $\mathrm{H}_{2} \mathrm{~S}$ in mol kg${ }^{-1}$ versus experimental time/day after heating during heating to $400^{\circ} \mathrm{C}$ in presence of the greywacke

Figure 4.5a: The concentration in mol kg-1 of 2,6-NDS, 2,7-NDS, 1,5-NDS, 1,6-NDS, 1NSA, 2-NSA and $\mathrm{pH}_{25^{\circ}} \mathrm{C}$ versus experimental time/day during heating to $400^{\circ} \mathrm{C}$ in presence of the pumice

Figure 4.5b: The concentrations of 2,6-NDS, 2,7-NDS, 1,5-NDS, 1,6-NDS, 1-NSA, 2-NSA and $\mathrm{SiO}_{2}$ in mol kg${ }^{-1}$ versus experimental time/day after heating during heating to $400^{\circ} \mathrm{C}$ in presence of the greywacke

Figure 4.5c: The concentrations of 2,6-NDS, 2,7-NDS, 1,5-NDS, 1,6-NDS, 1-NSA, 2-NSA and $\mathrm{Na}, \mathrm{Al}, \mathrm{Cl}$ and $\mathrm{SO}_{4}\left(\mathrm{~mol} \mathrm{~kg}^{-1}\right)$ versus experimental time/day after heating during heating to $400^{\circ} \mathrm{C}$ in presence of the greywacke

Figure 4.6a: The concentration in mol kg-1 of 2,6-NDS, 2,7-NDS, 1,5-NDS, 1,6-NDS, 1-

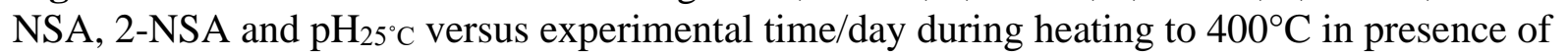
the quartz. 102

Figure 4.6b: The concentrations of 2,6-NDS, 2,7-NDS, 1,5-NDS, 1,6-NDS, 1-NSA, 2-NSA and $\mathrm{SiO}_{2}$ in mol kg${ }^{-1}$ versus experimental time/day after heating during heating to $400^{\circ} \mathrm{C}$ in presence of the greywacke 102

Figure 5.1: Effect of organic solvents ethanol and methanol on the analyte extraction 109

Figure 5.2: Chromatogram of a $10 \mathrm{ug} \mathrm{kg}^{-1}$ mix-standard consisting of 2-naphthol in $\mathrm{NaCl}=1.00 \mathrm{~m}, \mathrm{NaCl}=0.50 \mathrm{~m}, \mathrm{NaCl}=0.05 \mathrm{~m}$ and distilled water. 
Figure 6.1: Total ion chromatograms showing changes in naphthalene vs. internal standard concentration in 1,5-NDS thermal decomposition $\left(250^{\circ} \mathrm{C}\right.$; GC-MS analysis)

Figure 6.2: Total ion chromatogram of 1,5-NDS breakdown products at $300^{\circ} \mathrm{C}$ distribution as well as mass spectra of naphthalene and 1-naphthol (GC-MS analysis).

Figure 6.3: Molal concentrations of the 1,6-NDS isomer and its decay products 1-NSA, 2-NSA, 1-NAP and 2-NAP after heating at $200^{\circ} \mathrm{C}$

Figure 6.4: Molal concentrations of the 1,6-NDS isomer and its decay products NAP, 1-NSA, 2-NSA, 1-NAP and 2-NAP after heating at $250^{\circ} \mathrm{C}$

Figure 6.5: Molal concentrations of the 1,6-NDS isomer and its decay products NAP, 1-NSA, 2-NSA, 1-NAP and 2-NAP after heating at $270^{\circ} \mathrm{C}$

Figure 6.6: Molal concentrations of the 1,6-NDS isomer and its decay products NAP, 1-NSA, 2-NSA, 1-NAP and 2-NAP after heating at $300^{\circ} \mathrm{C}$.

Figure 6.7: Molal concentrations of the 1,5-NDS isomer and its decay products 1-NSA, 1 -NAP and 2-NAP after heating at $200^{\circ} \mathrm{C}$.

Figure 6.8: Molal concentrations of the 1,5-NDS isomer and its decay products NAP, 1-NSA and 1-NAP after heating at $250^{\circ} \mathrm{C}$

Figure 6.9: Molal concentrations of the 1,5-NDS isomer and its decay products NAP, 1-NAP and 2-NAP after heating at $300^{\circ} \mathrm{C}$

Figure 6.10: Structures of possible products of 1,6-NDS decomposition and representation of reaction pathways at $200^{\circ} \mathrm{C}$ in an aqueous solution

Figure 6.11: Structures of possible products of 1,6-NDS decomposition and representation of reaction pathways at $\geq 270^{\circ} \mathrm{C}$ in an aqueous solution

Figure 6.12: Structures of possible products of 1,5-NDS decomposition and representation of reaction pathways at $200^{\circ} \mathrm{C}$ in an aqueous solution

Figure 6.13: Structures of major products of 1,5-NDS decomposition and representation of reaction pathways at $\geq 250^{\circ} \mathrm{C}$ in an aqueous solution

Figure 6.14: The steric hindrance in 1,5-NDS

Figure 6.15: Proposed breakdown reaction mechanism for 1,5-NDS and 1,6-NDS thermal decomposition at $\geq 200^{\circ} \mathrm{C}$ in an aqueous solution

Figure 6.16: Proposed breakdown reaction mechanism for 1,6-NDS thermal decomposition at $\geq 300^{\circ} \mathrm{C}$ in an aqueous solution 135

Figure 6.17: Resonance structures for 1-chloronaphthalene (a) and 2-chloronaphthalene (b) in which the aromatic character is retained by one of the benzene rings 136

Figure A.1: Total concentration of all NDS/NSA in distilled water and brine 148

Figure A.2.1: The flow-through experimental setup 150

Figure A.2.2: The injection valve attached to the flow-through experimental apparatus ..... 150

Figure A.2.3: Naphthalene (di)sulfonates concentrations ............................................... 153

Figure A.2.4: Cumulative NDS/NSA concentration versus time after injection ................. 154

Figure B.16a: Batch adsorption experimental results ..................................................203

Figure B.16b: Batch adsorption experimental results ....................................................2204 


\section{List of tables}

Table 1.1: Example of active geothermal reservoirs fluid temperatures, $\mathrm{pH}$ values and ionic strengths values

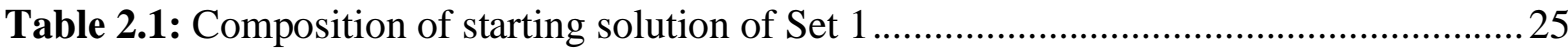

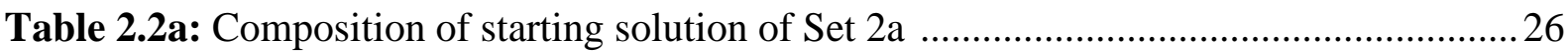

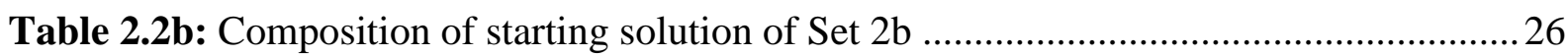

Table 2.3: Rate constants for the decomposition of 1,5-naphthalene disulfonate at temperature, experimental $\mathrm{pH}$ and equilibrium saturated vapour pressure

Table 2.4a: Rate constants for the decomposition of 1,5-NDS at temperature, experimental $\mathrm{pH}$ and temperatures in distilled water at equilibrium saturated vapour pressure

Table 2.4b: Rate constants for the decomposition of 1,5-NDS at temperature, experimental $\mathrm{pH}$ and temperatures in $\mathrm{NaCl}$ solutions at equilibrium saturated vapour pressure .................35

Table 2.5: Arrhenius constants for the decomposition of 1,5-naphthalene disulfonate .......... 36

Table 2.6: Composition of geothermal fluid from Rotokawa geothermal field .................... 37

Table 2.7a: Rate constants for the decomposition of 2-NSA at temperature, experimental $\mathrm{pH}$ and temperatures in distilled water at equilibrium saturated vapour pressure.

Table 2.7b: Rate constants for the decomposition of 2-NSA at temperature, experimental pH and temperatures at equilibrium saturated vapour pressure.

Table 3.1: Composition of starting solutions of Set 1 and 2 .............................................. 64

Table 3.2: Composition of solutions of Set 2 (i.e. with greywacke) ...................................64

Table 3.3: Rate constants for the decomposition of 1,5-NDS at temperature, experimental $\mathrm{pH}$ and at equilibrium saturated vapour pressure

Table 3.4: Rate constants for the decomposition of 1,6-NDS at temperature, experimental $\mathrm{pH}$ and at equilibrium saturated vapour pressure.

Table 3.5: Rate constants for the decomposition of 2,6-NDS at temperature, experimental $\mathrm{pH}$ and at equilibrium saturated vapour pressure

Table 3.6: Rate constants for the decomposition of 2,7-NDS at temperature, experimental $\mathrm{pH}$ and at equilibrium saturated vapour pressure

Table 3.7a: Rate constants for the decomposition of 2-NSA at temperature, experimental $\mathrm{pH}$ and at equilibrium saturated vapour pressure

Table 3.7b: Rate constants for the formation of 2-NSA at temperature, experimental $\mathrm{pH}$ and at equilibrium saturated vapour pressure

Table 3.8: Arrhenius constants for the decomposition of NDS 78

Table 3.9: Arrhenius constants for the formation of 2-NSA 81

Table 3.10: Calculated mass kg-1 of naphthalene sulfonates (1-NSA and 2-NSA) and naphthalene disulfonates (1,5-NDS, 1,6-NDS, 2,6-NDS and 2,7-NDS) within the reservoir over time

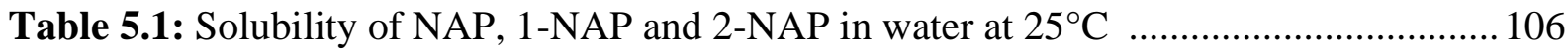

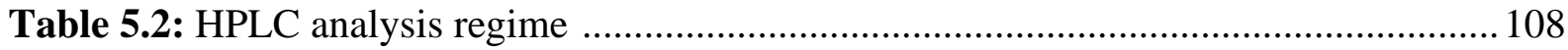

Table 5.3: SPE analysis regime for different cartridges ................................................ 109 
Table 5.4: Recovery and relative standard deviation of naphthalene, 1-naphthol and 2-naphthol in percentages on different solid phase cartridges considered in this study

Table 5.5: Calibration Parameters of the Overall Method, Including SPE and HPLC Detection. Concentrations in nanomole

Table 5.6: Concentration (molal) of NAP, 1-NAP and 2-NAP measured in steam condensate samples collected from different active geothermal fields

Table 6.1: GC-MS analysis for presence of NAP, 1-NAP, 2-NAP and 1-chloronaphthtalene in experimental solutions after reacting 1,6-NDS at 200,250 and $300^{\circ} \mathrm{C}$

Table 6.2: Average concentration (mol kg-1) of the 1,6-NDS and its decay products from HPLC analysis at $200,250,270$ and $300^{\circ} \mathrm{C}$

Table 6.3: GC-MS analysis for presence of NAP, 1-NAP, 2-NAP and 1-chloronaphthtalene in experimental solutions after reacting $1,5-\mathrm{NDS}$ at 200,250 and $300^{\circ} \mathrm{C}$ 128

Table 6.4: Average concentration (mol kg-1) of the 1,5-NDS and its decay products from

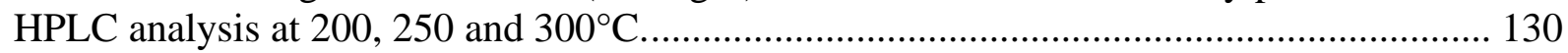

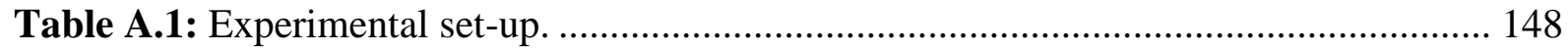

Table A.2.1: Composition of geothermal fluid from Rotokawa geothermal field ................ 150

Table A.2.2: Type and size of solid material used in the batch experiments....................... 151

Table A.2.3: Mineral composition of the greywacke used in both experiments .................. 151

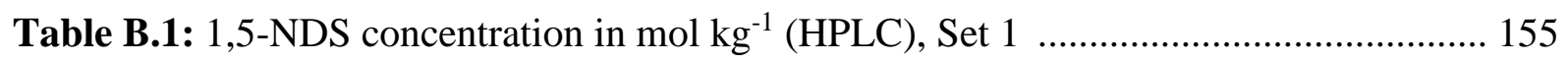

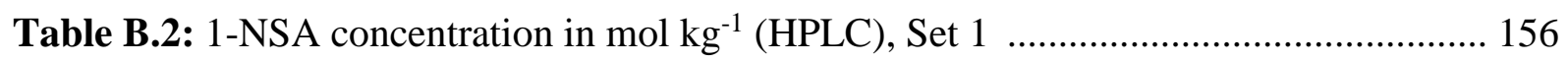

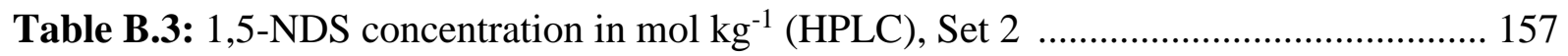

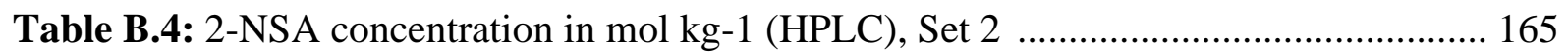

Table B.5: 1-NSA concentration in mol kg-1 (HPLC), Set 2 ......................................... 174

Table B.6: $1,5-\mathrm{NDS}$ concentration in $\mathrm{mol} \mathrm{kg}^{-1}$ (HPLC) .................................................. 184

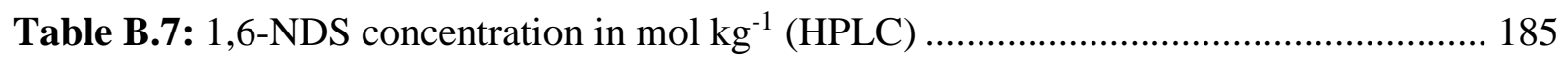

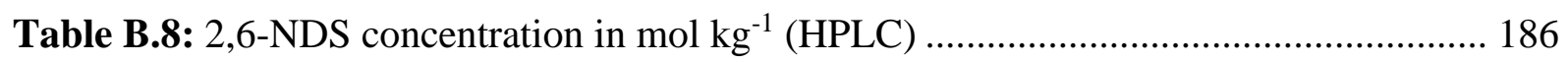

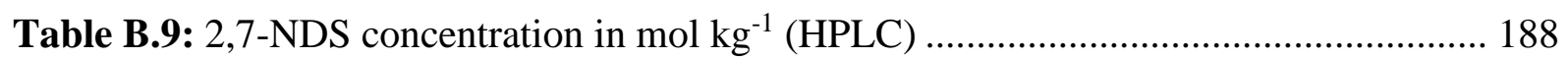

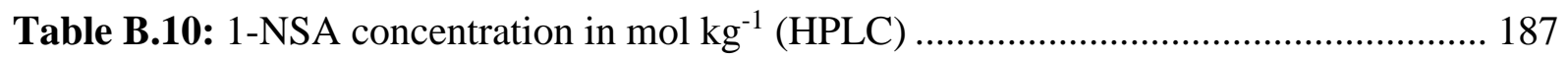

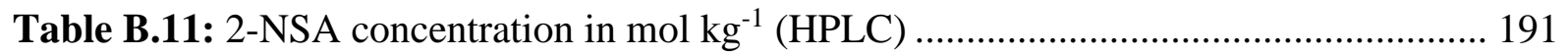

Table B.12: Full ICP and HPLC data for Chapter 4, greywacke experiment ..................... 193

Table B.13: Full ICP and HPLC data for Chapter 4, pumice experiment .......................... 196

Table B.14: Full ICP and HPLC data for Chapter 4, quartz experiment ............................ 199

Table B.15a: Full HPLC data for Chapter 6, 1,6-NDS decomposition. ............................. 202

Table B.15b: Full HPLC data for Chapter 6, 1,5-NDS decomposition. ............................ 202 


\section{Introduction}

\subsection{Background and motivation}

Growing demand for renewable energy is generating a worldwide incentive to increase geothermal developments. Well-managed geothermal resources are a source of clean, reliable and sustainable energy. Nevertheless, improvements in technology and research and development are required to keep geothermal electricity generation relevant among the rapidly growing various low-cost, renewable energy sources.

Geothermal fluids extracted from production wells are used to generate electricity. Subsequently, the energy-depleted fluid is injected back into the reservoir through reinjection wells. The reinjected fluid flows through the fracture network (i.e. permeability) of the reservoir, extracting more thermal energy from the rocks as it flows back to the production well (Figure 1.1; Blodgett \& Slack, 2009). Reinjection acts as a wastewater disposal system, and simultaneously supports pressure maintenance of the reservoir and increases energy extraction potential over the life of the resource (Axelsson, 2013).

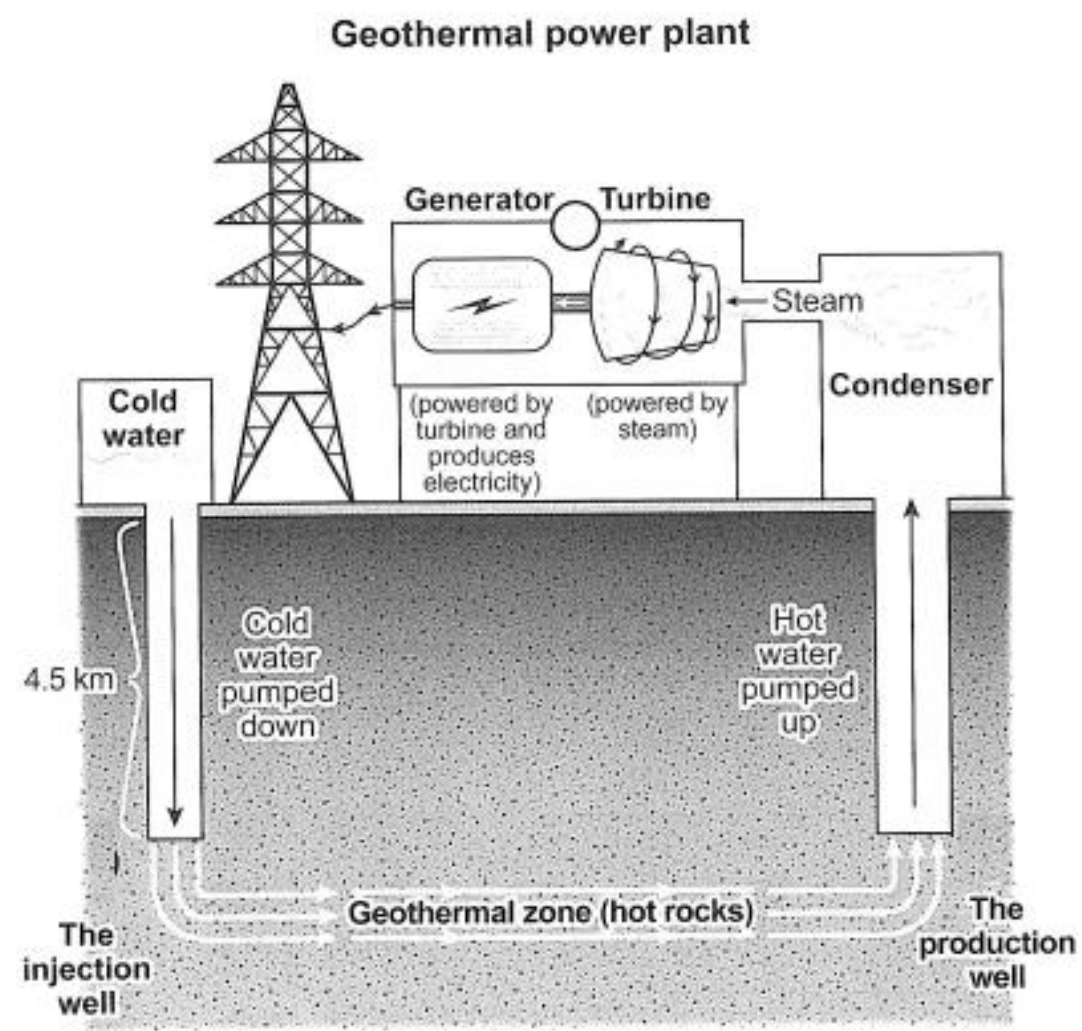

Figure 1.1: Geothermal power production diagram (Cambridge IELTS academic 12) 
One of the risks associated with reinjection is the possibility of the cooling of the reservoir which will eventually decrease energy production (Axelsson et al., 2005). Cooling can be minimised by locating reinjection wells distant from production wells which will prevent fluid short-circuiting (Shook, 1999), while reinjection benefits are the greatest when injection wells are located close to production wells (Axelsson et al., 2005). Only a wellbalanced system where wells are not too far away or too close to each other, will provide long term successful geothermal reservoir usage.

Monitoring reinjection returns, and optimising reinjection strategy, is important to sustain the generation capacity of geothermal fields. To constrain fluid movement and geothermal reservoir models, the operators rely on tracer tests (Shook, 1999; Axelsson, 2013). Tracer testing involves injecting a fixed quantity of a stable trace-compound into reinjection well or wells and then detecting/measuring the injected tracers in nearby production wells. The movement of the tracer within the system is controlled by the volume of the fluid flow path between the injection and the production wells. The integrated data are used to study hydrodynamic reservoir properties including fluid velocities, flow-paths, surface areas and phase volumes. Therefore, tracer tests are an important tool for understanding reinjection phenomena in energy producing geothermal reservoirs (Shook et al., 2004; Axelsson et al., 2005; Jumei \& District, 2010; Mondejar, 2012; Addison et al., 2015a).

Tracer tests can be conducted in different ways and may, for example, involve different amounts and types of tracers, different well configurations and different methods of sampling (Shook et al., 2004). For this reason, we can group tracer tests into three different categories: (1) conservative tracer tests, (2) reactive tracer tests and (3) partitioning tracer tests.

(1) Conservative tracer tests are the most preferable and assume that the introduced tracer is being transported and distributed in the same way as the circulating fluid. The conservative tracer will remain in a single phase. Such a tracer should not undergo any chemical and physical reactions including decay, isomerisation or sorption onto mineral surfaces (Shook et al., 2004; Nottebohm \& Sauter, 2011). An example of a conservative tracer is 2-naphthalene sulfonate injected into an active geothermal reservoir at neutral $\mathrm{pH}$ and $200^{\circ} \mathrm{C}$ (Chapter 2 and 3).

(2) Less common, reactive tracer tests involve tracers not limited to a single phase and tracers which interact with the physiochemical properties of the system (Haggerty et al., 2008; Nottebohm \& Sauter, 2011). Possible thermal decay of the tracer could 
lead to a reservoir temperature interpretation, whereas $\mathrm{pH}$-dependent behaviour of a tracer could be used as a $\mathrm{pH}$ indicator (Chapter 2). As an example, the application of sorbing tracers such as safranin $\mathrm{T}$ (Rose et al. 2012) has been proposed to quantify fracture surface areas (Pruess et al., 2005).

(3) A partitioning tracer test involves the injection of more than one conservative tracer along with two or more partitioning tracers. A partitioning tracer is a compound (e.g. various esters) that will partially partition into another phase(s) (Tomich et al. 1973). By comparing the return of the conservative tracer to the partitioning tracer, it is possible to determine the volume of the other phase (Shook et al., 2004).

Consequently, it is important to employ a suitable compound or element for well connectivity tests to obtain reliable and interpretable data. Preferably the chosen compound is the one which has been the subject of extensive laboratory studies of its stability and reactivity under geothermal conditions. Note, that different active geothermal reservoirs are characterised by, for example, diverse temperatures, $\mathrm{pH}$ values and fluid compositions (Table 1.1); thus, the laboratory studies should consider various environments which are encountered in nature.

Table 1.1: Example of active geothermal reservoirs fluid temperatures, $\mathrm{pH}$ values and ionic strengths values.

\begin{tabular}{|c|c|c|c|c|}
\hline Field & $\begin{array}{c}\text { Max } \\
\text { Temp. }{ }^{\circ} \mathrm{C}\end{array}$ & $\mathrm{pH}_{25^{\circ} \mathrm{C}}$ & $\begin{array}{l}\text { Ionic Strength } \\
\qquad[\mathrm{mM}]\end{array}$ & Source \\
\hline Kizildere, Turkey & 86 & 7.2 & $40-70$ & Kaya 2005 \\
\hline Raft River Valley, Idaho & 162 & $6.9-8.0$ & $20-70$ & Glaspey et al. 2008 \\
\hline Dixie Valley, Nevada & 250 & $7.6-9.4$ & $20-70$ & McLin et al. 2012 \\
\hline Mahanagdong, Philippines & 280 & $3.3-8.1$ & $10-22$ & Angcoy 2010 \\
\hline Rotokawa, New Zealand & 320 & $6.0-7.0$ & $20-30$ & Krupp \& Seward, 1987 \\
\hline Krafla, Iceland & 340 & $6.5-9.6$ & $10-20$ & Fridleifsson et al. 2006 \\
\hline
\end{tabular}

From the many different chemicals compounds available, choosing an appropriate one for a specific geothermal reservoir is challenging due to the absence of data on their 
physicochemical properties at elevated temperatures. The requirements include: thermal stability, low detection limit, nontoxicity, low natural background concentration, nonadsorptivity onto mineral surfaces, good solubility for injection, known effect on transport properties ( $\mathrm{pH}$, ionic strength, density, viscosity, etc.), as well as being available and affordable.

An example of currently used permeability and well connectivity tracers includes ${ }^{125} \mathrm{I}$ and ${ }^{131}$ I, which have half-lives of 60 days and 8.02 days (IAEA, 2012), respectively. The two iodine isotopes are suitable for use as geothermal tracers because they can be detected over periods of months to years. They have low detection limits and only occur naturally in very low, steady state concentrations (Ungemach et al., 2002, Winick at al., 2015). Both are radioactive and require special health and safety requirements and environmental precautions when being used.

More common elements like bromide and lithium can also be used as a tracers. However, it requires extremely large amounts to be injected, due to their high background concentrations (Jiurong, 1999). Organic fluorescent dyes can be also successfully used as tracers. The natural background concentrations of rhodamine and fluorescein are typically undetectable. However, they are not thermally stable at the high temperatures encountered in high enthalpy geothermal reservoirs (Adams \& Davis, 1991; Adams et al., 1992).

A group of organic, UV-fluorescent polyaromatic compounds, the naphthalene sulfonates (NSA) and disulfonates (NDS) isomers are good candidates for geothermal tracers. They have low detection limits $\left(\mathrm{pg} \mathrm{kg}^{-1}\right)$, low natural background concentrations and are not harmful to the environment. These compounds are used worldwide in geothermal reservoirs of various settings (Sanjuan et al., 2006; Addison et al., 2015a, 2015b). Despite their common use, there is limited quantitative information on the thermal stability of these compounds.

This thesis focuses on the NDS and NSA isomers which are part of a group of hydrocarbons referred to as aromatic compounds. They are composed of planar ring-shaped molecules built of six carbon atoms. The polycyclic aromatic compounds are made up of multiple aromatic rings joined together along their edges. Naphthalene is a simple polyraromatic carbon compound, created by bonding between two adjacent benzene rings (Figure 1.2).

Naphthalene is responsive to electrophilic aromatic substitution (i.e. hydrogen that is attached to an aromatic system is replaced by an electrophile). There are two uneven positions, 
$\alpha$ or $\beta$ ( 1 or 2 ) where the hydrogen $(\mathrm{H})$ atom may be substituted by an electrophile such as sulfonate $\left(-\mathrm{SO}_{3}{ }^{-}\right)$as illustrated in Figure 1.2. Substitution into the $\alpha$ position is favoured kinetically over substitution at the $\beta$ position, however, the $\beta$ position is thermodynamically more stable (Chapter 2 and 3). Sulfonation is a reversible reaction and desulfonation reactions are therefore possible. Sulfonation of naphthalene can result in many different isomers, of which the six are commonly used in the geothermal industry and were chosen for investigation in this thesis (Figure 1.3).

The presence of at least one sulfonate group $\left(-\mathrm{SO}_{3}{ }^{-}\right)$makes these compounds highly water soluble and mobile (Hossein et al., 2018). The first deprotonation constants $\left(\mathrm{pK}_{\mathrm{a}}\right)$ are less than 2 for these tracers (Nottebohm et al., 2012) which means that all the naphthalene sulfonates are ionic species at $\mathrm{pH}$ values typical for geothermal fluids.

It should be noted as well that the concentrations of sulfonated aromatic compounds in the geothermal fluids $(<10 \mathrm{ppb})$ are orders of magnitude below the toxic effect levels typical of sulfonated compounds (Greim et al. 1994).<smiles>CCCC1CCCC[C@@H]1[InH]</smiles>

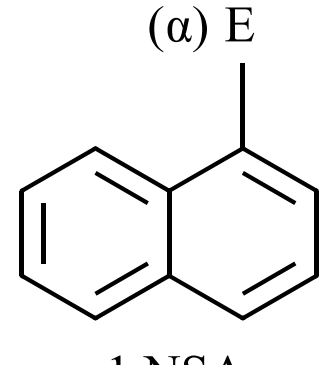

$1-\mathrm{NSA}$

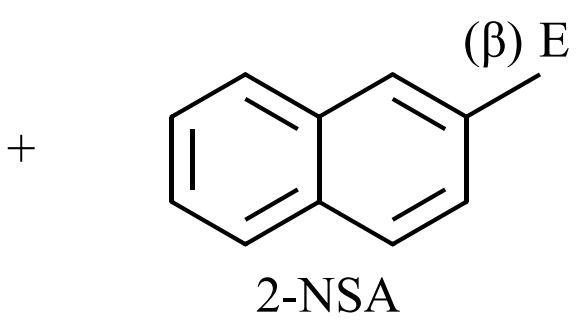

Figure 1.2: Electrophilic aromatic substitution onto naphthalene, to form 1-naphthalene sulfonic acid (1-NSA) and 2-naphthalene sulfonic acid (2-NSA); E-electrophile, $\alpha$ - position $\mathrm{C}_{1}$, $\beta$ - position $\mathrm{C}_{2}$. 
<smiles>O=S(=O)(O)c1cccc2ccccc12</smiles>

1-naphthalene sulfonic acid (1-NSA) $\mathrm{C}_{10} \mathrm{H}_{8} \mathrm{O}_{3} \mathrm{~S}$<smiles>O=S(=O)(O)c1cccc2c(S(=O)(=O)O)cccc12</smiles>

1,5-naphthalene disulfonic acid (1,5-NDS) $\mathrm{C}_{10} \mathrm{H}_{8} \mathrm{O}_{6} \mathrm{~S}_{2}$<smiles>O=S(=O)(O)c1ccc2ccc(S(=O)(=O)O)cc2c1</smiles>

2,7-naphthalene disulfonic acid (2,7-NDS) $\mathrm{C}_{10} \mathrm{H}_{8} \mathrm{O}_{6} \mathrm{~S}_{2}$<smiles>O=S(=O)(O)c1ccc2ccccc2c1</smiles>

2-naphthalene sulfonic acid (2-NSA) $\mathrm{C}_{10} \mathrm{H}_{8} \mathrm{O}_{3} \mathrm{~S}$<smiles>O=S(=O)(O)c1ccc2c(S(=O)(=O)O)cccc2c1</smiles>

1,6-naphthalene disulfonic acid (1,6-NDS) $\mathrm{C}_{10} \mathrm{H}_{8} \mathrm{O}_{6} \mathrm{~S}_{2}$<smiles>O=S(=O)(O)c1ccc2cc(S(=O)(=O)O)ccc2c1</smiles>

2,6-naphthalene disulfonic acid (2,6-NDS) $\mathrm{C}_{10} \mathrm{H}_{8} \mathrm{O}_{6} \mathrm{~S}_{2}$

Figure 1.3: Chemical structures of the naphthalene sulfonates and disulfonates used in this study.

\subsection{Naphthalene (di)sulfonates utilisation}

Permeability and well connectivity tests of geothermal reservoirs are not a new tool, moreover, naphthalene sulfonate isomers have already been used by the geothermal industry worldwide. For example, in Soultz, France, 1,5-NDS, 1,6-NDS, 2,6-NDS and 2,7-NDS were injected into the reservoir. The compounds were present for at least three years (Sanjuan et al., 2006). Another example is the Habanero EGS site, Central Australia, where 2,6-NDS and 2,7NDS were injected and about $70 \%$ of the NDS recovered (Ayling et al., 2015). In another test, 1,6-NDS was used in the Mindanao geothermal field, Philippines, $20.39 \%$ of 1,6-NDS was recovered (Nogara \& Sambrano, 2005).

Tracer recovery does not commonly reach $100 \%$ during the test. However, an extreme case was reported in the Rotokawa, geothermal field, New Zealand. In 2011, four naphthalene 
disulfonate isomers (2,6-NDS, 2,7-NDS, 1,5-NDS and 1,6-NDS) were injected into the active geothermal field, one of the hottest operating geothermal reservoirs $\left(337^{\circ} \mathrm{C}\right)$ in the world and none of the original NDSs were detected (i.e. recovered; Addison et al., 2015a) and instead, 2NSA was detected (Dashkevich et al., 2015). In a comparable tracer test in the Awibengkok geothermal field located in Indonesia (up to $312^{\circ} \mathrm{C}$ ) no return of injected 1,5-NDS was reported (Rose et al., 2000). Another example from 2013 where 1,5-NDS was injected into wells at Húsmúli, Iceland, for a tracer test at the Hellisheidi geothermal area. Reservoir temperatures were reported as $200-220^{\circ} \mathrm{C}$ below $200-600 \mathrm{~m}$ (Franzson et al., 2005) and as high as $300^{\circ} \mathrm{C}$ at $2808 \mathrm{~m}$ deep (Bjornsson, 2004). The 1,5-NDS tracer was detected in some production wells after 24 days. However, it was concluded that knowledge of the possible breakdown of 1,5NDS was needed to interpret tracer test results over the longer term (Kristjansson et al., 2016).

When tracers return is small (i.e. low recovery), it can be interpreted in diverse ways and the key to an accurate interpretation lies in the understanding of the tracer compound behaviour under geothermal conditions. This thesis addresses the gap in this knowledge and in doing so, was motivated to provide important data which will support geothermal tracer test planning and assist tracer test result interpretation worldwide.

\subsection{Previous work}

Even though naphthalene sulfonates are widely used by the geothermal industry (Nogara \& Sambrano, 2005; Mondejar, 2012; Addison et al., 2015a; Ayling et al., 2015), there are few experimental studies which examine their behaviour under geothermal conditions (i.e. at high temperatures up to $400^{\circ} \mathrm{C}$ ).

Rose et al. (2001a) have simulated geothermal conditions in batch autoclave reactors to test the thermal stability of selected naphthalene sulfonic acids including 1,3,6-naphthalene trisulfonate (1,3,6-NTS), 1,5-naphthalene disulfonate (1,5-NDS), 2,7-naphthalene disulfonate (2,7-NDS), and 2-naphthalene sulfonates (2-NSA) as well as the related 1,3,6,8-pyrene tetrasulfonate $(1,3,6,8$-PTS). These were dissolved in $\mathrm{pH}=6.5$ buffered solutions sealed in quartz glass ampoules and heated up to $330^{\circ} \mathrm{C}$ for one week. They found that 2-NSA and 2,7-NDS were "stable" under these conditions. When comparing this experiment to a field test, one week is a short time period and thus, the results for 2,7-NDS and 2-NSA are not useful in terms of being able to evaluate the rate of thermal decay. In addition, only three samples at each temperature were measured. 
Further experiments were conducted by Mountain and Winick (2012) and re-examined by Dashkevich et al. (2015), who investigated the thermal stability of six tracers (1-NSA, 2NSA, 1,6-NDS, 2,7-NDS, 1,5-NDS, 1,6-NDS) with a hydrothermal flow reactor. A pHmodified geothermal brine containing the six NDS and NSA was passed through crushed greywacke in a pressure vessel heated from 270 to $390^{\circ} \mathrm{C}$. The residence time was 6 to 60 hours. The results showed a sequence in stability of the naphthalene sulfonic acids, from least to most stable according to: $1,5-\mathrm{NDS}<1,6-\mathrm{NDS}<1$-NSA $<2,6-\mathrm{NDS} \approx 2,7-\mathrm{NDS}<2-\mathrm{NSA}$. They also noted an increase in concentration of some NSA at the expense of others between 300 and $340^{\circ} \mathrm{C}$. Above $390^{\circ} \mathrm{C}$, all NDS and NSA were thermally degraded (Figure 1.4). However, the very short experiments time (up to $60 \mathrm{~h}$ ) relative to a field test, which can take many months, means that the results give only an indication of the thermal stability in the longer term.

Dashkevich et al. (2014) provided preliminary data on the thermal stability of 1,5-NDS. The experiments involved differing 1,5-NDS concentrations $\left(0.1 \mathrm{mg} \mathrm{kg}{ }^{-1}, 1.5 \mathrm{mg} \mathrm{kg}{ }^{-1}\right.$, $25 \mathrm{mg} \mathrm{kg}^{-1}$ ) dissolved in solutions of variable composition including distilled water, phosphate buffer solution $\left(\mathrm{pH}_{25^{\circ} \mathrm{C}}=6.5\right)$, a geothermal reinjection brine and $\mathrm{NaCl}$ solution $\left(0.4 \mathrm{~mol} \mathrm{~kg}^{-1}\right)$. The experiments were conducted in sealed quartz glass tubes heated from 260 to $350^{\circ} \mathrm{C}$ for 10 and 40 hours. They reported that 1,5-NDS stability depends on the solution composition and $\mathrm{pH}$. They also found evidence of $1,5-\mathrm{NDS}$ degradation to 1 -NSA near $300^{\circ} \mathrm{C}$. To date, no other systematic experimental research exists which addresses the question of the thermal stability of the various naphthalene sulfonate isomers under geothermal conditions.
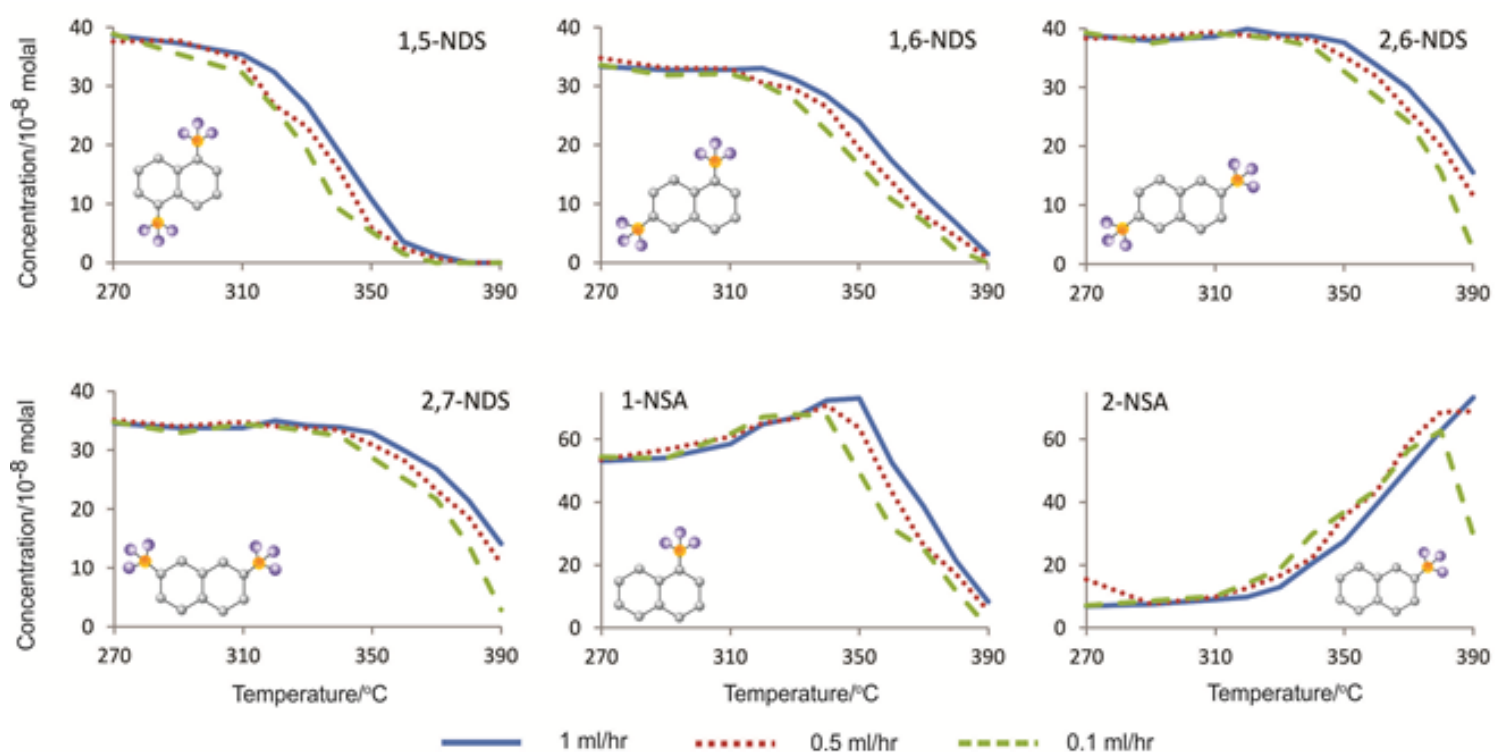

Figure 1.4: Concentration of six naphthalene sulfonic acids versus temperature at three different flow rates after Dashkevich et al. (2015). 


\subsection{Research questions}

The main objective in this thesis is to determine the range of thermal stabilities of the polyaromatic sulfonates, their rates of decay, their breakdown products and adsorption properties in contact with various minerals at geothermal conditions. The results of this research will hopefully lead to significant advances in the application of naphthalene sulfonic acids as geothermal high temperature tracers. This thesis aims to address the following questions:

What is the influence of the fluid composition and the temperature on the stability of naphthalene sulfonates and disulfonates?

The chemical composition of a fluid circulating in an active geothermal field may change (i.e. $\mathrm{pH}$ and changes in solution composition) and this can affect the stability of naphthalene sulfonates and disulfonates. In 2014, Dashkevich et al. observed increased stability of 1,5-naphthalene disulfonate in salt solution $\left(\mathrm{NaCl}=0.006 \mathrm{~mol} / \mathrm{dm}^{3}\right)$ when heated (between 295 and $350^{\circ} \mathrm{C}$ ) in comparison to distilled water. However, the correlation between the salt concentration and 1,5-NDS stability has never been studied in detail until this study. Likewise, the $\mathrm{pH}$ effect on the polyaromatic sulfonates has not been a subject of study (Chapter 2).

The present research encompasses a series of laboratory experiments using batch autoclave reactors and a hydrothermal flow-through autoclave to test different electrolyte salts $\left(\mathrm{NaCl}, \mathrm{Na}_{2} \mathrm{SO}_{4}\right)$ and different $\mathrm{pH}$ value $\left(\mathrm{pH}_{25}{ }^{\circ} \mathrm{C}\right.$ between 3.0 and 11.0) at different temperatures (between 100 and $400^{\circ} \mathrm{C}$ ). A portion of the experiments described in this work was conducted in the presence of solid material (i.e. pyrite, quartz, pumice and greywacke) in order to intentionally complicate the experimental conditions. The results provide important findings critical in the selection of appropriate compounds for future permeability and connectivity tests in various active geothermal reservoirs.

What are the breakdown kinetics of the naphthalene sulfonates and disulfonates?

Rose et al. (2001b) proposed that 1,5-NDS, 2,7-NDS and 2-NSA might be suitable for use in reservoirs having temperatures up to $340^{\circ} \mathrm{C}$. Since they are affordable, ecologically friendly and have low detection limits, they have become extensively used by the geothermal industry around the world (Nogara \& Sambrano, 2005; Sanjuan et al., 2006; Addison et al., 2015b; Ayling et al. 2015;), with varying effectiveness (Addison et al. 2015a). 
The current research encompasses a series of laboratory experiments using batch autoclave reactors with the goal to obtain kinetic data on naphthalene sulfonate and naphthalene disulfonate thermal decay between 200 and $330^{\circ} \mathrm{C}$. Data on the naphthalene disulfonates physicochemical behaviour under given reservoir conditions are critical for correct and insightful interpretation of geothermal tracer test results (Chapter 3).

What are the secondary breakdown products of the naphthalene (di)sulfonates decay?

While information on naphthalene sulfonate formation, isomerisation and transformation are available for industrial processes, there are few data pertaining to geothermal conditions (Foster, 1997; Rokade \& Sayyed, 2009; Li, 2011). The extent of isomerisation and decay as processes in geothermal reservoir permeability tests were briefly considered by Rose et al. (2000, 2001a,b) and Kristjansson et al. (2016). However, actual experiments on isomerisation and naphthalene (di)sulfonates decay under geothermal conditions are very limited (Nottebohm et al., 2010; Mountain \& Winick, 2012; Dashkevich et al., 2014; Dashkevich et al., 2015). Furthermore, the previous experiments were of short duration, a few hours to a week (Rose et al., 2001a; Dashkevich et al., 2014), whereas actual reservoir permeability and well connectivity test returns normally take months. Additionally, the previous studies did not employ an analytical method to measure possible reaction products of the naphthalene (di)sulfonate disproportionation, and experimental conditions did not fully represent an actual geothermal environment, such as for example, the presence of atmospheric oxygen inside the experimental system (Nottebohm et al., 2010).

In this study, experiments have been conducted to identify previously undetected products of naphthalene (di)sulfonate decay and isomerisation. The decay products were analysed with liquid chromatography (HPLC) and gas chromatography mass spectrometry (GC-MS; Chapter 5 and 6).

\subsection{Thesis content}

The body of this thesis comprises four self-contained studies (Chapter 2, 3, 5 and 6), that have been prepared for publication in academic journals and one supplementary study (Chapters 4). The four main chapters contain individual abstracts, introductions, methods, results, discussions and conclusion sections. As a result, there is some repetition of the discussion of some processes between chapters. The publication-style chapters and the 
supplementary study are followed by concluding remarks and directions for future studies (Chapter 7). The thesis is structured in the following way:

\section{Chapter 2:}

The focus of this chapter is the influence of $\mathrm{pH}$, temperature and salt concentration on NSA and NDS isomers stability under geothermal conditions. Two series of experiments were conducted to measure the rate of the thermal breakdown of 1,5-naphthalene disulfonate $(1,5-$ NDS) and 2-naphthalene sulfonate (2-NSA). The first series focused exclusively on 1,5-NDS breakdown rate in $\mathrm{NaCl}(0.050 \mathrm{~m})$ and $\mathrm{Na}_{2} \mathrm{SO}_{4}(0.020 \mathrm{~m})$ at 250,270 and $300^{\circ} \mathrm{C}$. The second series considered $\mathrm{NaCl}$ and distilled water solutions containing both 1,5-NDS and 2-NSA, sealed in glass ampoules and heated in autoclave reactors to 200 and $300^{\circ} \mathrm{C}$ for up to one week. The experimental $\mathrm{pH}$ was varied.

\section{Chapter 3:}

This chapter introduces kinetic studies of the five polyaromatic sulfonates, 2-NSA, 2,6NDS, 2,7-NDS, 1,5-NDS and 1,6-NDS in aqueous solution. The thermal stabilities were studied as a function of temperature (from 200 to $330^{\circ} \mathrm{C}$ ), with and without the presence of greywacke.

\section{Chapter 4:}

This chapter discusses the influence of $\mathrm{pH}$ and temperature on the polyaromatic sulfonates stability, and on thermal disproportionation products of the NDS breakdown. The experiments were conducted in a high temperature and pressure hydrothermal flow-through autoclave in the presence of rock and mineral substrates (i.e. quartz, pumice and greywacke). The experimental studies presented in this chapter comprise the initial reconnaissance experiments on NDS and NSA conducted by the author. The results support conclusions presented in other chapters and provide further details on behaviour of NSA and NDS isomers under geothermal conditions.

\section{Chapter 5:}

In order to facilitate sensitive and rapid analysis of breakdown products of naphthalene (di)sulfonates decay, we have developed a new high-performance liquid chromatography (HPLC) method combined with solid-phase extraction (SPE) for detection of naphthalene (NAP), 1-naphthol (1-NAP) and 2-naphthol (2-NAP) in geothermal fluids. The method was further utilised in Chapter 6. 


\section{Chapter 6:}

This chapter focuses on the breakdown products of 1,6-NDS and 1,5-NDS. Two series of batch experiments were conducted. The first series involved 1,6-NDS and $\mathrm{NaCl}=0.050 \mathrm{~mol}$ $\mathrm{kg}^{-1}$. The second series comprised 1,5-NDS with the same amount of $\mathrm{NaCl}$. Both series of experiments were heated between 200 and $300^{\circ} \mathrm{C}$ for one, two and three weeks. The solutions were analysed for presence of the initial NDS and different polycyclic aromatic hydrocarbons with high performance liquid chromatography with fluorescence detection (HPLC) and gas chromatography combined with mass spectrometry (GC-MS).

\section{Chapter 7:}

In the final chapter, the key findings are examined with respect to the objectives outlined in Section 1.7 and directions and recommendations for future work.

\section{Appendix:}

This section provides details on minor side projects (including experiments on NDS and NSA adsorption processes) and presented in a format of tables experimental data.

Knowledge of adsorption properties of geothermal tracers is critical for successful tracer test interpretation, as compounds used as permeability tracers should not react with mineral surfaces (Axelsson, 2013). Until now, naphthalene (di)sulfonates were only selectively tested for their sorption properties (Chang et al., 2003; Keith-Roach and Höglund, 2018). However, no comprehensive sorption studies have been done. This thesis provides the first study of the adsorption characteristics of naphthalene sulfonate and disulfonates on different mineral surfaces with the use of column and batch experiments.

\subsection{Statement of contribution}

Although the results of this work are largely my personal contributions, I will use the first-person plural "we" throughout my thesis in favour of "I" to acknowledge the contributions of my co-authors on these publication-style chapters. All work has been conducted by myself unless stated otherwise. I am the primary author of all chapters in this thesis. My contributions include data collection and data analyses: laboratory experiments (i.e. flame sealing of glass ampoules, solutions preparation, set-up and operation of the flow-through autoclave apparatus); solid substrate preparations (i.e. sieving, washing) for flow-through and adsorption experiments; naphthalene (di)sulfonates, naphthalene, 1-naphthol and 2-naphthol analysis with 
high performance liquid chromatography (HPLC), cation analysis with inductively coupled plasma (ICP) and hydrogen sulfide analysis by UV spectroscopy at GNS Science, Wairakei Research Center. Additionally, experimental solutions were analysed for anions by ion chromatography (IC) by the New Zealand Geothermal Analytical Laboratory at GNS Sciences in Taupo. Gas chromatography - mass spectrometry (GC-MS) analyses were conducted by Prof. Leszek Marynowski at University of Silesia, Sosnowiec, Poland. Greywacke samples were analysed for individual minerals by Dr Isabelle Chambefort, GNS Science.

My supervisors Prof. Terry Seward and Dr. Bruce Mountain provided general guidance throughout the project. All chapters were reviewed and edited by my supervisors. We would like to thank Mercury NZ Ltd. for providing partial funding for this work. Support for LS was provided by a Victoria University of Wellington PhD Scholarship. Support was also provided by the Government of New Zealand through funding of the GNS's Geothermal Resources of New Zealand research programme. At the time of writing, four publications are anticipated.

\subsection{References}

Adams, M.C., Davis, J., 1991. Kinetics of fluorescein decay and its application as a geothermal tracer. Geothermics, 20, $53-66$.

Adams, M.C., Moore, J.N., Fabry, L.G., Ahn, J.-H., 1992. Thermal stabilities of aromatic acids as geothermal tracers. Geothermics, 21, $323-339$.

Addison, S., Winick, J.A., Sewell, S., Buscarlet, E., Hernandez, D., Siega, F.L., $2015 a$. Geochemical response of the Rotokawa reservoir to the first 5 years of Nga Awa Purua. Proceedings $38^{\text {th }}$ New Zealand Geothermal Workshop.

Addison, S. J., Winick, J.A., Mountain, B. W., Siega, F. L., 2015b. Rotokawa reservoir tracer test history. Proceedings $38^{\text {th }}$ New Zealand Geothermal Workshop.

Angcoy, Jr., E.C., 2010: Geochemical Modelling of the High-Temperature Mahanagdong Geothermal Field, Leyte, Philippines, Master's thesis, Faculty of Science, University of Iceland.

Axelsson, G., Björnsson, G., Montalvo, F., 2005. Quantitative interpretation of tracer test data. Proceedings World Geothermal Congress. Antalya, Turkey

Axelsson, G., 2013. Tracer tests in geothermal resource management. EPJ Web of Conferences, 50 . 
Ayling, B.F., Hogarth, R.A., Rose, P.E., 2015. Tracer testing at the Habanero EGS site, central Australia. Geothermics, 63, 15 - 26.

Bjornsson, G., 2004. Reservoir Conditions at 3 - $6 \mathrm{Km}$ Depth in the Hellisheidi geothermal field, Sw-Iceland, estimated by deep drilling, cold water injection and seismic monitoring, in: $29^{\text {th }}$ Workshop on Geothermal Reservoir Engineering.

Blodgett, L., Slack, K., 2009. Geothermal 101: basics of geothermal energy production and use. Geothermal Energy Association.

Chang, C.F., Chang, C.Y., Höll, W., 2003. Adsorption behavior of 2naphthalenesulfonate on activated carbon from aqueous systems. Industrial \& Engineering Chemistry Research, 42.

Dashkevich, Y.G., Mountain, B.W., Seward, T.M., Winick, J.A., 2014. Temperature stability of 1,5-naphthalene disulfonate at simulated geothermal conditions, Proceedings $36^{\text {th }}$ New Zealand Geothermal Workshop, Auckland.

Dashkevich, Y.G., Mountain, B.W., Seward, T.M., Winick, J.A., 2015. Temperature stability of naphthalene sulfonic and naphthalene disulfonic acids at geothermal conditions. Proceedings World Geothermal Congress 2015. Melbourne, Australia.

Foster, N.C., 1997. Sulfonation and Sulfation Processes. Chemithon.

Franzson, H., Kristjánsson, B.R., Gunnarsson, G., Björnsson, G., Hjartarson, A., Steingrímsson, B., Gunnlaugsson, E., Gíslason, G., 2005. The Hengill-Hellisheiði geothermal field. Development of a conceptual geothermal model. Proceedings World Geothermal Congress. Antalya, Turkey.

Fridleifsson, G. O., Ármannsson, H, Mortensen A. K., 2006. Geothermal conditions in the Krafla caldera with focus on well KG-26. A review in relation to the Iceland Deep Drilling. Íslenskar orkurannsóknir. Report ÍSOR-2006/030.

Glaspey, D., Kitz, K., Teplow, B., Sanyal, S., Faulder, D., 2008. Final Technical Report for Resource Confirmation Testing at the Raft River Geothermal Project, Cassia County, Idaho. DOE/AL/68229. Boise, Idaho, US Geothermal Inc.

Greim H., Ahlers J., Bias R., Broecker B., Hollander H., Gelbke H. P., Klimisch H. J., Mangelsdorf I., Paetz A., Schon N., Stropp G., Vogel R., Weber C., Ziegler K., Skylakakis C., Bayer E., 1994. Toxicity and Ecotoxicity of Sulfonic Acids: Structure-Activity Relationship. Chemosphere, 28, 12, $2203-2236$. 
Hossein, S., Kaykhaii, M., Tabehzar, F., 2018. Spectrophotometric determination of four naphthalene sulfonates in seawater after their molecularly imprinted stir bar sorptive extraction. Journal of the Chilean Chemical Society, 3, 4057 - 4063.

IAEA, 2012. Application of radiotracer techniques for interwell studies. IAEA Radiat. Technology Series, 18.

Jiurong, L., 1999. Reinjection and tracer tests in the Laugaland. Geothermal Training Programme, Iceland.

Jumei, P., District, H., 2010. Reinjection into well st0902 and tracer testing in the Xiongxian geothermal field, Hebei Province, China. Geothermal Training Programme, Iceland.

Kaya T., 2005. Characterization of Kizilcahamam Geothermal Field by Tracer Testing. Master's thesis, Middle East Technical University.

Keith-Roach, M., Höglund, L.O., 2018. Review of the long-term risks associated with the use of superplasticizers 31. Working Report 2017-52. Eurajok, Findland.

Kristjansson, B., Axelsson, G., Gunnarsson, G., Gunnarsson, I., Oskarsson, F., 2016. Comprehensive tracer testing in the Hellisheidi geothermal field in SW-Iceland 2013-14. Proceedings, $41^{\text {st }}$ Workshop on Geothermal Reservoir Engineering Stanford University.

Krupp, R. E., Seward T. M., 1987. The Rotokawa geothermal system, New Zealand; an active epithermal gold-depositing environment. Economic Geology, 82, 1109 - 1129.

Li, Y., 2011. Research on the key technology of polynaphthalene sulphonate preparation. Advanced Materials Research, 1361 - 1365.

McLin, K. S. Moore, J. N. Bowman, J. R., McCulloch J. E., 2012. Mineralogy and fluid inclusion gas chemistry of production well mineral scale deposits at the Dixie Valley geothermal field, USA. Geofluids, 12, 3, 216- 227.

Mondejar, G.C., 2012. Hydrological flow and thermal interference modelling in the Mahanagdong geothermal field, Philippines, using four types of naphthalene disulfonate tracer. Geothermal Training Programme, Iceland.

Mountain, B.W., Winick, J., 2012. The thermal stability of the naphthalene sulfonic and naphthalene disulfonic acids under geothermal conditions : Experimental Results and a Field-Based Example 1 - 5. Proceedings $34^{\text {th }}$ New Zealand Geothermal Workshop. 
Nogara, J.B., Sambrano, B.M.G., 2005. Tracer tests using naphthalene di-sulfonates in Mindanao geothermal production field, Philippines. Proceedings World Geothermal Congress. Antalya, Turkey.

Nottebohm, M., Licha, T., Ghergut, I., Nödler, K., Sauter, M., 2010. Development of thermosensitive tracers for push-pull experiments in geothermal reservoir characterization. Proceedings World Geothermal Congress. Bali, Indonesia.

Nottebohm, M., Sauter, M., 2011. Stability and reactivity of organic molecules in geothermal reservoirs. der Mathematisch-Naturwissenschaftlichen Fakultäten der Georg August Universität zu Göttingen. Doctorate, 85.

Nottebohm, M., Licha, T., Sauter, M., 2012. Tracer design for tracking thermal fronts in geothermal reservoirs. Geothermics, 43, $37-44$.

Pruess, K., Heel, T. Van, Shan, C., 2005. Tracer testing for estimating heat transfer area in fractured reservoirs. Proceedings World Geothermal Congress. Antalya, Turkey.

Rokade, Y.B., Sayyed, R.Z., 2009. Naphthalene derivatives: a new range of antimicrobials with high therapeutic value. Rasayan Journal of Chemistry, 2, 972 - 980.

Rose, P., Benoit, D., Lee, S.G., Tandia, B., Kilbourn, P., 2000. Testing the naphthalene sulfonates as geothermal tracers at Dixie Valley, Ohaaki, and Awibengkok. Proceedings, $25^{\text {st }}$ Workshop on Geothermal Reservoir Engineering Stanford University.

Rose, P., Benoit, W.R., Kilbourn, P.M., 2001a. The application of the polyaromatic sulfonates as tracers in geothermal reservoirs. Geothermics 30, $617-640$.

Rose, P., Johnson, S.D., Kilbourn, P., 2001b. Tracer testing at Dixie Valley, Nevada, using 2-naphthalene sulfonate and 2,7-naphthalene disulfonate. Proceedings, $26^{\text {th }}$ Workshop on Geothermal Reservoir Engineering Stanford University, Stanford, California.

Rose, P., Leecaster, K., Clausen, S., Sanjuan R., Ames M., Reimus P., Williams M., Vermeul V., Benoit D., 2012. A tracer test at the Soda Lake, Nevada geothermal field using a sorbing tracer, Proceedings, $27^{\text {th }}$ Workshop on Geothermal Reservoir Engineering Stanford University, Stanford, California.

Sanjuan, B., Pinault, J.L., Rose, P., Gérard, A., Brach, M., Braibant, G., Crouzet, C., Foucher, J.C., Gautier, A., Touzelet, S., 2006. Tracer testing of the geothermal heat exchanger at Soultz-sous-Forêts (France) between 2000 and 2005. Geothermics, 35, 622 - 653. 
Shook, G.M., 1999. Prediction of thermal breakthrough from tracer tests. Proceedings, $24^{\text {th }}$ Workshop on Geothermal Reservoir Engineering Stanford University, Stanford, California.

Shook, G.M., Ansley, L.S., Wylie, A., 2004. Tracers and tracer testing: design, implementation, and interpretation methods. Idaho National Engineering and Environmental Laboratory Bechtel BWXT Idaho, LLC

Tomich, J. F., Dalton, R. L. Jr., Deans, H. A., Shallenberger, L. K., 1973, Single-Well Tracer Method to Measure Residual Oil Saturation. Journal of Petroleum TechnologyTransact, $255,211-218$.

Ungemach, P., Veronique, V.A., Sebastien, N., 2002. Tracer leak off tests as means of checking well integrity. application to Paris Basin geothermal production wells. Proceedings, $26^{\text {th }}$ Workshop on Geothermal Reservoir Engineering Stanford University. Stanford, California.

Winick, J., Siega, F., Addison, S., Richardson, I., Mountain, B., Barry, B., 2015. Coupled Iodine-125 and 2-NSA reservoir tracer testing at the Rotokawa geothermal field, New Zealand. Proceedings World Geothermal Congress. Melbourne, Australia. 


\section{The stability of 1,5-naphthalene disulfonate (1,5-NDS) and 2-naphthalene sulfonate (2-NSA) as a function of $\mathbf{p H}$ and salinity under geothermal conditions}

\subsection{Abstract}

Naphthalene sulfonates have been widely used in the geothermal industry as tracer chemicals and a knowledge of their rate of thermal breakdown is essential to ensure successful use of these organic compounds. The main goal of this study is to expand the understanding of the processes taking place when naphthalene sulfonates and disulfonates are exposed to high temperature conditions encountered in active geothermal reservoirs with an emphasis on the effect of $\mathrm{pH}$ and salinity.

Two series of experiments were conducted to measure the rate of thermal breakdown of 1,5-naphthalene disulfonate (1,5-NDS) and 2-naphthalene sulfonate (2-NSA). The first series focused exclusively on 1,5-NDS breakdown rate in $\mathrm{NaCl}, \mathrm{Na}_{2} \mathrm{SO}_{4}, \mathrm{Na}_{2} \mathrm{~S}$ solutions and in presence of pyrite at 250,270 and $300^{\circ} \mathrm{C}$. The second series contained a combination of both 1,5-NDS and 2-NSA dissolved in distilled water as well as in $0.05 \mathrm{~mol} \mathrm{~kg}^{-1} \mathrm{NaCl}$ solutions. The solutions were sealed in glass ampoules and heated in autoclave reactors to 200 and $300^{\circ} \mathrm{C}$ for up to one week. The experimental $\mathrm{pH}$ was varied.

The solutions were analysed by high performance liquid chromatography (HPLC) using fluorescence detection. As described, and as far as we are aware, this is the first rigorous experimental study of 1,5-NDS and 2-NSA stability as a function of $\mathrm{pH}$ and $\mathrm{NaCl}$ concentration at elevated temperatures up to $300^{\circ} \mathrm{C}$.

At $200^{\circ} \mathrm{C}$, the rate constant for $1,5-\mathrm{NDS}$ breakdown is $\mathrm{pH}$-dependent whereas 2-NSA disproportionates at $\mathrm{pH}_{\mathrm{t}} \geq 7.3$. Increasing $\mathrm{NaCl}$ concentration slows the breakdown reactions while decreasing $\mathrm{pH}$ increases the breakdown rate for both 1,5-NDS and 2-NSA. Results at $300^{\circ} \mathrm{C}$ show similar trends, however, the overall rates of reaction are more rapid. 2-NSA is not stable at $300^{\circ} \mathrm{C}$. 1-naphthalene sulfonate (1-NSA) was detected as the stable 1,5-NDS breakdown product. 1-NSA stability decreases with increasing temperature and decreasing $\mathrm{pH}$. 


\subsection{Introduction}

\subsubsection{Geothermal tracers}

Tracers are a valuable tool utilised in the geothermal industry to investigate the hydrodynamics and permeability of geothermal reservoirs. To be used successfully, they must satisfy several criteria including: (1) high solubility in water; (2) sufficient thermal stability; (3) low detection limit (i.e. $50 \mathrm{ng} \mathrm{L}^{-1}$ ); (4) low natural background concentration; (5) nonabsorptivity onto mineral surfaces; and (6) cost effectiveness (Rose et al., 2001).

Elements such as bromine and lithium can be used as tracers, however, they require large amounts to be injected due to their natural background concentrations in geothermal reservoirs (Jiurong, 1999). Organic fluorescent dyes have also been effectively used as tracers. Two of these dyes, rhodamine and fluorescein have negligible natural background concentrations, however, they are not thermally stable at the high temperatures encountered in high enthalpy geothermal reservoirs (Adams et al., 1992; Adams \& Davis, 1991).

Two radioisotopes of iodine, ${ }^{125} \mathrm{I}$ and ${ }^{131} \mathrm{I}$, are suitable for use as geothermal tracers. Their respective half-lives of 60 and 8 days mean that they can be detected over a period of weeks to months. They have extremely low detection limits (IAEA, 2012) and low natural background concentrations (Ungemach et al., 2002). However, as both are radioactive, they require special health and safety procedures and environmental precautions when injected into wells in active geothermal environments. They are also time-consuming to extract and analyse.

The UV-fluorescent polyaromatic compounds, naphthalene sulfonates and naphthalene disulfonates, are also appropriate as geothermal tracers (Rose et al., 2000; 2001). they have very low detection limits ( $\mathrm{ng} \mathrm{L}^{-1}$ ) and extremely low to undetectable natural background concentrations. They have been assumed to be thermally stable over a wide range of conditions, however, there are only minimal experimental data supporting this assumption (Rose et al., 2001). It is crucial to the detection and interpretation of these injected tracers to understand their stability in high temperature geothermal fluids.

The naphthalene sulfonates are part of a group of hydrocarbons referred to as aromatic compounds because they are composed of planar ring-shaped molecules built of six carbon atoms (Figure 2.1). 1,5-naphthalene disulfonate acid (1,5-NDS) is composed of two conjoined benzene rings (i.e. naphthalene) where two of the $\mathrm{H}$ atoms are substituted by sulfonate groups [-SO $\left.{ }_{3} \mathrm{H}\right]$. 2-naphthalene sulfonate (2-NSA) has a similar structure but only one sulfonate 
substitution. Both compounds are highly water-soluble and have first deprotonation constants $\left(\mathrm{pK}_{\mathrm{a}}\right)$ less than 2 (Nottebohm et al., 2012).
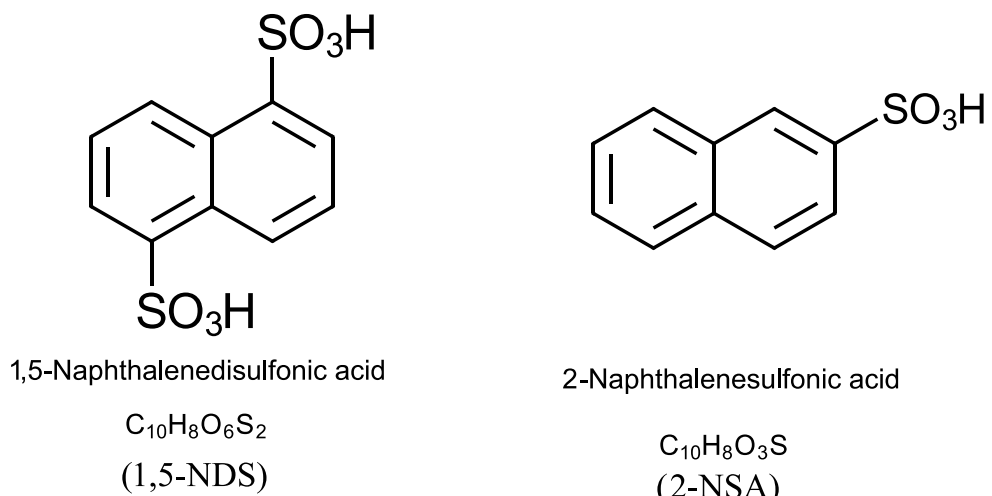

Figure 2.1: Chemical structures of the polyaromatic sulfonates addressed in this study.

Naphthalene 1,5-disulfonate (1,5-NDS) is one of the disulfonic acids that has been used widely in the geothermal industry. An example of the successful use of 1,5-NDS is at Soultzsous-Forêts, France, in July 2000 (Sanjuan et al., 2006a), where the tracer exhibited apparent stable behaviour based on its detection almost 3 years after injection. The field temperature was estimated to be close to $200^{\circ} \mathrm{C}$ and reservoir brine $\mathrm{pH}_{25}{ }^{\circ} \mathrm{C}$ and ionic strength were $>5.5$ and 1.49 M, respectively (Sanjuan et al., 2006b).

In contrast, 1,5-NDS together with other naphthalene disulfonates (2,6-naphthalene disulfonate, 2,7-naphthalene disulfonate and 1,6-naphthalene disulfonate) were utilised in 2011 at the Rotokawa field, New Zealand (Addison et al., 2015a). The reservoir's highest measured temperature is $337^{\circ} \mathrm{C}, \mathrm{pH}$ at temperature is 5.75 and ionic strength $=0.02-0.03 \mathrm{M}$ (Krupp \& Seward, 1987). After a period of one year, no trace of the original 1,5-NDS and other NDS compounds was detected. Subsequent experimental work showed that the NDS species thermally decayed in the Rotokawa fluid (Mountain \& Winick, 2012). The authors suggested that 2-naphthalene sulfonic acid (2-NSA) may have formed as a breakdown product. The samples were reanalysed, and the presence of 2-NSA was confirmed. Undoubtedly 2-NSA was a product of injected tracer's desulfonation, thus confirming thermal breakdown of the injected 1,5-NDS isomer (Addison et al., 2015b).

In 2013, 1,5-NDS was injected into wells at Húsmúli, Iceland, for a tracer test at the Hellisheidi geothermal area. Reservoir temperatures were 200 to $220^{\circ} \mathrm{C}$ below $200-600 \mathrm{~m}$

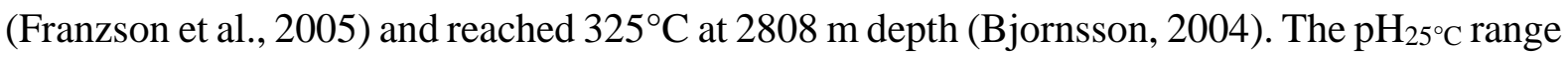


is alkaline (7.0 to 7.4) and ionic strength $0.005-0.008 \mathrm{M}$ (Remoroza, 2010). The 1,5-NDS was detected in some production wells after 24 days. However, it was concluded that knowledge of the possible breakdown of 1,5-NDS was required to interpret the test results over the longer term (Kristjansson et al., 2016).

\subsubsection{Thermal stability of the naphthalene sulfonates - previous studies}

Rose et al. (2001) simulated geothermal conditions in batch autoclave reactors to test the thermal stability of selected naphthalene sulfonic acids (i.e. 1,3,6-naphthalene trisulfonate (1,3,6-NTS), 1,5-naphthalene disulfonate (1,5-NDS), 2,7-naphthalene disulfonate (2,7-NDS), and 2-naphthalene sulfonate (2-NSA), as well as, 1,3,6,8-pyrene tetrasulfonate (1,3,6,8-PTS)). These were dissolved in $\mathrm{pH}_{25^{\circ} \mathrm{C}}=6.5$ phosphate buffered solutions $\left(0.747 \mathrm{~g} \mathrm{~L}^{-1}\right.$ of $\mathrm{KH}_{2} \mathrm{PO}_{4}$ and $0.403 \mathrm{~g} \mathrm{~L}^{-1}$ of $\mathrm{Na}_{2} \mathrm{HPO}_{4}$ ) and sealed in quartz glass ampoules that were heated up to 310,320 and $330^{\circ} \mathrm{C}$ for seven days. They observed no decay of 2-NSA and 2,7-NDS under these conditions.

Mountain and Winick (2012) conducted an experiment to investigate the thermal stability of six naphthalene sulfonates 1-NSA, 2-NSA, 1,6-NDS, 2,7-NDS, 1,5-NDS and 1,6NDS using a continuous flow reactor. Acid-dosed geothermal brine $\left(\mathrm{pH}_{25^{\circ}} \mathrm{C}=4.2\right)$ containing the six compounds was passed through crushed greywacke contained in a pressure vessel heated sequentially from 270 to $390^{\circ} \mathrm{C}$. Three different flow rates gave residence times of 6 to 60 hours. The observed stability of the naphthalene sulfonic acids (from least to most stable) was in the sequence: $1,5-\mathrm{NDS}<1,6-\mathrm{NDS}<1-\mathrm{NSA}<2,6-\mathrm{NDS} \approx 2,7-\mathrm{NDS}<2-\mathrm{NSA}$. They also noted an increase in concentration of the two NSA isomers, 1-NSA and 2-NSA, between 300 and $340^{\circ} \mathrm{C}$. At $390^{\circ} \mathrm{C}$, all the NDS and NSA isomers were thermally degraded (Figure 2.2). The very short residence time (up to $60 \mathrm{~h}$ ) relative to a field test, which can take many months, means that the results give only an indication of the thermal stability in the longer term.

Dashkevich et al. (2015) conducted thermal stability experiments on 1,5-NDS based on the conclusion that it was the least stable naphthalene sulfonate of the six used by Mountain and Winick (2012). The experiments involved three different 1,5-NDS concentrations $\left(0.10 \mathrm{mg} \mathrm{kg}^{-1}, 1.5 \mathrm{mg} \mathrm{kg}^{-1}\right.$ and $\left.25 \mathrm{mg} \mathrm{kg}^{-1}\right)$ dissolved in solutions of variable composition including: distilled water; $\mathrm{pH}_{25^{\circ} \mathrm{C}}=6.5$ phosphate buffer solution; acidified geothermal brine; and $0.40 \mathrm{~mol} \mathrm{~kg}^{-1} \mathrm{NaCl}$ solution. The experiments used sealed quartz glass tubes heated to between 260 and $350^{\circ} \mathrm{C}$ for 10 and 40 hours. They reported that 1,5-NDS stability depends on 
the solution ionic strength and $\mathrm{pH}$. They also found evidence of 1,5-NDS degradation to 1$\mathrm{NSA}$ at $\mathrm{t} \approx 300^{\circ} \mathrm{C}$.

The overall aim of this study has been to measure the breakdown kinetics of various NDS and NSA isomers under conditions relevant to active geothermal reservoirs. The thermal stability of 1,5-NDS ( $\pm 2-\mathrm{NSA})$ as a function of temperature, $\mathrm{pH}$ and salinity of the solution has been investigated. The intent is to provide data that can be used to: 1) allow critical assessment of the suitability of 1,5-NDS and 2-NSA for a particular geothermal field or field tracer test; 2) provide kinetic information that can be incorporated into reservoir models allowing better prediction of tracer returns; and (3) to identify potential breakdown products of 1,5-NDS and 2-NSA thermal decay through laboratory experiments, in order to enhance tracer test interpretations. It is possible that the returns of multiple tracers, some of which are less thermally stable, could also provide valuable information on the temperature profile of geothermal fields (Nottebohm et al., 2012);
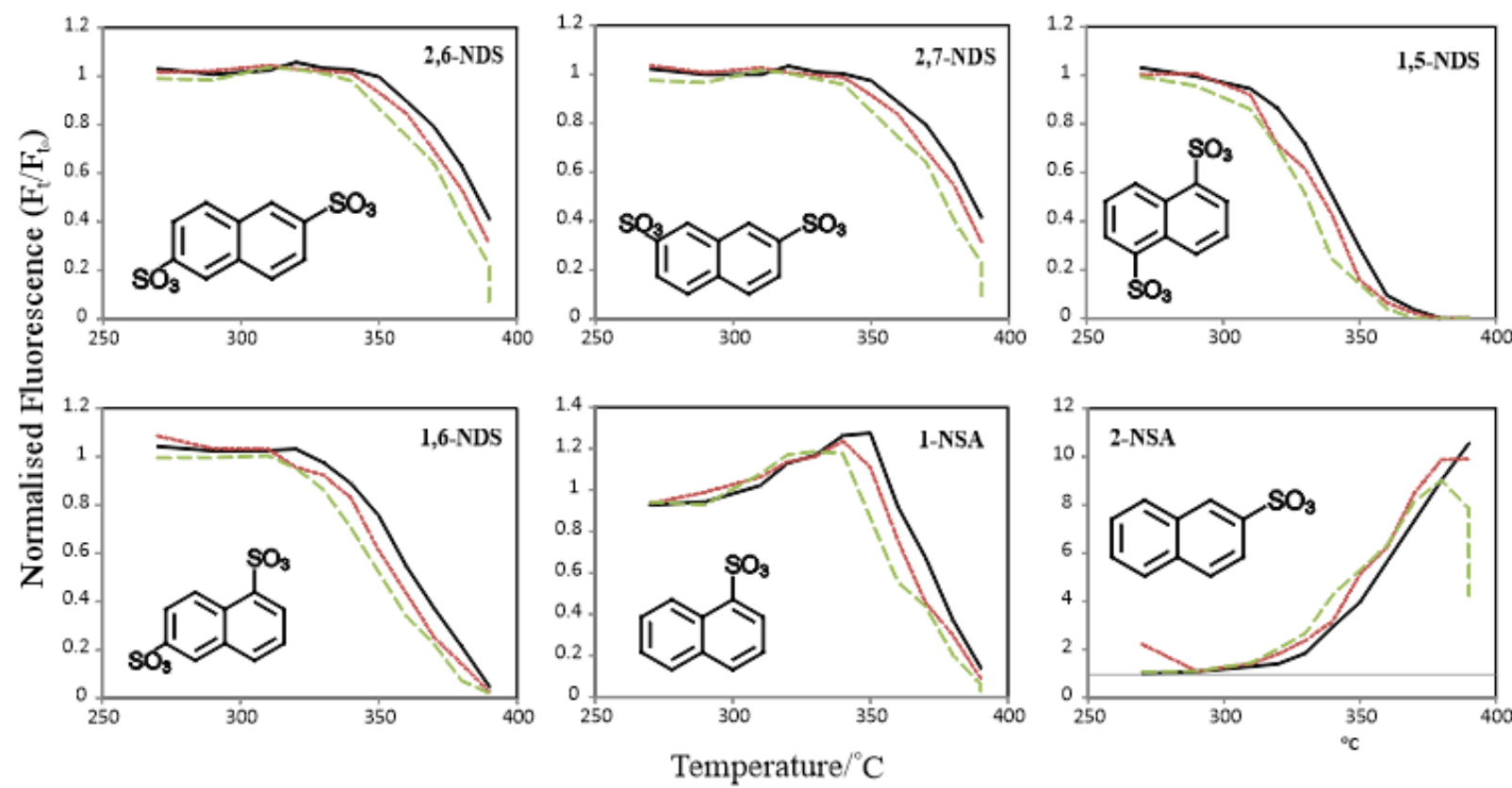

$-1 \mathrm{ml} / \mathrm{hr}$

$=-0.5 \mathrm{ml} / \mathrm{hr} \quad-* 0.1 \mathrm{ml} / \mathrm{hr}$

Figure 2.2: Normalised fluorescence (proportional to concentration) of six naphthalene sulfonic acids versus temperature at three different flow rates (Mountain \& Winick, 2012). The normalised fluorescence $=\frac{\boldsymbol{F}_{t}}{\boldsymbol{F}_{t_{0}}}$, where $\boldsymbol{F}_{\boldsymbol{t}}=$ fluorescence at time $\mathrm{t}$, and $\boldsymbol{F}_{\boldsymbol{t}_{\mathbf{0}}}=$ fluorescence of the initial NDS concentration at $\mathrm{t}=0$. 


\subsection{Experimental methods}

\subsubsection{Reagents}

Napthalene-1-sulfonic acid sodium salt (80\%), naphthalene-2-sulfonic acid sodium salt (99\%), and 1,5-naphthalene disulfonic acid disodium salt (95\%) were supplied by SigmaAldrich. Other compounds were: tetrabutyl ammonium phosphate (TBAP); sodium chloride (99\%) (Sigma-Aldrich); methanol HPLC fluorescence grade (Bio-Strategy); sodium hydroxide pellets (97\%, Fischer Scientific $\mathrm{GmbH})$; hydrochloric acid (36\%, Acros Organics); sodium sulfate ( $\geq 99 \%)$; and sodium sulfide nonahydrate ( $\geq 98 \%$, Sigma-Aldrich). Ultrapure water with

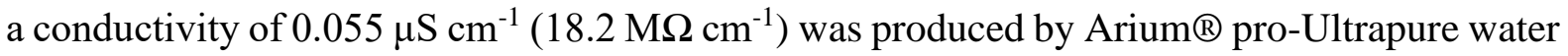
system. Pyrite was sourced from Excalibur Mineral Company, USA.

\subsubsection{Quartz glass ampoule experiments}

A series of solution compositions was chosen which have relevance to the aqueous chemistry encountered in active geothermal reservoirs. The thermal stability of NDS and NSA compounds has therefore been studied in distilled water, $\mathrm{NaCl}$ solution, and sulfate and sulfide containing solutions in contact with pyrite $\left(\mathrm{FeS}_{2}\right)$. Removal of atmospheric oxygen is important because aromatic compounds readily oxidise in the presence of oxygen at elevated temperatures (Gosetti et al., 2005). It should be noted, as well, that geothermal fluids are typically characterised by a hydrogen partial pressure of 0.01 to 0.1 bar (Seward, 1974; Ellis \& Mahon 1977). In this study, experimental solutions ( $1.5 \mathrm{~L})$ were pre-deoxygenated by bubbling with $0.01 \% \mathrm{H}_{2}$ in $\mathrm{N}_{2}$ for 10 minutes and aliquots $(2.5 \mathrm{ml})$ were then transferred to open quartz glass ampoules (ID $7 \mathrm{~mm}$, OD $9 \mathrm{~mm}$ ) which were actively purged with $\mathrm{H}_{2}-\mathrm{N}_{2}$ gas mixture. This left approximately $2 \mathrm{ml}$ of headspace in the ampoule which was evacuated using a vacuum pump and then sealed with an oxygen-acetylene torch. The transfer, evacuation and sealing took $<10$ seconds. Numerous experiments were conducted to ensure a series of reproduceable data. Previous studies on 1,5-NDS or 2-NSA (e.g. Rose et al., 2001, Dashkevich et al., 2014) did not employ pre-deoxygenation and evacuation to keep the system oxygen-free.

The first set of experiments contained only 1,5-NDS and included three subsets (Table 2.1). The experiments were designed to evaluate the influence of different solution chemistries on 1,5-NDS stability. Each subset comprised different experimental temperatures, reaction times and solution compositions: (i) $\mathrm{Na}_{2} \mathrm{SO}_{4}=0.020 \mathrm{~mol} \mathrm{~kg}^{-1}$; (ii) $\mathrm{NaCl}=0.050 \mathrm{~mol} \mathrm{~kg}^{-1}+$ $\mathrm{Na}_{2} \mathrm{~S}=2.69 \times 10^{-5} \mathrm{~mol} \mathrm{~kg}^{-1}$; and (iii) $\mathrm{NaCl}=0.050 \mathrm{~m}$. Additionally, subset (iii) contained grains 
of cleaned pyrite ( $\sim 0.025 \mathrm{~g}$ inside each ampoule). All experiments, in the first set, had a similar starting composition of 1,5-NDS (Table 2.1). There were at least three replicates in each subset for a total of 72 experiments. The ampoules were heated to 250,270 and $300^{\circ} \mathrm{C}$ for times ranging from 4 to 21 days.

The second set of experiments were designed to study the stability and kinetics of a 1,5NDS and 2-NSA mixture in aqueous solution. The experiment consisted of sixteen subsets of six replicates. Each subset represented eight $\mathrm{pH}$ values in distilled water (Set 2a; Table 2.2a) and $\mathrm{NaCl}=0.050 \mathrm{~mol} \mathrm{~kg}^{-1}$ solution (concentration of salts typical for New Zealand geothermal fluids; Set 2b; Table 2.2b). $\mathrm{HCl}$ and $\mathrm{NaOH}$ were used to fix $\mathrm{pH}$. To each tube, 1,5-NDS and 2NSA were added to obtain a concentration of $7.0 \times 10^{-8} \mathrm{~mol} \mathrm{~kg}^{-1}$ and $4.5 \times 10^{-8} \mathrm{~mol} \mathrm{~kg}^{-1}$, respectively. The 1,5-NDS and 2-NSA concentrations were selected to mimic concentrations of geothermal tracers present in geothermal reservoirs during a tracer test. The ampoules were heated to 200 and $300^{\circ} \mathrm{C}$ for $10,20,40,60,100$ and 166 hours ( 1 week). There were at least three replicates in each set for each experimental time comprising a total of 336 experiments.

Duplicate ampoules were enclosed in $120 \mathrm{ml}$ stainless steel autoclaves which were partially filled with water to provide the confining pressure and placed into a preheated Carbolite LHT 5/60 oven. The time required to heat the autoclaves to the target temperature was about 2 hours while cooling down to below $100^{\circ} \mathrm{C}$ took about 1 hour.

Table 2.1: Composition of initial solution for Set 1 . This set of experiments contained only 1,5NDS as the initial naphthalene sulfonate and involved three different matrices: (i) $\mathrm{Na}_{2} \mathrm{SO}_{4}=$ $0.020 \mathrm{~mol} \mathrm{~kg}^{-1}$; (ii) $\mathrm{NaCl}=0.050 \mathrm{~mol} \mathrm{~kg}^{-1}$ and $\mathrm{Na}_{2} \mathrm{~S}=2.69 \times 10^{-5} \mathrm{~mol} \mathrm{~kg}^{-1}$; and (iii) contained grains of pyrite $(\sim 0.025 \mathrm{~g}$ inside each ampoule $)$ and $\mathrm{NaCl}=0.050 \mathrm{~mol} \mathrm{~kg}{ }^{-1}$. The experiments were conducted at 250,270 and $300^{\circ} \mathrm{C}$ up to 3 weeks.

\begin{tabular}{ccccccccc}
\hline & $\begin{array}{c}\mathrm{Na}^{+} \\
\text {molal }\end{array}$ & $\begin{array}{c}\mathrm{Cl}^{-} \\
\text {molal }\end{array}$ & $\begin{array}{c}\mathrm{SO}_{4}{ }^{2-} \\
\text { molal }\end{array}$ & $\begin{array}{c}\mathrm{Na}_{2} \mathrm{~S} \\
\text { molal }\end{array}$ & $\mathrm{pH}_{25^{\circ} \mathrm{C}}$ & $\begin{array}{c}1,5-\mathrm{NDS} \\
\text { molal }\end{array}$ & solid & time/days \\
\hline (i) & 0.040 & 0.000 & 0.020 & - & 7.0 & $8.06 \times 10^{-8}$ & - & 14 to 40 \\
(ii) & 0.051 & 0.050 & - & $2.69 \times 10^{-5}$ & 7.0 & $9.21 \times 10^{-8}$ & - & 14 to 40 \\
(iii) & 0.051 & 0.051 & - & - & 7.0 & $7.87 \times 10^{-8}$ & pyrite & 14 to 40 \\
\hline \multicolumn{7}{l}{ n.d. = below detection limit: $1.40 \times 10^{-10} \mathrm{~mol} \mathrm{~kg}^{-1}$ for the NDS, $1.93 \times 10^{-9} \mathrm{~mol} \mathrm{~kg}^{-1}$ for NSA }
\end{tabular}


Table 2.2a: Composition of starting solutions for Set 2a. This set of experiments contained 1,5-NDS and 2-NSA dissolved in distilled water. The experiments were conducted at 200 and $300^{\circ} \mathrm{C}$ for up to 7 days.

\begin{tabular}{cccc}
\hline $\mathrm{pH}_{25^{\circ} \mathrm{C}}$ & $\begin{array}{c}1,5-\mathrm{NDS} \\
\text { molal }\end{array}$ & $\begin{array}{c}2-\mathrm{NSA} \\
\text { molal }\end{array}$ & time/days \\
\hline 3 & $5.54 \times 10^{-8}$ & $3.04 \times 10^{-8}$ & 7 \\
4 & $7.29 \times 10^{-8}$ & $4.27 \times 10^{-8}$ & 7 \\
5 & $7.11 \times 10^{-8}$ & $4.87 \times 10^{-8}$ & 7 \\
6 & $6.92 \times 10^{-8}$ & $4.73 \times 10^{-8}$ & 7 \\
8 & $7.21 \times 10^{-8}$ & $4.57 \times 10^{-8}$ & 7 \\
9 & $8.58 \times 10^{-8}$ & $5.41 \times 10^{-8}$ & 7 \\
10 & $7.25 \times 10^{-8}$ & $4.95 \times 10^{-8}$ & 7 \\
11 & $7.29 \times 10^{-8}$ & $4.04 \times 10^{-8}$ & 7 \\
\hline
\end{tabular}

n.d. = below detection limit: $1.40 \times 10^{-10} \mathrm{~mol} \mathrm{~kg}^{-1}$ for the NDS,

$1.93 \times 10^{-9} \mathrm{~mol} \mathrm{~kg}^{-1}$ for NSA
Table 2.2b: Composition of starting solution for Set $2 \mathrm{~b}$. This set of experiments contained 1,5-NDS and 2-NSA dissolved in a $\mathrm{NaCl}=0.050 \mathrm{~mol} \mathrm{~kg}^{-1}$ solution. The experiments were conducted at 200 and $300^{\circ} \mathrm{C}$ for up to 7 days.

\begin{tabular}{cccccc}
\hline $\begin{array}{c}\mathrm{Na}^{+} \\
\text {molal }\end{array}$ & $\begin{array}{c}\mathrm{Cl}^{-} \\
\text {molal }\end{array}$ & $\mathrm{pH}_{25^{\circ} \mathrm{C}}$ & $\begin{array}{c}1,5-\mathrm{NDS} \\
\text { molal }\end{array}$ & $\begin{array}{c}\text { 2-NSA } \\
\text { molal }\end{array}$ & time/days \\
\hline 0.051 & 0.051 & 3 & $6.75 \times 10^{-8}$ & $4.15 \times 10^{-8}$ & 7 \\
0.050 & 0.050 & 4 & $6.47 \times 10^{-8}$ & $4.39 \times 10^{-8}$ & 7 \\
0.050 & 0.050 & 5 & $5.89 \times 10^{-8}$ & $4.07 \times 10^{-8}$ & 7 \\
0.050 & 0.050 & 6 & $6.13 \times 10^{-8}$ & $4.24 \times 10^{-8}$ & 7 \\
0.049 & 0.049 & 8 & $6.57 \times 10^{-8}$ & $4.69 \times 10^{-8}$ & 7 \\
0.050 & 0.050 & 9 & $6.82 \times 10^{-8}$ & $4.09 \times 10^{-8}$ & 7 \\
0.049 & 0.049 & 10 & $6.51 \times 10^{-8}$ & $3.84 \times 10^{-8}$ & 7 \\
0.049 & 0.049 & 11 & $6.02 \times 10^{-8}$ & $5.30 \times 10^{-8}$ & 7 \\
\hline n.d. $=$ below detection limit: $1.40 \times 10^{-10} \mathrm{~mol} \mathrm{~kg}^{-1}$ for the NDS, $1.93 \times 10^{-9} \mathrm{~mol} \mathrm{~kg}^{-1}$ for \\
NSA
\end{tabular}




\subsubsection{Analytical procedure}

At the end of an experiment, the autoclaves were cooled, the ampoules opened and a sample of the aqueous phase was taken and filtered through $0.2 \mu \mathrm{m}$ Minisart ${ }^{\circledR} \mathrm{NML}$ Surfactant-free cellulose acetate filters to protect the HPLC column from fine particles.

The naphthalene sulfonates were analysed by high performance liquid chromatography (HPLC) with fluorescence detection using a Shimadzu RF-20Axs instrument. The separation of the various isomers in the HPLC column occurs due to the different number and location of sulfonate groups $\left[-\mathrm{SO}_{3} \mathrm{H}\right]$ on the naphthalene ring.

The HPLC method uses a mobile phase of $5 \mathrm{mM}$ tetrabutylammonium phosphate in a 29:71 (volume \%) methanol/water mixture. Detection limits were $1.40 \times 10^{-10} \mathrm{~mol} \mathrm{~kg}^{-1}$ for the NDS and $1.93 \times 10^{-9} \mathrm{~mol} \mathrm{~kg}^{-1}$ for the NSA. The column temperature was maintained at $35^{\circ} \mathrm{C}$. Sample injection volume was $50 \mu \mathrm{L}$ and a $50 \mu \mathrm{L}$ ultrapure water blank was run between each standard/sample.

\subsubsection{Speciation of solutions and calculation of $\mathrm{pH}$}

Calculation of the $\mathrm{pH}$ and the degree of $\mathrm{NaCl}$ ion paring in the solution at the experimental temperature and pressure were important in the interpretation of the results. Only concentrations of $\mathrm{OH}^{-}, \mathrm{H}^{+}, \mathrm{Na}^{+}, \mathrm{Cl}^{-}, \mathrm{HCl}^{\circ}, \mathrm{NaOH}^{\circ}, \mathrm{SO}_{4}^{2-}, \mathrm{HSO}_{4}^{-}, \mathrm{NaSO}_{4}^{-}$and $\mathrm{NaCl}^{\circ}$ were considered.

The following independent reactions define the equilibrium concentrations in the solution:

$$
\begin{aligned}
& \mathrm{H}_{2} \mathrm{O}=\mathrm{H}^{+}+\mathrm{OH}^{-} \\
& \mathrm{NaCl}^{\circ}=\mathrm{Na}^{+}+\mathrm{Cl}^{-} \\
& \mathrm{NaOH}^{\circ}=\mathrm{Na}^{+}+\mathrm{OH}^{-} \\
& \mathrm{HCl}^{\circ}=\mathrm{H}^{+}+\mathrm{Cl}^{-}
\end{aligned}
$$

For these reactions, the following charge balance equation can be written:

$$
\mathrm{m}_{\mathrm{Na}^{+}}+\mathrm{m}_{\mathrm{H}^{+}}=\mathrm{m}_{\mathrm{Cl}^{-}}+\mathrm{m}_{\mathrm{OH}^{-}}
$$

Additionally, the $\mathrm{Na}$ and $\mathrm{Cl}$ species are constrained by the two mass balance equations:

$$
\mathrm{m}_{\mathrm{Na}_{\text {total }}}=\mathrm{m}_{\mathrm{NaCl}^{\circ}}+\mathrm{m}_{\mathrm{Na}^{+}}+\mathrm{m}_{\mathrm{NaOH}^{\circ}}
$$




$$
\mathrm{m}_{\mathrm{Cl}_{\text {total }}}=\mathrm{m}_{\mathrm{NaCl}^{\circ}}+\mathrm{m}_{\mathrm{Cl}^{-}}+\mathrm{m}_{\mathrm{HCl}}{ }^{\circ}
$$

and for these reactions, the equilibrium constants can be written:

$$
\begin{aligned}
& \mathrm{K}_{\mathrm{W}}=\mathrm{a}_{\mathrm{H}^{+}} \cdot \mathrm{a}_{\mathrm{OH}^{-}} \cdot \mathrm{a}_{\mathrm{H}_{2} \mathrm{O}}^{-1} \\
& \mathrm{~K}_{\mathrm{NaCl}}=\mathrm{m}_{\mathrm{Na}^{+}} \cdot \gamma_{\mathrm{Na}^{+}} \cdot \mathrm{m}_{\mathrm{Cl}^{-}} \cdot \gamma_{\mathrm{Cl}^{-}} \cdot \mathrm{m}_{\mathrm{NaCl}}^{-1} \cdot \gamma_{\mathrm{NaCl}^{\circ}}^{-1} \\
& \mathrm{~K}_{\mathrm{NaOH}}=\mathrm{m}_{\mathrm{Na}^{+}} \cdot \gamma_{\mathrm{Na}^{+}} \cdot \mathrm{m}_{\mathrm{OH}^{-}} \cdot \gamma_{\mathrm{OH}^{-}} \cdot \mathrm{m}_{\mathrm{NaOH}^{\circ}}^{-1} \cdot \gamma_{\mathrm{NaOH}^{\circ}}^{-1} \\
& \mathrm{~K}_{\mathrm{HCl}}=\mathrm{m}_{\mathrm{H}^{+}} \cdot \gamma_{\mathrm{H}^{+}} \cdot \mathrm{m}_{\mathrm{Cl}^{-}} \cdot \gamma_{\mathrm{Cl}^{-}} \cdot \mathrm{m}_{\mathrm{HCl}}^{-1} \cdot \gamma_{\mathrm{HCl}^{\circ}}^{-1}
\end{aligned}
$$

If the solution contains sulfate (as in Set 1), then two additional reactions are required:

$$
\begin{aligned}
& \mathrm{NaSO}_{4}^{-}=\mathrm{Na}^{+}+\mathrm{SO}_{4}^{2-} \\
& \mathrm{HSO}_{4}^{-}=\mathrm{H}^{+}+\mathrm{SO}_{4}^{2-}
\end{aligned}
$$

together with the relevant mass balance equations:

$$
\begin{aligned}
& \mathrm{m}_{\mathrm{Na}_{\text {total }}}=\mathrm{m}_{\mathrm{Na}^{+}}+\mathrm{m}_{\mathrm{NaOH}^{\circ}}+\mathrm{m}_{\mathrm{NaSO}_{4}^{-}} \\
& \mathrm{m}_{\mathrm{SO}_{4} \text { total }}=\mathrm{m}_{\mathrm{SO}_{4}^{2-}}+\mathrm{m}_{\mathrm{NaSO}_{4}^{-}}+\mathrm{m}_{\mathrm{HSO}_{4}^{-}}
\end{aligned}
$$

and the equilibrium constant for sulfate containing solutions are,

$$
\begin{aligned}
& \mathrm{K}_{\mathrm{HSO}_{4}^{-}}=\mathrm{m}_{\mathrm{H}^{+}} \cdot \gamma_{\mathrm{H}^{+}} \cdot \mathrm{m}_{\mathrm{SO}_{4}^{2-}} \cdot \gamma_{\mathrm{SO}_{4}^{2-}} \cdot \mathrm{m}_{\mathrm{HSO}_{4}^{-1}}^{-1} \cdot \gamma_{\mathrm{HSO}_{4}^{-1}} \\
& \mathrm{~K}_{\mathrm{NaSO}_{4}^{-}}=\mathrm{m}_{\mathrm{Na}^{+}} \cdot \gamma_{\mathrm{Na}^{+}} \cdot \mathrm{m}_{\mathrm{SO}_{4}^{2}} \cdot \gamma_{\mathrm{SO}_{4}^{2-}} \cdot \mathrm{m}_{\mathrm{NaSO}_{4}^{-1}} \cdot \gamma_{\mathrm{NaSO}_{4}^{-}}^{-1}
\end{aligned}
$$

The final expressions for $\mathrm{pH}$ for experiments containing $\mathrm{NaOH}$ or $\mathrm{HCl}$ (2.18) and $\mathrm{Na}_{2} \mathrm{SO}_{4}$ (2.19) are given by:

$$
\begin{aligned}
& 0=\mathrm{a}_{\mathrm{H}^{+}} \cdot \gamma_{\mathrm{H}^{+}}^{-1}-\mathrm{a}_{\mathrm{OH}^{-}} \cdot \gamma_{\mathrm{OH}^{-}}^{-1}-\mathrm{m}_{\mathrm{Cl}_{\text {total }}} \cdot \frac{\mathrm{m}_{\mathrm{Cl}^{-}}}{\mathrm{m}_{\mathrm{Cl}_{\text {total }}}}+\mathrm{m}_{\mathrm{Na}_{\text {total }}} \cdot \frac{\mathrm{m}_{\mathrm{Na}^{+}}}{\mathrm{m}_{\mathrm{Na}_{\text {total }}}} \\
& 0=\mathrm{a}_{\mathrm{H}^{+}} \cdot \gamma_{\mathrm{H}^{+}}^{-1}-\mathrm{a}_{\mathrm{OH}^{-}} \cdot \gamma_{\mathrm{OH}^{-}}^{-1}-\mathrm{m}_{\mathrm{SO}_{4 \text { (total) }}} \cdot \frac{\mathrm{m}_{\mathrm{SO}_{4}^{2-}}}{\mathrm{m}_{\mathrm{SO}_{4} \text { (total) }}}+\mathrm{m}_{\mathrm{Na}_{\text {total }}} \cdot \frac{\mathrm{m}_{\mathrm{Na}^{+}}}{\mathrm{m}_{\mathrm{Na}_{\text {total }}}}
\end{aligned}
$$

To fit the data, the equations were solved numerically using the multiroot function according to Albarede (1995) within RStudio software linked to EqSolvR library (Mroczek \& Mroczek, 2017). Initially, a first estimate of speciation and charge balance had to be made. The ionic strength calculated from the first interaction was used to re-speciate the solution and the process was repeated until the ionic strength of consecutive iterations converged. The concentration of naphthalene (di)sulfonates was so low that they were considered negligible 
for all $\mathrm{pH}$ calculations. The calculated values of $\mathrm{pH}$ at given temperature and pressure (i.e. saturated vapour pressure) are given as $\mathrm{pH}_{\mathrm{t}}$ (Tables $\left.2.3,2.4 \mathrm{a}, \mathrm{b}\right)$.

The equilibrium constants at different temperatures for equation 2.9 to 2.11 are from Ho et al. (1994, 2000 and 2001) and equation 2.16 from Cobble et al. (1982). The equilibrium association constant for $\mathrm{NaSO}_{4}{ }^{-}$was taken from the SUPCRT92 data base (Johnson et al., 1992). The ion product constant, $K_{w}$, for the water solvent is from Bandura and Lvov (2006). An extended Debye-Hückel expression (Robinson and Stokes, 1968) was used to calculate the individual ion molal activity coefficients, $\gamma_{i}$, for the charged species,

$$
-\log \gamma_{\mathrm{i}}=\frac{\mathrm{Az_{i } ^ { 2 } \sqrt { \mathrm { I } }}}{1+\mathrm{Bă}_{\mathrm{i}} \sqrt{\mathrm{I}}}+\dot{\mathrm{B}} \cdot \mathrm{I}
$$

where $\mathrm{z}$ is the charge of the ion whose activity coefficient is being calculated, A and B are constants whose values depend on the density and dielectric constant of the water solvent and temperature, å is the effective diameter of the ion in the solution in $\AA$ (Kielland, 1937) and $\dot{B}$ is a deviation function. I is the ionic strength of the solution, in molal units, given by:

$$
\mathrm{I}=\frac{1}{2} \sum \mathrm{m}_{\mathrm{i}} \cdot \mathrm{z}_{\mathrm{i}}^{2}
$$

where $m_{i}$ and $z_{i}$ are the molality charge of the product of each species, $i$, in the solution.

\subsubsection{Determination of the rate constant}

All results are tabulated and shown in plots of $\ln$ (concentration/molal) vs time/days in Figures 2.3, 2.4, 2.5, 2.10 and 2.11 and Tables 2.3, 2.4 and 2.7. The rate constant was determined from the slope of log-concentration ( $\mathrm{mol} \mathrm{kg}^{-1}$ ) vs time (days) using GraphPad Prism 8.2.1 by the linear least squares method (Section 2.4.3). To reject outliers, which can lead to significant errors in fitting, the modified Z-score method for small data sets (Iglewicz \& Hoaglin, 1993), was used:

$$
\mathrm{Z}=\frac{0.6745\left(\mathrm{x}_{\mathrm{i}}-\tilde{\mathrm{x}}\right)}{\mathrm{MAD}}
$$

where MAD is an estimator described by median of the absolute deviations about the median:

$$
\mathrm{MAD}=\operatorname{median}_{\mathrm{i}}\left\{\left|\mathrm{x}_{\mathrm{i}}-\tilde{\mathrm{x}}\right|\right\}
$$

where $x_{i}$ is the data point and $\tilde{x}$ is the median of the dataset. A value of $\mathrm{Z}>3.5$ leads to rejection of the data point. 


\subsection{Results}

\subsubsection{Set 1: 1,5-NDS stability in $\mathrm{NaCl}, \mathrm{Na}_{2} \mathrm{SO}_{4}, \mathrm{Na}_{2} \mathrm{~S}$ solutions and $\mathrm{FeS}_{2}$}

Figure 2.3 shows concentration $\left(\mathrm{mol} \mathrm{kg}^{-1}\right)$ versus experimental time (day) at 250, 270 and $300^{\circ} \mathrm{C}$, at saturated vapour pressure, for experiments in which only 1,5-NDS was present in the initial solutions: (i) $\mathrm{Na}_{2} \mathrm{SO}_{4}=0.020 \mathrm{~mol} \mathrm{~kg}^{-1}$; (ii) $\mathrm{NaCl}=0.050 \mathrm{~mol} \mathrm{~kg}^{-1}+\mathrm{Na}_{2} \mathrm{~S}=2.69$ $\mathrm{x} 10^{-5} \mathrm{~mol} \mathrm{~kg}^{-1}$; and (iii) $\mathrm{NaCl}=0.050 \mathrm{~m}+$ pyrite. The $1,5-\mathrm{NDS}$ breakdown rates are listed in Table 2.3.

For all experiments, the 1,5-NDS decomposition rate increases with increasing temperature (Table 2.3). However, the rate of disproportionation was the slowest for $\mathrm{Na}_{2} \mathrm{SO}_{4}$ containing solutions at $250^{\circ} \mathrm{C}\left(0.016\right.$ day $\left.^{-1} \pm 0.001\right)$ and fastest for the $\mathrm{NaCl}$ solutions with pyrite grains at $300^{\circ} \mathrm{C}\left(0.669\right.$ day $\left.^{-1} \pm 0.047\right)$.

In general, decrease in $\mathrm{pH}_{\mathrm{t}}$ (at 250,270 and $300^{\circ} \mathrm{C}$ ) results in increase of the rate as shown in Table 2.3.

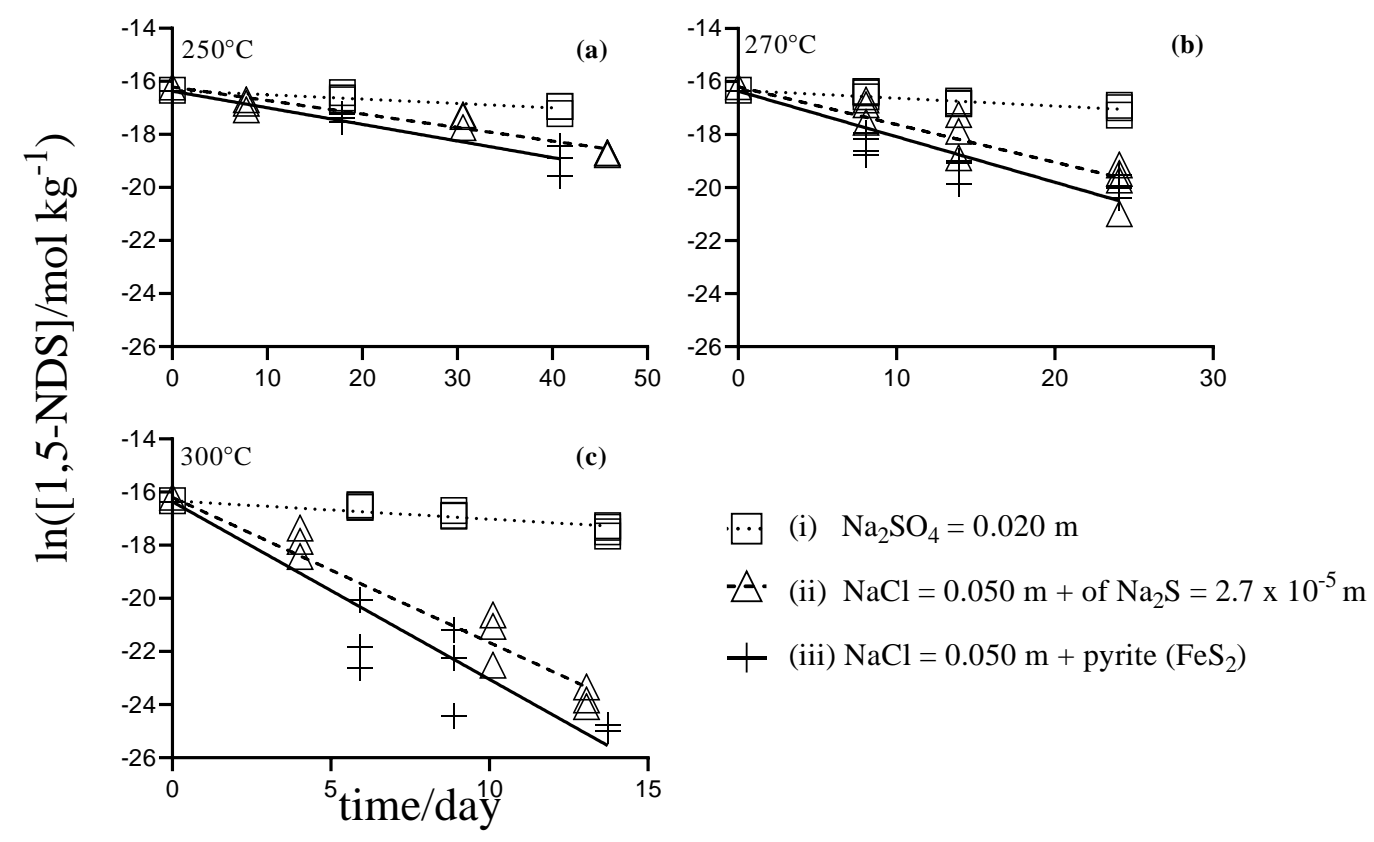

Figure 2.3: Set 1 (Table 2.1). Concentrations of 1,5-NDS (mol kg${ }^{-1}$ ) after heating at (a) $250^{\circ} \mathrm{C}$, (b) $270^{\circ} \mathrm{C}$ and (c) $300^{\circ} \mathrm{C}$ at the equilibrium saturated vapour pressure. Experimental solutions: (i) $\mathrm{Na}_{2} \mathrm{SO}_{4}=0.020 \mathrm{~mol} \mathrm{~kg}^{-1}$; (ii) $\mathrm{NaCl}=0.050 \mathrm{~mol} \mathrm{~kg}^{-1}$ and $\mathrm{Na}_{2} \mathrm{~S}=2.69 \times 10^{-5} \mathrm{~mol} \mathrm{~kg}^{-1}$; and (iii) $\mathrm{NaCl}=0.050 \mathrm{~mol} \mathrm{~kg}^{-1}+$ pyrite. 
Table 2.3: Set 1 (see Table 2.1). Rate constants for the decomposition of 1,5-naphthalene disulfonate at temperature, experimental $\mathrm{pH}$ and saturated vapour pressure.

\begin{tabular}{|c|c|c|c|c|c|}
\hline $\mathrm{t} /{ }^{\circ} \mathrm{C}$ & $\mathrm{pH}_{25^{\circ} \mathrm{C}}$ & $\mathrm{pH}_{\mathrm{t}}{ }^{*}$ & salinity & $\begin{array}{l}1^{\text {st }} \text { order reaction rate constant } \\
\qquad / \text { day }^{-1}\end{array}$ & $\begin{array}{l}1^{\text {st }} \text { order reaction rate constant } \\
\mathrm{k} / \mathrm{s}^{-1}\end{array}$ \\
\hline \multicolumn{6}{|c|}{ (i) $\mathrm{Na}_{2} \mathrm{SO}_{4}=0.020 \mathrm{~m}$} \\
\hline 250 & 7.0 & 7.0 & 0.02 & $0.016 \pm 0.001$ & $1.9 \times 10^{-7} \pm 1.2 \times 10^{-8}$ \\
\hline 270 & 7.0 & 7.2 & 0.02 & $0.021 \pm 0.005$ & $2.4 \times 10^{-7} \pm 5.8 \times 10^{-8}$ \\
\hline 300 & 7.0 & 7.4 & 0.02 & $0.069 \pm 0.009$ & $8.0 \times 10^{-7} \pm 1.0 \times 10^{-7}$ \\
\hline \multicolumn{6}{|c|}{ (ii) $\mathrm{NaCl}=0.050 \mathrm{~m}+\mathrm{Na}_{2} \mathrm{~S} 2.69 \times 10^{-5} \mathrm{~m}$} \\
\hline 250 & 7.0 & 5.6 & 0.05 & $0.051 \pm 0.005$ & $5.9 \times 10^{-6} \pm 5.8 \times 10^{-8}$ \\
\hline 270 & 7.0 & 5.6 & 0.05 & $0.142 \pm 0.008$ & $1.6 \times 10^{-6} \pm 9.3 \times 10^{-8}$ \\
\hline 300 & 7.0 & 5.7 & 0.05 & $0.546 \pm 0.025$ & $6.3 \times 10^{-6} \pm 2.9 \times 10^{-7}$ \\
\hline \multicolumn{6}{|c|}{ (iii) $\mathrm{NaCl}=0.050 \mathrm{~m}+$ pyrite $\left(\mathrm{FeS}_{2}\right)$} \\
\hline 250 & 7.0 & 5.6 & 0.05 & $0.063 \pm 0.002$ & $7.3 \times 10^{-7} \pm 2.3 \times 10^{-8}$ \\
\hline 270 & 7.0 & 5.6 & 0.05 & $0.172 \pm 0.020$ & $2.0 \times 10^{-6} \pm 2.3 \times 10^{-7}$ \\
\hline 300 & 7.0 & 5.5 & 0.05 & $0.669 \pm 0.047$ & $7.7 \times 10^{-6} \pm 5.4 \times 10^{-7}$ \\
\hline
\end{tabular}

\section{*pH at temperature}




\subsubsection{Set 2: 1,5-NDS stability in water and $\mathrm{NaCl}$ solution}

Concentrations $\left(\mathrm{mol} \mathrm{kg}{ }^{-1}\right.$ ) versus time (day) are presented in Figures 2.4 and 2.5, whereas the rate constant, $\mathrm{k}\left(\mathrm{day}^{-1}\right)$, versus experimental $\mathrm{pH}$ for 1,5-NDS in distilled water are listed in Table 2.4a and for 1,5-NDS in $\mathrm{NaCl}=0.050 \mathrm{~m}$ solutions are listed in Table 2.4b.

In experiments involving distilled water at $200^{\circ} \mathrm{C}$, $\mathrm{k}$ decreases with increasing $\mathrm{pH}$, from $\sim 0.36$ day $^{-1}\left(\mathrm{pH}=3.0\right.$ and 4.0) to $\sim 0.07 \mathrm{day}^{-1}$ at alkaline $\mathrm{pH}(\mathrm{pH}=8-11)$. At $300^{\circ} \mathrm{C}$ and in distilled water, $\mathrm{k}$ is $\sim 4$ day $^{-1}$ at $\mathrm{pH}_{\mathrm{t}}=5.0$ and decreases to 0.5 day $^{-1}$ at $\mathrm{pH}_{\mathrm{t}}=8.0$. Note, however, these breakdown rates are still faster than in $\mathrm{NaCl}=0.050 \mathrm{~m}$ solutions. At $300^{\circ} \mathrm{C}$ and in distilled water at $\mathrm{pH}_{\mathrm{t}}=3.0$ and 4.0, there is complete and rapid breakdown of 1,5-NDS and it was not detected after 576 minutes (Table 2.4a).

For solutions containing $\mathrm{NaCl}=0.050 \mathrm{~m}$ at $200^{\circ} \mathrm{C}$, $\mathrm{k}$ decreases from a maximum value of 0.15 day $^{-1}$ at $\mathrm{pH}_{\mathrm{t}}=3.0$ down to 0.01 day $^{-1}$ at $\mathrm{pH}_{\mathrm{t}}=6.0$, after which $\mathrm{k}$ increases with increasing $\mathrm{pH}$ to a value of $0.06 \mathrm{day}^{-1}$ at $\mathrm{pH}_{\mathrm{t}}=8$. At $300^{\circ} \mathrm{C}$ and $\mathrm{NaCl}=0.050 \mathrm{~m}$, the rate constant decreases from 2.3 day $^{-1}$ at $\mathrm{pH}_{\mathrm{t}}=4.0$ down to 0.12 day $^{-1}$ at $\mathrm{pH}_{\mathrm{t}}=8.0$ (Table 2.4b).

In general, values of the rate constant, $\mathrm{k}$, decrease with increasing $\mathrm{pH}$ and $\mathrm{NaCl}$ concentration. The $\mathrm{k}$ values are also temperature-dependent and are greater at higher temperatures.

\subsubsection{1,5-NDS: decay kinetics of the polyaromatic disulfonate}

An exponential decrease in concentration of the naphthalene disulfonate (i.e. 1,5-NDS) with increasing time was noticed in all samples. If the decay of 1,5-NDS follows a first order reaction,

$$
-\frac{\mathrm{d} \mathrm{C}_{\mathrm{t}}}{\mathrm{dt}}=\mathrm{k} \cdot \mathrm{C}_{\mathrm{t}}
$$

where $C_{t}$ is the concentration of naphthalene sulfonate at time $t$, and $k$ is the first order rate constant. Equation (2.24) may be reorganised as follow,

$$
\begin{gathered}
\frac{\mathrm{d} C_{t}}{\mathrm{dt}}=-\mathrm{k} \cdot \mathrm{C}_{\mathrm{t}} \\
\mathrm{dC}_{\mathrm{t}} \cdot \frac{1}{\mathrm{C}_{\mathrm{t}}}=-\mathrm{k} \cdot \mathrm{dt} \\
\int \frac{1}{C_{t}} \cdot \mathrm{dC}_{\mathrm{t}}=\int-\mathrm{k} \cdot \mathrm{dt}
\end{gathered}
$$


distilled water
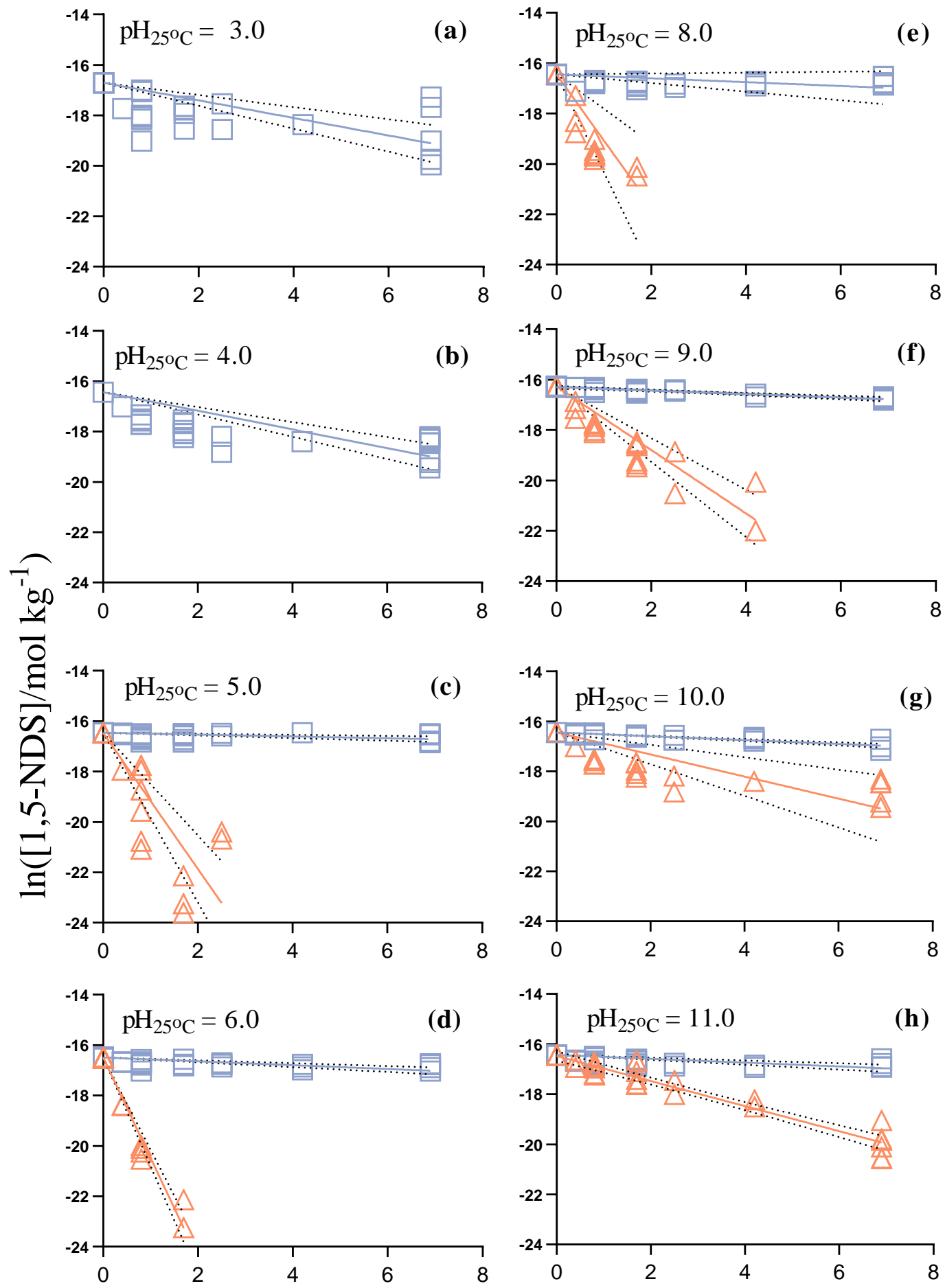

time/day $\square 200^{\circ} \mathrm{C} \triangle 300^{\circ} \mathrm{C}$

Figure 2.4: Set 2. Concentrations $\left(\mathrm{mol} \mathrm{kg}^{-1}\right)$ of $1,5-\mathrm{NDS}$ after heating at 200 and $300^{\circ} \mathrm{C}$ at saturated vapour pressure and $\mathrm{pH}_{25^{\circ} \mathrm{C}}=3.0-11.0$ and distilled water for $10,20,40,60,100$ and 166 hours. The linear least squares line (solid) lies within the $95 \%$ confidence band (dashed). 


\section{$\mathrm{NaCl}$ solutions}
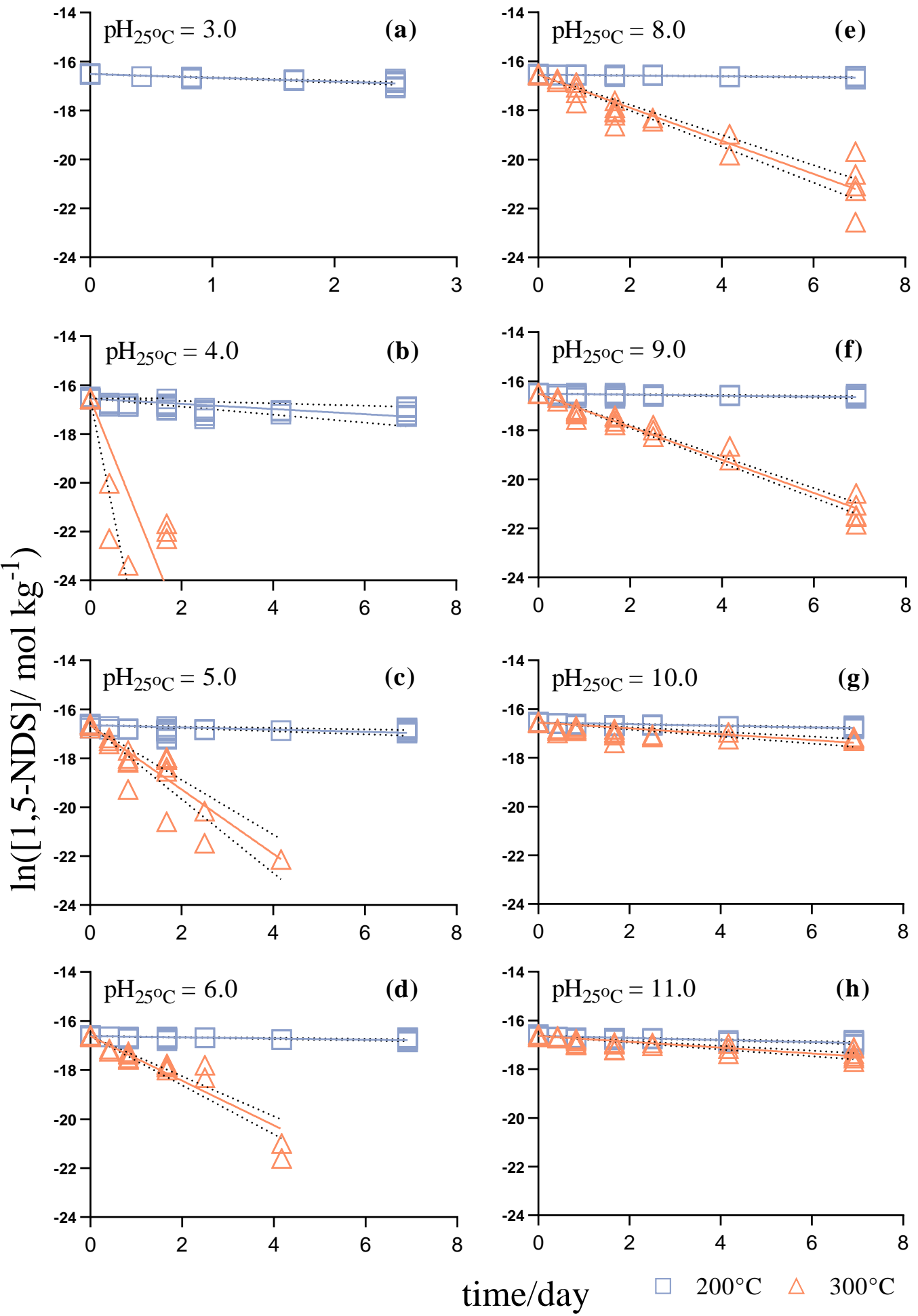

Figure 2.5: Set 2. Concentrations $\left(\mathrm{mol} \mathrm{kg}^{-1}\right)$ of $1,5-\mathrm{NDS}$ after heating at 200 and $300^{\circ} \mathrm{C}$ at saturated vapour pressure and $\mathrm{pH}_{25^{\circ} \mathrm{C}}=3.0-11.0, \mathrm{NaCl}=0.050 \mathrm{~mol} \mathrm{~kg}^{-1}$ for $10,20,40,60$, 100 and 166 hours. The linear least squares line (solid) lies within the 95\% confidence band (dashed). 
Table 2.4a: Set 2 (see Table 2.2a). Rate constants for the decomposition of 1,5-NDS at temperature, experimental $\mathrm{pH}$ and temperatures in distilled water at saturated vapour pressure. At $300^{\circ} \mathrm{C}$ and at $\mathrm{pH}_{\mathrm{t}}=3.0$ and 4.0, there is complete and rapid breakdown of 1,5-NDS and it was not detected after 576 minutes.

\begin{tabular}{|c|c|c|c|c|}
\hline $\mathrm{t} /{ }^{\circ} \mathrm{C}$ & $\mathrm{pH}_{25^{\circ} \mathrm{C}}$ & $\mathrm{pH}_{\mathrm{t}}^{*}$ & $\begin{array}{c}1^{\text {st }} \text { order reaction rate } \\
\text { constant } \mathrm{k} / \mathrm{day}^{-1}\end{array}$ & $\begin{array}{c}1^{\text {st }} \text { order reaction rate } \\
\text { constant } \mathrm{k} / \mathrm{s}^{-1}\end{array}$ \\
\hline 200 & 3.0 & 3.0 & $0.348 \pm 0.052$ & $4.0 \times 10^{-6} \pm 6.0 \times 10^{-7}$ \\
\hline 200 & 4.0 & 4.0 & $0.369 \pm 0.031$ & $4.3 \times 10^{-6} \pm 3.6 \times 10^{-7}$ \\
\hline 200 & 5.0 & 5.0 & $0.059 \pm 0.008$ & $6.8 \times 10^{-7} \pm 9.3 \times 10^{-8}$ \\
\hline 200 & 6.0 & 5.6 & $0.076 \pm 0.010$ & $8.8 \times 10^{-7} \pm 1.2 \times 10^{-7}$ \\
\hline 200 & 8.0 & 5.7 & $0.077 \pm 0.039$ & $8.9 \times 10^{-7} \pm 4.5 \times 10^{-7}$ \\
\hline 200 & 9.0 & 6.3 & $0.068 \pm 0.007$ & $7.9 \times 10^{-7} \pm 8.1 \times 10^{-8}$ \\
\hline 200 & 10.0 & 7.3 & $0.076 \pm 0.004$ & $8.8 \times 10^{-7} \pm 4.9 \times 10^{-8}$ \\
\hline 200 & 11.0 & 8.2 & $0.076 \pm 0.010$ & $8.8 \times 10^{-7} \pm 1.2 \times 10^{-7}$ \\
\hline 300 & 5.0 & 5.0 & $3.752 \pm 0.258$ & $4.3 \times 10^{-5} \pm 3.0 \times 10^{-6}$ \\
\hline 300 & 6.0 & 5.6 & $3.993 \pm 0.126$ & $4.6 \times 10^{-5} \pm 1.5 \times 10^{-6}$ \\
\hline 300 & 8.0 & 5.7 & $3.877 \pm 0.386$ & $4.5 \times 10^{-5} \pm 4.5 \times 10^{-6}$ \\
\hline 300 & 9.0 & 6.3 & $1.400 \pm 0.083$ & $1.6 \times 10^{-5} \pm 9.6 \times 10^{-7}$ \\
\hline 300 & 10.0 & 7.3 & $0.442 \pm 0.079$ & $5.1 \times 10^{-6} \pm 9.1 \times 10^{-7}$ \\
\hline 300 & 11.0 & 8.3 & $0.501 \pm 0.026$ & $5.8 \times 10^{-6} \pm 3.0 \times 10^{-7}$ \\
\hline
\end{tabular}

$* \mathrm{pH}$ at temperature
Table 2.4b: Set 2 (see Table 2.2b). Rate constants for the decomposition of 1,5-NDS at temperature, experimental $\mathrm{pH}$ and temperatures in $\mathrm{NaCl}=0.050 \mathrm{~mol} \mathrm{~kg}^{-1}$ solutions at saturated vapour pressure. At $300^{\circ} \mathrm{C}$ and at $\mathrm{pH}_{\mathrm{t}}=3.0$, there is complete and rapid breakdown of 1,5-NDS and it was not detected after 576 minutes.

\begin{tabular}{|c|c|c|c|c|}
\hline $\mathrm{t} /{ }^{\circ} \mathrm{C}$ & $\mathrm{pH}_{25^{\circ} \mathrm{C}}$ & $\mathrm{pH}_{\mathrm{t}}^{*}$ & $\begin{array}{l}1^{\text {st }} \text { order reaction rate } \\
\text { constant } \mathrm{k} / \mathrm{day}^{-1}\end{array}$ & $\begin{array}{l}1^{\text {st }} \text { order reaction rate } \\
\text { constant } \mathrm{k} / \mathrm{s}^{-1}\end{array}$ \\
\hline 200 & 3.0 & 3.0 & $0.154 \pm 0.007$ & $1.8 \times 10^{-6} \pm 8.1 \times 10^{-8}$ \\
\hline 200 & 4.0 & 4.0 & $0.080 \pm 0.024$ & $9.3 \times 10^{-7} \pm 2.8 \times 10^{-7}$ \\
\hline 200 & 5.0 & 5.0 & $0.028 \pm 0.008$ & $3.2 \times 10^{-7} \pm 9.3 \times 10^{-8}$ \\
\hline 200 & 6.0 & 5.5 & $0.019 \pm 0.003$ & $2.2 \times 10^{-7} \pm 3.5 \times 10^{-8}$ \\
\hline 200 & 8.0 & 5.7 & $0.014 \pm 0.002$ & $1.6 \times 10^{-7} \pm 2.3 \times 10^{-8}$ \\
\hline 200 & 9.0 & 6.3 & $0.014 \pm 0.003$ & $1.6 \times 10^{-7} \pm 3.5 \times 10^{-8}$ \\
\hline 200 & 10.0 & 7.3 & $0.029 \pm 0.003$ & $3.4 \times 10^{-7} \pm 3.5 \times 10^{-8}$ \\
\hline 200 & 11.0 & 8.2 & $0.055 \pm 0.003$ & $6.4 \times 10^{-7} \pm 3.5 \times 10^{-8}$ \\
\hline 300 & 4.0 & 4.2 & $2.330 \pm 0.612$ & $2.7 \times 10^{-5} \pm 7.1 \times 10^{-6}$ \\
\hline 300 & 5.0 & 5.2 & $1.315 \pm 0.095$ & $1.5 \times 10^{-5} \pm 1.1 \times 10^{-6}$ \\
\hline 300 & 6.0 & 5.6 & $0.909 \pm 0.045$ & $1.1 \times 10^{-5} \pm 5.2 \times 10^{-7}$ \\
\hline 300 & 8.0 & 5.7 & $0.675 \pm 0.029$ & $7.8 \times 10^{-6} \pm 3.4 \times 10^{-7}$ \\
\hline 300 & 9.0 & 6.6 & $0.676 \pm 0.016$ & $7.8 \times 10^{-6} \pm 1.9 \times 10^{-7}$ \\
\hline 300 & 10.0 & 7.3 & $0.121 \pm 0.012$ & $1.4 \times 10^{-6} \pm 1.4 \times 10^{-7}$ \\
\hline 300 & 11.0 & 8.2 & $0.121 \pm 0.009$ & $1.4 \times 10^{-6} \pm 1.0 \times 10^{-7}$ \\
\hline
\end{tabular}

$* \mathrm{pH}$ at temperatur 
and be logarithmically expressed as,

$$
\ln \left(C_{t}\right)=-\mathrm{kt}+\text { const }
$$

where 'const' is the constant of integration. Consequently,

$$
\begin{aligned}
& C_{t}=e^{-k t+\text { const }} \\
& C_{t}=e^{\text {const }} \cdot e^{-k t} \\
& e^{\text {const }}=C_{0}
\end{aligned}
$$

where,

Therefore, the final form of the rate law is:

$$
\mathrm{C}_{\mathrm{t}}=\mathrm{C}_{0} \cdot \mathrm{e}^{-\mathrm{kt}}
$$

which can be used to calculate concentration of the reactant at any time.

The Arrhenius plot of $\ln \mathrm{k}$ versus 1/T (Figure 2.6a) for 1,5-NDS shows the effect of the change of temperature on the rate constant. The activation energy, $E_{a}$, and pre-exponential factor, $\mathrm{A}_{0}$, are listed in Table 2.5. The resulting data were used to obtain a plot of half-life vs temperature (Figure 2.6b). Results from previous publications are included for comparison.

\begin{tabular}{|c|c|c|c|c|c|c|c|c|}
\hline solution & $\mathrm{t} /{ }^{\circ} \mathrm{C}$ & duration & $\mathrm{pH}_{25^{\circ} \mathrm{C}}$ & salinity & $\mathrm{A}_{0} / \mathrm{day}^{-1}$ & $\mathrm{E}_{\mathrm{a}} / \mathrm{kJ} \mathrm{mol}^{-1}$ & $\mathrm{R}^{2}$ & source \\
\hline Phosphate buffer & $310-330$ & 1 week & 6.5 & 0.01 & $3.5 \times 10^{16}$ & 205 & 0.94 & $\mathrm{i}$ \\
\hline Phosphate buffer & $260-350$ & $40 \mathrm{~h}$ & 6.5 & 0.01 & $4.1 \times 10^{13}$ & 150 & 0.93 & ii \\
\hline Geothermal brine* & $260-350$ & $40 \mathrm{~h}$ & 4.2 & 0.01 & $2.3 \times 10^{11}$ & 125 & 0.78 & ii \\
\hline Geothermal brine ${ }^{* *}$ & $270-330$ & $60 \mathrm{~h}$ & 6.1 & 0.01 & $2.1 \times 10^{15}$ & 183 & 0.99 & iii \\
\hline $\mathrm{NaCl}$ & $260-350$ & $40 \mathrm{~h}$ & 7.0 & 0.04 & $4.4 \times 10^{11}$ & 129 & 0.78 & ii \\
\hline Deionized water & $260-350$ & $40 \mathrm{~h}$ & ” & - & $9.6 \times 10^{12}$ & 133 & 0.94 & ii \\
\hline $\mathrm{NaCl}$ & $200-330$ & up to 3 months & 7.0 & 0.05 & $2.2 \times 10^{10}$ & 117 & 0.99 & this study \\
\hline $\mathrm{NaCl}+$ pyrite & $250-300$ & up to 1.5 months & ” & 0.05 & $3.9 \times 10^{10}$ & 118 & 0.99 & ” \\
\hline $\mathrm{Na}_{2} \mathrm{SO}_{4}$ & $250-300$ & ” & $"$ & 0.02 & $7.4 \times 10^{6}$ & 88 & 0.98 & ” \\
\hline $\mathrm{NaCl}$ and $\mathrm{Na}_{2} \mathrm{~S}$ & $250-300$ & $"$ & ” & 0.05 & $3.4 \times 10^{10}$ & 118 & 0.99 & $"$ \\
\hline
\end{tabular}

Table 2.5: Arrhenius constants for the decomposition of 1,5-naphthalene disulfonate.

Geothermal brine: $\mathrm{pH}$-modified* and raw brine** from the Rotokawa geothermal field (see Table 2.6.). Salinity refers to total concentration of dissolved salts (molal) at $25^{\circ} \mathrm{C} . \mathrm{A}_{0}$ is the pre-exponential factor. $\mathrm{E}_{\mathrm{a}}$ is the activation energy. $\mathrm{R}^{2}=$ minimised sum of squares from linear regression.

(i): Rose et al., 2001, (ii): Dashkevich et al., 2014, (iii): Mountain \& Winick, 2012. 
Table 2.6: Composition of geothermal fluid from Rotokawa geothermal field, $\mathrm{pH}_{\mathrm{t}}=5.75$ (Krupp \& Seward, 1987).

\begin{tabular}{rlrl}
\hline species & mmol kg-1 & species & $\mathrm{mmol} \mathrm{kg}^{-1}$ \\
\hline $\mathrm{Na}^{+}$ & 19.40 & $\mathrm{Li}^{+}$ & 1.07 \\
$\mathrm{~K}^{+}$ & 3.47 & $\mathrm{SiO}_{2}$ & 11.164 \\
$\mathrm{Ca}^{+}$ & $40.67 \times 10^{-3}$ & $\mathrm{Cl}^{-}$ & 22.74 \\
$\mathrm{Mg}^{+}$ & $0.41 \times 10^{-3}$ & $\mathrm{SO}_{4}^{-}$ & $56.52 \times 10^{-3}$
\end{tabular}

\subsubsection{The formation of 1-NSA}

\subsubsection{Set 1}

In the experiments, where only $1,5-\mathrm{NDS}$ is present in the initial solution (i.e. Set 1), decay of 1,5-NDS to 1-NSA is observed (Figure 2.7). $\mathrm{In} \mathrm{NaCl}=0.050 \mathrm{~m}$ solutions (with pyrite and $\mathrm{Na}_{2} \mathrm{~S}=2.69 \times 10^{-5} \mathrm{~m}$ ) at 250 and $270^{\circ} \mathrm{C}, 1-\mathrm{NSA}$ is formed with its concentration initially increasing and then is decreasing with time. This suggests that 1-NSA is initially formed and then followed by subsequent 1-NSA breakdown. In $\mathrm{Na}_{2} \mathrm{SO}_{4}=0.020 \mathrm{~m}$ solution at 250 and $270^{\circ} \mathrm{C}, 1-\mathrm{NSA}$ is stable to the end of the experiment (i.e. 41 and 24 days respectively; Figure 2.7a,b).

At $300^{\circ} \mathrm{C}$, and for the $\mathrm{NaCl}=0.050 \mathrm{~m}+$ pyrite experiment, $1-\mathrm{NSA}$ remains close to detection limit over the entire experiment (Figure 2.7c). At $300^{\circ} \mathrm{C}$, and $\mathrm{NaCl}=0.050 \mathrm{~m}+\mathrm{Na}_{2} \mathrm{~S}$ $=2.69 \times 10^{-5} \mathrm{~m}$ (pyrite not present), 1-NSA concentration increases in the first 4 days, and then decreases until day 10, after which it remains below detection limit (Figure 2.7c). At $300^{\circ} \mathrm{C}$ and $\mathrm{Na}_{2} \mathrm{SO}_{4}=0.020 \mathrm{~m}, 1$-NSA concentration increases for the first 8 days and then decreases with time (Figure 2.7c). In general, 1-NSA stability is $\mathrm{pH}$ and temperature-dependent and its formation is dependent on the 1,5-NDS decomposition rate.

\subsubsection{Set 2}

In the Set 2, the 1-NSA isomer is also detected as a breakdown product of 1,5-NDS; however, the results are dependent on the $\mathrm{pH}$ and temperature of each experiment. Note that 1-NSA is also observed as a breakdown product of various other NSA and NDS isomers by Mountain and Winick (2012).

At $200^{\circ} \mathrm{C}, \mathrm{NaCl}=0.050 \mathrm{~m}$ and $\mathrm{pH}_{25^{\circ} \mathrm{C}}=4.0$ to $11.0,1-\mathrm{NSA}$ increases slowly and remained stable for one week (Figure 2.8). The most significant increase in concentration of 


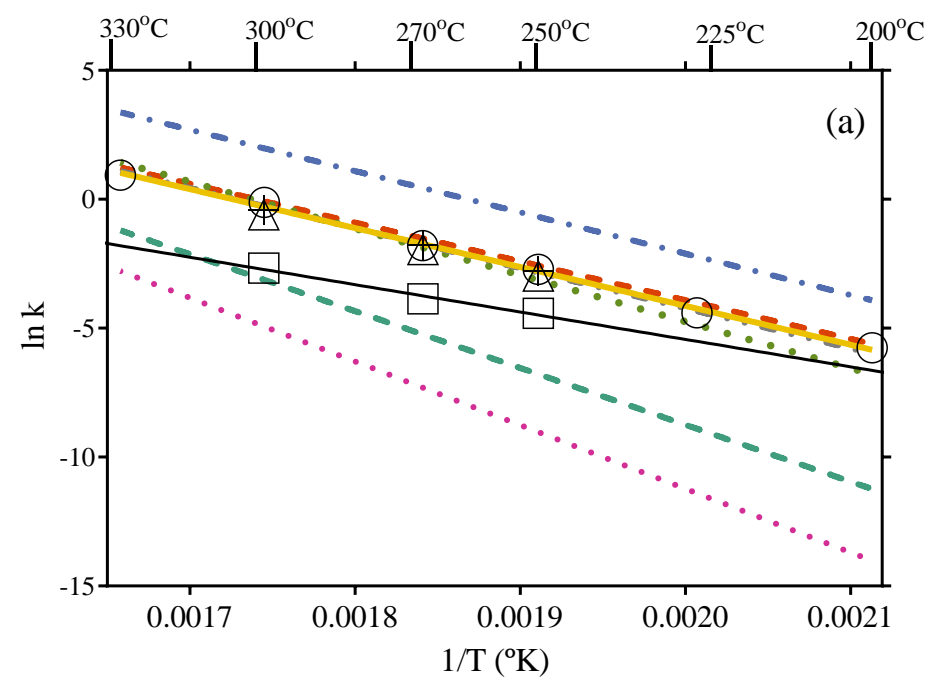

This study:

$+\mathrm{NaCl}=0.050 \mathrm{~mol} \mathrm{~kg}^{-1}+$ pyrite $\left(\mathrm{FeS}_{2}\right)$,

$\square \mathrm{Na}_{2} \mathrm{SO}_{4}=0.020 \mathrm{~mol} \mathrm{~kg}^{-1}$,

$\triangle \mathrm{NaCl}=0.050 \mathrm{~mol} \mathrm{~kg}^{-1}+\mathrm{Na}_{2} \mathrm{~S}=2.69 \times 10^{-5} \mathrm{~mol} \mathrm{~kg}^{-1}$,

$\mathrm{NaCl}=0.050 \mathrm{~mol} \mathrm{~kg}^{-1}$,

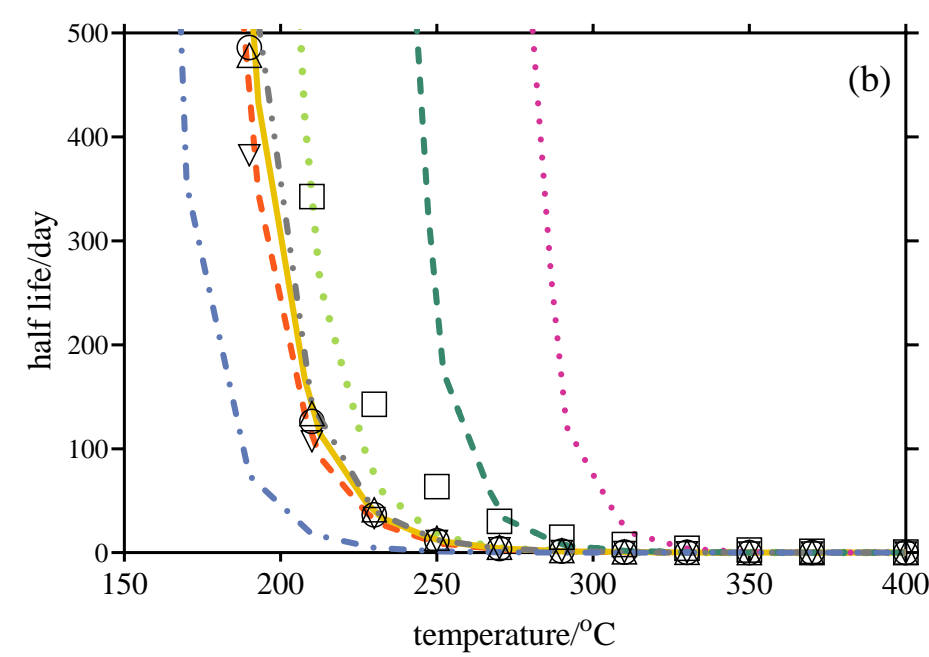

previous studies:

. phosphate buffer $=0.01 \mathrm{~mol} \mathrm{~kg}^{-1}, \mathrm{pH}_{25^{\circ} \mathrm{C}}=6.5$, (i)

- geothermal brine, $\mathrm{pH}_{25^{\circ} \mathrm{C}}=4.2$, (ii)

- deionized water, (ii)

- $\mathrm{NaCl}=0.4 \mathrm{~mol} \mathrm{~kg}^{-1}$, (ii)

- phosphate buffer $=0.01 \mathrm{~mol} \mathrm{~kg}^{-1}, \mathrm{pH}_{25^{\circ} \mathrm{C}}=6.5$, (ii)

- geothermal brine, $\mathrm{pH}_{25^{\circ} \mathrm{C}}=6.1$, (iii)

Figure 2.6: (a) Arrhenius plots of $\ln \mathrm{k}$ (for 1,5-NDS) versus $1 / \mathrm{T}\left({ }^{\circ} \mathrm{K}\right)$ between 200 and $330^{\circ} \mathrm{C}$ and saturated vapour pressure. (b) Half-life vs. temperature based on the Arrhenius decay results. Buffer: Monopotassium phosphate / Disodium phosphate; Geothermal brine - pH-modified brine from Nga Awa Purua power station, Rotokawa geothermal field; (i) Rose et al., 2001; (ii) Dashkevich et al., 2014; (iii) Mountain \& Winick, 2012. 
1-NSA is observed at $\mathrm{pH}_{25^{\circ} \mathrm{C}}=11.0$, however, the 1-NSA measured concentrations are low and close to the detection limit.

At $200^{\circ} \mathrm{C}$ and distilled water (Figure 2.8), comparable results to $\mathrm{NaCl}=0.050 \mathrm{~m}$ are found, except at $\mathrm{pH}_{25^{\circ} \mathrm{C}}=3.0$ and 4.0, with 1-NSA concentration increasing to a maximum after 0.83 days, and then slowly decreasing.

At $300^{\circ} \mathrm{C}, \mathrm{NaCl}=0.050 \mathrm{~m}$ and $\mathrm{pH}_{25^{\circ} \mathrm{C}}=4.0$ to $6.0,1-\mathrm{NSA}$ concentration initially increases during the first three days (Figure 2.9a,d) and thereafter decreases with increasing time. At $\mathrm{pH} \geq 8.0,1$-NSA isomer remains stable to the end of the experiments (i.e. 7 days; Figure $2.9 \mathrm{e}, \mathrm{h}$ ), at $\mathrm{pH}_{25^{\circ} \mathrm{C}}=3.0$, the 1 -NSA concentration is below detection limit. It should be noted that the formation of $1-\mathrm{NSA}$ was greater at $300^{\circ} \mathrm{C}$ than at $200^{\circ} \mathrm{C}$. In distilled water, the concentration of 1-NSA increases over first three days and then gradually decreases with increasing time at $300^{\circ} \mathrm{C}$.

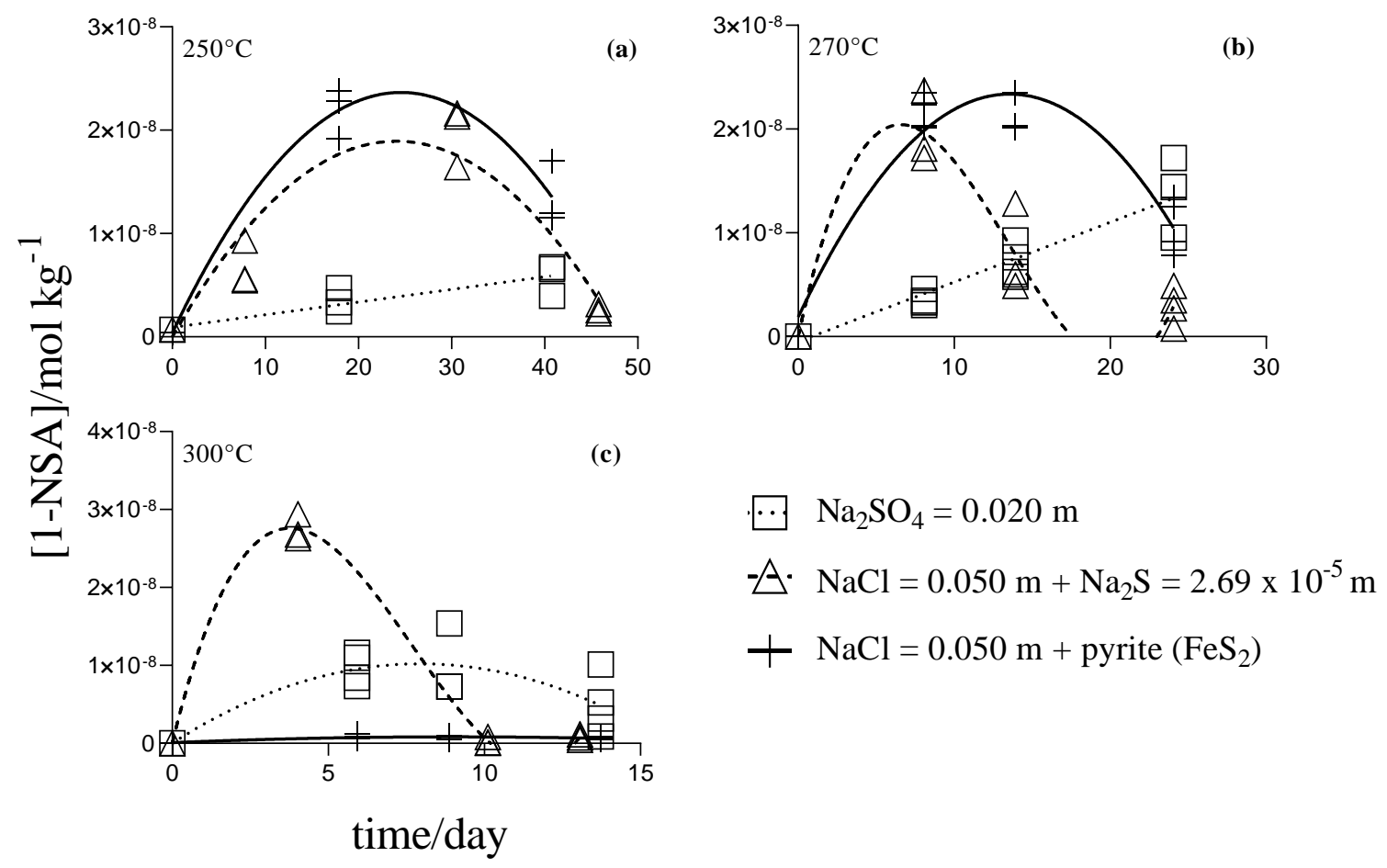

Figure 2.7: Set 1 (Table 2.1). Concentrations $\left(\mathrm{mol} \mathrm{kg}^{-1}\right)$ of 1-NSA versus time (days) after heating at (a) $250^{\circ} \mathrm{C}$, (b) $270^{\circ} \mathrm{C}$ and (c) $300^{\circ} \mathrm{C}$ and the saturated vapour pressure. Experimental solutions: $\mathrm{NaCl}=0.050$ mol $\mathrm{kg}^{-1}+$ pyrite; $\mathrm{Na}_{2} \mathrm{SO}_{4}=0.020 \mathrm{~mol} \mathrm{~kg}^{-1}$; and $\mathrm{NaCl}=0.050 \mathrm{~mol} \mathrm{~kg}^{-1}+\mathrm{Na}_{2} \mathrm{~S}=2.69 \times 10^{-5} \mathrm{~mol} \mathrm{~kg}^{-1}$. 


$$
\mathrm{t}=200^{\circ} \mathrm{C}
$$
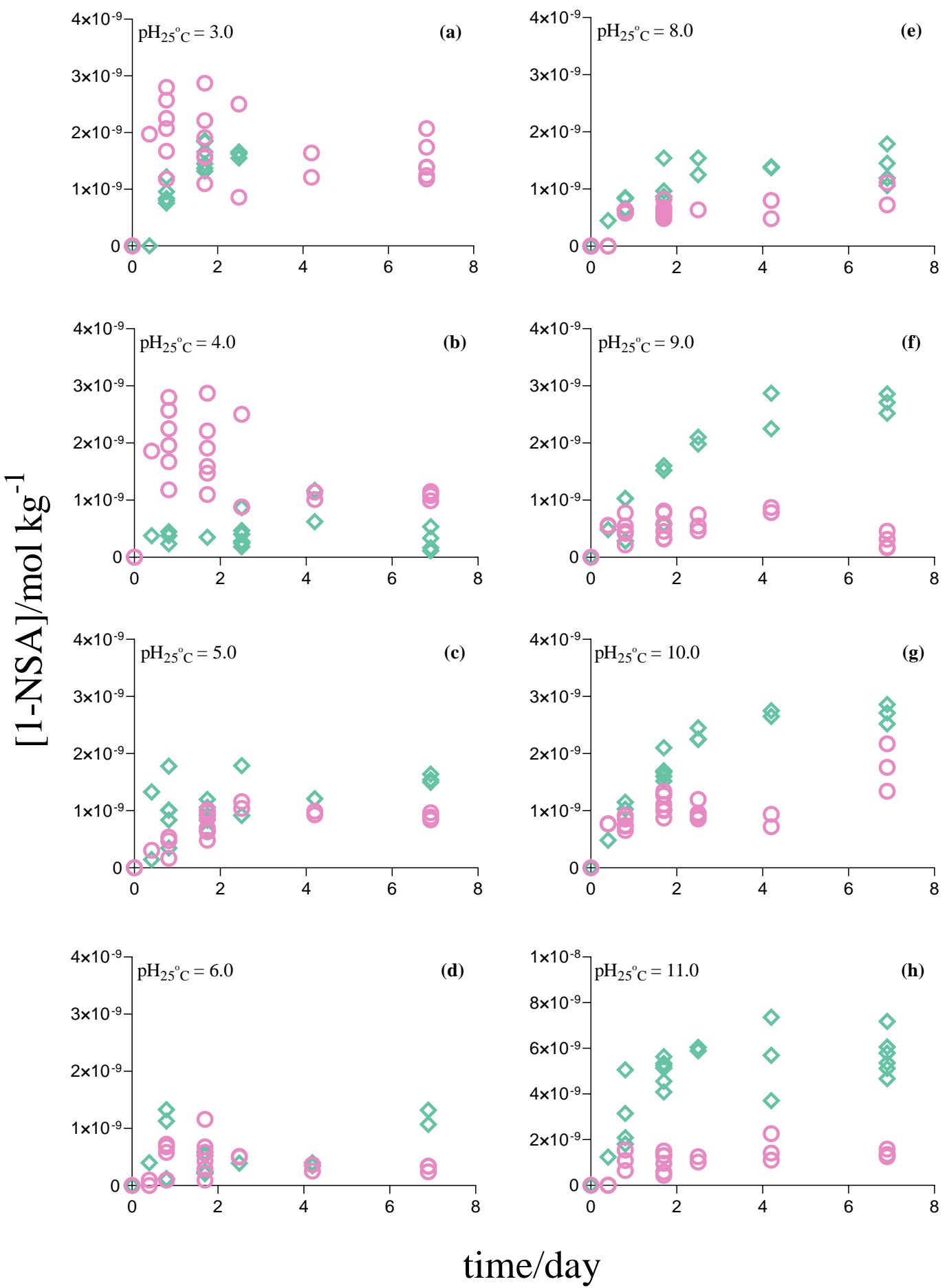

distilled water

$\mathrm{NaCl}=0.050 \mathrm{~m}$

Figure 2.8: Set 2. Concentrations $\left(\mathrm{mol} \mathrm{kg}^{-1}\right)$ of 1-NSA (distilled water and $\mathrm{NaCl}$ solution) versus time (day) after heating at $200^{\circ} \mathrm{C}$ and $\mathrm{pH}_{25^{\circ} \mathrm{C}}=3.0-11.0$ at saturated vapour pressure. Distilled water (pink), $\mathrm{NaCl}=0.050 \mathrm{~mol} \mathrm{~kg}^{-1}$ (green) for 7 days. 
$\mathrm{t}=300^{\circ} \mathrm{C}$
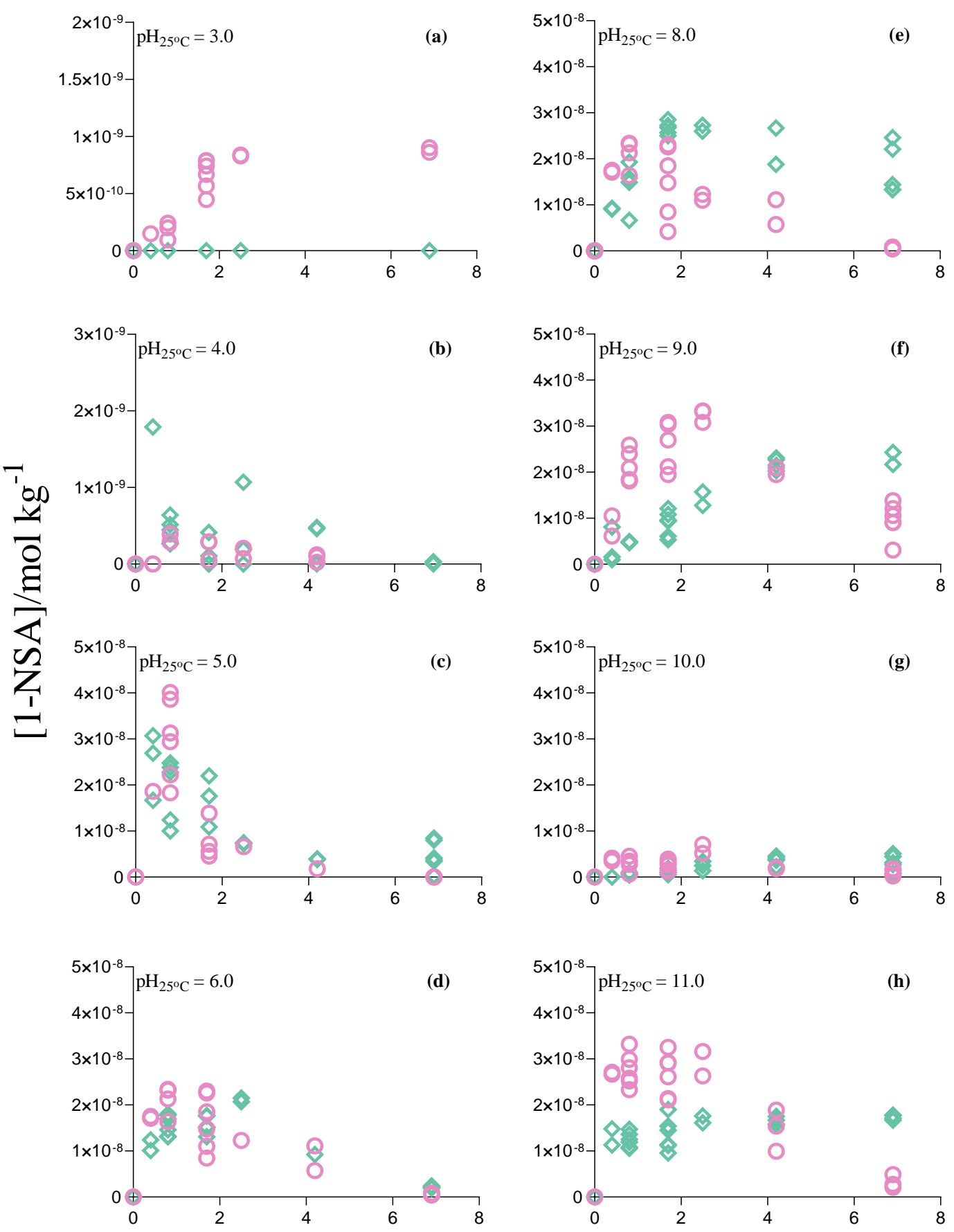

\section{time/day}

distilled water

$\mathrm{NaCl}=0.050 \mathrm{~m}$

Figure 2.9: Set 2. Concentrations $\left(\mathrm{mol} \mathrm{kg}^{-1}\right)$ of 1-NSA (distilled water and $\mathrm{NaCl}$ solution) versus time (day) after heating at $300^{\circ} \mathrm{C}$ and $\mathrm{pH}_{25^{\circ} \mathrm{C}}=3.0-11.0$ at saturated vapour pressure. Distilled water (pink), $\mathrm{NaCl}=0.050 \mathrm{~mol} \mathrm{~kg}^{-1}$ (green) for 7 days. 


\subsubsection{The stability of 2-NSA}

The kinetic data derived from measurements of 2-NSA concentration changes (Figure 2.10 and 2.11) as function of time are listed in Tables $2.7 \mathrm{a}$ and $2.7 \mathrm{~b}$.

At $200^{\circ} \mathrm{C}$ in distilled water, 2-NSA breakdown is detectable in all experiments. The rate constant, $\mathrm{k}$, decreases with increasing $\mathrm{pH}$ from $\mathrm{k}=0.210$ day $^{-1}$ at $\mathrm{pH}_{25^{\circ} \mathrm{C}}=3.0$ to $\mathrm{k}=0.025$ day $^{-1}$ at $\mathrm{pH}_{25^{\circ} \mathrm{C}}=5.0-10.0$. It increases again at $\mathrm{pH}_{25^{\circ} \mathrm{C}}=11.0$ to $\mathrm{k}=0.087$ day $^{-1}$ (Table 2.7a). In $\mathrm{NaCl}=0.050 \mathrm{~m}, 2-\mathrm{NSA}$ did not change its concentration over time from $\mathrm{pH}_{25^{\circ} \mathrm{C}}=3.0$ to 10.0 . At $\mathrm{pH}_{25^{\circ} \mathrm{C}} \geq 11.0,2-\mathrm{NSA}$ is destabilised and the rate constant, $\mathrm{k}$, increased to 0.079 day $^{-1}$ (Table 2.7b). The overall rate of decomposition is very slow compared to experimental results at $300^{\circ} \mathrm{C}$

At $300^{\circ} \mathrm{C}$ and distilled water, 2-NSA responds similarly to $\mathrm{pH}$ changes. The lowest value of $\mathrm{k}=0.026 \mathrm{day}^{-1}$ is observed at $\mathrm{pH}_{25^{\circ} \mathrm{C}}=10.0$ (Table 2.7a). $\mathrm{In} \mathrm{NaCl}=0.050 \mathrm{~m}$, the decomposition rate of 2-NSA decreases from $\mathrm{k}=1.746$ day $^{-1}$ at $\mathrm{pH}_{25^{\circ} \mathrm{C}}=3.0$ to $\mathrm{k}=0$ day $^{-1}$ at $\mathrm{pH}_{25^{\circ} \mathrm{C}}=6.0$ - 9.0. It increases again to $\mathrm{k}=0.060$ day $^{-1}$ at $\mathrm{pH}_{25^{\circ} \mathrm{C}}=11.0$ (Table 2.7b).

Decreasing $\mathrm{k}$ values at near neutral $\mathrm{pH}$ is an overall trend at 200 and $300^{\circ} \mathrm{C}$ both in $\mathrm{NaCl}=0.050 \mathrm{~m}$ and distilled water, except at $200^{\circ} \mathrm{C}$ and $\mathrm{NaCl}=0.050 \mathrm{~m}$ where 2-NSA is not destabilised by $\mathrm{pH}_{25}{ }^{\circ} \mathrm{C} \leq 9.0$. A similar pattern was observed for 1,5-NDS. Note that 2-NSA was not added to the Set 1 experiments and did not form from 1,5-NDS decay. 2-NSA concentration remains below detection limit for all three experiments where only 1,5-NDS is present in the initial solution (i.e. Set 1). Consequently, it has not been considered in Figures 2.10 and 2.11 .

In summary, in distilled water at $\mathrm{pH}_{25^{\circ} \mathrm{C}} \geq 5$ at both 200 and $300^{\circ} \mathrm{C}$, the breakdown of 2-NSA after 7 days is either negligible or small. At $\mathrm{pH}_{25^{\circ} \mathrm{C}} \leq 4$, a small but measurable disproportionation of 2-NSA is observed at $200^{\circ} \mathrm{C}$, however at $300^{\circ} \mathrm{C}, 2-\mathrm{NSA}$ breakdown proceeds more rapidly. In $\mathrm{NaCl}$ solution, 2-NSA is apparently stable until $\mathrm{pH}_{25^{\circ} \mathrm{C}} \geq 10$ at $200^{\circ} \mathrm{C}$. At $300^{\circ} \mathrm{C}$ and at $\mathrm{pH}_{25^{\circ} \mathrm{C}} \leq 4,2-\mathrm{NSA}$ exhibits breakdown but at $\mathrm{pH}_{25^{\circ} \mathrm{C}} \geq 5$ is little effected by temperature increase up to at $\mathrm{pH}_{25^{\circ} \mathrm{C}}=11$. 


\section{distilled water}
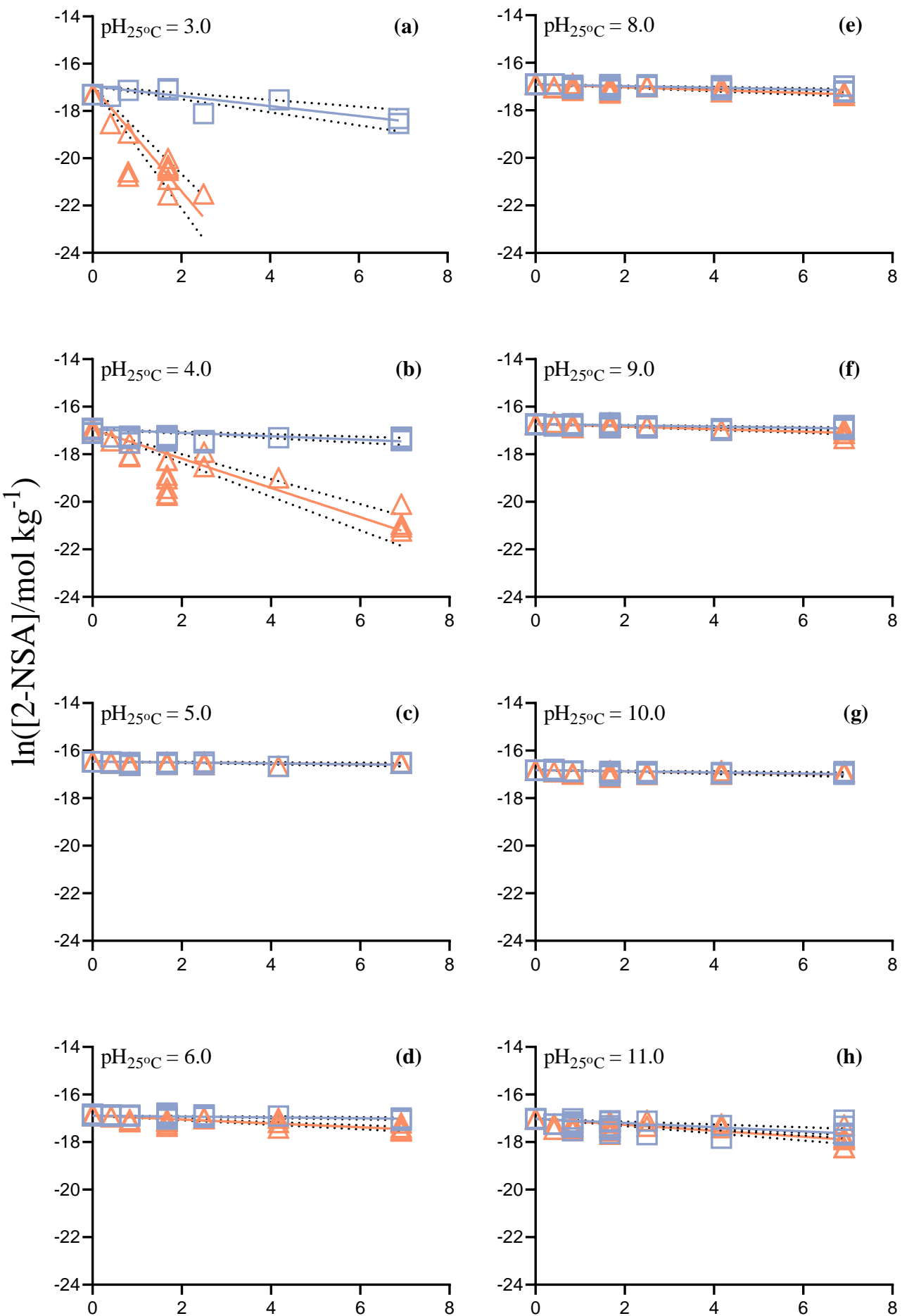

Figure 2.10: Set 2. Concentrations $\left(\mathrm{mol} \mathrm{kg}^{-1}\right)$ of 2-NSA in distilled water at 200 and $300^{\circ} \mathrm{C}$, and at saturated vapour pressure, and $\mathrm{pH}_{25^{\circ} \mathrm{C}}=3.0-11.0$ for $10,20,40,60,100$ and 166 hours. The linear least squares line (solid) lies within the 95\% confidence band (dashed). 
$\mathrm{NaCl}$ solutions
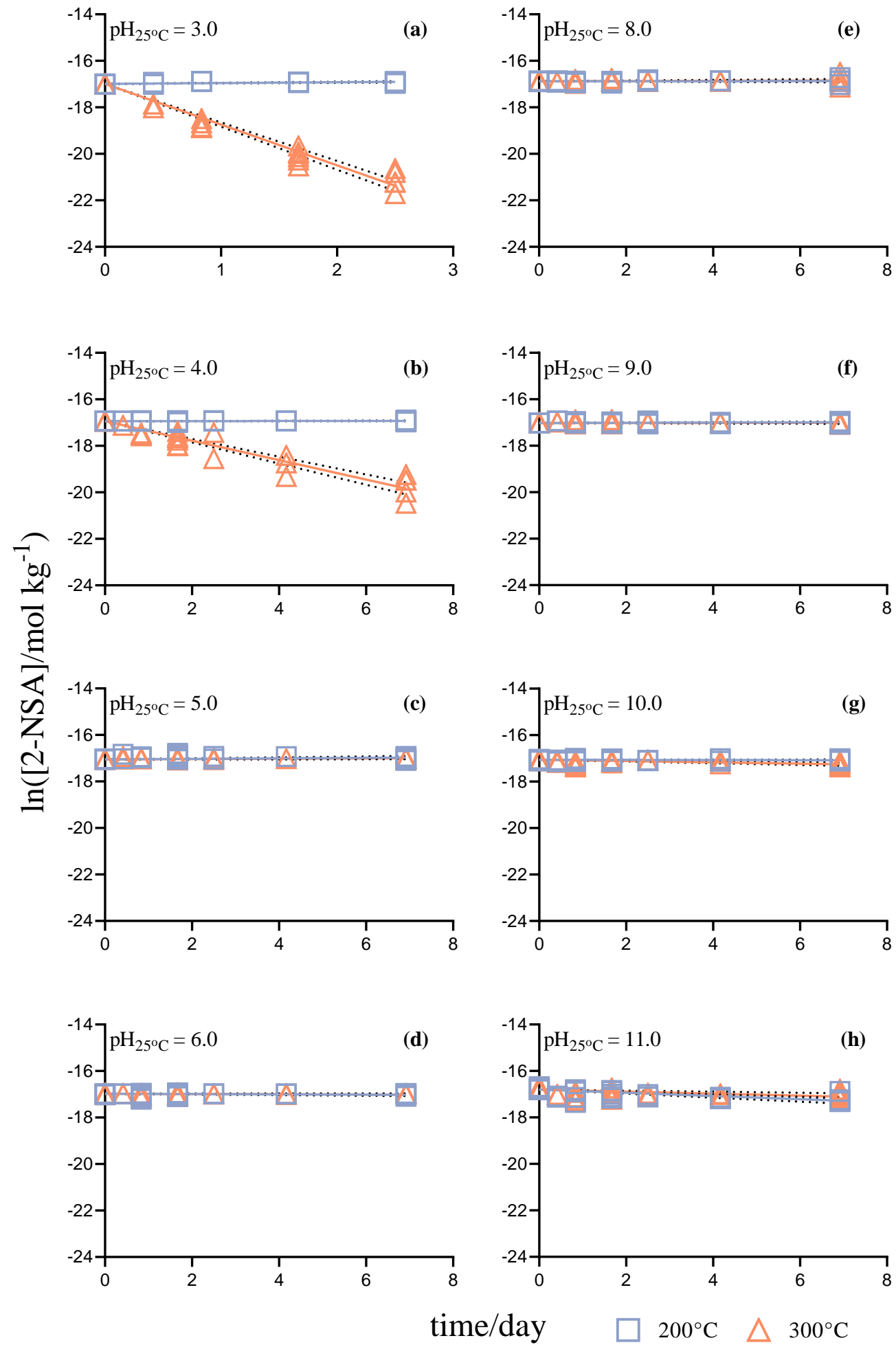

Figure 2.11: Set 2. Concentrations $\left(\mathrm{mol} \mathrm{kg}^{-1}\right)$ of 2-NSA in $\mathrm{NaCl}=0.050 \mathrm{~mol} \mathrm{~kg}^{-1}$ solution at 200 and $300^{\circ} \mathrm{C}$ and at saturated vapour pressure, and $\mathrm{pH}_{25^{\circ} \mathrm{C}}=3.0-11.0$ for $10,20,40,60,100$ and 166 hours. The linear least squares line (solid) lies within the 95\% confidence band (dashed). 
Table 2.7a: Set 2 (see Table 2.2a). Rate constants for the decomposition of 2-NSA at temperature and experimental $\mathrm{pH}$ in distilled water at saturated vapour pressure.

\begin{tabular}{ccccl}
\hline $\mathrm{t} /{ }^{\circ} \mathrm{C}$ & $\mathrm{pH}_{25^{\circ} \mathrm{C}}$ & $\mathrm{pH}_{\mathrm{t}}^{*}$ & $\begin{array}{c}1^{\text {st }} \text { order reaction rate } \\
\text { constant } \mathrm{k} / \text { day }^{-1}\end{array}$ & $\begin{array}{c}1^{\text {st }} \text { order reaction rate } \\
\text { constant } \mathrm{k} / \mathrm{s}^{-1}\end{array}$ \\
\hline 200 & 3.0 & 3.0 & $0.210 \pm 0.030$ & $6.9 \times 10^{-8} \pm 1.4 \times 10^{-7}$ \\
200 & 4.0 & 4.0 & $0.069 \pm 0.015$ & $8.0 \times 10^{-7} \pm 1.7 \times 10^{-7}$ \\
200 & 5.0 & 5.0 & $0.019 \pm 0.005$ & $2.2 \times 10^{-7} \pm 5.8 \times 10^{-8}$ \\
200 & 6.0 & 5.6 & $0.021 \pm 0.004$ & $2.4 \times 10^{-7} \pm 4.6 \times 10^{-8}$ \\
200 & 8.0 & 5.7 & $0.037 \pm 0.004$ & $4.3 \times 10^{-7} \pm 4.6 \times 10^{-8}$ \\
200 & 9.0 & 6.3 & $0.026 \pm 0.003$ & $3.0 \times 10^{-7} \pm 3.5 \times 10^{-8}$ \\
200 & 10.0 & 7.3 & $0.024 \pm 0.003$ & $2.8 \times 10^{-7} \pm 3.5 \times 10^{-8}$ \\
200 & 11.0 & 8.2 & $0.087 \pm 0.014$ & $1.0 \times 10^{-6} \pm 1.6 \times 10^{-7}$ \\
& & & & \\
300 & 3.0 & 3.2 & $1.904 \pm 0.223$ & $2.2 \times 10^{-5} \pm 2.6 \times 10^{-6}$ \\
300 & 4.0 & 4.4 & $0.569 \pm 0.061$ & $6.6 \times 10^{-6} \pm 7.1 \times 10^{-7}$ \\
300 & 5.0 & 5.0 & $0.147 \pm 0.056$ & $1.7 \times 10^{-6} \pm 6.5 \times 10^{-7}$ \\
300 & 6.0 & 5.6 & $0.081 \pm 0.011$ & $9.4 \times 10^{-7} \pm 1.3 \times 10^{-7}$ \\
300 & 8.0 & 5.7 & $0.043 \pm 0.012$ & $5.0 \times 10^{-7} \pm 1.4 \times 10^{-7}$ \\
300 & 9.0 & 6.3 & $0.043 \pm 0.012$ & $5.0 \times 10^{-7} \pm 1.4 \times 10^{-7}$ \\
300 & 10.0 & 7.3 & $0.026 \pm 0.010$ & $3.0 \times 10^{-7} \pm 1.2 \times 10^{-7}$ \\
300 & 11.0 & 8.3 & $0.115 \pm 0.022$ & $1.3 \times 10^{-6} \pm 2.5 \times 10^{-7}$ \\
\hline$* \mathrm{pH}$ at temperature & & &
\end{tabular}

*pH at temperature
Table 2.7b: Set 2 (see Table 2.2b). Rate constants for the decomposition of 2-NSA at temperature and experimental $\mathrm{pH}$ in $\mathrm{NaCl}=0.050 \mathrm{~mol} \mathrm{~kg}^{-1}$ at saturated vapour pressure.

\begin{tabular}{|c|c|c|c|c|}
\hline $\mathrm{t} /{ }^{\circ} \mathrm{C}$ & $\mathrm{pH}_{25^{\circ} \mathrm{C}}$ & $\mathrm{pH}_{\mathrm{t}}^{*}$ & $\begin{array}{c}1^{\text {st }} \text { order reaction rate } \\
\text { constant } \mathrm{k} / \mathrm{day}^{-1}\end{array}$ & $\begin{array}{l}1^{\text {st }} \text { order reaction rate } \\
\text { constant k/ } / \mathrm{s}^{-1}\end{array}$ \\
\hline 200 & 3.0 & 3.0 & no breakdown & no breakdown \\
\hline 200 & 4.0 & 4.0 & no breakdown & no breakdown \\
\hline 200 & 5.0 & 5.0 & no breakdown & no breakdown \\
\hline 200 & 6.0 & 5.5 & no breakdown & no breakdown \\
\hline 200 & 8.0 & 5.7 & no breakdown & no breakdown \\
\hline 200 & 9.0 & 6.3 & no breakdown & no breakdown \\
\hline 200 & 10.0 & 7.3 & no breakdown & no breakdown \\
\hline 200 & 11.0 & 8.2 & $0.079 \pm 0.010$ & $9.1 \times 10^{-7} \pm 1.2 \times 10^{-7}$ \\
\hline 300 & 3.0 & 3.2 & $1.746 \pm 0.075$ & $2.0 \times 10^{-5} \pm 8.7 \times 10^{-7}$ \\
\hline 300 & 4.0 & 4.2 & $0.421 \pm 0.014$ & $4.9 \times 10^{-6} \pm 1.6 \times 10^{-7}$ \\
\hline 300 & 5.0 & 5.2 & no breakdown & no breakdown \\
\hline 300 & 6.0 & 5.6 & no breakdown & no breakdown \\
\hline 300 & 8.0 & 5.7 & no breakdown & no breakdown \\
\hline 300 & 9.0 & 6.6 & $0.023 \pm 0.007$ & $2.7 \times 10^{-7} \pm 8.1 \times 10^{-8}$ \\
\hline 300 & 10.0 & 7.3 & $0.023 \pm 0.007$ & $2.7 \times 10^{-7} \pm 8.1 \times 10^{-8}$ \\
\hline 300 & 11.0 & 8.2 & $0.060 \pm 0.022$ & $6.9 \times 10^{-7} \pm 2.5 \times 10^{-7}$ \\
\hline
\end{tabular}




\subsection{Discussion}

The experimental results demonstrate that $1,5-\mathrm{NDS}$ starts to decompose at $200^{\circ} \mathrm{C}$ and $\mathrm{pH}_{\mathrm{t}}=3.0$ to 8.3 in both distilled water and $\mathrm{NaCl}=0.050 \mathrm{~m}$. Thus, the decomposition rate must be considered when using 1,5-NDS as a geothermal tracer in high enthalpy systems. At $200^{\circ} \mathrm{C}$, $\mathrm{NaCl}=0.050 \mathrm{~m}$ and neutral to alkaline $\mathrm{pH}, 1,5-\mathrm{NDS}$ and its breakdown product, 1-NSA, may be of use as tracers to delineate well connectivity and permeability. However, at $300^{\circ} \mathrm{C}$, 1,5 -NDS decays completely and only 1 -NSA is detected. $1,5-\mathrm{NDS}$ exposed to $200^{\circ} \mathrm{C}$, in $\mathrm{NaCl}$ $=0.050 \mathrm{~m}$ solution at $\mathrm{pH}_{\mathrm{t}} \approx 6$ exhibits the highest stability.

This study has measured the relationship between the 1,5-NDS breakdown product, $1-\mathrm{NSA}$, and $\mathrm{pH}$ of the solution at elevated temperature. At $300^{\circ} \mathrm{C}$ and $\mathrm{NaCl}=0.050 \mathrm{~m}, 1-\mathrm{NSA}$ can be used as a $\mathrm{pH}$ indicator in active geothermal reservoirs. Returns of 1-NDS would be expected as a breakdown product of 1,5-NDS decomposition. However, only at neutral to alkaline $\mathrm{pH}$ (i.e. $\mathrm{pH}_{\mathrm{t}}=5.7-8.3$ ) at $300^{\circ} \mathrm{C}$, is 1-NSA, stable for more than one week. At acidic $\mathrm{pH}$ (i.e. $\left.\mathrm{pH}_{\mathrm{t}} \leq 4\right), 1-\mathrm{NSA}$ detection may be useful if fast returns are observed. If 1-NSA was not injected but is detected within first few weeks (as a breakdown product of 1,5-NDS), the $\mathrm{pH}$ of the geothermal reservoir can be assumed to be acidic if temperature is known. The shorter the period 1-NSA can be detected, the lower is the implied $\mathrm{pH}$ of the reservoir all else being equal.

Our experimental results indicate that 1-NSA, if injected during a tracer test, should be detectable at $\leq 250^{\circ} \mathrm{C}$ for at least 40 days at $\mathrm{pH}_{\mathrm{t}}=5.6-7.0$ and for at least 10 days at $300^{\circ} \mathrm{C}$, at near neutral $\mathrm{pH}$ (Figure 2.7).

\subsubsection{2-NSA - the most stable isomer}

2-NSA is the isomer which is most resistant to temperature, $\mathrm{pH}$ and salinity changes. Its high stability is explained by two inequivalent positions, $\alpha$ or $\beta$ ( 1 or 2 ) of electrophilic substitution of the $-\mathrm{SO}_{3}$ group (Figure 2.12). Substitution at the $\alpha$ position is favoured kinetically over substitution at the $\beta$ position, however, the $\beta$ carbon is thermodynamically more stable (Cerfontain \& Telder, 1967), therefore, for all NDS/NSA, the position of $-\mathrm{SO}_{3}$ group(s) attached to the naphthalene moiety influences their stabilities.

In distilled water, 2-NSA breaks down at both 200 and $300^{\circ} \mathrm{C}$, while 2-NSA stability decreases with increasing $\mathrm{H}^{+}$or $\mathrm{OH}^{-}$concentration with respect to neutral $\mathrm{pH}$. The addition of $\mathrm{NaCl}$ inhibits that process, especially at $200^{\circ} \mathrm{C}$. Additionally, the experiments showed that the 
breakdown of 1,5-NDS does not form significant amounts of 2-NSA at least for the duration of the experiments.

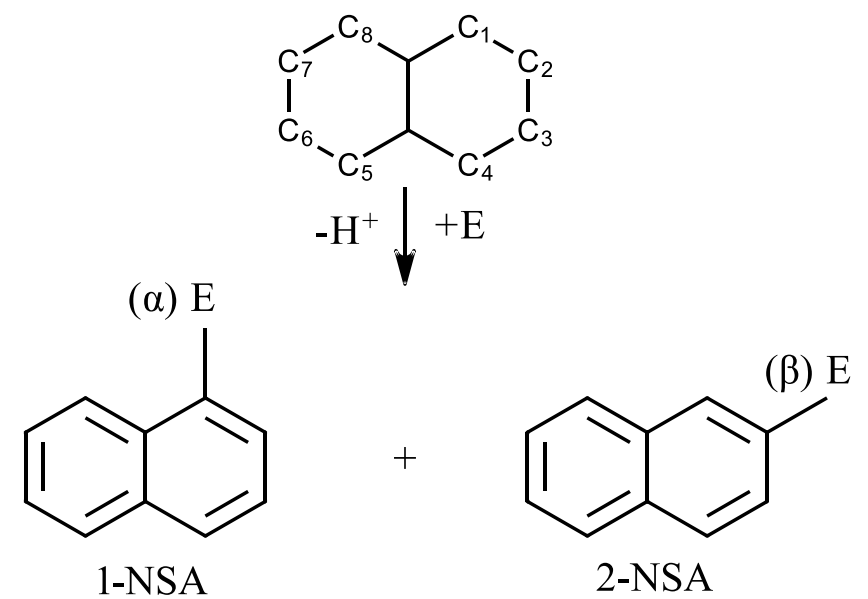

Figure 2.12: Electrophilic aromatic substitution in naphthalene. E: electrophile $\alpha$ - position $C_{1}$, $\beta$ - position $\mathrm{C}_{2}$.

\subsubsection{The pH-dependence of the rate constant}

Figure 2.13 reveals a significant $\mathrm{pH}$ influence on both NDS and NSA molecules decomposition rates. Both 1,5-NDS and 2-NSA are affected by changes in $\mathrm{H}^{+}$and $\mathrm{OH}^{-}$ concentrations. These results are consistent with findings in Chapter 4. It is also noted that the effect of $\mathrm{pH}$ is diminished by increasing salinity.

1,5-NDS experiences the slowest breakdown rates between $\mathrm{pH}_{\mathrm{t}}=6.0$ and 7.0 at all temperatures, whereas, 2-NSA is stable at $200^{\circ} \mathrm{C}$ between $\mathrm{pH}_{\mathrm{t}}=3.0$ and 7.0. This is explained by the higher energy required to protonate 2-NSA in comparison to 1,5-NDS protonation in the $\alpha$ position (Figure 2.12).

The $\mathrm{pH}$-dependence of NDS stability can be explained by a desulfonation mechanism at acid $\mathrm{pH}$. Similar reactions occurring with benzene sulfonates have been well studied. The addition of heat in the presence of excess protons causes replacement of $\mathrm{SO}_{3}{ }^{-}$by $\mathrm{H}^{+}$creating benzene and sulfur trioxide (Bruckner et al., 2010; Wade, 2013, Kozlov et al., 2017). The rate of this process is dependent on the proton $\left(\mathrm{H}^{+}\right)$concentration and the breakdown occurs faster the lower the $\mathrm{pH}$. The protonation rate also increases with temperature increase. It is suggested here that naphthalene sulfonic acids behave similarly. The possible 1,5-NDS acid desulfonation reaction mechanism is thus given by: 


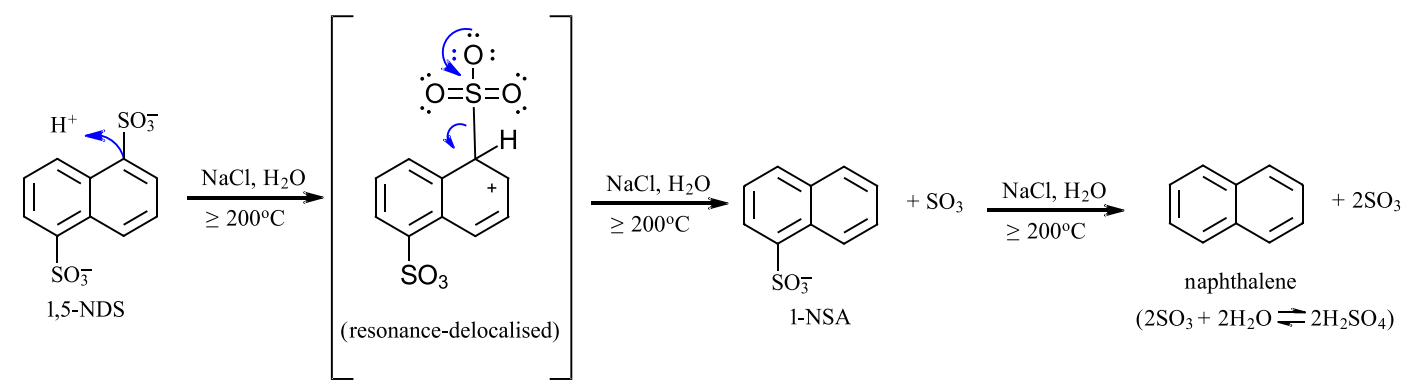

Furthermore, in laboratory experiments, 1,5-NDS reacted with sulfuric acid at $\mathrm{t}=160$ - $220^{\circ} \mathrm{C}$, converts to naphthalene though hydrolysis (Lynch and Scanlan, 1927). The assumption is made here that similar processes take place in geothermal environments.

The experimental findings from this work demonstrate that alkalisation also destabilises both 1,5-NDS and 2-NSA at $\geq 200^{\circ} \mathrm{C}$. Increasing salinity lessens this effect. Simultaneously, naphthol (the monohydroxy derivative of naphthalene) can be created through nucleophilic substitution. Indeed, the reaction of naphthalene sulfonic acids with sodium hydroxide at $300^{\circ} \mathrm{C}$, followed by acidification, is the main industrial method for preparing phenols and naphthols. Thus, nucleophilic substitution of 2-NSA with $\mathrm{NaOH}$ proceeds to sodium 2-naphthoxide and 2-naphthol,<smiles></smiles>

Aromatic nucleophilic substitutions have high activation energies and take place either at high temperature or in presence of R-groups that decrease the activation energy by extending the conjugation of the transition state (Smith and March, 2007; Rokade and Sayyed, 2009). A possible breakdown product of high $\mathrm{pH}$ experiments can be the hygroscopic and alkaline salt of a strong base and a weak acid such as sodium naphthoxide.

In summary, the effect of $\mathrm{pH}$ on stability of NDS and NSA is significant. For example, 2-NSA injected to a reservoir at $300^{\circ} \mathrm{C}$ with near neutral $\mathrm{pH}_{\mathrm{t}}$ will remain detectable for years, whereas injection into a reservoir at the same temperature but lower $\mathrm{pH}$ (e.g. at $\mathrm{pH}_{\mathrm{t}} \leq 5$ ), would lead to 2-NSA disproportionation within weeks to months. 

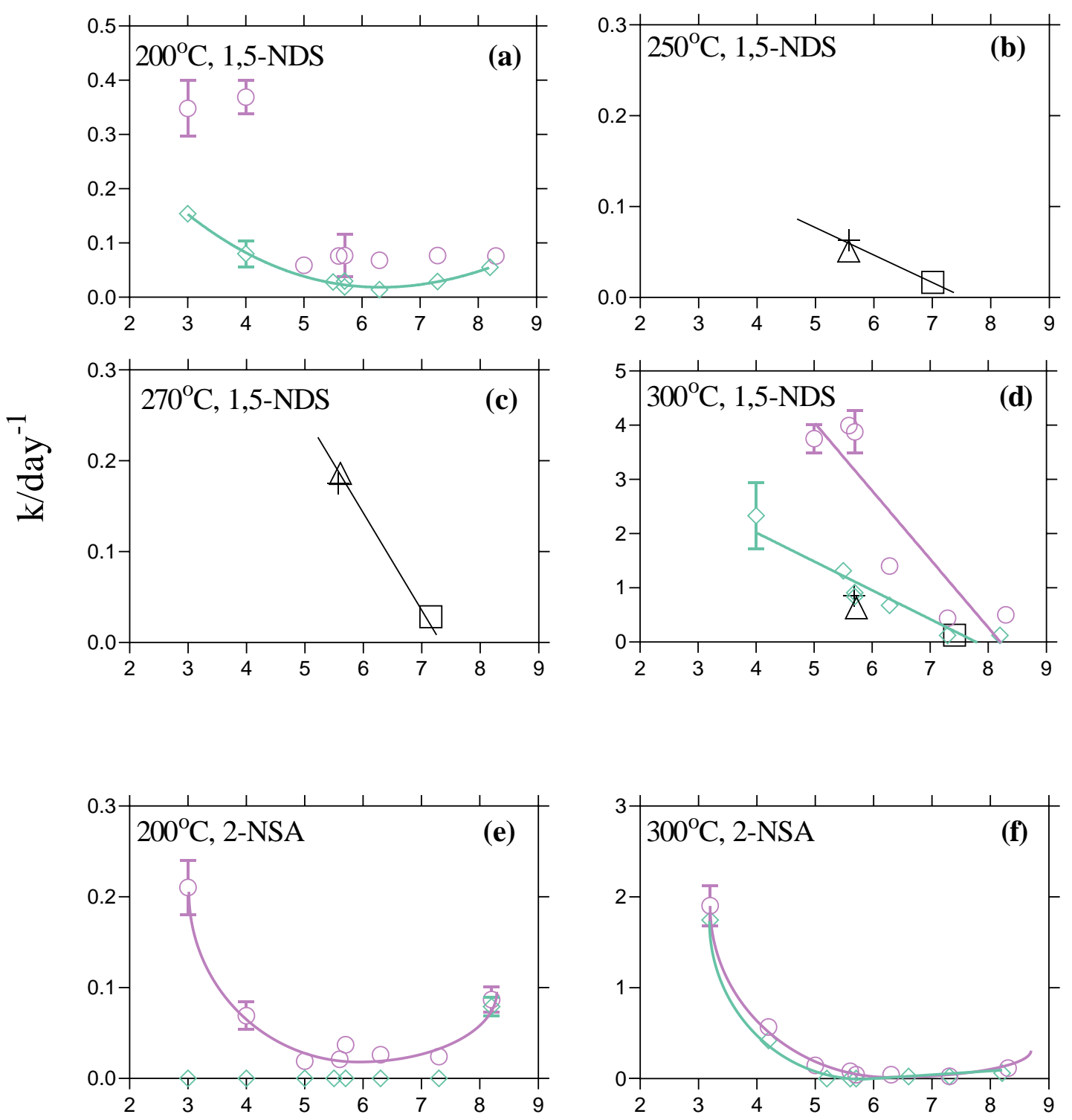

Set 1:

$\mathrm{pH}_{\mathrm{t}}$

$\diamond \mathrm{NaCl}=0.050 \mathrm{~m}$

Set 2:

distilled water

$+\mathrm{NaCl}=0.050 \mathrm{~m}+$ pyrite $\left(\mathrm{FeS}_{2}\right)$

$\square \quad \mathrm{Na}_{2} \mathrm{SO}_{4}=0.020 \mathrm{~m}$

$\triangle \mathrm{NaCl}=0.050 \mathrm{~m}+\mathrm{Na}_{2} \mathrm{~S} 2.69 \times 10^{-05} \mathrm{~m}$

Figure 2.13: Rate constant $\mathrm{k} \mathrm{day}^{-1}$ versus $\mathrm{pH}_{\mathrm{t}}$ for the decay of 1,5-NDS (a - d) and 2-NSA $(\mathrm{e}-\mathrm{f})$ at different temperatures and in different salinities at saturated vapour pressure. $\mathrm{pH}_{\mathrm{t}}$ refers to the $\mathrm{pH}$ at temperature. Error bars smaller than the symbol size have been omitted. Errors are listed in Tables 2.2, 2.3 and 2.4. 


\subsubsection{Steric hindrance and reaction kinetics}

Steric hindrance plays an important role in determining the stability of 1,5-NDS. Steric hindrance occurs when $-\mathrm{SO}_{3}$ substitution on $\mathrm{C}_{1}$ interacts with the adjacent $\mathrm{C}_{8}-\mathrm{H}$ bond, and the $-\mathrm{SO}_{3}$ group attached to $\mathrm{C}_{5}$ interacts with the adjacent $\mathrm{C}_{4}-\mathrm{H}$ bond (Figure 2.14). In both cases, this causes 1,5-NDS to become more unstable. Substitutions in $\alpha$-substitution (e.g. $C_{1}, C_{4}, C_{5}$, $\mathrm{C}_{8}$ ) are favoured by kinetics and have a lower activation energy than $\beta$-substitution (e.g. $\mathrm{C}_{2}$, $\left.\mathrm{C}_{3}, \mathrm{C}_{6}, \mathrm{C}_{7}\right)$.

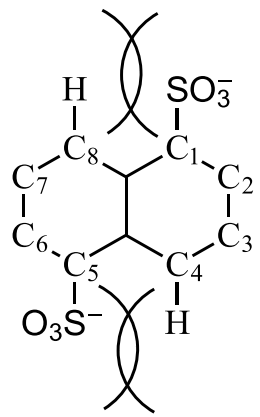

Figure 2.14: The steric hindrance in 1,5-NDS.

\subsubsection{The breakdown products}

The experiments show that the breakdown of 1,5-NDS produces 1-NSA (Figure 2.7, 2.8 and 2.9). In Set 1, where 1,5-NDS was the only naphthalene sulfonate compound, 2-NSA was not produced from thermal breakdown of 1,5-NDS within experimental time range. Moreover, 2-NSA, which is present in the second set of experiments (i.e. Set 2), remained constant and does not form from 1,5-NDS decomposition.

In all experiments, the rate of 1-NSA formation is dependent on 1,5-NDS breakdown rate. Desulfonation of one $-\mathrm{SO}_{3}$ group from the naphthalene backbone results in the creation of 1-NSA and is enhanced by steric hindrance, i.e.,

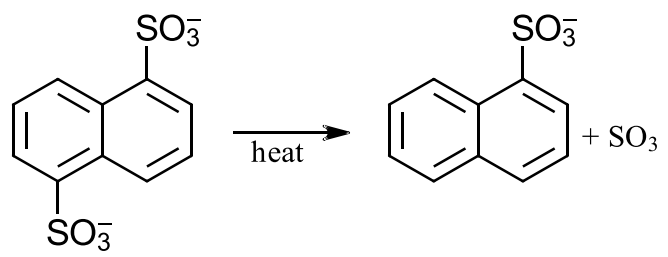

At $\mathrm{t} \geq 300^{\circ} \mathrm{C}$, an additional step in the reaction must be considered, where 1-NSA is the intermediate, and naphthalene ( \pm naphthols) is the final product (Chapter 6$)$, as given by, 


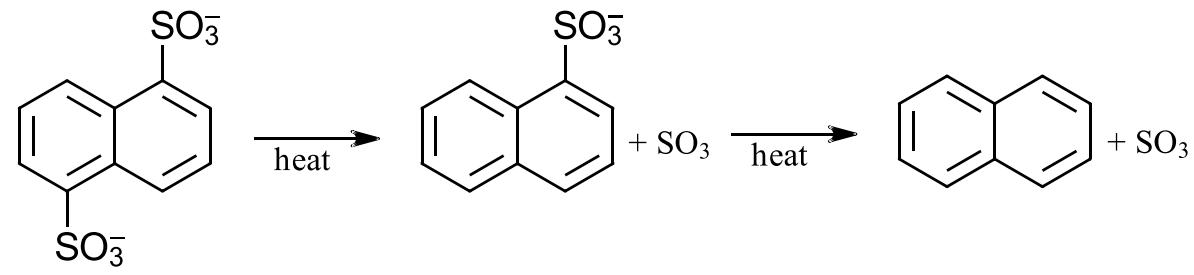

At acidic conditions, 1-NSA undergoes protonation resulting in its thermal decay, even at $250^{\circ} \mathrm{C}$, whereas at the same temperature, at neutral $\mathrm{pH}$, it remains stable for at least 40 days. At all studied temperatures $\left(200-300^{\circ} \mathrm{C}\right), 1,5$-NDS decomposition and 1-NSA formation rates are $\mathrm{pH}$-dependent. 1-NSA formed through 1,5-NDS decomposition is stabilised by the presence of dissolved salt. Thus, in experiments with $\mathrm{NaCl}=0.050 \mathrm{~m}$ and $\mathrm{Na}_{2} \mathrm{SO}_{4}=0.020 \mathrm{~m}$, 1-NSA exhibits higher stability in comparison to that in distilled water.

\subsubsection{The effect of salinity}

In general, naphthalene disulfonate and sulfonate breakdown rates were slower in electrolyte solutions than in distilled water. The slowest decay rate of 1,5-NDS was measured in $\mathrm{Na}_{2} \mathrm{SO}_{4}$ solution.

The effect of $\mathrm{NaCl}$ concentration on 1,5-NDS stability can be explained by ion association, that is, the attachment of $\mathrm{Na}^{+}$to a sulfonate group on the naphthalene moiety. Two possible interactions can take place: (1) negatively-charged $\mathrm{SO}_{3}^{-}$can be stabilised by positive charges from the salt $\left(\mathrm{Na}^{+}\right)$or (2) $\mathrm{Cl}^{-}$can interact with naphthalene backbone causing a change in bonding energy stabilising the whole molecule. The result is that the rate at which naphthalene disulfonate decay decreases with increasing salinity.

In the first set of experiments (Table 2.1) containing $\mathrm{NaCl}=0.050 \mathrm{~m}^{\text {or }} \mathrm{Na}_{2} \mathrm{SO}_{4}=0.020$ $\mathrm{m}$, the 1,5-NDS breakdown rate is slowest in the $\mathrm{Na}_{2} \mathrm{SO}_{4}$ solution. The encountered stability effect may be due to $\mathrm{pH}_{\mathrm{t}}$ difference between $\mathrm{Na}_{2} \mathrm{SO}_{4}$ and $\mathrm{NaCl}$ solutions at elevated temperature, rather than $\mathrm{Na}^{+}$or $\mathrm{SO}_{4}^{2-}$ interactions with NDS molecule. Calculated $\mathrm{pH}_{\mathrm{t}}$ for sodium sulfate solution was close to neutral, whereas $\mathrm{pH}$ for the $\mathrm{NaCl}$ solutions remained slightly acidic (Table 2.3).

In the experiments where pyrite was present, $\mathrm{FeS}_{2}$ will react with deoxygenated $\mathrm{NaCl}$ solution at 200 and $300^{\circ} \mathrm{C}$ and generate $\mathrm{HS}^{-}$and $\mathrm{H}_{2} \mathrm{~S}$,

$$
\begin{aligned}
& \mathrm{FeS}_{2(\mathrm{~s})}+2 \mathrm{H}^{+} \rightarrow \mathrm{FeS}_{(\mathrm{s})}+\mathrm{H}_{2} \mathrm{~S} \\
& \mathrm{FeS}_{(\mathrm{s})}+\mathrm{H}^{+} \rightarrow \mathrm{Fe}^{2+}+\mathrm{HS}^{-}
\end{aligned}
$$


The small quantities of reduced sulfur produced may exceed the concentration of 1,5NDS, perhaps giving rise to an interaction between $\mathrm{HS}^{-} / \mathrm{H}_{2} \mathrm{~S}$ and 1,5-NDS. However, there was no increase in 1,5-NDS stability when pyrite is present in comparison to experiments without pyrite and hence no evidence that aqueous reduced sulfur plays a role in stabilising the naphthalene disulfonate molecule. Furthermore, In the experiment with a solution containing both $\mathrm{Na}_{2} \mathrm{~S}$ and $\mathrm{NaCl}$, the $1,5-\mathrm{NDS}$ decay rate was similar to that measured for $\mathrm{NaCl}$ solution alone. It is concluded therefore that aqueous sulfide species (i.e. $\mathrm{H}_{2} \mathrm{~S}$ and $\mathrm{HS}^{-}$) do not stabilise or destabilise the 1,5-naphthalene sulfonate molecule.

In general, in simple systems, where the only electrolyte is $\mathrm{NaCl}$, addition of salt stabilises 1,5-NDS and 2-NSA over the studied temperature and $\mathrm{pH}$ range. However, additional studies which target the influence of different ions on naphthalene (di)sulfonate stability are required to further interpret these results.

\subsubsection{Examples of the fate of 1,5-NDS as a function of $p H$, ionic strength and temperature}

It is critical to consider the effect of temperature and $\mathrm{pH}$ on NDS/NSA stability when planning a tracer survey. The assumption of the thermal and $\mathrm{pH}$ stability could potentially lead to incorrect and misleading results. Thus, to demonstrate the significance of the presented data two scenarios where 1,5-NDS and 1-NSA are used, as geothermal reservoir tracers are considered. It is assumed that the geothermal reservoir is at constant temperature, $\mathrm{pH}$ and $\mathrm{NaCl}$ concentration and there is $100 \%$ connectivity between wells.

(1) Assuming temperature of $200^{\circ} \mathrm{C}, \mathrm{pH}_{\mathrm{t}}=5.0$, and $\mathrm{NaCl}=0.05 \mathrm{~mol} \mathrm{~kg}{ }^{-1}, 1000 \mathrm{~kg}$ $\mathrm{m}^{3-1}$ of pure 1,5-NDS is injected into the reservoir through a reinjection well. If the first returns of 1,5-NDS at a production well were detectable after 14 days, then as expected, more than $67 \%$ of $1,5-\mathrm{NDS}$ will remain inside the active geothermal reservoir, according to equation (2.32) and data in Table 2.4b. After 100 days, only $6 \%$ of initially injected $1,5-$ NDS will persist. During this time, the formation of 1-NSA and other decay products will also occur. 1-NSA concentration will increase proportionally to the 1,5-NDS loss (Figure 2.15a).

(2) Assuming a temperature of $300^{\circ} \mathrm{C}, \mathrm{pH}_{\mathrm{t}}=5.6$, and $\mathrm{NaCl}=0.05 \mathrm{~mol} \mathrm{~kg}{ }^{-1}, 1000 \mathrm{~kg}$ $\mathrm{m}^{3-1}$ of pure 1,5-NDS is injected into the reinjection well. The decay of 1,5-NDS will be rapid (Figure 2.15b) and 1,5-NDS will not be detectable. The intermediate product (1-NSA) of 1,5-NDS decomposition will be formed only a few days after 
injection (Figure 2.15b). Consequently, the end product(s) of the decomposition (such as naphthalene or naphthol) may be present and increase in concentration. Seven days after injection, only the end product(s) would be detectable.

(a)

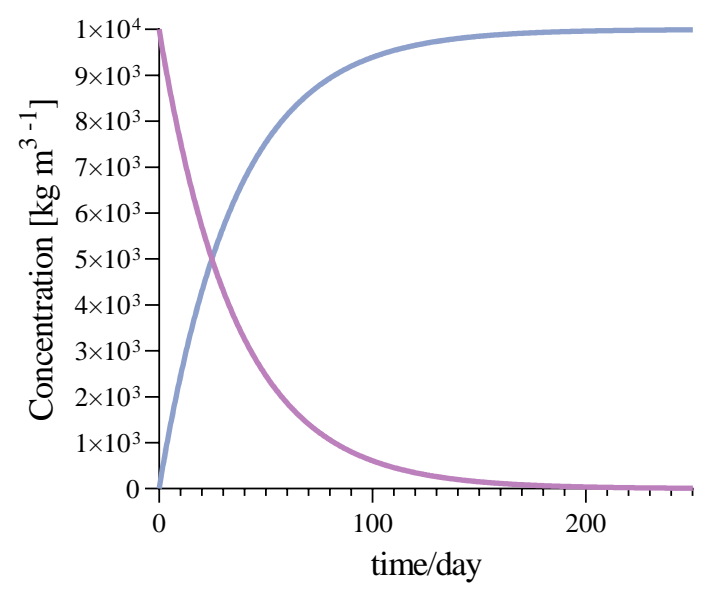

(b)

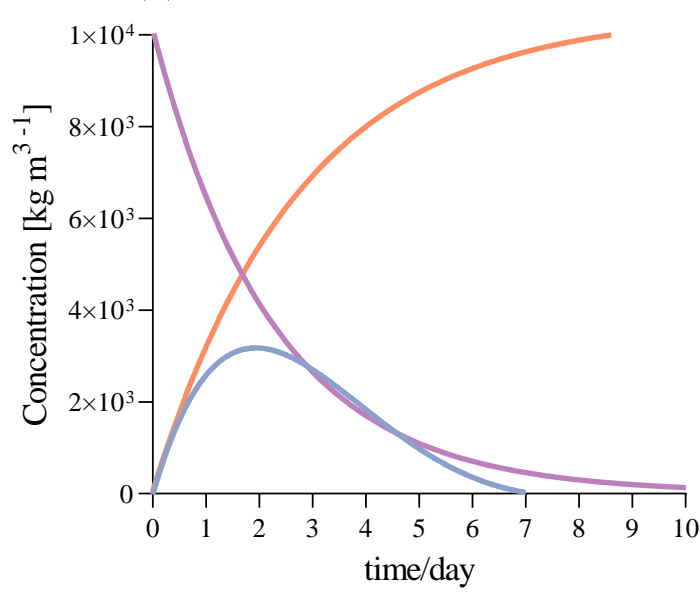

1,5-NDS $\quad$ 1-NSA $\quad$ Naphthalene

Figure 2.15: (a) scenario one, (b) scenario two. Percentage by weight of 1,5-NDS, 1-NSA and end products over time (days). Concentration change reflects 1,5-NDS breakdown reaction (equation 2.32) and the contribution of formed breakdown product(s) in an active geothermal reservoir at 200 and $300^{\circ} \mathrm{C}, \mathrm{pH}_{\mathrm{t}}=5.0$ and 5.6, and $\mathrm{NaCl}=0.05 \mathrm{~mol} \mathrm{~kg}^{-1}$.

\subsection{Conclusions}

An experimental study of 1,5-NDS and 2-NSA stability has been conducted. The first set of experiments focused on $1,5-\mathrm{NDS}$ at $\mathrm{pH}_{25^{\circ} \mathrm{C}}=7.0$. The stability of $1,5-\mathrm{NDS}$ was measured in different solutions including: $\mathrm{NaCl}=0.050 \mathrm{~m} ; \mathrm{Na}_{2} \mathrm{SO}_{4}=0.020 \mathrm{~m}$; and $\mathrm{NaCl}=0.050 \mathrm{~m}$ with $\mathrm{Na}_{2} \mathrm{~S}=2.69 \times 10^{-5} \mathrm{~m}$. Additionally, one subset of experiments with $\mathrm{NaCl}=0.050 \mathrm{~m}$ contained pyrite. The experiments were conducted over a time period of 96 to 1100 hours (up to $~ 7.5$ weeks) at $\mathrm{t}=250,270$ and $300^{\circ} \mathrm{C}$. The second set of experiments focused on 1,5-NDS and 2NSA stabilities at varying $\mathrm{pH}_{\mathrm{t}}=3.0$ to $8.3, \mathrm{t}=200$ and $300^{\circ} \mathrm{C}$ and $\mathrm{NaCl}=0.050 \mathrm{~m}$ and distilled water. The reaction times extended from 10 and 166 hours (i.e. up to $\sim 1$ week).

The results show the following:

(1) 1,5-NDS stability is pH-dependent with its breakdown rate decreasing with increasing $\mathrm{pH}$ and increasing $\mathrm{NaCl}$ concentration; 
(2) 1,5-NDS breaks down to 1-NSA with increasing temperature;

(3) there is no evidence of isomerisation of $1,5-\mathrm{NDS}$ to 2 -NSA in these experiments;

(4) 2-NSA is not stable at $200^{\circ} \mathrm{C}$ and distilled water;

(5) 2-NSA is stable at $\leq 200^{\circ} \mathrm{CpH}_{\mathrm{t}}=3.0$ to 7.3 in $\mathrm{NaCl}=0.050 \mathrm{~m}$;

(6) 2-NSA is not stable at $300^{\circ} \mathrm{C}$ and above;

(7) 1-NSA stability is a function of temperature and $\mathrm{pH}$;

(8) 1-NSA is stable at $270^{\circ} \mathrm{C}, \mathrm{pH}_{\mathrm{t}}=5.6$ to $7.2, \mathrm{NaCl}=0.050 \mathrm{~m}$ and distilled water for at least 24 days, however, at $300^{\circ} \mathrm{C}, 1-\mathrm{NSA}$ decays or disulfonates rapidly.

In summary, there is evidence that properties of a fluid such as temperature, $\mathrm{pH}$ and salinity have a major influence on NDS/NSA stability. Therefore, it is important to consider geothermal fluid chemical compositions and physical properties when selecting an appropriate NSA or NDS for a tracer test.

\subsection{References}

Adams, M.C., Davis, J., 1991. Kinetics of fluorescein decay and its application as a geothermal tracer. Geothermics, 20, $53-66$.

Adams, M.C., Moore, J.N., Fabry, L.G., Ahn, J.-H., 1992. Thermal stabilities of aromatic acids as geothermal tracers. Geothermics, 21, $323-339$.

Addison, S., Winick, J.A., Sewell, S., Buscarlet, E., Hernandez, D., Siega, F.L., 2015a. Geochemical Response of the Rotokawa Reservoir to the First 5 Years of Nga Awa Purua. Proceedings $38^{\text {th }}$ New Zealand Geothermal Workshop.

Addison, S. J., Winick, J.A., Mountain, B. W., Siega, F. L., 2015b. Rotokawa Reservoir Tracer Test History. Proceedings $38^{\text {th }}$ New Zealand Geothermal Workshop.

Albarède, F., 1995. Introduction to geochemical modelling, 318 - 340.

Bandura, A. V., Lvov S. N., 2006. The ionization constant of water over wide ranges of temperature and density. Journal of Physical and Chemical Reference Data, 35, 1, 15 - 30.

Bjornsson, G., 2004. Reservoir Conditions At 3-6 Km Depth in the Hellisheidi Geothermal Field, Sw-Iceland, Estimated By Deep Drilling, Cold Water Injection and Seismic 
Monitoring. 29 ${ }^{\text {th }}$ Workshop on Geothermal Reservoir Engineering, Stanford University, Stanford, California.

Bruckner, R., Harmata, M., Wender, P. a., 2010. Organic mechanisms: Reactions, stereochemistry and synthesis, Organic Mechanisms: Reactions, Stereochemistry and Synthesis.

Cobble, J. W., Murray, Jr. R. C., Turner, P. J., Chen, K., 1982. High-temperature thermodynamic data for species in aqueous solution. Research project report $1167-1$. EPRI NP-2400.

Dashkevich, Y.G., Mountain, B.W., Seward, T.M., Winick, J.A., 2014. Temperature stability of 1,5-naphthalene disulfonate at simulated geothermal conditions, Proceedings $36^{\text {th }}$ New Zealand Geothermal Workshop, Auckland.

Dashkevich, Y.G., Mountain, B.W., Seward, T.M., Winick, J.A., 2015. Temperature stability of naphthalene sulfonic and naphthalene disulfonic acids at geothermal conditions. Proceedings World Geothermal Congress. Melbourne, Australia.

Ellis, A. J., Mahon, W. A. J., 1977. Chemistry and geothermal systems. Academic Press, New York, N. Y., 392.

Franzson, H., Kristjánsson, B.R., Gunnarsson, G., Björnsson, G., Hjartarson, A., Steingrímsson, B., Gunnlaugsson, E., Gíslason, G., 2005. The Hengill-Hellisheiði Geothermal Field. Development of a Conceptual Geothermal Model. Proceedings World Geothermal Congress 2005.

Gosetti, F., Gianotti, V., Ravera, M., Gennaro, M.C., 2005. HPLC-MSn to investigate the oxidative destruction pathway of aromatic sulfonate wastes. Journal of Environmental Quality, 34, $2328-2333$.

Ho, P. C., Palmer, D. A., and Gruszkiewicz, M.S., 2001. Conductivity measurements of dilute aqueous $\mathrm{HCl}$ solutions to high temperatures and pressures using a flow-through cell. Journal of Physical Chemistry B, 105, 1260 - 1266.

Ho, P.C., Palmer, D.A., Wood, R.H., 2000. Conductivity measurements of dilute aqueous $\mathrm{LiOH}, \mathrm{NaOH}$, and $\mathrm{KOH}$ solutions to high temperatures and pressures using a flowthrough cell. Journal of Physcial Chemistry B, 104, 12084 - 12089. 
Ho, P.C., Palmer, D.A., Mesmer, R.E., 1994. Electrical conductivity measurements of aqueous sodium chloride solutions to $600^{\circ} \mathrm{C}$ and $300 \mathrm{MPa}$. Journal of Solution Chemistry, 23, $997-1018$.

IAEA, 2012. Application of Radiotracer Techniques for Interwell Studies. IAEA Radiation Technology Series, 18.

Iglewicz, B. and Hoaglin, D., 1993. The ASQC Basic References in Quality Control: Statistical Techniques. How to Detect and Handle Outliers, ASQC Quality Press, Milwaukee, 16.

Jiurong, L., 1999. Reinjection and Tracer Tests in the Laugaland. Geothermal Training Programme, 6, $141-164$.

Johnson J. W., Oelkers E. H., Helgeson H. C., 1992. SUPCRT92: A software package for calculating the standard molal thermodynamic properties of minerals, gases, aqueous species, and reactions from 1 to 5000 bar and 0 to $1000^{\circ} \mathrm{C}$. Computers \& Geosciences, 18, 7, $899-947$.

Kielland, J., 1937. Individual activity coefficients of ions in aqueous solutions. Journal of the American Chemical Society, 59, $1675-1678$.

Krupp, R. E., Seward T. M., 1987. The Rotokawa geothermal system, New Zealand; an active epithermal gold-depositing environment. Economic Geology, 82, 1109 - 1129.

Kozlov, V.A., Ivanov, S.N., Koifman, O.I., 2017. Solvated proton as the main reagent and a catalyst in the single-stage aromatic sulfonation and protodesulfonation of sulfonic acids. Journal of Physical Organic Chemistry, 30, 3715.

Kristjansson, B., Axelsson, G., Gunnarsson, G., Gunnarsson, I., Oskarsson, F., 2016. Comprehensive Tracer Testing in the Hellisheidi Geothermal Field in SW-Iceland 2013 - 14. Proceedings, $41^{\text {st }}$ Workshop on Geothermal Reservoir Engineering Stanford University, 399 419.

Lynch, D.F.J., Scanlan, J.T., 1927. Naphthalenesulfonic acids: VIII - hydrolysis of naphthalene-1,5-disulfonic acid. Industrial \& Engineering Chemistry Research, 19, 1010 1012.

Mountain, B.W., Winick, J., 2012. The thermal stability of the naphthalene sulfonic and naphthalene disulfonic acids under geothermal conditions: experimental results and a field- 
based example 1-5. Proceedings $34^{\text {th }}$ New Zealand Geothermal Workshop, Auckland, New Zealand.

Mroczek, S., Mroczek, E., 2017. EqSolvR: Chemical Equilibrium Solver. R package version 1.1.0. https://github.com/shearwavesplitter/EqSolvR.

Nottebohm, M., Licha, T., Sauter, M., 2012. Tracer design for tracking thermal fronts in geothermal reservoirs. Geothermics, 43, $37-44$.

Remoroza, A.I., 2010. Calcite mineral scaling potentials of high-temperature geothermal wells, Master's thesis, Faculty of Science, University of Iceland, 99.

Robinson, R. A., Stokes, R. H., 1968. Electrolyte Solutions, Butterworths, 2nd Edition, 571.

Rokade, Y.B., Sayyed, R.Z., 2009. Naphthalene derivatives: a new range of antimicrobials with high therapeutic value. Rasayan Journal of Chemistry, 2, $972-980$.

Rose, P., Benoit, D., Lee, S.G., Tandia, B., Kilbourn, P., 2000. Testing the naphthalene sulfonates as geothermal tracers at Dixie Valley, Ohaaki, and Awibengkok. 25 ${ }^{\text {th }}$ Workshop on Geothermal Reservoir Engineering Stanford University, Stanford, California.

Rose, P., Benoit, W.R., Kilbourn, P.M., 2001. The application of the polyaromatic sulfonates as tracers in geothermal reservoirs. Geothermics, 30, $617-640$.

Rose, P., Johnson, S. D., Kilbourn, P., Kastler, C., 2002. Tracer testing at dixie valley, nevada using 1-naphthalene sulfonate and 2,6-naphthalene disulfonate. $27^{\text {th }}$ Workshop on Geothermal Reservoir Engineering Stanford University, Stanford, California.

Rose, P., Leecaster, K., Drakos, P., Roberson-Tait, A., 2009. Tracer testing at the Desert Peak EGS Project. Transactions - Geothermal Resources Council, 33, 241 - 249.

Rose, P., Mcculloch, J., Buck, C., Mella, M., Rambani, M., 2012. The use of butanols as tracers at the Coso geothermal field the thermal stability and detectability of butanol tracers. Transactions - Geothermal Resources Council, 36,1377 - 1382.

Sanjuan, B., Pinault, J.L., Rose, P., Gérard, A., Brach, M., Braibant, G., Crouzet, C., Foucher, J.C., Gautier, A., Touzelet, S., 2006a. Tracer testing of the geothermal heat exchanger at Soultz-sous-Forêts (France) between 2000 and 2005. Geothermics, 35, 622 - 653.

Sanjuan, B., Rose, P., Brach, M., Braibant, G., Foucher, J., Gautier, A., Sanjuan, B., Rose, P., Brach, M., Braibant, G., 2006b. Geo-chemical fluid characteristics and main 
achievements about tracer tests at Soultz-sous-Forets (France). EHDRA Scientific Conference. Soultz-sous-Forets, France, 1 - 14.

Seward, T. M., 1974. Equilibrium and oxidation potential in geothermal waters at Broadlands, New Zealand. American Journal of Science, 274, 190 - 192.

Smith, M.B., March, J., 2007. March's advanced organic chemistry reactions, mechanisms, and structure, $6^{\text {th }}$ edit. ed. John Wiley $\&$ Sons, Inc., Hoboken, New Jersey.

Ungemach, P., Veronique, V.A., Sebastien, N., 2002. Tracer leak off tests as means of checking well Integrity. Application to Paris Basin geothermal production wells. $27^{\text {th }}$ Workshop on Geothermal Reservoir Engineering Stanford University, Stanford, California.

Wade, L.G.J., 2013. Organic Chemistry, $8^{\text {th }}$ edition, Prentice Hall, $346-405$. 


\section{Naphthalene sulfonate and disulfonate (2-NSA, 2,6- NDS, 2,7-NDS, 1,5-NDS and 1,6-NDS) breakdown kinetics at elevated temperature in the presence of greywacke}

\subsection{Abstract}

The stability of five polyaromatic sulfonates, 2-naphthalene sulfonate (2-NSA), 2,6naphthalene disulfonate (2,6-NDS), 2,7-naphthalene disulfonate (2,7-NDS), 1,5- naphthalene disulfonate (1,5-NDS) and 1,6-naphtahlene disulfonate (1,6-NDS) in aqueous solution were considered in this study. The thermal stabilities were studied as a function of temperature (from 200 to $330^{\circ} \mathrm{C}$ ) with, and without, the presence of greywacke.

The solutions were analysed by high performance liquid chromatography (HPLC) using fluorescence detection. The breakdown kinetics indicated that NDS/NSA stabilities are temperature and $\mathrm{pH}$-dependent with stabilities increasing as follows: 1,5-NDS < 1,6-NDS < 2,6 -NDS $\approx 2,7-N D S<2$-NSA. Thermal decay of naphthalene disulfonates results in naphthalene sulfonate formation (i.e. 1-NSA and 2-NSA). The formation of 1-NSA is temperature and $\mathrm{pH}$-dependent and its stability increases with decrease in temperature and increase in $\mathrm{pH}$. At $\geq 300^{\circ} \mathrm{C}, 2-\mathrm{NSA}$ exhibits slow disproportionation.

\subsection{Introduction}

Naphthalene (di)sulfonate acids have been widely used as permeability and well connectivity indicators or tracers in energy producing geothermal reservoirs (Ayling et al., 2015; Jiurong, 1999; Winick et al., 2015) and mixtures of these compounds, in which one or two sulfonate groups are bound to the naphthalene backbone, can be injected into an active geothermal reservoir simultaneously (Nogara \& Sambrano, 2005; Rose et al., 2001a; Rose et al., 2001b; Sanjuan et al., 2006).

The mixture of naphthalene (di)sulfonate compounds undergoes changes as the different components disproportionate and form new isomers during their migration and residence time in the geothermal reservoir at elevated temperature. The interpretation of the new assemblage of naphthalene sulfonate isomers requires kinetic information on their stability as a function of temperature and solution conditions (e.g. $\mathrm{pH}$ and salinity). 
We have previously studied (Chapter 2), in detail, the kinetics of 1,5-NDS, 2-NSA and the breakdown product 1-NSA at elevated temperatures to $300^{\circ} \mathrm{C}$ at different $\mathrm{pH}$ and solution composition (i.e. distilled water, $\mathrm{NaCl}=0.050 \mathrm{~m}, \mathrm{Na}_{2} \mathrm{SO}_{4}=0.020 \mathrm{~m}, \mathrm{Na}_{2} \mathrm{~S}=2.69 \times 10^{-5} \mathrm{~m}+$ $\mathrm{FeS}_{2}$ ). The aim of this study is to investigate the stability of NSA and NDS compounds under geothermal conditions with and without the presence of rock material. Figure 3.1 shows the structural formulae of six naphthalene sulfonic and disulfonic acids considered in this study.

The stability of several naphthalene (di)sulfonates (including 2-NSA, 1-NSA, 2,6-NDS, 2,7-NDS and 1,5-NDS) were studied by Rose et al. (2001a, 2001b). Phosphate buffer solutions $\left(\mathrm{pH}_{25^{\circ} \mathrm{C}}=6.5\right)$ containing NSA and NDS were heated in sealed silica glass ampoules for 7 days. They reported that 2-NSA and 2,7-NDS, in contrast to 1,5-NDS, were stable up to $330^{\circ} \mathrm{C}$ over the experimental time. Similarly, in another experiment, 1-NSA and 2,6-NDS exhibited no decay at $330^{\circ} \mathrm{C}$ over one week (Rose et al., 2002). More recently a mixture of six naphthalene sulfonates and disulfonates (Dashkevich et al., 2015), dissolved in geothermal brine $\left(\mathrm{pH}_{25^{\circ} \mathrm{C}}=6.1\right)$, and heated to $270-390^{\circ} \mathrm{C}$ for up to 60 hours was investigated. 2,6-NDS, 2,7NDS and 1,6-NDS were stable up to $330^{\circ} \mathrm{C}$ and $1,5-\mathrm{NDS}$ up to $280^{\circ} \mathrm{C}$. An increase in concentration of $1-\mathrm{NSA}$ and $2-\mathrm{NSA}$, at $\mathrm{t}>330^{\circ} \mathrm{C}$, suggested that both were the breakdown products of other NSA/NDS compounds. However, during a tracer test in an active geothermal reservoir, the NSA/NDS compounds would be exposed for a considerably longer time at high temperatures. Nevertheless, despite the lack of kinetic data needed to adequately interpret the results of NDS/NSA injection, these compounds have been injected in a number of active geothermal reservoirs.

For example, 1,5-NDS, 1,6-NDS, 2,6-NDS and 2,7-NDS have been successfully used in Soultz, France. In this high salinity fluid reservoir $\left(200^{\circ} \mathrm{C}\right)$, the concentration of the injected NDS tracers remained unchanged at least for three years (Sanjuan et al., 2006). At the Habanero site, in central Australia, 2,6-NDS and 2,7-NDS were injected into the reservoir (Ayling et al., 2015 ), having a maximum temperature of $244^{\circ} \mathrm{C}$. The authors reported that $\approx 70 \%$ of the NDS were recovered with the remaining $30 \%$ of NDS trapped in more poorly-connected parts of the field. In another test, 1,6-NDS was used in Mindanao geothermal field, Philippines $\left(\sim 250^{\circ} \mathrm{C}\right)$ with $20.39 \%$ of 1,6-NDS being recovered after more than 9 months (Nogara \& Sambrano, 2005).

The effect of higher temperatures $\left(t \geq 300^{\circ} \mathrm{C}\right)$ is more pronounced. Four naphthalene disulfonate isomers (2,6-NDS, 2,7-NDS, 1,5-NDS and 1,6-NDS) were injected into one of the hottest operating geothermal reservoirs $\left(337^{\circ} \mathrm{C}\right)$ in the world at Rotokawa, New Zealand. None 
of the original NDS isomers were detected (Addison et al., 2015). Instead, 2-NSA had formed (Dashkevich et al., 2015). In a comparable NDS injection test, in the Awibengkok geothermal field (Indonesia) at $\mathrm{t}=312^{\circ} \mathrm{C}$, no return of injected 1,5-NDS was reported (Rose et al., 2000). Lack of recovery of these organic compounds can be interpreted in many ways and the key to an accurate interpretation lies in understanding NSA and NDS stabilities and transformations under geothermal conditions.

The experiments reported in this study were designed to assess the use of naphthalene sulfonate and disulfonate permeability tracers under geothermal conditions. They were planned, specifically, to determine the activation energies for each of the naphthalene sulfonates/disulfonates (i.e. 2-NSA, 1,5-NDS, 1,6-NDS, 2,6-NDS and 2,7-NDS), to gain insight into their stabilities and resulting breakdown products as a function of temperature and time.<smiles>O=S(=O)(O)c1cccc2ccccc12</smiles>

1-naphthalene sulfonic acid (1-NSA) $\mathrm{C}_{10} \mathrm{H}_{8} \mathrm{O}_{3} \mathrm{~S}$<smiles>O=S(=O)(O)c1cccc2c(S(=O)(=O)O)cccc12</smiles>

1,5-naphthalene disulfonic acid (1,5-NDS) $\mathrm{C}_{10} \mathrm{H}_{8} \mathrm{O}_{6} \mathrm{~S}_{2}$<smiles>O=S(=O)(O)c1ccc2ccc(S(=O)(=O)O)cc2c1</smiles>

2,7-naphthalene disulfonic acid (2,7-NDS) $\mathrm{C}_{10} \mathrm{H}_{8} \mathrm{O}_{6} \mathrm{~S}_{2}$<smiles>O=S(=O)(O)c1ccc2ccccc2c1</smiles>

2-naphthalene sulfonic acid (2-NSA) $\mathrm{C}_{10} \mathrm{H}_{8} \mathrm{O}_{3} \mathrm{~S}$<smiles>O=S(=O)(O)c1ccc2c(S(=O)(=O)O)cccc2c1</smiles>

1,6-naphthalene disulfonic acid (1,6-NDS) $\mathrm{C}_{10} \mathrm{H}_{8} \mathrm{O}_{6} \mathrm{~S}_{2}$<smiles>O=S(=O)(O)c1ccc2cc(S(=O)(=O)O)ccc2c1</smiles>

2,6-naphthalene disulfonic acid (2,6-NDS) $\mathrm{C}_{10} \mathrm{H}_{8} \mathrm{O}_{6} \mathrm{~S}_{2}$

Figure 3.1: Chemical names and structures for the six polyaromatic sulfonates considered in this study. 


\subsection{Materials and methods}

Several series of experiments were conducted to determine the influence of temperature on naphthalene sulfonate stability.

The first set of experiments were designed to measure kinetic data for the five polyaromatic sulfonates: 1,5-NDS, 1,6-NDS, 2,6-NDS, 2,7-NDS and 2-NSA. 1-NSA was not added to any of the initial experimental solutions as this species was expected to result as the 1,5-NDS breakdown product (Chapter 2). This set comprised six series of ampoules at six temperatures (i.e. $200,225,250,270,300$ and $330^{\circ} \mathrm{C}$ ). Each series was made of six to eight subsets representing different reaction times. Six replicates for each temperature were made (i.e. one set consists of 36 to 48 reactions). All the experiments had the same initial composition. Each reaction tube contained an initial solution of a naphthalene disulfonates: 1,5-NDS, 1,6-NDS, 2,6-NDS, 2,7-NDS and 2-NSA with $\mathrm{NaCl}=0.050 \mathrm{~mol} \mathrm{~kg}^{-1}$ (Table 3.1). The tubes were heated for various times ranging from 20 to 2134 hours ( $\sim 3$ months).

The second set of experiments contained 1,5-NDS, 1,6-NDS, 2,6-NDS, 2,7-NDS and 2-NSA with $\mathrm{NaCl}=0.050 \mathrm{~mol} \mathrm{~kg}^{-1}$ together with crushed and sieved greywacke grains (Rotokawa, $0.5-1 \mathrm{~mm}, \sim 0.5 \mathrm{~g}$ ) added to each of the ampoules (Table 3.1). The greywacke was composed of quartz, plagioclase, minor K-feldspar and biotite with abundant ( $\sim 30 \%)$ clay-rich matrix (illite). The rock was characterised by numerous thin veinlets filled with chlorite, calcite and quartz. The main alteration minerals were calcite, quartz, clays (montmorillonite), pyrite and rare pyrrhotite. This set of experiments comprised three series of tubes representing different experimental temperatures (i.e. 250,270 and $300^{\circ} \mathrm{C}$ ) and were heated for various times ranging from 336 to 1008 hours (i.e. 1.4 months).

In both sets of experiments, the four naphthalene disulfonic acids (NDS) and naphthalene sulfonic acid (2-NSA) were dissolved in de-oxygenated solutions (i.e. purged of atmospheric oxygen) which were placed in quartz glass tubes. They were evacuated and sealed using an oxygen-acetylene flame. The tubes were enclosed in standard cold-seal pressure vessels and placed in an oven at the appropriate temperature. The deoxygenation procedure is described in detail in Chapter 2.

The NDS and NSA concentrations were measured using isocratic reversed phase ionpaired high-performance liquid chromatography (HPLC) with fluorescence detection (see details given in Chapter 2 and 4). The values of the observed molal concentrations after 
different heating times were plotted as concentration $\left(\mathrm{mol} \mathrm{kg}^{-1}\right)$ vs time (days) in Figures 3.2 3.6. The rate constants, $\mathrm{k}$, were fitted using a linear least squares procedure (GraphPad Prism 8.21 software), as described previously in Chapter 2.

\subsubsection{Speciation of solutions and calculation of $\mathrm{pH}$}

The $\mathrm{pH}$ of the solution at the temperature and pressure of Set 1 was calculated from the charge balance of the solution considering the following species: $\mathrm{OH}^{-}, \mathrm{H}^{+}, \mathrm{Na}^{+}, \mathrm{Cl}^{-}, \mathrm{HCl}^{\circ}$, $\mathrm{NaCl}^{\circ}$ and $\mathrm{NaOH}^{\circ}$. The following independent reactions define the equilibrium relationships for Set 1:

$$
\begin{aligned}
& \mathrm{H}_{2} \mathrm{O}=\mathrm{H}^{+}+\mathrm{OH}^{-} \\
& \mathrm{NaCl}^{\circ}=\mathrm{Na}^{+}+\mathrm{Cl}^{-} \\
& \mathrm{NaOH}^{\circ}=\mathrm{Na}^{+}+\mathrm{OH}^{-} \\
& \mathrm{HCl}^{\circ}=\mathrm{H}^{+}+\mathrm{Cl}^{-}
\end{aligned}
$$

The experiments in the second set (Set 2) had greywacke present. The water-rock interactions result in complex chemistry changes affecting $\mathrm{pH}$ and composition of the experimental solutions (Table 3.2). To calculated $\mathrm{pH}$ at temperature for Set 2, several additional aqueous species were considered including $\mathrm{K}^{+}, \mathrm{Ca}^{2+}, \mathrm{SO}_{4}^{2-}, \mathrm{KCl}^{\circ}, \mathrm{KOH}^{\circ}, \mathrm{CaSO}_{4}^{\circ}, \mathrm{CaCl}^{+}, \mathrm{CaCl}_{2}^{\circ}$, $\mathrm{NaSO}_{4}^{-}, \mathrm{KSO}_{4}^{-}$, and $\mathrm{H}_{3} \mathrm{SiO}_{4}^{-}$. The experimental solution can form additional ion pairs according to the following dissociation reactions:

$$
\begin{aligned}
& \mathrm{KCl}^{\circ}=\mathrm{K}^{+}+\mathrm{Cl}^{-} \\
& \mathrm{KOH}^{\circ}=\mathrm{K}^{+}+\mathrm{OH}^{-} \\
& \mathrm{KSO}_{4}^{-}=\mathrm{K}^{+}+\mathrm{SO}_{4}^{2-} \\
& \mathrm{CaSO}_{4}^{\circ}=\mathrm{Ca}^{+2}+\mathrm{SO}_{4}^{2-}
\end{aligned}
$$


Table 3.1: Composition of initial solutions of Set 1 and 2. Set 1 was conducted at 200 to $330^{\circ} \mathrm{C}$ up to three months. Set 2 refers to reactions from 250 to $300^{\circ} \mathrm{C}$, reacted up to three weeks in presence of greywacke. Elements and NDS/NSA concentrations in mol kg-1.

\begin{tabular}{cccccccccc}
\hline & $\mathrm{Na}^{+}$ & $\mathrm{Cl}^{-}$ & $\mathrm{pH}_{25}{ }^{\circ} \mathrm{C}$ & $1,5-\mathrm{NDS}$ & 2-NSA & 2,6-NDS & 2,7-NDS & $1,6-\mathrm{NDS}$ & time/days \\
\hline Set 1 & 0.050 & 0.050 & 7.0 & $7.28 \times 10^{-8}$ & $1.19 \times 10^{-7}$ & $8.40 \times 10^{-8}$ & $6.85 \times 10^{-8}$ & $7.89 \times 10^{-8}$ & up to 81 \\
Set 2 & 0.049 & 0.049 & 7.0 & $9.61 \times 10^{-8}$ & $1.35 \times 10^{-6}$ & $1.01 \times 10^{-7}$ & $1.17 \times 10^{-7}$ & $1.03 \times 10^{-7}$ & up to 42
\end{tabular}

detection limits: $1.40 \times 10^{-10} \mathrm{~mol} \mathrm{~kg}^{-1}$ for the NDS and $1.93 \times 10^{-9} \mathrm{~mol} \mathrm{~kg}^{-1}$ for NSA

Table 3.2: Composition of Set 2 (i.e. with greywacke) after 4 weeks at 250,270 and $300{ }^{\circ} \mathrm{C}$ and at the saturated vapour pressure. Concentrations in $\mathrm{mol} \mathrm{kg}^{-1}$.

\begin{tabular}{cccccccc}
\hline $\mathrm{t} /{ }^{\circ} \mathrm{C}$ & $\mathrm{pH}_{25}{ }^{\circ} \mathrm{C}$ & $\mathrm{Na}^{+}$ & $\mathrm{K}^{+}$ & $\mathrm{Ca}^{2+}$ & $\mathrm{SiO}_{2}^{\circ}$ & $\mathrm{Cl}^{-}$ & $\mathrm{SO}_{4}^{2-}$ \\
\hline 250 & 7.54 & 0.049 & $1.1 \times 10^{-3}$ & $2.6 \times 10^{-3}$ & $5.4 \times 10^{-3}$ & 0.049 & $1.0 \times 10^{-4}$ \\
270 & 7.65 & 0.050 & $1.3 \times 10^{-3}$ & $2.6 \times 10^{-3}$ & $4.6 \times 10^{-3}$ & 0.050 & $9.4 \times 10^{-5}$ \\
300 & 8.32 & 0.049 & $1.4 \times 10^{-3}$ & $2.5 \times 10^{-3}$ & $2.9 \times 10^{-3}$ & 0.049 & $1.2 \times 10^{-4}$ \\
\hline
\end{tabular}




$$
\begin{aligned}
& \mathrm{CaCl}^{+}=\mathrm{Ca}^{+2}+\mathrm{Cl}^{-} \\
& \mathrm{CaCl}_{2}^{\circ}=\mathrm{Ca}^{+2}+2 \mathrm{Cl}^{-} \\
& \mathrm{NaSO}_{4}^{-}=\mathrm{Na}^{+}+\mathrm{SO}_{4}^{2-} \\
& \mathrm{HSO}_{4}^{2-}=\mathrm{H}^{+}+\mathrm{SO}_{4}^{2-} \\
& \mathrm{H}_{4} \mathrm{SiO}_{4}^{\circ}=\mathrm{H}^{+}+\mathrm{H}_{3} \mathrm{SiO}_{4}^{-}
\end{aligned}
$$

the equilibrium constants for which, are

$$
\begin{aligned}
& \mathrm{K}_{\mathrm{W}}=\mathrm{a}_{\mathrm{H}^{+}} \cdot \mathrm{a}_{\mathrm{OH}^{-}} \cdot \mathrm{a}_{\mathrm{H}_{2} \mathrm{O}}{ }^{-1} \\
& \mathrm{~K}_{\mathrm{NaCl}}=\mathrm{a}_{\mathrm{Na}^{+}} \cdot \mathrm{a}_{\mathrm{Cl}^{-}} \cdot \mathrm{a}_{\mathrm{NaCl}^{\circ}} \\
& \mathrm{K}_{\mathrm{NaOH}}=\mathrm{a}_{\mathrm{Na}^{+}} \cdot \mathrm{a}_{\mathrm{OH}^{-}} \cdot \mathrm{a}_{\mathrm{NaOH}^{\circ}}^{-1} \\
& \mathrm{~K}_{\mathrm{HCl}}=\mathrm{a}_{\mathrm{H}^{+}} \cdot \mathrm{a}_{\mathrm{Cl}^{-}} \cdot \mathrm{a}_{\mathrm{HCl}^{\circ}}^{-1} \\
& \mathrm{~K}_{\mathrm{KCl}^{\circ}}=\mathrm{a}_{\mathrm{K}^{+}} \cdot \mathrm{a}_{\mathrm{Cl}^{-}} \cdot \mathrm{a}_{\mathrm{KCl}^{\circ}}^{-1} \\
& \mathrm{~K}_{\mathrm{KOH}^{\circ}}=\mathrm{a}_{\mathrm{K}^{+}} \cdot \mathrm{a}_{\mathrm{OH}^{-}} \cdot \mathrm{a}_{\mathrm{KOH}^{\circ}}{ }^{-1} \\
& \mathrm{~K}_{\mathrm{KSO}_{4}^{-}}=\mathrm{a}_{\mathrm{K}^{+}} \cdot \mathrm{a}_{\mathrm{SO}_{4}^{2-}} \cdot \mathrm{a}_{\mathrm{KSO}_{4}^{-}}^{-1} \\
& \mathrm{~K}_{\mathrm{CaSO}_{4}^{\circ}}=\mathrm{a}_{\mathrm{Ca}^{2+}} \cdot \mathrm{a}_{\mathrm{SO}_{4}^{2-}} \cdot \mathrm{a}_{\mathrm{CaSO}_{4}^{-}}^{-1} \\
& \mathrm{~K}_{\mathrm{CaCl}^{+}}=\mathrm{a}_{\mathrm{Ca}^{2+}} \cdot \mathrm{a}_{\mathrm{Cl}^{-}} \cdot \mathrm{a}_{\mathrm{CaCl}^{+}}^{-1} \\
& \mathrm{~K}_{\mathrm{CaCl}_{2}^{\circ}}=\mathrm{a}_{\mathrm{Ca}^{2+}} \cdot \mathrm{a}_{2 \mathrm{Cl}^{-}} \cdot \mathrm{a}_{\mathrm{CaCl}_{2}^{\circ}}^{-1} \\
& \mathrm{~K}_{\mathrm{NaSO}_{4}^{-}}=\mathrm{a}_{\mathrm{Na}^{+}} \cdot \mathrm{a}_{\mathrm{SO}_{4}^{2-}} \cdot \mathrm{a}_{\mathrm{NaSO}_{4}^{-}}^{-1} \\
& \mathrm{~K}_{\mathrm{HSO}_{4}^{2-}}=\mathrm{a}_{\mathrm{H}^{+}} \cdot \mathrm{a}_{\mathrm{SO}_{4}^{2-}} \cdot \mathrm{a}_{\mathrm{HSO}_{4}^{1-}}^{-1} \\
& \mathrm{~K}_{\mathrm{H}_{4} \mathrm{SiO}_{4}^{\circ}}=\mathrm{a}_{\mathrm{H}^{+}} \cdot \mathrm{a}_{\mathrm{H}_{3} \mathrm{SiO}_{4}^{-}} \cdot \mathrm{a}_{\mathrm{H}_{4} \mathrm{SiO}_{4}^{\circ}}^{-1}
\end{aligned}
$$

With the charge balance equation, for the Set 1 ,

$$
\mathrm{m}_{\mathrm{Na}^{+}}+\mathrm{m}_{\mathrm{H}^{+}}=\mathrm{m}_{\mathrm{Cl}^{-}}+\mathrm{m}_{\mathrm{OH}^{-}}
$$

and for the Set 2, including greywacke,

$$
\mathrm{m}_{\mathrm{Na}^{+}}+\mathrm{m}_{\mathrm{H}^{+}}+\mathrm{m}_{\mathrm{K}^{+}}+\mathrm{m}_{\mathrm{Ca}^{2+}}=\mathrm{m}_{\mathrm{Cl}^{-}}+\mathrm{m}_{\mathrm{OH}^{-}}+\mathrm{m}_{\mathrm{H}_{3} \mathrm{SiO}_{4}^{-}}+\mathrm{m}_{\mathrm{SO}_{4}^{2-}}
$$


We can solve the equations for concentration of the complexes:

$$
\begin{aligned}
& \mathrm{m}_{\mathrm{NaCl}}=\mathrm{a}_{\mathrm{Na}^{+}} \cdot \mathrm{a}_{\mathrm{Cl}^{-}} \cdot\left(\mathrm{K}_{\mathrm{NaCl}} \cdot \gamma_{\mathrm{NaCl}}\right)^{-1} \\
& \mathrm{~m}_{\mathrm{HSO}_{4}^{2-}}=\mathrm{a}_{\mathrm{H}^{+}} \cdot \mathrm{a}_{\mathrm{SO}_{4}^{2-}} \cdot\left(\mathrm{K}_{\mathrm{HSO}_{4}^{1-}} \cdot \gamma_{\mathrm{HSO}_{4}^{2-}}\right)^{-1} \\
& \mathrm{~m}_{\mathrm{KCl}^{\circ}}=\mathrm{a}_{\mathrm{K}^{+}} \cdot \mathrm{a}_{\mathrm{Cl}^{-}} \cdot\left(\mathrm{K}_{\mathrm{KCl}^{\circ}} \cdot \gamma_{\mathrm{KCl}^{\circ}}\right)^{-1} \\
& \mathrm{~m}_{\mathrm{KOH}^{\circ}}=\mathrm{a}_{\mathrm{K}^{+}} \cdot \mathrm{a}_{\mathrm{OH}^{-}} \cdot\left(\mathrm{K}_{\mathrm{KOH}^{\circ}} \cdot \gamma_{\mathrm{KOH}^{\circ}}\right)^{-1} \\
& \mathrm{~m}_{\mathrm{KSO}_{4}^{-}}=\mathrm{a}_{\mathrm{K}^{+}} \cdot \mathrm{a}_{\mathrm{SO}_{4}^{2-}} \cdot\left(\mathrm{K}_{\mathrm{KSO}_{4}^{-}} \cdot \gamma_{\mathrm{KSO}_{4}^{-}}\right)^{-1} \\
& \mathrm{~m}_{\mathrm{CaSO}_{4}^{\circ}}=\mathrm{a}_{\mathrm{Ca}^{2+}} \cdot \mathrm{a}_{\mathrm{SO}_{4}^{2-}} \cdot\left(\mathrm{K}_{\mathrm{KSO}_{4}^{-}} \cdot \gamma_{\mathrm{KSO}_{4}^{-}}\right)^{-1} \\
& \mathrm{~m}_{\mathrm{CaCl}^{+}}=\mathrm{a}_{\mathrm{Ca}^{2+}} \cdot \mathrm{a}_{\mathrm{Cl}^{-}} \cdot\left(\mathrm{K}_{\mathrm{CaCl}^{+}} \cdot \gamma_{\mathrm{CaCl}^{+}}\right)^{-1} \\
& \mathrm{~m}_{\mathrm{CaCl}_{2}^{\circ}}=\mathrm{a}_{\mathrm{Ca}^{2+}} \cdot \mathrm{a}_{2 \mathrm{Cl}^{-}} \cdot\left(\mathrm{K}_{\mathrm{CaCl}_{2}^{\circ}} \cdot \gamma_{\mathrm{CaCl}_{2}^{\circ}}\right)^{-1} \\
& \mathrm{~m}_{\mathrm{NaSO}_{4}^{-}}=\mathrm{a}_{2 \mathrm{Na}^{+}} \cdot \mathrm{a}_{\mathrm{SO}_{4}^{2-}} \cdot\left(\mathrm{K}_{\mathrm{NaSO}_{4}^{-}} \cdot \gamma_{\mathrm{NaSO}_{4}^{-}}\right)^{-1} \\
& \mathrm{~m}_{\mathrm{H}_{4} \mathrm{SiO}_{4}^{\circ}}=\mathrm{a}_{\mathrm{H}^{+}} \cdot \mathrm{a}_{\mathrm{H}_{3} \mathrm{SiO}_{4}^{-}} \cdot\left(\mathrm{K}_{\mathrm{NH}_{4} \mathrm{SiO}_{4}^{\circ}} \cdot \gamma_{\mathrm{H}_{4} \mathrm{SiO}_{4}^{\circ}}\right)^{-1}
\end{aligned}
$$

where activity, $a$, follows,

$$
\mathrm{a}=\mathrm{m}_{i} \cdot \gamma_{i}
$$

where, $\mathrm{m}_{\mathrm{i}}$, is the concentration of the species $\mathrm{i}$ and $\gamma_{\mathrm{i}}$ is its activity coefficient. It follows that, the aqueous species are constrained by mass balance equations:

$$
\begin{aligned}
& \mathrm{m}_{\mathrm{Na}_{\text {total }}}=\mathrm{m}_{\mathrm{NaCl}^{\circ}}+\mathrm{m}_{\mathrm{Na}^{+}}+\mathrm{m}_{\mathrm{NaOH}^{\circ}}+\mathrm{m}_{\mathrm{NaSO}_{4}^{-}} \\
& \mathrm{m}_{\mathrm{Cl}_{\text {total }}}=\mathrm{m}_{\mathrm{NaCl}^{\circ}}+\mathrm{m}_{\mathrm{Cl}^{-}}+\mathrm{m}_{\mathrm{HCl}^{\circ}}+\mathrm{m}_{\mathrm{CaCl}^{+}}+\mathrm{m}_{\mathrm{CaCl}_{2}^{\circ}}+\mathrm{m}_{\mathrm{KCl}^{\circ}} \\
& \mathrm{m}_{\mathrm{SO}_{4 \text { total }}}=\mathrm{m}_{\mathrm{SO}_{4}^{2-}}+\mathrm{m}_{\mathrm{KSO}_{4}^{-}}+\mathrm{m}_{\mathrm{CaSO}_{4}^{\circ}}+\mathrm{m}_{\mathrm{NaSO}_{4}^{-}}+\mathrm{m}_{\mathrm{HSO}_{4}^{1-}} \\
& \mathrm{m}_{\mathrm{K}_{\text {total }}}=\mathrm{m}_{\mathrm{K}^{+}}+\mathrm{m}_{\mathrm{KCl}^{\circ}}+\mathrm{m}_{\mathrm{KSO}_{4}^{-}}+\mathrm{m}_{\mathrm{KOH}^{\circ}} \\
& \mathrm{m}_{\mathrm{Ca}_{\text {total }}}=\mathrm{m}_{\mathrm{Ca}^{2+}}+\mathrm{m}_{\mathrm{CaSO}_{4}^{\circ}}+\mathrm{m}_{\mathrm{CaCl}^{+}}+\mathrm{m}_{\mathrm{CaCl}_{2}^{\circ}} \\
& \mathrm{m}_{\mathrm{SiO}_{2} \text { total }}=\mathrm{m}_{\mathrm{H}_{4} \mathrm{SiO}_{4}^{\circ}}+\mathrm{m}_{\mathrm{H}_{3} \mathrm{SiO}_{4}^{-}}
\end{aligned}
$$

The final expressions for $\mathrm{pH}$ of the experiments containing only $\mathrm{NaCl}$ (3.46) and greywacke (3.47) are given by 


$$
\begin{aligned}
& 0= \mathrm{a}_{\mathrm{H}^{+}} \cdot \gamma_{\mathrm{H}^{+}}^{-1}-\mathrm{a}_{\mathrm{OH}^{-}} \cdot \gamma_{\mathrm{OH}^{-}}^{-1}-\mathrm{m}_{\mathrm{Cl}_{\text {total }}} \cdot \frac{\mathrm{m}_{\mathrm{Cl}^{-}}}{\mathrm{m}_{\mathrm{Cl}_{\text {total }}}}+\mathrm{m}_{\mathrm{Na}_{\text {total }}} \cdot \frac{\mathrm{m}_{\mathrm{Na}^{+}}}{\mathrm{m}_{\mathrm{Na}_{\text {total }}}} \\
& 0= \mathrm{a}_{\mathrm{H}^{+}} \cdot \gamma_{\mathrm{H}^{+}}^{-1} \mathrm{a}_{\mathrm{OH}^{-}} \cdot \gamma_{\mathrm{OH}^{-}}^{-1}-\mathrm{m}_{\mathrm{Cl}_{\text {total }}} \cdot \frac{\mathrm{m}_{\mathrm{Cl}^{-}}}{\mathrm{m}_{\mathrm{Cl}_{\text {total }}}}+\mathrm{m}_{\mathrm{Na}_{\text {total }}} \cdot \frac{\mathrm{m}_{\mathrm{Na}^{+}}}{\mathrm{m}_{\mathrm{Na}_{\text {total }}}}+\mathrm{m}_{\mathrm{SO}_{4} \text { total }} \\
& \cdot \frac{\mathrm{m}_{\mathrm{SO}_{4}^{2-}}}{\mathrm{m}_{\mathrm{SO}_{4} \text { total }}}+\mathrm{m}_{\mathrm{K}_{\text {total }}} \cdot \frac{\mathrm{m}_{\mathrm{K}^{+}}}{\mathrm{m}_{\mathrm{K}} \text { total }}+\mathrm{m}_{\mathrm{Ca}_{\text {total }}} \cdot \frac{\mathrm{m}_{\mathrm{Ca}^{2+}}}{\mathrm{m}_{\mathrm{Ca}_{\text {total }}}}+\mathrm{m}_{\mathrm{SiO}_{2 \text { total }}} \cdot \frac{\mathrm{m}_{\mathrm{H}_{3} \mathrm{SiO}_{4}^{-}}}{\mathrm{m}_{\mathrm{SiO}_{2} \text { total }}}
\end{aligned}
$$

Initial values were used in the fitting procedure to calculate species distribution at temperature. The non-linear system of equations was solved numerically using a multiroot function according to Albarede (1995) within RStudio software linked to EqSolvR library (Mroczek \& Mroczek, 2017).

The equilibrium constants at different temperatures for equation 3.2 to 3.4 and 3.19 are from Ho et al. (1994, 2000 and 2001), equation 3.21 and 3.25 from Cobble et al. (1982), and equation 3.26 from Seward (1974). The equilibrium association constant for equation 3.20 to 3.24 were taken from the SUPCRT92 data bases (Johnson et al., 1992). The ion product constant, $\mathrm{K}_{\mathrm{w}}$, for the water solvent are from Bandura and Lvov (2006). An extended DebyeHückel expression (Robinson \& Stokes, 1968) was used to calculate the individual ion molal activity coefficients, $\gamma_{i}$, for the charged species,

$$
-\log \gamma_{\mathrm{i}}=\frac{\mathrm{Az} \mathrm{z}_{\mathrm{i}}^{2} \sqrt{\mathrm{I}}}{1+\mathrm{Bå}_{\mathrm{i}} \sqrt{\mathrm{I}}}+\dot{\mathrm{B}} \cdot \mathrm{I}
$$

where $\mathrm{z}$ is the charge of the ion whose activity coefficient is being calculated, A and B are constants whose values depend on the density and dielectric constant of the solvent and the given temperature and pressure, $\stackrel{\AA}{\text { is }}$ the effective diameter of the ion in the solution in $\AA$ (Kielland, 1937) and $\dot{B}$ is the deviation function. I is the ionic strength of the solution, in molal units, given by:

$$
\mathrm{I}=\frac{1}{2} \sum \mathrm{m}_{\mathrm{i}} \cdot \mathrm{z}_{\mathrm{i}}^{2}
$$

where $m_{i}$ and $z_{i}$ are the molality charge of the product of each species, $i$, in the solution. 


\subsection{Results}

\subsubsection{1,5-NDS}

The concentration in $\mathrm{mol} \mathrm{kg}^{-1}$ of 1,5-NDS versus time are presented in Figure 3.2, and breakdown reaction rates are listed in Table 3.3.

1,5-NDS experiences disproportionation under all tested conditions. In all experiments, 1,5-NDS breakdown rates increases with temperature increase. In experiments without the greywacke (Set 1), at $200^{\circ} \mathrm{C}, \mathrm{k}=0.003 \mathrm{day}^{-1}$ and increases to $2.554 \mathrm{day}^{-1}$ at $330^{\circ} \mathrm{C}$. In experiments with greywacke (Set 2), values of $\mathrm{k}$, were significantly lower, at $250^{\circ} \mathrm{C}$, $\mathrm{k}=0.003 \mathrm{day}^{-1}$, and reaches $0.045 \mathrm{day}^{-1}$ at $300^{\circ} \mathrm{C}$.

\subsubsection{1,6-NDS}

1,6-NDS concentration $\left(\mathrm{mol} \mathrm{kg}^{-1}\right)$ changes with time are presented in Figure 3.3. The kinetic data are listed in Table 3.4.

Between 200 and $330^{\circ} \mathrm{C}, 1,6-\mathrm{NDS}$ concentration decreases over experimental time in all experimental conditions. The 1,6-NDS breakdown rates increases with temperature increase for both Set 1 (without greywacke) and Set 2 (with greywacke). At $200^{\circ} \mathrm{C}, \mathrm{NaCl}=0.050 \mathrm{~m}$, Set 1 , the measured 1,6-NDS breakdown rate is the slowest $\left(\mathrm{k}=0.002 \mathrm{day}^{-1}\right)$ and reaches the maximum of $\mathrm{k}=0.806 \mathrm{day}^{-1}$ at $330^{\circ} \mathrm{C}$. In experiments with greywacke (Set 2), rates are much slower. At $250^{\circ} \mathrm{C}, \mathrm{k}=0.001 \mathrm{day}^{-1}$ and reaches a maximum of $\mathrm{k}=0.016 \mathrm{day}^{-1}$ at $300^{\circ} \mathrm{C}$.

\subsubsection{2,6-NDS}

The concentration changes $\left(\mathrm{mol} \mathrm{kg}^{-1}\right)$ of 2,6-NDS over time are presented in Figure 3.4. The kinetic data obtained are listed in Table 3.5.

2,6-NDS breakdown rate is similar to other isomers (i.e. 1,5-NDS, 1,6-NDS). The 2,6NDS decay rate is temperature dependent and notably slower in experiments with greywacke (Set 2) compared to experiments with $\mathrm{NaCl}$ solution only (Set 1 ). At $200^{\circ} \mathrm{C}, \mathrm{NaCl}=0.050 \mathrm{~m}$ (Set 1 ), $\mathrm{k}<0.001$ day $^{-1}$ and increases to 0.120 day $^{-1}$ at $330^{\circ} \mathrm{C}$. In the presence of rock (Set 2), at $250^{\circ} \mathrm{C}, \mathrm{k}=0.001 \mathrm{day}^{-1}$, reaches $0.009 \mathrm{day}^{-1}$ at $300^{\circ} \mathrm{C}$. 


\subsubsection{2,7-NDS}

The concentration $\left(\mathrm{mol} \mathrm{kg}^{-1}\right)$ of 2,7-NDS versus time is presented in Figure 3.5, and breakdown rates are listed in Table 3.6.

The breakdown rate of 2,7-NDS is temperature dependent. At $200^{\circ} \mathrm{C}$, in experiments without the greywacke (Set 1), $\mathrm{k}<0.001 \mathrm{day}^{-1}$ and increases to $0.118 \mathrm{day}^{-1}$ at $330^{\circ} \mathrm{C}$. In the presence of greywacke (Set 2), at $250^{\circ} \mathrm{C}$ and $270^{\circ} \mathrm{C}, \mathrm{k}<0.001$ day $^{-1}$ increase to 0.004 day $^{-1}$ at $300^{\circ} \mathrm{C}$.

\subsubsection{2-NSA}

The 2-NSA concentration $\left(\mathrm{mol} \mathrm{kg}^{-1}\right)$ changes with time are presented in Figure 3.6. and listed in Table 3.7a and 3.7b.

Between 200 and $270^{\circ} \mathrm{C}$, the concentration of 2-NSA increases in both series of experiments, with and without greywacke (Set 1 and Set 2). At $300^{\circ} \mathrm{C}, \mathrm{NaCl}=0.050 \mathrm{~m}$ (Set 1), 2-NSA breaks down with $\mathrm{k}=0.009 \mathrm{day}^{-1}$. At $330^{\circ} \mathrm{C}$, the rate constant increases to $\mathrm{k}=0.014$ day $^{-1}$. At $300^{\circ} \mathrm{C}, \mathrm{NaCl}=0.050 \mathrm{~m}+$ greywacke (Set 2), 2-NSA increases in concentration, $\mathrm{k}=0.014$ day $^{-1}$.

\subsubsection{1-NSA}

1 -NSA is not present in the initial solution but is detected at $250,270,300$ and $330^{\circ} \mathrm{C}$ and at saturated vapour pressure, as shown in Figure 3.7.

At 250 and $270^{\circ} \mathrm{C}, 1$-NSA concentration increases over experimental time for both Set 1 and Set 2 . At $300^{\circ} \mathrm{C}$ and $\mathrm{NaCl}=0.050 \mathrm{~m}$ (Set 1), the concentration of 1-NSA increases over the first three days and then rapidly decreases and remains below detection limit at the end of the experiment. With greywacke, at this temperature (i.e. $300^{\circ} \mathrm{C}$; Set 2), the 1 -NSA concentration increases until day 28 and thereafter significantly decreases. At $330^{\circ} \mathrm{C}$ and $\mathrm{NaCl}$ $=0.050 \mathrm{~m}($ Set 1$), 1-\mathrm{NSA}$ is formed and reaches its maximum concentration after two days. It then subsequently decreases to concentrations below detection limits. 


\section{1,5-NDS}
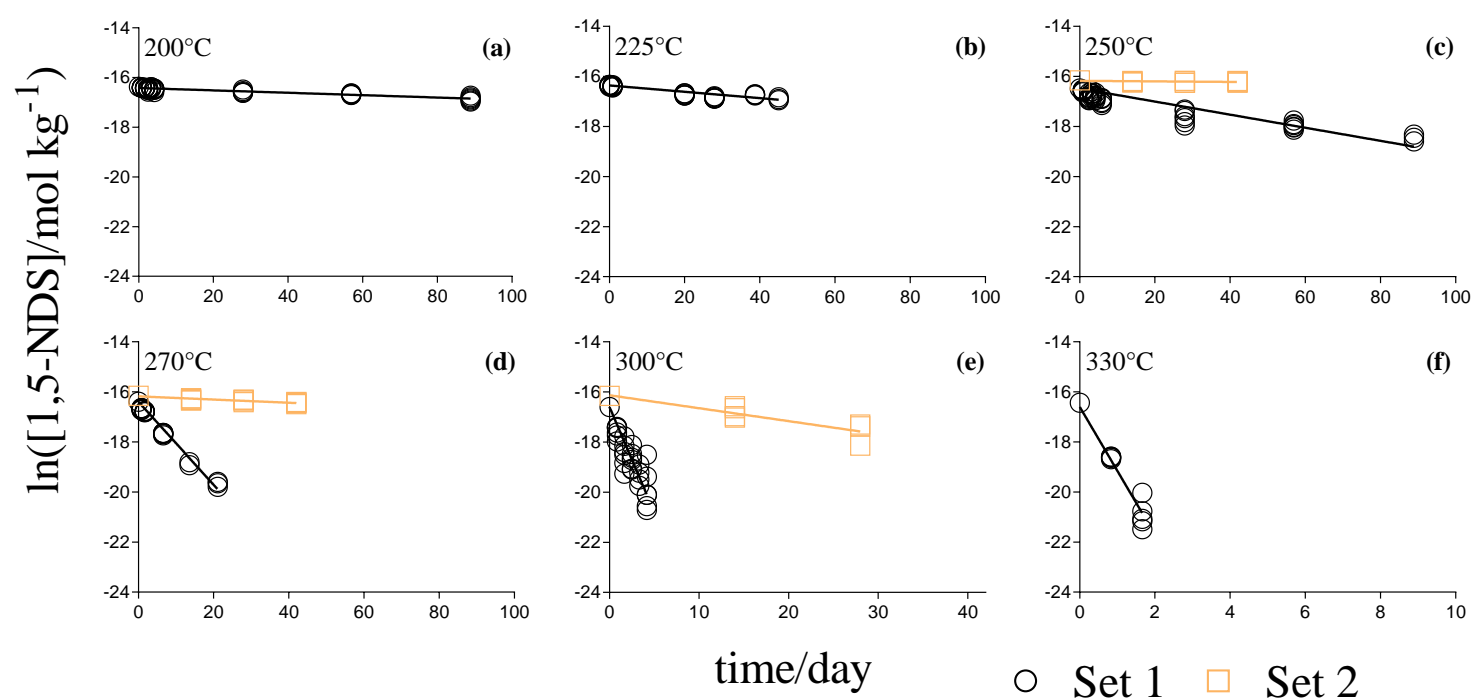

$\circ$ Set $1 \square$ Set 2

Figure 3.2: Concentrations $\left(\mathrm{mol} \mathrm{kg}^{-1}\right)$ of 1,5-NDS after heating at 200, 225, 250, 270, 300 and $330^{\circ} \mathrm{C}$ and at saturated vapour pressure. Set $1: \mathrm{pH}_{25^{\circ} \mathrm{C}}=7.0, \mathrm{NaCl}=0.050 \mathrm{~mol} \mathrm{~kg}^{-1}$; Set 2 , $\mathrm{pH}_{25^{\circ} \mathrm{C}}=7.0, \mathrm{NaCl}=0.050 \mathrm{~mol} \mathrm{~kg}^{-1}+$ greywacke.

Table 3.3: Rate constants for the decomposition of 1,5-NDS at temperature, experimental $\mathrm{pH}$ and at the saturated vapour pressure.

\begin{tabular}{cccc}
\hline $\mathrm{t} /{ }^{\circ} \mathrm{C}$ & $\mathrm{pH}_{\mathrm{t}}{ }^{*}$ & $\begin{array}{c}1^{\text {st }} \text { order reaction rate } \\
\text { constant k/day }\end{array}$ & $\begin{array}{c}1^{\text {st }} \text { order reaction rate } \\
\text { constant } \mathrm{k} / \mathrm{s}^{-1}\end{array}$ \\
\hline \multicolumn{2}{l}{ Set $1(\mathrm{NaCl}=0.050 \mathrm{~m})$} & & \\
200 & 5.6 & $0.003 \pm 0.001$ & $3.5 \times 10^{-8} \pm 1.2 \times 10^{-8}$ \\
225 & 5.6 & $0.013 \pm 0.002$ & $1.5 \times 10^{-7} \pm 2.3 \times 10^{-8}$ \\
250 & 5.6 & $0.066 \pm 0.002$ & $7.6 \times 10^{-7} \pm 2.3 \times 10^{-8}$ \\
270 & 5.6 & $0.166 \pm 0.007$ & $1.9 \times 10^{-6} \pm 8.1 \times 10^{-8}$ \\
300 & 5.7 & $0.839 \pm 0.044$ & $9.7 \times 10^{-6} \pm 5.1 \times 10^{-7}$ \\
330 & 5.8 & $2.554 \pm 0.076$ & $3.0 \times 10^{-5} \pm 8.8 \times 10^{-7}$ \\
\hline Set $2(\mathrm{NaCl}=0.050 \mathrm{~m}+$ greywacke $)$ & \\
250 & 6.4 & $0.003 \pm 0.001$ & $3.5 \times 10^{-8} \pm 1.2 \times 10^{-8}$ \\
270 & 6.4 & $0.008 \pm 0.003$ & $9.3 \times 10^{-8} \pm 3.5 \times 10^{-8}$ \\
300 & 6.5 & $0.045 \pm 0.003$ & $5.2 \times 10^{-7} \pm 3.5 \times 10^{-8}$ \\
\hline
\end{tabular}




\section{1,6-NDS}

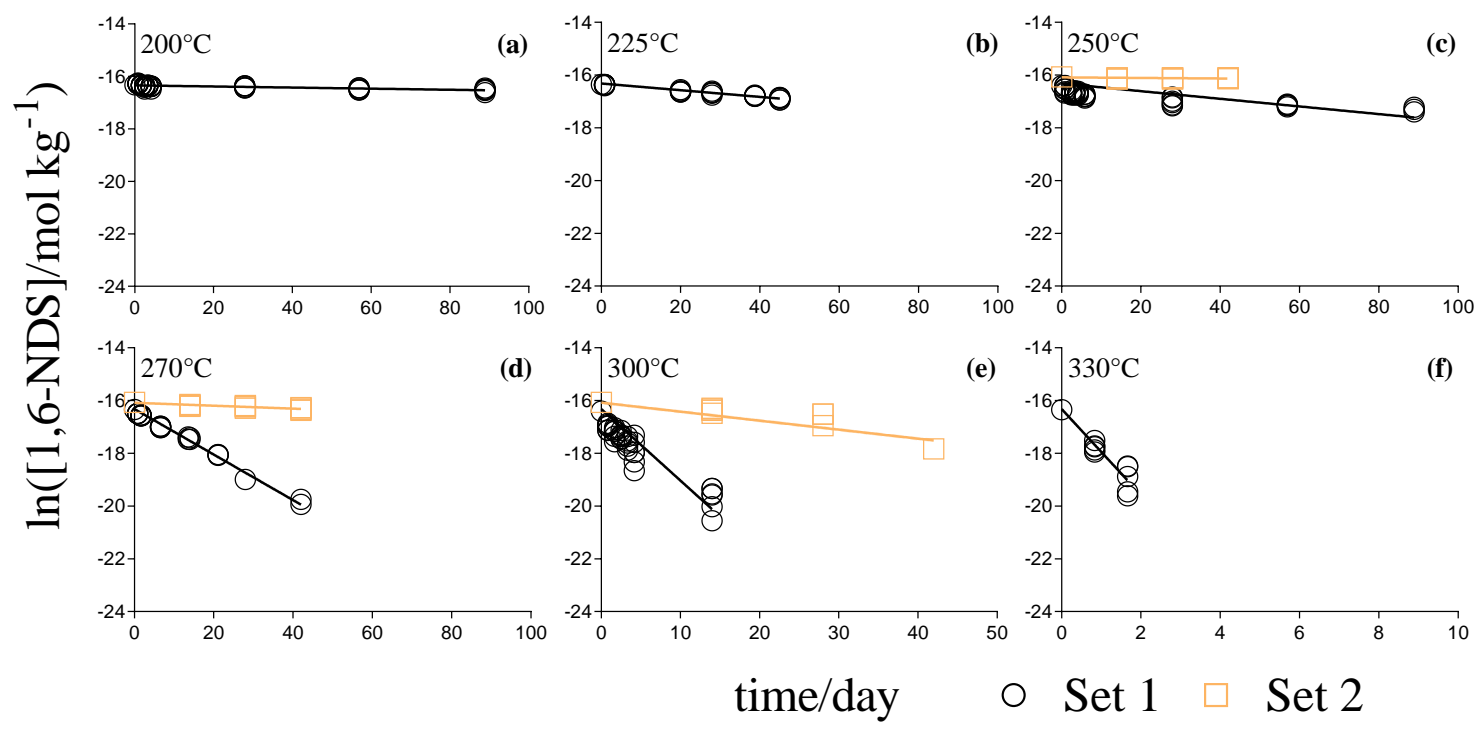

Figure 3.3: Concentrations $\left(\mathrm{mol} \mathrm{kg}^{-1}\right)$ of 1,6-NDS after heating at 200, 225, 250, 270, 300 and $330^{\circ} \mathrm{C}$ and at saturated vapour pressure. Set $1: \mathrm{pH}_{25^{\circ} \mathrm{C}}=7.0, \mathrm{NaCl}=0.050 \mathrm{~mol} \mathrm{~kg}^{-1}$; Set 2, $\mathrm{pH}_{25^{\circ} \mathrm{C}}=7.0, \mathrm{NaCl}=0.050 \mathrm{~mol} \mathrm{~kg}^{-1}+$ greywacke.

Table 3.4: Rate constants for the decomposition of 1,6-NDS at temperature, experimental $\mathrm{pH}$ and at the saturated vapour pressure.

\begin{tabular}{|c|c|c|c|}
\hline $\mathrm{t} /{ }^{\circ} \mathrm{C}$ & $\mathrm{pH}_{\mathrm{t}}{ }^{*}$ & $\begin{array}{c}1^{\text {st }} \text { order reaction rate } \\
\text { constant } \mathrm{k} / \mathrm{day}^{-1}\end{array}$ & $\begin{array}{c}1^{\text {st }} \text { order reaction rate } \\
\text { constant } \mathrm{k} / \mathrm{s}^{-1}\end{array}$ \\
\hline \multicolumn{4}{|c|}{ Set $1(\mathrm{NaCl}=0.050 \mathrm{~m})$} \\
\hline 200 & 5.6 & $0.002 \pm 0.000$ & $2.3 \times 10^{-8} \pm 1.2 \times 10^{-8}$ \\
\hline 225 & 5.6 & $0.012 \pm 0.000$ & $1.4 \times 10^{-7} \pm 1.2 \times 10^{-8}$ \\
\hline 250 & 5.6 & $0.017 \pm 0.000$ & $2.0 \times 10^{-7} \pm 1.2 \times 10^{-8}$ \\
\hline 270 & 5.6 & $0.085 \pm 0.004$ & $9.8 \times 10^{-7} \pm 4.6 \times 10^{-8}$ \\
\hline 300 & 5.7 & $0.245 \pm 0.015$ & $2.8 \times 10^{-6} \pm 1.7 \times 10^{-7}$ \\
\hline 330 & 5.8 & $0.806 \pm 0.125$ & $9.3 \times 10^{-6} \pm 1.4 \times 10^{-6}$ \\
\hline \multicolumn{4}{|c|}{ Set $2(\mathrm{NaCl}=0.050 \mathrm{~m}+$ greywacke $)$} \\
\hline 250 & 6.4 & $0.001 \pm 0.001$ & $1.2 \times 10^{-8} \pm 1.2 \times 10^{-8}$ \\
\hline 270 & 6.4 & $0.006 \pm 0.001$ & $6.4 \times 10^{-8} \pm 1.2 \times 10^{-8}$ \\
\hline 300 & 6.5 & $0.016 \pm 0.001$ & $1.8 \times 10^{-7} \pm 1.2 \times 10^{-8}$ \\
\hline
\end{tabular}




\section{2,6-NDS}

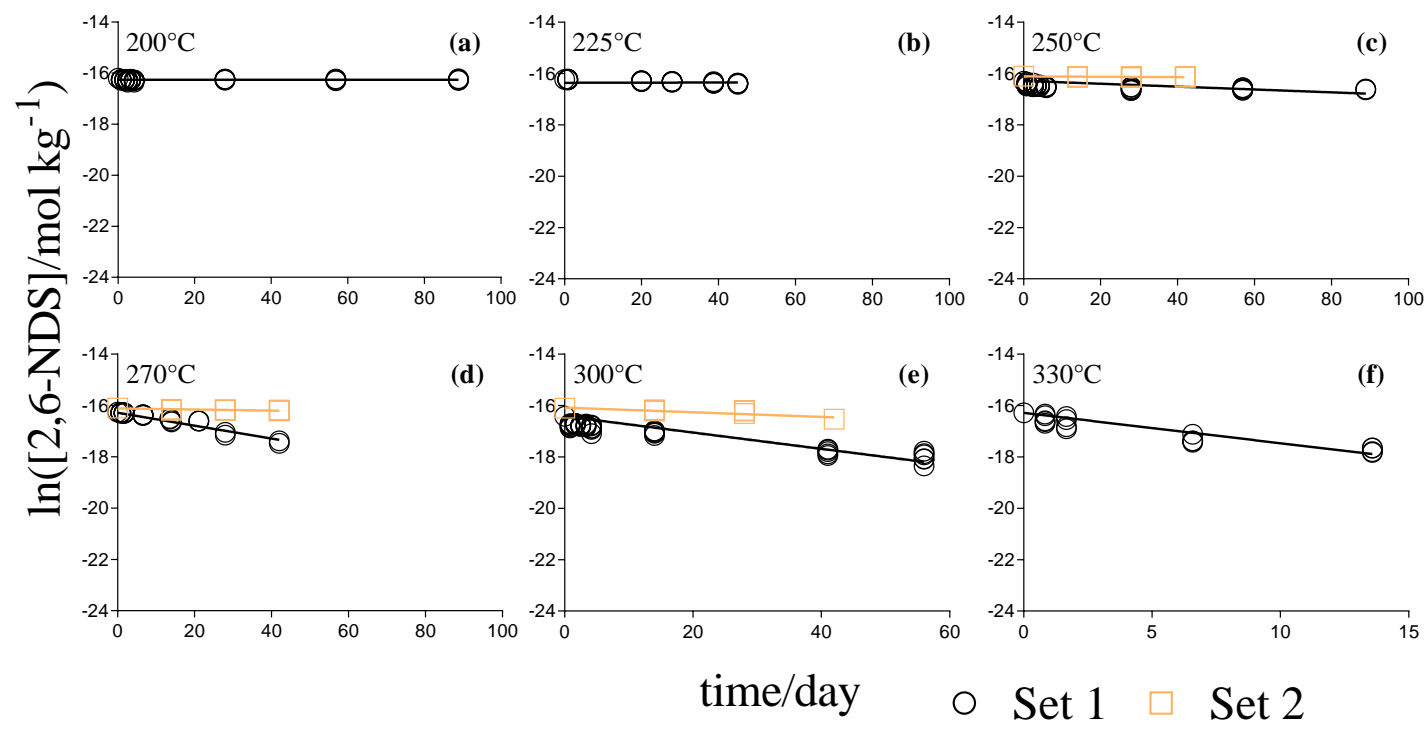

Figure 3.4: Concentrations $\left(\mathrm{mol} \mathrm{kg}^{-1}\right)$ of 2,6-NDS after heating at 200, 225, 250, 270, 300 and $330^{\circ} \mathrm{C}$ and at saturated vapour pressure. Set $1: \mathrm{pH}_{25^{\circ} \mathrm{C}}=7.0, \mathrm{NaCl}=0.050 \mathrm{~mol} \mathrm{~kg}^{-1}$; Set 2 , $\mathrm{pH}_{25^{\circ} \mathrm{C}}=7.0, \mathrm{NaCl}=0.050 \mathrm{~mol} \mathrm{~kg}^{-1}+$ greywacke.

Table 3.5: Rate constants for the decomposition of 2,6-NDS at temperature, experimental $\mathrm{pH}$ and at the saturated vapour pressure.

\begin{tabular}{cccc}
\hline $\mathrm{t} /{ }^{\circ} \mathrm{C}$ & $\mathrm{pH}_{\mathrm{t}}{ }^{*}$ & $\begin{array}{c}1^{\text {st }} \text { order reaction rate } \\
\text { constant k/day }\end{array}$ & $\begin{array}{c}1^{\text {st }} \text { order reaction rate } \\
\text { constant k/s }\end{array}$ \\
\hline Set $1(\mathrm{NaCl}=$ & $0.050 \mathrm{~m})$ & & \\
200 & 5.6 & $3.9 \times 10^{-5}$ & $4.5 \times 10^{-10}$ \\
225 & 5.6 & $0.001 \pm 0.001$ & $1.2 \times 10^{-8} \pm 1.2 \times 10^{-8}$ \\
250 & 5.6 & $0.005 \pm 0.001$ & $5.8 \times 10^{-8} \pm 1.2 \times 10^{-8}$ \\
270 & 5.6 & $0.021 \pm 0.007$ & $2.4 \times 10^{-7} \pm 8.1 \times 10^{-7}$ \\
300 & 5.7 & $0.049 \pm 0.008$ & $5.7 \times 10^{-7} \pm 9.3 \times 10^{-8}$ \\
330 & 5.8 & $0.120 \pm 0.019$ & $1.4 \times 10^{-6} \pm 2.2 \times 10^{-7}$ \\
\hline Set $2(\mathrm{NaCl}=0.050 \mathrm{~m}+$ greywacke $)$ & \\
250 & 6.4 & $0.001 \pm 0.001$ & $1.2 \times 10^{-8} \pm 1.2 \times 10^{-8}$ \\
270 & 6.4 & $0.002 \pm 0.001$ & $2.3 \times 10^{-8} \pm 1.2 \times 10^{-8}$ \\
300 & 6.5 & $0.009 \pm 0.002$ & $1.0 \times 10^{-7} \pm 2.3 \times 10^{-8}$ \\
\hline
\end{tabular}

* pH at temperature 

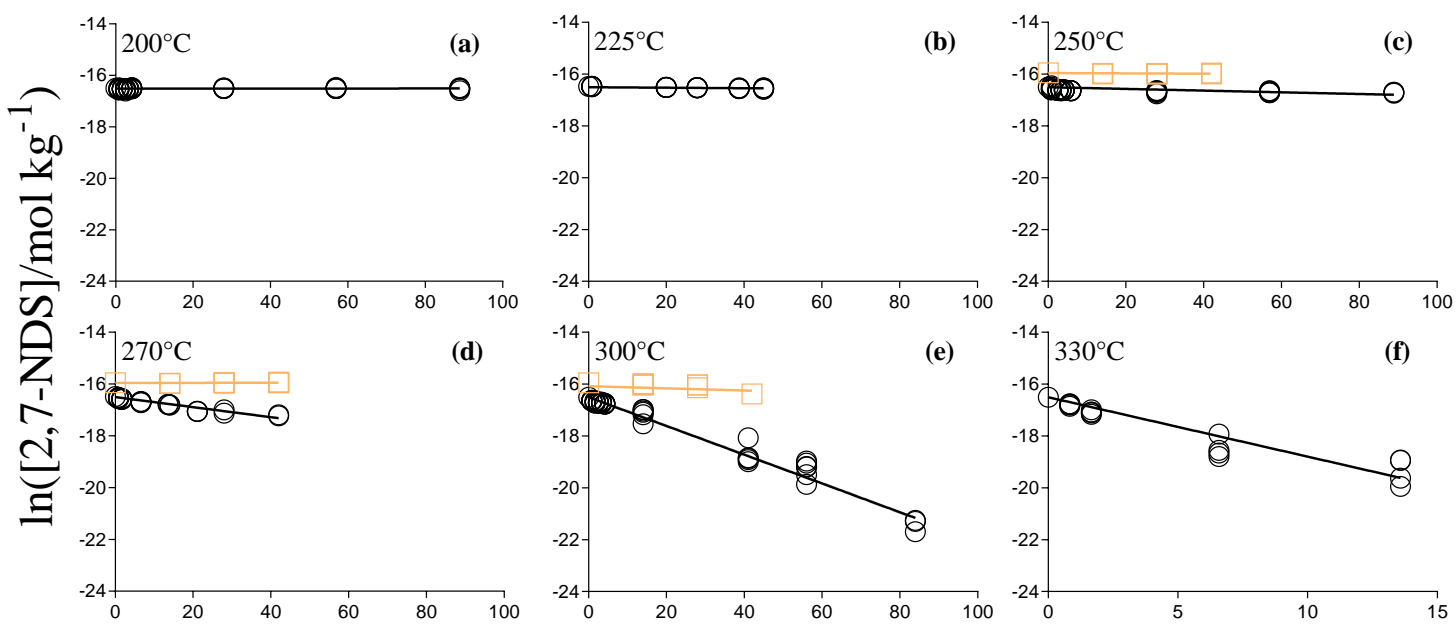

time/day

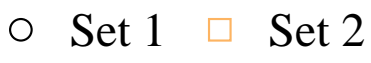

Figure 3.5: Concentrations $\left(\mathrm{mol} \mathrm{kg}^{-1}\right)$ of 2,7-NDS after heating at 200, 225, 250, 270, 300 and $330^{\circ} \mathrm{C}$ and at saturated vapour pressure. Set 1: $\mathrm{pH}_{25^{\circ} \mathrm{C}}=7.0, \mathrm{NaCl}=0.050 \mathrm{~mol} \mathrm{~kg}^{-1}$; Set 2, $\mathrm{pH}_{25^{\circ} \mathrm{C}}=7.0, \mathrm{NaCl}=0.050 \mathrm{~mol} \mathrm{~kg}^{-1}+$ greywacke.

Table 3.6: Rate constants for the decomposition of 2,7-NDS at temperature, experimental $\mathrm{pH}$ and at the saturated vapour pressure.

\begin{tabular}{cccl}
\hline $\mathrm{t} /{ }^{\circ} \mathrm{C}$ & $\mathrm{pH}_{\mathrm{t}}{ }^{*}$ & $\begin{array}{c}1^{\text {st }} \text { order reaction rate } \\
\text { constant k/day }\end{array}$ & $\begin{array}{c}1^{\text {st }} \text { order reaction rate } \\
\text { constant } \mathrm{k} / \mathrm{s}^{-1}\end{array}$ \\
\hline Set $1(\mathrm{NaCl}=$ & $0.050 \mathrm{~m})$ & & \\
200 & 5.6 & $9.4 \times 10^{-5}$ & $1.1 \times 10^{-9}$ \\
225 & 5.6 & $0.002 \pm 0.002$ & $2.3 \times 10^{-8} \pm 2.3 \times 10^{-8}$ \\
250 & 5.6 & $0.005 \pm 0.002$ & $5.8 \times 10^{-8} \pm 2.3 \times 10^{-8}$ \\
270 & 5.6 & $0.015 \pm 0.001$ & $1.7 \times 10^{-7} \pm 1.2 \times 10^{-7}$ \\
300 & 5.7 & $0.039 \pm 0.002$ & $4.5 \times 10^{-7} \pm 2.3 \times 10^{-8}$ \\
330 & 5.8 & $0.118 \pm 0.021$ & $1.4 \times 10^{-6} \pm 2.4 \times 10^{-7}$ \\
\hline Set $2(\mathrm{NaCl}=$ & $0.050 \mathrm{~m}+$ greywacke) & \\
250 & 6.4 & $5.7 \times 10^{-4}$ & $6.6 \times 10^{-9}$ \\
270 & 6.4 & $1.7 \times 10^{-3}$ & $2.0 \times 10^{-8}$ \\
300 & 6.5 & $0.004 \pm 0.003$ & $1.6 \times 10^{-8} \pm 3.5 \times 10^{-8}$ \\
\hline
\end{tabular}




\section{2-NSA}
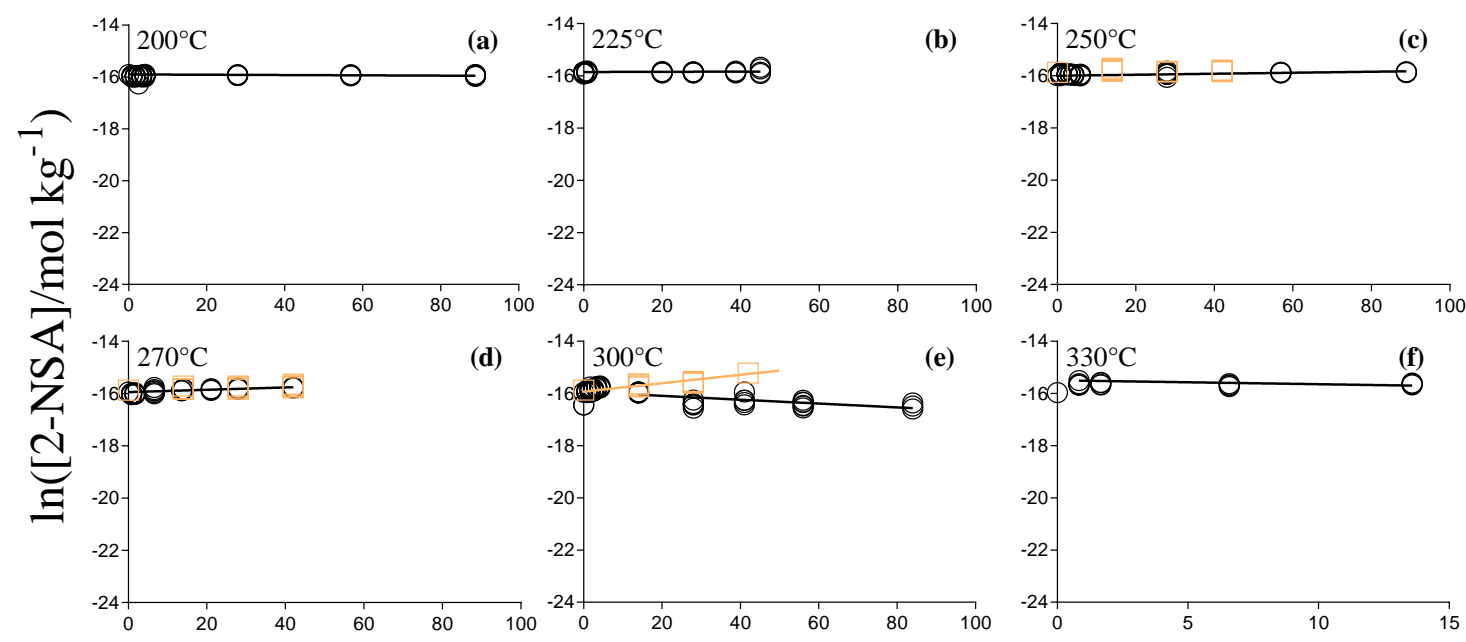

time/day

○ Set 1

Set 2

Figure 3.6: Concentrations $\left(\mathrm{mol} \mathrm{kg}^{-1}\right)$ of 2-NSA after heating at 200, 225, 250, 270, 300 and $330^{\circ} \mathrm{C}$ and at saturated vapour pressure. Set 1: $\mathrm{pH}_{25^{\circ} \mathrm{C}}=7.0, \mathrm{NaCl}=0.050 \mathrm{~mol} \mathrm{~kg}^{-1}$; Set 2, $\mathrm{pH}_{25^{\circ} \mathrm{C}}=7.0, \mathrm{NaCl}=0.050 \mathrm{~mol} \mathrm{~kg}{ }^{-1}+$ greywacke.

Table 3.7a: Rate constants for the decomposition of 2-NSA at temperature, experimental $\mathrm{pH}$ and at saturated vapour pressure.

\begin{tabular}{cccc}
\hline $\mathrm{t} /{ }^{\circ} \mathrm{C}$ & $\mathrm{pH}_{\mathrm{t}}^{*}$ & $\begin{array}{r}1^{\text {st }} \text { order reaction rate } \\
\text { constant } \mathrm{k} / \mathrm{day}^{-1}\end{array}$ & $\begin{array}{c}1^{\text {st }} \text { order reaction rate } \\
\text { constant } \mathrm{k} / \mathrm{s}^{-1}\end{array}$ \\
\hline $\mathrm{Set} 1(\mathrm{NaCl}=0.050 \mathrm{~m})$ \\
300 & 5.7 & $0.009 \pm 0.001$ & $1.0 \times 10^{-7} \pm 1.2 \times 10^{-8}$ \\
330 & 5.8 & $0.014 \pm 0.016$ & $1.6 \times 10^{-7} \pm 1.9 \times 10^{-7}$ \\
\hline \multicolumn{3}{c}{${ }^{*} \mathrm{pH}$ at temperature }
\end{tabular}

Table 3.7b: Rate constants for the formation of 2$\mathrm{NSA}$ at temperature, experimental $\mathrm{pH}$ and at saturated vapour pressure.

\begin{tabular}{|c|c|c|c|}
\hline $\mathrm{t} /{ }^{\circ} \mathrm{C}$ & $\mathrm{pH}_{\mathrm{t}}{ }^{*}$ & $\begin{array}{l}1^{\text {st }} \text { order reaction rate } \\
\text { constant } \mathrm{k} / \mathrm{day}^{-1}\end{array}$ & $\begin{array}{c}1^{\text {st }} \text { order reaction rate } \\
\text { constant } \mathrm{k} / \mathrm{s}^{-1}\end{array}$ \\
\hline \multicolumn{4}{|c|}{ Set $1(\mathrm{NaCl}=0.050 \mathrm{~m})$} \\
\hline 225 & 5.6 & $3.6 \times 10^{-3}$ & $4.3 \times 10^{-8}$ \\
\hline 250 & 5.6 & $0.002 \pm 0.001$ & $2.2 \times 10^{-8} \pm 1.2 \times 10^{-8}$ \\
\hline 270 & 5.6 & $0.004 \pm 0.001$ & $5.2 \times 10^{-8} \pm 1.2 \times 10^{-8}$ \\
\hline \multicolumn{4}{|c|}{ Set $2(\mathrm{NaCl}=0.050 \mathrm{~m}+$ greywacke $)$} \\
\hline 250 & 6.4 & $0.002 \pm 0.001$ & $1.8 \times 10^{-8} \pm 1.2 \times 10^{-8}$ \\
\hline 270 & 6.4 & $0.004 \pm 0.001$ & $4.5 \times 10^{-8} \pm 1.2 \times 10^{-8}$ \\
\hline 300 & 6.5 & $0.014 \pm 0.001$ & $1.6 \times 10^{-7} \pm 1.2 \times 10^{-8}$ \\
\hline
\end{tabular}




\section{1-NSA}

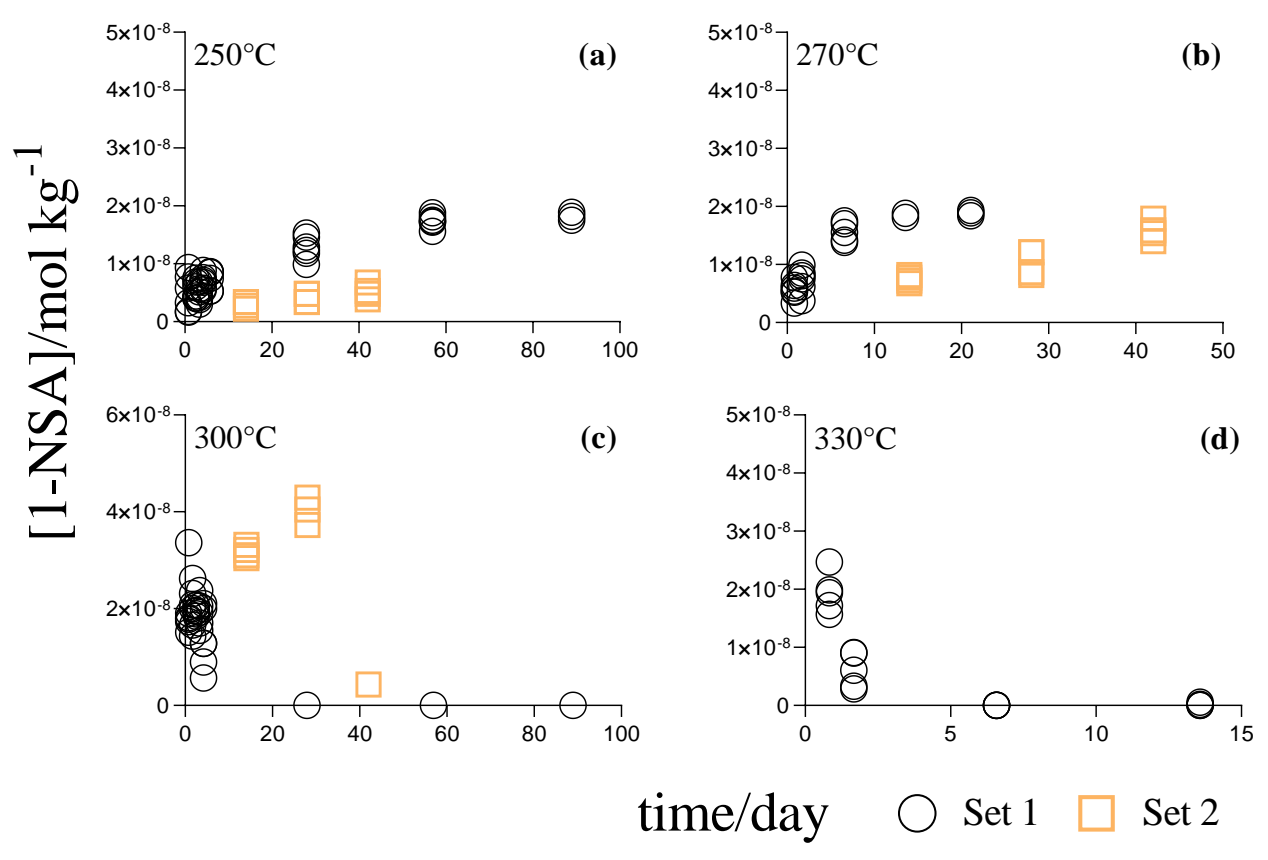

Figure 3.7: Concentrations $\left(\mathrm{mol} \mathrm{kg}{ }^{-1}\right.$ ) of 1-NSA after heating at $250,270,300$ and $330^{\circ} \mathrm{C}$ and at saturated vapour pressure. Set 1: $\mathrm{pH}_{25^{\circ} \mathrm{C}}=7.0, \mathrm{NaCl}=0.050 \mathrm{~mol} \mathrm{~kg}^{-1} ;$ Set $2, \mathrm{pH}_{25^{\circ} \mathrm{C}}=7.0$, $\mathrm{NaCl}=0.050 \mathrm{~mol} \mathrm{~kg}^{-1}+$ greywacke.

\subsection{Discussion}

The aim of this study was to provide a more detailed understanding of the conditions under which naphthalene sulfonates and disulfonates degrade and/or transform to other compounds and to demonstrate the applicability of the results of this study. The results show that NDS/NSA degradation is temperature dependent. Kinetic data, i.e. the pre-exponential factor, $\mathrm{A}_{0}$, and the activation energy, $\mathrm{E}_{\mathrm{a}}$, have been derived from the experimental data.

\subsubsection{The naphthalene disulfonate decomposition}

The naphthalene disulfonate decay rates at $200^{\circ} \mathrm{C}$ are slow (for 1,5-NDS $\mathrm{k} \leq 0.003$ day $^{-1}$ ), making them reasonably "stable" at this temperature, with their relative stabilities according to $2,6-\mathrm{NDS} \approx 2,7-\mathrm{NDS}<1,6-\mathrm{NDS}<1,5-\mathrm{NDS}$. 
At $225^{\circ} \mathrm{C}$, disproportionation rate increases for all NDS isomers and the trend in stability is similar up to $330^{\circ} \mathrm{C}$ (i.e. 1,5 -NDS is the least stable and 2,6-NDS $\approx 2,7$-NDS are the most stable; Table 3.3 - 3.6).

All four of the studied NDS isomers decrease in stability with increasing temperature. Note that 2-NSA remains stable up to $270^{\circ} \mathrm{C}$ in the Set 1 and persists at $300^{\circ} \mathrm{C}$ over the whole experimental time in the presence of greywacke (Set 2).

The exponential decrease in the concentration of naphthalene disulfonates over time suggests first order reactions. If the decay of a NDS follows a first order reaction, then,

$$
-\frac{\mathrm{dC}_{\mathrm{t}}}{\mathrm{dt}}=\mathrm{k} \cdot \mathrm{C}_{\mathrm{t}}
$$

where $C_{t}$ is the concentration of naphthalene sulfonate at time $t$ and $k$ is the first order rate constant the following expression is obtained,

$$
\begin{gathered}
\frac{\mathrm{dC}_{\mathrm{t}}}{\mathrm{dt}}=-\mathrm{k} \cdot \mathrm{C}_{\mathrm{t}} \\
\mathrm{dC}_{\mathrm{t}} \cdot \frac{1}{\mathrm{C}_{\mathrm{t}}}=-\mathrm{k} \cdot \mathrm{dt} \\
\int \frac{1}{C_{t}} \cdot \mathrm{dC}_{\mathrm{t}}=\int-\mathrm{k} \cdot \mathrm{dt}
\end{gathered}
$$

and be logarithmically expressed as,

$$
\ln \left(C_{t}\right)=-\mathrm{kt}+\mathrm{const}
$$

where 'const' is the constant of integration. Consequently,

$$
\begin{aligned}
& C_{t}=e^{-k t+\text { const }} \\
& C_{t}=e^{\text {const }} \cdot e^{-k t}
\end{aligned}
$$

where,

$$
e^{\text {const }}=C_{0}
$$

with simplification, the final form of the rate law is obtained, 


$$
\mathrm{C}_{\mathrm{t}}=\mathrm{C}_{0} \cdot \mathrm{e}^{-\mathrm{kt}}
$$

which can be used to calculate concentration of the NDS at any time.

The results indicate that temperature has an influence on rate constants of 1,5-NDS, 1,6-NDS, 2,6-NDS and 2,7-NDS as shown in the Figure 3.8. The straight lines in this figure are linear least-square fits to the data (Table 3.3 - 3.6). The activation energy, $\mathrm{E}_{\mathrm{a}}$, and preexponential factor, $A_{0}$, are listed in Table 3.8. Experimental data were also used to plot halflife/day vs temperature $/{ }^{\circ} \mathrm{C}$ (Figure 3.9). The sensitivity of the reaction rate to temperature is indicated by the activation energy, $\mathrm{E}_{\mathrm{a}}$ (Table 3.8). Higher values of the activation energy indicate that the rate of the breakdown reaction is more sensitive to temperature changes.

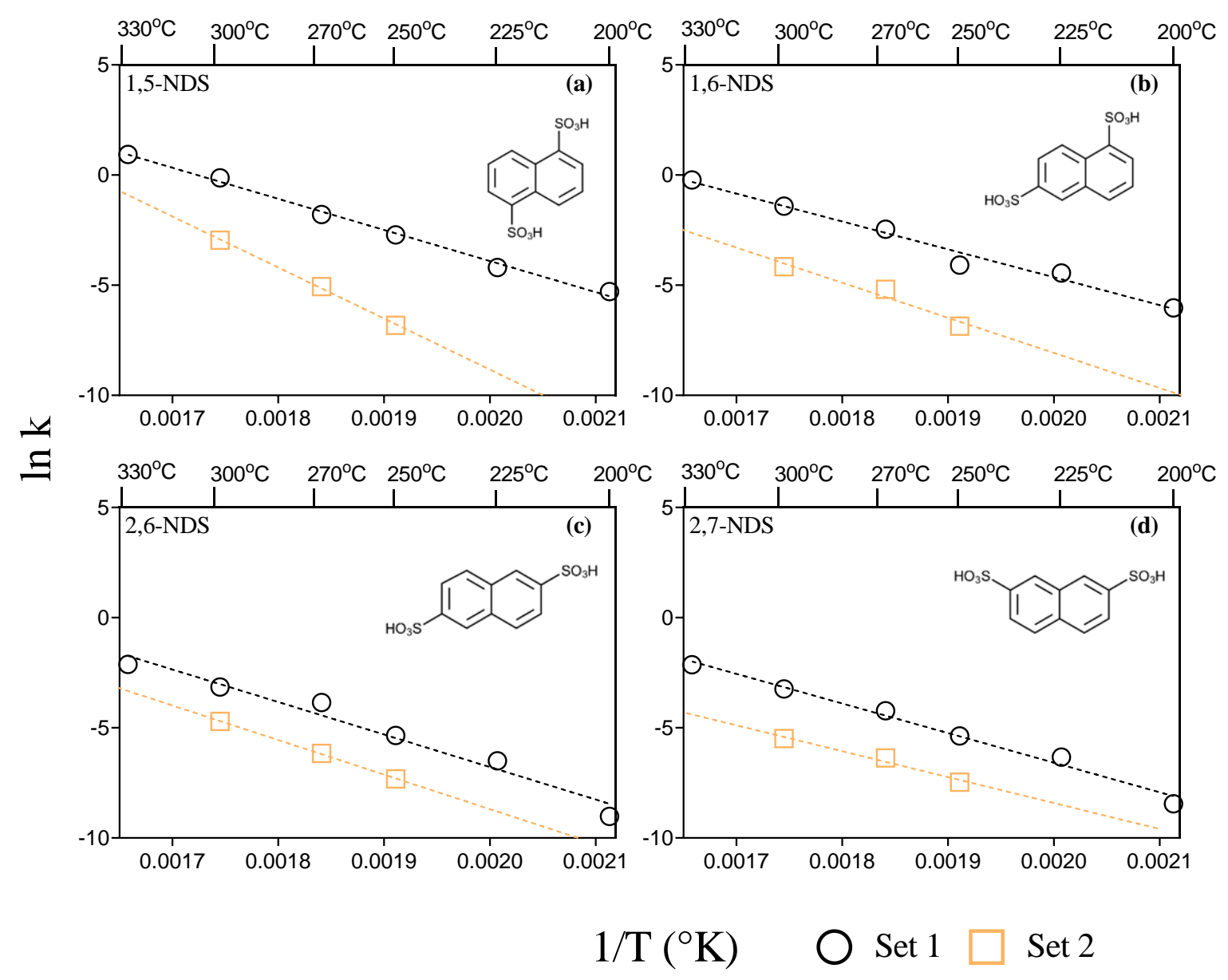

Figure 3.8: Arrhenius plots of $\ln (\mathrm{k})$ vs. $1 / \mathrm{T}\left({ }^{\circ} \mathrm{K}\right)$ between 200 and $330^{\circ} \mathrm{C}$ for (a) 1,5-NDS, (b) 1,6-NDS, (c) 2,6-NDS and (d) 2,7-NDS. Set 1: $\mathrm{NaCl}=0.050 \mathrm{~mol} \mathrm{~kg}^{-1}$ solution; Set 2: $\mathrm{NaCl}=$ $0.050 \mathrm{~mol} \mathrm{~kg}^{-1}+$ greywacke. 


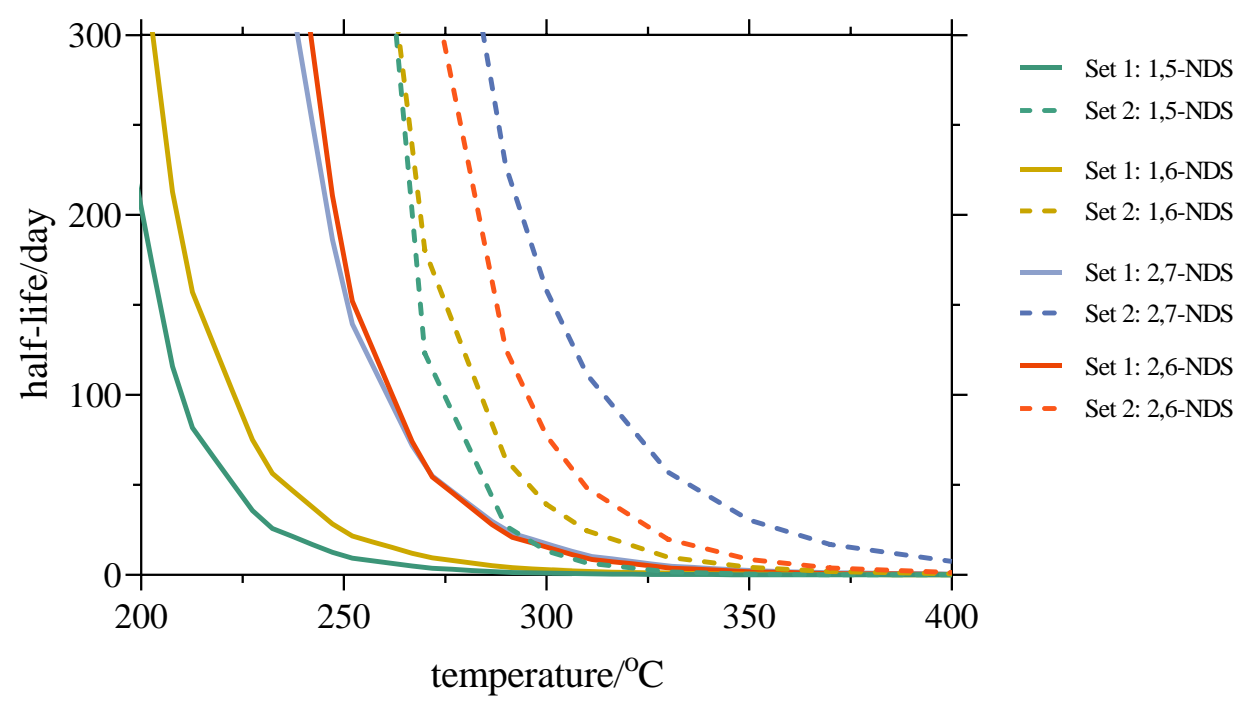

Figure 3.9: Half-life vs. temperature based upon the Arrhenius decay data. Set 1: $\mathrm{NaCl}=0.050 \mathrm{~mol} \mathrm{~kg}^{-1}$ solution only; Set $2: \mathrm{NaCl}=0.050 \mathrm{~mol} \mathrm{~kg}^{-1}+$ greywacke .

Table 3.8: Arrhenius constants for the decomposition of 2,6-naphthalene disulfonate (2,6-NDS), 2,7-naphthalene disulfonate (2,7-NDS), 1,6-naphtahlene disulfonate (1,6NDS) and 1,5-naphthalene disulfonate (1,5-NDS).

$\mathrm{A}_{0}=$ the pre-exponential factor, $\mathrm{E}_{\mathrm{a}}=$ the activation energy, $\mathrm{R}^{2}=$ minimised sum of squares from the linear regression.

\begin{tabular}{|c|c|c|c|c|c|c|c|}
\hline & NDS & $\mathrm{t} /{ }^{\circ} \mathrm{C}$ & duration & $\mathrm{A}_{0} / \mathrm{day}^{-1}$ & $\mathrm{Ea} / \mathrm{kJ} / \mathrm{mol}$ & $\mathrm{R}^{2}$ & $\begin{array}{c}\text { time }_{1 / 2} / \text { day } \\
\text { at } 300^{\circ} \mathrm{C}\end{array}$ \\
\hline \multirow[t]{4}{*}{ Set 1} & 1,5-NDS & $200-330$ & 3 months & $3.68 \times 10^{10}$ & 117 & 0.99 & 1 \\
\hline & 1,6-NDS & $200-330$ & 3 months & $9.58 \times 10^{8}$ & 105 & 0.98 & 3 \\
\hline & $2,6-\mathrm{NDS}$ & $200-330$ & 3 months & $7.44 \times 10^{9}$ & 123 & 0.97 & 14 \\
\hline & 2,7-NDS & $200-330$ & 3 months & $6.48 \times 10^{8}$ & 112 & 0.99 & 16 \\
\hline \multirow[t]{4}{*}{ Set 2} & 1,5-NDS & $250-300$ & 3 weeks & $1.56 \times 10^{16}$ & 192 & 0.99 & 13 \\
\hline & 1,6-NDS & $250-300$ & 3 weeks & $1.71 \times 10^{10}$ & 131 & 0.95 & 39 \\
\hline & 2,6-NDS & $250-300$ & 3 weeks & $6.52 \times 10^{9}$ & 130 & 0.99 & 77 \\
\hline & 2,7-NDS & $250-300$ & 3 weeks & $3.41 \times 10^{6}$ & 97 & 0.98 & 158 \\
\hline
\end{tabular}

Set $1: \mathrm{NaCl}=0.050 \mathrm{~mol} \mathrm{~kg}^{-1}$ and $\mathrm{pH}_{\mathrm{t}} \approx 5.6$; Set $2: \mathrm{NaCl}=0.050 \mathrm{~mol} \mathrm{~kg}^{-1}+$ greywacke and $\mathrm{pH}_{\mathrm{t}} \approx 6.4$ 


\subsubsection{2-NSA - the most stable isomer}

2-NSA is the isomer which is most resistant to temperature/pH/salinity changes. Its higher stability is explained by two uneven positions, $\alpha$ or $\beta$ ( 1 or 2$)$ of electrophilic substitution of the $-\mathrm{SO}_{3}$ group (Figure 3.10). The $\beta$ carbon substitution is thermodynamically more stable (Cerfontain \& Telder, 1967).

$(\alpha) \mathrm{E}$

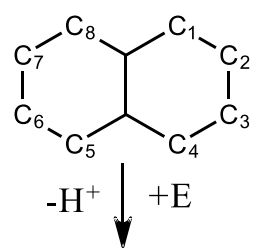<smiles>Cc1cccc2ccccc12</smiles>

1-NSA<smiles>[123I]c1ccc2ccccc2c1</smiles>

2-NSA

Figure 3.10: Electrophilic aromatic substitution in the naphthalene. E- electrophile $\alpha$ - position $1, \beta$ - position 2.

The experiments show that breakdown of the polyaromatic sulfonates 1,6-NDS, 2,6NDS and 2,7-NDS does produce some 2-NSA (note that 1,5-NDS does not form 2-NSA as concluded in Chapter 2). At $\geq 250^{\circ} \mathrm{C}$, the various NDSs decay significantly with a concomitant increase in 2-NSA. For example, 2,6-NDS disproportionates to 2-NSA according to,

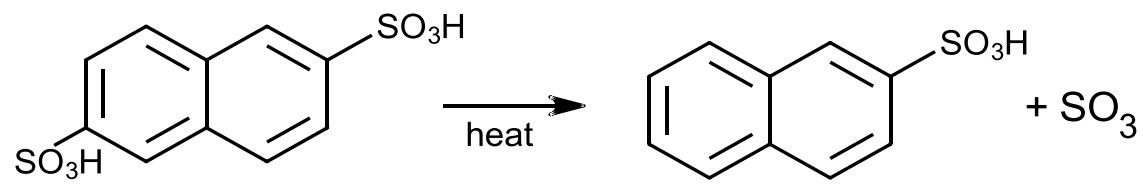

2-NSA concentration increases over time between $225^{\circ} \mathrm{C}$ and $330^{\circ} \mathrm{C}$, however, the naphthalene sulfonate (2-NSA), formed remains stable only at $\leq 270^{\circ} \mathrm{C}$ and $\leq 300^{\circ} \mathrm{C}$ when greywacke is present (Figure 3.6a-d). When the temperature is $\geq 300^{\circ} \mathrm{C}$ for experiments with $\mathrm{NaCl}=0.050 \mathrm{~m}$ (Set 1, solution only), 2-NSA undergoes further decay (Figure 3.6e - f), creating naphthalene (NAP) as a final product (Chapter 6) as follow, 


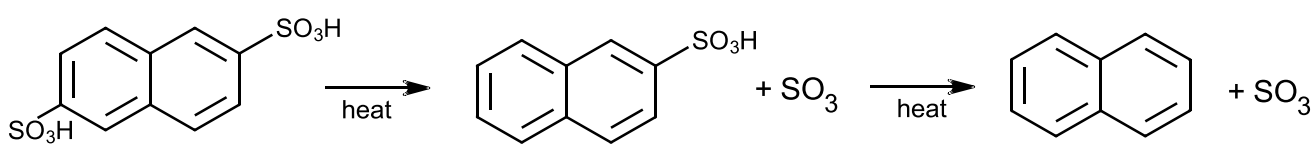

The breakdown rate of 2-NSA at $300^{\circ} \mathrm{C}$ was interpolated from data points starting at day 14 (Figure 3.6e). The decay rate obtained, $\mathrm{k}=0.009$ day $^{-1}$, is notably slower in comparison to decay rates of the naphthalene disulfonates at that temperature (Table 3.3 - 3.6). Note that the value of $\mathrm{k}$ for 2-NSA is influenced by decomposition of the other naphthalene disulfonates at $300^{\circ} \mathrm{C}$. If 2-NSA was the only NDS/NSA in the system, its apparent decay rate would be greater. The decay rate, $\mathrm{k}$, at $330^{\circ} \mathrm{C}$ for 2 -NSA was obtained similarly $\left(\mathrm{k}=0.014\right.$ day $^{-1}$; Table 3.7b).

The results from the second series of experiments, with greywacke, show the formation of 2-NSA, as a consequence of naphthalene disulfonate disproportionation up to $300^{\circ} \mathrm{C}$ at least for 3 weeks (Figure 3.6e). Thus, addition of greywacke to the experiment (Set 2) resulted in water-rock interaction, which causes $\mathrm{pH}$ changes (i.e. higher $\mathrm{pH}_{\mathrm{t}}=6.5$ ) that stabilises 2-NSA. Formation rates vary linearly with inverse temperature and is similar to Set 1 data as shown in Figure 3.11. Thus, suggests that 2-NSA formation is governed by the same mechanism. The relevant Arrhenius constants and activation energies are given in Table 3.9.

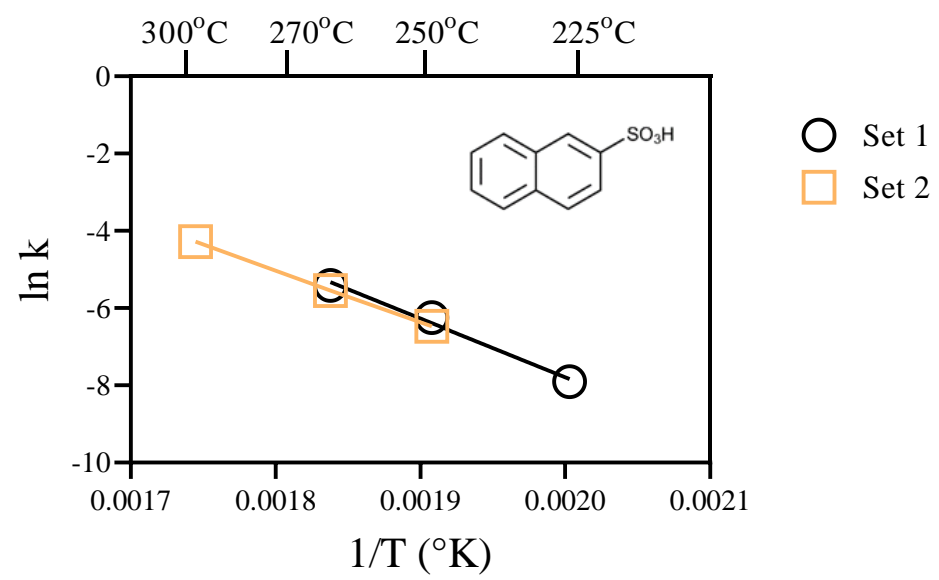

Figure 3.11: Arrhenius plots of $\ln (\mathrm{k})$ vs. $1 / \mathrm{T}\left({ }^{\circ} \mathrm{K}\right)$ between 200 and $270^{\circ} \mathrm{C}$ (Set 1$)$ and between 250 and $300^{\circ} \mathrm{C}$ (Set 2) for 2-NSA formation. Set $1: \mathrm{NaCl}=0.050 \mathrm{~mol} \mathrm{~kg}^{-1} ;$ Set $2: \mathrm{NaCl}=0.050$ mol kg-1 and greywacke. 
Table 3.9: Arrhenius constants for the formation of 2-NSA (Figure 3.11).

$\mathrm{A}_{0}=$ the pre-exponential factor, $\mathrm{E}_{\mathrm{a}}=$ the activation energy, $\mathrm{R}^{2}=$ minimised sum of squares from the linear regression.

\begin{tabular}{ccccccc}
\hline & $\mathrm{t} /{ }^{\circ} \mathrm{C}$ & duration & $\mathrm{NaCl} / \mathrm{m}$ & $\mathrm{A}_{0} / \mathrm{day}^{-1}$ & $\mathrm{Ea} / \mathrm{kJ} / \mathrm{mol}$ & $\mathrm{R}^{2}$ \\
\hline Set 1 & $200-270$ & up to 3 months & 0.050 & $6.87 \times 10^{9}$ & 125 & 0.99 \\
Set 2 & $250-300$ & up to 3 weeks & 0.050 & $2.03 \times 10^{8}$ & 109 & 0.99 \\
\hline
\end{tabular}

Set $1: \mathrm{NaCl}=0.050 \mathrm{~mol} \mathrm{~kg}^{-1}$ and $\mathrm{pH}_{\mathrm{t}} \approx 5.6 ;$ Set $2: \mathrm{NaCl}=0.050 \mathrm{~mol} \mathrm{~kg}^{-1}+$ greywacke and $\mathrm{pH}_{\mathrm{t}} \approx 6.4$

\subsubsection{1-NSA - the important breakdown product}

1-NSA was formed in the experiments above $250^{\circ} \mathrm{C}$ (both in Set 1 and Set 2) as a breakdown product of naphthalene disulfonate. It is possible that it formed mainly as a product of 1,5-NDS decay, as described in Chapter 2 and 6. The produced 1-NSA remains stable over experimental time between 250 and $270^{\circ} \mathrm{C}$.

At temperatures $\geq 300^{\circ} \mathrm{C}, \mathrm{pH}_{\mathrm{t}}=5.7,1$-NSA appears only as a transient species (Figure 3.7; Set 1) and 1-NSA could only be detected for several days. However, in the experiments with greywacke $\left(\mathrm{pH}_{\mathrm{t}}=6.5\right.$, Set 2), 1-NSA remains detectable even after 42 days.

\subsection{4 pH effect on NDS/NSA stability}

The second set of experiments include greywacke which reacts with the experimental solution $(\mathrm{NaCl}=0.050 \mathrm{~m})$. The fluid-mineral interactions result in ion concentration and $\mathrm{pH}$ changes (Set $2 \mathrm{pH}_{\mathrm{t}} \approx 6.4$, Set $1 \mathrm{pH}_{\mathrm{t}} \approx 5.6$; Table 3.1 and 3.2), which stabilise NDS and NSA. This is consistent with results presented in Chapter 2 and 4 . The mechanism that determines $\mathrm{pH}$ influence in naphthalene (di) sulfonate is described in Chapter 2.

\subsubsection{Examples of the fate of NDS as a function of $\mathrm{pH}$, ionic strength and temperature}

The proposed geothermal reservoir tested in this scenario has a constant temperature of $260^{\circ} \mathrm{C}$, brine $\mathrm{pH}_{\mathrm{t}}=5.6$, and $\mathrm{NaCl}=0.050 \mathrm{~m}$. A mixture of 1,5-NDS, 1,6-NDS, 2,6-NDS and 2,7-NDS ( $25 \mathrm{~kg}$ of each) is injected into the reservoir through a reinjection well. It is assumed that: (1) NDS decays according to first order reaction (equation 3.58); (2) 1,5-NDS decays only to 1-NSA; (3) other naphthalene disulfonates present in the simulation breakdown only to 2-NSA; (4) 1-NSA is not isomerising into 2-NSA; and (5) no NDS/NSA isomers were trapped in more poorly-connected parts of the field or lost to the far-field; and there is connection between injection and production well. 
The concentrations of polyaromatic sulfonate and their breakdown products were calculated and presented in Table 3.10. and Figure 3.12.

The simulation shows that the composition of originally injected NDS will significantly change over time. After 14 days from injection, significant amounts of breakdown product (1-NSA and 2-NSA) can be detected and the polyaromatic sulfonate mixture will be considerably depleted in 1,5-NDS. Over 448 days (14.7 months) of the test, the bulk of the naphthalene disulfonates will breakdown forming 1-NSA and 2-NSA. This simulation shows the importance of kinetics in the interpretation of retrieved NDS and NSA data in well injection tests.

Table 3.10: Calculated mass (kg) of naphthalene sulfonates (1-NSA and 2-NSA) and naphthalene disulfonates (1,5-NDS, 1,6-NDS, 2,6-NDS and 2,7-NDS) within the reservoir over time, $t$, after injection into a hypothetical geothermal reservoir at $260^{\circ} \mathrm{C}$ and saturated vapour pressure, $\mathrm{pH}_{\mathrm{t}}=5.6$, and $\mathrm{NaCl}=0.050 \mathrm{~mol} \mathrm{~kg}^{-1}$.

\begin{tabular}{|c|c|c|c|c|c|c|c|}
\hline time (day) & 0 & 7 & 14 & 28 & 112 & 224 & 448 \\
\hline \multicolumn{8}{|c|}{ mass in $\mathrm{kg}$} \\
\hline $1,5-\mathrm{NDS}$ & 25.0 & 10.3 & 4.2 & 0.7 & 0.0 & 0.0 & 0.0 \\
\hline 1,6-NDS & 25.0 & 17.7 & 12.5 & 6.3 & 0.1 & 0.0 & 0.0 \\
\hline 2,6-NDS & 25.0 & 23.9 & 22.8 & 20.8 & 11.9 & 5.7 & 1.3 \\
\hline 2,7-NDS & 25.0 & 23.8 & 22.7 & 20.6 & 11.6 & 5.3 & 1.1 \\
\hline 1-NSA & 0.0 & 0.9 & 2.5 & 4.7 & 7.9 & 10.9 & 11.9 \\
\hline 2-NSA & 0.0 & 3.0 & 5.2 & 5.7 & 5.7 & 5.7 & 5.7 \\
\hline
\end{tabular}

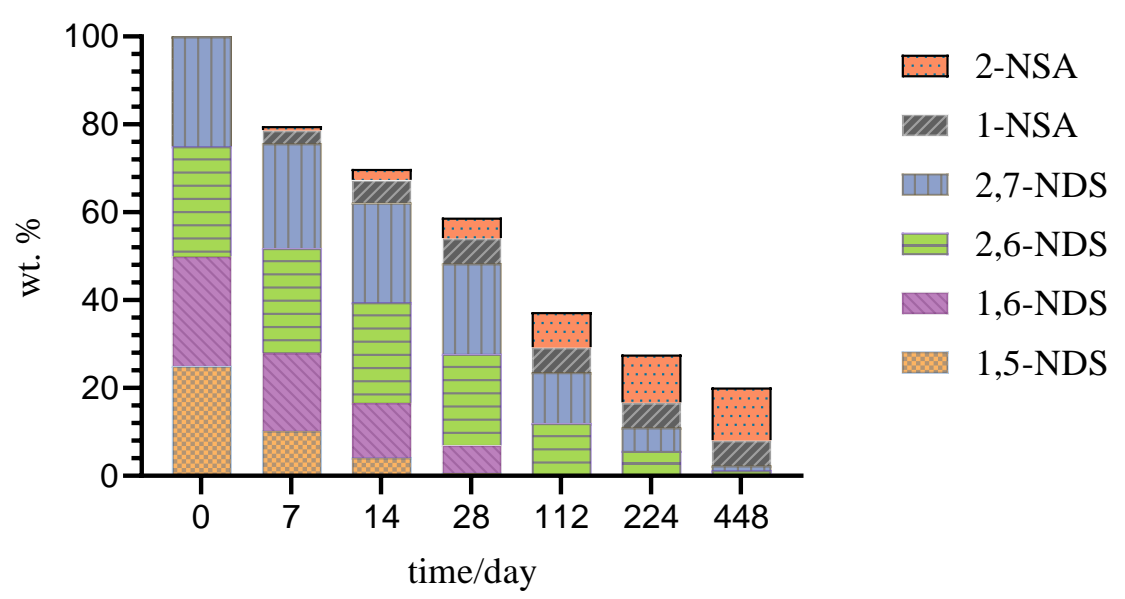

Figure 3.12: Concentrations (wt. \% of total NSA + NDS) of 1-NSA, 2-NSA, 1,5-NDS, 1,6-NDS, 2,6-NDS and 2,7-NDS after exposure to $260^{\circ} \mathrm{C}$ and saturated vapour pressure for 448 days. 


\subsection{Conclusions}

Two series of experiments comprising 2-NSA, 1,5-NDS, 1,6-NDS, 2,6-NDS and 2,7-NDS have been conducted. The first series consisted of $\mathrm{NaCl}=0.050 \mathrm{~m}$ solution at $\mathrm{pH}_{25^{\circ} \mathrm{C}}=7.0$ and was conducted over the range of temperatures from 200 to $330^{\circ} \mathrm{C}$ at the saturated vapour pressure for up to 89 days. The second series comprised a $\mathrm{NaCl}=0.050 \mathrm{~m}$ solution at $\mathrm{pH}_{25^{\circ} \mathrm{C}}=7.0$ and greywacke grains. This series was heated to 250,270 and $300^{\circ} \mathrm{C}$ at the saturated vapour pressure for up to 42 days.

The results show the following:

(1) naphthalene disulfonate stability (1,5-NDS, 1,6-NDS, 2,6-NDS and 2,7-NDS) is temperature and $\mathrm{pH}-$ dependent;

(2) 1-NSA and 2-NSA appear as breakdown products of NDS thermal decomposition;

(3) NDS and NSA stabilities are as follows:

$1,5-\mathrm{NDS}<1,6-\mathrm{NDS}<2,6-\mathrm{NDS} \approx 2,7-\mathrm{NDS}<2-\mathrm{NSA}$;

(4) 2-NSA is not stable at $300^{\circ} \mathrm{C}$ and near neutral $\mathrm{pH}_{\mathrm{t}}$;

(5) 1-NSA is temperature and $\mathrm{pH}$-dependent with; its stability increasing with decreasing temperature and increasing $\mathrm{pH}$.

The results presented in this study emphasise the importance of employing kinetic data while modelling an active geothermal field if NDS/NSA isomers are used as a geothermal reservoir model calibration tool. Future research should consider studies of each NDS/NSA isomer separately at different $\mathrm{pH}$ conditions, as at this point, the influence of NDS/NSA isomers on each other has not been determined.

\subsection{References}

Addison S. J., Winick J.A., Mountain B. W., Siega F. L., 2015. Rotokawa Reservoir Tracer Test History. Proceedings $38^{\text {th }}$ New Zealand Geothermal Workshop, Auckland, New Zealand.

Ayling, B. F., Hogarth, R. A., Rose, P., 2015. Tracer testing at the Habanero EGS site, central Australia. Proceedings World Geothermal Congress, Melbourne, Australia. 
Albarède, F., 1995. Introduction to Geochemical Modelling. Cambridge University Press, Great Britain. 543, 318 - 340.

Bandura A. V., Lvov S. N., 2006. The ionization constant of water over wide ranges of temperature and density. Journal of Physical and Chemical Reference Data, 35, 1, 15 - 30.

Dashkevich, Y.G., Mountain, B.W., Seward, T.M., Winick, J.A., 2015. Temperature stability of naphthalene sulfonic and naphthalene disulfonic acids at geothermal conditions. Proceedings World Geothermal Congress, Melbourne, Australia.

Cerfontain, H., Telder A., 1967. Aromatic Sulfonation. Part XVI: Sulfonation of naphthalene and its monosulfonic acids in concentrated aqueous sulfuric acid. Recueil Des Travaux Chimiques Des Pays-Bas, 86, 527 - 536.

Cobble, J. W., Murray, Jr. R. C., Turner, P. J., Chen, K., 1982. High-temperature thermodynamic data for species in aqueous solution. Research project report, $1167-1$. EPRI NP-2400.

Ho, P. C., Palmer, D. A., and Gruszkiewicz, M.S., 2001. Conductivity measurements of dilute aqueous $\mathrm{HCl}$ solutions to high temperatures and pressures using a flow-through cell. Journal of Physical Chemistry B, 105, 1260 - 1266.

Ho, P.C., Palmer, D.A., Wood, R.H., 2000. Conductivity measurements of dilute aqueous $\mathrm{LiOH}, \mathrm{NaOH}$, and $\mathrm{KOH}$ solutions to high temperatures and pressures using a flowthrough cell. Journal of Physcial Chemistry B, 104, 12084 - 12089.

Ho, P.C., Palmer, D.A., Mesmer, R.E., 1994. Electrical conductivity measurements of aqueous sodium chloride solutions to $600^{\circ} \mathrm{C}$ and $300 \mathrm{MPa}$. Journal of Solution Chemistry, 23, $997-1018$.

Jiurong, L., 1999. Reinjection and Tracer Tests in the Laugaland. Geothermal Training Programme, 6, $141-164$.

Johnson, J.W., Oelkers, E.H., Helgeson, H.C., 1992. SUPCRT92: A software package for calculating the standard molal thermodynamic properties of minerals, gases, aqueous species, and reactions from 1 to 5000 bars and 0 to $1000^{\circ} \mathrm{C}$ Computers \& Geoscience, 18,899 $-947$.

Kielland J., 1937. Individual activity coefficients of ions in aqueous solutions. Journal of the American Chemical Society, 59, $1675-1678$. 
Mroczek S., Mroczek E., 2017. EqSolvR: Chemical Equilibrium Solver. R package version 1.1.0. https://github.com/shearwavesplitter/EqSolvR.

Nogara, J. B., Sambrano, B. M. G., 2005. Tracer tests using naphthalene di-sulfonates in Mindanao geothermal production field, Philippines Q $2 \pi$ Dt. Proceedings World Geothermal Congress, Antalya, Turkey.

Robinson R. A., Stokes R. H., 1968. Electrolyte Solutions, Butterworths, $2^{\text {nd }}$ Edition, 571.

Rose, P., Benoit, D., Lee, S.G., Tandia, B., Kilbourn, P., 2000. testing the naphthalene sulfonates as geothermal tracers at Dixie Valley, Ohaaki, and Awibengkok. 25 ${ }^{\text {th }}$ Workshop on Geothermal Reservoir Engineering Stanford University, Stanford, California.

Rose, P., Benoit, W.R., Kilbourn, P.M., 2001a. The application of the polyaromatic sulfonates as tracers in geothermal reservoirs. Geothermics, 30, $617-640$.

Rose, P., Johnson, S. D., Kilbourn, P., 2001b. Tracer testing at Dixie Valley, Nevada, using 2-naphthalene sulfonate and 2,7-naphthalene disulfonate. $26^{\text {th }}$ Workshop on Geothermal Reservoir Engineering.

Rose, P., Capuno, V., Peh, A., Kilbourn, P., Kastler, C., 2002. The use of the naphthalene sulfonates as tracers in high temperature geothermal systems Pete. Proceedings, $23^{\text {rd }}$ PNOC Geothermal Conference, Makati City, Philippines.

Sanjuan, B., Pinault, J.L., Rose, P., Gérard, A., Brach, M., Braibant, G., Crouzet, C., Foucher, J.C., Gautier, A., Touzelet, S., 2006. Tracer testing of the geothermal heat exchanger at Soultz-sous-Forêts (France) between 2000 and 2005. Geothermics, 35, 622 - 653.

Seward T. M., 1974. Equilibrium and oxidation potential in geothermal waters at Broadlands, New Zealand. American Journal of Science, 274, 190 - 192.

Winick, J., Siega, F., Addison, S., Richardson, I., Mountain, B., Barry, B., 2015. Coupled Iodine-125 and 2-NSA reservoir tracer testing at the Rotokawa Geothermal field, New Zealand. Proceedings World Geothermal Congress, Melbourne, Australia. 


\section{A flow-through autoclave study of trace naphthalene disulfonate compounds in presence of solid materials at conditions relevant to active geothermal reservoirs}

\subsection{Introduction}

Polyaromatic sulfonate compounds have been used extensively in the geothermal industry as injected compounds to elucidate permeability and well connectivity, however, their stabilities and breakdown reactions have been little studied. Previously published studies constituted a brief insight into NDS/NSA stability under geothermal conditions (Rose et al., 2001; Mountain \& Winick, 2012; Dashkevich et al., 2015) and are insufficient to determine the behaviour of these compounds under the extremes of temperature and pressure encountered in active geothermal reservoirs. The need for further research was emphasised in 2011 by a tracer test where naphthalene disulfonates (NDS) were injected into the high temperature reservoir at Rotokawa, New Zealand. No trace of the originally injected NDS was detected in production wells (Addison et al., 2015).

It is challenging to examine naphthalene sulfonates and disulfonates at high temperatures $\left(\leq 400^{\circ} \mathrm{C}\right)$ while simultaneously simulating extremely complex geothermal reservoir chemistry. Certainly, it is impossible to reproduce these conditions in a laboratory exactly, however, the flow-through system apparatus described in this chapter allowed us to conduct dynamic experiments in which a continuous flow of aqueous fluid was pumped through rock (greywacke or pumice) or mineral material (quartz), generating waterrock/mineral interaction at given elevated temperature. Observations made during these experiments brought to attention the role of $\mathrm{pH}$ and temperature in determining the stability of aromatic sulfonates under high pressure/temperature conditions. Additionally, these observations intimated questions about the possible transformation/isomerisation processes of the NDS and NSA and the final products of their thermal breakdown, as explained later in Chapter 6.

The aim of this study was to determine naphthalene disulfonate stability in a dynamic flow-through environment in which mineral (or rock)-solution reaction is occurring. 


\subsection{Materials and methods}

\subsubsection{Hydrothermal Flow System HFS-340}

The flow-through autoclave (Figure 4.1 and 4.2) is designed to simulate the conditions at high temperature (ambient to $400^{\circ} \mathrm{C}$ ) and pressure (from atmospheric to 500 bars) and enables continuous fluid flow between 0.001 to $15 \mathrm{ml} \mathrm{min}^{-1}$. It is linked to a computer that automatically $\operatorname{logs}$ pressure, temperature, flow-rate and accumulated volume. Fluid flow is maintained by a computer-controlled double-piston metering pump. The pump delivers distilled water into the bottom of a titanium separator containing a movable piston. The experimental fluid, contained above the piston, is pressurised and forced through the system.

The fluid flows through titanium tubing and into the titanium pressure vessel (internal diameter $25 \mathrm{~mm}$ x $150 \mathrm{~mm}$ length, $19.3 \mathrm{ml}$ internal volume) which is contained in an insulated furnace. The mineral or rock substrate used in the experiment is placed in the pressure vessel. The rock or mineral material is crushed and sieved to a particular size fraction and washed ultrasonically to eliminate fine material. Crushed material is used to increase the reactive surface area. The system temperature is monitored by a thermocouple inserted into the top of the pressure vessel and pressure is maintained by a back-pressure regulator (BPR) connected with the top of the pressure vessel. All wetted parts of the flow-through apparatus in contact with the experimental fluid are composed of titanium except for the Teflon diaphragm in the BPR. Samples are collected daily in a syringe connected to the BPR.

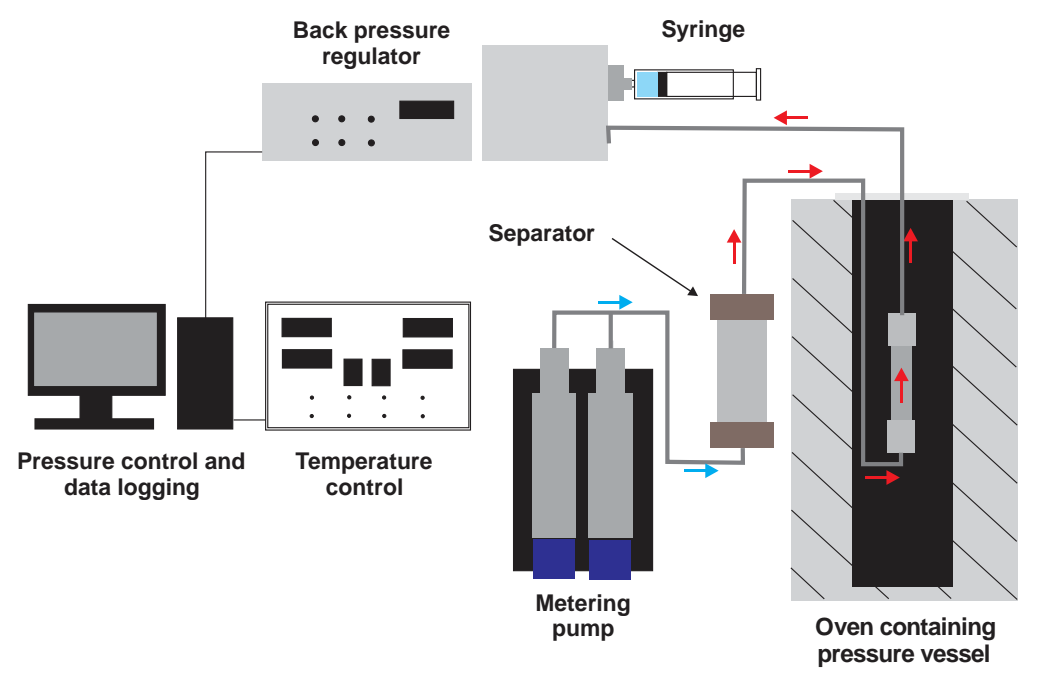

Figure 4.1: Schematic diagram of the high temperature and pressure hydrothermal flow simulator. 


\subsubsection{Experimental flow system setup}

Three flow-through experiments were conducted. The first with greywacke, the second with pumice, and a third control experiment with quartz. All experiments involved containing four different naphthalene disulfonates: 2,6-naphthalene disulfonate (2,6-NDS); 2,7-naphthalene disulfonate (2,7-NDS); 1,5-naphthalene disulfonate (1,5-NDS); and 1,6-naphtahlene disulfonate (1,6-NDS). It is worth noting that the primary goal of these experiments was to test whether the dominant rock in the New Zealand geothermal reservoirs can be the source for sulfur (and variable $\mathrm{Cl}$ ) in the deep fluids. The authors (Mountain et al. 2016 ; 2017) of this work used the opportunity to investigate NDS stability in the water-rock reaction experiments.

The mixture of disulfonates $\left(\sim 10 \mu \mathrm{g} \mathrm{kg}^{-1}\right.$ each) was dissolved in ultrapure water $\left(18.2 \mathrm{M} \Omega \mathrm{cm}^{-1}\right)$ and deoxygenated with a $\mathrm{N}_{2}: \mathrm{H}_{2}$ gas mixture (i.e. purged of atmospheric oxygen). The average residence time of naphthalene disulfonate solution in the pressure vessel was $\sim 10$ hours at a flow rate of $1 \mathrm{ml} \mathrm{hr}^{-1}$. The experimental temperature ranged from ambient to $400^{\circ} \mathrm{C}$ and pressure from 21 to 415 bar (Figure 4.2). Both are logged every five minutes during each flow-through experiment. An effluent sample was collected every 24 hours for analysis of $\mathrm{pH}$, major cations, sulfate, chloride, hydrogen sulphide, and naphthalene disulfonates and sulfonates.

The first experiment involved a greywacke rock sourced from the Waotu Quarry, west of Tokoroa, New Zealand. Similar greywackes represent the dominant reservoir rock for geothermal brine re-injection in New Zealand geothermal reservoirs. The greywacke is composed of sedimentary clasts dominated by quartz, plagioclase and lithic fragments. Secondary minerals forming the matrix are quartz, feldspar, chlorite, and illite. The rock was crushed and sieved to retrieve the $0.35-0.5 \mathrm{~mm}$ size fraction. The size of particles was selected to obtain a reasonably large surface area for water-rock interaction, to avoid "channelling" of the fluid within the column. The crushed rock was also cleaned in an ultrasonic bath before loading into the pressure vessel. The cleaning procedure was conducted to clean of the oxidation layers present at surface of minerals and to dispose fine materials created during crushing process. The experiment was conducted for 96 days (Figure 4.2a).

The pumice for the second flow-through experiment was selected from the Taupo 1.8 Ka plinian fall Unit Y5 (Sample courtesy of M. Rosenberg). Taupo pumice is crystal poor with less than $3 \%$ pyroxene, plagioclase and magnetite crystals. It has a characteristic high silica 
rhyolite composition with $74.0 \mathrm{wt} \% \mathrm{SiO}_{2}, 13.6 \mathrm{wt} \% \mathrm{Al}_{2} \mathrm{O}_{3}, 2.7 \mathrm{wt} \% \mathrm{~K}_{2} \mathrm{O}$, and $\sim 2$ wt $\%$ losson-ignition (Barker et al., 2015). The flow-through experiment was conducted for 73 days (Figure 4.2b)

The third experiment used a monomineralic substrate which consisted of crushed and cleaned inclusion-free Brazilian quartz at the $0.25-0.75 \mathrm{~mm}$ size fraction. The pressuretemperature path was similar to the greywacke and pumice experiments (Figure 4.2c). Samples were taken daily for 66 days.
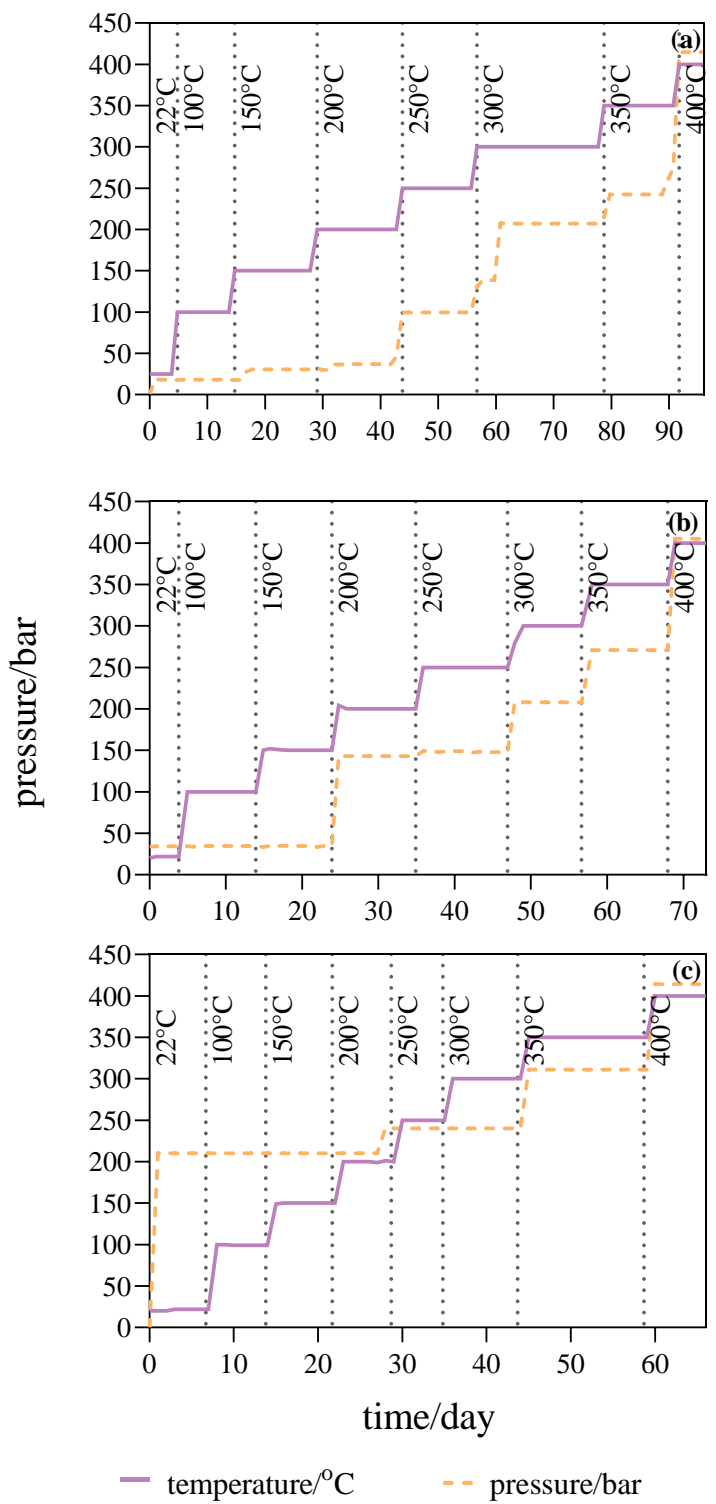

Figure 4.2: Pressure-temperature path for (a) the greywacke, (b) the pumice, and (c) the quartz experiments. 


\subsubsection{High performance liquid chromatography}

High performance liquid chromatography (HPLC) with a fluorescence detector was used to analyse the naphthalene sulfonic acids. The separation of the various isomers in the HPLC column occurs as a result of the different number and location of sulfonate groups $\left(-\mathrm{SO}_{3}\right)$ on the naphthalene backbone. The intensities are determined by the sulfonate group's interactions with electrons in the naphthalene backbone. Figure 2.3 shows the chromatographically separated peaks for different NDS and NSA isomers relevant to these experiments.

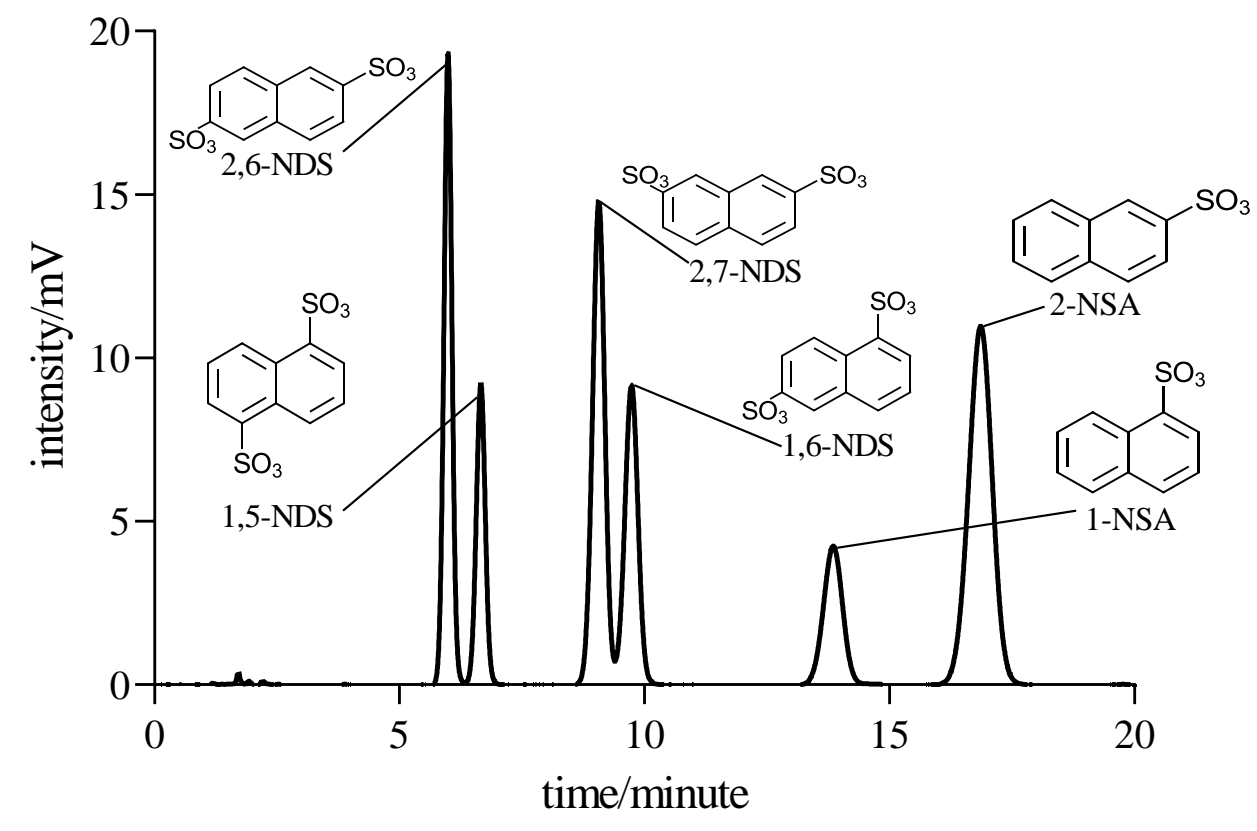

Figure 4.3: Six naphthalene sulfonates peaks in a HPLC chromatogram. Concentration: $10 \mathrm{mg}$ $\mathrm{kg}^{-1}$; flow rate: $1,5 \mathrm{ml} \mathrm{min}{ }^{-1}$; mobile phase: $29 \% \mathrm{MeOH}$; fluorescence mode: Excitation: 222nm, Emission: 338nm.

To protect the column from particulates, samples were filtered through $0.2 \mu \mathrm{m}$ Minisart ${ }^{\circledR}$ NML Surfactant-free cellulose acetate filters. The mobile phase was $5 \mathrm{mM}$ tetrabutylammonium phosphate (Sigma-Aldrich) in 29:71 (volume \%) methanol/water mixture. The methanol was HPLC grade from ThermoFisher Scientific. Ultrapure water with a conductivity of $0.055 \mu \mathrm{S} \mathrm{cm}^{-1}\left(18.2 \mathrm{M} \Omega \mathrm{cm}^{-1}\right)$ was produced by an Arium ${ }^{\circledR}$ pro-Ultrapure water system. Detection limits were $1.40 \times 10^{-10} \mathrm{~mol} \mathrm{~kg}^{-1}$ for the NDS and 
$1.93 \times 10^{-9} \mathrm{~mol} \mathrm{~kg}^{-1}$ for the NSA. The column was kept at $35^{\circ} \mathrm{C}$. Sample injection volume was $50 \mu \mathrm{L}$ and a $50 \mu \mathrm{L}$ ultrapure water blank was run between each standard/sample.

\subsubsection{Analytical methods}

The $\mathrm{pH}$ of experimental solutions was measured with a Metrohm $\mathrm{pH}$ meter (with a temperature probe). The $\mathrm{pH}$ meter was calibrated against standard buffer solutions daily. The concentrations of hydrogen sulfide were determined spectrophotometrically by the methylene blue method/UV-Vis (detection limit $2.90 \times 10^{-7} \mathrm{~mol} \mathrm{~kg}^{-1}$ ) with a Dynamica DB-30 UV/VIS spectrophotometer. The major cation concentrations were measured by inductively-coupled plasma-optical emission spectroscopy (ICP-OES) with a Thermo Scientific iCap 7600 Duo ICP-OES. The aliquotesfor ICP-OES analysis were acidified with $\mathrm{HNO}_{3}$ such that the final concentration was $2 \%$ (by wt.). The elements measured by ICP were: $\mathrm{Ca}, \mathrm{Fe}, \mathrm{K}, \mathrm{Al}, \mathrm{Mg}, \mathrm{Na}$ and $\mathrm{Si}\left(\mathrm{as} \mathrm{SiO}_{2}\right)$ with detection limits $1.5 \times 10^{-6} \mathrm{~mol} \mathrm{~kg}^{-1}$ for all cations except silica where detection limit was $1.70 \times 10^{-5} \mathrm{~mol} \mathrm{~kg}^{-1}$. Anions (sulfate and chloride) were analysed with a DIONEX ICS 5000 ion chromatograph. Detection limit for chloride was $1.40 \times 10^{-6} \mathrm{~mol} \mathrm{~kg}^{-1}$ and $3.10 \times 10^{-7} \mathrm{~mol} \mathrm{~kg}^{-1}$ for sulfate.

\subsubsection{Estimation of $\mathrm{pH}$ at elevated temperatures}

In order to calculate $\mathrm{pH}$ at elevated temperature $\left(\mathrm{pH}_{\mathrm{t}}\right)$ the following procedure was employed. At least seven samples were collected at each temperature during each experiment and the median of the molal concentration of analysed ions and the measured $\mathrm{pH}_{25^{\circ}} \mathrm{C}$, were used to calculate the $\mathrm{pH}_{\mathrm{t}}$ for each temperature.

The calculation of $\mathrm{pH}_{\mathrm{t}}$ considered the following base species: $\mathrm{Na}^{+}, \mathrm{Cl}^{-}, \mathrm{Ca}^{2+}, \mathrm{K}^{+}, \mathrm{OH}^{-}$, $\mathrm{H}^{+}, \mathrm{SO}_{4}{ }^{2-}$ and associated species $\mathrm{NaCl}^{\circ}, \mathrm{HCl}^{\circ}, \mathrm{NaOH}^{\circ}, \mathrm{KCl}^{\circ}, \mathrm{KOH}^{\circ}, \mathrm{CaSO}_{4}^{\circ}, \mathrm{NaSO}_{4}^{-}, \mathrm{HSO}_{4}^{-}$, $\mathrm{KSO}_{4}^{-}, \mathrm{CaCl}^{+}, \mathrm{CaCl}_{2}^{\circ}$. It is assumed that the fluid, for which $\mathrm{pH}$ is being calculated, was in local equilibrium with the rock/mineral present in the system.

All calculations have been conducted in spreadsheets linked to the EqSolvR software package (Mroczek \& Mroczek, 2017). To model the distribution of species in experimental fluid the spreadsheet uses the method described by Albarede (1995). The activities of the aqueous species were calculated using reaction and mass balance constraints. The following independent reactions define the equilibrium relationships between involved species:

$$
\begin{aligned}
& \mathrm{H}_{2} \mathrm{O}=\mathrm{H}^{+}+\mathrm{OH}^{-} \\
& \mathrm{NaCl}^{\circ}=\mathrm{Na}^{+}+\mathrm{Cl}^{-}
\end{aligned}
$$




$$
\begin{aligned}
& \mathrm{NaOH}^{\circ}=\mathrm{Na}^{+}+\mathrm{OH}^{-} \\
& \mathrm{HCl}^{\circ}=\mathrm{H}^{+}+\mathrm{Cl}^{-} \\
& \mathrm{KCl}^{\circ}=\mathrm{K}^{+}+\mathrm{Cl}^{-} \\
& \mathrm{KOH}^{\circ}=\mathrm{K}^{+}+\mathrm{OH}^{-} \\
& \mathrm{KSO}_{4}^{-}=\mathrm{Na}^{+}+\mathrm{SO}_{4}^{2-} \\
& \mathrm{CaSO}_{4}^{\circ}=\mathrm{Ca}^{+2}+\mathrm{SO}_{4}^{2-} \\
& \mathrm{CaCl}^{+}=\mathrm{Ca}^{+2}+\mathrm{Cl}^{-} \\
& \mathrm{CaCl}_{2}^{\circ}=\mathrm{Ca}^{+2}+2 \mathrm{Cl}^{-} \\
& \mathrm{NaSO}_{4}^{-}=\mathrm{Na}^{+}+\mathrm{SO}_{4}^{-2} \\
& \mathrm{HSO}_{4}^{-}=\mathrm{H}^{+}+\mathrm{SO}_{4}^{-2} \\
& \mathrm{H}_{4} \mathrm{SiO}_{4}^{\circ}=\mathrm{H}^{+}+\mathrm{H}_{3} \mathrm{SiO}_{4}^{-}
\end{aligned}
$$

for which the equilibrium constants are defined as,

$$
\begin{aligned}
& \mathrm{K}_{\mathrm{w}}=\mathrm{a}_{\mathrm{H}^{+}} \cdot \mathrm{a}_{\mathrm{OH}^{-}} \cdot \mathrm{a}_{\mathrm{H}_{2} \mathrm{O}}{ }^{-1} \\
& \mathrm{~K}_{\mathrm{NaCl}}=\mathrm{a}_{\mathrm{Na}^{+}} \cdot \mathrm{a}_{\mathrm{Cl}^{-}} \cdot \mathrm{a}_{\mathrm{NaCl}^{\circ}}{ }^{-1} \\
& \mathrm{~K}_{\mathrm{NaOH}}=\mathrm{a}_{\mathrm{Na}^{a}} \cdot \mathrm{a}_{\mathrm{OH}^{-}} \cdot \mathrm{a}_{\mathrm{NaOH}^{\circ}}{ }^{-1} \\
& \mathrm{~K}_{\mathrm{HCl}}=\mathrm{a}_{\mathrm{H}^{+}} \cdot \mathrm{a}_{\mathrm{Cl}^{-}} \cdot \mathrm{a}_{\mathrm{HCl}}{ }^{-1} \\
& \mathrm{~K}_{\mathrm{KCl}^{\circ}}=\mathrm{a}_{\mathrm{K}^{+}} \cdot \mathrm{a}_{\mathrm{Cl}^{-}} \cdot \mathrm{a}_{\mathrm{KCl}^{\circ}}{ }^{-1} \\
& \mathrm{~K}_{\mathrm{KOH}^{\circ}}=\mathrm{a}_{\mathrm{K}^{+}} \cdot \mathrm{a}_{\mathrm{OH}^{-}} \cdot \mathrm{a}_{\mathrm{KOH}^{\circ}}{ }^{-1} \\
& \mathrm{~K}_{\mathrm{KSO}_{4}^{-}}=\mathrm{a}_{\mathrm{K}^{+}} \cdot \mathrm{a}_{\mathrm{SO}_{4}^{2-}} \cdot \mathrm{a}_{\mathrm{KSO}_{4}^{-}}^{-1}
\end{aligned}
$$

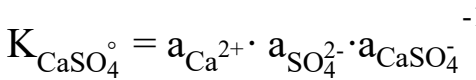

$$
\begin{aligned}
& \mathrm{K}_{\mathrm{CaCl}^{+}}=\mathrm{a}_{\mathrm{Ca}^{2+}} \cdot \mathrm{a}_{\mathrm{Cl}^{-}} \cdot \mathrm{a}_{\mathrm{CaCl}^{+}}{ }^{-}
\end{aligned}
$$

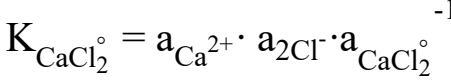

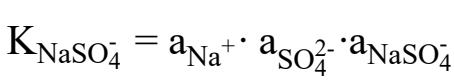

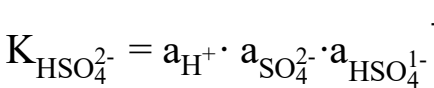

$$
\begin{aligned}
& \mathrm{K}_{\mathrm{H}_{4} \mathrm{SiO}_{4}^{\circ}}=\mathrm{a}_{\mathrm{H}^{+}} \cdot \mathrm{a}_{\mathrm{H}_{3} \mathrm{SiO}_{4}^{-}} \cdot \mathrm{a}_{\mathrm{H}_{4} \mathrm{SiO}_{4}^{\circ}}
\end{aligned}
$$

With the charge balance equation, 


$$
\mathrm{m}_{\mathrm{Na}^{+}}+\mathrm{m}_{\mathrm{H}^{+}}+\mathrm{m}_{\mathrm{K}^{+}}+\mathrm{m}_{\mathrm{Ca}^{2+}}=\mathrm{m}_{\mathrm{Cl}^{-}}+\mathrm{m}_{\mathrm{OH}^{-}}+\mathrm{m}_{\mathrm{H}_{3} \mathrm{SiO}_{4}^{-}}+\mathrm{m}_{\mathrm{SO}_{4}^{2-}}
$$

Rearranging the equilibrium constant expressions gives,

$$
\begin{aligned}
& \mathrm{m}_{\mathrm{NaCl}}=\mathrm{a}_{\mathrm{Na}^{+}} \cdot \mathrm{a}_{\mathrm{Cl}} \cdot\left(\mathrm{K}_{\mathrm{NaCl}} \cdot \gamma_{\mathrm{NaCl}}\right)^{-1} \\
& \mathrm{~m}_{\mathrm{HSO}_{4}^{2-}}=\mathrm{a}_{\mathrm{H}^{+}} \cdot \mathrm{a}_{\mathrm{SO}_{4}^{2-}} \cdot\left(\mathrm{K}_{\mathrm{HSO}_{4}^{1-}} \cdot \gamma_{\mathrm{HSO}_{4}^{2-}}{ }^{-1}\right. \\
& \mathrm{m}_{\mathrm{KCl}}=\mathrm{a}_{\mathrm{K}^{+}} \cdot \mathrm{a}_{\mathrm{Cl}^{-}} \cdot\left(\mathrm{K}_{\mathrm{KCl}^{\circ}} \cdot \gamma_{\mathrm{KCl}^{\circ}}\right)^{-1} \\
& \mathrm{~m}_{\mathrm{KOH}^{\circ}}=\mathrm{a}_{\mathrm{K}^{+}} \cdot \mathrm{a}_{\mathrm{OH}^{-}} \cdot\left(\mathrm{K}_{\mathrm{KOH}^{\circ}} \cdot \gamma_{\mathrm{KOH}^{\circ}}\right)^{-1} \\
& \mathrm{~m}_{\mathrm{KSO}_{4}^{-}}=\mathrm{a}_{\mathrm{K}^{+}} \cdot \mathrm{a}_{\mathrm{SO}_{4}^{2-}} \cdot\left(\mathrm{K}_{\mathrm{KSO}_{4}^{-}} \cdot \gamma_{\mathrm{KSO}_{4}^{-}}\right)^{-1} \\
& \mathrm{~m}_{\mathrm{CaSO}_{4}^{\circ}}=\mathrm{a}_{\mathrm{Ca}^{2+}} \cdot \mathrm{a}_{\mathrm{SO}_{4}^{2-}} \cdot\left(\mathrm{K}_{\mathrm{KSO}_{4}^{-}} \cdot \gamma_{\mathrm{KSO}_{4}^{-}}\right)^{-1} \\
& \mathrm{~m}_{\mathrm{CaCl}^{+}}=\mathrm{a}_{\mathrm{Ca}^{2+}} \cdot \mathrm{a}_{\mathrm{Cl}^{-}} \cdot\left(\mathrm{K}_{\mathrm{CaCl}^{+}} \cdot \gamma_{\mathrm{CaCl}^{+}}\right)^{-1} \\
& \mathrm{~m}_{\mathrm{CaCl}_{2}^{\circ}}=\mathrm{a}_{\mathrm{Ca}^{2+}} \cdot \mathrm{a}_{2 \mathrm{Cl}^{-}} \cdot\left(\mathrm{K}_{\mathrm{CaCl}_{2}^{\circ}} \cdot \gamma_{\mathrm{CaCl}_{2}^{\circ}}\right)^{-1} \\
& \mathrm{~m}_{\mathrm{NaSO}_{4}^{-}}=\mathrm{a}_{2 \mathrm{Na}^{+}} \cdot \mathrm{a}_{\mathrm{SO}_{4}^{2-}} \cdot\left(\mathrm{K}_{\mathrm{NaSO}_{4}^{-}} \cdot \gamma_{\mathrm{NaSO}_{4}^{-}}\right)^{-1} \\
& \mathrm{~m}_{\mathrm{H}_{4} \mathrm{SiO}_{4}^{\circ}}=\mathrm{a}_{\mathrm{H}^{+}} \cdot \mathrm{a}_{\mathrm{H}_{3} \mathrm{SiO}_{4}^{-}} \cdot\left(\mathrm{K}_{\mathrm{NH}_{4} \mathrm{SiO}_{4}^{\circ}} \cdot \gamma_{\mathrm{H}_{4} \mathrm{SiO}_{4}^{\circ}}\right)^{-1}
\end{aligned}
$$

Where $a_{i}$ is the activity of an individual species, i.e.,

$$
\mathrm{a}_{\mathrm{i}}=\mathrm{m}_{\mathrm{i}} \cdot \gamma_{\mathrm{i}}
$$

$m_{i}$ is the concentration of the species $i$ and $\gamma_{i}$ is its activity coefficient. The following mass balance equations apply,

$$
\begin{aligned}
& \mathrm{m}_{\mathrm{Na}_{\text {total }}}=\mathrm{m}_{\mathrm{NaCl}^{\circ}}+\mathrm{m}_{\mathrm{Na}^{+}}+\mathrm{m}_{\mathrm{NaOH}^{\circ}}+\mathrm{m}_{\mathrm{NaSO}_{4}^{-}} \\
& \mathrm{m}_{\mathrm{Cl}_{\text {total }}}=\mathrm{m}_{\mathrm{NaCl}^{\circ}}+\mathrm{m}_{\mathrm{Cl}^{-}}+\mathrm{m}_{\mathrm{HCl}^{\circ}}+\mathrm{m}_{\mathrm{CaCl}^{+}}+\mathrm{m}_{\mathrm{CaCl}_{2}^{\circ}}+\mathrm{m}_{\mathrm{KCl}^{\circ}} \\
& \mathrm{m}_{\mathrm{SO}_{4} \text { total }}=\mathrm{m}_{\mathrm{SO}_{4}^{2-}}+\mathrm{m}_{\mathrm{KSO}_{4}^{-}}+\mathrm{m}_{\mathrm{CaSO}_{4}^{\circ}}+\mathrm{m}_{\mathrm{NaSO}_{4}^{-}}+\mathrm{m}_{\mathrm{HSO}_{4}^{1-}} \\
& \mathrm{m}_{\mathrm{K}_{\text {total }}}=\mathrm{m}_{\mathrm{K}^{+}}+\mathrm{m}_{\mathrm{KCl}^{\circ}}+\mathrm{m}_{\mathrm{KSO}_{4}^{-}}+\mathrm{m}_{\mathrm{KOH}^{\circ}} \\
& \mathrm{m}_{\mathrm{Ca}_{\text {total }}}=\mathrm{m}_{\mathrm{Ca}^{2+}}+\mathrm{m}_{\mathrm{CaSO}_{4}^{\circ}}+\mathrm{m}_{\mathrm{CaCl}^{+}}+\mathrm{m}_{\mathrm{CaCl}_{2}^{\circ}} \\
& \mathrm{m}_{\mathrm{SiO}_{2} \text { total }}=\mathrm{m}_{\mathrm{H}_{4} \mathrm{SiO}_{4}^{\circ}}+\mathrm{m}_{\mathrm{H}_{3} \mathrm{SiO}_{4}^{-}}
\end{aligned}
$$

Combining the above equilibrium, charge and mass balance equations, the $\mathrm{pH}$ at given $\mathrm{T}$ and $\mathrm{P}$ is given by, 


$$
\begin{gathered}
0=\mathrm{a}_{\mathrm{H}^{+}} \cdot \gamma_{\mathrm{H}^{+}}^{-1}-\mathrm{a}_{\mathrm{OH}^{-}} \cdot \gamma_{\mathrm{OH}^{-}}^{-1}-\mathrm{m}_{\mathrm{Cl}_{\text {total }}} \cdot \frac{\mathrm{m}_{\mathrm{Cl}^{-}}}{\mathrm{m}_{\mathrm{Cl}_{\text {total }}}}+\mathrm{m}_{\mathrm{Na}_{\text {total }}} \cdot \frac{\mathrm{m}_{\mathrm{Na}^{+}}}{\mathrm{m}_{\mathrm{Na}_{\text {total }}}}+\mathrm{m}_{\mathrm{SO}_{4} \text { (total) }} \cdot \frac{\mathrm{m}_{\mathrm{SO}_{4}^{2-}}}{\mathrm{m}_{\mathrm{SO}_{4} \text { (total) }}} \\
+\mathrm{m}_{\mathrm{K}_{\text {total }}} \cdot \frac{\mathrm{m}_{\mathrm{K}^{+}}}{\mathrm{m}_{\mathrm{K}_{\text {total }}}}+\mathrm{m}_{\mathrm{Ca}_{\text {total }}} \cdot \frac{\mathrm{m}_{\mathrm{Ca}^{2+}}}{\mathrm{m}_{\mathrm{Ca}_{\text {total }}}}+\mathrm{m}_{\mathrm{SiO}_{2 \text { (total) }}} \cdot \frac{\mathrm{m}_{\mathrm{H}_{3} \mathrm{SiO}_{4}^{-}}}{\mathrm{m}_{\mathrm{SiO}_{2} \text { (total) }}}
\end{gathered}
$$

The equilibrium constants for equation 4.15 to 4.17 and 4.19 are from Ho et al. (1994, 2000, 2001) and for equation 4.21 and 4.25 from Cobble et al. (1982). The equilibrium association constants for equation 4.20 to 4.24 were taken from the SUPCRT92 data base (Johnson et al., 1992). The ion product constant, $\mathrm{K}_{\mathrm{w}}$, for the water solvent is from Bandura and Lvov (2006). An extended Debye-Hückel expression (Robinson \& Stokes, 1968) was used to calculate the individual ion molal activity coefficients, $\gamma_{i}$, for the charged species,

$$
-\log \gamma_{\mathrm{i}}=\frac{\mathrm{Az} z_{\mathrm{i}}^{2} \sqrt{ } \mathrm{I}}{1+\mathrm{Bă}_{\mathrm{i}} \sqrt{ } \mathrm{I}}+\dot{\mathrm{B}} \cdot \mathrm{I}
$$

where $\mathrm{z}$ is the charge of the ion whose activity coefficient is being calculated, A and B are constants whose values depend on the density and dielectric constant of the solvent, å is the effective diameter of the ion in the solution in $\AA$ (Kielland, 1937), and $\dot{B}$ is the deviation function. I is the ionic strength of the solution, in molal units, given by:

$$
\mathrm{I}=\frac{1}{2} \sum \mathrm{m}_{\mathrm{i}} \cdot \mathrm{z}_{\mathrm{i}}^{2}
$$

where $m_{i}$ and $z_{i}$ are the molality charge of the product of each species, i, in the solution.

\subsection{Results and discussion}

\subsubsection{The greywacke experiment}

In the first experiment (greywacke; Figure 4.4a,b), naphthalene disulfonates exhibit small disproportionations from 150 to $300^{\circ} \mathrm{C}$. However, as a consequence of increasing the temperature of the experimental system (from 150 to $200^{\circ} \mathrm{C}$ ), the fluid $\mathrm{pH}_{\mathrm{t}}$ shifted from 7.4 at $150^{\circ} \mathrm{C}$ initially to 5.2 at $200^{\circ} \mathrm{C}$. Thus, change in $\mathrm{pH}$ had a significant effect on naphthalene disulfonates stability, resulting in rapid disproportionation of the NDS. Once pH shifted to near neutral at $200^{\circ} \mathrm{C}$, naphthalene disulfonate stability increases. Note that the subsequent shift in $\mathrm{pH}$, after heating the system up to $250^{\circ} \mathrm{C}$, is too small to affect the NDS stability. Thus, there were not enough free protons to cause desulfonation of polyaromatic sulfonic acids (Chapter 2). 
Similarly, there is a $\mathrm{pH}$ shift when the temperature increased from 250 to $300^{\circ} \mathrm{C}$. The $\mathrm{pH}_{\mathrm{t}}=7.1$ at $250^{\circ} \mathrm{C}$ decreases to $\mathrm{pH}_{\mathrm{t}}=4.6$ at $300^{\circ} \mathrm{C}$. The sudden drop in $\mathrm{pH}$ and increase in temperature results in a substantial decrease in NDS concentration (note there are no equivalent $\mathrm{pH}$ changes in the pumice and quartz experiments). Once the system re-equilibrated and the $\mathrm{pH}$ stabilised, the polyaromatic disulfonates were in detectable quantities. However, 1,5-NDS, 1,6-NDS, 2,6-NDS and 2,7-NDS are nevertheless extensively thermally disproportionated and 2-NSA and 1-NSA are formed as reaction products.

Changes in $\mathrm{pH}$ encountered with increasing temperature are due to changes in fluidmineral equilibria as new equilibrium conditions are established. A few days after a temperature shift, $\mathrm{pH}$ values of the reacted fluid stabilise as the heterogynous system reaches equilibrium.

Eight days after heating the system up to $300^{\circ} \mathrm{C}$, the naphthalene disulfonate concentrations slightly increases, along with $\mathrm{pH}$, and the concentrations of sulfate or sulfide (Figure $4.4 \mathrm{a}$ and $4.4 \mathrm{~b}$ ). It is assumed that the increase in $\mathrm{pH}$ was primarily responsible for the stability increase, not the presence of sulfate or sulfide, as the results presented in Chapter 2 do not provide evidence for stabilising effects of sulfate or sulfide on NDS or NSA stability.

At $350^{\circ} \mathrm{C}$, only 2-NSA remains detectable (Figure $4.4 \mathrm{a}$ ), as both high temperature and low $\mathrm{pH}$ destabilises the naphthalene disulfonates. At $400^{\circ} \mathrm{C}$, none of the initial naphthalene disulfonate or their breakdown products (i.e. naphthalene sulfonates) are present. Within only ten hours (the average residence time), all polyraromatic sulfonates (NDS + NSA) disintegrates to unknown compounds, presumably to naphthalene and naphthols, as discussed in detail in Chapter 5 and 6.

The greywacke experiment emphasises the significance of $\mathrm{pH}$ on the polyaromatic disulfonates stability. Low $\mathrm{pH}$ destabilises these molecules through protonation of the naphthalene ring (Chapter 2). Also, temperature $\geq 300^{\circ} \mathrm{C}$ plays a significant role in the NDS disproportionation, which is discussed in detail in Chapter 3. 


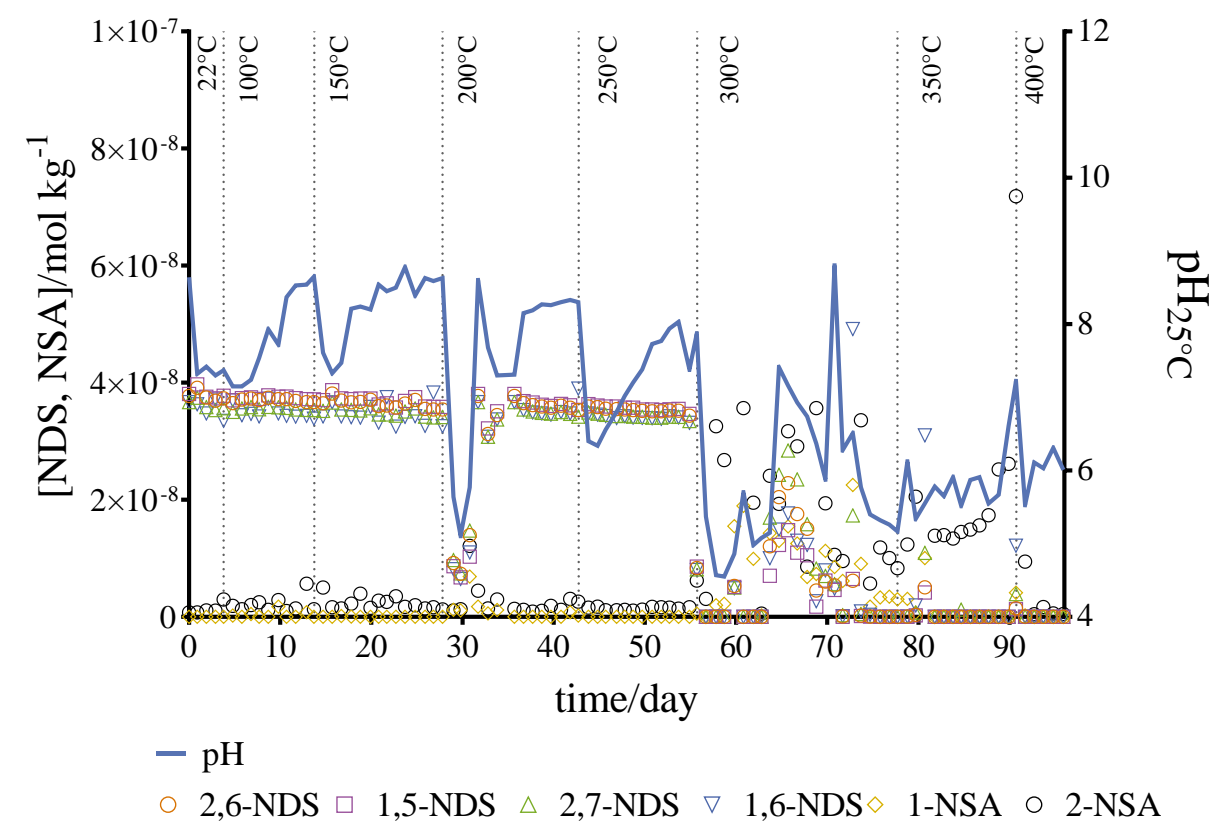

Figure 4.4a: The concentration $\left(\mathrm{mol} \mathrm{kg}^{-1}\right)$ of 2,6-NDS, 2,7-NDS, 1,5-NDS, 1,6-NDS, 1-NSA, 2-NSA and $\mathrm{pH}_{25^{\circ} \mathrm{C}}$ versus experimental time (day) during heating to $400^{\circ} \mathrm{C}$ in presence of greywacke.

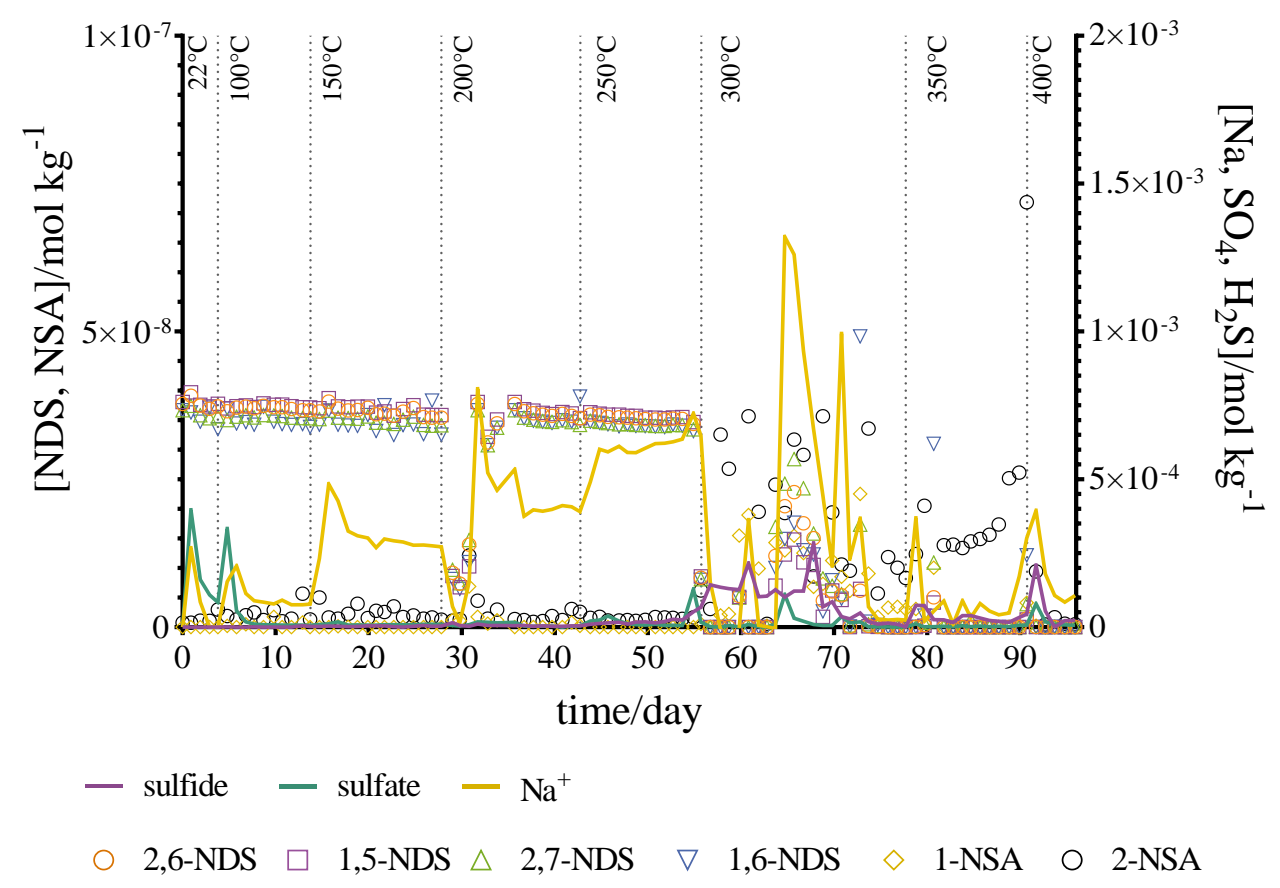

Figure 4.4b: The concentrations of 2,6-NDS, 2,7-NDS, 1,5-NDS, 1,6-NDS, 1-NSA, 2-NSA, $\mathrm{Na}, \mathrm{SO}_{4}$ and $\mathrm{H}_{2} \mathrm{~S}$ ( $\mathrm{mol} \mathrm{kg}^{-1}$ ) versus experimental time (day) after heating to $400^{\circ} \mathrm{C}$ in presence of greywacke. 


\subsubsection{The pumice experiment}

In this experiment (Figure $4.5 \mathrm{a}, \mathrm{b}$ and c), the concentration of naphthalene disulfonates decreases with increasing temperature to $400^{\circ} \mathrm{C}$. NDS disproportionation rate and resulting breakdown products are different from those observed in the greywacke experiment. This is because of the different fluid compositions generated during the pumice-solution reaction at various temperatures. Note that the experimental $\mathrm{pH}$ remains alkaline it during the pumice experiment (Figure 4.5a). The alkaline $\mathrm{pH}$ of the fluid is a result of dissolution of the glassy pumice matrix which liberates cations (e.g. $\mathrm{Al}^{3+}, \mathrm{Na}^{+}, \mathrm{K}^{+}$) throughout hydrolysis reactions. The alkaline $\mathrm{pH}$ of the fluid is in contrast to the greywacke experiment, which is characterised by lower $\mathrm{pH}$ values (Figure 4.4a). Additionally, the aqueous phase in the pumice experiments experiences much higher solute concentrations than the greywacke experiment. The pyrite, which is one of minerals, found within the greywacke generates reduced sulfur $\left(\mathrm{H}_{2} \mathrm{~S}+\mathrm{HS}^{-}\right)$. Pyrite was not present in the pumice experiment (Figure $4.4 \mathrm{~b}$ and $4.5 \mathrm{~b}$ ).

From ambient temperature to $200^{\circ} \mathrm{C}$, the NDS concentration changes slightly, initially decreasing and rising again in response to increasing $\mathrm{pH}$ up to $150^{\circ} \mathrm{C}$. The solute concentrations also increases with increasing temperature (Figure $4.5 \mathrm{~b}, \mathrm{c}$ ). Note that at $100^{\circ} \mathrm{C}$, the total amount of solutes is close to $2.12 \times 10^{-3} \mathrm{~mol} \mathrm{~kg}^{-1}$ and constitutes mainly $\mathrm{SiO}_{2}$; at $150^{\circ} \mathrm{C}$, the dissolved components rise to $9.00 \times 10^{-3} \mathrm{~mol} \mathrm{~kg}^{-1}$, and the $\mathrm{Na}$ and $\mathrm{Al}$ ions become relevant (Figure $4.5 \mathrm{~b}$ ). At $200^{\circ} \mathrm{C}$, the total solute concentration increases even further to $1.47 \times 10^{-2} \mathrm{~mol} \mathrm{~kg}^{-1}$ as does the NDS concentration, which may suggest a stabilising effect of some ionic or molecular species on NDS compounds together with the stabilising effect of alkaline $\mathrm{pH}$. Chapter 2 discusses both salinity and $\mathrm{pH}$ influence on the polyaromatic sulfonates and lends support this hypothesis.

At $250^{\circ} \mathrm{C}$, a large decrease in the NDS concentration is observed. The decrease is accompanied by the formation of 2-NSA. At $300^{\circ} \mathrm{C}$, NDS molecules undergo further decay and the differences in the thermal stability of the various isomers becomes clear. The naphthalene sulfonate and disulfonates stabilities are as follows: 1,5-NDS < 1,6-NDS < 2,6NDS < 2,7-NDS. The variation in the decomposition rates of these isomers is discussed in Chapter 3. This chapter outlines results of the kinetic study and confirms the differences in the stability of the isomers. It suggests that the position of the sulfonate groups explains this phenomenon. Note that at $300^{\circ} \mathrm{C}$, low concentrations of the 2-NSA and 1-NSA are produced. The other decomposition products (e.g. naphthalene and naphthols) were not measured (Chapter 6). It was only at a later stage of this thesis research that GC-MS confirmation of 
presence of naphthalene and naphthols was confirmed. At the time a new HPLC analytical methodology allowed quantitative analysis of their presence (see Chapter 5).

At $350^{\circ} \mathrm{C}$, NDS molecules are destabilised, only small amounts of NDS manage to return and minor quantities of NSA are detected. At $400^{\circ} \mathrm{C}$, 2,6-NDS, 2,7-NDS, 1,5-NDS and 1,6-NDS are fully thermally decayed and only 2-NSA and 1-NSA are detected.

The influence of the pumice on $\mathrm{pH}$ and concentration of solute species provides the stabilising chemical environment for the polyaromatic compounds. In comparison to the greywacke experiment, both naphthalene disulfonates and sulfonates are more resistant to temperature changes. At 350 and $400^{\circ} \mathrm{C}$, polyaromatic disulfonates are not detected in the greywacke experiment but are present in measurable quantities in the pumice experiment. Note that at $400^{\circ} \mathrm{C}$ none of the initial NDS or breakdown products (i.e. NSA) are detected in the greywacke experiments, whereas 1-NSA and 2-NSA are measurable in the pumice experiment.

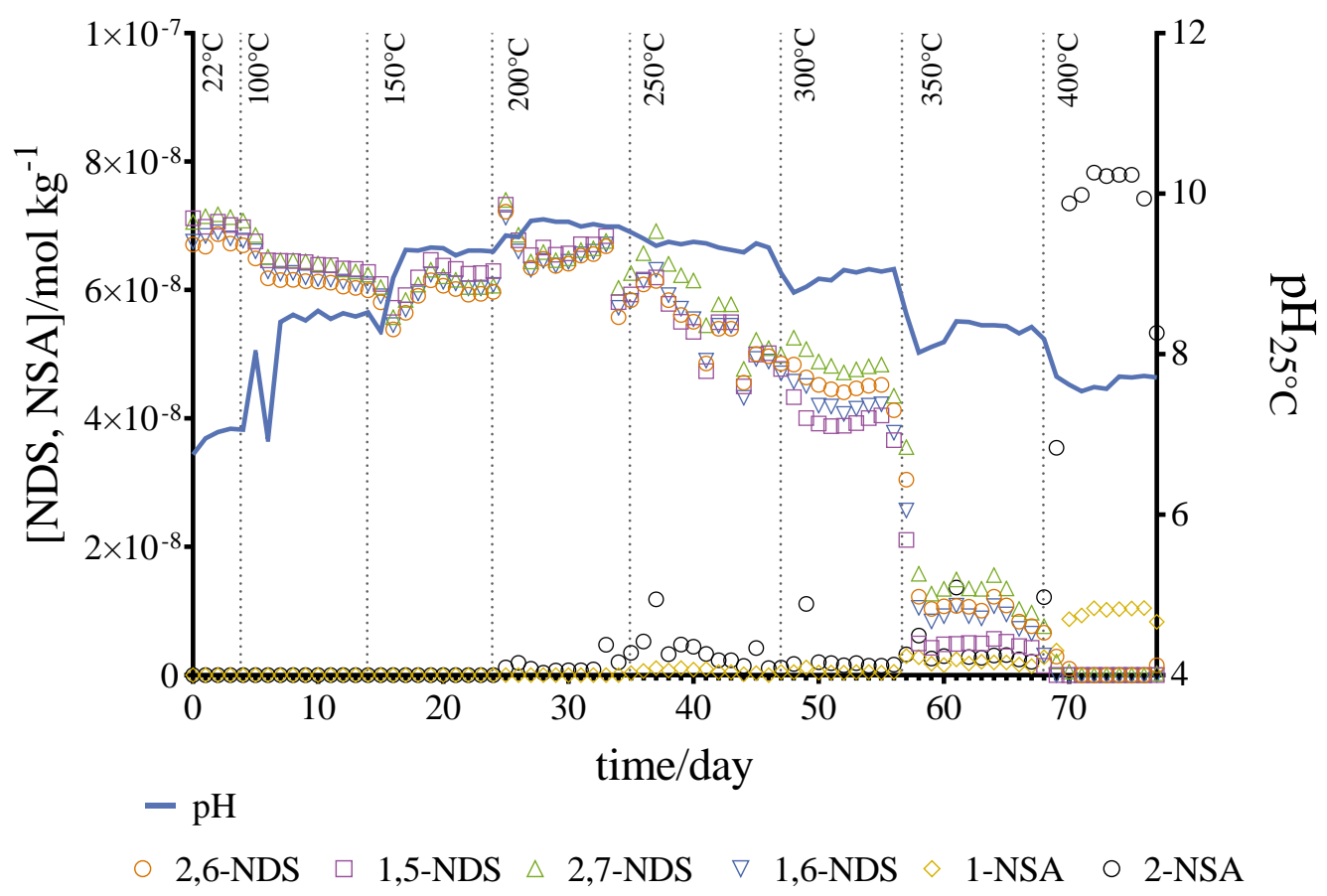

Figure 4.5a: The concentration $\left(\mathrm{mol} \mathrm{kg}^{-1}\right)$ of 2,6-NDS, 2,7-NDS, 1,5-NDS, 1,6-NDS, 1-NSA, 2-NSA and $\mathrm{pH}_{25^{\circ}} \mathrm{C}$ versus experimental time (day) during heating to $400^{\circ} \mathrm{C}$ in presence of the pumice. 


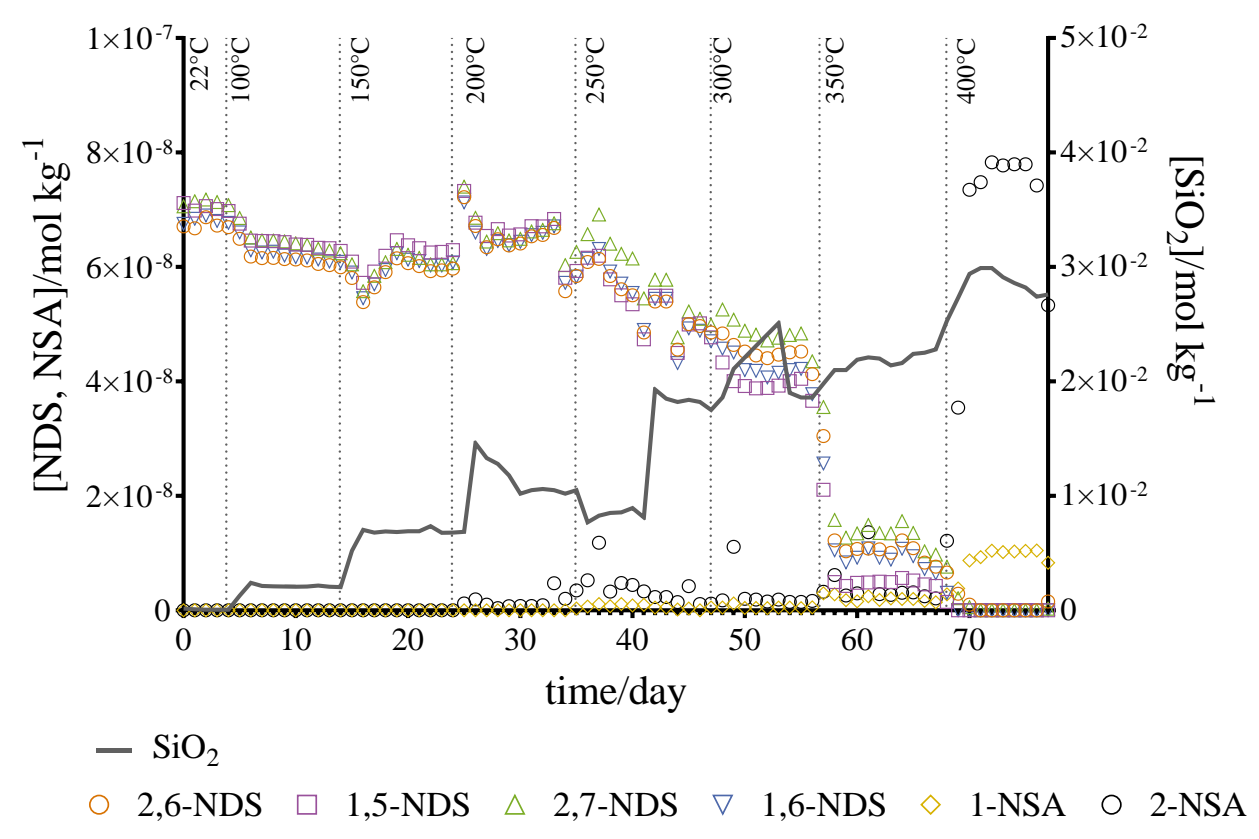

Figure 4.5b: The concentrations of 2,6-NDS, 2,7-NDS, 1,5-NDS, 1,6-NDS, 1-NSA, 2-NSA and $\mathrm{SiO}_{2}\left(\mathrm{~mol} \mathrm{~kg}{ }^{-1}\right)$ versus experimental time/day after heating during heating to $400^{\circ} \mathrm{C}$ in the presence of pumice.

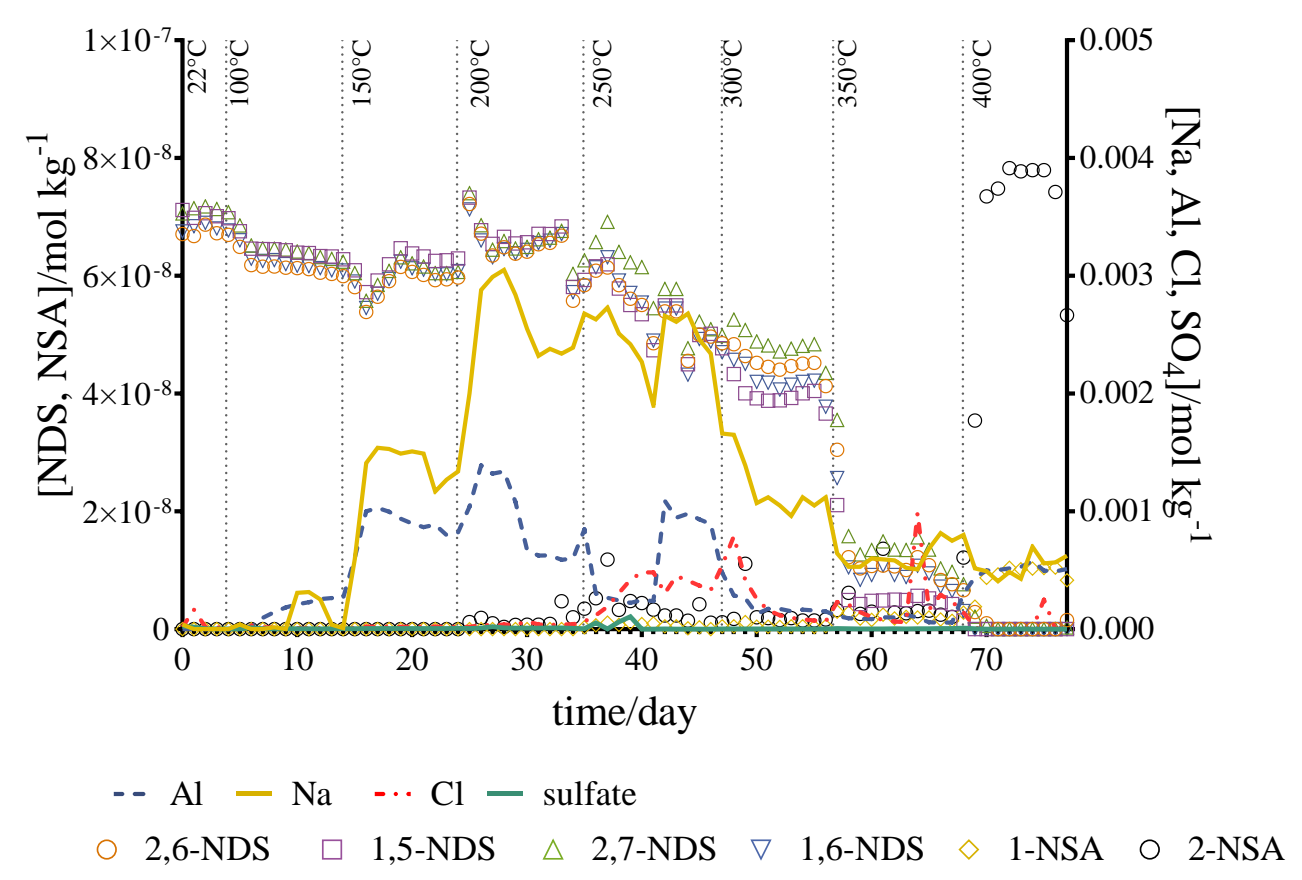

Figure 4.5c: The concentrations of 2,6-NDS, 2,7-NDS, 1,5-NDS, 1,6-NDS, 1-NSA, 2-NSA and $\mathrm{Na}, \mathrm{Al}, \mathrm{Cl}$ and $\mathrm{SO}_{4}\left(\mathrm{~mol} \mathrm{~kg}^{-1}\right)$ versus experimental time (day) after heating during heating to $400^{\circ} \mathrm{C}$ in presence of pumice. 


\subsubsection{The quartz experiment}

The interaction of aqueous solution (containing NDS isomers) with quartz results in an increase in $\mathrm{SiO}_{2}$ concentration with increasing temperature. Additionally, all measured samples contained chloride below $1.41 \times 10^{-5} \mathrm{~mol} \mathrm{~kg}^{-1}$ and sulfate below $2.08 \times 10^{-5} \mathrm{~mol} \mathrm{~kg}^{-1}$. None of the measured solute species exceeds a concentration of $5.10 \times 10^{-5} \mathrm{~mol} \mathrm{~kg}^{-1}$, except for $\mathrm{SiO}_{2}$. There is a slow but steady decrease in $\mathrm{pH}$ from near neutral at the beginning of the experiment to $\mathrm{pH} \approx 5$ at $400^{\circ} \mathrm{C}$ (Figure 4.6a,b). The slow decrease in concentration of NDS accompanies the decreasing $\mathrm{pH}$ of the fluid. The origin of the $\mathrm{pH}$ shift in the experiment is due to minor titanium alloy hydrolysis (Figure 4.1). Additionally, the quartz experiment is complicated by the precipitation of amorphous silica inside the connecting tubes resulting in blockage of equipment. This had apparently no effect on NDS and NSA stability.

At $250^{\circ} \mathrm{C}$, the first notable decrease of naphthalene disulfonate concentration is observed. This is inconsistent with observations from the two previous experiments (i.e. greywacke and pumice). In the greywacke and pumice experiments, the first significant NDS concentration decrease is encountered at $300^{\circ} \mathrm{C}$. Again, the main difference between the experiments lies in the $\mathrm{pH}$ values and solute concentrations. In the quartz experiment, there is no sodium or chloride which can potentially stabilise the naphthalene sulfonate molecules. According to the results from Chapter 2, dissolved salts will have a stabilising effect. At $250^{\circ} \mathrm{C}, \mathrm{pH}_{\left(250^{\circ} \mathrm{C}\right)}$ is 5.0 in the quartz experiment, whereas it is $\mathrm{pH}_{\left(250^{\circ} \mathrm{C}\right)}=6.7$ and 8.2 in greywacke and pumice experiments, respectively. This significant difference in the $\mathrm{pH}$ affected the polyaromatic disulfonates stability according to results presented in Chapter 2.

At $300^{\circ} \mathrm{C}$, the stabilities of 2,6-NDS and 2,7-NDS unexpectedly increase, almost reaching their initial concentration. To a lesser extent, 1,6-NDS and 1,5-NDS are also stabilised. Note that 1-NSA and 2-NSA are also detected at this temperature. As mentioned before, only $\mathrm{pH}$ and $\mathrm{SiO}_{2}$ concentrations vary significantly during this experiment as seen in Figure 4.6a,b. Three days after increasing temperature from 250 to $300^{\circ} \mathrm{C}$, the concentration of dissolved silica increases and is above quartz saturation level at this temperature and pressure (Figure 4.6b).

At $350^{\circ} \mathrm{C}, 2-\mathrm{NSA}$ remains detectable, accompanied by minor amounts of the 1-NSA. At $400^{\circ} \mathrm{C}$, the first sample after heating exhibits an $\mathrm{SiO}_{2}$ and $\mathrm{pH}$ increase and a subtle NDS/NSA concentration increase. Subsequently, only the 2-NSA remains measurable. Note that at this temperature, in the pumice experiment, both 1-NSA and 2-NSA are detectable, whereas, in the 


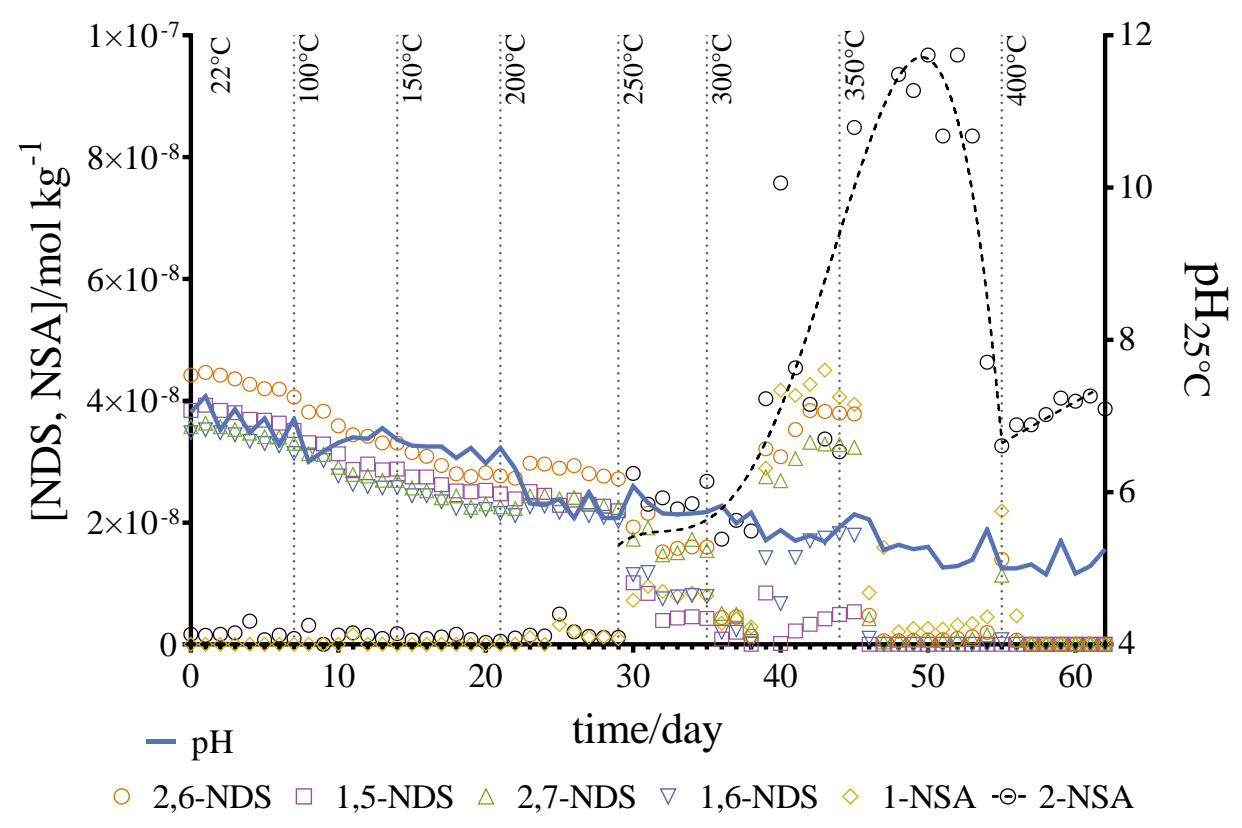

Figure 4.6a: The concentration $\left(\mathrm{mol} \mathrm{kg}^{-1}\right)$ of 2,6-NDS, 2,7-NDS, 1,5-NDS, 1,6-NDS, 1-NSA,

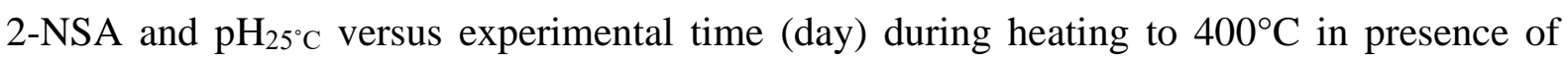
quartz.

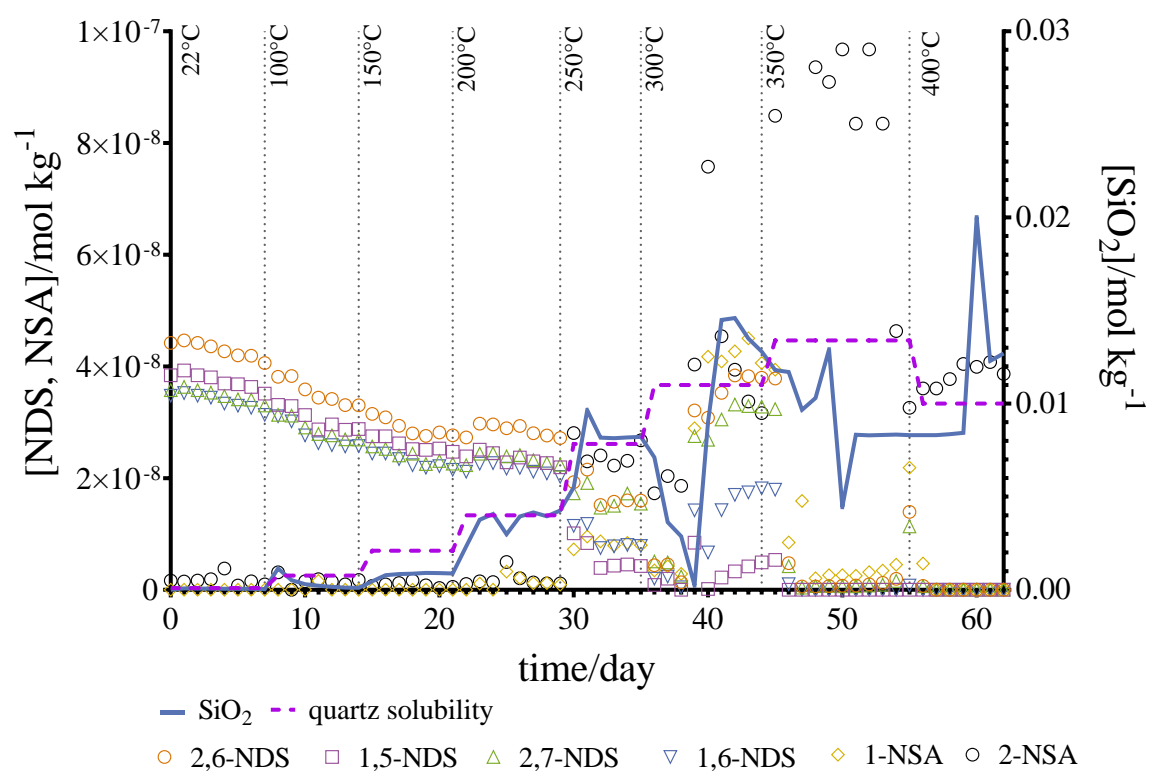

Figure 4.6b: The concentrations of 2,6-NDS, 2,7-NDS, 1,5-NDS, 1,6-NDS, 1-NSA, 2-NSA, $\mathrm{SiO}_{2}\left(\mathrm{~mol} \mathrm{~kg}^{-1}\right)$ and quartz solubility (Walther \& Helgeson, 1977) versus experimental time (day) after heating to $400^{\circ} \mathrm{C}$ in presence of quartz. 
greywacke experiment no NDS or NSA isomers are detectable. There is no clear explanation for this difference.

\subsection{Conclusions}

Three reconnaissance flow-through experiments on the stability of NDS isomers under geothermal conditions in presence of solid substrates have been conducted. Increases in temperature result in decreases in stability of the naphthalene disulfonates. Also, an increase of solute concentration enhances the stability of aromatic sulfonates. In agreement with results from Chapter 2, NDS isomers stabilities decrease with decreasing and increasing $\mathrm{pH}$ from neutral values. Naphthalene disulfonate stabilities increase as follows: 1,5-NDS < 1,6-NDS < 2,6-NDS < 2,7-NDS. 1-NSA and 2-NSA are thermal breakdown products of naphthalene disulfonates, which is consistent with the finding discussed in Chapter 3. There is no correlation between NDS and NSA isomers stabilities and $\mathrm{SiO}_{2}$ concentration. This is significant as the experiments described in Chapter 2, 3 and 6 were conducted in quartz glass ampules.

\subsection{References}

Addison S. J., Winick J.A., Mountain B. W., Siega F. L., 2015. Rotokawa Reservoir Tracer Test History. Proceedings $38^{\text {th }}$ New Zealand Geothermal Workshop, Auckland, New Zealand.

Albarède, F., 1995. Introduction to geochemical modelling, 318 - 340.

Barker, S.J., Wilson, C.J.N., Allan, A.S.R., Schipper, C.I., 2015. Fine-scale temporal recovery, reconstruction and evolution of a post-supereruption magmatic system. Contributions to Mineralogy and Petrology, 170, $2-40$.

Cobble, J. W., Murray, Jr. R. C., Turner, P. J., Chen, K., 1982. High-temperature thermodynamic data for species in aqueous solution. Research project report ,1167 - 1. EPRI NP-2400.

Dashkevich, Y.G., Mountain, B.W., Seward, T.M., Winick, J.A., 2015. temperature stability of naphthalene sulfonic and naphthalene disulfonic acids at geothermal conditions. Proceedings World Geothermal Congress, Melbourne, Australia. 
Ho, P.C., Palmer, D.A., Grusckiewicz, M.S., 2001. Conductivity measurements of dilute aqueous hcl solutions to high temperatures and pressures using a flow-through cell. Journal of Physcial Chemistry B, 105, 1260 - 1266.

Ho, P.C., Palmer, D.A., Wood, R.H., 2000. Conductivity measurements of dilute aqueous $\mathrm{LiOH}, \mathrm{NaOH}$, and $\mathrm{KOH}$ solutions to high temperatures and pressures using a flowthrough cell. Journal of Physcial Chemistry B, 104, 12084 - 12089.

Ho, P.C., Palmer, D.A., Mesmer, R.E., 1994. Electrical conductivity measurements of aqueous sodium chloride solutions to $600^{\circ} \mathrm{C}$ and $300 \mathrm{mpa}$. Journal of Solution Chemistry, 23, $997-1018$.

Johnson, J.W., Oelkers, E.H., Helgeson, H.C., 1992. SUPCRT92: A software package for calculating the standard molal thermodynamic properties of minerals, gases, aqueous species, and reactions from 1 to 5000 bars and 0 to $1000^{\circ} \mathrm{C}$ Computers \& Geoscience, 18,899 $-947$.

Mountain, B., Chambefort, I., Sajkowski, L., 2016. Progressive devolitization of greywacke from sub-critical to supercritical conditions. Goldschmidt Abstracts, 2167.

Mountain, B.W., Chambefort, I., Sajkowski, L., 2017. Progressive devolitisation of New Zealand reservoir rocks from sub-critical to supercritical conditions. Proceedings $39^{\text {th }}$ New Zealand Geothermal Workshop, Rotorua, New Zealand.

Mountain, B.W., Winick, J., 2012. The thermal stability of the naphthalene sulfonic and naphthalene disulfonic acids under geothermal conditions: Experimental Results and a Field-Based Example $1-5$. Proceedings $34^{\text {th }}$ New Zealand Geothermal Workshop.

Mroczek S., Mroczek E., 2017. EqSolvR: Chemical Equilibrium Solver. R package version 1.1.0.

Rose, P., Benoit, W.R., Kilbourn, P.M., 2001. The application of the polyaromatic sulfonates as tracers in geothermal reservoirs. Geothermics, 30, $617-640$.

Walther J. V., Helgeson H. C., 1977. Calculation of the thermodynamic properties of aqueous silica and the solubility of quartz and its polymorphs at high pressures and temperatures. American Journal of Science, 277, 1315 - 1351. 


\section{Quantitative analysis of naphthalene, 1-naphthol and 2-naphthol at nanomol levels in geothermal fluids using solid-phase extraction with high performance liquid chromatography - fluorescence detection}

\subsection{Abstract}

Naphthalene (NAP), 1-naphthol (1-NAP) and 2-naphthol (2-NAP) are the thermal decomposition products of naphthalene sulfonates making them potentially new geothermal reservoir permeability tracers, however, to date, no sensitive and fast detection method for these compounds has been developed.

In order to facilitate sensitive and rapid analysis of these compounds in geothermal brines and associated steam condensates, a high-performance liquid chromatography (HPLC) method combined with solid-phase extraction (SPE) for detection of NAP, 1-NAP and 2-NAP in geothermal fluids has been developed. The targeted compounds were isolated with ethanol by using solid phase extraction columns (Discovery DSC-18). Separation was achieved on reverse-phase Synergi Hydro column using 50\% HPLC grade acetonitrile as the mobile phase. The minimum detection limits achieved with fluorescence detector were determined to be $3.6 \mathrm{nmol} \mathrm{kg}{ }^{-1}$ for $1-\mathrm{NAP}, 3.4 \mathrm{nmol} \mathrm{kg}{ }^{-1}$ for $2-\mathrm{NAP}$ and $3.1 \mathrm{nmol} \mathrm{kg}^{-1}$ for NAP.

This study shows that SPE and a single HPLC run can be applied to the extraction and quantification of NAP, 1-NAP and 2-NAP in geothermal brine and steam condensates.

\subsection{Introduction}

Naphthalene (NAP), 1-naphthol (1-NAP) and 2-naphthol (2-NAP) are polycyclic aromatic hydrocarbons (PAHs). All three compounds are used to produce dyes, synthetic rubbers, pesticides, and in the pharmaceutical industry (Fierz-David \& Blangey, 1949; Huang et al., 2012; Krugly et al., 2015; Zhou et al., 2016). As naphthalene and its derivatives are toxic (Bruce et al., 1998; Zang \& Lian, 2009), the wide use of these compounds means they can be present in the environment as contaminants (Santana et al., 2009; Jia \& Batterman, 2010; Zang et al., 2010; Yang et al., 2014). Naphthalene has also been shown to occur naturally in volcanic gases (Schwandner et al., 2013). Additionally, it has also been proven that NAP, 1-NAP and 
2-NAP are formed through thermal degradation of naphthalene sulfonates (Chapter 6). In order to measure the concentration of these breakdown products in geothermal brines, a successful detection method is required, with potential useful applications to the geothermal industry.

NAP, 1-NAP and 2-NAP have low solubility in water at ambient temperature (Table 5.1), however, their solubility increases with temperature increase. Experiments to examine their solubility at elevated temperatures have been conducted. These experiments show an increase in solubility of these compounds as temperature increases up to $75^{\circ} \mathrm{C}$. For example, 2-NAP solubility increases from $4.95 \times 10^{-3}$ to $4.16 \times 10^{-2} \mathrm{~mol} \mathrm{~kg}^{-1}$ as the temperature increases from 25 to $75^{\circ} \mathrm{C}$ (Moyle \& Tyner, 1953; Mackay \& Shiu, 1977; Maharajh, 1986). The increase in solubility makes these aromatic compounds very mobile within geothermal reservoirs. Naphthalene is a volatile organic compound (Ambrose et al., 1975), which will fractionate into the steam phase, and may also become a useful indicator of steam formation (i.e. boiling) in active geothermal reservoirs.

Table 5.1: Solubility of NAP, 1-NAP and 2-NAP in water at $25^{\circ} \mathrm{C}$.

\begin{tabular}{lcl}
\hline compound & $\begin{array}{c}\text { solubility at } 25^{\circ} \mathrm{C} \\
\left(\mathrm{mol} \mathrm{kg}^{-1}\right)\end{array}$ & source \\
\hline naphthalene (NAP) & $2.36 \times 10^{-4}$ & Schwartz, 1977 \\
1-naphthol (1-NAP) & $6.01 \times 10^{-3}$ & Hassett et al., 1980 \\
2-naphthol (2-NAP) & $4.95 \times 10^{-3}$ & Moyle \& Tyner, 1953
\end{tabular}

Current analytical methods used to quantify these compounds are not suitable for rapid and sensitive analysis of geothermal brines. Furthermore, none of the currently established methods target NAP, 1-NAP and 2-NAP in saline solutions simultaneously. Amongst available methods, the most popular are gas chromatography (GC) and liquid chromatography with UV detection (LC-UV; Sancho et al., 2003; Watanabe et al., 2003; Preuss \& Angerer, 2004). The GC method with mass spectrometry (MS) has been employed in analyses of environmental river water samples for the presence of NAP (Zogorski et al., 2006), but this method does not include 1-NAP or 2-NAP. Other studies describe the LC-UV method that targets 1-NAP and 2-NAP in water samples (Zhou et al., 2016). An alternative method, cloud point extraction (CPE), prior to performing capillary zone electrophoresis (CZE; to analyse river water samples for naphthol concentrations) was developed by Zhong et al., (2011), however, it does not target 
naphthalene and this method is not sufficiently sensitive for use at geothermal tracer concentrations.

The method presented in this chapter involves sample concentration and purification through solid phase extraction (SPE). SPE methods are commonly used for waste waters and river samples (Santana et al., 2009; Zhou et al., 2016), but these have not been applied to geothermal fluid or steam samples.

As there were no available HPLC methods designed to detect sufficiently low concentrations (i.e. at nmol levels) of NAP, 1-NAP and 2-NAP from geothermal fluids, a HPLC with fluorescence detector methodology combined with SPE is proposed.

\subsection{Experimental}

\subsubsection{Reagents}

Naphthalene (>99\%,), 2-naphthol (>99\%, $\beta$-naphthol) and 1-naphthol (>99\%, $\alpha$-naphthol) were purchased from Sigma-Aldrich, acetonitrile (HPLC grade) was obtained from Fischer Scientific GmbH. Ethanol and methanol were HPLC grade from Bio-Strategy. Ultrapure water with a conductivity of $0.055 \mu \mathrm{S} \mathrm{cm}^{-1}\left(18.2 \mathrm{M} \Omega \mathrm{cm}^{-1}\right)$ was produced by Arium® pro-ultrapure water system.

\subsubsection{Chromatographic separation}

The naphthalene and naphthols are analysed by high performance liquid chromatography (HPLC) with fluorescence detection using a Shimadzu Prominence RF20Axs. The separation of the compounds is made using reversed-phase Synergi Hydro-RP column with particle size $4 \mu \mathrm{m}$ and pore size $80 \AA$, 150 x $4.6 \mathrm{~mm}$ (Phenomenex Inc.) thermostated at $25^{\circ} \mathrm{C}$. The column is protected with a SecurityGuard AQ C18 guard column, $3 \mu \mathrm{m}, 4.0 \times 3.0 \mathrm{~mm}$ (Phenomenex Inc.). A 50\% (v/v) aqueous acetonitrile solution was used as a carrier phase. The flow-rate is $1.5 \mathrm{ml} \mathrm{min}^{-1}$ and $2 \mathrm{ml} \mathrm{min}^{-1}$. A $25 \mu \mathrm{l}$ volume of sample is injected each time and a $25 \mu \mathrm{L}$ ultrapure water blank is run between each standard/sample. A multiple excitation and emission configuration is used. The detector operates at excitation wavelengths of $219 \mathrm{~nm}$ and $254 \mathrm{~nm}$ and emission wavelengths of $330 \mathrm{~nm}$ and $445 \mathrm{~nm}$ as shown in Table 5.2. 
Table 5.2: The HPLC analysis configuration.

\begin{tabular}{cccc}
\hline $\begin{array}{c}\text { time } \\
(\mathrm{min})\end{array}$ & $\begin{array}{c}\text { flow } \\
\left(\mathrm{ml} \mathrm{min}^{-1}\right)\end{array}$ & $\begin{array}{c}\text { excitation } \\
(\mathrm{nm})\end{array}$ & $\begin{array}{c}\text { emission } \\
(\mathrm{nm})\end{array}$ \\
\hline $0-5$ & 1.5 & 219 & 445 \\
$5-13$ & 2.0 & 254 & 330
\end{tabular}

\subsubsection{Standard preparation and calibration procedure}

The stock solution for calibration standards is prepared by spiking ethanol with a mixture of naphthalene $\left(7.80 \mathrm{x} \quad 10^{-5} \mathrm{~mol} \mathrm{~kg}^{-1}\right)$, 1-naphthol and 2-naphthol $\left(6.94 \times 10^{-5} \mathrm{~mol} \mathrm{~kg}^{-1}\right)$. Eight standards are selected in the range $2.9-1170 \mathrm{nmol} \mathrm{kg}{ }^{-1}$. Unspiked HPLC grade ethanol is used as a blank. Linear calibration curves are obtained by plotting the quotients of the integrated peaks as a function of the standard concentrations. These graphs were used to determine the unknown naphthalene and naphthol concentration in the brine samples. The calibration curves give good linearity with correlation coefficients $\left(\mathrm{R}^{2}\right)$ between 0.9992 and 0.9998 .

\subsubsection{Solid-phase extraction}

To isolate and increase analyte recovery, a solid phase extraction method was developed. Three different SPE cartridges were tested. Two of them with the same polymer base but different amounts of sorbent, (i.e. Discovery DSC-18 with either $100 \mathrm{mg}$ and $500 \mathrm{mg}$ sorbent and Strata-X $33 \mu \mathrm{m}$ Polymeric Reversed Phase, $30 \mathrm{mg}$ ). Before using the cartridges, they were eluted with ethanol and then conditioned with water (Table 5.3) after which, $1 \mathrm{ml}$ of sample was loaded. The cartridges are dried with nitrogen gas for $5 \mathrm{~min}$. Subsequently, the analyte was eluted with ethanol (or methanol) and collected into a vial and analysed with HPLC.

To improve SPE performance, all steps (conditioning, sample load, wash, elute, modifiers) had to be adjusted. As these steps can influence extraction efficiency, all were investigated for each kind of sorbent. The method was tested using a sample of geothermal brine spiked with a known concentration of NAP, 1-NAP and 2-NAP. The goal was to obtain the highest possible recovery. The elution is critical for successful SPE process and choosing the right organic solvent is important for the elution preference. Two available solvents were chosen (i.e. methanol and ethanol) and tested at different concentrations (from 10\% to 100\%; Figure 5.1). Results show a recovery increase when ethanol is used in comparison to methanol, thus ethanol was chosen as the eluent. In addition, $30 \%$ ethanol solution was used as the wash 
solution, as it was the lowest concentration of the organic solvent which did not elute targeted PAHs. To try to minimise any contamination from plastic (i.e. pipettes, storage containers etc.) samples and standards are stored in glass bottles/vials and solutions handled with glass pipettes.

Among different SPE cartridges, the Discovery-C18 (100 mg) cartridge give the most effective (almost complete) recovery (Table 5.4). Satisfactory results are also observed on the Strata-X $33 \mu \mathrm{m}(30 \mathrm{mg})$ cartridge. The cartridge Discovery-C18 (500 mg) provided low recoveries, while Strata-X $33 \mu \mathrm{m}(500 \mathrm{mg}$ ) retains all analysed compounds (i.e. no recovery). The Discovery-C18 (100 mg) was selected as the most effective (i.e. high recoveries) and further employed as the SPE cartridge for this method.

Table 5.3: SPE analysis protocol for the different cartridges.

\begin{tabular}{ccccccc}
\hline & $\begin{array}{c}\text { Strata-X } \\
33 \mu \mathrm{m}, \\
(30 \mathrm{mg})\end{array}$ & $\begin{array}{c}\text { Strata-X } \\
33 \mu \mathrm{m}, \\
(500 \mathrm{mg})\end{array}$ & $\begin{array}{c}\text { Discovery } \\
\text { DSC-18, } \\
(100 \mathrm{mg})\end{array}$ & $\begin{array}{c}\text { Discovery } \\
\text { DSC-18, } \\
(500 \mathrm{mg})\end{array}$ & $\begin{array}{c}\text { Flow rate } \\
\left(\mathrm{ml} \mathrm{min}^{-1}\right)\end{array}$ & solvent/gas \\
\hline rinse & $1 \mathrm{ml}$ & $5 \mathrm{ml}$ & $1 \mathrm{ml}$ & $5 \mathrm{ml}$ & 5 & methanol/ethanol \\
conditioning & $1 \mathrm{ml}$ & $5 \mathrm{ml}$ & $1 \mathrm{ml}$ & $5 \mathrm{ml}$ & 5 & pure water \\
load & $1 \mathrm{ml}$ & $1 \mathrm{ml}$ & $1 \mathrm{ml}$ & $1 \mathrm{ml}$ & 2 & sample \\
wash & $2 \mathrm{ml}$ & $2 \mathrm{ml}$ & $2 \mathrm{ml}$ & $2 \mathrm{ml}$ & 2 & methanol/ethanol* \\
dry & $5 \mathrm{~min}$ & $5 \mathrm{~min}$ & $5 \mathrm{~min}$ & $5 \mathrm{~min}$ & - & nitrogen gas \\
elute & $2 \times 0.5 \mathrm{ml}$ & $2 \times 0.5 \mathrm{ml}$ & $2 \times 0.5 \mathrm{ml}$ & $2 \times 0.5 \mathrm{ml}$ & 2 & methanol/ethanol** \\
\hline
\end{tabular}

*as the wash solution: 30:70, v/v, ethanol/water solution was used, or: 40:60, v/v, methanol/water.

**eluent used in this study: $99.9 \%$ ethanol or $100 \%$ methanol HPLC grade.

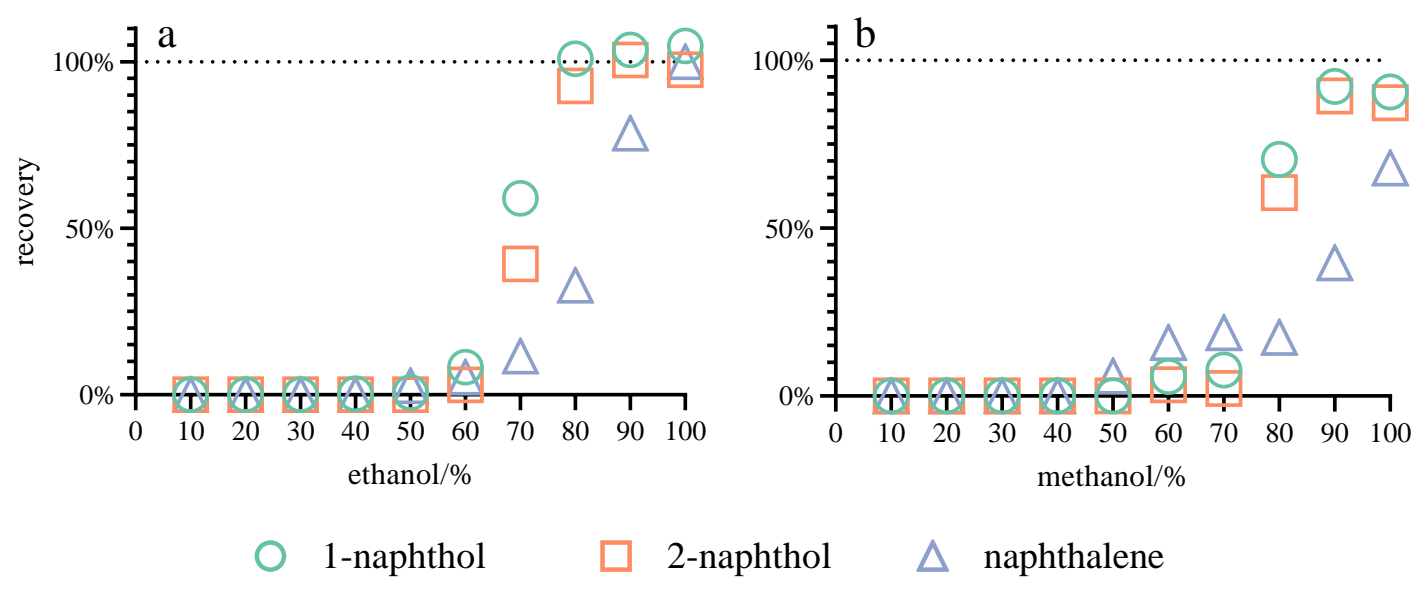

Figure 5.1: Effect of organic solvents (a) ethanol and (b) methanol on the analyte extraction. SPE cartridges: 100 mg Discovery-C18. 
Table 5.4: Recovery and relative standard deviation (RSD) of naphthalene, 1-naphthol and 2-naphthol in percentages for different solid phase cartridges considered in this study (10 ug kg-1 of each compound added to $1 \mathrm{ml}$ samples).

\begin{tabular}{|c|c|c|c|c|}
\hline \multirow[b]{2}{*}{ compound } & \multicolumn{2}{|c|}{$\begin{array}{l}\text { Discovery DSC-18, } \\
\quad(100 \mathrm{mg})\end{array}$} & \multicolumn{2}{|c|}{$\begin{array}{l}\text { Discovery DSC-18, } \\
\qquad(500 \mathrm{mg})\end{array}$} \\
\hline & recovery [\%] & $\pm \operatorname{RSD}[\%]$ & recovery [\%] & $\pm \mathrm{RSD}[\%]$ \\
\hline 1-naphthol & 99.58 & 0.30 & 94.15 & 12.10 \\
\hline 2-naphthol & 99.73 & 0.19 & 84.24 & 4.26 \\
\hline \multirow[t]{2}{*}{ naphthalene } & 99.92 & 0.05 & 96.77 & 2.32 \\
\hline & \multicolumn{2}{|c|}{$\begin{array}{l}\text { Strata-X } 33 \mu \mathrm{m}, \\
\qquad(30 \mathrm{mg})\end{array}$} & \multicolumn{2}{|c|}{$\begin{array}{l}\text { Strata-X } 33 \mu \mathrm{m}, \\
\quad(500 \mathrm{mg})\end{array}$} \\
\hline compound & recovery [\%] & $\pm \mathrm{RSD}[\%]$ & recovery [\%] & $\pm \mathrm{RSD}[\%]$ \\
\hline 1-naphthol & 98.52 & 1.06 & 0.00 & - \\
\hline 2-naphthol & 99.52 & 0.49 & 0.00 & - \\
\hline naphthalene & 96.00 & 2.88 & 0.36 & - \\
\hline
\end{tabular}

\subsubsection{The effect of salinity on HPLC results}

The total salinity of a geothermal fluids differs for different geothermal fields. It can be low (e.g. $0.04 \mathrm{~mol} \mathrm{~kg}^{-1}$ for Rotokawa, New Zealand; Krupp \& Seward, 1987, $0.23 \mathrm{~mol} \mathrm{~kg}^{-1}$ in Bacman Geothermal Field, Philippines; See, 1995) or as high as $1 \mathrm{~mol} \mathrm{~kg}^{-1}$ in Reykjanes, Iceland (Bjamason, 1984) or Salton Sea, USA, where $\mathrm{NaCl}=4.8 \mathrm{~mol} \mathrm{~kg}^{-1}$ (Thompson \& Fournier, 1988). It was previously reported that high salt concentration has a negative influence on the analysis of naphthalene sulfonates (Nottebohm \& Licha, 2012) and other PAHs (Zhou et al., 2016). The HPLC method presented in this chapter is designed to analyse low concentrations of NAP, 1-NAP and 2-NAP (Table 5.5) in saline solutions $\left(\leq 1.00 \mathrm{~mol} \mathrm{~kg}^{-1}\right)$.

Three different background salt concentrations (i.e. $0.05 \mathrm{~mol} \mathrm{~kg}-1,0.50 \mathrm{~mol} \mathrm{~kg}^{-1}$ and $1.00 \mathrm{~mol} \mathrm{~kg}^{-1} \mathrm{NaCl}$ ) and distilled water are employed. The experimental data shows that there is no loss in resolution with the different salt matrices during analysis (Figure 5.2) and no further need for other sample treatment is required. 


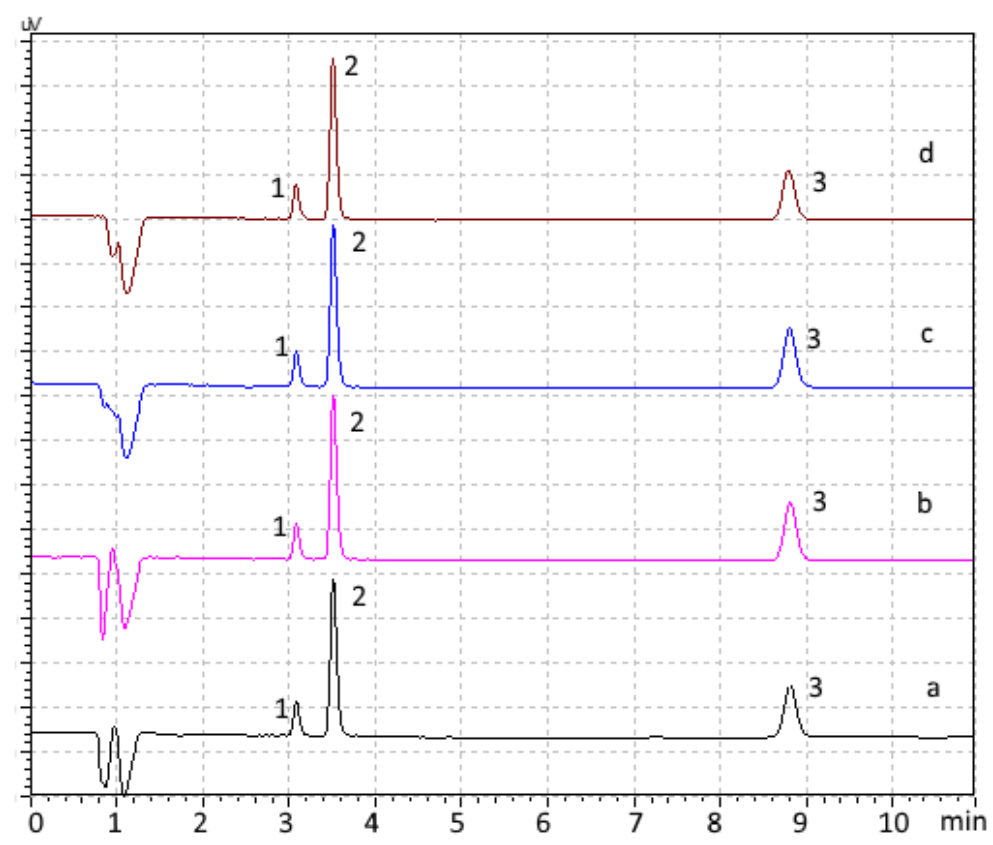

Figure 5.2: Chromatogram of a $10 \mathrm{ug} \mathrm{kg}^{-1}$ mix-standard consisting of 2-naphthol (peak 1), 1-naphthol (peak 2) and naphthalene (peak 3) in $\mathrm{NaCl}=1.00 \mathrm{~mol} \mathrm{~kg}^{-1}(\mathrm{a}), \mathrm{NaCl}=0.50 \mathrm{~mol}$ $\mathrm{kg}^{-1}$ (b), $\mathrm{NaCl}=0.05 \mathrm{~mol} \mathrm{~kg}^{-1}$ (c) and distilled water (a) using a Phenomenex Synergi Hydro-RP C18 column and direct injection.

\subsubsection{Validation}

Method validation was performed according to the guidelines set by the United States Environmental Protection Agency. Method detection limit (MDL) refers to the smallest concentration of a substance that can be measured by an analytical procedure with 99-percent confidence that the analyte concentration is greater than zero (Gibbons \& Coleman, 2001). The MDL is calculated using the formula:

$$
\mathrm{MDL}=\mathrm{s} \cdot \mathrm{t}_{(\mathrm{n}-1,1-\alpha=0.99)}
$$

where, $\mathrm{n}$ is number of replicate spike determinations, $\mathrm{s}$ is standard deviation of measured concentrations of $n$ spike determinations, $t$ is the Student's value at $n-1$ degrees of freedom and 1- $\alpha$ refers to the $99 \%$ confidence level.

Minimum level (ML) is the lowest concentration of an analyte which can be determined with the method and constitutes a calibration point (Gibbons \& Coleman, 2001). The ML is defined as,

$$
\mathrm{ML}=3.18 \cdot \mathrm{MDL}
$$


Repeatability and recovery were validated through several runs by replicate $(n=15)$ analyses of spiked ethanol at different concentration levels (Table 5.5). Calibration curves for NAP, 1-NAP and 2-NAP are linear with correlation coefficients $>0.999$. Method Detection Limit and Minimum Level are presented in Table 5.5.

Table 5.5: Calibration Parameters of the Overall Method, Including SPE and HPLC Detection.

\begin{tabular}{cccc}
\hline compound & $\begin{array}{c}\text { linear range } \\
\mathrm{nmol} \mathrm{kg}\end{array}$ & $\begin{array}{c}\mathrm{MDL} \\
\mathrm{nmol} \mathrm{kg}\end{array}$ & $\begin{array}{c}\mathrm{ML} \\
\mathrm{nmol} \mathrm{kg}^{-1}\end{array}$ \\
\hline 1-naphthol & $4.86-1.04$ & 1.11 & 3.61 \\
2-naphthol & $4.86-1.04$ & 1.04 & 3.40 \\
naphthalene & $6.24-1.17$ & 1.01 & 3.12 \\
\hline
\end{tabular}

$\mathrm{MDL}=$ method detection limit; $\mathrm{ML}=$ minimum level

\subsection{Conclusions}

This study describes a sensitive method for determination of naphthalene, 1-naphthol and 2-naphthol from saline brines (up to $1.00 \mathrm{~mol} \mathrm{~kg}^{-1} \mathrm{NaCl}$ ) using HPLC-fluorescence detector combined with SPE methodology.

The method can be applied in future hydrogeological and permeability tracer tests in geothermal reservoirs. Measurable amounts of naphthalene and 1- and 2-napthol have been successfully detected in geothermal steam samples from different New Zealand geothermal fields using the analytical the method presented in this study (Table 5.6).

Table 5.6: Concentration ( $\mathrm{mol} \mathrm{kg}^{-1}$ ) of NAP, 1-NAP and 2-NAP measured in steam condensate samples collected from different active geothermal fields.

\begin{tabular}{rccc}
\hline compound & Site 1 & Site 2 & Site 3 \\
\hline 1-naphthol & $1.25 \times 10^{-6}$ & $9.02 \times 10^{-7}$ & $1.94 \times 10^{-6}$ \\
2-naphthol & $2.57 \times 10^{-6}$ & n.d. & n.d. \\
naphthalene & $3.67 \times 10^{-5}$ & $8.50 \times 10^{-5}$ & $5.09 \times 10^{-4}$ \\
\hline
\end{tabular}

n.d. $=$ not detected 


\subsection{References}

Ambrose, D., Lawrenson I. J., Sprake C. H. S., 1975. The vapour pressure of naphthalene. The Journal of Chemical Thermodynamics, 7, 12, 1173 - 1176.

Bruce R., Haber L., McClure P., 1998. Toxicological review of naphthalene. 1998. In support of summary information on the integrated risk information system (IRIS). (CAS No. 91-20-3)

Bjamason, J. O., 1984. Chemical composition of brine and steam from well 9, Reykjanes Report OS-840491JHD-13B, National Energy Authority, Iceland (in Icelandic)

Dashkevich, Y.G., Mountain, B.W., Seward, T.M., Winick, J.A., 2014. Temperature stability of 1,5-naphthalene disulfonate at simulated geothermal conditions. Proceedings 36th New Zealand Geothermal Workshop, Auckland, New Zealand.

Fierz-David, H.E., Blangey, L., 1949. Dye chemistry, Interscience Publishers, INC., New York, 239 - 296.

Hassett J. J., Means J. C., Banwart W. L., Wood S. G., 1980. Sorption properties of sediments and energy-related pollutants. EPA-600/3-80-041

Huang, X., Zhao, G., Liu, M., Li, F., Qiao, J., Zhao, S., 2012. Highly sensitive electrochemical determination of 1-naphthol based on high-index facet $\mathrm{SnO}_{2}$ modified electrode. Electrochimica Acta, 83, 478 - 484.

Jia, C., Batterman, S., 2010. A critical review of naphthalene sources and exposures relevant to indoor and outdoor air. International Journal of Environmental Research and Public Health, 7, $2903-2939$.

Krugly, E., Martuzevicius, D., Tichonovas, M., Jankunaite, D., Rumskaite, I., Sedlina, J., Racys, V., Baltrusaitis, J., 2015. Decomposition of 2-naphthol in water using a non-thermal plasma reactor. Chemical Engineering Journal, 260, 188 - 198.

Krupp, R. E., Seward T. M., 1987. The Rotokawa geothermal system, New Zealand; an active epithermal gold-depositing environment. Economic Geology, 82, 1109 - 1129.

Mackay, D., Shiu, W.Y., 1977. Aqueous solubility of polynuclear aromatic hydrocarbons. Journal of Chemical \& Engineering Data, 22, 399 - 402. 
Maharajh, D.M., 1986. Thermodynamics of solution of naphthalene in various tetramethylurea-water mixtures. Thermochimica Acta, 105, $71-78$.

Moyle, M.P., Tyner, M., 1953. Solubility and diffusivity of 2-naphthol in water. Industrial and Engineering Chemistry. 45, 1794 - 1797.

Nottebohm, M., Licha, T., 2012. Detection of naphthalene sulfonates from highly saline brines with high-performance liquid chromatography in conjunction with fluorescence detection and solid-phase extraction. Journal of Chromatographic Science, 50, $477-481$.

Preuss, R., Angerer, J., 2004. Simultaneous determination of 1- and 2-naphthol in human urine using on-line clean-up column-switching liquid chromatography-fluorescence detection. Journal of Chromatography B: Analytical Technologies in the Biomedical and Life Sciences, 801, $307-316$.

Sancho, J.V., Cabanes, R.A., López, F.J., Hernández, F., 2003. Direct determination of 1-naphthol in human urine by coupled-column liquid chromatography with fluorescence detection. Chromatographia, 58, $565-566$.

Santana, C.M., Ferrera, Z.S., Padrón, M.E.T., Rodríguez, J.J.S., 2009. Methodologies for the Extraction of Phenolic Compounds from Environmental Samples: New approaches. Molecules, 14, 298 - 320.

Schwandner, F.M., Seward, T.M., Gize, A.P., Hall, K., \& Dietrich, V.J., 2013. Halocarbons and other trace heteroatomic organic compounds in volcanic gases from Vulcano (Aeolian Islands, Italy). Geochimica et Cosmochimica Acta, 101, 191 - 221.

Schwarz F.P., 1977. Determination of temperature dependence of solubilities of polycyclic aromatic hydrocarbons in aqueous solutions by a fluorescence method. Journal of Chemical \& Engineering Data, 22, 3, 273 - 277

See S. F., 1995. Anhydrite deposition in Cawayan wells, Bacman geothermal field, Philippines: prediction and possmle remedies. United Nations University Geothermal Training Programme, Reykjavik, Iceland, 321 - 348.

Shrivastava, A., Gupta, V., 2011. Methods for the determination of limit of detection and limit of quantitation of the analytical methods. Chronicles of Young scientists, 2, $21-25$.

Thompson, J., M., Fournier, R., O., 1988. Chemistry and geothermometry of brine produced from the Salton Sea scientific drill hole, Imperial Valley, California. Journal of Geophysical Research, 93, 13, 165 - 13. 
Watanabe, K., Okamoto, N., Yamagishi, I., Nozawa, H., Ishii, A., Suzuki, O., 2003. Simple analysis of amphetamines in human whole blood and urine by headspace capillary gas chromatography with large volume injection. Chromatographia, 58, 455 - 458.

Yang, S., Gao, M., Luo, Z., 2014. Adsorption of 2-Naphthol on the organomontmorillonites modified by Gemini surfactants with different spacers. Chemical Engineering Journal, 256, 39 - 50 .

Zang, S., Lian, B., 2009. Synergistic degradation of 2-naphthol by Fusarium proliferatum and Bacillus subtilis in wastewater. Journal of Hazardous Materials, 166, 33 - 38.

Zang S., Lian B., Wang J., Yang Y., 2010. Biodegradation of 2-naphthol and its metabolites by coupling Aspergillus niger with Bacillus subtilis. Journal of Environmental Sciences-China, 22, $669-74$.

Zhong, S., Tan, S.N., Ge, L., Wang, W., Chen, J., 2011. Determination of bisphenol A and naphthols in river water samples by capillary zone electrophoresis after cloud point extraction. Talanta, $85,488-492$.

Zhou, Q., Lei, M., Li, J., Zhao, K., Liu, Y., 2016. Determination of 1-naphthol and 2naphthol from environmental waters by magnetic solid phase extraction with Fe@MgAllayered double hydroxides nanoparticles as the adsorbents prior to high performance liquid chromatography. Journal of Chromatography A, 1441, $1-7$.

Zogorski, J.S., Carter, J.M., Ivahnenko, Tamara, Lapham, W.W., Moran, M.J., Rowe, B.L., Squillace, P.J., and Toccalino, P.L., 2006, The quality of our Nation's waters-Volatile organic compounds in the Nation's ground water and drinking-water supply wells: U.S. Geological Survey Circular, 1292, 101. 


\section{Reaction pathways of 1,6-NDS and 1,5-NDS: decomposition in aqueous solutions at elevated temperatures to $300^{\circ} \mathrm{C}$ and the formation of naphthalene, naphthols and 1-chloronaphthalene}

\subsection{Abstract}

1,6-napthalene disulfonate (1,6-NDS) and 1,5-naphthalene disulfonate (1,5-NDS) served as model compounds to investigate the thermal breakdown reaction pathways of naphthalene disulfonates and naphthalene sulfonates in oxygen-free sodium chloride solutions at elevated temperatures to $300^{\circ} \mathrm{C}$ at saturated vapour pressure.

Two series of experiments were conducted using quartz glass ampoules. The first series involved 1,6-NDS and $\mathrm{NaCl}=0.050 \mathrm{~mol} \mathrm{~kg}^{-1}$. The second series comprised 1,5-NDS with the same concnetration of $\mathrm{NaCl}$. Both series of the experiments were heated to between 200 and $300^{\circ} \mathrm{C}$, for one, two and three weeks at each temperature. The solutions were analysed for the presence of the initial NDS isomer and different polycyclic aromatic hydrocarbons using high performance liquid chromatography-fluorescence detector (HPLC) and gas chromatography with a mass spectrometry detector (GC-MS).

Results show that both 1,6-NDS and 1,5-NDS breakdown to a temperature-dependent mixture of products. At $200^{\circ} \mathrm{C}$, the 1,6-NDS main breakdown reaction leads to 2-napthalene sulfonate (2-NSA), whereas, 1,5-NDS breakdown forms mainly 1-NSA. At $250^{\circ} \mathrm{C}$, both 1,6-NDS and 1,5-NDS generated measurable amounts of naphthalene (NAP). At $300^{\circ} \mathrm{C}$, NAP constituted a major breakdown product of 1,6-NDS and 1,5-NDS.

\subsection{Introduction}

The naphthalene sulfonates (NSA) and disulfonates (NDS) are useful permeability and well connectivity indicators in energy producing geothermal reservoirs. The most commonly employed NDS/NSA compounds used by the geothermal industry are 1-napthalene sulfonate (1-NSA), 2-napthalene sulfonate (2-NSA), 1,5-napthalene disulfonate (1,5-NDS), 1,6-naphthalene disulfonate (1,6-NDS), 2,6-napthalene disulfonate (2,6-NDS), and 2,7napthalene disulfonate (2,7-NDS). All of the above are UV-fluorescent polyaromatic 
compounds with very low detection limits $\left(\mathrm{pg} \mathrm{kg}^{-1}\right)$ and have extremely low, to undetectable, natural background concentrations.

The polyaromatic sulfonate isomers previously have been the subject of experimental studies (including this thesis) with a focus on their thermal stabilities (Rose et al., 2001; Mountain \& Winick, 2012; Dashkevich et al., 2015). These studies have shown that temperature, $\mathrm{pH}$ and/or salinity will influence the stability of the isomers. In general, the stability of each NSA or NDS isomer decreases with increasing temperature and salinity. They are $\mathrm{pH}$ sensitive and any changes in $\mathrm{pH}$ from near neutral will decrease their stability.

Previous research on the polyaromatic sulfonates thermal decay products is limited and stated that at higher temperatures (between 270 and $330^{\circ} \mathrm{C}$ ), 1,5-NDS will transform into 1-NSA, whereas above $330^{\circ} \mathrm{C}$, disulfonates (1,5-, 1,6-, 2,6- and 2,7-NDS) will produce a mixture of 1-NSA and 2-NSA (Mountain \& Winick, 2012). The results suggest possible isomerisation processes, but without quantitative data, and no reaction pathways were provided. Additionally, experiments were of short duration (between six and 60 hours) and were analysed only for presence of NDS and NSA.

Dashkevich et al. (2014) described different possible breakdown mechanisms. They reported that at elevated temperatures (from 260 to $350^{\circ} \mathrm{C}$ ) 1,5-NDS degraded into 1-NSA through electrophilic desulfonation, in the presence of deionised water, geothermal brine and in $\mathrm{NaCl}\left(0.40 \mathrm{~mol} \mathrm{~kg}^{-1}\right)$ solution. However, when 1,5-NDS was dissolved in a phosphate buffer solution $\left(\mathrm{pH}_{25^{\circ} \mathrm{C}}=6.5\right)$ and heated to the same temperatures, a smaller amount of 1-NSA was generated, even though the 1,5-NDS concentration decreased and no other breakdown product other than 1-NSA was detected. The authors proposed that 1,5-NDS possibly underwent hydrolysis, creating 1,5-dihydroxynaphthalene, but this was not measured at the time.

Rose and Clausen (2014) reported 2-naphthol formation as a bi-product of the decomposition of 7-amino-1,3-naphthalene disulfonate. In another study, Gosetti et al. (2005) investigated 1,5 -NDS degradation at $80^{\circ} \mathrm{C}$, in the presence of oxygen and showed that the naphthalene structure is broken during an oxidative process, however, they were unable to identify the exact specie(s) formed.

This chapter provides insight into the breakdown products of naphthalene disulfonates during thermal degradation and aims to provide: (1) qualitative and quantitative data on species created during 1,6-NDS and 1,5-NDS thermal degradation; (2) possible pathways of the 
breakdown products formation reactions; and (3) information on stabilities of the resulting breakdown products.

\subsection{Experimental methods}

\subsubsection{Experimental setup}

In order to detect unknown breakdown products of naphthalene disulfonate thermal decomposition, two sets of experiments were conducted. The experimental method utilised in this study was described in detail in Chapter 2. An initial experimental solution was deoxygenated with $0.01 \% \mathrm{H}_{2}$ in $\mathrm{N}_{2}$ for 10 minutes and then $2.5 \mathrm{ml}$ aliquots of this solution were transferred to open quartz glass ampoules (ID $7 \mathrm{~mm}$, OD $9 \mathrm{~mm}$ ). This left approximately $2 \mathrm{ml}$ of headspace in the ampoule which was evacuated using a vacuum pump and simultaneously sealed with an oxygen-acetylene torch. The transfer, evacuation, and sealing took $<10$ seconds. Numerous experiments were conducted to ensure a series of reproduceable data.

The first set of experiments focused on 1,6-NDS stability and consisted of four subsets with six replicates each, comprising a total of 72 experiments (Table 6.1). Each subset represented a different temperature $\left(200,250,270\right.$ and $\left.300^{\circ} \mathrm{C}\right)$ and a different heating time (7, 14 and 21 days). The initial experimental solution consisted of 1,6-NDS $\left(6.9 \times 10^{-4} \mathrm{~mol} \mathrm{~kg}^{-1}\right)$ in a sodium chloride $\left(0.050 \mathrm{~mol} \mathrm{~kg}^{-1}\right)$ solution.

The second set of 54 experiments targeted 1,5-NDS and included three subsets which represented 200,250 and $300^{\circ} \mathrm{C}$ at different heating times (7, 14 and 21 days; Table 6.2). The initial solution contained 1,5-NDS $\left(6.8 \times 10^{-4} \mathrm{~mol} \mathrm{~kg}^{-1}\right)$ in a sodium chloride $(0.050 \mathrm{~mol}$ $\mathrm{kg}^{-1}$ ) solution.

The 1,5-NDS and 1,6-NDS concentrations were higher than the ones used in previous chapters in order to produce sufficient amounts of breakdown products. In other words, the high concentration was used to ensure that potential thermal breakdown reactions products are above detection limits of the employed methods (HPLC and GC-MS).

Duplicate ampoules were enclosed in $120 \mathrm{ml}$ stainless autoclaves which were partially filled with water to provide the confining pressure around the ampoules and were placed into the preheated Carbolite LHT 5/60 oven. The time required to heat the autoclaves to the target temperature is about two hours while cooling down to $100^{\circ} \mathrm{C}$ takes about one hour. The reacted samples were analysed with GC-MS and HPLC. 


\subsubsection{High-performance liquid chromatography}

Replicates were analysed for presence of naphthalene sulfonates and disulfonates by high performance liquid chromatography (HPLC) with fluorescence detection using the Shimadzu RF-20Axs instrument with further details given in Chapter 2. Additionally, to the standard HPLC analysis for NSA/NDS, a recently developed HPLC method combined with solid phase extraction (SPE) for detection of naphthalene (NAP) and 1-napthol (1-NAP) and 2-naphthol (2-NAP) was employed. The method is described in detail in Chapter 5.

The values of the observed molal concentrations of detected compounds after different heating times are plotted as concentration(molal) vs time(days). The rate constants, $\mathrm{k}$, are fitted using a linear least squares procedure (GraphPad Prism 8.21 software) as described previously in Chapter 2.

\subsubsection{Gas chromatography - mass spectrometry}

Replicates were also analysed qualitatively with GC-MS. The reacted solutions for GCMS analyses were ultrasonically extracted for 20 minutes and subsequently stirred for 10 minutes using vortex stirring with n-hexane as the solvent. The GC-MS analyses were carried out using an Agilent 7890A gas chromatograph coupled to an Agilent 5975C Network mass spectrometer with a Triple-Axis Detector at the Faculty of Earth Sciences, Sosnowiec, Poland. Helium (6.0 Grade) was used as the carrier gas at a constant flow of $2.4 \mathrm{~mL} \mathrm{~min}^{-1}$. Separation was either on a fused silica column (Macherey-Nagel Optima 624 LB; $30 \mu \mathrm{m}$ x $320 \mu \mathrm{m}$ i.d., $0.25 \mu \mathrm{m}$ film thickness) coated with a chemically bonded phase (6\% cyanopropyl-phenyl / $94 \%$ dimethylpolysiloxane). The GC oven temperature was programmed from $35^{\circ} \mathrm{C}$ (held for $1 \mathrm{~min}$ ) to $85^{\circ} \mathrm{C}$ at $5^{\circ} \mathrm{C} / \mathrm{min}$, then to $250^{\circ} \mathrm{C}$ (held for $35 \mathrm{~min}$ ) at $10^{\circ} \mathrm{C} / \mathrm{min}$. The $\mathrm{GC}$ column outlet was connected directly to the ion source of the mass spectrometry detector (MSD). Injection volume was $1 \mu \mathrm{L}$. Spectra were recorded from 45 to $550 \mathrm{~m} / \mathrm{z}$. The mass spectrometer was operated in the electron impact mode (ionisation energy $70 \mathrm{eV}$ ). The unknown compounds were identified by Agilent Technologies MSD ChemStation E.02.01.1177 and the Wiley Registry of Mass Spectral Data ( $9^{\text {th }}$ edition) software.

Example chromatograms as well as mass spectra obtained from analysis of the reacted solutions are presented in Figure 6.1 and 6.2. 
TIC

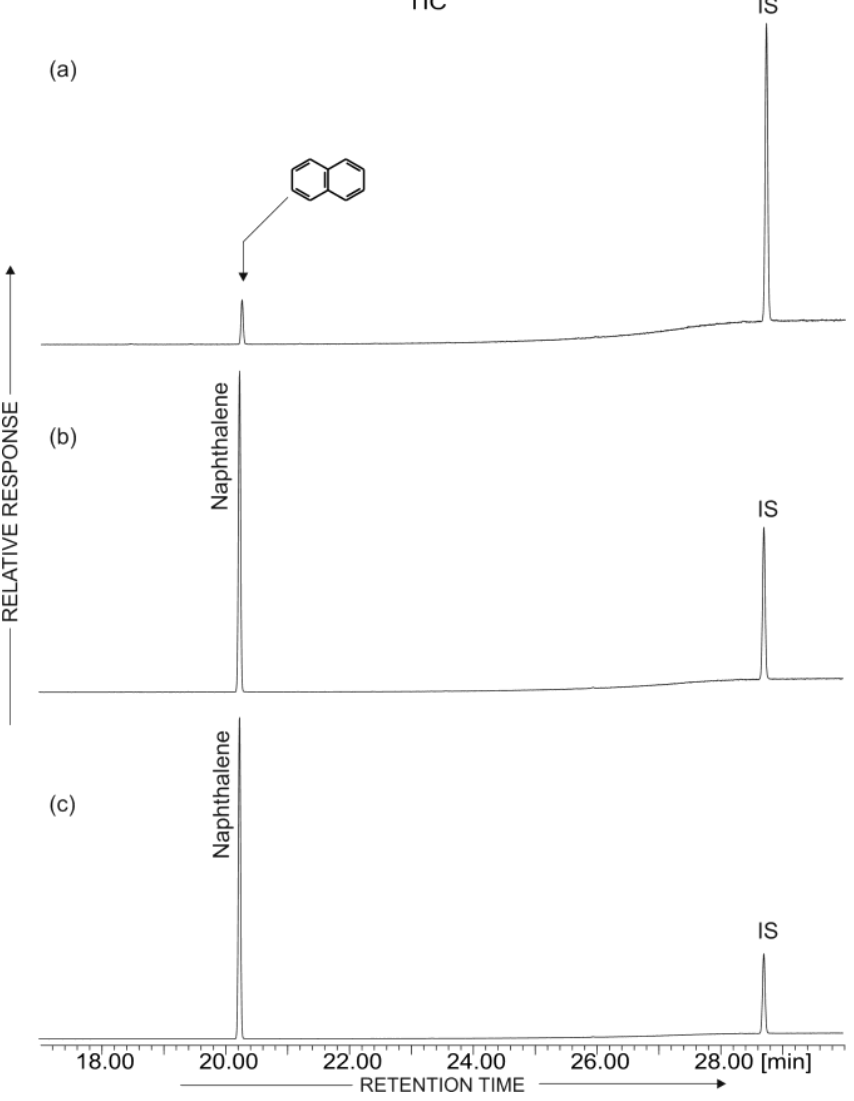

Figure 6.1: Total ion chromatograms (TIC) showing changes in decomposition $\left(250^{\circ} \mathrm{C}\right)$ by (a) one week, (b) two weeks and (c) three weeks (GC-MS analysis).
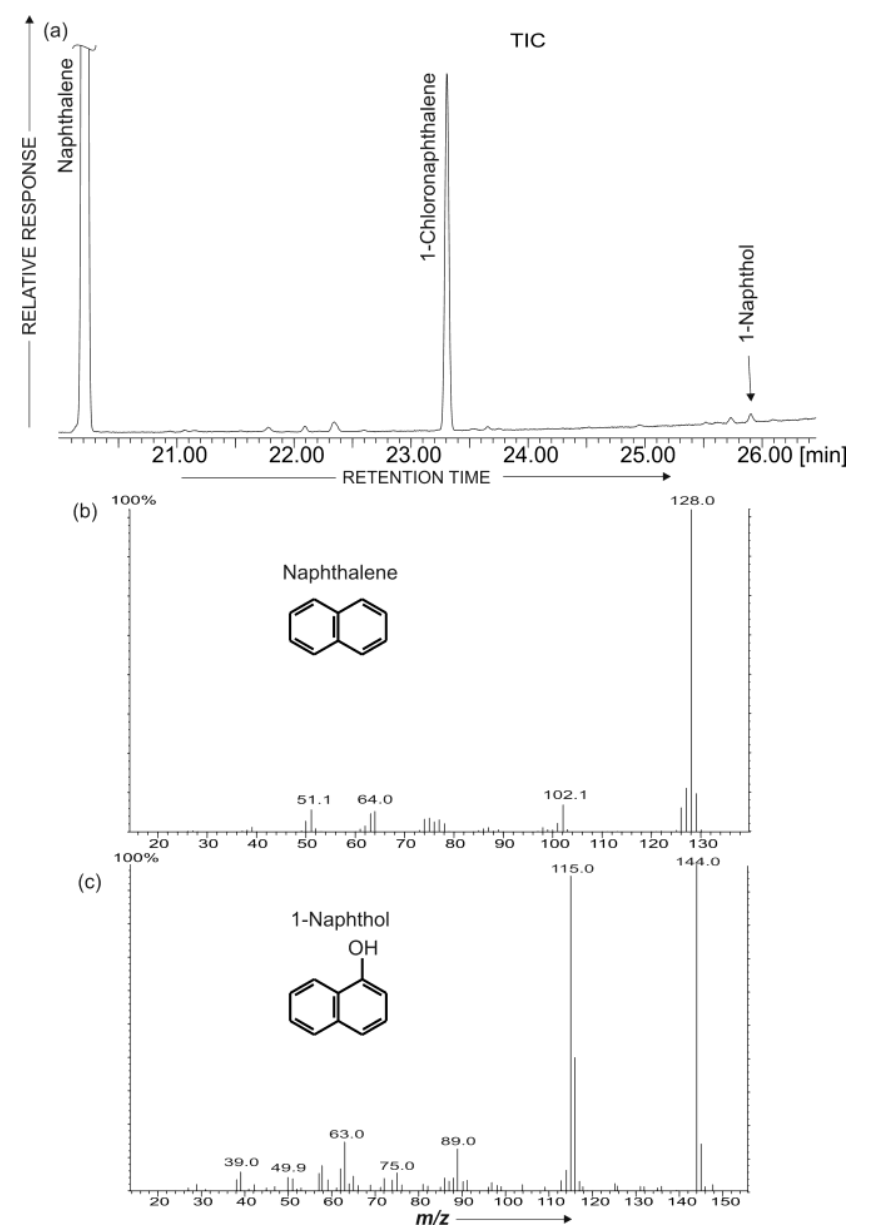

Figure 6.2: Total ion chromatogram (TIC) of (a) 1,5-NDS breakdown products at $300^{\circ} \mathrm{C}$ as well as mass spectra of (b) naphthalene and (c) 1-naphthol (GC-MS analysis). 


\subsection{Results}

\subsubsection{Set 1: 1,6-NDS decomposition}

The first set of the experiments comprised 1,6-NDS $\left(6.86 \times 10^{-4} \mathrm{~mol} \mathrm{~kg}^{-1}\right)$ dissolved in $\mathrm{NaCl}=0.050 \mathrm{~mol} \mathrm{~kg}{ }^{-1}$ aqueous solution at $\mathrm{pH}_{25^{\circ} \mathrm{C}}=7.0$. Products of 1,6-NDS thermal breakdown (at 200, 250, 270 and $300^{\circ} \mathrm{C}$ ) are presented in Figures 6.3 - 6.6 and listed in Table 6.1 and 6.2. The main products of 1,6-NDS disproportionation are 2-NSA and NAP. At lower temperatures (i.e. $\left.\leq 250^{\circ} \mathrm{C}\right)$ 2-NSA constitutes a major breakdown product, whereas at $\geq 270^{\circ} \mathrm{C}$, NAP becomes the main reaction product, especially after 21 days.

At $200^{\circ} \mathrm{C}, 1,6-\mathrm{NDS}$ undergoes slow thermal decomposition via several simultaneous pathways. The breakdown reactions lead to 2-NSA, 1-NSA, 1-NAP and 2-NAP formation. The main reaction results in 2-NSA formation $\left(2.71 \times 10^{-6} \mathrm{~mol} \mathrm{~kg}^{-1}\right.$ after 21 days $)$, the second most abundant decomposition product is 1 -NSA $\left(6.91 \times 10^{-7} \mathrm{~mol} \mathrm{~kg}^{-1}\right.$ after 21 days), and minor amounts of 2-NAP and 1-NAP. The concentrations of breakdown products increase over time (Figure 6.3, Table 6.2). Neither 2-NAP nor 1-NAP are detected by GC-MS analysis, probably due to their low concentrations (Table 6.1).

At $250^{\circ} \mathrm{C}$, similar to $200^{\circ} \mathrm{C}, 1,6-\mathrm{NDS}$ breakdown leads to a mixture of different products formed through parallel reactions (Figure 6.4; Table 6.2). The main reaction leads to 2-NSA formation (2.32 x 10-4 $\mathrm{mol} \mathrm{kg}^{-1}$ after 21 days), whereas side reactions produce NAP, 1 NSA, 1-NAP and 2-NAP. Additionally, GC-MS analysis confirms the presence of naphthalene (Table 6.1).

At $270^{\circ} \mathrm{C}, 1,6-\mathrm{NDS}$ disproportionates to 2-NSA, NAP, 1-NSA, 1-NAP and 2-NAP (Figure 6.5, Table 6.2). The 2-NSA and 1-NSA concentrations slowly increase until day 21, while NAP concentration increases significantly from day 7 until day 21. Simultaneously, a small increase of 1-NAP and 2-NAP is measured. This set (i.e. at $270^{\circ} \mathrm{C}$ ) was not analysed by GC-MS.

At $300^{\circ} \mathrm{C}$, after seven days, the rapid 1,6-NDS breakdown yields a mixture of NAP, 1-NSA, 2-NSA, 2-NAP and 1-NAP (Figure 6.6). However, only naphthalene concentration increases significantly over the 21 days, making NAP a major breakdown product of 1,6-NDS disproportionation (2.54 x $10^{-4} \mathrm{~mol} \mathrm{~kg}^{-1}$ after 21 days; Table 6.2). Side reaction give rise to 1-NSA, 2-NSA, 1-NAP and 2-NAP. The 1-NSA and 2-NSA concentration increases until day 14 and then (as noted previously in Chapter 2), decreases with further increase in 
reaction time. Similarly, the 1-NAP concentration increases after seven days and subsequently decreases towards the end of the experiment, while the 2-NAP consistently increases in concentration over the experimental duration. Note that at day 21 the total sum of all detected breakdown products does not make up the expected total concentration of 1,6-NDS breakdown products (i.e. it was assumed that 1 mol of 1,6-NDS will result in 1 mol of breakdown products). Qualitative GC-MS results confirm the formation of naphthalene and 1-NAP, whereas 2-NAP is not detected. However, the presence of 1-chloronaphthalene was confirmed (Table 6.1).

Table 6.1: GC-MS analysis for the presence of NAP, 1-NAP, 2-NAP and 1chloronaphthtalene in experimental solutions after reacting 1,6-NDS at 200, 250 and $300^{\circ} \mathrm{C}$.

\begin{tabular}{ccccc}
\hline & & & \multicolumn{3}{c}{ temperature $/{ }^{\circ} \mathrm{C}$} \\
\cline { 3 - 4 } & compound & 200 & 250 & 300 \\
\hline Set 1 & naphthalene (NAP) & n.d. & $\checkmark$ & $\checkmark$ \\
$(1,6-\mathrm{NDS})$ & & n.d. & n.d. & $\checkmark$ \\
& 2-naphthol (2-NAP) & n.d. & n.d. & n.d. \\
& 1-chloronaphthalene & n.d. & n.d. & $\checkmark$ \\
\hline
\end{tabular}




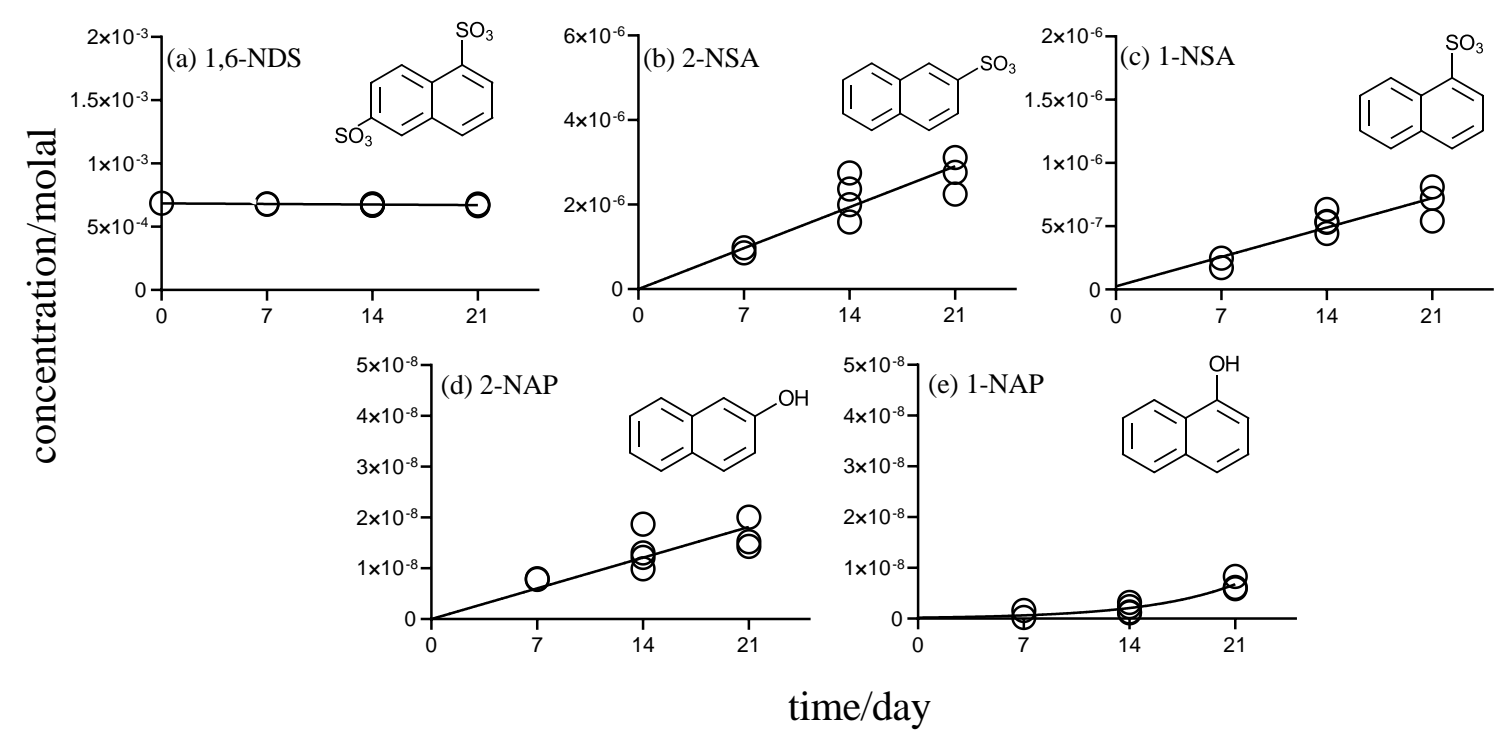

Figure 6.3: Concentrations $\left(\mathrm{mol} \mathrm{kg}^{-1}\right)$ of the 1,6-NDS isomer and its decay products 1-NSA, 2-NSA, 1-NAP and 2-NAP after heating at $200^{\circ} \mathrm{C}, \mathrm{pH}_{\mathrm{t}}=5.6$ and saturated vapour pressure for 7, 14 and 21 days, $\mathrm{NaCl}=0.050 \mathrm{~mol} \mathrm{~kg}^{-1}$ (HPLC analysis).

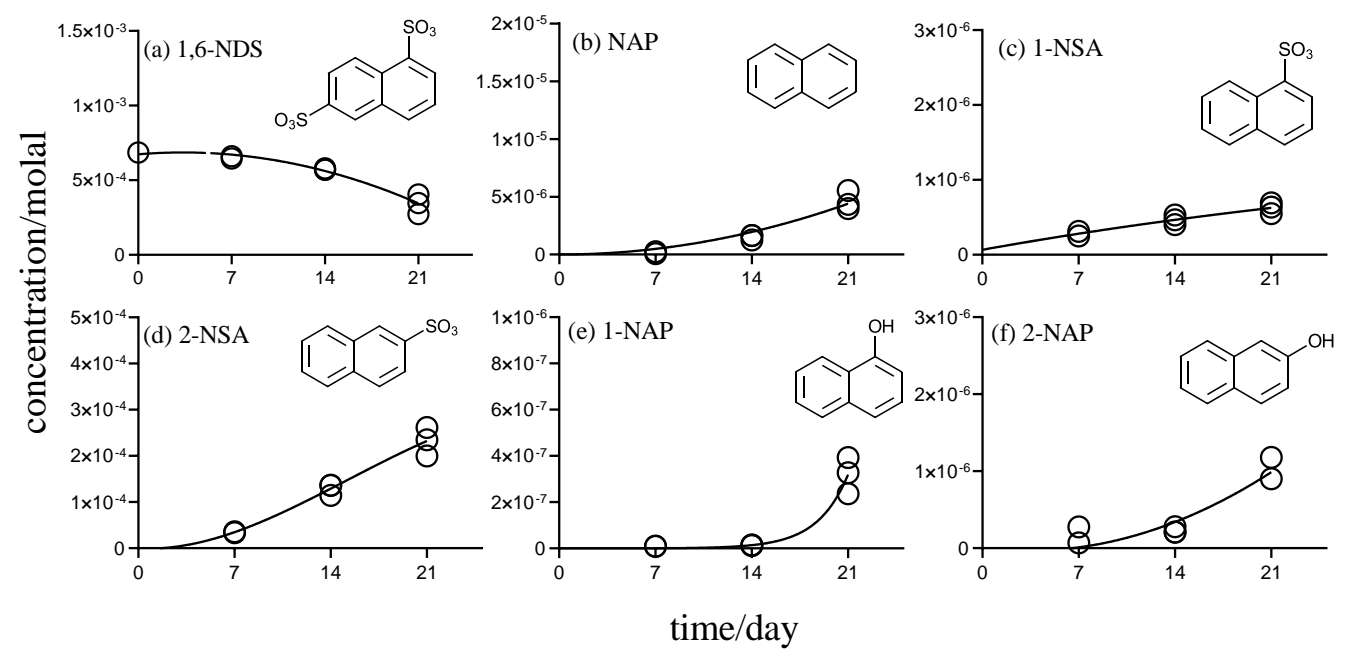

Figure 6.4: Concentrations $\left(\mathrm{mol} \mathrm{kg}^{-1}\right.$ ) of the 1,6-NDS isomer and its decay products NAP, 1-NSA, 2-NSA, 1-NAP and 2-NAP after heating at $250^{\circ} \mathrm{C}, \mathrm{pH}_{\mathrm{t}}=5.6$ and saturated vapour pressure for 7, 14 and 21 days, $\mathrm{NaCl}=0.050 \mathrm{~mol} \mathrm{~kg}^{-1}$ (HPLC analysis). 

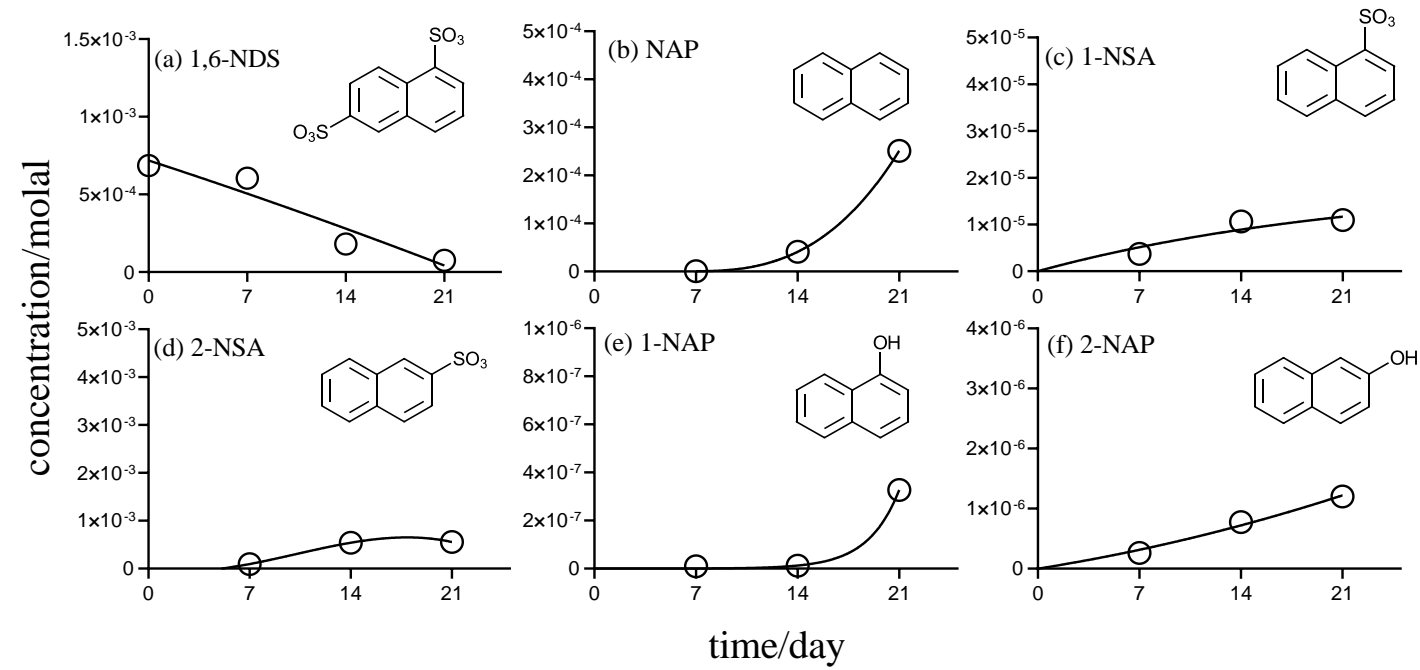

Figure 6.5: Concentrations ( $\mathrm{mol} \mathrm{kg} \mathrm{kg}^{-1}$ ) of the 1,6-NDS isomer and its decay products NAP, 1-NSA, 2-NSA, 1-NAP and 2-NAP after heating at $270^{\circ} \mathrm{C}, \mathrm{pH}_{\mathrm{t}}=5.6$ and saturated vapour pressure for 7, 14 and 21 days, $\mathrm{NaCl}=0.050 \mathrm{~mol} \mathrm{~kg}^{-1}$ (HPLC analysis).

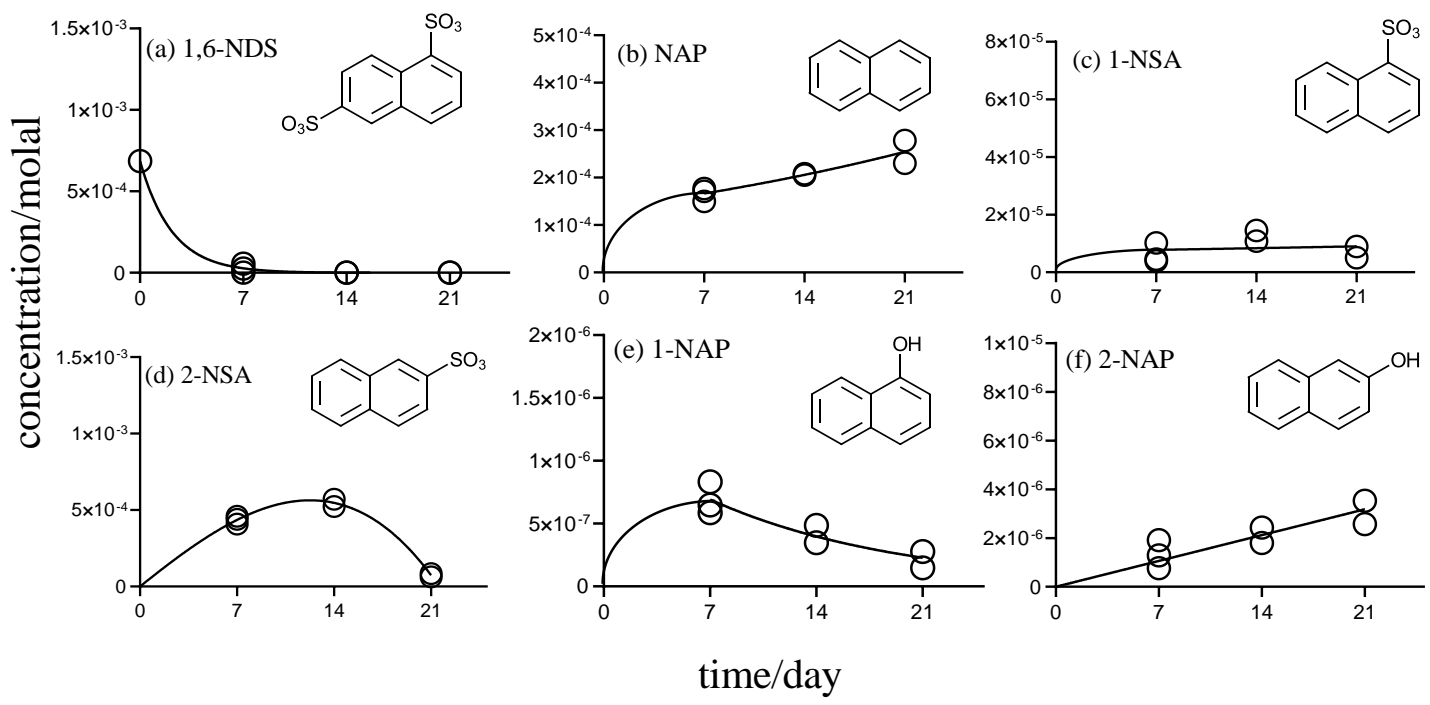

Figure 6.6: Concentrations ( $\mathrm{mol} \mathrm{kg} \mathrm{kg}^{-1}$ ) of the 1,6-NDS isomer and its decay products NAP, 1-NSA, 2-NSA, 1-NAP and 2-NAP after heating at $300^{\circ} \mathrm{C}, \mathrm{pH}_{\mathrm{t}}=5.7$ and saturated vapour pressure for 7, 14 and 21 days, $\mathrm{NaCl}=0.050 \mathrm{~mol} \mathrm{~kg}^{-1}$ (HPLC analysis). 
Table 6.2: Average concentration $\left(\mathrm{mol} \mathrm{kg}^{-1}\right)$ of the 1,6-NDS and its decay products from HPLC analysis for $200,250,270$ and $300^{\circ} \mathrm{C}$.

\begin{tabular}{|c|c|c|c|c|}
\hline temperature & compound & initial concentration & time: 7 days & time: 14 days \\
\hline \multirow{6}{*}{$200^{\circ} \mathrm{C}$} & 1,6-NDS & $6.86 \times 10^{-4}$ & $6.79 \times 10^{-4}$ & $6.74 \times 10^{-4}$ \\
\hline & $1-N S A$ & - & $2.11 \times 10^{-7}$ & $5.36 \times 10^{-7}$ \\
\hline & 2-NSA & - & $9.16 \times 10^{-7}$ & $2.17 \times 10^{-6}$ \\
\hline & 1-NAP & - & $9.15 \times 10^{-10}$ & $2.00 \times 10^{-9}$ \\
\hline & 2-NAP & - & $7.88 \times 10^{-9}$ & $1.34 \times 10^{-8}$ \\
\hline & NAP & - & n.d. & n.d. \\
\hline \multirow{6}{*}{$250^{\circ} \mathrm{C}$} & 1,6-NDS & $6.86 \times 10^{-4}$ & $6.54 \times 10^{-4}$ & $5.74 \times 10^{-4}$ \\
\hline & 1-NSA & - & $2.81 \times 10^{-7}$ & $4.66 \times 10^{-7}$ \\
\hline & 2-NSA & - & $3.47 \times 10^{-5}$ & $1.29 \times 10^{-4}$ \\
\hline & 1-NAP & - & $9.13 \times 10^{-9}$ & $1.34 \times 10^{-8}$ \\
\hline & 2-NAP & - & $1.73 \times 10^{-7}$ & $2.31 \times 10^{-7}$ \\
\hline & NAP & - & $1.56 \times 10^{-7}$ & $1.51 \times 10^{-6}$ \\
\hline \multirow{6}{*}{$270^{\circ} \mathrm{C}$} & 1,6-NDS & $6.86 \times 10^{-4}$ & $6.04 \times 10^{-4}$ & $1.81 \times 10^{-4}$ \\
\hline & $1-\mathrm{NSA}$ & - & $3.70 \times 10^{-6}$ & $1.07 \times 10^{-5}$ \\
\hline & 2-NSA & - & $9.47 \times 10^{-5}$ & $5.40 \times 10^{-4}$ \\
\hline & 1-NAP & - & $9.23 \times 10^{-9}$ & $1.20 \times 10^{-8}$ \\
\hline & 2-NAP & - & $2.61 \times 10^{-7}$ & $7.84 \times 10^{-7}$ \\
\hline & NAP & - & $7.66 \times 10^{-7}$ & $4.09 \times 10^{-5}$ \\
\hline \multirow{6}{*}{$300^{\circ} \mathrm{C}$} & 1,6-NDS & $6.86 \times 10^{-4}$ & $2.71 \times 10^{-5}$ & $3.49 \times 10^{-8}$ \\
\hline & 1-NSA & - & $6.23 \times 10^{-6}$ & $1.27 \times 10^{-5}$ \\
\hline & 2-NSA & - & $4.45 \times 10^{-4}$ & $5.47 \times 10^{-4}$ \\
\hline & 1-NAP & - & $3.37 \times 10^{-9}$ & $1.02 \times 10^{-7}$ \\
\hline & 2-NAP & - & $1.32 \times 10^{-6}$ & $2.12 \times 10^{-6}$ \\
\hline & NAP & - & $1.66 \times 10^{-4}$ & $2.07 \times 10^{-4}$ \\
\hline
\end{tabular}

detection limits: $1.40 \times 10^{-10} \mathrm{~mol} \mathrm{~kg}^{-1}$ for the NDS, $1.93 \times 10^{-9} \mathrm{~mol} \mathrm{~kg}^{-1}$ for NSA, $3.61 \times 10^{-9} \mathrm{~mol} \mathrm{~kg}^{-1}$ for $1-\mathrm{NAP}, 3.40 \mathrm{x}$ $10^{-9} \mathrm{~mol} \mathrm{~kg}^{-1}$ for $2-\mathrm{NAP}, 3.12 \times 10^{-9} \mathrm{~mol} \mathrm{~kg}^{-1}$ for $2-\mathrm{NAP}$, n.d. = below detection limit 


\subsubsection{Set 2: 1,5-NDS decomposition}

The second set of the experiments comprised 1,5-NDS $\left(6.94 \times 10^{-4} \mathrm{~mol} \mathrm{~kg}^{-1}\right)$ dissolved in $\mathrm{NaCl}=0.050 \mathrm{~mol} \mathrm{~kg}^{-1}$ aqueous solution at $\mathrm{pH}_{25^{\circ} \mathrm{C}}=7.0$. Products of $1,5-\mathrm{NDS}$ thermal breakdown (at 200,250 and $300^{\circ} \mathrm{C}$ ) are presented in Figures $6.7-6.9$. and listed in Table 6.3 and 6.4. Experimental results show that 1,5-NDS disproportionates mainly into 1-NSA and NAP and the ratio and diversity of concentrations of the resulting breakdown products are temperature dependent. Note that 2-NSA is not detected in any of the experiments where only 1,5-NDS was present in the initial solution.

At $200^{\circ} \mathrm{C}, 1,5-\mathrm{NDS}$ undergoes thermal decomposition which leads to 1-NSA, NAP, 1-NAP and 2-NAP formation (Figure 6.7). The main reaction results in 1-NSA formation (6.07 x $10^{-5} \mathrm{~mol} \mathrm{~kg}^{-1}$ after 21 days; Table 6.4), accompanied by 1-NAP formation and minor amounts of NAP and 2-NAP. Concentrations of all detected compounds increases from day 7 to day 21. Only naphthalene is detected with GC-MS at this temperature (Table 6.3).

At $250^{\circ} \mathrm{C}, 1,5$-NDS disproportionates mainly to 1-NSA and NAP (Figure 6.8) and the amounts of these two breakdown products changes over time (Table 6.4). After seven days 1-NSA constitutes the main breakdown product $\left(2.34 \times 10^{-4} \mathrm{~mol} \mathrm{~kg}^{-1}\right)$ and only minor quantities of NAP are measured $\left(2.12 \times 10^{-5} \mathrm{~mol} \mathrm{~kg}^{-1}\right)$, whereas after 21 days NAP concentration increases to $2.40 \times 10^{-4} \mathrm{~mol} \mathrm{~kg}^{-1}$ while 1 -NSA increase is minor $\left(3.16 \times 10^{-4} \mathrm{~m}\right)$. Additionally, small quantities of 1-NAP are measured (7.14 x $10^{-7} \mathrm{~mol} \mathrm{~kg}^{-1}$ after 21 days). The GC-MS analyses of the reacted solutions confirms the presence of naphthalene, 1-napthol and 1-chloronaphthalene at $250^{\circ} \mathrm{C}$ (Table 6.3).

At $300^{\circ} \mathrm{C}, 1,5-\mathrm{NDS}$ decays into NAP and small amounts of 1-NAP and 2-NAP (Figure 6.9). NAP and 1-NAP concentrations increase significantly at day 7 and then slightly increase to the end of the experiment $\left(\mathrm{NAP}=2.14 \times 10^{-4} \mathrm{~mol} \mathrm{~kg}^{-1} ; 1-\mathrm{NAP}=3.3 \times 10^{-4} \mathrm{~mol} \mathrm{~kg}^{-1}\right)$, whereas 2-NAP concentration increases until day 14 and then decreases. Note that total concentration of 1,5-NDS breakdown products did not constitute the expected amount of breakdown products (i.e. it was assumed that $1 \mathrm{~mol}$ of 1,5-NDS will result in $1 \mathrm{~mol}$ of breakdown products), which means that not all breakdown products were detected (Table 6.4). However, the limiting solubility of NAP could explain the NAP concentration being lower than anticipated. The measured NAP concentration stabilised at $\approx 2.16 \times 10^{-4} \mathrm{~mol} \mathrm{~kg}^{-1}$ after seven days. Schwarz (1977) measured solubility of naphthalene in water at $23.2^{\circ} \mathrm{C}$ to be $2.22 \times 10^{-4} \mathrm{~mol} \mathrm{~kg}^{-1}$. At $300^{\circ} \mathrm{C}$, the solubility of NAP is greater than that at $25^{\circ} \mathrm{C}$. However, upon cooling, NAP could 
have deposited on the walls of the quartz glass ampoules and/or partitioned into the vapour space. The GC-MS analyses confirm the presence of naphthalene, 1-naphthol and 1-chloronaphthalene (Table 6.3).

Table 6.3: GC-MS analysis for the presence of NAP, 1-NAP, 2-NAP and 1chloronaphthtalene in experimental solutions after reacting 1,5-NDS at 200, 250 and $300^{\circ} \mathrm{C}$.

\begin{tabular}{ccccc}
\hline & & \multicolumn{3}{c}{ temperature $/{ }^{\circ} \mathrm{C}$} \\
\cline { 3 - 5 } & compound & 200 & 250 & 300 \\
\hline \multirow{2}{*}{ Set 2} & naphthalene (NAP) & $\checkmark$ & $\checkmark$ & $\checkmark$ \\
$(1,5$-NDS) & 1-naphthol (1-NAP) & n.d. & $\checkmark$ & $\checkmark$ \\
& 2-naphthol (2-NAP) & n.d. & n.d. & n.d. \\
& 1-chloronaphthalene & n.d. & $\checkmark$ & $\checkmark$ \\
\hline
\end{tabular}

n.d. $=$ not detected

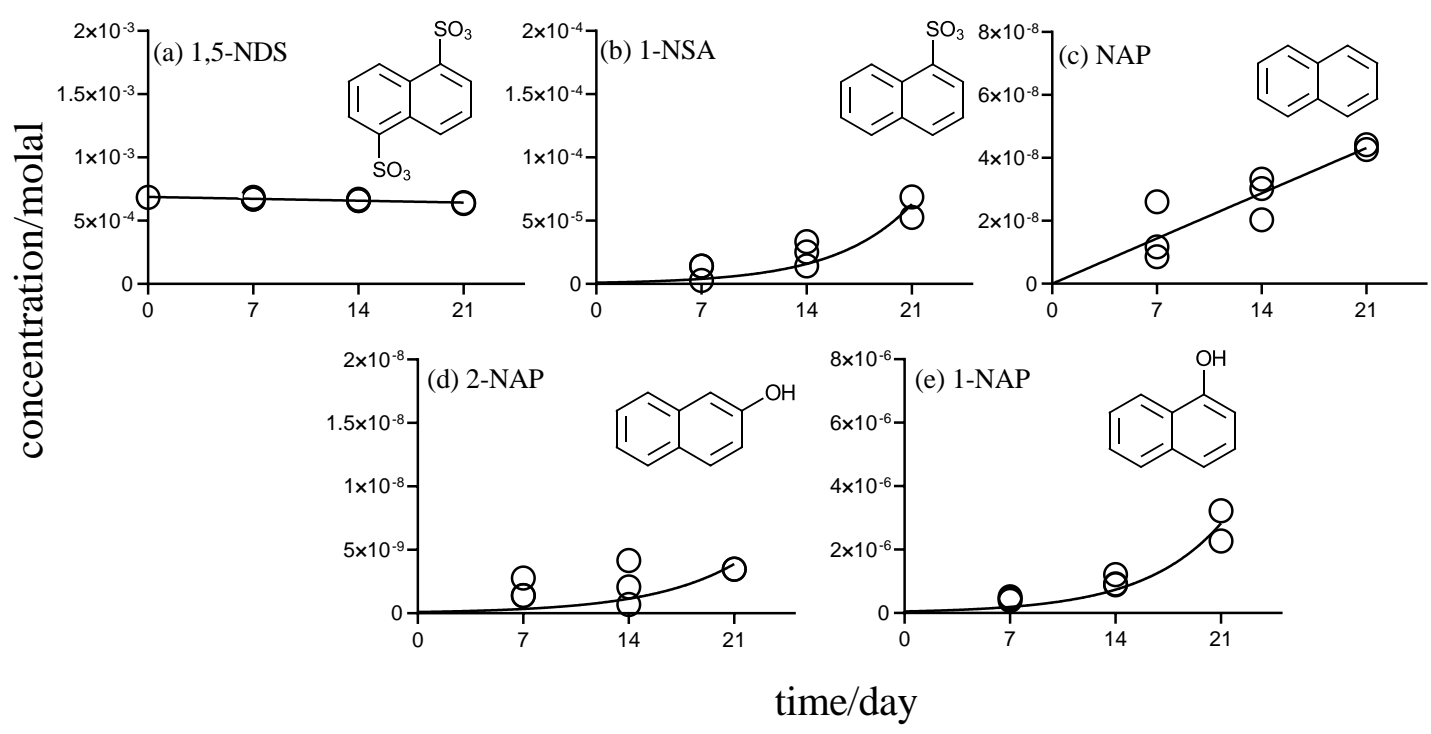

Figure 6.7: Concentrations $\left(\mathrm{mol} \mathrm{kg}^{-1}\right)$ of the 1,5-NDS isomer and its decay products 1-NSA, 1-NAP and 2-NAP after heating at $200^{\circ} \mathrm{C}, \mathrm{pH}_{\mathrm{t}}=5.6$ and saturated vapour pressure for 7,14 and 21 days, $\mathrm{NaCl}=0.050 \mathrm{~mol} \mathrm{~kg}^{-1}$ (HPLC analysis). 


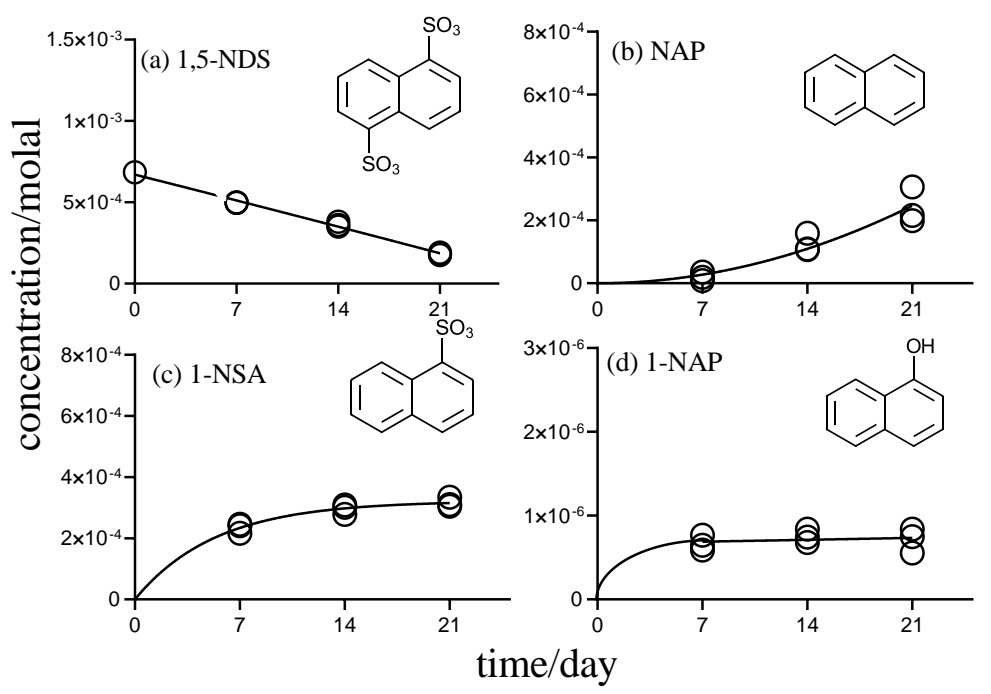

Figure 6.8: Concentrations $\left(\mathrm{mol} \mathrm{kg}^{-1}\right)$ of the 1,5-NDS isomer and its decay products NAP, 1-NSA and 1-NAP after heating at $250^{\circ} \mathrm{C}, \mathrm{pH}_{\mathrm{t}}=5.6$ and saturated vapour pressure for 7,14 and 21 days, $\mathrm{NaCl}=0.050 \mathrm{~mol} \mathrm{~kg}^{-1}$ (HPLC analysis).

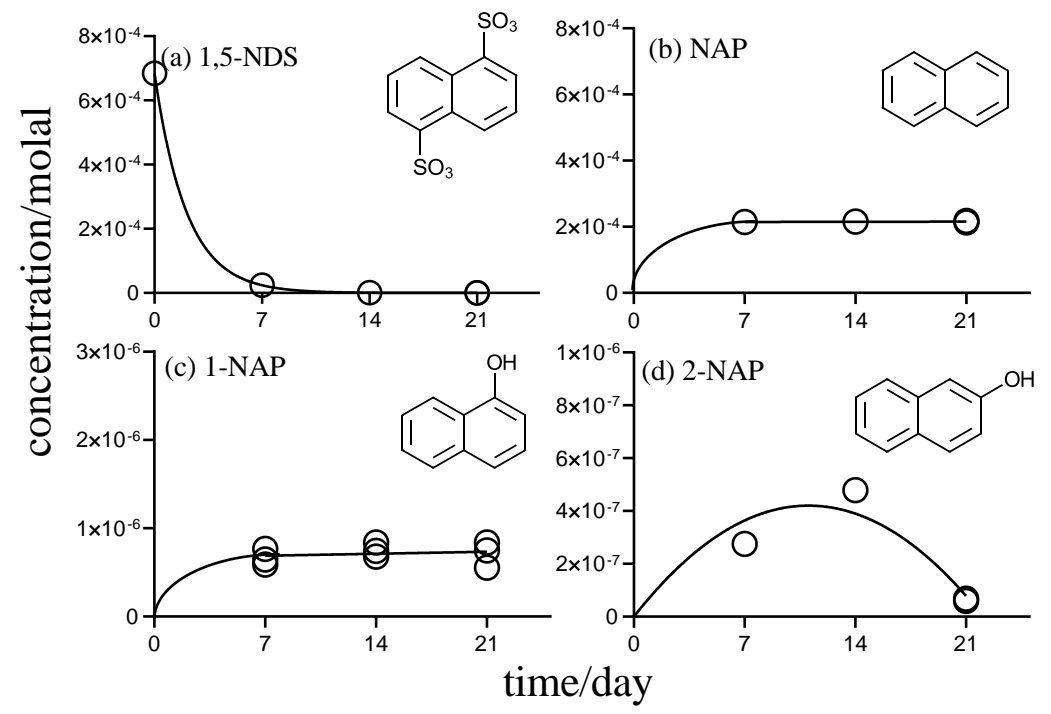

Figure 6.9: Concentrations $\left(\mathrm{mol} \mathrm{kg}^{-1}\right)$ of the 1,5-NDS isomer and its decay products NAP, 1-NAP and 2-NAP after heating at $300^{\circ} \mathrm{C}, \mathrm{pH}_{\mathrm{t}}=5.6$ and saturated vapour pressure for 7, 14 and 21 days, $\mathrm{NaCl}=0.050 \mathrm{~mol} \mathrm{~kg}^{-1}$ (HPLC analysis). 
Table 6.4: Average concentration $\left(\mathrm{mol} \mathrm{kg}^{-1}\right)$ of the 1,5-NDS and its decay products from HPLC analysis for 200,250 and $300^{\circ} \mathrm{C}$.

\begin{tabular}{|c|c|c|c|c|}
\hline temperature & compound & initial concentration & time: 7 days & time: 14 days \\
\hline \multirow{6}{*}{$200^{\circ} \mathrm{C}$} & 1,5-NDS & $6.84 \times 10^{-4}$ & $6.76 \times 10^{-4}$ & $6.62 \times 10^{-4}$ \\
\hline & 1-NSA & - & $1.03 \times 10^{-5}$ & $2.43 \times 10^{-5}$ \\
\hline & 2-NSA & - & n.d. & n.d. \\
\hline & 1-NAP & - & $4.57 \times 10^{-7}$ & $1.01 \times 10^{-6}$ \\
\hline & 2-NAP & - & $1.85 \times 10^{-9}$ & $2.31 \times 10^{-9}$ \\
\hline & NAP & - & $1.54 \times 10^{-8}$ & $2.79 \times 10^{-8}$ \\
\hline \multirow{6}{*}{$250^{\circ} \mathrm{C}$} & $1,5-\mathrm{NDS}$ & $6.84 \times 10^{-4}$ & $4.98 \times 10^{-4}$ & $3.64 \times 10^{-4}$ \\
\hline & $1-\mathrm{NSA}$ & - & $2.34 \times 10^{-4}$ & $2.96 \times 10^{-4}$ \\
\hline & 2-NSA & - & n.d. & n.d. \\
\hline & $1-\mathrm{NAP}$ & - & $6.67 \times 10^{-7}$ & $7.54 \times 10^{-7}$ \\
\hline & 2-NAP & - & n.d. & n.d. \\
\hline & NAP & - & $2.12 \times 10^{-5}$ & $1.25 \times 10^{-4}$ \\
\hline \multirow{6}{*}{$300^{\circ} \mathrm{C}$} & 1,5-NDS & $6.84 \times 10^{-4}$ & $2.42 \times 10^{-5}$ & $8.55 \times 10^{-7}$ \\
\hline & $1-\mathrm{NSA}$ & - & n.d. & n.d. \\
\hline & 2-NSA & - & n.d. & n.d. \\
\hline & 1-NAP & - & $3.31 \times 10^{-6}$ & $3.91 \times 10^{-6}$ \\
\hline & 2-NAP & - & $2.75 \times 10^{-7}$ & $4.79 \times 10^{-7}$ \\
\hline & NAP & - & $2.14 \times 10^{-4}$ & $2.16 \times 10^{-4}$ \\
\hline
\end{tabular}

\subsection{Discussion and conclusions}

\subsubsection{Set 1: 1,6-NDS decomposition}

At $200^{\circ} \mathrm{C}$, 1,6-NDS undergoes thermal decomposition and forms four breakdown products through parallel reactions (i.e. 2-NSA, 1-NSA, 1-NAP and 2-NAP). The main reaction results in 2-NSA and 1-NSA formation (Table 6.2; Figure 6.3 and 6.10). 


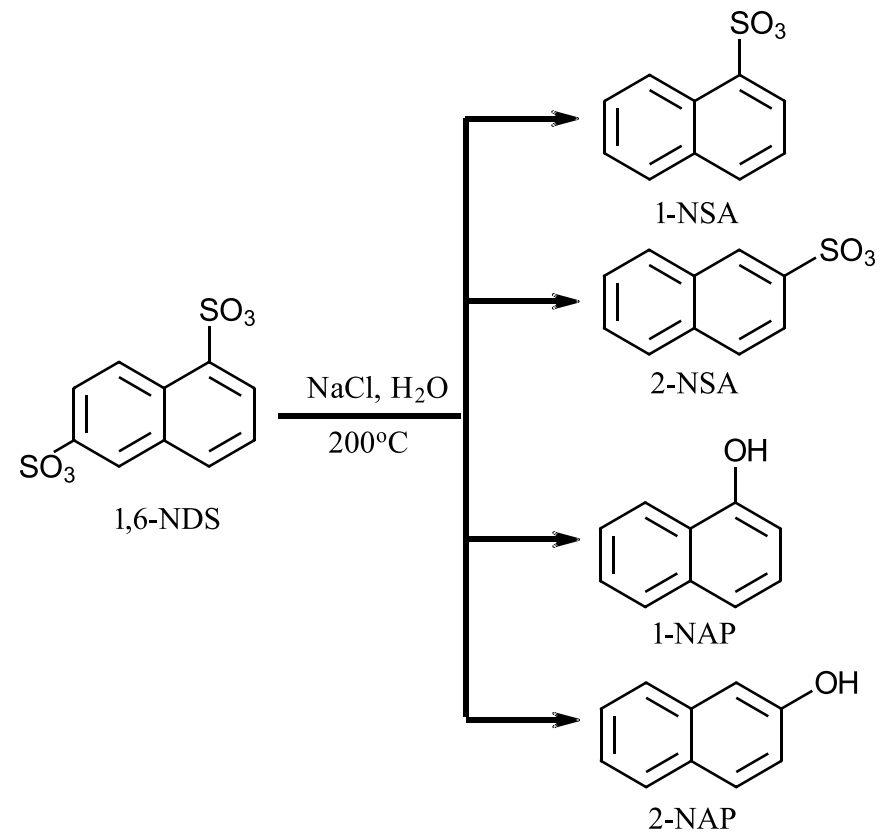

Figure 6.10: Structure of possible products of 1,6-NDS decomposition and representation of reaction pathways at $200^{\circ} \mathrm{C}$ in aqueous solution $(\mathrm{NaCl}=0.050 \mathrm{~m})$.

At $250^{\circ} \mathrm{C}$, five products are formed (i.e. 2-NSA, 1-NSA, NAP, 2-NAP and 1-NAP). Similarly, as at $200^{\circ} \mathrm{C}$, the main breakdown product is 2-NSA. However, significantly greater quantities of 2-NSA in comparison to 1-NSA are formed (Figure 6.4).

At $200^{\circ} \mathrm{C}$, among others compounds, 1-NAP and 2-NAP are also detected, while at $250^{\circ} \mathrm{C}, 2-\mathrm{NAP}$ is not detected. Note that, the concentrations of 1-NAP and 2-NAP remained minor, in comparison to other formed breakdown products (i.e. 2-NSA and 1-NSA; Figure 6.3 and 6.4).

At $\geq 270^{\circ} \mathrm{C} 1,6-\mathrm{NDS}$ breakdown yields a mixture of NAP, 2-NSA, 1-NSA, 2-NAP and 1-NAP (Figure 6.5 and 6.11). However, only naphthalene concentration increases significantly over 21 days, making NAP the major breakdown product of the 1,6-NDS disproportionation at $\geq 270^{\circ} \mathrm{C}$. Naphthalene has been previously reported to be present at $450^{\circ} \mathrm{C}$ in aqueous-pyrolysis experiments (Price, 1993) and it is possible that naphthalene can be preserved at high temperatures and transported with a geothermal fluid through a geothermal reservoir. Naphthalene is a refractory compound which has been detected in volcanic gases (Schwandner et al. 2013). 
At this temperature $\left(270^{\circ} \mathrm{C}\right)$, side reactions of 1,6-NDS decay form 2-NSA, 1-NSA, 1NAP and 2-NAP. At $\geq 270^{\circ} \mathrm{C}, 1-\mathrm{NSA}$ and 2-NSA appear as intermediate breakdown products both of which eventually breakdown to NAP (Figure 6.11). At the same temperature, 1-NAP forms and is stable for at least 21 days, while at $300^{\circ} \mathrm{C}, 1-\mathrm{NAP}$ is present as a transient breakdown product of 1,6-NDS disproportionation (Figure 6.6), whereas, 2-NAP consistently increases in concentration over the experimental duration at 270 and $300^{\circ} \mathrm{C}$.

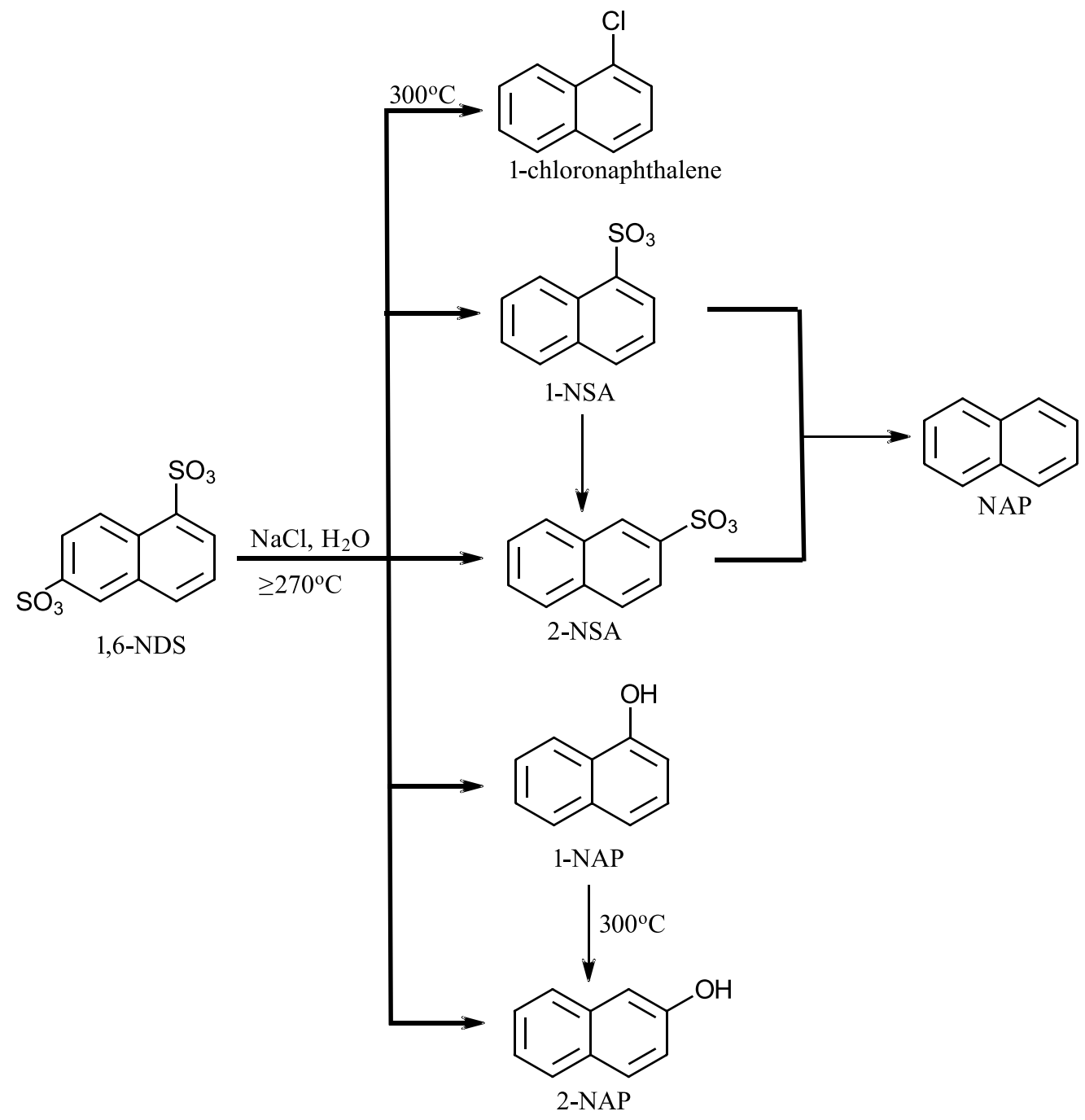

Figure 6.11: Structures of possible products of 1,6-NDS decomposition and representation of reaction pathways at $\geq 270^{\circ} \mathrm{C}$ in an aqueous solution $(\mathrm{NaCl}=0.050 \mathrm{~m})$.

\subsubsection{Set 2: 1,5-NDS decomposition}

At $200^{\circ} \mathrm{C}, 1,5-\mathrm{NDS}$ decomposition leads to formation of 1-NSA, 1-NAP, NAP and 2-NAP with the main breakdown product being 1-NSA (Table 6.4; Figure 6.7 and 6.12). At 
$250^{\circ} \mathrm{C}, 1,5-\mathrm{NDS}$ simultaneously disproportionates into 1-NSA and NAP, and the 1-NSA formed undergoes furthers disproportionation to NAP (Figure 6.13). At $\geq 250^{\circ} \mathrm{C}$, 1-chloronaphthalene is also detected with GC-MS together with NAP and 1-NAP (Table 6.3). At $300^{\circ} \mathrm{C}$, the decay of 1-NSA to NAP takes place (Figure 6.9 and 6.14).

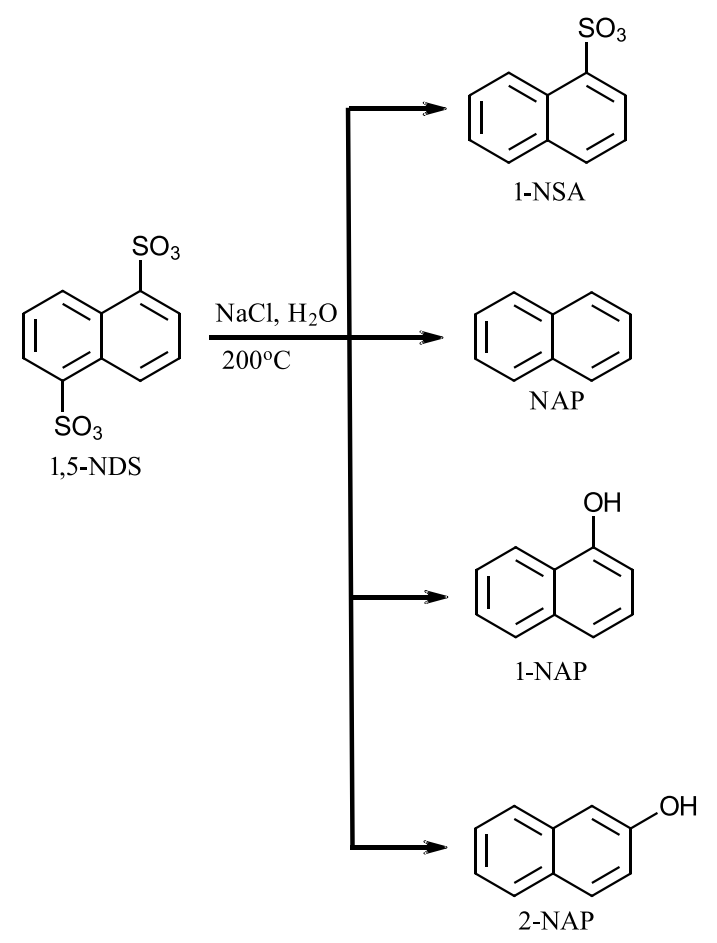

Figure 6.12: Structure of possible products of 1,5-NDS decomposition and representation of reaction pathways at $200^{\circ} \mathrm{C}$ in aqueous solution $\left(\mathrm{NaCl}=0.050 \mathrm{~mol} \mathrm{~kg}^{-1}\right)$.

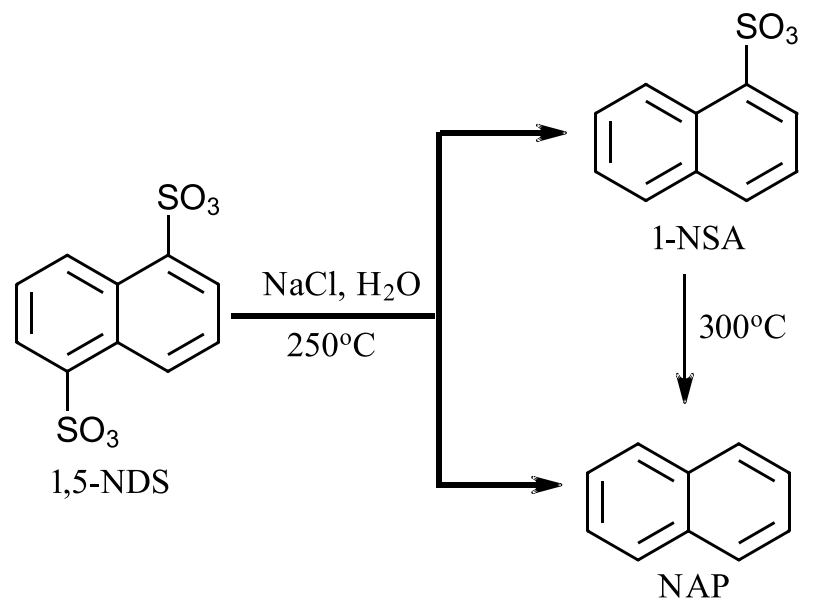

Figure 6.13: Structure of major products of 1,5-NDS decomposition and representation of reaction pathways at $\geq 250^{\circ} \mathrm{C}$ in aqueous solution $\left(\mathrm{NaCl}=0.050 \mathrm{~mol} \mathrm{~kg}^{-1}\right)$. 


\subsubsection{1-NSA and 2-NSA}

2-NSA constitutes the main breakdown product of 1,6-NDS decomposition, while 1,5-NDS leads to 1 -NSA at $200^{\circ} \mathrm{C}$. A process of replacement of $\mathrm{SO}_{3}{ }^{-}$by $\mathrm{H}^{+}$on $\mathrm{C}_{1}$-carbon is favourable because a bulky $\mathrm{SO}_{3}{ }^{-}$group in this position (at $\mathrm{C}_{1}$ ) experiences steric hindrance from a neighbouring hydrogen attached to carbon $\mathrm{C}_{8}$ (Figure 6.14). Proposed mechanisms for 1,6-NDS disproportionation to 2-NSA and 1,5-NDS disproportionation into 1-NSA are presented in the Figure 6.17. The generated 1-NSA and 2-NSA are stable at $200^{\circ} \mathrm{C}$, however, at higher temperatures, 1-NSA and 2-NSA eventually decay into naphthalene (Figure 6.15).

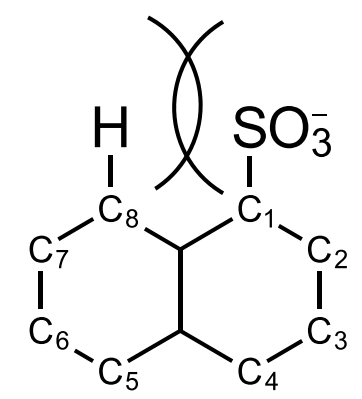

Figure 6.14: The steric hindrance in 1,5-NDS.

(a)

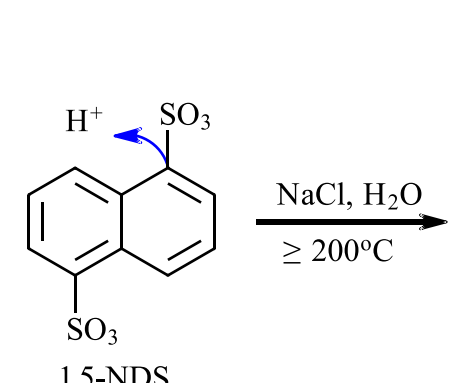

$1,5-\mathrm{NDS}$<smiles>OC1OC2CCCC1O2</smiles><smiles>CC(S)c1cccc2c(S(=O)(=O)O)cccc12</smiles>

(resonance-delocalised)

1-NSA

(b)

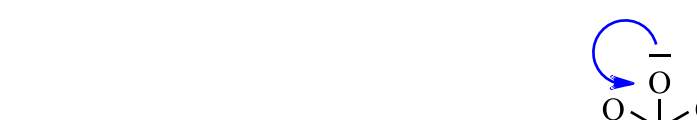<smiles></smiles>

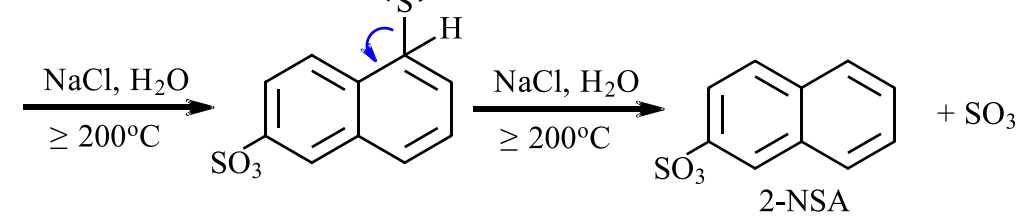

(resonance-delocalised)

Figure 6.15: Proposed breakdown reaction mechanism for (a) 1,5-NDS and (b) 1,6-NDS thermal decomposition at $\geq 200^{\circ} \mathrm{C}$ in aqueous solution $\left(\mathrm{NaCl}=0.050 \mathrm{~mol} \mathrm{~kg}^{-1}\right)$. 


\subsubsection{Naphthalene: the most stable breakdown product}

Naphthalene forms in all of the experiments with temperatures from $>200$ to $300^{\circ} \mathrm{C}$ and appears to be the most stable, final breakdown product of 1,6-NDS and 1,5-NDS thermal decomposition. It is possible that at $\mathrm{t} \geq 300^{\circ} \mathrm{C}$, naphthalene disulfonates disproportionate into naphthalene through sequential reactions, rather than through a direct process. For example, in the first step 1,6-NDS will disproportionate into 2-NSA (intermediate stage), and in the second step 2-NSA will form naphthalene as the final product (Figure 6.16).

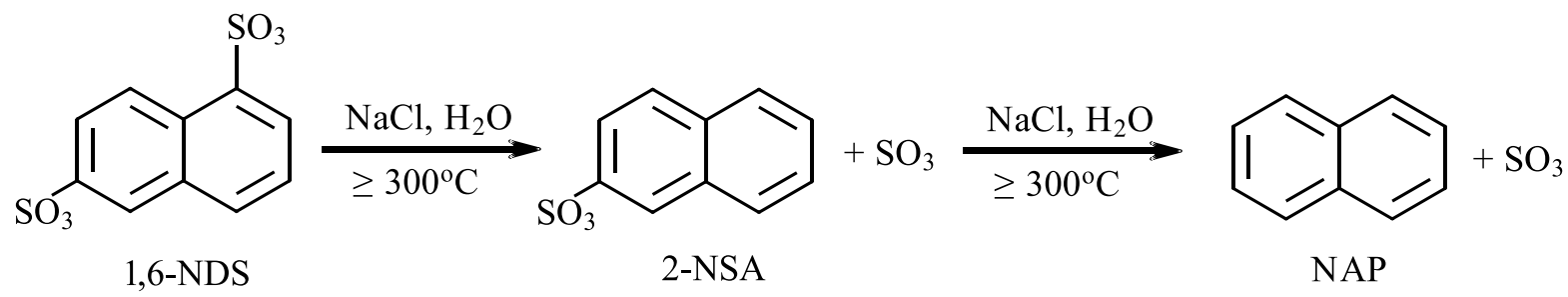

Figure 6.16: Proposed breakdown reaction mechanism for 1,6-NDS thermal decomposition at $\geq 300^{\circ} \mathrm{C}$ in aqueous solution $\left(\mathrm{NaCl}=0.050 \mathrm{~mol} \mathrm{~kg}^{-1}\right) ; 2$-NSA is a transient intermediate.

\subsubsection{1-NAP and 2-NAP}

The process of formation 1-napthol or 2-napthol is known from industrial processes by alkali fusion of sodium naphthalene sulfonate at $270-318^{\circ} \mathrm{C}$ and can be reversed by the action of concentrated sulfuric acid (Fierz-David \& Blangey, 1949). In our experiments 1-NAP and 2-NAP form in small quantities as side reactions from 1,6-NDS and 1,5-NDS decomposition over the duration of the experiments and thus have potential to be used as permeability tracers.

\subsubsection{1-Chloronaphthalene}

GC-MS analysis confirms presence of 1-chloronaphthalene (Figure 6.2), as one of breakdown products of $1,6-\mathrm{NDS}$ decomposition (at $300^{\circ} \mathrm{C}$ ) and for $1,5-\mathrm{NDS}$ (at $\geq 250^{\circ} \mathrm{C}$ ). 1-chloronapthalene is detected only in samples where appreciable amounts of naphthalene are also present (Table 6.1 and 6.3). At this stage, the mechanism of formation of 1-chloronaphthalene is unclear, however, it is apparently formed through nucleophilic substitution of a hydrogen in naphthalene by chloride $\left(\mathrm{Cl}^{-}\right)$in concentrated aqueous electrolyte solutions (i.e. the "ionic liquid" of Shi et al., 2011). The reason for formation of 1-chloronaphthalene instead of 2-chloronaphthalene is that the attack of a nucleophile is much more possible in the position $\mathrm{C}_{1}$ (Figure 6.14). It is stabilised by four contributing resonance structures in which the aromatic character is retained by one of the benzene rings in comparison to the $\mathrm{C}_{2}$ position (Figure 6.17), where only two contributing structures in which the aromatic 
character is retained in one of the rings. Thus, nucleophile substitution will occur preferably at $\mathrm{C}_{1}$ position (Mehta \& Mehta, 2015).

(a)

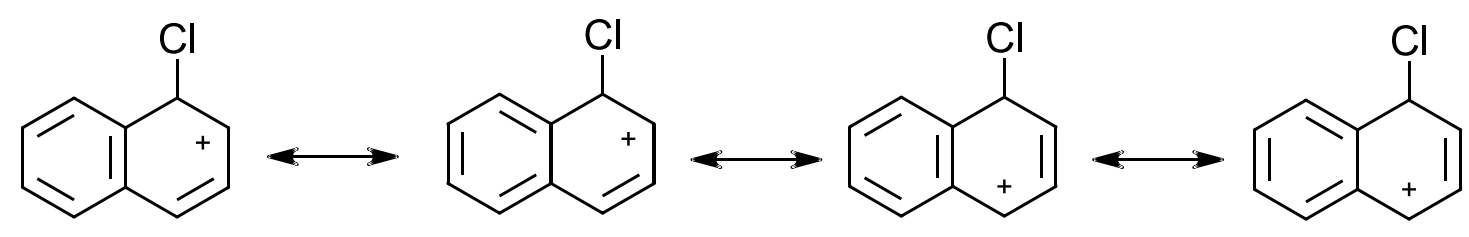

(b)

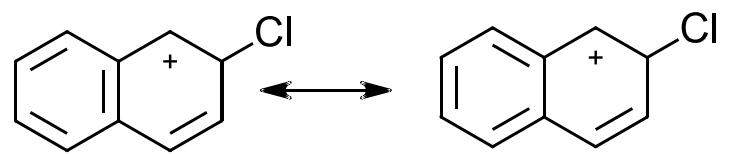

Figure 6.17: Resonance structures for 1-chloronaphthalene (a) and 2-chloronaphthalene (b) in which the aromatic character is retained by one of the benzene rings.

\subsubsection{Summary}

These results constitute insight into the thermal breakdown products of 1,6-NDS and $1,5-\mathrm{NDS}$ between 200 and $300^{\circ} \mathrm{C}$ in aqueous $\mathrm{NaCl}=0.050 \mathrm{~mol} \mathrm{\textrm {kg } ^ { - 1 }}$ solution. The decomposition of both 1,6-NDS and 1,5-NDS begin with the loss of a $\mathrm{SO}_{3}$ - group attached to ring in $\mathrm{C}_{1}$ position, resulting in 2-NSA from 1,6-NDS and 1-NSA from 1,5-NDS. Further, with temperature increase, both 2-NSA and 1-NSA give rise to naphthalene (NAP), the most stable, and probably the final breakdown product of 1,6-NDS and 1,5-NDS. Therefore, NAP is a potential candidate for a new permeability tracer. Note that along with the main breakdown products of 1,6-NDS and 1,5-NDS decomposition described in this chapter and in chapters 2 , 3 and 4 (i.e. 1-NSA and 2-NSA), 1,6-NDS and 1,5-NDS disproportionation also results in 1-NAP, 2-NAP and 1-chloronaphthalene (the latter detected only with GC-MS).

The findings presented in this chapter represent the early steps of the 1,6-NDS and 1,5-NDS decomposition mechanism on the way to their final and stable products. However, the three weeks duration of the experiments was not long enough to reach equilibrium state, even at $300^{\circ} \mathrm{C}$. Thus, future studies should be carried out for a longer time and involve a kinetic study. Additionally, future studies should also comprise different experimental $\mathrm{pH}$ and salt composition to understand their effect on the possible breakdown products. 


\subsection{References}

Bruckner, R., Harmata, M., Wender, P. a., 2010. Organic mechanisms: Reactions, stereochemistry and synthesis, Organic Mechanisms: Reactions, Stereochemistry and Synthesis.

Dashkevich, Y.G., Mountain, B.W., Seward, T.M., Winick, J.A., 2014. Temperature stability of 1,5-naphthalene disulfonate at simulated geothermal conditions, Proceedings $36^{\text {th }}$ New Zealand Geothermal Workshop, Auckland.

Dashkevich, Y.G., Mountain, B.W., Seward, T.M., Winick, J.A., 2015. temperature stability of naphthalene sulfonic and naphthalene disulfonic acids at geothermal conditions. Proceedings World Geothermal Congress 2015. Melbourne, Australia.

Fierz-David, H. E., Blangey, L., 1949. Fundamental Processes of Dye Chemistry. Interscience Publishers, Inc., New York. 479, 175 - 223.

Gosetti, F., Gianotti, V., Ravera, M., Gennaro, M.C., 2005. HPLC-MS n to investigate the oxidative destruction pathway of aromatic sulfonate wastes. Journal of Environmental Quality 34, 2328 - 2333.

Mehta, B., Mehta, M., 2015. Organic Chemistry. Second Edition. New Delhi, 852 - 855.

Mountain, B.W., Winick, J., 2012. The Thermal stability of the naphthalene sulfonic and naphthalene disulfonic acids under geothermal conditions: experimental results and a field-based example 1-5. Proceedings 34th New Zealand Geothermal Workshop.

Price, L. C., 1993. Thermal stability of hydrocarbons in nature: limits, evidence, characteristics, and possible controls. Geochimica et Cosmochimica Acta, 57, 14, 3261 - 3280.

Rose, P., Benoit, W.R., Kilbourn, P.M., 2001. The application of the polyaromatic sulfonates as tracers in geothermal reservoirs. Geothermics, 30, $617-640$.

Rose, P., Clausen S., 2014. The Use of Amino G as a Thermally Reactive Tracer for Geothermal Applications. Proceedings The application of the polyaromatic sulfonates as tracers in geothermal reservoirs. Proceedings, 39th Workshop on Geothermal Reservoir Engineering Stanford University.

Schwandner, F. M., Seward T. M., Giże A. P., Hall K., Dietrich J. V., 2013. Halocarbons and other trace heteroatomic organic compounds in volcanic gases from Vulcano (Aeolian Islands, Italy). Geochimica Cosmochimica Acta 101, 191 - 221.

Schwarz, F.P., 1977. Determination of temperature dependence of solubilities of polycyclic aromatic hydrocarbons in aqueous solutions by a fluorescence method. Journal of Chemical \& Engineering Data. 22, 3, 273 - 277. 
Shi, S. Y., Kong, A. G., Zhao, X. H., Ding, H. M., Yang, F., Shan Y. K., 2011. Nucleophilic substitution of hydrogen in naphthalene by chloride $\left(\mathrm{Cl}^{-}\right)$in ionic liquids, Chinese Chemical Letters, 22, 2, $147-150$. 


\section{Thermal stability of naphthalene disulfonates and naphthalene sulfonates under geothermal conditions: Concluding remarks}

\subsection{Summary of results}

The work presented in this thesis was designed to determine the thermal stability of naphthalene disulfonates (NDS) and naphthalene sulfonates (NSA) under geothermal conditions. This is to improve interpretation of well connectivity and permeability tests when NDS and NSA are utilised. Several series of experiments were conducted to simulate a complex geothermal environment. Each of the experiments targeted various $\mathrm{pH}$ values $\left(\mathrm{pH}_{25^{\circ} \mathrm{C}}=3-11\right)$ and solutions compositions (distilled water, $\mathrm{NaCl}, \mathrm{Na}_{2} \mathrm{SO}_{4}, \mathrm{Na}_{2} \mathrm{~S}$ ) and temperatures $\left(100-400^{\circ} \mathrm{C}\right)$. This was to understand behaviour of NDS/NSA in these conditions. A primary goal of this thesis was to obtain kinetic data for the breakdown reactions of NSA/NDS which can be applied to geothermal reservoir models. The secondary aim was to investigate NDS/NSA breakdown reactions pathways, isomerisation processes, and to identify products of NDS/NSA thermal disproportionation.

The objectives were accomplished by conducting quartz glass ampoule batch experiments: to investigate the influence of temperature, $\mathrm{pH}$, and salinity on the stability of NDS/NSA (Chapter 2); to obtain kinetic data on the breakdown reactions of these compounds (Chapter 3); and to detect and quantify the breakdown reaction products (Chapter 6); to determine decomposition reaction pathways and to identify different breakdown products, for which a new analytical method was developed (Chapter 5). Additionally, high-temperature flow-through experiments in the presence of different solid materials were undertaken to investigate NDS/NSA stability in presence of rock material in a dynamic system (Chapter 4). The main findings from these Chapters are:

Chapter 2: The stability of 1,5-naphthalene disulfonate (1,5-NDS) and 2naphthalene sulfonate (2-NSA) as a function of $\mathrm{pH}$ and salinity under geothermal conditions

Both 1,5-NDS and 2-NSA stabilities are pH-dependent and their breakdown rates decrease with increasing $\mathrm{pH}$ and the addition of $\mathrm{NaCl}$. In general, 2-NSA is notably more stable than 1,5-NDS at any of the tested conditions. 1,5-NDS undergoes a thermal breakdown at 
$\geq 200^{\circ} \mathrm{C}$, whereas, $2-\mathrm{NSA}$ is stable at $\leq 200^{\circ} \mathrm{C}$ and is not be detected at $300^{\circ} \mathrm{C}$. 1-NSA was shown to be a reaction product of 1,5-NDS thermal decay. The stability of 1-NSA is also pHdependent and it is stable at $270^{\circ} \mathrm{C}$ for at least 24 days. Rate constants for the decomposition of 1,5-NDS and 2-NSA under different conditions are summarised in Tables 2.3., 2.4. and 2.7.

Chapter 3: Naphthalene sulfonate and disulfonate (2-NSA, 2,6-NDS, 2,7-NDS, 1,5NDS and 1,6-NDS) breakdown kinetics at elevated temperature in the presence of greywacke

The experimental data show that 1,5-NDS, 1,6-NDS, 2,6-NDS and 2,7-NDS stabilities are temperature and $\mathrm{pH}$-dependent and NDS and NSA stabilities increase as follows: 1,5-NDS $<1,6-N D S<2,6-N D S \approx 2,7-N D S<2-N S A$. Both, 1-NSA and 2-NSA appear as breakdown products of NDS thermal decomposition. Rate constants for the decomposition of 1,5-NDS, 1,6-NDS, 2,6-NDS and 2,7-NDS are provided in Tables 3.2, 3.3, 3.4 and 3.5. Rate constants for the decomposition and formation of 2-NSA are summarised in Tables 3.6 and 3.7. Arrhenius constants for the decomposition of 2,6-NDS, 2,7-NDS, 1,6-NDS and 1,5-NDS are presented in Table 3.8. The kinetic data presented in this chapter can be used to predict NDS/NSA stability for conditions from 200 to $330^{\circ} \mathrm{C}$.

Chapter 4: A flow-through autoclave study of trace naphthalene disulfonate compounds in presence of solid materials at conditions relevant to active geothermal reservoirs

The results of the flow-through experiments are consistent with results presented in Chapter 2 and 3. The stability of 2,6-NDS, 2,7-NDS, 1,5-NDS and 1,6-NDS are controlled by solution $\mathrm{pH}$ and temperature. Additionally, experiments that included rock(or mineral)-fluid interactions generate solutes in solution that enhanced the stability of NDS in comparison to experiments with low solute concentrations. 1-NSA and 2-NSA are detected as products of NDS decomposition.

Chapter 5: Quantitative analysis of naphthalene, 1-naphthol and 2-naphthol at nanomol levels in geothermal fluids using solid-phase extraction with high-performance liquid chromatography - fluorescence detection

A new high-performance liquid chromatography (HPLC) method combined with solidphase extraction (SPE) for the detection of NAP, 1-NAP and 2-NAP geothermal fluids is presented in this chapter. The method was used to complete the final part of this thesis (Chapter 6). The method provides new opportunities for the geothermal industry to use NDS/NSA thermal decomposition products as new well connectivity and permeability tracers. It is 
possible that naphthalene can be utilised in future as a steam tracer. It was shown that during the method evaluation, measurable amounts of naphthalene and 1- and 2-napthol were successfully detected in several geothermal steam samples from different New Zealand geothermal fields.

Chapter 6: Reaction pathways of 1,6-NDS and 1,5-NDS decomposition in aqueous solutions at elevated temperatures to $300^{\circ} \mathrm{C}$ and the formation of naphthalene, naphthols and 1-chloronaphthalene

The results of this chapter provide the first published information on the breakdown products of naphthalene disulfonates between 200 and $300^{\circ} \mathrm{C}$ in aqueous $\mathrm{NaCl}$ solution. The experiments provide evidence for the formation of 1-NSA, 2-NSA, NAP, 1-NAP and 2-NAP under these conditions. The results presented in this chapter can be utilised in reservoir tracer tests. For example, when naphthalene disulfonates are injected into an active geothermal reservoir and low recoveries are experienced, the geothermal fluid can be analysed for the presence of these breakdown products (i.e. NAP, 1-NAP and 2-NAP) to gain insight into well connectivity and to avoid misinterpretation of the injection results (i.e. the apparent non-return of the originally injected NSA or NDS isomers).

\section{Conclusion}

The results of the experiments carried out during this thesis indicate that the stabilities of the naphthalene mono- and disulfonates are a function of temperature, $\mathrm{pH}$, and salinity. The naphthalene sulfonates transform to different isomers and the kinetics of these isomerisation reactions have been determined. At temperatures $\geq 300^{\circ} \mathrm{C}$, the NDS and NSA compounds disproportionate to the naphthalene "backbone" molecule as well as to the two stable naphthols and 1-chloronaphthalene (in chloride-containing solutions). The application of naphthalene sulfonates is to determine well connectivity and local permeabilities in active geothermal reservoirs is thus rather more complicated than previously appreciated. An understanding of the various isomer transformations and their kinetics is required. Furthermore, naphthalene sulfonates injected into high temperature geothermal reservoirs are unstable and breakdown to naphthalene, naphthols and probable halogenated naphthalene compounds, none of which have been considered in the interpretation of NDS/NSA recovery data in active geothermal reservoirs. The thermal stabilities of NAP, 1- and 2-NAP and 1-chloronaphthalene indicate that these compounds may also be employed as permeability tracers in high temperature $\left(\mathrm{t} \geq 300^{\circ} \mathrm{C}\right)$ systems. 


\subsection{Scope of current study and ideas for future research}

This thesis provides a set of baseline data for future naphthalene (di)sulfonates studies to build upon. Although extensive experiments have been conducted, some questions have still not been answered as mentioned briefly below.

\subsubsection{Complementary experiments with varied salt concentration and pH}

Despite the extensive use of naphthalene (di)sulfonates by the geothermal industry, there are limited data on the thermal stability of these compounds under geothermal conditions. The experiments described in this thesis constitute the first comprehensive study of NDS/NSA stability in hot aqueous fluids $\left(100-330^{\circ} \mathrm{C}\right)$. However, the solutes considered, and their concentrations cover a limited range (i.e. $\mathrm{NaCl}=0.050 \mathrm{~mol} \mathrm{~kg}{ }^{-1}, \mathrm{Na}_{2} \mathrm{SO}_{4}=0.020 \mathrm{~mol} \mathrm{~kg}^{-1}$, $\left.\mathrm{Na}_{2} \mathrm{~S}=2.69 \times 10^{-5} \mathrm{~mol} \mathrm{~kg}^{-1}\right)$. The acid and base used to define the $\mathrm{pH}$ were also limited to $\mathrm{HCl}$ and $\mathrm{NaOH}$. Geothermal field fluid chemistry is much more diverse and complex and other solutes may have differing effects on NDS/NSA stability.

The results allow the prediction of the NDS breakdown rates at different $\mathrm{pH}$ values (i.e. $\mathrm{pH}_{\mathrm{t}}$ between 3.0 and 8.2) at 200 and $300^{\circ} \mathrm{C}$ in $\mathrm{NaCl}=0.050 \mathrm{~mol} \mathrm{~kg}^{-1}$ solution and in distilled water. However, more experiments at different temperatures (for example 250,270 or $330^{\circ} \mathrm{C}$ ) are required to obtain additional activation energy data and pre-exponential factors for the thermal decomposition of NDS. Additional experiments with varying $\mathrm{NaCl}$ concentration (e.g. $0.100,0.500$ and $1.00 \mathrm{~mol} \mathrm{~kg}^{-1}$ ) will demonstrate the influence of salinity on the thermal stability of these compounds and experiments with different salts (e.g. $\mathrm{MgSO}_{4}$ or $\mathrm{KCl}$ ) will characterise the effect of different solutes on NDS/NSA stability.

\subsubsection{Influence of NDS/NSA interactions on their thermal stability}

The kinetic studies presented in Chapter 3 were conducted with an initial aqueous mixture of NDS/NSA (i.e. 1,6-NDS, 1,5-NDS, 2,6-NDS, 2,7-NDS and 2-NSA). However, different isomerisation processes are possible and these would affect decomposition rates, thus, complementary kinetic studies of each individual NDS/NSA will provide a clearer picture of the decomposition rates of the individual compounds.

\subsubsection{NDS/NSA breakdown products long-term experiments}

A series of experiments to study NDS breakdown products were undertaken in this study. The experiments measured the products of 1,5-NDS and 1,6-NDS decomposition after one, two and three weeks at 200,250 and $300^{\circ} \mathrm{C}$ at saturated vapour pressure. The $\mathrm{pH}$ and $\mathrm{NaCl}$ 
concentration of these solutions were fixed (i.e. $\mathrm{pH}_{25^{\circ} \mathrm{C}}=7.0, \mathrm{NaCl}=0.050 \mathrm{~mol} \mathrm{~kg}^{-1}$ ). The next step would be to extend experimental time (three weeks is not long enough to attain equilibrium) and examine the breakdown products at different $\mathrm{pH}$ and different salts at different salinities.

\subsubsection{Naphthalene detection in steam phase of active geothermal reservoirs}

The experimental data presented in Chapter 6 suggest that naphthalene should be the main breakdown product of naphthalene sulfonate and disulfonate disproportionation. However, analytical analyses (described in Chapter 5) of various geothermal brine samples (from current NDS tracer tests) did not confirm the presence of naphthalene because it has likely partitioned into the unanalysed steam phase. Naphthalene and other compounds (1-naphthol, 2-naphtol and 1-chloronaphthalene) have been detected recently in steam samples from several active New Zealand geothermal fields (unpublished results). The number of analysed steam samples was small and further samples need to be collected and analysed in order to verify the presence of naphthalene as an indicator of NDS/NSA breakdown.

\subsubsection{Modelling}

Software-based reservoir models are frequently used during geothermal field management of production and reinjection or drilling to locate target location and help to predict temperatures, pressures and flows within a system. It is an important tool to forecast the consequences of production and reinjection into the geothermal reservoir (Burnell \& Kissling, 2005; Ngugi, 2008; Akar \& Young, 2015). Development of a reservoir model involves calibration against field measurements, including tracer tests (Burnell \& Kissling, 2005). For this reason, it would be beneficial to incorporate NDS/NSA breakdown kinetic into existing geothermal field reservoir models. This will allow comparison with real tracer return results allowing better interpretation of flow paths, temperatures and connectivities.

\subsubsection{Naphthalene solubility at $\geq 200^{\circ} \mathrm{C}$ in aqueous fluids}

The discovery of a naphthalene as a breakdown product of naphthalene disulfonates was one of the interesting outcomes of this thesis. This means that naphthalene can potentially be used as a new geothermal tracer, however, before naphthalene can be reliably used as a possible tracer, additional studies need to be conducted. There are no available data on naphthalene solubility in geothermal fluids (i.e. high salinity) at $\mathrm{t} \geq 200^{\circ} \mathrm{C}$. The existing data are confined to distilled water or aqueous organic solvent mixtures at temperatures up to $150^{\circ} \mathrm{C}$ 
(Mannhard et al. 1943; Mackay \& Shiu, 1977). It is critical to investigate the solubility of naphthalene in geothermal brines to predict if naphthalene will be mobile (i.e. can be transported) within active geothermal reservoirs.

\subsection{References}

Akar, S., Young K. R., 2015. Assessment of new approaches in geothermal exploration decision making, $40^{\text {th }}$ Workshop on Geothermal Reservoir Engineering, Stanford University, Stanford, California.

Burnell, J., Kissling, W., 2005. Rotorua Geothermal reservoir modelling part 1 : model update $2004,1-58$.

Höll, W., 2003. Adsorption behavior of 2-naphthalenesulfonate on activated carbon from aqueous systems. Industrial \& Engineering Chemistry Research, 42, $6904-6910$.

Licha, T. and Sauter, M., 2002a. Short-chained alkylphenols (SCAP) as reactive tracers. Dechema, European Conference on Natural Attenuation, Heidelberg, 49 - 51.

Licha, T. and Sauter, M., 2002b. Use of short-chained alkylphenols (scap) in analysis of transport behaviour of oil contaminated groundwater. Journal of Agricultural and Marine Sciences, 7, 2, $29-38$.

Nogara, J. B., Sambrano, B. M. G., 2005. Tracer tests using naphthalene di-sulfonates in Mindanao Geothermal production field, Philippines. Proceedings World Geothermal Congress. Antalya, Turkey.

Mackay, D., Shiu, W. Y., 1977. Aqueous solubility of polynuclear aromatic hydrocarbons. Journal of chemical and engineering Data, 22, 4, 399 - 402.

Mannhardt, O. W., De Right, R. E., Martin, W. H., Burmaster C. H., Wadt W. F., 1943. The solubility of naphthalene in aqueous solutions of methanol, ethanol, 1-propanol; and 1butanol at several temperatures. The Journal of Physical Chemistry, 479, 685 - 702. 
Appendix 


\section{A Ancillary projects}

\section{A.1 Long term storage conditions}

One of the goals of this project was to provide information to help the geothermal industry to better interpret permeability and well connectivity tracer test results. The majority of the experiments were conducted at high temperatures (i.e. $\geq 200^{\circ} \mathrm{C}$ ), however, there are no data published on the long-term stability (years) of NDS/NSA at low temperatures $\left(3-25^{\circ} \mathrm{C}\right)$. These conditions are typical for storage of tracer test samples in the laboratory. It is also important to understand how long these samples can be stored and if the storage conditions affect NDS/NSA stability. Consequently, a minor project task was to test how long after collection of a brine sample would the solution preserve the NDS/NSA concentrations.

The storage experiments were conducted over a period of 37 months ( $~ 3$ years). Two sets of the experiments were prepared. The Set 1 contained mixture of four NDS (1,5-NDS, 1,6-NDS, 2,6-NDS and 2,7-NDS; $20 \mu \mathrm{g} \mathrm{kg}^{-1}$ of each compound) and the two NSA (1-NSA $\sim 10 \mu \mathrm{g} \mathrm{kg}^{-1}$ and 2-NSA $\sim 20 \mu \mathrm{g} \mathrm{kg}^{-1}$ ) dissolved in distilled water. Set 2 involved a geothermal brine spiked with the same mixture of the six NDS/NSA. Aliquots of solution from both sets were transferred to plastic and glass containers, and placed in three locations (i.e. a refrigerator, a dark cupboard and a benchtop open to sunlight). All together, a total of ten different storage conditions were investigated (Table A.1).

Each of the containers was sampled every few months and the solutions were analysed for NDS/NSA concentration by high-performance liquid chromatography (HPLC). A total of 100 samples were collected over the 37 months.

Experimental results show that NDS and NSA undergo slow decomposition at all tested conditions (Figure A.1). However, 1-NSA and 2-NSA are more stable than 1,5-NDS, 1,6-NDS, 2,6-NDS and 2,7-NDS (Figure A.1c). The compounds tend to be less stable when kept in distilled water in comparison to the brine (Figure A.1ab). After the 37 months, the maximum decrease in NDS/NSA concentration was 7\% in distilled water (Figure A.1a) and the minimum was $2 \%$ total decrease in brine samples (Figure A.1b). Otherwise, neither the type of the container nor the location of the container, exposure to sun (benchtop), or low temperature (the refrigerator at $3^{\circ} \mathrm{C}$ ) had an influence on NDS/NSA stability.

The difference in concentration between the initial solution and the solution after 14 months was small ( $\sim 0.3 \mu \mathrm{g}$ NDS and $\sim 0.1 \mu \mathrm{g}$ for NSA), therefore, samples can be stored and 
Table A.1: Experiments on the storage of aqueous NSA and NDS solutions and types of container for a long time periods.

\begin{tabular}{cclcc}
\hline & $\#$ & \multicolumn{1}{c}{ location } & solution & container \\
\hline set 1 & 1 & refrigerator $\left(3^{\circ} \mathrm{C}\right)$ & distilled water & plastic \\
& 2 & dark cupboard & distilled water & glass \\
& 3 & dark cupboard & distilled water & plastic \\
& 4 & benchtop & distilled water & glass \\
& 5 & benchtop & distilled water & plastic \\
\hline set 2 & 6 & refrigerator $\left(3^{\circ} \mathrm{C}\right)$ & geothermal brine & plastic \\
& 7 & dark cupboard & geothermal brine & glass \\
& 8 & dark cupboard & geothermal brine & plastic \\
& 9 & benchtop & geothermal brine & glass \\
& 10 & benchtop & geothermal brine & plastic \\
\hline
\end{tabular}
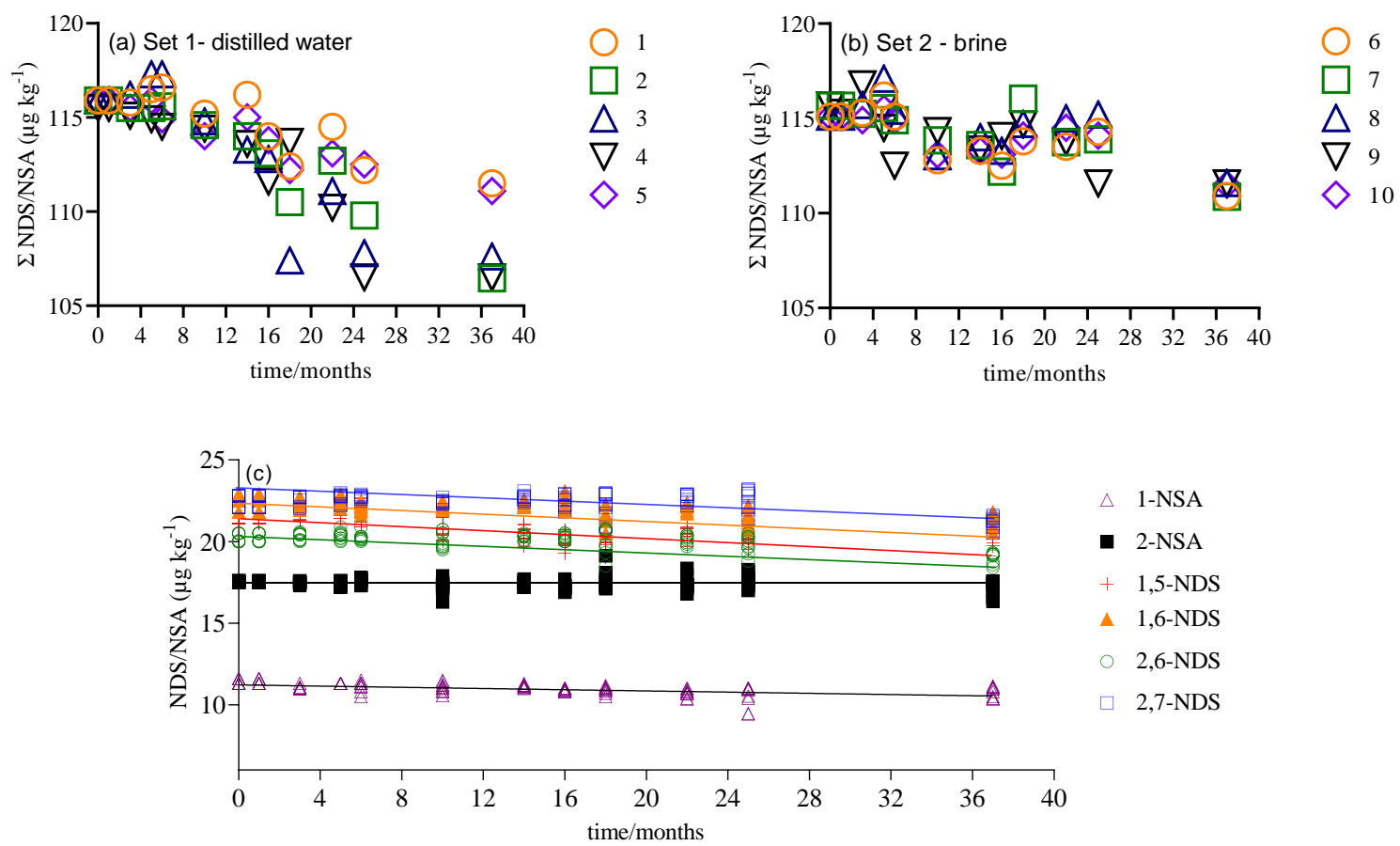

Figure A.1: Total concentration $\left(\mu \mathrm{g} \mathrm{kg}^{-1}\right)$ of all NDS/NSA in (a) distilled water and (b) geothermal brine and (c) concentration $\left(\mu \mathrm{g} \mathrm{kg}^{-1}\right)$ of each compound over time in months. Numbers represent the conditions listed in Table A.1. 
reanalysed with confidence over this period. If the samples are to be stored for a longer time, then caution is necessary. It is also advisable to prepare new HPLC NDS/NSA standards at least every six months.

\section{A.2 The adsorption of naphthalene sulfonates under geothermal conditions}

Naphthalene (di)sulfonates (NDS and NSA) are widely used in the geothermal industry as reservoir tracers. However, there are few experimental data on the adsorption of these compounds onto solid substrates under geothermal conditions. In this preliminary study, we investigated NDS/NSA adsorption onto rock surfaces under geothermal conditions. Two different types of experiments were employed. The first involved a flow-through autoclave at several temperatures up to $250^{\circ} \mathrm{C}$ (see Chapter 4), while the second was based on simple benchtop batch experiments at room temperature.

Both types of experiment involved six compounds: 2-naphthalene sulfonate (2-NSA), 1-naphthalene sulfonate (1-NSA), 1,5-naphthalene disulfonate (1,5-NDS), 1,6-naphthalene disulfonate (1,6-NDS), 2,6-naphthalene disulfonate (2,6-NDS) and 2,7- naphthalene disulfonate (2,7-NDS).

Four preliminary experiments of the first type (i.e. flow-through autoclave) were conducted. The experimental apparatus is shown in Figure A.2.1 Three experiments used $22 \mathrm{~g}$ of crushed and sieved greywacke (size: 180 - $220 \mu \mathrm{m}$; Chapter 4) and one experiment used $21.6 \mathrm{~g}$ of crushed quartz (size: $180-220 \mu \mathrm{m}$ ). The pressure vessel was exposed to 25, 100 and $250^{\circ} \mathrm{C}$. A metering pump created the flow of geothermal brine (Table A.2.1) through the pressure vessel at the rate of $2 \mathrm{ml} \mathrm{hr}^{-1}$. The greywacke or quartz material was in contact with geothermal brine within the pressure vessel for 24 hours prior to each experiment. A $0.025 \mathrm{ml}$ volume of solution containing a six-NDS/NSA mixture (i.e. $400 \mu \mathrm{g} \mathrm{kg}^{-1}$; 2,6-NDS, 2,7-NDS, 1,5-NDS, 1,6-NDS, 1-NSA and 2-NSA) was injected into the system through an injection valve (Figure A.2.2). Samples were collected every hour for 20 hours via a collection syringe. 
Table A.2.1: Composition of geothermal fluid from Rotokawa geothermal field, $\mathrm{pH}_{\mathrm{t}}=5.75$ (Krupp and Seward, 1987).

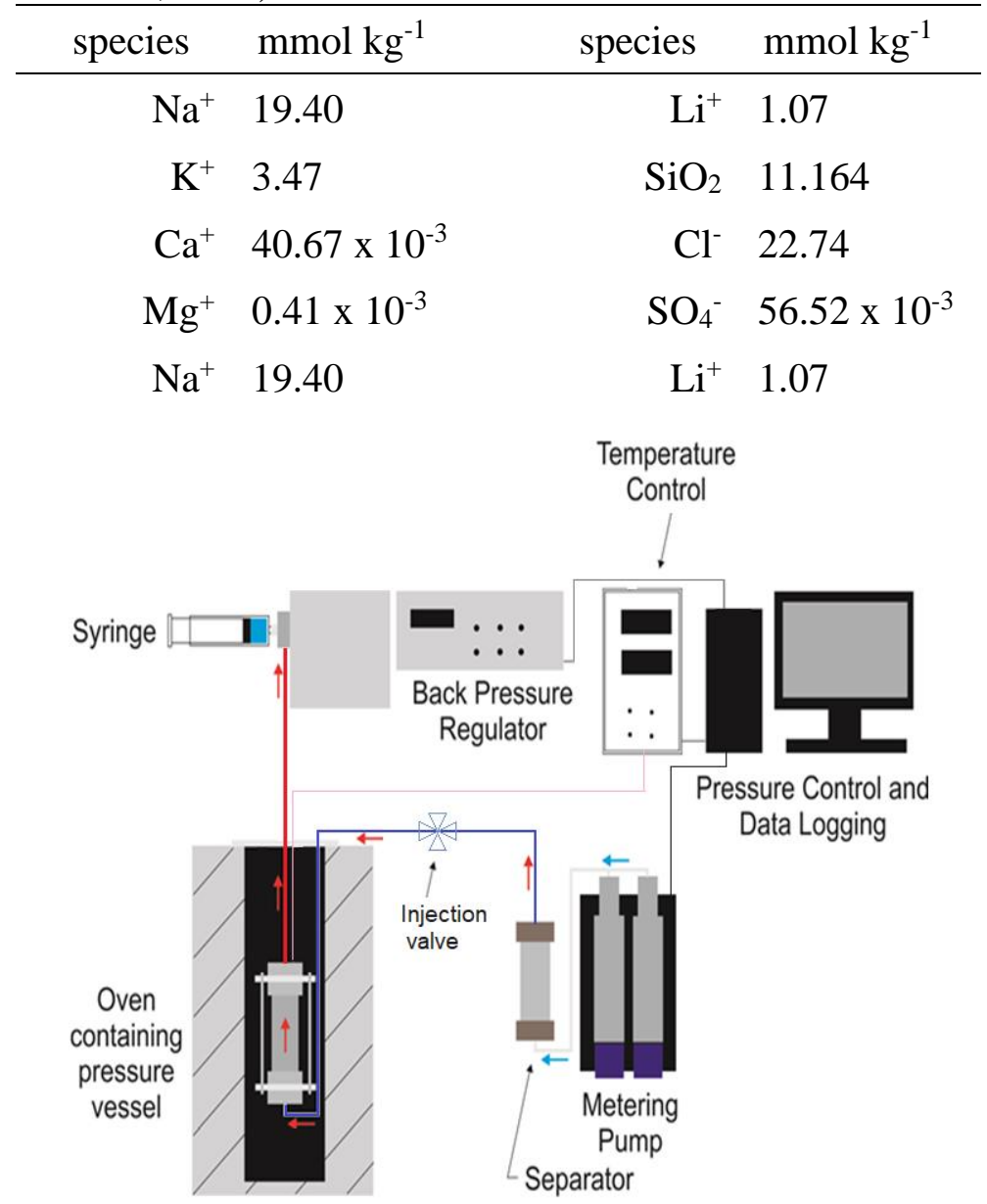

Figure A.2.1: The flow-through experimental setup.

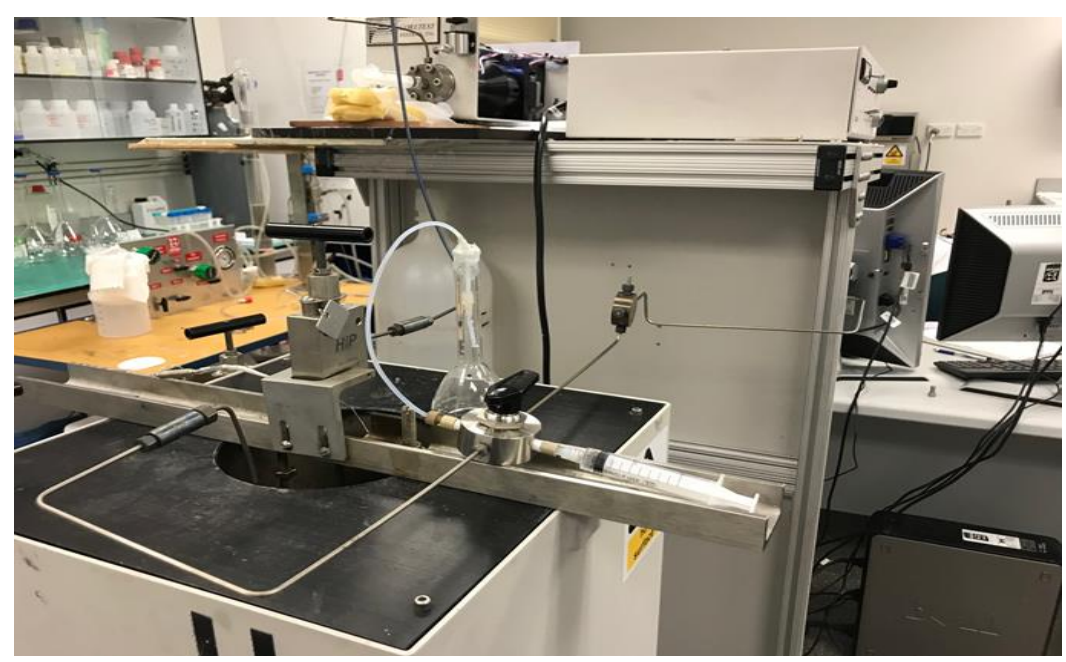

Figure A.2.2: The injection valve attached to the flow-through experimental apparatus. 
The second type of experiment, batch experiments, was carried out to find the potential adsorption effect of different solid materials at $25^{\circ} \mathrm{C}$ (Table A.2.2). Falcon centrifuge tubes (50 $\mathrm{ml}$ ) were employed. The procedure involved filling the tubes with $0.5 \mathrm{~g}$ of different rock/mineral material and with $20 \mathrm{ml}$ of the brine (Table A.2.1) spiked with six-NDS/NSA mixtures $\left(\sim 50 \mu \mathrm{g} \mathrm{kg}^{-1}\right)$. Each mineral/rock sample was in contact with experimental solution for 24 hours before the NDS/NSA was added. Three different $\mathrm{pH}$ values were used to study the possible $\mathrm{pH}$ effect on the adsorption processes. The brine $\mathrm{pH}$ was adjusted with $\mathrm{HCl}$ or $\mathrm{NaOH}$ to obtain $\mathrm{pH}_{25^{\circ} \mathrm{C}}=4.0,7.0$ and 8.0. During the experiment (90 minutes duration), small volumes of sample were taken for analysis every 10 minutes. Samples were shaken at five minute intervals during the 90 minutes of the experiment. Two control experiments were conducted. The first had no solid material to examine the possible adsorption of NDS/NSA on the walls of the container. The second used activated carbon added to test the methodology as NDS/NSA adsorption was expected (Höll, 2003).

Table A.2.2: Type and size of solid material used in the batch experiments.

\begin{tabular}{lc}
\hline solid material & size \\
\hline greywacke $^{*}$ & $<0.5 \mathrm{~mm}$ \\
pumice & $180-220 \mathrm{um}$ \\
magnetite & $<0.5 \mathrm{~mm}$ \\
illite & $<2 \mu \mathrm{m}$ \\
smectite & $<2 \mu \mathrm{m}$ \\
activated carbon & $<2 \mu \mathrm{m}$ \\
\hline
\end{tabular}

* mineral composition of the greywacke presented in Table 7.4

Table A.2.3: Mineral composition of the greywacke used in both experiments (i.e. flowthrough and batch experiments) see Chapter 4 .

\begin{tabular}{lclclc}
\hline Minerals & $\begin{array}{c}\text { Abundance } \\
\text { vol } \%\end{array}$ & Minerals & $\begin{array}{c}\text { Abundance } \\
\text { vol\% }\end{array}$ & Minerals & $\begin{array}{c}\text { Abundance } \\
\text { vol\% }\end{array}$ \\
\hline quartz & 20 & K-feldspar & 5 & oxide-sulfide & $<5$ \\
plagioclase & 5 & calcite & $<5$ & chlorite & 10 \\
albite & 5 & epidote & $<5$ & illite & 40 \\
\hline
\end{tabular}


The flow-through results are presented in Figure A.2.3 which show concentration $(\mu \mathrm{g}$ $\mathrm{kg}^{-1}$ ), of each NDS/NSA after injection versus time, Figure A.2.4 shows the total concentration $\left(\mu \mathrm{g} \mathrm{kg}^{-1}\right)$, of injected compounds as a function of time.

The experiment with the quartz at room temperature was a control to provide a comparison with the multi-mineral rock, as no adsorption on the surface of quartz was expected. The NDS/NSA mixture appears six hours after injection and by hour 16 all compounds are returned. The results show that all injected NDS/NSA return over the same time period, hence there is no evidence of adsorption on the quartz surface.

The experiment using the greywacke at room temperature shows comparable results to the quartz (Figure A.2.3b). The first detectable NDS/NSA appears after six hours, similar to the quartz, and the concentrations are below detection limit by hour 16 . At $100^{\circ} \mathrm{C}$ and $250^{\circ} \mathrm{C}$, the first NDS/NSA returns after 4.5 hours and 4 hours, respectively (Figure A.2.3c,d). After 14 hours at $100^{\circ} \mathrm{C}$ and after 12 hours at $250^{\circ} \mathrm{C}$, NDS/NSA concentrations drop below detection limit.

Within each individual experiment, no measurable differences were found between the return times of each NDS/NSA. This indicates that all naphthalene sulfonates and disulfonates interact with the rock in a similar way (Figure A.2.3). However, NDS/NSA breakthrough time decreases with increasing temperature (Figure A.2.4). Total (i.e. total NDS + NSA) NDS/NSA return curves have half-widths that narrow with increased temperature. This can be explained by changes in water density and increased diffusivity. Note that the area under the peaks at 25 and $100^{\circ} \mathrm{C}$ have the same size but were noticeably smaller at $250^{\circ} \mathrm{C}$. This can be explained by the thermal breakdown of the NDS at this higher temperature rather than adsorption processes. The slight asymmetry in the return curves with the greywacke experiment at least at 25 and $100^{\circ} \mathrm{C}$ suggest some rock-NDS/NSA interaction that is not observed with quartz alone.

Future flow-through experiments are planned where a species that is not affected by adsorption onto a mineral substrate will be added to the injection mixture to test for possible weak interactions between NDS and the rock. In addition, decreasing the average grain size of the rock particles will increase the available surface area and thus adsorptive capacity of the rock. The effective surface area during an actual field test will be vastly larger than that presented in the experiments.

In addition to flow-through experiments, a series of batch experiments were conducted at room temperature (i.e. $25^{\circ} \mathrm{C}$ and $\mathrm{pH}=4,7$ and 8). Among the different solid substrates, 
adsorption of NDS/NSA was only observed on activated carbon. The change in $\mathrm{pH}$ of the solution did not affect the adsorption.

Generally, adsorption was observed only on activated carbon. However, more data are required to confirm non-absorptivity of the NDS/NSA. Future laboratory studies should be conducted by changing the concentrations of adsorbate (rock/minerals) or the dose of adsorbent (NDS/NSA). Additionally, the presence of other competing ions can influence adsorption from aqueous solution. It is reasonable to suggest that the lack of adsorption of NDS/NSA on mineral/rock surfaces (except activated carbon) reported in this preliminary study may not be a reliable representation of a true field test.

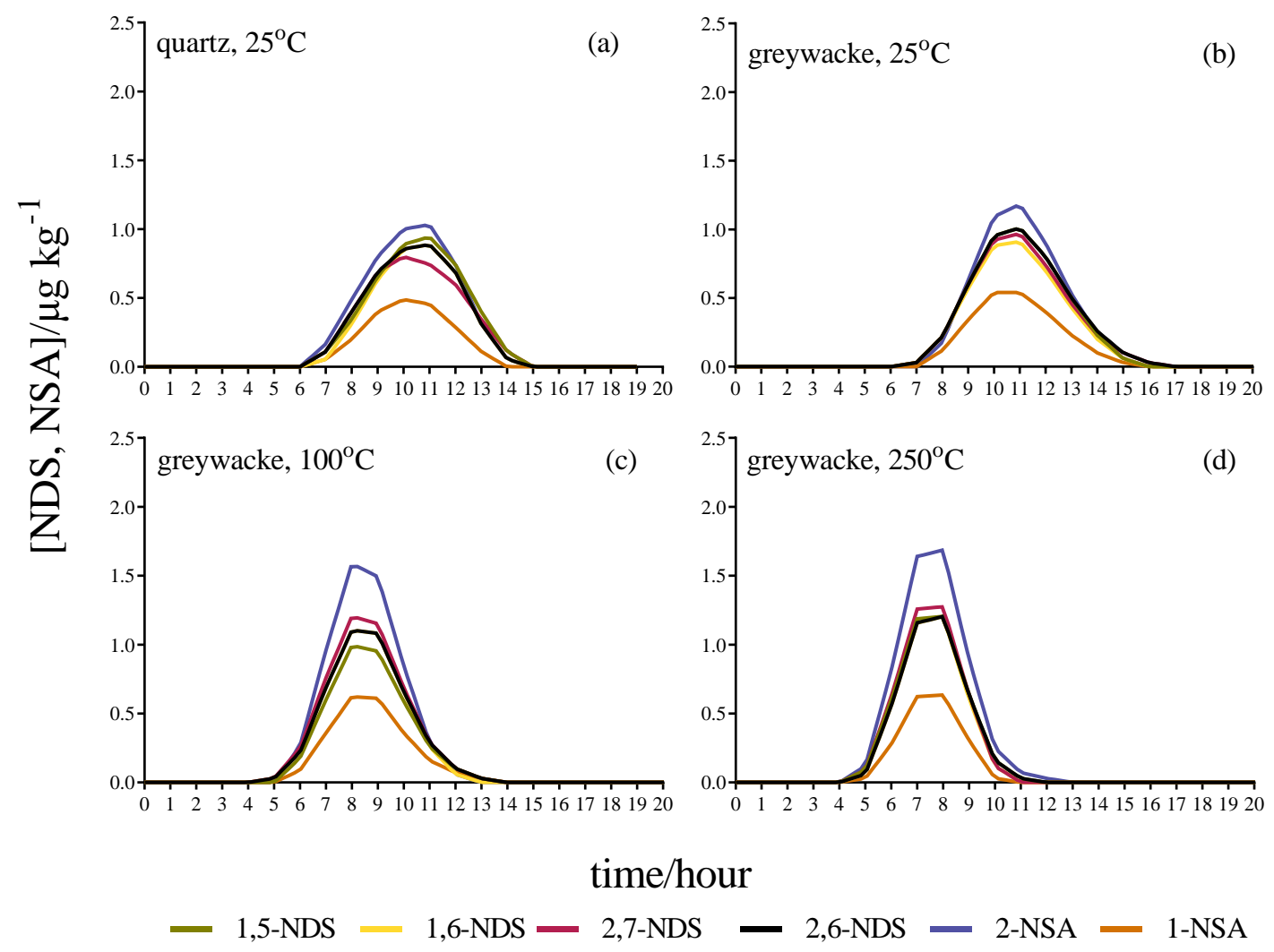

Figure A.2.3: Naphthalene (di)sulfonates concentrations $\left(\mu \mathrm{g} \mathrm{kg}^{-1}\right)$ in flow-through autoclave experiments measured at one hour intervals after injection of the $0.025 \mathrm{ml}$ aliquot of initial solution. (a) $25^{\circ} \mathrm{C}$, quartz, (b) $25^{\circ} \mathrm{C}$, greywacke, (c) $100^{\circ} \mathrm{C}$, greywacke, (d) $250^{\circ} \mathrm{C}$, greywacke. 


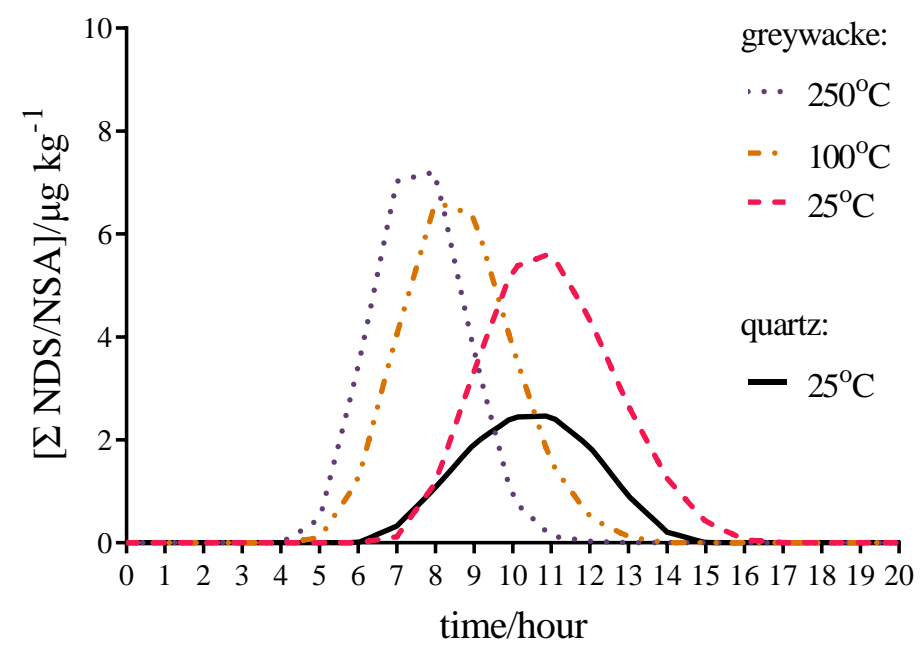

Figure A.2.4: Total NDS/NSA concentration $\left(\mu \mathrm{g} \mathrm{kg}{ }^{-1}\right)$ versus time after injection at $25^{\circ} \mathrm{C}$ quartz, $25^{\circ} \mathrm{C}$ - greywacke, $100^{\circ} \mathrm{C}$ - greywacke, $250^{\circ} \mathrm{C}$ - greywacke. 


\section{B Experimental data}

\section{B.1 Supplementary material Chapter 2, Set 1, 1,5-NDS}

Table B.1: $1,5-\mathrm{NDS}$ concentration in $\mathrm{mol} \mathrm{kg}^{-1}$ (HPLC).

\begin{tabular}{|c|c|c|c|c|c|}
\hline \multirow{2}{*}{ Identifier } & \multirow[b]{2}{*}{ time/day } & \multicolumn{4}{|c|}{ replicates/mol· $\mathrm{kg}^{-1}$} \\
\hline & & $\# 1$ & \#2 & \#3 & $\# 4$ \\
\hline \multirow{4}{*}{$\begin{array}{c}\mathrm{pH}=7.0 \\
\mathrm{NaCl}=0.050 \mathrm{~m} \text { and } \\
\mathrm{Na}_{2} \mathrm{~S}=2.69 \times 10^{-05} \mathrm{~m}, \\
250^{\circ} \mathrm{C}\end{array}$} & 0.0 & $9.11 \mathrm{E}-08$ & & & \\
\hline & 7.8 & $5.58 \mathrm{E}-08$ & $3.81 \mathrm{E}-08$ & 4.91E-08 & \\
\hline & 30.6 & $2.98 \mathrm{E}-08$ & $3.17 \mathrm{E}-08$ & $1.96 \mathrm{E}-08$ & \\
\hline & 45.8 & $7.66 \mathrm{E}-09$ & $7.08 \mathrm{E}-09$ & 7.67E-09 & \\
\hline \multirow{4}{*}{$\begin{array}{c}\mathrm{pH}=7.0 \\
\mathrm{NaCl}=0.050 \mathrm{~m} \text { and } \\
\mathrm{Na}_{2} \mathrm{~S}=2.69 \times 10^{-05} \mathrm{~m}, \\
270^{\circ} \mathrm{C}\end{array}$} & 0.0 & $9.21 \mathrm{E}-08$ & & & \\
\hline & 8.1 & $4.68 \mathrm{E}-08$ & $5.66 \mathrm{E}-08$ & $2.43 \mathrm{E}-08$ & \\
\hline & 13.9 & $6.4 \mathrm{E}-09$ & $1.71 \mathrm{E}-08$ & $3.23 \mathrm{E}-08$ & \\
\hline & 24.1 & 7.67E-10 & 4.88E-09 & 3.49E-09 & 2.72E-09 \\
\hline \multirow{4}{*}{$\begin{array}{c}\mathrm{pH}=7.0 \\
\mathrm{NaCl}=0.050 \mathrm{~m} \text { and } \\
\mathrm{Na}_{2} \mathrm{~S}=2.69 \times 10^{-05} \mathrm{~m}, \\
300^{\circ} \mathrm{C}\end{array}$} & 0.0 & $9.21 \mathrm{E}-08$ & & & \\
\hline & 4.0 & $1.00 \mathrm{E}-08$ & $2.93 \mathrm{E}-08$ & $1.76 \mathrm{E}-08$ & \\
\hline & 10.1 & $1.11 \mathrm{E}-09$ & $1.68 \mathrm{E}-10$ & $7.16 \mathrm{E}-10$ & \\
\hline & 13.1 & $3.49 \mathrm{E}-11$ & $4.54 \mathrm{E}-11$ & 7.34E-11 & \\
\hline \multirow{3}{*}{$\begin{array}{c}\mathrm{pH}=7.0 \\
\mathrm{Na}_{2} \mathrm{SO}_{4}=0.020 \mathrm{~m}, \\
250^{\circ} \mathrm{C}\end{array}$} & 0.0 & $7.99 \mathrm{E}-08$ & & & \\
\hline & 17.9 & $5.62 \mathrm{E}-08$ & 7.36E-08 & $5.99 \mathrm{E}-08$ & \\
\hline & 40.8 & $3.32 \mathrm{E}-08$ & $4.41 \mathrm{E}-08$ & $4.38 \mathrm{E}-08$ & \\
\hline \multirow{4}{*}{$\begin{array}{c}\mathrm{pH}=7.0 \\
\mathrm{Na}_{2} \mathrm{SO}_{4}=0.020 \mathrm{~m}, \\
270^{\circ} \mathrm{C}\end{array}$} & 0.0 & $8.06 \mathrm{E}-08$ & & & \\
\hline & 8.1 & 7.33E-08 & $7.68 \mathrm{E}-08$ & $7.68 \mathrm{E}-08$ & $6.31 \mathrm{E}-08$ \\
\hline & 13.9 & $4.93 \mathrm{E}-08$ & $5.38 \mathrm{E}-08$ & 4.86E-08 & $4.96 \mathrm{E}-08$ \\
\hline & 24.1 & 4.18E-08 & 4.6E-08 & $3.2 \mathrm{E}-08$ & \\
\hline \multirow{4}{*}{$\begin{array}{c}\mathrm{pH}=7.0 \\
\mathrm{Na}_{2} \mathrm{SO}_{4}=0.020 \mathrm{~m}, \\
300^{\circ} \mathrm{C}\end{array}$} & 0.0 & $8.06 \mathrm{E}-08$ & & & \\
\hline & 5.9 & $6.97 \mathrm{E}-08$ & $6.43 \mathrm{E}-08$ & $6.32 \mathrm{E}-08$ & $6.91 \mathrm{E}-08$ \\
\hline & 8.9 & $5.59 \mathrm{E}-08$ & $4.70 \mathrm{E}-08$ & $4.54 \mathrm{E}-08$ & \\
\hline & 13.7 & $3.18 \mathrm{E}-08$ & $2.98 \mathrm{E}-08$ & $2.52 \mathrm{E}-08$ & $2.15 \mathrm{E}-08$ \\
\hline \multirow{3}{*}{$\begin{array}{c}\mathrm{pH}=7.0, \\
\mathrm{NaCl}=0.050 \mathrm{~m}+ \\
\text { pyrite, } 250^{\circ} \mathrm{C}\end{array}$} & 0.0 & 7.77E-08 & & & \\
\hline & 17.9 & $3.31 \mathrm{E}-08$ & $2.84 \mathrm{E}-08$ & $2.45 \mathrm{E}-08$ & \\
\hline & 40.8 & $3.11 \mathrm{E}-09$ & $6.20 \mathrm{E}-09$ & $9.90 \mathrm{E}-09$ & \\
\hline \multirow{4}{*}{$\begin{array}{c}\mathrm{pH}=7.0, \\
\mathrm{NaCl}=0.050 \mathrm{~m}+ \\
\text { pyrite, } 270^{\circ} \mathrm{C}\end{array}$} & 0.0 & $7.87 \mathrm{E}-08$ & & & \\
\hline & 8.1 & $8.14 \mathrm{E}-09$ & $1.27 \mathrm{E}-08$ & $1.64 \mathrm{E}-08$ & 7.14E-09 \\
\hline & 13.9 & $5.59 \mathrm{E}-09$ & $5.13 \mathrm{E}-09$ & 2.39E-09 & \\
\hline & 24.1 & $2.2 \mathrm{E}-09$ & $2.06 \mathrm{E}-09$ & $3.31 \mathrm{E}-09$ & $1.38 \mathrm{E}-09$ \\
\hline \multirow{4}{*}{$\begin{array}{c}\mathrm{pH}=7.0, \\
\mathrm{NaCl}=0.050 \mathrm{~m}+ \\
\text { pyrite }, 300^{\circ} \mathrm{C}\end{array}$} & 0.0 & $7.87 \mathrm{E}-08$ & & & \\
\hline & 5.9 & $3.32 \mathrm{E}-10$ & $1.92 \mathrm{E}-09$ & $1.5 \mathrm{E}-10$ & \\
\hline & 8.9 & $2.45 \mathrm{E}-11$ & $6.43 \mathrm{E}-10$ & $2.20 \mathrm{E}-10$ & \\
\hline & 13.7 & $1.75 \mathrm{E}-11$ & $1.75 \mathrm{E}-11$ & $1.75 \mathrm{E}-11$ & $1.40 \mathrm{E}-11$ \\
\hline
\end{tabular}


B.2 Supplementary material Chapter 2, Set 1, 1-NSA

Table B.2: 1-NSA concentration in $\mathrm{mol} \mathrm{kg}^{-1}$ (HPLC).

\begin{tabular}{|c|c|c|c|c|c|}
\hline \multirow{6}{*}{$\begin{array}{c}\text { Identifier } \\
\mathrm{pH}=7.0 \\
\mathrm{NaCl}=0.050 \mathrm{~m} \text { and } \\
\mathrm{Na}_{2} \mathrm{~S}=2.69 \times 10^{-05} \mathrm{~m}, \\
250^{\circ} \mathrm{C}\end{array}$} & \multicolumn{5}{|c|}{ replicates $/ \mathrm{mol} \cdot \mathrm{kg}^{-1}$} \\
\hline & \multirow{2}{*}{$\begin{array}{c}\text { time/day } \\
0.0\end{array}$} & $\# 1$ & \multirow[t]{2}{*}{$\# 2$} & $\# \mathbf{3}$ & \multirow[t]{5}{*}{$\# 4$} \\
\hline & & $7.02 \mathrm{E}-10$ & & & \\
\hline & 7.8 & $9.3 \mathrm{E}-09$ & 5.59E-09 & $5.47 \mathrm{E}-09$ & \\
\hline & 30.6 & $2.16 \mathrm{E}-08$ & $2.13 \mathrm{E}-08$ & $1.64 \mathrm{E}-08$ & \\
\hline & 45.8 & $2.55 \mathrm{E}-09$ & $3.15 \mathrm{E}-09$ & $2.25 \mathrm{E}-09$ & \\
\hline \multirow{4}{*}{$\begin{array}{c}\mathrm{pH}=7.0 \\
\mathrm{NaCl}=0.050 \mathrm{~m} \text { and } \\
\mathrm{Na}_{2} \mathrm{~S}=2.69 \times 10^{-05} \mathrm{~m}, \\
270^{\circ} \mathrm{C}\end{array}$} & 0.0 & $0.00 \mathrm{E}+00$ & & & \\
\hline & 8.1 & $1.72 \mathrm{E}-08$ & $2.37 \mathrm{E}-08$ & $1.81 \mathrm{E}-08$ & \\
\hline & 13.9 & 4.88E-09 & $5.98 \mathrm{E}-09$ & $1.28 \mathrm{E}-08$ & \\
\hline & 24.1 & 7.67E-10 & 4.88E-09 & 3.49E-09 & $2.72 \mathrm{E}-09$ \\
\hline \multirow{4}{*}{$\begin{array}{c}\mathrm{pH}=7.0 \\
\mathrm{NaCl}=0.050 \mathrm{~m} \text { and } \\
\mathrm{Na}_{2} \mathrm{~S}=2.69 \times 10^{-05} \mathrm{~m}, \\
300^{\circ} \mathrm{C}\end{array}$} & 0.0 & $0.00 \mathrm{E}+00$ & & & \\
\hline & 4.0 & $2.68 \mathrm{E}-08$ & $2.94 \mathrm{E}-08$ & 2.63E-08 & \\
\hline & 10.1 & $1.22 \mathrm{E}-10$ & $8.10 \mathrm{E}-10$ & $5.24 \mathrm{E}-11$ & \\
\hline & 13.1 & $4.63 \mathrm{E}-10$ & $7.58 \mathrm{E}-10$ & $1.14 \mathrm{E}-09$ & \\
\hline \multirow{3}{*}{$\begin{array}{c}\mathrm{pH}=7.0 \\
\mathrm{Na}_{2} \mathrm{SO}_{4}=0.020 \mathrm{~m}, \\
250^{\circ} \mathrm{C}\end{array}$} & 0.0 & $6.86 \mathrm{E}-10$ & & & \\
\hline & 17.9 & 4.71E-09 & $2.45 \mathrm{E}-09$ & 3.34E-09 & \\
\hline & 40.8 & $6.73 \mathrm{E}-09$ & $6.56 \mathrm{E}-09$ & $3.96 \mathrm{E}-09$ & \\
\hline \multirow{4}{*}{$\begin{array}{c}\mathrm{pH}=7.0 \\
\mathrm{Na}_{2} \mathrm{SO}_{4}=0.020 \mathrm{~m}, \\
270^{\circ} \mathrm{C}\end{array}$} & 0.0 & $0.00 \mathrm{E}+00$ & & & \\
\hline & 8.1 & $3.04 \mathrm{E}-09$ & 3.47E-09 & $3.28 \mathrm{E}-09$ & $4.58 \mathrm{E}-09$ \\
\hline & 13.9 & $5.76 \mathrm{E}-09$ & $6.24 \mathrm{E}-09$ & $9.26 \mathrm{E}-09$ & 7.63E-09 \\
\hline & 24.1 & $1.72 \mathrm{E}-08$ & $1.44 \mathrm{E}-08$ & $9.54 \mathrm{E}-09$ & \\
\hline \multirow{4}{*}{$\begin{array}{c}\mathrm{pH}=7.0 \\
\mathrm{Na}_{2} \mathrm{SO}_{4}=0.020 \mathrm{~m} \\
300^{\circ} \mathrm{C}\end{array}$} & 0.0 & $0.00 \mathrm{E}+00$ & & & \\
\hline & 5.9 & $8.41 \mathrm{E}-09$ & 7.35E-09 & $1.16 \mathrm{E}-08$ & $1.1 \mathrm{E}-08$ \\
\hline & 8.9 & 7.29E-09 & 7.28E-09 & 1.54E-08 & \\
\hline & 13.7 & $8.83 \mathrm{E}-10$ & $1.01 \mathrm{E}-08$ & $5.24 \mathrm{E}-09$ & $3.19 \mathrm{E}-09$ \\
\hline \multirow{3}{*}{$\begin{array}{c}\mathrm{pH}=7.0, \\
\mathrm{NaCl}=0.050 \mathrm{~m}+ \\
\text { pyrite }, 250^{\circ} \mathrm{C}\end{array}$} & 0.0 & $3.78 \mathrm{E}-10$ & & & \\
\hline & 17.9 & $1.92 \mathrm{E}-08$ & $2.28 \mathrm{E}-08$ & $2.38 \mathrm{E}-08$ & \\
\hline & 40.8 & $1.15 \mathrm{E}-08$ & $1.70 \mathrm{E}-08$ & $1.20 \mathrm{E}-08$ & \\
\hline \multirow{4}{*}{$\begin{array}{c}\mathrm{pH}=7.0, \\
\mathrm{NaCl}=0.050 \mathrm{~m}+ \\
\text { pyrite }, 270^{\circ} \mathrm{C}\end{array}$} & 0.0 & $0.00 \mathrm{E}+00$ & & & \\
\hline & 8.1 & $2.01 \mathrm{E}-08$ & $2.03 \mathrm{E}-08$ & 2.35E-08 & $2.23 \mathrm{E}-08$ \\
\hline & 13.9 & 2.01E-08 & $2.03 \mathrm{E}-08$ & $2.35 \mathrm{E}-08$ & \\
\hline & 24.1 & $1.25 \mathrm{E}-08$ & 9.17E-09 & $1.34 \mathrm{E}-08$ & 7.87E-09 \\
\hline \multirow{4}{*}{$\begin{array}{c}\mathrm{pH}=7.0, \\
\mathrm{NaCl}=0.050 \mathrm{~m}+ \\
\text { pyrite }, 300^{\circ} \mathrm{C}\end{array}$} & 0.0 & $0.00 \mathrm{E}+00$ & & & \\
\hline & 5.9 & $8.54 \mathrm{E}-10$ & $5.94 \mathrm{E}-10$ & $1.25 \mathrm{E}-09$ & \\
\hline & 8.9 & $5.55 \mathrm{E}-10$ & $9.36 \mathrm{E}-10$ & $5.21 \mathrm{E}-10$ & \\
\hline & 13.7 & $4.54 \mathrm{E}-10$ & $9.31 \mathrm{E}-10$ & $4.78 \mathrm{E}-10$ & $7.91 \mathrm{E}-10$ \\
\hline
\end{tabular}




\section{B.3 Supplementary material Chapter 2, Set 2, 1,5-NDS}

Table B.3: $1,5-\mathrm{NDS}$ concentration in $\mathrm{mol} \mathrm{kg}^{-1}$ (HPLC).

\begin{tabular}{|c|c|c|c|c|c|c|c|c|c|c|c|}
\hline & & & & & licates/mo & & not detect & & & & \\
\hline Identifier & time/day & $\# 1$ & $\# 2$ & $\# 3$ & $\# 4$ & $\# 5$ & $\# 6$ & $\# 7$ & $\# 8$ & $\# 9$ & $\# 10$ \\
\hline \multirow{7}{*}{$\begin{array}{c}\mathrm{pH}=3.0, \text { pure water } \\
200^{\circ} \mathrm{C}\end{array}$} & 0.0 & 5.54E-08 & & & & & & & & & \\
\hline & 0.4 & $1.98 \mathrm{E}-08$ & & & & & & & & & \\
\hline & 0.8 & $5.48 \mathrm{E}-09$ & $3.89 \mathrm{E}-08$ & $1.44 \mathrm{E}-08$ & 4.19E-08 & $1.52 \mathrm{E}-08$ & $1.30 \mathrm{E}-08$ & & & & \\
\hline & 1.7 & $1.93 \mathrm{E}-08$ & $2.16 \mathrm{E}-08$ & 1.64E-08 & $2.16 \mathrm{E}-08$ & 8.81E-09 & & & & & \\
\hline & 2.5 & 8.72E-09 & $2.40 \mathrm{E}-08$ & & & & & & & & \\
\hline & 4.2 & $1.05 \mathrm{E}-08$ & $1.05 \mathrm{E}-08$ & & & & & & & & \\
\hline & 6.9 & 5.51E-09 & 2.69E-09 & 2.09E-08 & $3.15 \mathrm{E}-08$ & $2.15 \mathrm{E}-09$ & & & & & \\
\hline \multirow{6}{*}{$\begin{array}{c}\mathrm{pH}=3.0, \text { pure water, } \\
300^{\circ} \mathrm{C}\end{array}$} & 0.0 & $5.54 \mathrm{E}-08$ & & & & & & & & & \\
\hline & 0.4 & n.d & n.d & n.d & n.d & n.d & & & & & \\
\hline & 0.8 & n.d & n.d & n.d & & & & & & & \\
\hline & 1.7 & n.d & n.d & n.d & n.d & & & & & & \\
\hline & 2.5 & n.d & n.d & n.d & & & & & & & \\
\hline & 6.9 & n.d & n.d & n.d & & & & & & & \\
\hline \multirow{7}{*}{$\begin{array}{c}\mathrm{pH}=4.0, \text { pure water, } \\
200^{\circ} \mathrm{C}\end{array}$} & 0.0 & 7.29E-08 & & & & & & & & & \\
\hline & 0.4 & 4.05E-08 & & & & & & & & & \\
\hline & 0.8 & 2.37E-08 & $2.50 \mathrm{E}-08$ & 2.05E-08 & 2.02E-08 & 2.33E-08 & 2.97E-08 & & & & \\
\hline & 1.7 & $2.17 \mathrm{E}-08$ & $1.58 \mathrm{E}-08$ & $2.11 \mathrm{E}-08$ & $1.39 \mathrm{E}-08$ & $1.20 \mathrm{E}-08$ & $1.42 \mathrm{E}-08$ & 2.40E-08 & & & \\
\hline & 2.5 & $1.26 \mathrm{E}-08$ & $6.72 \mathrm{E}-09$ & & & & & & & & \\
\hline & 4.2 & $1.02 \mathrm{E}-08$ & & & & & & & & & \\
\hline & 6.9 & 4.47E-09 & $9.71 \mathrm{E}-09$ & $9.75 \mathrm{E}-09$ & 1.12E-08 & $3.60 \mathrm{E}-09$ & 4.86E-09 & $1.20 \mathrm{E}-08$ & $1.25 \mathrm{E}-08$ & $1.11 \mathrm{E}-08$ & \\
\hline \multirow{4}{*}{$\begin{array}{c}\mathrm{pH}=4.0, \text { pure water } \\
300^{\circ} \mathrm{C}\end{array}$} & 0.0 & 7.29E-08 & & & & & & & & & \\
\hline & 0.4 & n.d & n.d & n.d & n.d & n.d & & & & & \\
\hline & 0.8 & n.d & n.d & n.d & n.d & n.d & n.d & & & & \\
\hline & 1.7 & n.d & n.d & n.d & n.d & & & & & & \\
\hline
\end{tabular}




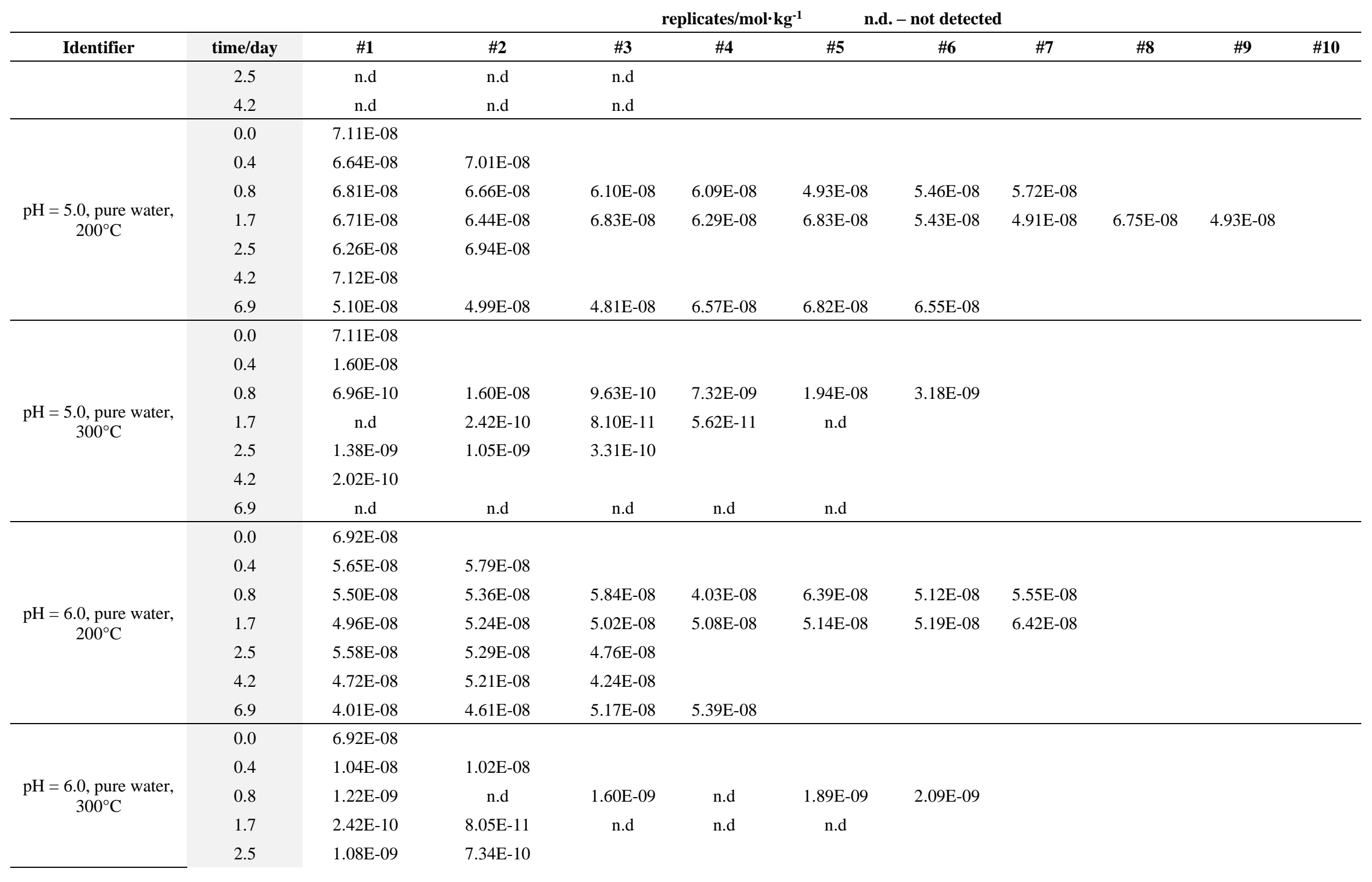




\begin{tabular}{|c|c|c|c|c|c|c|c|c|c|c|c|}
\hline & & & & & licates/mol & & - not detect & & & & \\
\hline Identifier & time/day & $\# 1$ & $\# 2$ & $\# \mathbf{3}$ & $\# 4$ & $\# 5$ & $\# 6$ & $\# 7$ & $\# 8$ & $\# 9$ & $\# 10$ \\
\hline & 4.2 & $4.52 \mathrm{E}-10$ & $9.05 \mathrm{E}-10$ & n.d & & & & & & & \\
\hline & 6.9 & n.d & n.d & n.d & n.d & n.d & & & & & \\
\hline \multirow{7}{*}{$\begin{array}{c}\mathrm{pH}=8.0, \text { pure water, } \\
200^{\circ} \mathrm{C}\end{array}$} & 0.0 & $7.21 \mathrm{E}-08$ & & & & & & & & & \\
\hline & 0.4 & $3.68 \mathrm{E}-08$ & & & & & & & & & \\
\hline & 0.8 & 4.95E-08 & $5.40 \mathrm{E}-08$ & $5.51 \mathrm{E}-08$ & $5.66 \mathrm{E}-08$ & $5.42 \mathrm{E}-08$ & $5.12 \mathrm{E}-08$ & & & & \\
\hline & 1.7 & 3.94E-08 & $5.35 \mathrm{E}-08$ & $5.12 \mathrm{E}-08$ & $4.50 \mathrm{E}-08$ & 4.64E-08 & $4.51 \mathrm{E}-08$ & 5.38E-08 & $5.53 \mathrm{E}-08$ & & \\
\hline & 2.5 & 4.89E-08 & 4.27E-08 & & & & & & & & \\
\hline & 4.2 & $5.04 \mathrm{E}-08$ & $5.50 \mathrm{E}-08$ & $4.58 \mathrm{E}-08$ & & & & & & & \\
\hline & 6.9 & $5.14 \mathrm{E}-08$ & $4.71 \mathrm{E}-08$ & $6.66 \mathrm{E}-08$ & $6.64 \mathrm{E}-08$ & $5.12 \mathrm{E}-08$ & 4.69E-08 & & & & \\
\hline \multirow{7}{*}{$\begin{array}{c}\mathrm{pH}=8.0, \text { pure water, } \\
300^{\circ} \mathrm{C}\end{array}$} & 0.0 & 7.21E-08 & & & & & & & & & \\
\hline & 0.4 & 4.12E-09 & 7.09E-09 & $1.14 \mathrm{E}-08$ & & & & & & & \\
\hline & 0.8 & $1.05 \mathrm{E}-09$ & $1.12 \mathrm{E}-09$ & $1.99 \mathrm{E}-09$ & $1.29 \mathrm{E}-09$ & $1.15 \mathrm{E}-09$ & $9.08 \mathrm{E}-10$ & & & & \\
\hline & 1.7 & n.d & n.d & n.d & n.d & n.d & n.d & $2.45 \mathrm{E}-10$ & & & \\
\hline & 2.5 & n.d & n.d & & & & & & & & \\
\hline & 4.2 & n.d & n.d & n.d & & & & & & & \\
\hline & 6.9 & n.d & n.d & n.d & n.d & n.d & n.d & n.d & & & \\
\hline \multirow{7}{*}{$\begin{array}{c}\mathrm{pH}=9.0, \text { pure water } \\
200^{\circ} \mathrm{C}\end{array}$} & 0.0 & $8.58 \mathrm{E}-08$ & & & & & & & & & \\
\hline & 0.4 & $8.31 \mathrm{E}-08$ & $8.16 \mathrm{E}-08$ & & & & & & & & \\
\hline & 0.8 & 7.44E-08 & 7.81E-08 & $7.96 \mathrm{E}-08$ & $8.28 \mathrm{E}-08$ & $7.81 \mathrm{E}-08$ & $6.76 \mathrm{E}-08$ & & & & \\
\hline & 1.7 & $7.58 \mathrm{E}-08$ & $6.69 \mathrm{E}-08$ & 7.16E-08 & $6.82 \mathrm{E}-08$ & 7.67E-08 & $6.61 \mathrm{E}-08$ & 7.29E-08 & 7.35E-08 & & \\
\hline & 2.5 & 7.47E-08 & 7.12E-08 & 7.47E-08 & & & & & & & \\
\hline & 4.2 & $6.34 \mathrm{E}-08$ & $5.67 \mathrm{E}-08$ & & & & & & & & \\
\hline & 6.9 & $5.23 \mathrm{E}-08$ & $5.73 \mathrm{E}-08$ & $5.08 \mathrm{E}-08$ & $5.54 \mathrm{E}-08$ & $5.40 \mathrm{E}-08$ & $5.02 \mathrm{E}-08$ & & & & \\
\hline \multirow{3}{*}{$\begin{array}{c}\mathrm{pH}=9.0, \text { pure water, } \\
300^{\circ} \mathrm{C}\end{array}$} & 1.0 & $1.69 \mathrm{E}-08$ & $1.61 \mathrm{E}-08$ & $1.64 \mathrm{E}-08$ & $1.22 \mathrm{E}-08$ & $1.28 \mathrm{E}-08$ & $3.01 \mathrm{E}-09$ & & & & \\
\hline & 2.0 & $1.72 \mathrm{E}-09$ & $2.25 \mathrm{E}-09$ & $1.72 \mathrm{E}-09$ & $1.71 \mathrm{E}-09$ & $1.61 \mathrm{E}-09$ & & & & & \\
\hline & 6.0 & $2.01 \mathrm{E}-11$ & $0.00 \mathrm{E}+00$ & $0.00 \mathrm{E}+00$ & $0.00 \mathrm{E}+00$ & $0.00 \mathrm{E}+00$ & $0.00 \mathrm{E}+00$ & & & & \\
\hline
\end{tabular}




\begin{tabular}{|c|c|c|c|c|c|c|c|c|c|c|c|}
\hline & & & & & licates/mol & & - not detect & & & & \\
\hline \multirow[t]{3}{*}{ Identifier } & time/day & $\# 1$ & $\# 2$ & $\# \mathbf{3}$ & $\# 4$ & $\# 5$ & $\# 6$ & \#7 & $\# 8$ & $\# 9$ & $\# 10$ \\
\hline & 12.0 & $0.00 \mathrm{E}+00$ & $0.00 \mathrm{E}+00$ & $0.00 \mathrm{E}+00$ & $0.00 \mathrm{E}+00$ & $0.00 \mathrm{E}+00$ & $0.00 \mathrm{E}+00$ & & & & \\
\hline & 21.0 & $0.00 \mathrm{E}+00$ & $0.00 \mathrm{E}+00$ & $0.00 \mathrm{E}+00$ & $0.00 \mathrm{E}+00$ & $0.00 \mathrm{E}+00$ & $0.00 \mathrm{E}+00$ & & & & \\
\hline \multirow{7}{*}{$\begin{array}{c}\mathrm{pH}=10.0, \text { pure } \\
\text { water, } 200^{\circ} \mathrm{C}\end{array}$} & 0.0 & $7.25 \mathrm{E}-08$ & & & & & & & & & \\
\hline & 0.4 & $6.55 \mathrm{E}-08$ & $6.49 \mathrm{E}-08$ & $7.08 \mathrm{E}-08$ & & & & & & & \\
\hline & 0.8 & $6.89 \mathrm{E}-08$ & $5.38 \mathrm{E}-08$ & $6.91 \mathrm{E}-08$ & $6.85 \mathrm{E}-08$ & $6.50 \mathrm{E}-08$ & 7.07E-08 & & & & \\
\hline & 1.7 & $6.02 \mathrm{E}-08$ & $6.49 \mathrm{E}-08$ & $6.48 \mathrm{E}-08$ & $5.93 \mathrm{E}-08$ & & & & & & \\
\hline & 2.5 & 5.32E-08 & 5.31E-08 & $6.45 \mathrm{E}-08$ & & & & & & & \\
\hline & 4.2 & $5.15 \mathrm{E}-08$ & $5.08 \mathrm{E}-08$ & 5.67E-08 & $5.96 \mathrm{E}-08$ & & & & & & \\
\hline & 6.9 & $5.50 \mathrm{E}-08$ & $4.08 \mathrm{E}-08$ & $3.55 \mathrm{E}-08$ & & & & & & & \\
\hline \multirow{7}{*}{$\begin{array}{c}\mathrm{pH}=10.0, \text { pure } \\
\text { water, } 300^{\circ} \mathrm{C}\end{array}$} & 0.0 & 7.25E-08 & & & & & & & & & \\
\hline & 0.4 & $4.05 \mathrm{E}-08$ & & & & & & & & & \\
\hline & 0.8 & 2.37E-08 & $2.50 \mathrm{E}-08$ & $2.05 \mathrm{E}-08$ & $2.02 \mathrm{E}-08$ & $2.33 \mathrm{E}-08$ & $2.97 \mathrm{E}-08$ & & & & \\
\hline & 1.7 & 2.17E-08 & $1.58 \mathrm{E}-08$ & $2.11 \mathrm{E}-08$ & $1.39 \mathrm{E}-08$ & $1.20 \mathrm{E}-08$ & $1.42 \mathrm{E}-08$ & $2.40 \mathrm{E}-08$ & & & \\
\hline & 2.5 & $1.26 \mathrm{E}-08$ & $6.72 \mathrm{E}-09$ & & & & & & & & \\
\hline & 4.2 & $1.02 \mathrm{E}-08$ & & & & & & & & & \\
\hline & 6.9 & 4.47E-09 & $9.71 \mathrm{E}-09$ & $9.75 \mathrm{E}-09$ & $1.12 \mathrm{E}-08$ & $3.60 \mathrm{E}-09$ & 4.86E-09 & $1.20 \mathrm{E}-08$ & $1.25 \mathrm{E}-08$ & & \\
\hline \multirow{7}{*}{$\begin{array}{c}\mathrm{pH}=11.0, \text { pure } \\
\text { water, } 200^{\circ} \mathrm{C}\end{array}$} & 0.0 & 7.29E-08 & & & & & & & & & \\
\hline & 0.4 & $5.64 \mathrm{E}-08$ & $5.93 \mathrm{E}-08$ & & & & & & & & \\
\hline & 0.8 & $5.34 \mathrm{E}-08$ & $6.90 \mathrm{E}-08$ & 4.99E-08 & $5.77 \mathrm{E}-08$ & $5.28 \mathrm{E}-08$ & $6.50 \mathrm{E}-08$ & & & & \\
\hline & 1.7 & $5.67 \mathrm{E}-08$ & $5.10 \mathrm{E}-08$ & $5.03 \mathrm{E}-08$ & $6.18 \mathrm{E}-08$ & $5.95 \mathrm{E}-08$ & $4.68 \mathrm{E}-08$ & & & & \\
\hline & 2.5 & $4.65 \mathrm{E}-08$ & $5.29 \mathrm{E}-08$ & & & & & & & & \\
\hline & 4.2 & 4.86E-08 & $4.45 \mathrm{E}-08$ & & & & & & & & \\
\hline & 6.9 & 4.59E-08 & $5.15 \mathrm{E}-08$ & $4.50 \mathrm{E}-08$ & $6.25 \mathrm{E}-08$ & 4.54E-08 & & & & & \\
\hline \multirow{3}{*}{$\begin{array}{c}\mathrm{pH}=11.0, \text { pure } \\
\text { water, } 300^{\circ} \mathrm{C}\end{array}$} & 0.0 & 7.29E-08 & & & & & & & & & \\
\hline & 0.4 & $5.88 \mathrm{E}-08$ & 4.44E-08 & & & & & & & & \\
\hline & 0.8 & $3.30 \mathrm{E}-08$ & $4.66 \mathrm{E}-08$ & $3.46 \mathrm{E}-08$ & 4.37E-08 & $3.29 \mathrm{E}-08$ & $5.42 \mathrm{E}-08$ & & & & \\
\hline
\end{tabular}

160 


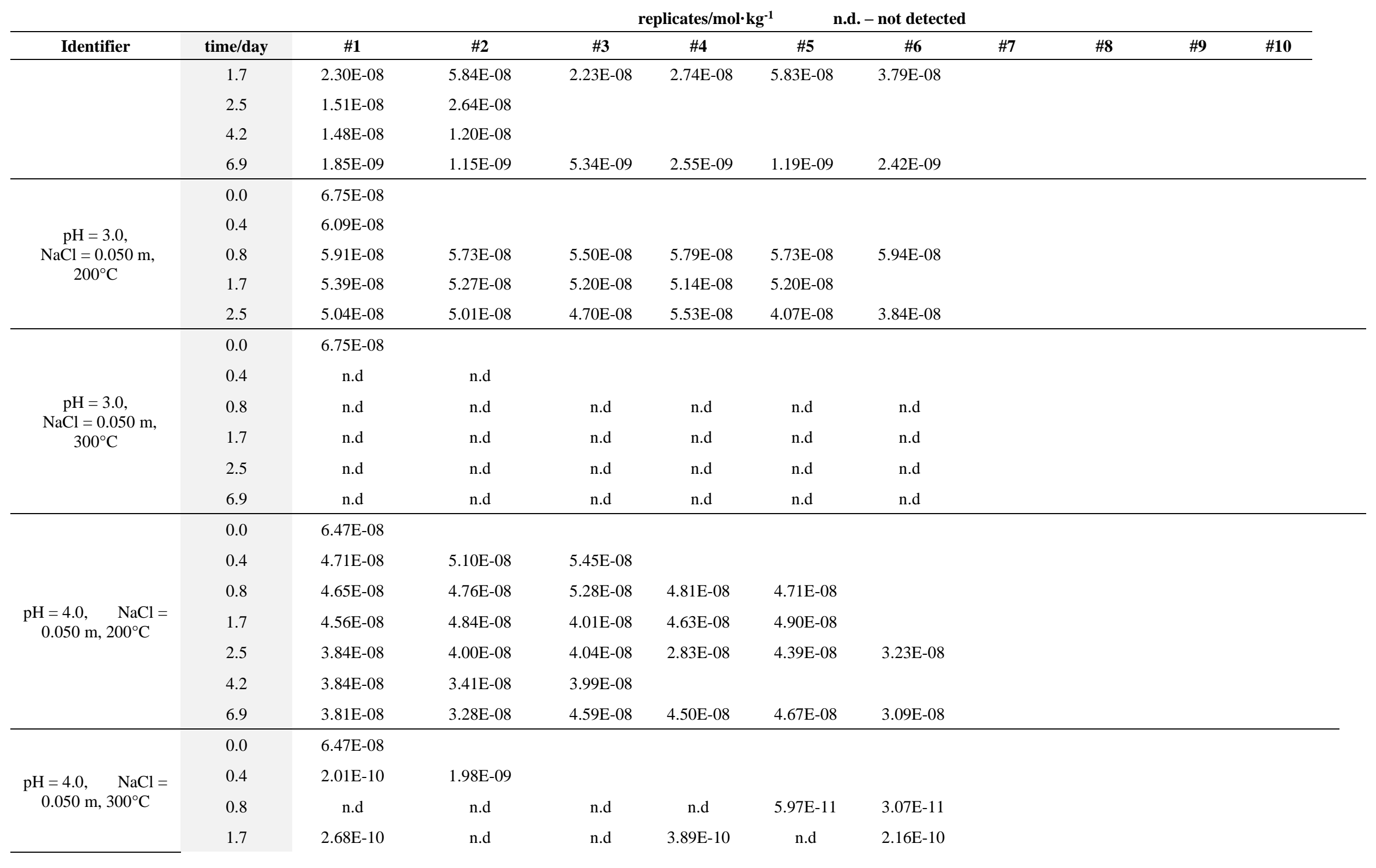




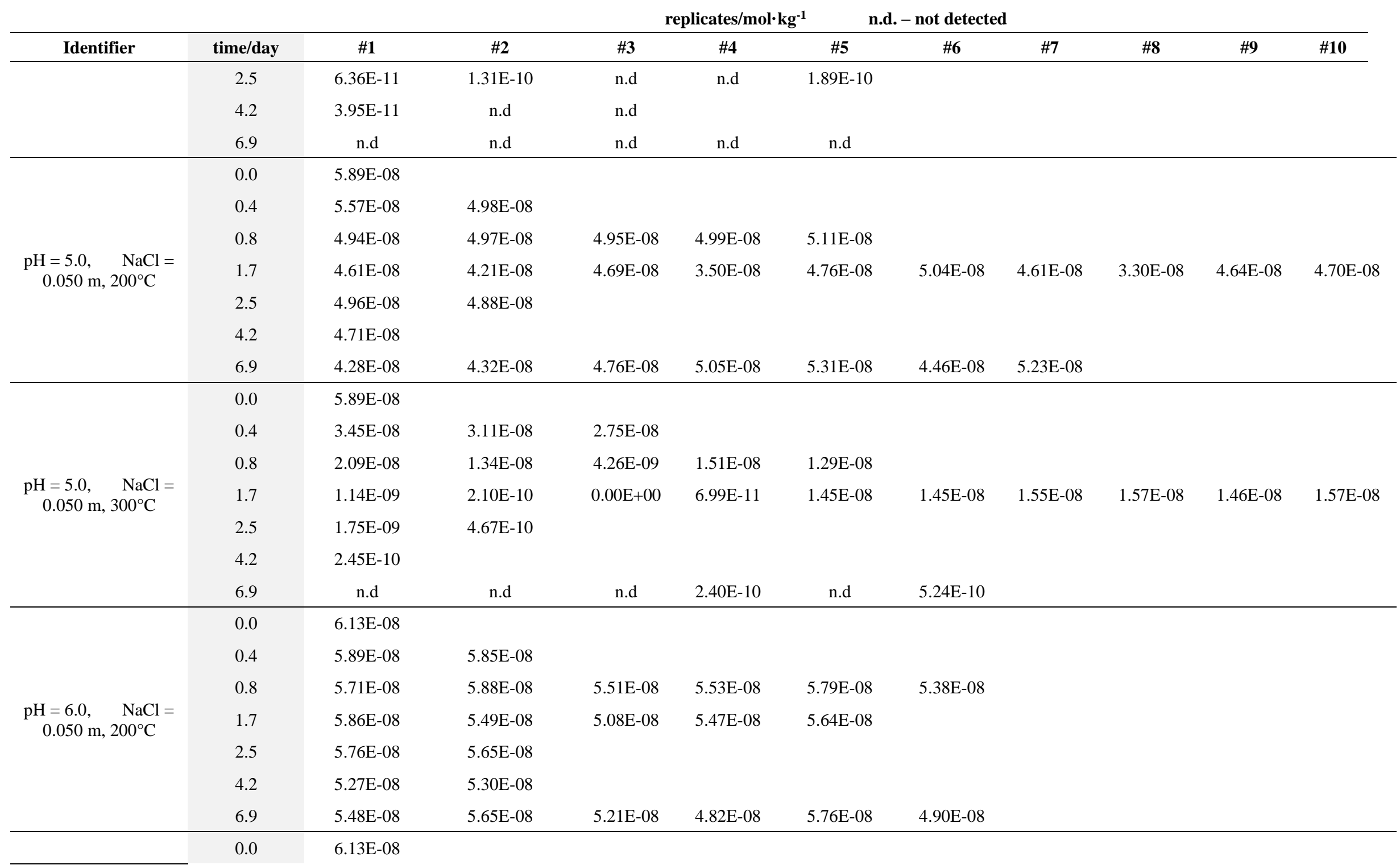




\begin{tabular}{|c|c|c|c|c|c|c|c|c|c|c|c|}
\hline & & & & & licates/mo & & not detecte & & & & \\
\hline Identifier & time/day & $\# 1$ & $\# 2$ & $\# \mathbf{3}$ & $\# 4$ & $\# 5$ & $\# 6$ & $\# 7$ & $\# 8$ & $\# 9$ & $\# 10$ \\
\hline \multirow{6}{*}{$\begin{array}{c}\mathrm{pH}=6.0, \quad \mathrm{NaCl}= \\
0.050 \mathrm{~m}, 300^{\circ} \mathrm{C}\end{array}$} & 0.4 & $3.25 \mathrm{E}-08$ & $3.56 \mathrm{E}-08$ & & & & & & & & \\
\hline & 0.8 & $2.38 \mathrm{E}-08$ & $2.87 \mathrm{E}-08$ & $3.18 \mathrm{E}-08$ & $2.35 \mathrm{E}-08$ & $2.98 \mathrm{E}-08$ & $2.52 \mathrm{E}-08$ & & & & \\
\hline & 1.7 & $1.89 \mathrm{E}-08$ & $1.74 \mathrm{E}-08$ & $1.74 \mathrm{E}-08$ & $1.52 \mathrm{E}-08$ & $1.96 \mathrm{E}-08$ & $1.87 \mathrm{E}-08$ & $1.01 \mathrm{E}-08$ & $1.77 \mathrm{E}-08$ & $1.72 \mathrm{E}-08$ & \\
\hline & 2.5 & $1.86 \mathrm{E}-08$ & $1.10 \mathrm{E}-08$ & & & & & & & & \\
\hline & 4.2 & $4.14 \mathrm{E}-10$ & $7.67 \mathrm{E}-10$ & & & & & & & & \\
\hline & 6.9 & n.d & n.d & n.d & n.d & n.d & n.d & & & & \\
\hline \multirow{7}{*}{$\begin{array}{c}\mathrm{pH}=8.0, \quad \mathrm{NaCl}= \\
0.050 \mathrm{~m}, 200^{\circ} \mathrm{C}\end{array}$} & 0.0 & $6.57 \mathrm{E}-08$ & & & & & & & & & \\
\hline & 0.4 & $6.49 \mathrm{E}-08$ & 6.39E-08 & & & & & & & & \\
\hline & 0.8 & $6.45 \mathrm{E}-08$ & 6.34E-08 & 6.57E-08 & 6.39E-08 & $6.46 \mathrm{E}-08$ & & & & & \\
\hline & 1.7 & $6.49 \mathrm{E}-08$ & $6.29 \mathrm{E}-08$ & $6.16 \mathrm{E}-08$ & $6.07 \mathrm{E}-08$ & 6.37E-08 & & & & & \\
\hline & 2.5 & $6.47 \mathrm{E}-08$ & $6.32 \mathrm{E}-08$ & & & & & & & & \\
\hline & 4.2 & $6.14 \mathrm{E}-08$ & 5.93E-08 & & & & & & & & \\
\hline & 6.9 & $5.87 \mathrm{E}-08$ & $5.43 \mathrm{E}-08$ & $6.19 \mathrm{E}-08$ & $6.05 \mathrm{E}-08$ & & & & & & \\
\hline \multirow{7}{*}{$\begin{array}{c}\mathrm{pH}=8.0, \quad \mathrm{NaCl}= \\
0.050 \mathrm{~m}, 300^{\circ} \mathrm{C}\end{array}$} & 0.0 & $6.57 \mathrm{E}-08$ & & & & & & & & & \\
\hline & 0.4 & $5.46 \mathrm{E}-08$ & 4.85E-08 & & & & & & & & \\
\hline & 0.8 & $4.76 \mathrm{E}-08$ & 2.04E-08 & $3.88 \mathrm{E}-08$ & $3.09 \mathrm{E}-08$ & & & & & & \\
\hline & 1.7 & 8.04E-09 & $1.25 \mathrm{E}-08$ & $2.22 \mathrm{E}-08$ & $1.70 \mathrm{E}-08$ & $1.42 \mathrm{E}-08$ & $1.46 \mathrm{E}-08$ & & & & \\
\hline & 2.5 & $9.78 \mathrm{E}-09$ & $1.10 \mathrm{E}-08$ & & & & & & & & \\
\hline & 4.2 & 2.44E-09 & $5.75 \mathrm{E}-09$ & & & & & & & & \\
\hline & 6.9 & $5.80 \mathrm{E}-10$ & n.d & $2.82 \mathrm{E}-09$ & n.d & $6.96 \mathrm{E}-10$ & $1.60 \mathrm{E}-10$ & 1.11E-09 & & & \\
\hline \multirow{5}{*}{$\begin{array}{c}\mathrm{pH}=9.0, \quad \mathrm{NaCl}= \\
0.050 \mathrm{~m}, 200^{\circ} \mathrm{C}\end{array}$} & 0.0 & $6.82 \mathrm{E}-08$ & & & & & & & & & \\
\hline & 0.4 & $6.17 \mathrm{E}-08$ & $6.72 \mathrm{E}-08$ & & & & & & & & \\
\hline & 0.8 & $6.71 \mathrm{E}-08$ & $6.13 \mathrm{E}-08$ & $6.91 \mathrm{E}-08$ & $6.32 \mathrm{E}-08$ & $6.71 \mathrm{E}-08$ & $5.66 \mathrm{E}-08$ & & & & \\
\hline & 1.7 & $6.20 \mathrm{E}-08$ & $6.39 \mathrm{E}-08$ & $5.96 \mathrm{E}-08$ & $6.64 \mathrm{E}-08$ & $5.58 \mathrm{E}-08$ & $6.98 \mathrm{E}-08$ & $6.13 \mathrm{E}-08$ & & & \\
\hline & 2.5 & $6.57 \mathrm{E}-08$ & $6.22 \mathrm{E}-08$ & $6.02 \mathrm{E}-08$ & & & & & & & \\
\hline
\end{tabular}




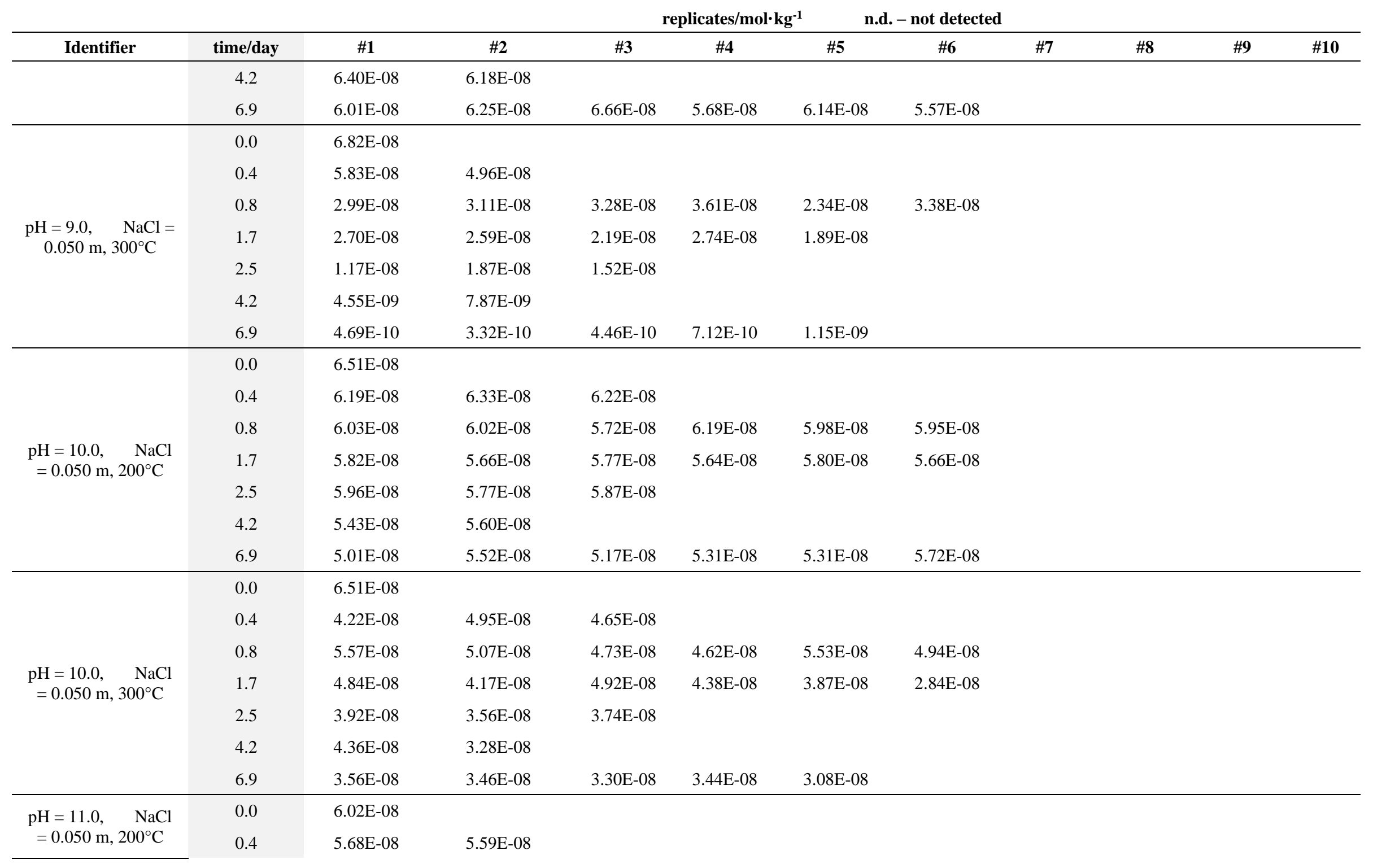




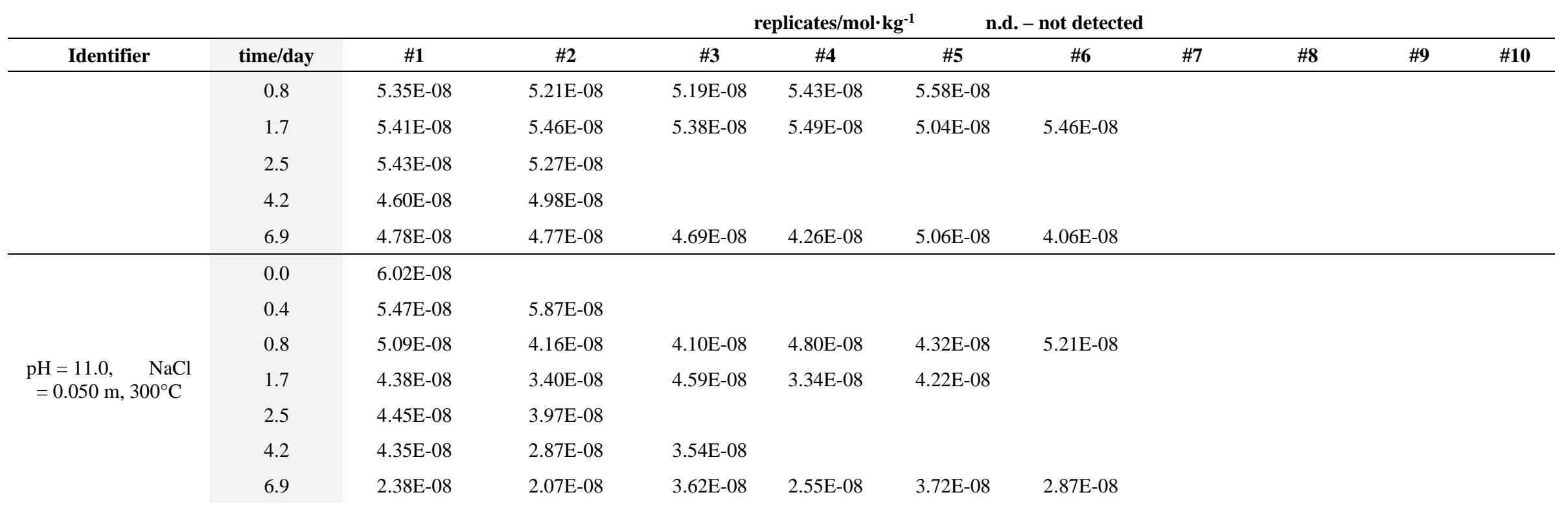

\section{B.4 Supplementary material Chapter 2, Set 2, 2-NSA}

Table B.4: 2-NSA concentration in $\mathrm{mol} \mathrm{kg}^{-1}$ (HPLC).

\begin{tabular}{|c|c|c|c|c|c|c|c|c|c|c|c|}
\hline & & & & & licates/mol & & not & & & & \\
\hline Identifier & time/day & $\# 1$ & $\# 2$ & $\# 3$ & $\# 4$ & $\# 5$ & \#6 & $\# 7$ & $\# 8$ & $\# 9$ & $\# 10$ \\
\hline \multirow{5}{*}{$\begin{array}{c}\mathrm{pH}=3.0, \text { pure } \\
\text { water, } 200^{\circ} \mathrm{C}\end{array}$} & 0.0 & $3.07 \mathrm{E}-08$ & \multirow[t]{3}{*}{ 3.07E-08 } & \multirow[t]{5}{*}{$3.01 \mathrm{E}-08$} & \multirow[t]{5}{*}{ 3.04E-08 } & \multirow[t]{5}{*}{$3.04 \mathrm{E}-08$} & & & & & \\
\hline & 0.4 & $2.83 \mathrm{E}-08$ & & & & & & & & & \\
\hline & 0.8 & 3.64E-08 & & & & & & & & & \\
\hline & 1.7 & $3.71 \mathrm{E}-08$ & \multirow[t]{2}{*}{ 3.94E-08 } & & & & & & & & \\
\hline & 2.5 & $1.36 \mathrm{E}-08$ & & & & & & & & & \\
\hline
\end{tabular}


replicates $/ \mathrm{mol} \cdot \mathrm{kg}^{-1}$

n.d. - not detected

\begin{tabular}{|c|c|c|c|c|c|c|c|c|c|c|c|}
\hline Identifier & time/day & $\# 1$ & $\# 2$ & $\# \mathbf{3}$ & $\# 4$ & $\# 5$ & $\# 6$ & $\# 7$ & $\# 8$ & $\# 9$ & $\# 10$ \\
\hline & 4.2 & $2.44 \mathrm{E}-08$ & & & & & & & & & \\
\hline & 6.9 & $1.11 \mathrm{E}-08$ & 8.96E-09 & & & & & & & & \\
\hline \multirow{7}{*}{$\begin{array}{c}\mathrm{pH}=3.0, \text { pure } \\
\text { water, } 300^{\circ} \mathrm{C}\end{array}$} & 0.0 & 3.07E-08 & 3.07E-08 & $3.01 \mathrm{E}-08$ & $3.04 \mathrm{E}-08$ & $3.04 \mathrm{E}-08$ & & & & & \\
\hline & 0.4 & $2.83 \mathrm{E}-08$ & & & & & & & & & \\
\hline & 0.8 & 3.64E-08 & & & & & & & & & \\
\hline & 1.7 & $3.71 \mathrm{E}-08$ & 3.94E-08 & & & & & & & & \\
\hline & 2.5 & $1.36 \mathrm{E}-08$ & & & & & & & & & \\
\hline & 4.2 & 2.44E-08 & & & & & & & & & \\
\hline & 6.9 & $1.11 \mathrm{E}-08$ & & & & & & & & & \\
\hline \multirow{7}{*}{$\begin{array}{c}\mathrm{pH}=4.0, \text { pure } \\
\text { water, } 200^{\circ} \mathrm{C}\end{array}$} & 0.0 & 4.31E-08 & 4.35E-08 & 4.40E-08 & 4.40E-08 & $3.67 \mathrm{E}-08$ & $3.78 \mathrm{E}-08$ & 4.53E-08 & 4.48E-08 & 4.48E-08 & \\
\hline & 0.4 & $3.16 \mathrm{E}-08$ & & & & & & & & & \\
\hline & 0.8 & $2.95 \mathrm{E}-08$ & $3.26 \mathrm{E}-08$ & $2.46 \mathrm{E}-08$ & $3.13 \mathrm{E}-08$ & $3.16 \mathrm{E}-08$ & $3.13 \mathrm{E}-08$ & & & & \\
\hline & 1.7 & 2.67E-08 & $2.89 \mathrm{E}-08$ & $3.22 \mathrm{E}-08$ & $2.80 \mathrm{E}-08$ & $3.10 \mathrm{E}-08$ & $3.36 \mathrm{E}-08$ & & & & \\
\hline & 2.5 & $2.72 \mathrm{E}-08$ & $2.46 \mathrm{E}-08$ & & & & & & & & \\
\hline & 4.2 & $3.07 \mathrm{E}-08$ & & & & & & & & & \\
\hline & 6.9 & 3.13E-08 & $2.69 \mathrm{E}-08$ & $2.80 \mathrm{E}-08$ & $3.10 \mathrm{E}-08$ & $3.07 \mathrm{E}-08$ & $3.04 \mathrm{E}-08$ & $2.78 \mathrm{E}-08$ & $2.92 \mathrm{E}-08$ & & \\
\hline \multirow{7}{*}{$\begin{array}{c}\mathrm{pH}=4.0, \text { pure } \\
\text { water, } 300^{\circ} \mathrm{C}\end{array}$} & 0.0 & $4.31 \mathrm{E}-08$ & 4.35E-08 & $4.40 \mathrm{E}-08$ & $4.40 \mathrm{E}-08$ & 3.67E-08 & $3.78 \mathrm{E}-08$ & $4.53 \mathrm{E}-08$ & $4.48 \mathrm{E}-08$ & $4.48 \mathrm{E}-08$ & \\
\hline & 0.4 & 2.67E-08 & & & & & & & & & \\
\hline & 0.8 & $1.38 \mathrm{E}-08$ & $1.45 \mathrm{E}-08$ & $2.41 \mathrm{E}-08$ & $1.45 \mathrm{E}-08$ & & & & & & \\
\hline & 1.7 & $1.19 \mathrm{E}-08$ & $1.17 \mathrm{E}-08$ & $5.44 \mathrm{E}-09$ & $3.61 \mathrm{E}-09$ & $2.70 \mathrm{E}-09$ & 2.90E-09 & $6.25 \mathrm{E}-09$ & & & \\
\hline & 2.5 & $1.67 \mathrm{E}-08$ & $9.05 \mathrm{E}-09$ & & & & & & & & \\
\hline & 4.2 & $5.60 \mathrm{E}-09$ & & & & & & & & & \\
\hline & 6.9 & $1.87 \mathrm{E}-09$ & $7.21 \mathrm{E}-10$ & $6.02 \mathrm{E}-10$ & $7.97 \mathrm{E}-10$ & & & & & & \\
\hline \multirow{2}{*}{$\begin{array}{c}\mathrm{pH}=5.0, \text { pure } \\
\text { water, } 200^{\circ} \mathrm{C}\end{array}$} & 0.0 & 7.10E-08 & 7.10E-08 & 7.03E-08 & 7.10E-08 & 7.03E-08 & & & & & \\
\hline & 0.4 & $6.62 \mathrm{E}-08$ & 7.03E-08 & & & & & & & & \\
\hline
\end{tabular}


replicates $/ \mathrm{mol} \mathrm{kg}^{-1}$

n.d. - not detected

\begin{tabular}{|c|c|c|c|c|c|c|c|c|c|c|c|}
\hline Identifier & time/day & $\# 1$ & $\# 2$ & $\# 3$ & $\# 4$ & $\# 5$ & $\# 6$ & $\# 7$ & $\# 8$ & \#9 & $\# 10$ \\
\hline & 0.8 & $6.83 \mathrm{E}-08$ & $6.69 \mathrm{E}-08$ & $6.11 \mathrm{E}-08$ & $6.11 \mathrm{E}-08$ & & & & & & \\
\hline & 1.7 & $6.69 \mathrm{E}-08$ & $6.43 \mathrm{E}-08$ & $6.83 \mathrm{E}-08$ & $6.30 \mathrm{E}-08$ & $6.83 \mathrm{E}-08$ & $6.76 \mathrm{E}-08$ & & & & \\
\hline & 2.5 & $6.24 \mathrm{E}-08$ & $6.96 \mathrm{E}-08$ & & & & & & & & \\
\hline & 4.2 & $5.82 \mathrm{E}-08$ & & & & & & & & & \\
\hline & 6.9 & $6.56 \mathrm{E}-08$ & $6.83 \mathrm{E}-08$ & $6.56 \mathrm{E}-08$ & & & & & & & \\
\hline \multirow{7}{*}{$\begin{array}{c}\mathrm{pH}=5.0, \text { pure } \\
\text { water, } 300^{\circ} \mathrm{C}\end{array}$} & 0.0 & 7.10E-08 & 7.10E-08 & 7.03E-08 & 7.10E-08 & 7.03E-08 & & & & & \\
\hline & 0.4 & $6.62 \mathrm{E}-08$ & 7.03E-08 & & & & & & & & \\
\hline & 0.8 & $6.83 \mathrm{E}-08$ & $6.69 \mathrm{E}-08$ & $6.11 \mathrm{E}-08$ & $6.11 \mathrm{E}-08$ & & & & & & \\
\hline & 1.7 & $6.69 \mathrm{E}-08$ & $6.43 \mathrm{E}-08$ & $6.83 \mathrm{E}-08$ & $6.30 \mathrm{E}-08$ & $6.83 \mathrm{E}-08$ & $6.76 \mathrm{E}-08$ & & & & \\
\hline & 2.5 & $6.24 \mathrm{E}-08$ & $6.96 \mathrm{E}-08$ & & & & & & & & \\
\hline & 4.2 & $5.82 \mathrm{E}-08$ & & & & & & & & & \\
\hline & 6.9 & $6.56 \mathrm{E}-08$ & $6.83 \mathrm{E}-08$ & $6.56 \mathrm{E}-08$ & & & & & & & \\
\hline \multirow{7}{*}{$\begin{array}{c}\mathrm{pH}=6.0, \text { pure } \\
\text { water, } 200^{\circ} \mathrm{C}\end{array}$} & 0.0 & 4.61E-08 & 4.62E-08 & 4.69E-08 & 4.74E-08 & 4.97E-08 & $4.88 \mathrm{E}-08$ & $4.70 \mathrm{E}-08$ & & & \\
\hline & 0.4 & 4.79E-08 & $4.51 \mathrm{E}-08$ & & & & & & & & \\
\hline & 0.8 & $4.66 \mathrm{E}-08$ & 4.73E-08 & $4.68 \mathrm{E}-08$ & $4.51 \mathrm{E}-08$ & 4.61E-08 & & & & & \\
\hline & 1.7 & 4.27E-08 & 4.47E-08 & 4.10E-08 & $5.18 \mathrm{E}-08$ & $4.00 \mathrm{E}-08$ & 4.42E-08 & 4.67E-08 & 4.86E-08 & & \\
\hline & 2.5 & 4.63E-08 & 4.77E-08 & 4.29E-08 & & & & & & & \\
\hline & 4.2 & $4.56 \mathrm{E}-08$ & & & & & & & & & \\
\hline & 6.9 & $3.78 \mathrm{E}-08$ & $3.96 \mathrm{E}-08$ & 4.18E-08 & & & & & & & \\
\hline \multirow{6}{*}{$\begin{array}{l}\mathrm{pH}=6.0, \text { pure } \\
\text { water, } 300^{\circ} \mathrm{C}\end{array}$} & 0.0 & 4.62E-08 & 4.62E-08 & 4.67E-08 & $4.76 \mathrm{E}-08$ & 4.96E-08 & $4.86 \mathrm{E}-08$ & 4.71E-08 & & & \\
\hline & 0.4 & 4.35E-08 & 4.48E-08 & & & & & & & & \\
\hline & 0.8 & $3.86 \mathrm{E}-08$ & $3.56 \mathrm{E}-08$ & $3.90 \mathrm{E}-08$ & & & & & & & \\
\hline & 1.7 & $3.60 \mathrm{E}-08$ & 3.67E-08 & 3.94E-08 & 3.67E-08 & $3.75 \mathrm{E}-08$ & $3.22 \mathrm{E}-08$ & $2.95 \mathrm{E}-08$ & & & \\
\hline & 2.5 & 4.27E-08 & 4.06E-08 & & & & & & & & \\
\hline & 4.2 & $3.46 \mathrm{E}-08$ & 4.14E-08 & $2.75 \mathrm{E}-08$ & & & & & & & \\
\hline
\end{tabular}


replicates $/ \mathbf{m o l} \cdot \mathbf{k g}^{-1}$

n.d. - not detected

\begin{tabular}{|c|c|c|c|c|c|c|c|c|c|c|c|}
\hline Identifier & time/day & $\# 1$ & $\# 2$ & $\# \mathbf{3}$ & $\# 4$ & $\# 5$ & $\# 6$ & $\# 7$ & $\# 8$ & \#9 & $\# 10$ \\
\hline & 6.9 & $2.80 \mathrm{E}-08$ & $2.41 \mathrm{E}-08$ & $2.54 \mathrm{E}-08$ & 3.39E-08 & $2.56 \mathrm{E}-08$ & & & & & \\
\hline \multirow{7}{*}{$\begin{array}{c}\mathrm{pH}=8.0, \text { pure } \\
\text { water, } 200^{\circ} \mathrm{C}\end{array}$} & 0.0 & 4.53E-08 & 4.53E-08 & 4.62E-08 & 4.62E-08 & $4.58 \mathrm{E}-08$ & 4.58E-08 & 4.62E-08 & $4.58 \mathrm{E}-08$ & & \\
\hline & 0.4 & 4.62E-08 & 4.62E-08 & $4.58 \mathrm{E}-08$ & & & & & & & \\
\hline & 0.8 & $3.82 \mathrm{E}-08$ & $4.27 \mathrm{E}-08$ & $4.31 \mathrm{E}-08$ & $4.35 \mathrm{E}-08$ & 4.10E-08 & $4.02 \mathrm{E}-08$ & & & & \\
\hline & 1.7 & 3.60E-08 & 4.53E-08 & $3.71 \mathrm{E}-08$ & 4.44E-08 & $3.90 \mathrm{E}-08$ & $3.82 \mathrm{E}-08$ & $4.06 \mathrm{E}-08$ & $4.35 \mathrm{E}-08$ & & \\
\hline & 2.5 & 4.14E-08 & $4.48 \mathrm{E}-08$ & & & & & & & & \\
\hline & 4.2 & $3.98 \mathrm{E}-08$ & 3.64E-08 & 4.31E-08 & & & & & & & \\
\hline & 6.9 & $3.42 \mathrm{E}-08$ & $3.29 \mathrm{E}-08$ & 4.22E-08 & 4.22E-08 & $3.42 \mathrm{E}-08$ & 3.32E-08 & & & & \\
\hline \multirow{7}{*}{$\begin{array}{c}\mathrm{pH}=8.0, \text { pure } \\
\text { water, } 300^{\circ} \mathrm{C}\end{array}$} & 0.0 & 4.53E-08 & 4.53E-08 & 4.62E-08 & 4.62E-08 & $4.58 \mathrm{E}-08$ & $4.58 \mathrm{E}-08$ & 4.62E-08 & $4.58 \mathrm{E}-08$ & & \\
\hline & 0.4 & $4.06 \mathrm{E}-08$ & $3.98 \mathrm{E}-08$ & 3.94E-08 & & & & & & & \\
\hline & 0.8 & $3.78 \mathrm{E}-08$ & $3.94 \mathrm{E}-08$ & 4.67E-08 & $3.71 \mathrm{E}-08$ & 3.53E-08 & & & & & \\
\hline & 1.7 & $3.82 \mathrm{E}-08$ & $3.42 \mathrm{E}-08$ & $3.16 \mathrm{E}-08$ & 4.18E-08 & 3.32E-08 & 4.31E-08 & & & & \\
\hline & 2.5 & 4.31E-08 & 4.10E-08 & & & & & & & & \\
\hline & 4.2 & 3.32E-08 & $4.18 \mathrm{E}-08$ & & & & & & & & \\
\hline & 6.9 & $2.89 \mathrm{E}-08$ & $2.86 \mathrm{E}-08$ & $3.19 \mathrm{E}-08$ & $3.22 \mathrm{E}-08$ & 3.22E-08 & & & & & \\
\hline \multirow{7}{*}{$\begin{array}{c}\mathrm{pH}=9.0, \text { pure } \\
\text { water, } 200^{\circ} \mathrm{C}\end{array}$} & 0.0 & $5.42 \mathrm{E}-08$ & 5.37E-08 & $5.48 \mathrm{E}-08$ & $5.48 \mathrm{E}-08$ & 5.42E-08 & $5.42 \mathrm{E}-08$ & $5.42 \mathrm{E}-08$ & 5.37E-08 & 5.26E-08 & \\
\hline & 0.4 & 5.01E-08 & 5.32E-08 & & & & & & & & \\
\hline & 0.8 & $5.53 \mathrm{E}-08$ & $5.01 \mathrm{E}-08$ & $5.42 \mathrm{E}-08$ & $5.42 \mathrm{E}-08$ & 5.16E-08 & & & & & \\
\hline & 1.7 & $5.16 \mathrm{E}-08$ & 4.91E-08 & $5.70 \mathrm{E}-08$ & $5.42 \mathrm{E}-08$ & $5.48 \mathrm{E}-08$ & $5.01 \mathrm{E}-08$ & $5.48 \mathrm{E}-08$ & 4.62E-08 & & \\
\hline & 2.5 & $5.06 \mathrm{E}-08$ & 4.58E-08 & & & & & & & & \\
\hline & 4.2 & 4.14E-08 & 4.48E-08 & & & & & & & & \\
\hline & 6.9 & $5.11 \mathrm{E}-08$ & $4.58 \mathrm{E}-08$ & 4.44E-08 & 4.67E-08 & $4.86 \mathrm{E}-08$ & 4.35E-08 & & & & \\
\hline \multirow{3}{*}{$\begin{array}{c}\mathrm{pH}=9.0, \text { pure } \\
\text { water, } 300^{\circ} \mathrm{C}\end{array}$} & 0.0 & $5.42 \mathrm{E}-08$ & 5.37E-08 & $5.48 \mathrm{E}-08$ & $5.48 \mathrm{E}-08$ & $5.42 \mathrm{E}-08$ & $5.42 \mathrm{E}-08$ & $5.42 \mathrm{E}-08$ & 5.37E-08 & $5.26 \mathrm{E}-08$ & \\
\hline & 0.4 & 5.82E-08 & 5.42E-08 & 5.64E-08 & & & & & & & \\
\hline & 0.8 & $5.16 \mathrm{E}-08$ & $4.76 \mathrm{E}-08$ & $5.16 \mathrm{E}-08$ & $5.48 \mathrm{E}-08$ & 4.67E-08 & $4.76 \mathrm{E}-08$ & & & & \\
\hline
\end{tabular}

168 
replicates $/ \mathrm{mol} \mathrm{kg}^{-1}$

n.d. - not detected

\begin{tabular}{|c|c|c|c|c|c|c|c|c|c|c|c|}
\hline Identifier & time/day & $\# 1$ & $\# 2$ & $\# \mathbf{3}$ & $\# 4$ & $\# 5$ & \#6 & \#7 & $\# 8$ & $\# 9$ & $\# 10$ \\
\hline & 1.7 & $4.86 \mathrm{E}-08$ & 4.62E-08 & $5.70 \mathrm{E}-08$ & 4.91E-08 & $5.21 \mathrm{E}-08$ & $4.96 \mathrm{E}-08$ & 4.91E-08 & & & \\
\hline & 2.5 & $4.86 \mathrm{E}-08$ & $5.01 \mathrm{E}-08$ & & & & & & & & \\
\hline & 4.2 & $4.18 \mathrm{E}-08$ & & & & & & & & & \\
\hline & 6.9 & $4.48 \mathrm{E}-08$ & $4.18 \mathrm{E}-08$ & $3.71 \mathrm{E}-08$ & $2.95 \mathrm{E}-08$ & $3.64 \mathrm{E}-08$ & & & & & \\
\hline \multirow{7}{*}{$\begin{array}{c}\mathrm{pH}=10.0, \text { pure } \\
\text { water, } 200^{\circ} \mathrm{C}\end{array}$} & 0.0 & $4.96 \mathrm{E}-08$ & $4.96 \mathrm{E}-08$ & $4.96 \mathrm{E}-08$ & 4.91E-08 & $4.96 \mathrm{E}-08$ & & & & & \\
\hline & 0.4 & $4.76 \mathrm{E}-08$ & $5.11 \mathrm{E}-08$ & $4.86 \mathrm{E}-08$ & & & & & & & \\
\hline & 0.8 & $4.76 \mathrm{E}-08$ & 4.71E-08 & 4.71E-08 & 4.71E-08 & 4.67E-08 & & & & & \\
\hline & 1.7 & $4.71 \mathrm{E}-08$ & 4.27E-08 & $4.53 \mathrm{E}-08$ & $4.48 \mathrm{E}-08$ & $3.94 \mathrm{E}-08$ & & & & & \\
\hline & 2.5 & $4.22 \mathrm{E}-08$ & 4.67E-08 & $4.48 \mathrm{E}-08$ & & & & & & & \\
\hline & 4.2 & 4.27E-08 & $4.35 \mathrm{E}-08$ & 4.48E-08 & & & & & & & \\
\hline & 6.9 & 4.14E-08 & $4.35 \mathrm{E}-08$ & 4.44E-08 & 4.27E-08 & 4.67E-08 & $4.31 \mathrm{E}-08$ & & & & \\
\hline \multirow{7}{*}{$\begin{array}{c}\mathrm{pH}=10.0, \text { pure } \\
\text { water, } 300^{\circ} \mathrm{C}\end{array}$} & 0.0 & $4.98 \mathrm{E}-08$ & $4.96 \mathrm{E}-08$ & $4.96 \mathrm{E}-08$ & 4.93E-08 & 4.93E-08 & & & & & \\
\hline & 0.4 & 4.64E-08 & $4.60 \mathrm{E}-08$ & & & & & & & & \\
\hline & 0.8 & 4.22E-08 & $4.25 \mathrm{E}-08$ & $4.31 \mathrm{E}-08$ & $4.20 \mathrm{E}-08$ & $4.20 \mathrm{E}-08$ & 4.32E-08 & & & & \\
\hline & 1.7 & $4.50 \mathrm{E}-08$ & $4.78 \mathrm{E}-08$ & $3.66 \mathrm{E}-08$ & & & & & & & \\
\hline & 2.5 & $4.48 \mathrm{E}-08$ & $4.14 \mathrm{E}-08$ & & & & & & & & \\
\hline & 4.2 & $4.81 \mathrm{E}-08$ & $4.14 \mathrm{E}-08$ & $4.40 \mathrm{E}-08$ & $4.27 \mathrm{E}-08$ & & & & & & \\
\hline & 6.9 & $4.68 \mathrm{E}-08$ & $4.28 \mathrm{E}-08$ & 4.48E-08 & & & & & & & \\
\hline \multirow{7}{*}{$\begin{array}{l}\mathrm{pH}=11.0, \text { pure } \\
\text { water, } 200^{\circ} \mathrm{C}\end{array}$} & 0.0 & $4.06 \mathrm{E}-08$ & $4.06 \mathrm{E}-08$ & $4.06 \mathrm{E}-08$ & $3.98 \mathrm{E}-08$ & $4.02 \mathrm{E}-08$ & & & & & \\
\hline & 0.4 & $3.22 \mathrm{E}-08$ & $3.26 \mathrm{E}-08$ & & & & & & & & \\
\hline & 0.8 & $2.86 \mathrm{E}-08$ & 4.06E-08 & $2.46 \mathrm{E}-08$ & $3.29 \mathrm{E}-08$ & $3.04 \mathrm{E}-08$ & $3.56 \mathrm{E}-08$ & & & & \\
\hline & 1.7 & $3.04 \mathrm{E}-08$ & $2.72 \mathrm{E}-08$ & $2.56 \mathrm{E}-08$ & $3.56 \mathrm{E}-08$ & $3.75 \mathrm{E}-08$ & $2.18 \mathrm{E}-08$ & & & & \\
\hline & 2.5 & $2.08 \mathrm{E}-08$ & $3.67 \mathrm{E}-08$ & & & & & & & & \\
\hline & 4.2 & 3.07E-08 & $1.79 \mathrm{E}-08$ & & & & & & & & \\
\hline & 6.9 & $2.20 \mathrm{E}-08$ & $2.95 \mathrm{E}-08$ & $2.04 \mathrm{E}-08$ & $3.82 \mathrm{E}-08$ & $2.16 \mathrm{E}-08$ & & & & & \\
\hline
\end{tabular}


replicates $/ \mathrm{mol} \cdot \mathrm{kg}^{-1}$

n.d. - not detected

\begin{tabular}{|c|c|c|c|c|c|c|c|c|c|c|c|}
\hline Identifier & time/day & $\# 1$ & $\# 2$ & $\# 3$ & \#4 & $\# 5$ & $\# 6$ & $\# 7$ & $\# 8$ & \#9 & $\# 10$ \\
\hline \multirow{7}{*}{$\begin{array}{c}\mathrm{pH}=11.0, \text { pure } \\
\text { water, } 300^{\circ} \mathrm{C}\end{array}$} & 0.0 & 4.06E-08 & $4.06 \mathrm{E}-08$ & 4.06E-08 & $3.98 \mathrm{E}-08$ & 4.02E-08 & & & & & \\
\hline & 0.4 & $3.22 \mathrm{E}-08$ & 2.61E-08 & & & & & & & & \\
\hline & 0.8 & $2.49 \mathrm{E}-08$ & $3.42 \mathrm{E}-08$ & $2.98 \mathrm{E}-08$ & $2.98 \mathrm{E}-08$ & $2.67 \mathrm{E}-08$ & $2.86 \mathrm{E}-08$ & & & & \\
\hline & 1.7 & $2.80 \mathrm{E}-08$ & $3.42 \mathrm{E}-08$ & 2.12E-08 & $2.44 \mathrm{E}-08$ & 3.64E-08 & $2.89 \mathrm{E}-08$ & & & & \\
\hline & 2.5 & $2.95 \mathrm{E}-08$ & $3.78 \mathrm{E}-08$ & & & & & & & & \\
\hline & 4.2 & $3.22 \mathrm{E}-08$ & $2.78 \mathrm{E}-08$ & & & & & & & & \\
\hline & 6.9 & $1.68 \mathrm{E}-08$ & $1.20 \mathrm{E}-08$ & $3.10 \mathrm{E}-08$ & $1.88 \mathrm{E}-08$ & $1.21 \mathrm{E}-08$ & $1.82 \mathrm{E}-08$ & & & & \\
\hline \multirow{5}{*}{$\begin{array}{c}\mathrm{pH}=3.0 \\
\mathrm{NaCl}=0.050 \\
\mathrm{~m}, 200^{\circ} \mathrm{C}\end{array}$} & 0.0 & 4.18E-08 & 4.10E-08 & 4.14E-08 & 4.14E-08 & 4.14E-08 & & & & & \\
\hline & 0.4 & 4.48E-08 & 4.10E-08 & & & & & & & & \\
\hline & 0.8 & 4.62E-08 & 4.62E-08 & $1.00 \mathrm{E}+00$ & $4.58 \mathrm{E}-08$ & 4.62E-08 & 4.67E-08 & & & & \\
\hline & 1.7 & $4.40 \mathrm{E}-08$ & $4.53 \mathrm{E}-08$ & 4.48E-08 & $4.48 \mathrm{E}-08$ & 4.48E-08 & 4.44E-08 & & & & \\
\hline & 2.5 & 4.44E-08 & $4.58 \mathrm{E}-08$ & 4.44E-08 & 4.62E-08 & 4.35E-08 & 4.27E-08 & & & & \\
\hline \multirow{5}{*}{$\begin{array}{c}\mathrm{pH}=3.0 \\
\mathrm{NaCl}=0.050 \\
\mathrm{~m}, 300^{\circ} \mathrm{C}\end{array}$} & 0.0 & $4.18 \mathrm{E}-08$ & 4.10E-08 & 4.14E-08 & 4.14E-08 & 4.14E-08 & & & & & \\
\hline & 0.4 & $1.49 \mathrm{E}-08$ & $1.75 \mathrm{E}-08$ & & & & & & & & \\
\hline & 0.8 & 7.79E-09 & $6.32 \mathrm{E}-09$ & $6.51 \mathrm{E}-09$ & 9.33E-09 & $6.64 \mathrm{E}-09$ & & & & & \\
\hline & 1.7 & $1.23 \mathrm{E}-09$ & $1.57 \mathrm{E}-09$ & 2.08E-09 & $2.90 \mathrm{E}-09$ & $1.81 \mathrm{E}-09$ & $2.21 \mathrm{E}-09$ & & & & \\
\hline & 2.5 & $1.09 \mathrm{E}-09$ & $6.09 \mathrm{E}-10$ & $9.26 \mathrm{E}-10$ & $3.73 \mathrm{E}-10$ & $6.09 \mathrm{E}-10$ & & & & & \\
\hline \multirow{8}{*}{$\begin{array}{c}\mathrm{pH}=4.0 \\
\mathrm{NaCl}=0.050 \\
\mathrm{~m}, 200^{\circ} \mathrm{C}\end{array}$} & 0.0 & 4.40E-08 & 4.40E-08 & 4.40E-08 & 4.40E-08 & 4.40E-08 & & & & & \\
\hline & 0.4 & 4.44E-08 & $4.40 \mathrm{E}-08$ & & & & & & & & \\
\hline & 0.8 & 4.35E-08 & 4.40E-08 & 4.44E-08 & $4.48 \mathrm{E}-08$ & 4.40E-08 & 4.53E-08 & & & & \\
\hline & 1.7 & 4.40E-08 & $4.35 \mathrm{E}-08$ & 4.40E-08 & $4.14 \mathrm{E}-08$ & 4.53E-08 & & & & & \\
\hline & 2.5 & 4.40E-08 & $4.53 \mathrm{E}-08$ & & & & & & & & \\
\hline & 4.2 & 4.44E-08 & $4.48 \mathrm{E}-08$ & 4.48E-08 & & & & & & & \\
\hline & 6.9 & 4.44E-08 & $4.58 \mathrm{E}-08$ & 4.44E-08 & 4.62E-08 & 4.35E-08 & 4.27E-08 & & & & \\
\hline & 0.0 & $4.41 \mathrm{E}-08$ & 4.40E-08 & 4.39E-08 & 4.39E-08 & 4.38E-08 & & & & & \\
\hline
\end{tabular}


replicates $/ \mathrm{mol} \mathrm{kg}^{-1}$

n.d. - not detected

\begin{tabular}{|c|c|c|c|c|c|c|c|c|c|c|c|}
\hline Identifier & time/day & $\# 1$ & $\# 2$ & $\# 3$ & $\# 4$ & $\# 5$ & $\# 6$ & $\# 7$ & $\# 8$ & $\# 9$ & $\# 10$ \\
\hline \multirow{6}{*}{$\begin{array}{c}\mathrm{pH}=4.0 \\
\mathrm{NaCl}=0.050 \\
\mathrm{~m}, 300^{\circ} \mathrm{C}\end{array}$} & 0.4 & $3.66 \mathrm{E}-08$ & & & & & & & & & \\
\hline & 0.8 & $2.62 \mathrm{E}-08$ & $2.44 \mathrm{E}-08$ & $2.57 \mathrm{E}-08$ & $2.34 \mathrm{E}-08$ & $2.54 \mathrm{E}-08$ & & & & & \\
\hline & 1.7 & $1.53 \mathrm{E}-08$ & $1.95 \mathrm{E}-08$ & $2.32 \mathrm{E}-08$ & $1.56 \mathrm{E}-08$ & $2.17 \mathrm{E}-08$ & $2.81 \mathrm{E}-08$ & & & & \\
\hline & 2.5 & 8.77E-09 & 2.69E-08 & & & & & & & & \\
\hline & 4.2 & $1.01 \mathrm{E}-08$ & 7.27E-09 & 4.07E-09 & & & & & & & \\
\hline & 6.9 & $3.47 \mathrm{E}-09$ & 4.43E-09 & $1.29 \mathrm{E}-09$ & $2.08 \mathrm{E}-09$ & 3.47E-09 & & & & & \\
\hline \multirow{7}{*}{$\begin{array}{c}\mathrm{pH}=5.0 \\
\mathrm{NaCl}=0.050 \\
\mathrm{~m}, 200^{\circ} \mathrm{C}\end{array}$} & 0.0 & 3.94E-08 & $3.94 \mathrm{E}-08$ & $3.98 \mathrm{E}-08$ & $3.98 \mathrm{E}-08$ & $4.02 \mathrm{E}-08$ & & & & & \\
\hline & 0.4 & 4.91E-08 & $4.06 \mathrm{E}-08$ & & & & & & & & \\
\hline & 0.8 & 4.27E-08 & $4.18 \mathrm{E}-08$ & 4.40E-08 & $4.18 \mathrm{E}-08$ & & & & & & \\
\hline & 1.7 & 4.14E-08 & $4.76 \mathrm{E}-08$ & $3.94 \mathrm{E}-08$ & $4.48 \mathrm{E}-08$ & 4.02E-08 & 4.18E-08 & $5.11 \mathrm{E}-08$ & $4.76 \mathrm{E}-08$ & $4.10 \mathrm{E}-08$ & $4.48 \mathrm{E}-08$ \\
\hline & 2.5 & 4.48E-08 & $3.98 \mathrm{E}-08$ & & & & & & & & \\
\hline & 4.2 & 4.44E-08 & & & & & & & & & \\
\hline & 6.9 & $3.78 \mathrm{E}-08$ & $3.78 \mathrm{E}-08$ & $3.86 \mathrm{E}-08$ & 4.35E-08 & $4.48 \mathrm{E}-08$ & 4.27E-08 & $3.94 \mathrm{E}-08$ & & & \\
\hline \multirow{7}{*}{$\begin{array}{c}\mathrm{pH}=5.0 \\
\mathrm{NaCl}=0.050 \\
\mathrm{~m}, 300^{\circ} \mathrm{C}\end{array}$} & 0.0 & 3.94E-08 & 3.94E-08 & $3.98 \mathrm{E}-08$ & $3.98 \mathrm{E}-08$ & $4.02 \mathrm{E}-08$ & & & & & \\
\hline & 0.4 & 4.44E-08 & $3.98 \mathrm{E}-08$ & $4.10 \mathrm{E}-08$ & & & & & & & \\
\hline & 0.8 & $4.06 \mathrm{E}-08$ & $4.18 \mathrm{E}-08$ & 4.02E-08 & $4.10 \mathrm{E}-08$ & & & & & & \\
\hline & 1.7 & $1.00 \mathrm{E}+00$ & $4.18 \mathrm{E}-08$ & $3.82 \mathrm{E}-08$ & & & & & & & \\
\hline & 2.5 & 4.14E-08 & $3.90 \mathrm{E}-08$ & & & & & & & & \\
\hline & 4.2 & 4.06E-08 & & & & & & & & & \\
\hline & 6.9 & 4.10E-08 & 4.14E-08 & $4.14 \mathrm{E}-08$ & 4.02E-08 & & & & & & \\
\hline \multirow{5}{*}{$\begin{array}{c}\mathrm{pH}=6.0 \\
\mathrm{NaCl}=0.050 \\
\mathrm{~m}, 200^{\circ} \mathrm{C}\end{array}$} & 0.0 & 4.24E-08 & $4.20 \mathrm{E}-08$ & $4.23 \mathrm{E}-08$ & $4.26 \mathrm{E}-08$ & $4.20 \mathrm{E}-08$ & 4.06E-08 & & & & \\
\hline & 0.4 & 4.18E-08 & 4.22E-08 & & & & & & & & \\
\hline & 0.8 & $1.00 \mathrm{E}+00$ & $4.34 \mathrm{E}-08$ & $3.77 \mathrm{E}-08$ & $3.34 \mathrm{E}-08$ & $4.09 \mathrm{E}-08$ & $3.56 \mathrm{E}-08$ & & & & \\
\hline & 1.7 & 3.79E-08 & $3.92 \mathrm{E}-08$ & $3.86 \mathrm{E}-08$ & $4.10 \mathrm{E}-08$ & $4.40 \mathrm{E}-08$ & $3.77 \mathrm{E}-08$ & $3.92 \mathrm{E}-08$ & 4.07E-08 & $3.79 \mathrm{E}-08$ & 4.33E-08 \\
\hline & 2.5 & 4.21E-08 & $4.22 \mathrm{E}-08$ & & & & & & & & \\
\hline
\end{tabular}


replicates $/ \mathrm{mol} \cdot \mathrm{kg}^{-1}$

n.d. - not detected

\begin{tabular}{|c|c|c|c|c|c|c|c|c|c|c|c|}
\hline Identifier & time/day & $\# 1$ & $\# 2$ & $\# \mathbf{3}$ & $\# 4$ & $\# 5$ & \#6 & $\# 7$ & $\# 8$ & $\# 9$ & \#10 \\
\hline & 4.2 & 4.19E-08 & $4.23 \mathrm{E}-08$ & & & & & & & & \\
\hline & 6.9 & 4.24E-08 & $4.18 \mathrm{E}-08$ & $3.80 \mathrm{E}-08$ & $4.16 \mathrm{E}-08$ & $4.29 \mathrm{E}-08$ & $4.26 \mathrm{E}-08$ & & & & \\
\hline \multirow{7}{*}{$\begin{array}{c}\mathrm{pH}=6.0, \\
\mathrm{NaCl}=0.050 \\
\mathrm{~m}, 300^{\circ} \mathrm{C}\end{array}$} & 0.0 & $4.22 \mathrm{E}-08$ & 4.22E-08 & 4.22E-08 & 4.27E-08 & 4.18E-08 & 4.06E-08 & 4.22E-08 & $4.18 \mathrm{E}-08$ & $4.31 \mathrm{E}-08$ & \\
\hline & 0.4 & 4.27E-08 & $4.22 \mathrm{E}-08$ & & & & & & & & \\
\hline & 0.8 & $4.06 \mathrm{E}-08$ & 4.10E-08 & $3.86 \mathrm{E}-08$ & $4.06 \mathrm{E}-08$ & $3.56 \mathrm{E}-08$ & $4.31 \mathrm{E}-08$ & & & & \\
\hline & 1.7 & 4.27E-08 & $3.94 \mathrm{E}-08$ & $4.10 \mathrm{E}-08$ & $4.10 \mathrm{E}-08$ & $4.40 \mathrm{E}-08$ & $3.78 \mathrm{E}-08$ & $3.94 \mathrm{E}-08$ & $4.06 \mathrm{E}-08$ & $3.78 \mathrm{E}-08$ & $4.31 \mathrm{E}-08$ \\
\hline & 2.5 & $4.14 \mathrm{E}-08$ & 4.22E-08 & & & & & & & & \\
\hline & 4.2 & $4.22 \mathrm{E}-08$ & $4.10 \mathrm{E}-08$ & & & & & & & & \\
\hline & 6.9 & 4.14E-08 & 4.22E-08 & $4.18 \mathrm{E}-08$ & $4.27 \mathrm{E}-08$ & & & & & & \\
\hline \multirow{7}{*}{$\begin{array}{c}\mathrm{pH}=8.0 \\
\mathrm{NaCl}=0.050 \\
\mathrm{~m}, 200^{\circ} \mathrm{C}\end{array}$} & 0.0 & $4.71 \mathrm{E}-08$ & 4.67E-08 & $4.58 \mathrm{E}-08$ & $4.71 \mathrm{E}-08$ & $4.71 \mathrm{E}-08$ & $4.71 \mathrm{E}-08$ & 4.67E-08 & & & \\
\hline & 0.4 & $4.81 \mathrm{E}-08$ & $4.48 \mathrm{E}-08$ & & & & & & & & \\
\hline & 0.8 & 4.40E- 08 & $4.71 \mathrm{E}-08$ & 4.35E-08 & $4.48 \mathrm{E}-08$ & 4.44E-08 & & & & & \\
\hline & 1.7 & 4.48E-08 & $4.48 \mathrm{E}-08$ & 4.62E-08 & 4.67E-08 & $4.31 \mathrm{E}-08$ & & & & & \\
\hline & 2.5 & $5.01 \mathrm{E}-08$ & 4.67E-08 & & & & & & & & \\
\hline & 4.2 & $4.81 \mathrm{E}-08$ & 4.76E-08 & & & & & & & & \\
\hline & 6.9 & $5.48 \mathrm{E}-08$ & $4.06 \mathrm{E}-08$ & $4.76 \mathrm{E}-08$ & $4.71 \mathrm{E}-08$ & & & & & & \\
\hline \multirow{7}{*}{$\begin{array}{c}\mathrm{pH}=8.0 \\
\mathrm{NaCl}=0.050 \\
\mathrm{~m}, 300^{\circ} \mathrm{C}\end{array}$} & 0.0 & 4.71E-08 & 4.67E-08 & $4.58 \mathrm{E}-08$ & $4.71 \mathrm{E}-08$ & $4.71 \mathrm{E}-08$ & $4.71 \mathrm{E}-08$ & 4.67E-08 & & & \\
\hline & 0.4 & $4.58 \mathrm{E}-08$ & 4.53E-08 & & & & & & & & \\
\hline & 0.8 & $4.71 \mathrm{E}-08$ & $5.06 \mathrm{E}-08$ & 4.27E-08 & & & & & & & \\
\hline & 1.7 & 4.67E-08 & $4.81 \mathrm{E}-08$ & 4.71E-08 & $4.71 \mathrm{E}-08$ & $5.26 \mathrm{E}-08$ & & & & & \\
\hline & 2.5 & $4.62 \mathrm{E}-08$ & 4.67E-08 & & & & & & & & \\
\hline & 4.2 & $4.71 \mathrm{E}-08$ & 4.62E-08 & & & & & & & & \\
\hline & 6.9 & 4.67E-08 & $4.81 \mathrm{E}-08$ & 4.67E-08 & 4.67E-08 & $3.64 \mathrm{E}-08$ & $5.11 \mathrm{E}-08$ & $6.83 \mathrm{E}-08$ & & & \\
\hline $\begin{array}{c}\mathrm{pH}=9.0 \\
\mathrm{NaCl}=0.050 \\
\mathrm{~m}, 200^{\circ} \mathrm{C}\end{array}$ & $\begin{array}{l}0.0 \\
0.4\end{array}$ & $\begin{array}{l}4.10 \mathrm{E}-08 \\
4.40 \mathrm{E}-08\end{array}$ & $\begin{array}{l}4.06 \mathrm{E}-08 \\
4.44 \mathrm{E}-08\end{array}$ & $4.10 \mathrm{E}-08$ & 4.10E-08 & $4.10 \mathrm{E}-08$ & $4.06 \mathrm{E}-08$ & & & & \\
\hline
\end{tabular}


replicates/mol· $\mathbf{k g}^{-1}$

n.d. - not detected

\begin{tabular}{|c|c|c|c|c|c|c|c|c|c|c|c|}
\hline Identifier & time/day & $\# 1$ & $\# 2$ & $\# \mathbf{3}$ & $\# 4$ & $\# 5$ & $\# 6$ & $\# 7$ & $\# 8$ & $\# 9$ & $\# 10$ \\
\hline & 0.8 & 4.31E-08 & 4.14E-08 & 4.18E-08 & $3.98 \mathrm{E}-08$ & $4.18 \mathrm{E}-08$ & $4.31 \mathrm{E}-08$ & & & & \\
\hline & 1.7 & $4.18 \mathrm{E}-08$ & $4.06 \mathrm{E}-08$ & $3.98 \mathrm{E}-08$ & 4.27E-08 & $4.18 \mathrm{E}-08$ & $4.06 \mathrm{E}-08$ & $3.98 \mathrm{E}-08$ & & & \\
\hline & 2.5 & $3.90 \mathrm{E}-08$ & 4.44E-08 & $4.18 \mathrm{E}-08$ & & & & & & & \\
\hline & 4.2 & $4.18 \mathrm{E}-08$ & $3.94 \mathrm{E}-08$ & & & & & & & & \\
\hline & 6.9 & 4.22E-08 & $4.31 \mathrm{E}-08$ & $4.35 \mathrm{E}-08$ & $4.18 \mathrm{E}-08$ & $3.86 \mathrm{E}-08$ & $4.10 \mathrm{E}-08$ & & & & \\
\hline \multirow{7}{*}{$\begin{array}{c}\mathrm{pH}=9.0 \\
\mathrm{NaCl}=0.050 \\
\mathrm{~m}, 300^{\circ} \mathrm{C}\end{array}$} & 0.0 & 4.10E-08 & $4.06 \mathrm{E}-08$ & $4.10 \mathrm{E}-08$ & $4.10 \mathrm{E}-08$ & $4.10 \mathrm{E}-08$ & $4.06 \mathrm{E}-08$ & & & & \\
\hline & 0.4 & 4.22E-08 & 4.27E-08 & & & & & & & & \\
\hline & 0.8 & 4.06E-08 & $4.40 \mathrm{E}-08$ & $3.90 \mathrm{E}-08$ & $3.94 \mathrm{E}-08$ & $3.98 \mathrm{E}-08$ & $4.62 \mathrm{E}-08$ & & & & \\
\hline & 1.7 & 4.22E-08 & $4.40 \mathrm{E}-08$ & 4.67E-08 & $3.90 \mathrm{E}-08$ & $4.02 \mathrm{E}-08$ & $4.02 \mathrm{E}-08$ & & & & \\
\hline & 2.5 & $4.18 \mathrm{E}-08$ & $4.10 \mathrm{E}-08$ & & & & & & & & \\
\hline & 4.2 & 4.10E-08 & 4.12E-08 & & & & & & & & \\
\hline & 6.9 & 4.14E-08 & $3.91 \mathrm{E}-08$ & $4.05 \mathrm{E}-08$ & $3.82 \mathrm{E}-08$ & $4.12 \mathrm{E}-08$ & & & & & \\
\hline \multirow{7}{*}{$\begin{array}{c}\mathrm{pH}=10.0 \\
\mathrm{NaCl}=0.050 \\
\mathrm{~m}, 200^{\circ} \mathrm{C}\end{array}$} & 0.0 & $3.82 \mathrm{E}-08$ & $3.82 \mathrm{E}-08$ & $3.78 \mathrm{E}-08$ & $3.75 \mathrm{E}-08$ & $3.75 \mathrm{E}-08$ & $3.82 \mathrm{E}-08$ & $3.86 \mathrm{E}-08$ & $3.90 \mathrm{E}-08$ & $3.94 \mathrm{E}-08$ & $3.98 \mathrm{E}-08$ \\
\hline & 0.4 & 3.82E-08 & $3.56 \mathrm{E}-08$ & $3.86 \mathrm{E}-08$ & & & & & & & \\
\hline & 0.8 & $3.86 \mathrm{E}-08$ & $3.60 \mathrm{E}-08$ & 4.14E-08 & $3.75 \mathrm{E}-08$ & $3.78 \mathrm{E}-08$ & 4.02E-08 & & & & \\
\hline & 1.7 & 3.94E-08 & $4.06 \mathrm{E}-08$ & $3.75 \mathrm{E}-08$ & $3.75 \mathrm{E}-08$ & $3.98 \mathrm{E}-08$ & $4.02 \mathrm{E}-08$ & 3.67E-08 & & & \\
\hline & 2.5 & $3.75 \mathrm{E}-08$ & $3.78 \mathrm{E}-08$ & $3.78 \mathrm{E}-08$ & & & & & & & \\
\hline & 4.2 & 3.67E-08 & $4.10 \mathrm{E}-08$ & & & & & & & & \\
\hline & 6.9 & $3.71 \mathrm{E}-08$ & $3.90 \mathrm{E}-08$ & $3.82 \mathrm{E}-08$ & $3.75 \mathrm{E}-08$ & & & & & & \\
\hline \multirow{6}{*}{$\begin{array}{c}\mathrm{pH}=10.0 \\
\mathrm{NaCl}=0.050 \\
\mathrm{~m}, 300^{\circ} \mathrm{C}\end{array}$} & 0.0 & $3.82 \mathrm{E}-08$ & $3.82 \mathrm{E}-08$ & $3.78 \mathrm{E}-08$ & $3.75 \mathrm{E}-08$ & $3.75 \mathrm{E}-08$ & $3.82 \mathrm{E}-08$ & $3.86 \mathrm{E}-08$ & $3.90 \mathrm{E}-08$ & $3.94 \mathrm{E}-08$ & $3.98 \mathrm{E}-08$ \\
\hline & 0.4 & $3.46 \mathrm{E}-08$ & $3.78 \mathrm{E}-08$ & $3.78 \mathrm{E}-08$ & & & & & & & \\
\hline & 0.8 & $2.86 \mathrm{E}-08$ & $3.49 \mathrm{E}-08$ & $3.01 \mathrm{E}-08$ & $3.56 \mathrm{E}-08$ & 3.22E-08 & $3.60 \mathrm{E}-08$ & & & & \\
\hline & 1.7 & $3.60 \mathrm{E}-08$ & $3.64 \mathrm{E}-08$ & $3.67 \mathrm{E}-08$ & $3.71 \mathrm{E}-08$ & $3.39 \mathrm{E}-08$ & $3.78 \mathrm{E}-08$ & & & & \\
\hline & 2.5 & $3.82 \mathrm{E}-08$ & $3.82 \mathrm{E}-08$ & $3.78 \mathrm{E}-08$ & & & & & & & \\
\hline & 4.2 & $3.26 \mathrm{E}-08$ & $3.75 \mathrm{E}-08$ & & & & & & & & \\
\hline
\end{tabular}


replicates $/ \mathrm{mol} \cdot \mathrm{kg}^{-1}$

n.d. - not detected

\begin{tabular}{|c|c|c|c|c|c|c|c|c|c|c|c|}
\hline Identifier & time/day & $\# 1$ & $\# 2$ & $\# 3$ & $\# 4$ & $\# 5$ & $\# 6$ & $\# 7$ & $\# 8$ & $\# 9$ & $\# 10$ \\
\hline & 6.9 & $2.86 \mathrm{E}-08$ & $3.49 \mathrm{E}-08$ & $3.01 \mathrm{E}-08$ & $3.56 \mathrm{E}-08$ & $3.22 \mathrm{E}-08$ & $3.60 \mathrm{E}-08$ & & & & \\
\hline \multirow{7}{*}{$\begin{array}{c}\mathrm{pH}=11.0 \\
\mathrm{NaCl}=0.050 \\
\mathrm{~m}, 200^{\circ} \mathrm{C}\end{array}$} & 0.0 & 5.37E- 08 & $5.21 \mathrm{E}-08$ & $5.16 \mathrm{E}-08$ & $5.06 \mathrm{E}-08$ & $5.06 \mathrm{E}-08$ & $5.70 \mathrm{E}-08$ & 5.64E-08 & & & \\
\hline & 0.4 & $3.64 \mathrm{E}-08$ & $3.82 \mathrm{E}-08$ & & & & & & & & \\
\hline & 0.8 & 2.92E-08 & $4.76 \mathrm{E}-08$ & 4.62E-08 & $5.06 \mathrm{E}-08$ & $4.62 \mathrm{E}-08$ & $3.60 \mathrm{E}-08$ & & & & \\
\hline & 1.7 & 4.71E-08 & $4.86 \mathrm{E}-08$ & $4.14 \mathrm{E}-08$ & $3.49 \mathrm{E}-08$ & $3.75 \mathrm{E}-08$ & & & & & \\
\hline & 2.5 & 4.10E-08 & $3.67 \mathrm{E}-08$ & & & & & & & & \\
\hline & 4.2 & $3.42 \mathrm{E}-08$ & $3.39 \mathrm{E}-08$ & $3.64 \mathrm{E}-08$ & & & & & & & \\
\hline & 6.9 & 3.22E-08 & $3.16 \mathrm{E}-08$ & 3.22E-08 & $3.19 \mathrm{E}-08$ & 4.67E-08 & $3.01 \mathrm{E}-08$ & & & & \\
\hline \multirow{7}{*}{$\begin{array}{c}\mathrm{pH}=11.0, \\
\mathrm{NaCl}=0.050 \\
\mathrm{~m}, 300^{\circ} \mathrm{C}\end{array}$} & 0.0 & 5.37E-08 & $5.21 \mathrm{E}-08$ & $5.16 \mathrm{E}-08$ & $5.06 \mathrm{E}-08$ & $5.06 \mathrm{E}-08$ & $5.70 \mathrm{E}-08$ & $5.64 \mathrm{E}-08$ & $3.90 \mathrm{E}-08$ & $3.94 \mathrm{E}-08$ & $3.98 \mathrm{E}-08$ \\
\hline & 0.4 & $3.98 \mathrm{E}-08$ & 4.10E-08 & & & & & & & & \\
\hline & 0.8 & $3.13 \mathrm{E}-08$ & $3.67 \mathrm{E}-08$ & $3.46 \mathrm{E}-08$ & 4.62E-08 & $4.48 \mathrm{E}-08$ & $3.53 \mathrm{E}-08$ & & & & \\
\hline & 1.7 & $5.37 \mathrm{E}-08$ & $4.31 \mathrm{E}-08$ & $3.39 \mathrm{E}-08$ & $3.64 \mathrm{E}-08$ & 3.32E-08 & $4.71 \mathrm{E}-08$ & & & & \\
\hline & 2.5 & $3.78 \mathrm{E}-08$ & $4.31 \mathrm{E}-08$ & & & & & & & & \\
\hline & 4.2 & $3.49 \mathrm{E}-08$ & $4.18 \mathrm{E}-08$ & $4.10 \mathrm{E}-08$ & & & & & & & \\
\hline & 6.9 & 4.27E-08 & $3.98 \mathrm{E}-08$ & $5.11 \mathrm{E}-08$ & $3.75 \mathrm{E}-08$ & $3.42 \mathrm{E}-08$ & 4.67E-08 & & & & \\
\hline
\end{tabular}

\section{B.5 Supplementary material Chapter 2, Set 2, 1-NSA}

Table B.5: 1-NSA concentration in $\mathrm{mol} \mathrm{kg}^{-1}$ (HPLC).

\begin{tabular}{|c|c|c|c|c|c|c|c|c|c|c|c|}
\hline & & & & & replicates & $\mathbf{l} \cdot \mathbf{k g}^{-1}$ & n.d. - not & & & & \\
\hline Identifier & time/day & $\# 1$ & $\# 2$ & $\# 3$ & $\# 4$ & $\# 5$ & $\# 6$ & $\# 7$ & $\# 8$ & \#9 & $\# 10$ \\
\hline \multirow{4}{*}{$\begin{array}{c}\mathrm{pH}=3.0, \\
\text { pure water, } \\
200^{\circ} \mathrm{C}\end{array}$} & 0.0 & n.d & & & & & & & & & \\
\hline & 0.4 & $1.97 \mathrm{E}-09$ & & & & & & & & & \\
\hline & 0.8 & 2.07E-09 & $1.18 \mathrm{E}-09$ & 2.25E-09 & 1.67E-09 & $2.57 \mathrm{E}-09$ & $2.80 \mathrm{E}-09$ & & & & \\
\hline & 1.7 & $1.56 \mathrm{E}-09$ & $1.91 \mathrm{E}-09$ & $1.10 \mathrm{E}-09$ & $2.21 \mathrm{E}-09$ & 2.87E-09 & $1.59 \mathrm{E}-09$ & & & & \\
\hline
\end{tabular}




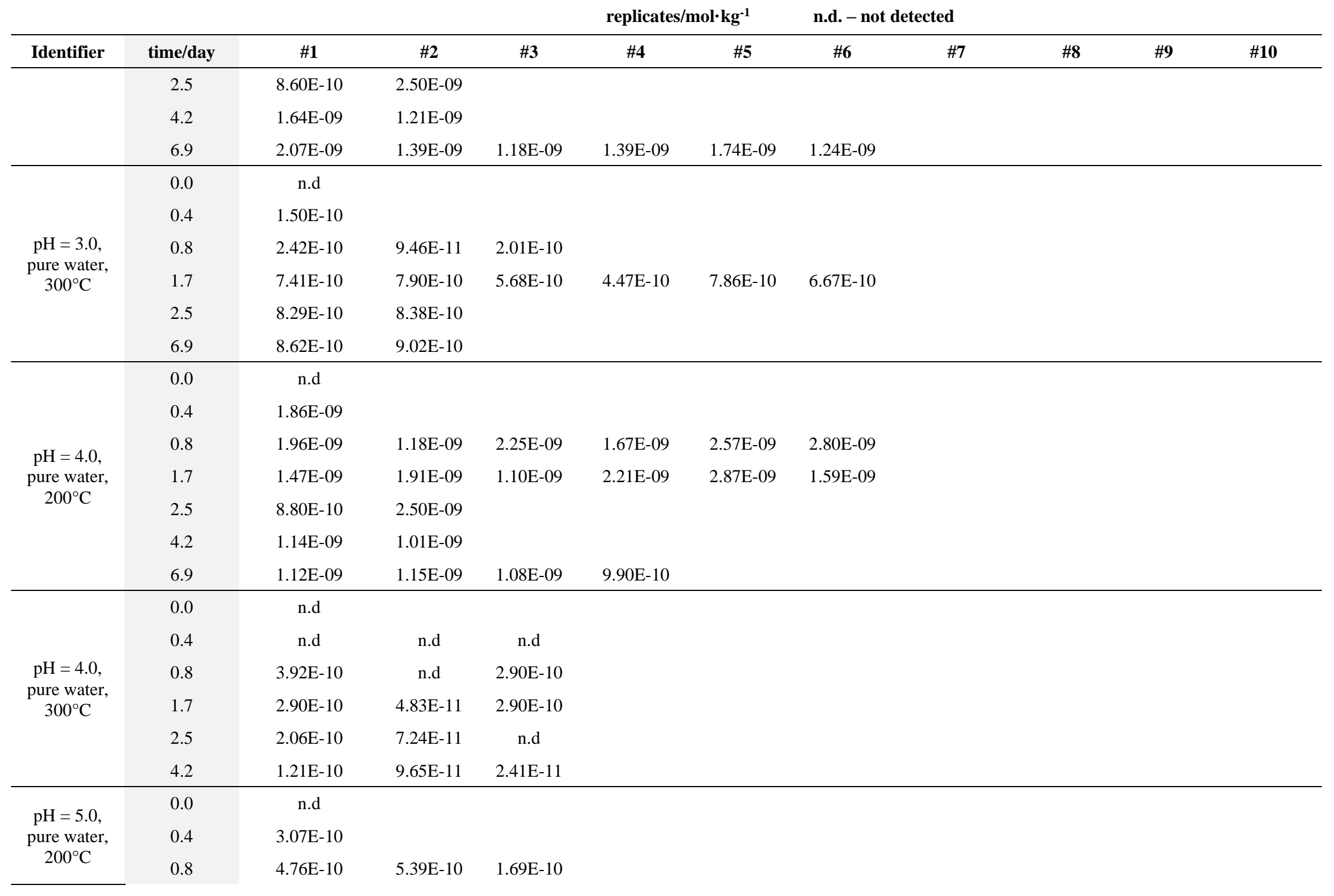


replicates/mol $\cdot \mathrm{kg}^{-1}$

n.d. - not detected

\begin{tabular}{|c|c|c|c|c|c|c|c|c|c|c|c|}
\hline Identifier & time/day & $\# 1$ & $\# 2$ & $\# \mathbf{3}$ & $\# 4$ & $\# 5$ & $\# 6$ & $\# 7$ & $\# 8$ & $\# 9$ & \#10 \\
\hline & 1.7 & $4.84 \mathrm{E}-10$ & 1.01E-09 & $8.72 \mathrm{E}-10$ & $9.68 \mathrm{E}-10$ & $6.97 \mathrm{E}-10$ & $6.33 \mathrm{E}-10$ & & & & \\
\hline & 2.5 & $1.04 \mathrm{E}-09$ & $1.16 \mathrm{E}-09$ & & & & & & & & \\
\hline & 6.9 & $8.88 \mathrm{E}-10$ & $8.42 \mathrm{E}-10$ & $9.64 \mathrm{E}-10$ & & & & & & & \\
\hline \multirow{7}{*}{$\begin{array}{c}\mathrm{pH}=5.0, \\
\text { pure water, } \\
300^{\circ} \mathrm{C}\end{array}$} & 0.0 & n.d & & & & & & & & & \\
\hline & 0.4 & $1.86 \mathrm{E}-08$ & & & & & & & & & \\
\hline & 0.8 & $1.83 \mathrm{E}-08$ & $2.94 \mathrm{E}-08$ & 2.22E-08 & $3.13 \mathrm{E}-08$ & $3.86 \mathrm{E}-08$ & 4.01E-08 & & & & \\
\hline & 1.7 & 7.15E-09 & $1.39 \mathrm{E}-08$ & 4.57E-09 & 5.59E-09 & & & & & & \\
\hline & 2.5 & 6.60E-09 & & & & & & & & & \\
\hline & 4.2 & $1.80 \mathrm{E}-09$ & & & & & & & & & \\
\hline & 6.9 & n.d & n.d & n.d & n.d & n.d & & & & & \\
\hline \multirow{6}{*}{$\begin{array}{c}\mathrm{pH}=6.0, \\
\text { pure water, } \\
200^{\circ} \mathrm{C}\end{array}$} & 0.0 & n.d & & & & & & & & & \\
\hline & 0.8 & 7.24E-10 & $6.76 \mathrm{E}-10$ & $5.79 \mathrm{E}-10$ & n.d & $9.65 \mathrm{E}-11$ & n.d & & & & \\
\hline & 1.7 & $6.76 \mathrm{E}-10$ & $1.16 \mathrm{E}-09$ & $2.90 \mathrm{E}-10$ & $7.72 \mathrm{E}-10$ & $4.34 \mathrm{E}-10$ & $9.65 \mathrm{E}-11$ & $5.79 \mathrm{E}-10$ & & & \\
\hline & 2.5 & $5.10 \mathrm{E}-10$ & $4.98 \mathrm{E}-10$ & & & & & & & & \\
\hline & 4.2 & $3.64 \mathrm{E}-10$ & $2.53 \mathrm{E}-10$ & & & & & & & & \\
\hline & 6.9 & $3.38 \mathrm{E}-10$ & $3.38 \mathrm{E}-10$ & $2.41 \mathrm{E}-10$ & & & & & & & \\
\hline \multirow{7}{*}{$\begin{array}{c}\mathrm{pH}=6.0, \\
\text { pure water, } \\
300^{\circ} \mathrm{C}\end{array}$} & 0.0 & n.d & & & & & & & & & \\
\hline & 0.4 & $1.71 \mathrm{E}-08$ & $1.75 \mathrm{E}-08$ & & & & & & & & \\
\hline & 0.8 & 2.32E-08 & 2.34E-08 & $2.13 \mathrm{E}-08$ & $1.64 \mathrm{E}-08$ & & & & & & \\
\hline & 1.7 & $1.85 \mathrm{E}-08$ & $2.26 \mathrm{E}-08$ & $1.48 \mathrm{E}-08$ & $8.45 \mathrm{E}-09$ & $2.30 \mathrm{E}-08$ & 4.20E-09 & $3.72 \mathrm{E}-09$ & $1.10 \mathrm{E}-08$ & & \\
\hline & 2.5 & $1.23 \mathrm{E}-08$ & & & & & & & & & \\
\hline & 4.2 & $5.75 \mathrm{E}-09$ & $1.11 \mathrm{E}-08$ & & & & & & & & \\
\hline & 6.9 & $5.79 \mathrm{E}-10$ & $4.34 \mathrm{E}-10$ & 7.72E-10 & $8.69 \mathrm{E}-10$ & $4.83 \mathrm{E}-10$ & & & & & \\
\hline
\end{tabular}


replicates $/ \mathrm{mol} \cdot \mathrm{kg}^{-1} \quad$ n.d. - not detected

\begin{tabular}{|c|c|c|c|c|c|c|c|c|c|c|c|}
\hline Identifier & time/day & $\# 1$ & $\# 2$ & $\# 3$ & $\# 4$ & $\# 5$ & $\# 6$ & $\# 7$ & $\# 8$ & $\# 9$ & $\# 10$ \\
\hline \multirow{6}{*}{$\begin{array}{c}\mathrm{pH}=8.0, \\
\text { pure water, } \\
200^{\circ} \mathrm{C}\end{array}$} & 0.0 & n.d & & & & & & & & & \\
\hline & 0.4 & n.d & n.d & n.d & & & & & & & \\
\hline & 1.7 & $8.20 \mathrm{E}-10$ & $5.79 \mathrm{E}-10$ & $4.83 \mathrm{E}-10$ & $5.31 \mathrm{E}-10$ & $6.76 \mathrm{E}-10$ & $6.27 \mathrm{E}-10$ & & & & \\
\hline & 2.5 & $6.35 \mathrm{E}-10$ & & & & & & & & & \\
\hline & 4.2 & $4.79 \mathrm{E}-10$ & $7.98 \mathrm{E}-10$ & & & & & & & & \\
\hline & 6.9 & $1.11 \mathrm{E}-09$ & $7.24 \mathrm{E}-10$ & & & & & & & & \\
\hline \multirow{6}{*}{$\begin{array}{c}\mathrm{pH}=8.0, \\
\text { pure water, } \\
300^{\circ} \mathrm{C}\end{array}$} & 0.0 & n.d & & & & & & & & & \\
\hline & 0.4 & $1.71 \mathrm{E}-08$ & $1.75 \mathrm{E}-08$ & & & & & & & & \\
\hline & 0.8 & 2.32E-08 & 2.34E-08 & $2.13 \mathrm{E}-08$ & $1.64 \mathrm{E}-08$ & & & & & & \\
\hline & 1.7 & $1.85 \mathrm{E}-08$ & $2.26 \mathrm{E}-08$ & $1.48 \mathrm{E}-08$ & 8.45E-09 & $2.30 \mathrm{E}-08$ & 4.20E-09 & 3.72E-09 & & & \\
\hline & 2.5 & $1.23 \mathrm{E}-08$ & $1.10 \mathrm{E}-08$ & & & & & & & & \\
\hline & 6.9 & 5.79E-10 & 4.34E-10 & 7.72E-10 & $8.69 \mathrm{E}-10$ & $4.83 \mathrm{E}-10$ & & & & & \\
\hline \multirow{7}{*}{$\begin{array}{c}\mathrm{pH}=9.0 \\
\text { pure water, } \\
200^{\circ} \mathrm{C}\end{array}$} & 0.0 & n.d & & & & & & & & & \\
\hline & 0.4 & $5.58 \mathrm{E}-10$ & $5.48 \mathrm{E}-10$ & & & & & & & & \\
\hline & 0.8 & $5.46 \mathrm{E}-10$ & $4.56 \mathrm{E}-10$ & $7.78 \mathrm{E}-10$ & $2.16 \mathrm{E}-10$ & $4.16 \mathrm{E}-10$ & & & & & \\
\hline & 1.7 & $7.78 \mathrm{E}-10$ & $3.19 \mathrm{E}-10$ & 4.53E-10 & 3.32E-10 & $8.11 \mathrm{E}-10$ & & & & & \\
\hline & 2.5 & $4.61 \mathrm{E}-10$ & $7.48 \mathrm{E}-10$ & $5.48 \mathrm{E}-10$ & & & & & & & \\
\hline & 4.2 & $7.84 \mathrm{E}-10$ & $8.70 \mathrm{E}-10$ & & & & & & & & \\
\hline & 6.9 & $4.55 \mathrm{E}-10$ & $1.64 \mathrm{E}-10$ & $1.80 \mathrm{E}-10$ & $3.13 \mathrm{E}-10$ & & & & & & \\
\hline \multirow{4}{*}{$\begin{array}{c}\mathrm{pH}=9.0, \\
\text { pure water, } \\
300^{\circ} \mathrm{C}\end{array}$} & 0.0 & n.d & & & & & & & & & \\
\hline & 0.4 & $1.02 \mathrm{E}-09$ & $8.08 \mathrm{E}-09$ & $1.61 \mathrm{E}-09$ & & & & & & & \\
\hline & 0.8 & $4.88 \mathrm{E}-09$ & 4.89E-09 & 4.71E-09 & 4.71E-09 & 4.87E-09 & & & & & \\
\hline & 1.7 & 9.37E-09 & $1.21 \mathrm{E}-08$ & $1.08 \mathrm{E}-08$ & $6.09 \mathrm{E}-09$ & 5.31E-09 & $9.59 \mathrm{E}-09$ & 9.19E-09 & & & \\
\hline
\end{tabular}


replicates $/ \mathrm{mol} \cdot \mathrm{kg}^{-1} \quad$ n.d. - not detected

\begin{tabular}{|c|c|c|c|c|c|c|c|c|c|c|c|}
\hline Identifier & time/day & $\# 1$ & $\# 2$ & $\# 3$ & $\# 4$ & $\# 5$ & $\# 6$ & $\# 7$ & $\# 8$ & \#9 & $\# 10$ \\
\hline & 2.5 & $1.57 \mathrm{E}-08$ & $1.28 \mathrm{E}-08$ & & & & & & & & \\
\hline & 4.2 & 2.27E-08 & 2.31E-08 & 2.15E-08 & 2.03E-08 & & & & & & \\
\hline \multirow{7}{*}{$\begin{array}{c}\mathrm{pH}=10.0, \\
\text { pure water, } \\
200^{\circ} \mathrm{C}\end{array}$} & 0.0 & n.d & & & & & & & & & \\
\hline & 0.4 & $7.72 \mathrm{E}-10$ & 7.72E-10 & & & & & & & & \\
\hline & 0.8 & $7.45 \mathrm{E}-10$ & $6.52 \mathrm{E}-10$ & $7.28 \mathrm{E}-10$ & $8.52 \mathrm{E}-10$ & $9.21 \mathrm{E}-10$ & & & & & \\
\hline & 1.7 & 1.11E-09 & $1.27 \mathrm{E}-09$ & 8.70E-10 & $1.00 \mathrm{E}-09$ & $1.02 \mathrm{E}-09$ & $1.34 \mathrm{E}-09$ & & & & \\
\hline & 2.5 & $8.56 \mathrm{E}-10$ & $9.56 \mathrm{E}-10$ & $9.10 \mathrm{E}-10$ & $1.20 \mathrm{E}-09$ & & & & & & \\
\hline & 4.2 & $7.20 \mathrm{E}-10$ & $9.37 \mathrm{E}-10$ & & & & & & & & \\
\hline & 6.9 & $1.76 \mathrm{E}-09$ & 2.17E-09 & $1.34 \mathrm{E}-09$ & & & & & & & \\
\hline \multirow{6}{*}{$\begin{array}{c}\mathrm{pH}=10.0, \\
\text { pure water, } \\
300^{\circ} \mathrm{C}\end{array}$} & 0.0 & n.d & & & & & & & & & \\
\hline & 0.4 & 4.10E-09 & $3.52 \mathrm{E}-09$ & & & & & & & & \\
\hline & 1.7 & $1.59 \mathrm{E}-09$ & 2.94E-09 & 1.30E-09 & 3.38E-09 & 3.91E-09 & 2.63E-09 & & & & \\
\hline & 2.5 & 5.16E-09 & 7.05E-09 & & & & & & & & \\
\hline & 4.2 & $1.82 \mathrm{E}-09$ & 2.04E-09 & & & & & & & & \\
\hline & 6.9 & $5.31 \mathrm{E}-10$ & $1.54 \mathrm{E}-09$ & $2.41 \mathrm{E}-10$ & $1.81 \mathrm{E}-09$ & & & & & & \\
\hline \multirow{7}{*}{$\begin{array}{c}\mathrm{pH}=11.0, \\
\text { pure water, } \\
200^{\circ} \mathrm{C}\end{array}$} & 0.0 & n.d & & & & & & & & & \\
\hline & 0.4 & n.d & n.d & & & & & & & & \\
\hline & 0.8 & $1.09 \mathrm{E}-09$ & $1.54 \mathrm{E}-09$ & $6.46 \mathrm{E}-10$ & & & & & & & \\
\hline & 1.7 & $9.65 \mathrm{E}-10$ & $5.79 \mathrm{E}-10$ & $4.34 \mathrm{E}-10$ & $1.50 \mathrm{E}-09$ & $3.86 \mathrm{E}-10$ & $1.30 \mathrm{E}-09$ & $1.30 \mathrm{E}-09$ & & & \\
\hline & 2.5 & $1.25 \mathrm{E}-09$ & $1.02 \mathrm{E}-09$ & & & & & & & & \\
\hline & 4.2 & 2.26E-09 & $1.41 \mathrm{E}-09$ & 1.10E-09 & & & & & & & \\
\hline & 6.9 & $1.59 \mathrm{E}-09$ & $1.25 \mathrm{E}-09$ & $1.30 \mathrm{E}-09$ & $1.35 \mathrm{E}-09$ & & & & & & \\
\hline
\end{tabular}


replicates $/ \mathrm{mol} \mathrm{kg}^{-1} \quad$ n.d. - not detected

\begin{tabular}{|c|c|c|c|c|c|c|c|c|c|c|c|}
\hline Identifier & time/day & $\# 1$ & $\# 2$ & $\# \mathbf{3}$ & $\# 4$ & $\# 5$ & $\# 6$ & \#7 & $\# 8$ & $\# 9$ & $\# 10$ \\
\hline \multirow{5}{*}{$\begin{array}{c}\mathrm{pH}=11.0, \\
\text { pure water, } \\
300^{\circ} \mathrm{C}\end{array}$} & 0.4 & $2.71 \mathrm{E}-08$ & $2.67 \mathrm{E}-08$ & & & & & & & & \\
\hline & 0.8 & $2.52 \mathrm{E}-08$ & 3.32E-08 & $2.81 \mathrm{E}-08$ & 2.33E-08 & $2.58 \mathrm{E}-08$ & 2.99E-08 & & & & \\
\hline & 2.5 & $2.63 \mathrm{E}-08$ & $3.16 \mathrm{E}-08$ & & & & & & & & \\
\hline & 4.2 & $1.54 \mathrm{E}-08$ & $1.89 \mathrm{E}-08$ & $9.95 \mathrm{E}-09$ & & & & & & & \\
\hline & 6.9 & $2.12 \mathrm{E}-09$ & $2.75 \mathrm{E}-09$ & 4.87E-09 & & & & & & & \\
\hline \multirow{5}{*}{$\begin{array}{c}\mathrm{pH}=3.0 \\
\mathrm{NaCl}= \\
0.050 \mathrm{~m} \\
200^{\circ} \mathrm{C}\end{array}$} & 0.0 & n.d & & & & & & & & & \\
\hline & 0.4 & n.d & n.d & & & & & & & & \\
\hline & 0.8 & $1.22 \mathrm{E}-09$ & $7.56 \mathrm{E}-10$ & $9.55 \mathrm{E}-10$ & $8.39 \mathrm{E}-10$ & $8.07 \mathrm{E}-10$ & & & & & \\
\hline & 1.7 & $1.32 \mathrm{E}-09$ & $1.84 \mathrm{E}-09$ & $1.66 \mathrm{E}-09$ & $1.45 \mathrm{E}-09$ & $1.37 \mathrm{E}-09$ & $1.86 \mathrm{E}-09$ & & & & \\
\hline & 2.5 & $1.55 \mathrm{E}-09$ & $1.63 \mathrm{E}-09$ & $1.66 \mathrm{E}-09$ & $1.63 \mathrm{E}-09$ & & & & & & \\
\hline \multirow{5}{*}{$\begin{array}{c}\mathrm{pH}=3.0 \\
\mathrm{NaCl}= \\
0.050 \mathrm{~m} \\
300^{\circ} \mathrm{C}\end{array}$} & 0.0 & n.d & & & & & & & & & \\
\hline & 0.4 & n.d & n.d & n.d & n.d & n.d & n.d & & & & \\
\hline & 1.7 & n.d & n.d & n.d & n.d & n.d & n.d & & & & \\
\hline & 2.5 & n.d & n.d & n.d & n.d & & & & & & \\
\hline & 6.9 & n.d & n.d & n.d & n.d & n.d & n.d & & & & \\
\hline \multirow{7}{*}{$\begin{array}{c}\mathrm{pH}=4.0 \\
\mathrm{NaCl}= \\
0.050 \mathrm{~m} \\
200^{\circ} \mathrm{C}\end{array}$} & 0.0 & n.d & & & & & & & & & \\
\hline & 0.4 & $3.76 \mathrm{E}-10$ & & & & & & & & & \\
\hline & 0.8 & $3.76 \mathrm{E}-10$ & $4.47 \mathrm{E}-10$ & $2.34 \mathrm{E}-10$ & & & & & & & \\
\hline & 1.7 & $3.49 \mathrm{E}-10$ & & & & & & & & & \\
\hline & 2.5 & $2.44 \mathrm{E}-10$ & $1.82 \mathrm{E}-10$ & $4.01 \mathrm{E}-10$ & $2.77 \mathrm{E}-10$ & 4.69E-10 & $8.69 \mathrm{E}-10$ & & & & \\
\hline & 4.2 & $6.23 \mathrm{E}-10$ & $1.17 \mathrm{E}-09$ & & & & & & & & \\
\hline & 6.9 & $1.66 \mathrm{E}-10$ & $3.34 \mathrm{E}-10$ & $5.34 \mathrm{E}-10$ & $1.14 \mathrm{E}-10$ & & & & & & \\
\hline \multirow{2}{*}{$\begin{array}{c}\mathrm{pH}=4.0 \\
\mathrm{NaCl}=\end{array}$} & 0.0 & n.d & & & & & & & & & \\
\hline & 0.4 & $1.79 \mathrm{E}-09$ & $1.05 \mathrm{E}-08$ & & & & & & & & \\
\hline
\end{tabular}


replicates $/ \mathrm{mol} \cdot \mathrm{kg}^{-1} \quad$ n.d. - not detected

\begin{tabular}{|c|c|c|c|c|c|c|c|c|c|c|c|}
\hline Identifier & time/day & $\# 1$ & $\# 2$ & $\# 3$ & $\# 4$ & $\# 5$ & $\# 6$ & $\# 7$ & $\# 8$ & $\# 9$ & $\# 10$ \\
\hline \multirow{4}{*}{$\begin{array}{c}0.050 \mathrm{~m} \\
300^{\circ} \mathrm{C}\end{array}$} & 0.8 & $5.15 \mathrm{E}-10$ & $2.70 \mathrm{E}-10$ & $6.40 \mathrm{E}-10$ & $2.62 \mathrm{E}-10$ & $4.47 \mathrm{E}-10$ & & & & & \\
\hline & 1.7 & n.d & n.d & n.d & n.d & $1.06 \mathrm{E}-10$ & 4.13E-10 & & & & \\
\hline & 4.2 & $4.62 \mathrm{E}-10$ & $4.79 \mathrm{E}-10$ & $1.61 \mathrm{E}-11$ & & & & & & & \\
\hline & 6.9 & $2.94 \mathrm{E}-11$ & n.d & n.d & n.d & $2.94 \mathrm{E}-11$ & n.d & & & & \\
\hline \multirow{7}{*}{$\begin{array}{c}\mathrm{pH}=5.0 \\
\mathrm{NaCl}= \\
0.050 \mathrm{~m} \\
200^{\circ} \mathrm{C}\end{array}$} & 0.0 & n.d & & & & & & & & & \\
\hline & 0.4 & $1.47 \mathrm{E}-10$ & $1.33 \mathrm{E}-09$ & & & & & & & & \\
\hline & 0.8 & $3.48 \mathrm{E}-10$ & $1.78 \mathrm{E}-09$ & $8.37 \mathrm{E}-10$ & $1.01 \mathrm{E}-09$ & $1.01 \mathrm{E}-09$ & & & & & \\
\hline & 1.7 & $8.34 \mathrm{E}-10$ & $6.41 \mathrm{E}-10$ & $1.06 \mathrm{E}-09$ & $9.17 \mathrm{E}-10$ & $1.20 \mathrm{E}-09$ & & & & & \\
\hline & 2.5 & $9.17 \mathrm{E}-10$ & $1.79 \mathrm{E}-09$ & & & & & & & & \\
\hline & 4.2 & $1.21 \mathrm{E}-09$ & & & & & & & & & \\
\hline & 6.9 & $1.50 \mathrm{E}-09$ & $1.54 \mathrm{E}-09$ & 1.64E-09 & & & & & & & \\
\hline \multirow{6}{*}{$\begin{array}{c}\mathrm{pH}=5.0 \\
\mathrm{NaCl}= \\
0.050 \mathrm{~m} \\
300^{\circ} \mathrm{C}\end{array}$} & 0.4 & $2.69 \mathrm{E}-08$ & $1.67 \mathrm{E}-08$ & $3.07 \mathrm{E}-08$ & & & & & & & \\
\hline & 0.8 & $2.28 \mathrm{E}-08$ & $2.48 \mathrm{E}-08$ & $1.00 \mathrm{E}-08$ & $2.38 \mathrm{E}-08$ & $1.24 \mathrm{E}-08$ & & & & & \\
\hline & 1.7 & $1.09 \mathrm{E}-08$ & $2.20 \mathrm{E}-08$ & $1.76 \mathrm{E}-08$ & & & & & & & \\
\hline & 2.5 & 7.44E-09 & 7.21E-09 & 7.38E-09 & & & & & & & \\
\hline & 4.2 & $3.86 \mathrm{E}-09$ & $3.90 \mathrm{E}-09$ & 3.94E-09 & & & & & & & \\
\hline & 6.9 & $2.90 \mathrm{E}-10$ & 4.15E-09 & $8.00 \mathrm{E}-09$ & 3.44E-09 & $1.78 \mathrm{E}-09$ & 3.77E-09 & $8.45 \mathrm{E}-09$ & & & \\
\hline \multirow{6}{*}{$\begin{array}{c}\mathrm{pH}=6.0 \\
\mathrm{NaCl}= \\
0.050 \mathrm{~m} \\
200^{\circ} \mathrm{C}\end{array}$} & 0.0 & n.d & & & & & & & & & \\
\hline & 0.4 & $3.99 \mathrm{E}-10$ & & & & & & & & & \\
\hline & 0.8 & $1.33 \mathrm{E}-09$ & $1.02 \mathrm{E}-10$ & 1.13E-09 & $1.24 \mathrm{E}-10$ & & & & & & \\
\hline & 1.7 & $2.41 \mathrm{E}-10$ & $2.41 \mathrm{E}-10$ & $5.79 \mathrm{E}-10$ & $2.11 \mathrm{E}-10$ & $2.31 \mathrm{E}-10$ & $5.19 \mathrm{E}-10$ & & & & \\
\hline & 2.5 & $3.91 \mathrm{E}-10$ & & & & & & & & & \\
\hline & 4.2 & $3.45 \mathrm{E}-10$ & $3.99 \mathrm{E}-10$ & & & & & & & & \\
\hline
\end{tabular}


replicates $/ \mathrm{mol} \cdot \mathrm{kg}^{-1} \quad$ n.d. - not detected

\begin{tabular}{|c|c|c|c|c|c|c|c|c|c|c|c|}
\hline Identifier & time/day & $\# 1$ & $\# 2$ & $\# \mathbf{3}$ & $\# 4$ & $\# 5$ & $\# 6$ & $\# 7$ & $\# 8$ & $\# 9$ & $\# 10$ \\
\hline & 6.9 & 1.32E-09 & $1.07 \mathrm{E}-09$ & & & & & & & & \\
\hline \multirow{7}{*}{$\begin{array}{c}\mathrm{pH}=6.0 \\
\mathrm{NaCl}= \\
0.050 \mathrm{~m} \\
300^{\circ} \mathrm{C}\end{array}$} & 0.0 & n.d & & & & & & & & & \\
\hline & 0.4 & $1.01 \mathrm{E}-08$ & $1.24 \mathrm{E}-08$ & & & & & & & & \\
\hline & 0.8 & $1.80 \mathrm{E}-08$ & $1.31 \mathrm{E}-08$ & $1.78 \mathrm{E}-08$ & $1.46 \mathrm{E}-08$ & $1.32 \mathrm{E}-08$ & $1.70 \mathrm{E}-08$ & & & & \\
\hline & 1.7 & $1.52 \mathrm{E}-08$ & $1.76 \mathrm{E}-08$ & $1.31 \mathrm{E}-08$ & $1.52 \mathrm{E}-08$ & $1.24 \mathrm{E}-08$ & $1.51 \mathrm{E}-08$ & $1.41 \mathrm{E}-08$ & $1.77 \mathrm{E}-08$ & $\begin{array}{c}1.75 \mathrm{E}- \\
08\end{array}$ & \\
\hline & 2.5 & 2.07E-08 & $2.15 \mathrm{E}-08$ & & & & & & & & \\
\hline & 4.2 & $9.22 \mathrm{E}-09$ & & & & & & & & & \\
\hline & 6.9 & $2.20 \mathrm{E}-09$ & 2.10E-09 & 2.40E-09 & $1.90 \mathrm{E}-09$ & & & & & & \\
\hline \multirow{7}{*}{$\begin{array}{c}\mathrm{pH}=8.0 \\
\mathrm{NaCl}= \\
0.050 \mathrm{~m} \\
200^{\circ} \mathrm{C}\end{array}$} & 0.0 & n.d & & & & & & & & & \\
\hline & 0.4 & $4.46 \mathrm{E}-10$ & & & & & & & & & \\
\hline & 0.8 & $8.51 \mathrm{E}-10$ & $8.31 \mathrm{E}-10$ & $6.29 \mathrm{E}-10$ & $6.59 \mathrm{E}-10$ & & & & & & \\
\hline & 1.7 & $8.20 \mathrm{E}-10$ & $8.69 \mathrm{E}-10$ & 8.69E-10 & $9.65 \mathrm{E}-10$ & $1.54 \mathrm{E}-09$ & & & & & \\
\hline & 2.5 & $1.54 \mathrm{E}-09$ & $1.25 \mathrm{E}-09$ & & & & & & & & \\
\hline & 4.2 & 1.39E-09 & $1.37 \mathrm{E}-09$ & & & & & & & & \\
\hline & 6.9 & 1.79E-09 & 1.19E-09 & $1.45 \mathrm{E}-09$ & $1.06 \mathrm{E}-09$ & & & & & & \\
\hline \multirow{7}{*}{$\begin{array}{c}\mathrm{pH}=8.0 \\
\mathrm{NaCl}= \\
0.050 \mathrm{~m} \\
300^{\circ} \mathrm{C}\end{array}$} & 0.0 & n.d & & & & & & & & & \\
\hline & 0.4 & $9.28 \mathrm{E}-09$ & $9.06 \mathrm{E}-09$ & & & & & & & & \\
\hline & 0.8 & $1.49 \mathrm{E}-08$ & $6.63 \mathrm{E}-09$ & $1.93 \mathrm{E}-08$ & $1.58 \mathrm{E}-08$ & & & & & & \\
\hline & 1.7 & $2.50 \mathrm{E}-08$ & $2.85 \mathrm{E}-08$ & $2.68 \mathrm{E}-08$ & 2.57E-08 & $2.72 \mathrm{E}-08$ & & & & & \\
\hline & 2.5 & $2.60 \mathrm{E}-08$ & $2.73 \mathrm{E}-08$ & & & & & & & & \\
\hline & 4.2 & 2.67E-08 & $1.88 \mathrm{E}-08$ & & & & & & & & \\
\hline & 6.9 & $1.33 \mathrm{E}-08$ & $2.46 \mathrm{E}-08$ & $2.21 \mathrm{E}-08$ & $1.44 \mathrm{E}-08$ & $1.33 \mathrm{E}-08$ & & & & & \\
\hline \multirow{3}{*}{$\begin{array}{c}\mathrm{pH}=9.0 \\
\mathrm{NaCl}= \\
0.050 \mathrm{~m} \\
200^{\circ} \mathrm{C}\end{array}$} & 0.0 & n.d & & & & & & & & & \\
\hline & 0.4 & 4.82E-10 & & & & & & & & & \\
\hline & 0.8 & $2.82 \mathrm{E}-10$ & $1.03 \mathrm{E}-09$ & $2.82 \mathrm{E}-10$ & $1.03 \mathrm{E}-09$ & & & & & & \\
\hline
\end{tabular}


replicates $/ \mathrm{mol}^{\prime} \mathrm{kg}^{-1} \quad$ n.d. - not detected

\begin{tabular}{|c|c|c|c|c|c|c|c|c|c|c|c|}
\hline Identifier & time/day & $\# 1$ & $\# 2$ & $\# 3$ & $\# 4$ & $\# 5$ & $\# 6$ & $\# 7$ & $\# 8$ & $\# 9$ & $\# 10$ \\
\hline & 1.7 & $1.52 \mathrm{E}-09$ & $1.60 \mathrm{E}-09$ & $5.83 \mathrm{E}-10$ & & & & & & & \\
\hline & 2.5 & $1.98 \mathrm{E}-09$ & 2.10E-09 & & & & & & & & \\
\hline & 6.9 & $2.86 \mathrm{E}-09$ & 2.71E-09 & 2.52E-09 & & & & & & & \\
\hline \multirow{7}{*}{$\begin{array}{c}\mathrm{pH}=9.0 \\
\mathrm{NaCl}= \\
0.050 \mathrm{~m} \\
300^{\circ} \mathrm{C}\end{array}$} & 0.0 & n.d & & & & & & & & & \\
\hline & 0.4 & $6.10 \mathrm{E}-09$ & $1.05 \mathrm{E}-08$ & & & & & & & & \\
\hline & 0.8 & 2.09E-08 & $1.81 \mathrm{E}-08$ & $1.84 \mathrm{E}-08$ & $2.40 \mathrm{E}-08$ & $2.59 \mathrm{E}-08$ & $1.84 \mathrm{E}-08$ & & & & \\
\hline & 1.7 & 2.12E-08 & $3.04 \mathrm{E}-08$ & $1.95 \mathrm{E}-08$ & 2.70E-08 & $3.08 \mathrm{E}-08$ & & & & & \\
\hline & 2.5 & $3.08 \mathrm{E}-08$ & 3.33E-08 & 3.32E-08 & & & & & & & \\
\hline & 4.2 & $1.95 \mathrm{E}-08$ & 2.10E-08 & & & & & & & & \\
\hline & 6.9 & $1.06 \mathrm{E}-08$ & $9.10 \mathrm{E}-09$ & 9.04E-09 & $1.21 \mathrm{E}-08$ & $1.38 \mathrm{E}-08$ & 3.10E-09 & & & & \\
\hline \multirow{6}{*}{$\begin{array}{c}\mathrm{pH}=10.0 \\
\mathrm{NaCl}= \\
0.050 \mathrm{~m} \\
200^{\circ} \mathrm{C}\end{array}$} & 0.0 & n.d & & & & & & & & & \\
\hline & 0.8 & $1.15 \mathrm{E}-09$ & $1.03 \mathrm{E}-09$ & & & & & & & & \\
\hline & 1.7 & $1.52 \mathrm{E}-09$ & $1.60 \mathrm{E}-09$ & $2.10 \mathrm{E}-09$ & $1.70 \mathrm{E}-09$ & 1.67E-09 & & & & & \\
\hline & 2.5 & 2.25E-09 & $2.25 \mathrm{E}-09$ & $2.25 \mathrm{E}-09$ & 2.45E-09 & & & & & & \\
\hline & 4.2 & $2.75 \mathrm{E}-09$ & $2.65 \mathrm{E}-09$ & & & & & & & & \\
\hline & 6.9 & 2.86E-09 & $2.71 \mathrm{E}-09$ & 2.52E-09 & & & & & & & \\
\hline \multirow{7}{*}{$\begin{array}{c}\mathrm{pH}=10.0 \\
\mathrm{NaCl}= \\
0.050 \mathrm{~m} \\
300^{\circ} \mathrm{C}\end{array}$} & 0.0 & n.d & & & & & & & & & \\
\hline & 0.4 & n.d & n.d & n.d & & & & & & & \\
\hline & 0.8 & $1.00 \mathrm{E}-09$ & $8.38 \mathrm{E}-10$ & $4.74 \mathrm{E}-10$ & 4.64E-10 & & & & & & \\
\hline & 1.7 & $1.90 \mathrm{E}-09$ & $5.12 \mathrm{E}-10$ & $9.52 \mathrm{E}-10$ & $9.54 \mathrm{E}-10$ & & & & & & \\
\hline & 2.5 & $1.38 \mathrm{E}-09$ & $2.48 \mathrm{E}-09$ & 3.43E-09 & & & & & & & \\
\hline & 4.2 & $3.89 \mathrm{E}-09$ & $2.24 \mathrm{E}-09$ & 4.25E-09 & 4.57E-09 & 3.67E-09 & & & & & \\
\hline & 6.9 & $8.27 \mathrm{E}-10$ & $2.71 \mathrm{E}-09$ & 5.11E-09 & $4.46 \mathrm{E}-09$ & $3.14 \mathrm{E}-09$ & & & & & \\
\hline
\end{tabular}


replicates $/ \mathrm{mol} \cdot \mathrm{kg}^{-1} \quad$ n.d. - not detected

\begin{tabular}{|c|c|c|c|c|c|c|c|c|c|c|c|}
\hline Identifier & time/day & $\# 1$ & $\# 2$ & $\# \mathbf{3}$ & $\# 4$ & $\# 5$ & $\# 6$ & $\# 7$ & $\# 8$ & $\# 9$ & $\# 10$ \\
\hline \multirow{6}{*}{$\begin{array}{c}\mathrm{pH}=11.0 \\
\mathrm{NaCl}= \\
0.050 \mathrm{~m} \\
200^{\circ} \mathrm{C}\end{array}$} & 0.0 & n.d & & & & & & & & & \\
\hline & 0.4 & $1.24 \mathrm{E}-09$ & & & & & & & & & \\
\hline & 0.8 & $3.15 \mathrm{E}-09$ & $5.06 \mathrm{E}-09$ & $1.81 \mathrm{E}-09$ & 2.09E-09 & & & & & & \\
\hline & 1.7 & 5.34E-09 & $5.13 \mathrm{E}-09$ & 5.63E-09 & $5.24 \mathrm{E}-09$ & 4.09E-09 & 4.56E-09 & & & & \\
\hline & 2.5 & $6.04 \mathrm{E}-09$ & 5.89E-09 & & & & & & & & \\
\hline & 6.9 & $5.36 \mathrm{E}-09$ & 4.67E-09 & $5.79 \mathrm{E}-09$ & 7.18E-09 & 5.12E-09 & $6.06 \mathrm{E}-09$ & & & & \\
\hline \multirow{6}{*}{$\begin{array}{c}\mathrm{pH}=11.0 \\
\mathrm{NaCl}= \\
0.050 \mathrm{~m} \\
300^{\circ} \mathrm{C}\end{array}$} & 0.0 & n.d & & & & & & & & & \\
\hline & 0.4 & $1.48 \mathrm{E}-08$ & $1.13 \mathrm{E}-08$ & & & & & & & & \\
\hline & 0.8 & $1.25 \mathrm{E}-08$ & $1.06 \mathrm{E}-08$ & $1.19 \mathrm{E}-08$ & $1.47 \mathrm{E}-08$ & $1.08 \mathrm{E}-08$ & $1.36 \mathrm{E}-08$ & & & & \\
\hline & 1.7 & $1.90 \mathrm{E}-08$ & $1.12 \mathrm{E}-08$ & $1.54 \mathrm{E}-08$ & $9.58 \mathrm{E}-09$ & $1.45 \mathrm{E}-08$ & $1.14 \mathrm{E}-08$ & & & & \\
\hline & 2.5 & $1.76 \mathrm{E}-08$ & $1.61 \mathrm{E}-08$ & & & & & & & & \\
\hline & 6.9 & $1.71 \mathrm{E}-08$ & $1.67 \mathrm{E}-08$ & $1.77 \mathrm{E}-08$ & $1.78 \mathrm{E}-08$ & & & & & & \\
\hline
\end{tabular}


B.6 Supplementary material Chapter 3, 1,5-NDS (Set 1 and Set 2)

Table B.6: $1,5-\mathrm{NDS}$ concentration in $\mathrm{mol} \mathrm{kg}^{-1}$ (HPLC).

\begin{tabular}{|c|c|c|c|c|c|c|c|}
\hline \multirow[b]{2}{*}{ Identifier } & \multirow[b]{2}{*}{ time/day } & \multirow[b]{2}{*}{$\# 1$} & \multicolumn{2}{|c|}{ replicates $/ \mathrm{mol} \cdot \mathrm{kg}^{-1}$} & \multicolumn{2}{|c|}{ n.d. - not detected } & \multirow[b]{2}{*}{ \#6 } \\
\hline & & & $\# 2$ & $\# \mathbf{3}$ & $\# 4$ & $\# 5$ & \\
\hline \multirow{9}{*}{$\begin{array}{c}\mathrm{pH}=7.0 \\
\mathrm{NaCl}=0.050 \mathrm{~m} \\
200^{\circ} \mathrm{C}\end{array}$} & 0.0 & 7.79E-08 & & & & & \\
\hline & 0.8 & 7.49E-08 & $7.50 \mathrm{E}-08$ & 7.45E-08 & $7.52 \mathrm{E}-08$ & 7.58E-08 & 7.41E-08 \\
\hline & 1.7 & 7.46E-08 & 7.38E-08 & 7.35E-08 & 7.23E-08 & $7.46 \mathrm{E}-08$ & 7.38E-08 \\
\hline & 2.5 & 7.30E-08 & $6.87 \mathrm{E}-08$ & $6.37 \mathrm{E}-08$ & 7.33E-08 & $6.77 \mathrm{E}-08$ & $7.21 \mathrm{E}-08$ \\
\hline & 3.3 & 7.37E-08 & 7.13E-08 & 7.66E-08 & 7.67E-08 & & \\
\hline & 4.2 & $7.00 \mathrm{E}-08$ & $6.87 \mathrm{E}-08$ & 7.17E-08 & $6.27 \mathrm{E}-08$ & 7.24E-08 & $6.87 \mathrm{E}-08$ \\
\hline & 27.9 & $6.06 \mathrm{E}-08$ & $6.12 \mathrm{E}-08$ & $6.27 \mathrm{E}-08$ & $6.51 \mathrm{E}-08$ & $6.95 \mathrm{E}-08$ & \\
\hline & 56.9 & 5.64E-08 & $5.86 \mathrm{E}-08$ & $5.58 \mathrm{E}-08$ & $5.70 \mathrm{E}-08$ & $5.99 \mathrm{E}-08$ & $5.76 \mathrm{E}-08$ \\
\hline & 88.9 & 4.29E-08 & $4.86 \mathrm{E}-08$ & $5.11 \mathrm{E}-08$ & $4.45 \mathrm{E}-08$ & $5.44 \mathrm{E}-08$ & 4.67E-08 \\
\hline \multirow{6}{*}{$\begin{array}{c}\mathrm{pH}=7.0 \\
\mathrm{NaCl}=0.050 \mathrm{~m} \\
225^{\circ} \mathrm{C}\end{array}$} & 0.0 & 7.87E-08 & 7.98E-08 & $7.76 \mathrm{E}-08$ & 7.52E-08 & $7.96 \mathrm{E}-08$ & $8.01 \mathrm{E}-08$ \\
\hline & 0.8 & 7.55E-08 & 7.57E-08 & 7.68E-08 & 7.26E-08 & 7.96E-08 & $7.41 \mathrm{E}-08$ \\
\hline & 20.0 & $5.78 \mathrm{E}-08$ & $5.67 \mathrm{E}-08$ & $5.55 \mathrm{E}-08$ & $5.24 \mathrm{E}-08$ & $5.31 \mathrm{E}-08$ & $5.24 \mathrm{E}-08$ \\
\hline & 27.9 & 4.72E-08 & $4.96 \mathrm{E}-08$ & $5.10 \mathrm{E}-08$ & 4.61E-08 & 4.73E-08 & 4.73E-08 \\
\hline & 38.7 & 5.40E-08 & $5.55 \mathrm{E}-08$ & $5.26 \mathrm{E}-08$ & $5.36 \mathrm{E}-08$ & & \\
\hline & 45.0 & 4.34E-08 & $4.58 \mathrm{E}-08$ & 4.92E-08 & & & \\
\hline \multirow{9}{*}{$\begin{array}{c}\mathrm{pH}=7.0 \\
\mathrm{NaCl}=0.050 \mathrm{~m} \\
250^{\circ} \mathrm{C}\end{array}$} & 0.0 & $6.96 \mathrm{E}-08$ & & & & & \\
\hline & 0.8 & $5.98 \mathrm{E}-08$ & $5.84 \mathrm{E}-08$ & 5.63E-08 & 5.99E-08 & $5.82 \mathrm{E}-08$ & 5.94E-08 \\
\hline & 2.5 & 4.77E-08 & $3.77 \mathrm{E}-08$ & $3.63 \mathrm{E}-08$ & $3.91 \mathrm{E}-08$ & $3.56 \mathrm{E}-08$ & $4.05 \mathrm{E}-08$ \\
\hline & 3.3 & $3.50 \mathrm{E}-08$ & 4.65E-08 & $3.99 \mathrm{E}-08$ & 4.64E-08 & $4.26 \mathrm{E}-08$ & $4.68 \mathrm{E}-08$ \\
\hline & 4.2 & $4.78 \mathrm{E}-08$ & $4.25 \mathrm{E}-08$ & $3.80 \mathrm{E}-08$ & $3.57 \mathrm{E}-08$ & $4.02 \mathrm{E}-08$ & $4.12 \mathrm{E}-08$ \\
\hline & 5.8 & $3.19 \mathrm{E}-08$ & $3.77 \mathrm{E}-08$ & $3.19 \mathrm{E}-08$ & $3.82 \mathrm{E}-08$ & 2.93E-08 & $3.32 \mathrm{E}-08$ \\
\hline & 27.9 & $1.59 \mathrm{E}-08$ & $1.82 \mathrm{E}-08$ & $3.00 \mathrm{E}-08$ & $2.84 \mathrm{E}-08$ & $2.31 \mathrm{E}-08$ & $2.14 \mathrm{E}-08$ \\
\hline & 56.9 & $1.34 \mathrm{E}-08$ & $1.68 \mathrm{E}-08$ & $1.47 \mathrm{E}-08$ & $1.94 \mathrm{E}-08$ & $1.61 \mathrm{E}-08$ & $1.50 \mathrm{E}-08$ \\
\hline & 88.9 & 8.41E-09 & $1.10 \mathrm{E}-08$ & $9.70 \mathrm{E}-09$ & & & \\
\hline \multirow{9}{*}{$\begin{array}{c}\mathrm{pH}=7.0 \\
\mathrm{NaCl}=0.050 \mathrm{~m} \\
270^{\circ} \mathrm{C}\end{array}$} & 0.0 & 7.60E-08 & & & & & \\
\hline & 0.8 & $5.88 \mathrm{E}-08$ & $5.51 \mathrm{E}-08$ & $5.89 \mathrm{E}-08$ & $5.79 \mathrm{E}-08$ & $5.45 \mathrm{E}-08$ & $5.68 \mathrm{E}-08$ \\
\hline & 1.7 & $5.11 \mathrm{E}-08$ & 4.99E-08 & $5.27 \mathrm{E}-08$ & $5.06 \mathrm{E}-08$ & $5.14 \mathrm{E}-08$ & $5.12 \mathrm{E}-08$ \\
\hline & 6.6 & $2.16 \mathrm{E}-08$ & $1.99 \mathrm{E}-08$ & $2.18 \mathrm{E}-08$ & 2.19E-08 & $2.08 \mathrm{E}-08$ & $2.09 \mathrm{E}-08$ \\
\hline & 13.6 & 6.04E-09 & $6.76 \mathrm{E}-09$ & & & & \\
\hline & 14.0 & n.d. & n.d. & n.d. & & & \\
\hline & 21.1 & n.d. & n.d. & n.d. & & & \\
\hline & 28.0 & n.d. & n.d. & n.d. & & & \\
\hline & 42.0 & n.d. & n.d. & n.d. & & & \\
\hline \multirow{8}{*}{$\begin{array}{c}\mathrm{pH}=7.0 \\
\mathrm{NaCl}=0.050 \mathrm{~m} \\
300^{\circ} \mathrm{C}\end{array}$} & 0.0 & $6.18 \mathrm{E}-08$ & & & & & \\
\hline & 0.8 & 2.69E-08 & $2.22 \mathrm{E}-08$ & $1.56 \mathrm{E}-08$ & $1.98 \mathrm{E}-08$ & $2.79 \mathrm{E}-08$ & $2.72 \mathrm{E}-08$ \\
\hline & 1.7 & $9.18 \mathrm{E}-09$ & $6.64 \mathrm{E}-09$ & $1.02 \mathrm{E}-08$ & $1.91 \mathrm{E}-08$ & $1.32 \mathrm{E}-08$ & 4.32E-09 \\
\hline & 2.5 & $1.36 \mathrm{E}-08$ & $9.44 \mathrm{E}-09$ & $5.24 \mathrm{E}-09$ & 7.43E-09 & $5.08 \mathrm{E}-09$ & $8.15 \mathrm{E}-09$ \\
\hline & 3.3 & $6.19 \mathrm{E}-09$ & $4.50 \mathrm{E}-09$ & $2.66 \mathrm{E}-09$ & $3.42 \mathrm{E}-09$ & & \\
\hline & 4.2 & $1.01 \mathrm{E}-09$ & 3.81E-09 & $1.18 \mathrm{E}-09$ & $9.15 \mathrm{E}-09$ & $1.85 \mathrm{E}-09$ & $1.85 \mathrm{E}-09$ \\
\hline & 14.0 & n.d & n.d & n.d & n.d & & \\
\hline & 41.0 & n.d & n.d & n.d & n.d & & \\
\hline
\end{tabular}




\begin{tabular}{|c|c|c|c|c|c|c|c|}
\hline \multirow[b]{2}{*}{ Identifier } & \multirow[b]{2}{*}{ time/day } & \multirow[b]{2}{*}{ \#1 } & \multicolumn{2}{|c|}{ replicates $/ \mathrm{mol} \cdot \mathrm{kg}^{-1}$} & \multicolumn{2}{|c|}{ n.d. - not detected } & \multirow[b]{2}{*}{ \#6 } \\
\hline & & & $\# 2$ & \#3 & \#4 & \#5 & \\
\hline & 56.0 & n.d & n.d & n.d & n.d & & \\
\hline & 84.0 & n.d & n.d & n.d & n.d & & \\
\hline \multirow{5}{*}{$\begin{array}{c}\mathrm{pH}=7.0 \\
\mathrm{NaCl}=0.050 \mathrm{~m}, \\
330^{\circ} \mathrm{C}\end{array}$} & 0.0 & $7.28 \mathrm{E}-08$ & & & & & \\
\hline & 0.8 & $5.65 \mathrm{E}-08$ & $5.96 \mathrm{E}-08$ & $6.19 \mathrm{E}-08$ & $6.24 \mathrm{E}-08$ & $6.01 \mathrm{E}-08$ & \\
\hline & 1.7 & 1.99E-09 & $7.04 \mathrm{E}-10$ & $6.41 \mathrm{E}-10$ & $4.66 \mathrm{E}-10$ & $9.51 \mathrm{E}-10$ & \\
\hline & 6.6 & n.d & n.d & n.d & & & \\
\hline & 13.6 & n.d & n.d & n.d & & & \\
\hline \multirow{4}{*}{$\begin{array}{c}\mathrm{pH}=7.0, \\
\mathrm{NaCl}=0.050 \mathrm{~m}, \\
\text { graywacke, } \\
250^{\circ} \mathrm{C}\end{array}$} & 0.0 & $9.61 \mathrm{E}-08$ & & & & & \\
\hline & 14.0 & $9.03 \mathrm{E}-08$ & 8.85E-08 & $9.40 \mathrm{E}-08$ & $9.21 \mathrm{E}-08$ & & \\
\hline & 28.0 & $8.76 \mathrm{E}-08$ & 8.76E-08 & $9.40 \mathrm{E}-08$ & $9.40 \mathrm{E}-08$ & & \\
\hline & 42.0 & $9.122 \mathrm{E}-08$ & $9.40 \mathrm{E}-08$ & $9.31 \mathrm{E}-08$ & $8.76 \mathrm{E}-08$ & & \\
\hline \multirow{4}{*}{$\begin{array}{c}\mathrm{pH}=7.0, \\
\mathrm{NaCl}=0.050 \mathrm{~m}, \\
\text { graywacke, } \\
270^{\circ} \mathrm{C}\end{array}$} & 0.0 & $9.61 \mathrm{E}-08$ & & & & & \\
\hline & 14.0 & 8.76E-08 & 7.93E-08 & $8.42 \mathrm{E}-08$ & $8.17 \mathrm{E}-08$ & & \\
\hline & 28.0 & $8.01 \mathrm{E}-08$ & $8.25 \mathrm{E}-08$ & $7.47 \mathrm{E}-08$ & 8.01E-08 & & \\
\hline & 42.0 & $7.321 \mathrm{E}-08$ & 7.25E-08 & 7.54E-08 & $6.89 \mathrm{E}-08$ & & \\
\hline \multirow{4}{*}{$\begin{array}{c}\mathrm{pH}=7.0, \\
\mathrm{NaCl}=0.050 \mathrm{~m}, \\
\text { graywacke, } \\
300^{\circ} \mathrm{C}\end{array}$} & 0.0 & $9.61 \mathrm{E}-08$ & & & & & \\
\hline & 14.0 & $4.06 \mathrm{E}-08$ & $5.87 \mathrm{E}-08$ & 4.27E-08 & $6.36 \mathrm{E}-08$ & & \\
\hline & 28.0 & $2.86 \mathrm{E}-08$ & $3.07 \mathrm{E}-08$ & $1.32 \mathrm{E}-08$ & $1.00 \mathrm{E}+00$ & & \\
\hline & 42.0 & n.d & n.d & n.d & & & \\
\hline
\end{tabular}

\section{B.7 Supplementary material Chapter 3, 1,6-NDS (Set 1 and Set 2)}

Table B.7: 1,6-NDS concentration in $\mathrm{mol} \mathrm{kg}^{-1}$ (HPLC).

\begin{tabular}{|c|c|c|c|c|c|c|c|}
\hline & & & \multicolumn{2}{|c|}{ replicates $/ \mathrm{mol} \cdot \mathrm{kg}^{-1}$} & \multicolumn{2}{|c|}{ n.d. - not detected } & \multirow[b]{2}{*}{ \#6 } \\
\hline Identifier & time/day & $\# 1$ & $\# 2$ & $\# \mathbf{3}$ & $\# 4$ & $\# 5$ & \\
\hline \multirow{9}{*}{$\begin{array}{c}\text { set } 1: \mathrm{pH}=7.0 \text {, } \\
\mathrm{NaCl}=0.050 \mathrm{~m}, \\
200^{\circ} \mathrm{C}\end{array}$} & 0.0 & $8.17 \mathrm{E}-08$ & & & & & \\
\hline & 0.8 & 8.54E-08 & 8.61E-08 & $8.42 \mathrm{E}-08$ & $8.52 \mathrm{E}-08$ & $8.75 \mathrm{E}-08$ & $8.46 \mathrm{E}-08$ \\
\hline & 1.7 & 8.01E-08 & 7.98E-08 & $8.10 \mathrm{E}-08$ & 7.90E-08 & $8.16 \mathrm{E}-08$ & 8.03E-08 \\
\hline & 2.5 & 7.87E-08 & 7.49E-08 & $6.95 \mathrm{E}-08$ & 7.89E-08 & 7.45E-08 & $7.85 \mathrm{E}-08$ \\
\hline & 3.3 & 8.07E-08 & $7.88 \mathrm{E}-08$ & 7.81E-08 & 7.84E-08 & 7.91E-08 & 8.09E-08 \\
\hline & 4.2 & 7.64E-08 & $7.70 \mathrm{E}-08$ & 7.83E-08 & $6.96 \mathrm{E}-08$ & 7.79E-08 & 7.71E-08 \\
\hline & 27.9 & 7.84E-08 & 7.25E-08 & $7.88 \mathrm{E}-08$ & $7.26 \mathrm{E}-08$ & 7.41E-08 & 7.77E-08 \\
\hline & 56.9 & 7.30E-08 & $6.81 \mathrm{E}-08$ & 7.29E-08 & 7.02E-08 & $6.80 \mathrm{E}-08$ & $6.70 \mathrm{E}-08$ \\
\hline & 88.9 & $6.08 \mathrm{E}-08$ & $6.84 \mathrm{E}-08$ & $6.96 \mathrm{E}-08$ & $6.79 \mathrm{E}-08$ & $7.26 \mathrm{E}-08$ & $6.59 \mathrm{E}-08$ \\
\hline \multirow{6}{*}{$\begin{array}{c}\text { set } 1: \mathrm{pH}=7.0 \text {, } \\
\mathrm{NaCl}=0.050 \mathrm{~m}, \\
225^{\circ} \mathrm{C}\end{array}$} & 0.0 & $7.87 \mathrm{E}-08$ & & & & & \\
\hline & 0.8 & $7.76 \mathrm{E}-08$ & $7.84 \mathrm{E}-08$ & 7.85E-08 & 7.74E-08 & $7.52 \mathrm{E}-08$ & 7.91E-08 \\
\hline & 20.0 & $5.93 \mathrm{E}-08$ & $6.48 \mathrm{E}-08$ & $6.17 \mathrm{E}-08$ & $6.03 \mathrm{E}-08$ & $5.93 \mathrm{E}-08$ & $6.13 \mathrm{E}-08$ \\
\hline & 27.9 & $5.26 \mathrm{E}-08$ & $5.64 \mathrm{E}-08$ & $6.13 \mathrm{E}-08$ & $5.78 \mathrm{E}-08$ & 5.83E-08 & $5.78 \mathrm{E}-08$ \\
\hline & 38.7 & $5.09 \mathrm{E}-08$ & $5.04 \mathrm{E}-08$ & $5.12 \mathrm{E}-08$ & $5.13 \mathrm{E}-08$ & $5.12 \mathrm{E}-08$ & $5.24 \mathrm{E}-08$ \\
\hline & 45.0 & $4.38 \mathrm{E}-08$ & 4.38E-08 & $4.73 \mathrm{E}-08$ & 4.62E-08 & 4.73E-08 & $4.81 \mathrm{E}-08$ \\
\hline \multirow{7}{*}{$\begin{array}{c}\text { set } 1: \mathrm{pH}=7.0 \text {, } \\
\mathrm{NaCl}=0.050 \mathrm{~m}, \\
250^{\circ} \mathrm{C}\end{array}$} & 0.0 & $7.76 \mathrm{E}-08$ & & & & & \\
\hline & 0.8 & $6.56 \mathrm{E}-08$ & $6.81 \mathrm{E}-08$ & 7.44E-08 & 7.61E-08 & 5.72E-08 & $5.95 \mathrm{E}-08$ \\
\hline & 2.5 & $6.24 \mathrm{E}-08$ & $5.38 \mathrm{E}-08$ & $5.75 \mathrm{E}-08$ & $5.63 \mathrm{E}-08$ & $5.30 \mathrm{E}-08$ & $5.71 \mathrm{E}-08$ \\
\hline & 3.3 & $5.25 \mathrm{E}-08$ & $6.15 \mathrm{E}-08$ & $5.62 \mathrm{E}-08$ & $6.02 \mathrm{E}-08$ & $5.84 \mathrm{E}-08$ & $6.18 \mathrm{E}-08$ \\
\hline & 4.2 & $6.05 \mathrm{E}-08$ & $5.79 \mathrm{E}-08$ & $5.41 \mathrm{E}-08$ & $5.30 \mathrm{E}-08$ & $5.71 \mathrm{E}-08$ & $5.70 \mathrm{E}-08$ \\
\hline & 5.8 & $4.96 \mathrm{E}-08$ & $5.43 \mathrm{E}-08$ & 4.99E-08 & $5.44 \mathrm{E}-08$ & 4.71E-08 & $5.04 \mathrm{E}-08$ \\
\hline & 27.9 & $3.52 \mathrm{E}-08$ & $3.61 \mathrm{E}-08$ & $4.73 \mathrm{E}-08$ & $4.90 \mathrm{E}-08$ & 4.19E-08 & $3.95 \mathrm{E}-08$ \\
\hline
\end{tabular}




\begin{tabular}{|c|c|c|c|c|c|c|c|}
\hline \multirow[b]{2}{*}{ Identifier } & \multirow[b]{2}{*}{ time/day } & \multirow[b]{2}{*}{$\# 1$} & \multicolumn{2}{|c|}{ replicates $/ \mathrm{mol} \cdot \mathrm{kg}^{-1}$} & \multicolumn{2}{|c|}{ n.d. - not detected } & \multirow[b]{2}{*}{ \#6 } \\
\hline & & & $\# 2$ & \#3 & \#4 & \#5 & \\
\hline & 56.9 & $3.64 \mathrm{E}-08$ & $3.57 \mathrm{E}-08$ & $3.39 \mathrm{E}-08$ & $3.75 \mathrm{E}-08$ & $3.53 \mathrm{E}-08$ & \\
\hline & 88.9 & 2.79E-08 & 3.33E-08 & $3.06 \mathrm{E}-08$ & & & \\
\hline \multirow{9}{*}{$\begin{array}{c}\text { set } 1: \mathrm{pH}=7.0, \\
\mathrm{NaCl}=0.050 \mathrm{~m}, \\
270^{\circ} \mathrm{C}\end{array}$} & 0.0 & $8.01 \mathrm{E}-08$ & & & & & \\
\hline & 0.8 & $6.92 \mathrm{E}-08$ & 6.84E-08 & 6.88E-08 & $6.88 \mathrm{E}-08$ & & \\
\hline & 1.7 & $6.51 \mathrm{E}-08$ & $6.39 \mathrm{E}-08$ & $6.26 \mathrm{E}-08$ & $6.35 \mathrm{E}-08$ & $6.33 \mathrm{E}-08$ & $6.40 \mathrm{E}-08$ \\
\hline & 6.6 & 4.24E-08 & 4.14E-08 & 4.24E-08 & $4.02 \mathrm{E}-08$ & 4.11E-08 & $4.06 \mathrm{E}-08$ \\
\hline & 13.6 & $2.83 \mathrm{E}-08$ & $2.59 \mathrm{E}-08$ & & & & \\
\hline & 21.1 & $1.41 \mathrm{E}-08$ & $1.46 \mathrm{E}-08$ & $1.44 \mathrm{E}-08$ & & & \\
\hline & 14.0 & $2.73 \mathrm{E}-08$ & $2.57 \mathrm{E}-08$ & & & & \\
\hline & 28.0 & $5.63 \mathrm{E}-09$ & & & & & \\
\hline & 42.0 & $8.04 \mathrm{E}-10$ & 7.24E-09 & & & & \\
\hline \multirow{10}{*}{$\begin{array}{c}\text { set } 1: \mathrm{pH}=7.0 \text {, } \\
\mathrm{NaCl}=0.050 \mathrm{~m}, \\
300^{\circ} \mathrm{C}\end{array}$} & 0.0 & 7.37E-08 & & & & & \\
\hline & 0.8 & 4.74E-08 & $4.25 \mathrm{E}-08$ & 3.69E-08 & $4.35 \mathrm{E}-08$ & $4.52 \mathrm{E}-08$ & $3.62 \mathrm{E}-08$ \\
\hline & 1.7 & $3.55 \mathrm{E}-08$ & $2.90 \mathrm{E}-08$ & $3.50 \mathrm{E}-08$ & 4.01E-08 & $3.75 \mathrm{E}-08$ & $2.36 \mathrm{E}-08$ \\
\hline & 2.5 & $3.63 \mathrm{E}-08$ & $3.07 \mathrm{E}-08$ & $2.66 \mathrm{E}-08$ & $2.87 \mathrm{E}-08$ & 2.61E-08 & $2.97 \mathrm{E}-08$ \\
\hline & 3.3 & $1.71 \mathrm{E}-08$ & 2.87E-08 & $2.43 \mathrm{E}-08$ & $2.00 \mathrm{E}-08$ & $2.25 \mathrm{E}-08$ & \\
\hline & 4.2 & $1.10 \mathrm{E}-08$ & 2.31E-08 & $7.86 \mathrm{E}-09$ & $3.03 \mathrm{E}-08$ & $1.58 \mathrm{E}-08$ & $1.58 \mathrm{E}-08$ \\
\hline & 14.0 & 4.01E-09 & 4.01E-09 & 2.01E-09 & $3.26 \mathrm{E}-09$ & 1.19E-09 & $3.13 \mathrm{E}-09$ \\
\hline & 41.0 & $1.04 \mathrm{E}-10$ & $4.51 \mathrm{E}-10$ & $3.88 \mathrm{E}-10$ & $3.42 \mathrm{E}-10$ & $9.37 \mathrm{E}-11$ & \\
\hline & 56.0 & $2.31 \mathrm{E}-10$ & $2.01 \mathrm{E}-10$ & $3.73 \mathrm{E}-10$ & $6.79 \mathrm{E}-11$ & $1.67 \mathrm{E}-10$ & $4.56 \mathrm{E}-10$ \\
\hline & 84.0 & $2.60 \mathrm{E}-10$ & $1.67 \mathrm{E}-10$ & $2.44 \mathrm{E}-10$ & & & \\
\hline \multirow{6}{*}{$\begin{array}{c}\text { set } 1: \mathrm{pH}=7.0, \\
\mathrm{NaCl}=0.050 \mathrm{~m}, \\
330^{\circ} \mathrm{C}\end{array}$} & 0.0 & 7.93E-08 & & & & & \\
\hline & 0.8 & $1.60 \mathrm{E}-08$ & $2.02 \mathrm{E}-08$ & $1.73 \mathrm{E}-08$ & $2.47 \mathrm{E}-08$ & $1.95 \mathrm{E}-08$ & \\
\hline & 1.7 & $9.15 \mathrm{E}-09$ & $3.04 \mathrm{E}-09$ & $3.54 \mathrm{E}-09$ & $9.42 \mathrm{E}-09$ & 6.29E-09 & \\
\hline & 6.6 & n.d. & $3.96 \mathrm{E}-10$ & n.d. & $7.92 \mathrm{E}-10$ & & \\
\hline & 13.6 & n.d. & n.d. & n.d. & n.d. & & \\
\hline & 21.1 & n.d. & n.d & n.d. & & & \\
\hline \multirow{4}{*}{$\begin{array}{c}\text { set } 2: \mathrm{pH}=7.0, \\
\mathrm{NaCl}=0.050 \mathrm{~m}, \\
\text { graywacke, } \\
250^{\circ} \mathrm{C}\end{array}$} & 0.0 & $1.05 \mathrm{E}-07$ & & & & & \\
\hline & 14.0 & $1.01 \mathrm{E}-07$ & 9.59E-08 & $1.01 \mathrm{E}-07$ & $9.98 \mathrm{E}-08$ & & \\
\hline & 28.0 & $9.78 \mathrm{E}-08$ & $9.69 \mathrm{E}-08$ & $1.02 \mathrm{E}-07$ & $1.02 \mathrm{E}-07$ & & \\
\hline & 42.0 & $9.981 \mathrm{E}-08$ & $1.02 \mathrm{E}-07$ & 9.98E-08 & $9.78 \mathrm{E}-08$ & & \\
\hline \multirow{4}{*}{$\begin{array}{c}\text { set } 2: \mathrm{pH}=7.0, \\
\mathrm{NaCl}=0.050 \mathrm{~m}, \\
\text { graywacke, } \\
270^{\circ} \mathrm{C}\end{array}$} & 0.0 & $1.05 \mathrm{E}-07$ & & & & & \\
\hline & 14.0 & $9.69 \mathrm{E}-08$ & $9.03 \mathrm{E}-08$ & 9.49E-08 & $9.21 \mathrm{E}-08$ & & \\
\hline & 28.0 & $8.85 \mathrm{E}-08$ & 9.03E-08 & $8.42 \mathrm{E}-08$ & $9.31 \mathrm{E}-08$ & & \\
\hline & 42.0 & 8.591E-08 & 8.09E-08 & $8.51 \mathrm{E}-08$ & 7.77E-08 & & \\
\hline \multirow{4}{*}{$\begin{array}{c}\text { set } 2: \mathrm{pH}=7.0, \\
\mathrm{NaCl}=0.050 \mathrm{~m}, \\
\text { graywacke, } \\
300^{\circ} \mathrm{C}\end{array}$} & 0.0 & $1.05 \mathrm{E}-07$ & & & & & \\
\hline & 14.0 & $6.96 \mathrm{E}-08$ & 8.17E-08 & 7.77E-08 & $8.42 \mathrm{E}-08$ & & \\
\hline & 28.0 & $6.76 \mathrm{E}-08$ & $6.76 \mathrm{E}-08$ & $4.35 \mathrm{E}-08$ & & & \\
\hline & 42.0 & $1.805 \mathrm{E}-08$ & & & & & \\
\hline
\end{tabular}

\section{B.8 Supplementary material Chapter 3, 2,6-NDS (Set 1 and Set 2)}

Table B.8: 2,6-NDS concentration in $\mathrm{mol} \mathrm{kg}^{-1}$ (HPLC).

\begin{tabular}{|c|c|c|c|c|c|c|c|}
\hline & & & replicates & $101 \cdot \mathrm{kg}^{-1}$ & n.d. - no & tected & \\
\hline Identifier & time/day & $\# 1$ & $\# 2$ & $\# 3$ & $\# 4$ & $\# 5$ & $\# 6$ \\
\hline \multirow{7}{*}{$\begin{array}{c}\text { set } 1: \mathrm{pH}=7.0 \text {, } \\
\mathrm{NaCl}=0.050 \mathrm{~m}, \\
200^{\circ} \mathrm{C}\end{array}$} & 0.0 & $8.80 \mathrm{E}-08$ & & & & & \\
\hline & 0.8 & $8.65 \mathrm{E}-08$ & 8.63E-08 & $8.65 \mathrm{E}-08$ & 8.69E-08 & 8.73E-08 & 8.54E-08 \\
\hline & 1.7 & 8.61E-08 & 8.59E-08 & $8.72 \mathrm{E}-08$ & $8.51 \mathrm{E}-08$ & 8.69E-08 & $8.62 \mathrm{E}-08$ \\
\hline & 2.5 & $8.62 \mathrm{E}-08$ & 8.30E-08 & 7.87E-08 & 8.57E-08 & 8.43E-08 & $8.52 \mathrm{E}-08$ \\
\hline & 3.3 & 8.87E-08 & 8.59E-08 & 8.53E-08 & $8.56 \mathrm{E}-08$ & 8.61E-08 & $8.80 \mathrm{E}-08$ \\
\hline & 4.2 & $8.48 \mathrm{E}-08$ & 8.43E-08 & $8.58 \mathrm{E}-08$ & 7.91E-08 & 8.54E-08 & $8.45 \mathrm{E}-08$ \\
\hline & 27.9 & 8.64E-08 & 8.79E-08 & 8.81E-08 & 8.95E-08 & $8.74 \mathrm{E}-08$ & $8.58 \mathrm{E}-08$ \\
\hline
\end{tabular}




\begin{tabular}{|c|c|c|c|c|c|c|c|}
\hline \multirow[b]{2}{*}{ Identifier } & \multirow[b]{2}{*}{ time/day } & \multirow[b]{2}{*}{$\# 1$} & \multicolumn{2}{|c|}{ replicates $/ \mathrm{mol} \cdot \mathrm{kg}^{-1}$} & \multicolumn{2}{|c|}{ n.d. - not detected } & \multirow[b]{2}{*}{$\# 6$} \\
\hline & & & $\# 2$ & $\# 3$ & $\# 4$ & $\# 5$ & \\
\hline & 56.9 & 8.57E-08 & 8.77E-08 & 8.94E-08 & 8.70E-08 & 8.69E-08 & $8.31 \mathrm{E}-08$ \\
\hline & 88.9 & $9.02 \mathrm{E}-08$ & $8.73 \mathrm{E}-08$ & 8.73E-08 & 8.49E-08 & 8.57E-08 & $8.66 \mathrm{E}-08$ \\
\hline \multirow{6}{*}{$\begin{array}{c}\text { set } 1: \mathrm{pH}=7.0 \\
\mathrm{NaCl}=0.050 \mathrm{~m} \\
225^{\circ} \mathrm{C}\end{array}$} & 0.0 & 8.95E-08 & & & & & \\
\hline & 0.8 & 8.91E-08 & 8.89E-08 & $8.96 \mathrm{E}-08$ & 8.72E-08 & $9.09 \mathrm{E}-08$ & 8.96E-08 \\
\hline & 20.0 & 8.38E-08 & $8.43 \mathrm{E}-08$ & $8.51 \mathrm{E}-08$ & $8.22 \mathrm{E}-08$ & 8.39E-08 & $8.39 \mathrm{E}-08$ \\
\hline & 27.9 & 8.03E-08 & $8.22 \mathrm{E}-08$ & 8.22E-08 & 8.19E-08 & $8.27 \mathrm{E}-08$ & $8.12 \mathrm{E}-08$ \\
\hline & 38.7 & $8.21 \mathrm{E}-08$ & 7.74E-08 & 7.93E-08 & $7.85 \mathrm{E}-08$ & 7.84E-08 & 7.73E-08 \\
\hline & 45.0 & 7.69E-08 & 7.76E-08 & 7.67E-08 & $7.56 \mathrm{E}-08$ & 7.41E-08 & 7.69E-08 \\
\hline \multirow{9}{*}{$\begin{array}{c}\text { set } 1: \mathrm{pH}=7.0 \\
\mathrm{NaCl}=0.050 \mathrm{~m} \\
250^{\circ} \mathrm{C}\end{array}$} & 0.0 & $8.15 \mathrm{E}-08$ & & & & & \\
\hline & 0.8 & 7.36E-08 & 7.44E-08 & $7.85 \mathrm{E}-08$ & 8.05E-08 & $6.97 \mathrm{E}-08$ & 7.01E-08 \\
\hline & 2.5 & 7.19E-08 & $6.76 \mathrm{E}-08$ & 7.75E-08 & $6.80 \mathrm{E}-08$ & $6.71 \mathrm{E}-08$ & $6.84 \mathrm{E}-08$ \\
\hline & 3.3 & $7.08 \mathrm{E}-08$ & $6.91 \mathrm{E}-08$ & $7.08 \mathrm{E}-08$ & 7.02E-08 & 7.10E-08 & \\
\hline & 4.2 & 7.26E-08 & 7.06E-08 & $6.83 \mathrm{E}-08$ & $6.81 \mathrm{E}-08$ & $6.98 \mathrm{E}-08$ & 7.04E-08 \\
\hline & 5.8 & $6.70 \mathrm{E}-08$ & $6.79 \mathrm{E}-08$ & $6.69 \mathrm{E}-08$ & $6.78 \mathrm{E}-08$ & $6.49 \mathrm{E}-08$ & $6.65 \mathrm{E}-08$ \\
\hline & 27.9 & 5.91E-08 & $5.79 \mathrm{E}-08$ & $6.57 \mathrm{E}-08$ & $6.66 \mathrm{E}-08$ & $6.23 \mathrm{E}-08$ & $6.09 \mathrm{E}-08$ \\
\hline & 56.9 & $6.46 \mathrm{E}-08$ & $5.86 \mathrm{E}-08$ & 5.93E-08 & $6.48 \mathrm{E}-08$ & $6.18 \mathrm{E}-08$ & $6.09 \mathrm{E}-08$ \\
\hline & 88.9 & 5.97E-08 & $6.15 \mathrm{E}-08$ & $6.06 \mathrm{E}-08$ & & & \\
\hline \multirow{9}{*}{$\begin{array}{c}\text { set } 1: \mathrm{pH}=7.0 \\
\mathrm{NaCl}=0.050 \mathrm{~m} \\
270^{\circ} \mathrm{C}\end{array}$} & 0.0 & 8.67E-08 & & & & & \\
\hline & 0.8 & $8.35 \mathrm{E}-08$ & $8.47 \mathrm{E}-08$ & $8.47 \mathrm{E}-08$ & 8.37E-08 & $8.49 \mathrm{E}-08$ & $8.52 \mathrm{E}-08$ \\
\hline & 1.7 & $8.43 \mathrm{E}-08$ & $8.40 \mathrm{E}-08$ & $8.40 \mathrm{E}-08$ & 8.34E-08 & 8.38E-08 & $8.30 \mathrm{E}-08$ \\
\hline & 6.6 & 7.74E-08 & 7.74E-08 & 7.73E-08 & 7.84E-08 & $7.81 \mathrm{E}-08$ & $7.66 \mathrm{E}-08$ \\
\hline & 13.6 & $6.78 \mathrm{E}-08$ & $6.63 \mathrm{E}-08$ & & & & \\
\hline & 21.1 & $6.18 \mathrm{E}-08$ & $6.12 \mathrm{E}-08$ & $6.16 \mathrm{E}-08$ & & & \\
\hline & 14.0 & $6.20 \mathrm{E}-08$ & 5.94E-08 & & & & \\
\hline & 28.0 & 3.96E-08 & 3.53E-08 & & & & \\
\hline & 42.0 & $2.84 \mathrm{E}-08$ & $2.58 \mathrm{E}-08$ & & & & \\
\hline \multirow{10}{*}{$\begin{array}{c}\text { set } 1: \mathrm{pH}=7.0 \\
\mathrm{NaCl}=0.050 \mathrm{~m} \\
300^{\circ} \mathrm{C}\end{array}$} & 0.0 & 7.42E-08 & & & & & \\
\hline & 0.8 & $5.52 \mathrm{E}-08$ & 5.15E-08 & 4.91E-08 & 5.51E-08 & $5.25 \mathrm{E}-08$ & $4.72 \mathrm{E}-08$ \\
\hline & 1.7 & 5.61E-08 & 5.27E-08 & 5.62E-08 & 5.49E-08 & $5.56 \mathrm{E}-08$ & \\
\hline & 2.5 & $5.17 \mathrm{E}-08$ & $5.23 \mathrm{E}-08$ & 4.97E-08 & $5.14 \mathrm{E}-08$ & $5.21 \mathrm{E}-08$ & \\
\hline & 3.3 & 4.97E-08 & $5.47 \mathrm{E}-08$ & $5.22 \mathrm{E}-08$ & $4.90 \mathrm{E}-08$ & $5.14 \mathrm{E}-08$ & \\
\hline & 4.2 & $4.45 \mathrm{E}-08$ & $5.09 \mathrm{E}-08$ & $3.76 \mathrm{E}-08$ & $5.27 \mathrm{E}-08$ & $4.66 \mathrm{E}-08$ & $4.66 \mathrm{E}-08$ \\
\hline & 14.0 & $4.18 \mathrm{E}-08$ & $4.18 \mathrm{E}-08$ & $3.84 \mathrm{E}-08$ & $3.98 \mathrm{E}-08$ & $3.52 \mathrm{E}-08$ & $3.98 \mathrm{E}-08$ \\
\hline & 41.0 & $1.62 \mathrm{E}-08$ & $2.00 \mathrm{E}-08$ & $1.88 \mathrm{E}-08$ & $1.83 \mathrm{E}-09$ & $1.72 \mathrm{E}-08$ & $2.06 \mathrm{E}-08$ \\
\hline & 56.0 & $1.07 \mathrm{E}-08$ & 1.40E-08 & $1.90 \mathrm{E}-08$ & $1.42 \mathrm{E}-08$ & $1.65 \mathrm{E}-08$ & $1.73 \mathrm{E}-08$ \\
\hline & 84.0 & $2.91 \mathrm{E}-10$ & $4.23 \mathrm{E}-10$ & 4.17E-10 & & & \\
\hline \multirow{5}{*}{$\begin{array}{c}\text { set } 1: \mathrm{pH}=7.0 \\
\mathrm{NaCl}=0.050 \mathrm{~m} \\
330^{\circ} \mathrm{C}\end{array}$} & 0.0 & $8.47 \mathrm{E}-08$ & & & & & \\
\hline & 0.8 & $5.65 \mathrm{E}-08$ & $5.96 \mathrm{E}-08$ & $6.19 \mathrm{E}-08$ & $6.24 \mathrm{E}-08$ & $6.01 \mathrm{E}-08$ & \\
\hline & 1.7 & 4.37E-08 & $4.55 \mathrm{E}-08$ & 4.95E-08 & 4.46E-08 & & \\
\hline & 6.6 & $2.82 \mathrm{E}-08$ & $3.02 \mathrm{E}-08$ & $2.70 \mathrm{E}-08$ & $2.85 \mathrm{E}-08$ & & \\
\hline & 13.6 & $1.82 \mathrm{E}-08$ & $2.14 \mathrm{E}-08$ & $2.17 \mathrm{E}-08$ & $1.88 \mathrm{E}-08$ & & \\
\hline \multirow{5}{*}{$\begin{array}{c}\text { set } 2: \mathrm{pH}=7.0 \\
\mathrm{NaCl}=0.050 \mathrm{~m} \\
\text { graywacke } \\
250^{\circ} \mathrm{C}\end{array}$} & 0.0 & $1.02 \mathrm{E}-07$ & & & & & \\
\hline & 14.0 & $9.88 \mathrm{E}-08$ & $9.78 \mathrm{E}-08$ & $9.98 \mathrm{E}-08$ & $9.78 \mathrm{E}-08$ & & \\
\hline & 28.0 & $9.69 \mathrm{E}-08$ & $9.69 \mathrm{E}-08$ & $9.98 \mathrm{E}-08$ & $9.98 \mathrm{E}-08$ & & \\
\hline & 42.0 & $9.88 \mathrm{E}-08$ & $9.98 \mathrm{E}-08$ & $9.88 \mathrm{E}-08$ & $9.78 \mathrm{E}-08$ & & \\
\hline & 0.0 & $1.02 \mathrm{E}-07$ & & & & & \\
\hline
\end{tabular}




\begin{tabular}{|c|c|c|c|c|c|c|c|}
\hline \multirow[b]{2}{*}{ Identifier } & \multirow[b]{2}{*}{ time/day } & \multirow[b]{2}{*}{$\# 1$} & \multicolumn{2}{|c|}{ replicates/mol $\cdot \mathbf{k g}^{-1}$} & \multicolumn{2}{|c|}{ n.d. - not detected } & \multirow[b]{2}{*}{ \#6 } \\
\hline & & & $\# 2$ & $\# 3$ & $\# 4$ & \#5 & \\
\hline \multirow{3}{*}{$\begin{array}{l}\text { set } 2: \mathrm{pH}=7.0, \\
\mathrm{NaCl}=0.050 \mathrm{~m}, \\
\text { graywacke, } \\
270^{\circ} \mathrm{C}\end{array}$} & 14.0 & $9.69 \mathrm{E}-08$ & $9.40 \mathrm{E}-08$ & $9.59 \mathrm{E}-08$ & $9.40 \mathrm{E}-08$ & & \\
\hline & 28.0 & $9.40 \mathrm{E}-08$ & $9.49 \mathrm{E}-08$ & $9.31 \mathrm{E}-08$ & $9.49 \mathrm{E}-08$ & & \\
\hline & 42.0 & $9.40 \mathrm{E}-08$ & $9.21 \mathrm{E}-08$ & $9.31 \mathrm{E}-08$ & $9.12 \mathrm{E}-08$ & & \\
\hline \multirow{4}{*}{$\begin{array}{l}\text { set } 2: \mathrm{pH}=7.0, \\
\mathrm{NaCl}=0.050 \mathrm{~m}, \\
\text { graywacke, } \\
300^{\circ} \mathrm{C}\end{array}$} & 0.0 & $1.02 \mathrm{E}-07$ & & & & & \\
\hline & 14.0 & $9.12 \mathrm{E}-08$ & $9.49 \mathrm{E}-08$ & $9.49 \mathrm{E}-08$ & $9.31 \mathrm{E}-08$ & & \\
\hline & 28.0 & $9.12 \mathrm{E}-08$ & $9.31 \mathrm{E}-08$ & $8.25 \mathrm{E}-08$ & & & \\
\hline & 42.0 & $6.62 \mathrm{E}-08$ & & & & & \\
\hline
\end{tabular}

\section{B.9 Supplementary material Chapter 3, 2,7-NDS (Set 1 and Set 2)}

Table B.9: 2,7-NDS concentration in $\mathrm{mol} \mathrm{kg}^{-1}$ (HPLC).

\begin{tabular}{|c|c|c|c|c|c|c|c|}
\hline \multirow[b]{2}{*}{ Identifier } & \multirow[b]{2}{*}{ time/day } & \multirow[b]{2}{*}{$\# 1$} & \multicolumn{2}{|c|}{ replicates $/ \mathrm{mol} \cdot \mathrm{kg}^{-1}$} & \multicolumn{2}{|c|}{ n.d. - not detected } & \multirow[b]{2}{*}{$\# 6$} \\
\hline & & & $\# 2$ & $\# \mathbf{3}$ & \#4 & $\# 5$ & \\
\hline \multirow{9}{*}{$\begin{array}{c}\text { set } 1: \mathrm{pH}=7.0 \\
\mathrm{NaCl}=0.050 \mathrm{~m} \\
200^{\circ} \mathrm{C}\end{array}$} & 0.0 & $6.85 \mathrm{E}-08$ & & & & & \\
\hline & 0.8 & $6.69 \mathrm{E}-08$ & $6.94 \mathrm{E}-08$ & $6.79 \mathrm{E}-08$ & $6.44 \mathrm{E}-08$ & $6.36 \mathrm{E}-08$ & $6.82 \mathrm{E}-08$ \\
\hline & 1.7 & $6.64 \mathrm{E}-08$ & $6.60 \mathrm{E}-08$ & $6.74 \mathrm{E}-08$ & $6.58 \mathrm{E}-08$ & $6.67 \mathrm{E}-08$ & $6.65 \mathrm{E}-08$ \\
\hline & 2.5 & $6.74 \mathrm{E}-08$ & $6.45 \mathrm{E}-08$ & $6.12 \mathrm{E}-08$ & $6.64 \mathrm{E}-08$ & $6.52 \mathrm{E}-08$ & $6.64 \mathrm{E}-08$ \\
\hline & 3.3 & $6.82 \mathrm{E}-08$ & $6.68 \mathrm{E}-08$ & $6.65 \mathrm{E}-08$ & $6.69 \mathrm{E}-08$ & $6.69 \mathrm{E}-08$ & $6.76 \mathrm{E}-08$ \\
\hline & 4.2 & $6.94 \mathrm{E}-08$ & $6.67 \mathrm{E}-08$ & $6.69 \mathrm{E}-08$ & $6.89 \mathrm{E}-08$ & $6.69 \mathrm{E}-08$ & $6.99 \mathrm{E}-08$ \\
\hline & 27.9 & $6.74 \mathrm{E}-08$ & $6.81 \mathrm{E}-08$ & $6.87 \mathrm{E}-08$ & $6.78 \mathrm{E}-08$ & $6.92 \mathrm{E}-08$ & $6.72 \mathrm{E}-08$ \\
\hline & 56.9 & $6.95 \mathrm{E}-08$ & $6.75 \mathrm{E}-08$ & $6.90 \mathrm{E}-08$ & $6.72 \mathrm{E}-08$ & $6.73 \mathrm{E}-08$ & 7.02E-08 \\
\hline & 88.9 & $6.20 \mathrm{E}-08$ & $6.83 \mathrm{E}-08$ & $6.80 \mathrm{E}-08$ & $6.63 \mathrm{E}-08$ & $6.94 \mathrm{E}-08$ & $6.73 \mathrm{E}-08$ \\
\hline \multirow{6}{*}{$\begin{array}{c}\text { set } 1: \mathrm{pH}=7.0 \\
\mathrm{NaCl}=0.050 \mathrm{~m} \\
225^{\circ} \mathrm{C}\end{array}$} & 0.0 & $6.99 \mathrm{E}-08$ & & & & & \\
\hline & 0.8 & $6.98 \mathrm{E}-08$ & 7.02E-08 & 7.02E-08 & $6.98 \mathrm{E}-08$ & $6.98 \mathrm{E}-08$ & $6.91 \mathrm{E}-08$ \\
\hline & 20.0 & $6.71 \mathrm{E}-08$ & $6.73 \mathrm{E}-08$ & $6.77 \mathrm{E}-08$ & $6.73 \mathrm{E}-08$ & $6.75 \mathrm{E}-08$ & $6.74 \mathrm{E}-08$ \\
\hline & 27.9 & $6.64 \mathrm{E}-08$ & $6.65 \mathrm{E}-08$ & $6.66 \mathrm{E}-08$ & $6.69 \mathrm{E}-08$ & $6.66 \mathrm{E}-08$ & $6.65 \mathrm{E}-08$ \\
\hline & 38.7 & $6.46 \mathrm{E}-08$ & $6.46 \mathrm{E}-08$ & $6.47 \mathrm{E}-08$ & $6.51 \mathrm{E}-08$ & $6.60 \mathrm{E}-08$ & $6.44 \mathrm{E}-08$ \\
\hline & 45.0 & $6.29 \mathrm{E}-08$ & $6.34 \mathrm{E}-08$ & $6.51 \mathrm{E}-08$ & $6.60 \mathrm{E}-08$ & $6.61 \mathrm{E}-08$ & \\
\hline \multirow{9}{*}{$\begin{array}{c}\text { set } 1: \mathrm{pH}=7.0 \\
\mathrm{NaCl}=0.050 \mathrm{~m} \\
250^{\circ} \mathrm{C}\end{array}$} & 0.0 & $6.80 \mathrm{E}-08$ & & & & & \\
\hline & 0.8 & $6.43 \mathrm{E}-08$ & $6.49 \mathrm{E}-08$ & $6.82 \mathrm{E}-08$ & $7.20 \mathrm{E}-08$ & $6.10 \mathrm{E}-08$ & $6.17 \mathrm{E}-08$ \\
\hline & 2.5 & $6.21 \mathrm{E}-08$ & $5.97 \mathrm{E}-08$ & $5.99 \mathrm{E}-08$ & $5.96 \mathrm{E}-08$ & $6.02 \mathrm{E}-08$ & \\
\hline & 3.3 & $5.87 \mathrm{E}-08$ & $6.14 \mathrm{E}-08$ & $5.99 \mathrm{E}-08$ & $6.11 \mathrm{E}-08$ & $6.04 \mathrm{E}-08$ & $6.15 \mathrm{E}-08$ \\
\hline & 4.2 & $6.09 \mathrm{E}-08$ & $6.08 \mathrm{E}-08$ & $6.06 \mathrm{E}-08$ & $6.10 \mathrm{E}-08$ & $6.11 \mathrm{E}-08$ & \\
\hline & 5.8 & $5.95 \mathrm{E}-08$ & $5.93 \mathrm{E}-08$ & $5.96 \mathrm{E}-08$ & 5.94E-08 & $5.91 \mathrm{E}-08$ & \\
\hline & 27.9 & $5.59 \mathrm{E}-08$ & $5.26 \mathrm{E}-08$ & $5.90 \mathrm{E}-08$ & $5.99 \mathrm{E}-08$ & $5.69 \mathrm{E}-08$ & $5.58 \mathrm{E}-08$ \\
\hline & 56.9 & $5.84 \mathrm{E}-08$ & $5.47 \mathrm{E}-08$ & $5.50 \mathrm{E}-08$ & 5.92E-08 & $5.68 \mathrm{E}-08$ & $5.60 \mathrm{E}-08$ \\
\hline & 88.9 & $5.41 \mathrm{E}-08$ & $5.62 \mathrm{E}-08$ & 5.51E-08 & & & \\
\hline \multirow{8}{*}{$\begin{array}{c}\text { set } 1: \mathrm{pH}=7.0 \\
\mathrm{NaCl}=0.050 \mathrm{~m} \\
270^{\circ} \mathrm{C}\end{array}$} & 0.0 & $6.97 \mathrm{E}-08$ & & & & & \\
\hline & 0.8 & $6.48 \mathrm{E}-08$ & $6.71 \mathrm{E}-08$ & $6.65 \mathrm{E}-08$ & $6.38 \mathrm{E}-08$ & $6.58 \mathrm{E}-08$ & $6.58 \mathrm{E}-08$ \\
\hline & 1.7 & $6.35 \mathrm{E}-08$ & $6.40 \mathrm{E}-08$ & $6.24 \mathrm{E}-08$ & $6.29 \mathrm{E}-08$ & $6.24 \mathrm{E}-08$ & $6.35 \mathrm{E}-08$ \\
\hline & 6.6 & $5.62 \mathrm{E}-08$ & $5.74 \mathrm{E}-08$ & $5.58 \mathrm{E}-08$ & $5.47 \mathrm{E}-08$ & $5.63 \mathrm{E}-08$ & $5.67 \mathrm{E}-08$ \\
\hline & 13.6 & $5.17 \mathrm{E}-08$ & $5.05 \mathrm{E}-08$ & & & & \\
\hline & 21.1 & 3.93E-08 & $3.91 \mathrm{E}-08$ & 3.92E-08 & & & \\
\hline & 14.0 & 4.98E-08 & $5.05 \mathrm{E}-08$ & & & & \\
\hline & 28.0 & $3.65 \mathrm{E}-08$ & 4.14E-08 & & & & \\
\hline
\end{tabular}




\begin{tabular}{|c|c|c|c|c|c|c|c|}
\hline \multirow[b]{2}{*}{ Identifier } & \multirow[b]{2}{*}{ time/day } & \multirow[b]{2}{*}{$\# 1$} & \multicolumn{2}{|c|}{ replicates $/ \mathrm{mol} \cdot \mathrm{kg}^{-1}$} & \multicolumn{2}{|c|}{ n.d. - not detected } & \multirow[b]{2}{*}{$\# 6$} \\
\hline & & & $\# 2$ & $\# 3$ & $\# 4$ & \#5 & \\
\hline & 42.0 & $3.44 \mathrm{E}-08$ & $3.29 \mathrm{E}-08$ & & & & \\
\hline \multirow{10}{*}{$\begin{array}{c}\text { set } 1: \mathrm{pH}=7.0 \\
\mathrm{NaCl}=0.050 \mathrm{~m} \\
300^{\circ} \mathrm{C}\end{array}$} & 0.0 & 6.77E-08 & & & & & \\
\hline & 0.8 & 6.03E-08 & $5.96 \mathrm{E}-08$ & $5.92 \mathrm{E}-08$ & 5.89E-08 & $5.90 \mathrm{E}-08$ & $6.02 \mathrm{E}-08$ \\
\hline & 1.7 & $5.57 \mathrm{E}-08$ & $5.90 \mathrm{E}-08$ & $5.44 \mathrm{E}-08$ & $5.41 \mathrm{E}-08$ & $5.73 \mathrm{E}-08$ & 5.89E-08 \\
\hline & 2.5 & $5.59 \mathrm{E}-08$ & $5.42 \mathrm{E}-08$ & 5.44E-08 & $5.67 \mathrm{E}-08$ & $5.44 \mathrm{E}-08$ & $5.47 \mathrm{E}-08$ \\
\hline & 3.3 & $5.52 \mathrm{E}-08$ & $5.55 \mathrm{E}-08$ & $5.36 \mathrm{E}-08$ & $5.30 \mathrm{E}-08$ & $5.61 \mathrm{E}-08$ & \\
\hline & 4.2 & $5.34 \mathrm{E}-08$ & $5.25 \mathrm{E}-08$ & $5.22 \mathrm{E}-08$ & $5.24 \mathrm{E}-08$ & $5.34 \mathrm{E}-08$ & $5.24 \mathrm{E}-08$ \\
\hline & 14.0 & 4.20E-08 & 4.20E-08 & $3.80 \mathrm{E}-08$ & $4.02 \mathrm{E}-08$ & $3.44 \mathrm{E}-08$ & $3.99 \mathrm{E}-08$ \\
\hline & 41.0 & $1.42 \mathrm{E}-08$ & $1.78 \mathrm{E}-08$ & 1.67E-08 & $1.54 \mathrm{E}-08$ & $1.74 \mathrm{E}-08$ & \\
\hline & 56.0 & 9.33E-09 & $1.28 \mathrm{E}-08$ & $1.74 \mathrm{E}-08$ & $1.25 \mathrm{E}-08$ & $1.45 \mathrm{E}-08$ & $1.57 \mathrm{E}-08$ \\
\hline & 84.0 & $5.66 \mathrm{E}-10$ & $3.78 \mathrm{E}-10$ & $5.87 \mathrm{E}-10$ & & & \\
\hline \multirow{5}{*}{$\begin{array}{c}\text { set } 1: \mathrm{pH}=7.0 \\
\mathrm{NaCl}=0.050 \mathrm{~m} \\
330^{\circ} \mathrm{C}\end{array}$} & 0.0 & $6.79 \mathrm{E}-08$ & & & & & \\
\hline & 0.8 & 4.76E-08 & $5.05 \mathrm{E}-08$ & $5.21 \mathrm{E}-08$ & $5.26 \mathrm{E}-08$ & $5.07 \mathrm{E}-08$ & \\
\hline & 1.7 & $3.51 \mathrm{E}-08$ & $3.70 \mathrm{E}-08$ & $3.82 \mathrm{E}-08$ & 4.20E-08 & 3.81E-08 & \\
\hline & 6.6 & 2.37E-08 & $2.21 \mathrm{E}-08$ & $1.87 \mathrm{E}-08$ & $2.15 \mathrm{E}-08$ & & \\
\hline & 13.6 & $2.45 \mathrm{E}-08$ & $2.21 \mathrm{E}-08$ & $1.08 \mathrm{E}-08$ & $1.61 \mathrm{E}-08$ & & \\
\hline \multirow{4}{*}{$\begin{array}{c}\text { set } 2: \mathrm{pH}=7.0, \\
\mathrm{NaCl}=0.050 \mathrm{~m}, \\
\text { graywacke, } \\
250^{\circ} \mathrm{C}\end{array}$} & 0.0 & $1.18 \mathrm{E}-07$ & & & & & \\
\hline & 14.0 & $1.16 \mathrm{E}-07$ & $1.14 \mathrm{E}-07$ & $1.16 \mathrm{E}-07$ & $1.15 \mathrm{E}-07$ & & \\
\hline & 28.0 & $1.14 \mathrm{E}-07$ & $1.13 \mathrm{E}-07$ & $1.16 \mathrm{E}-07$ & $1.16 \mathrm{E}-07$ & & \\
\hline & 42.0 & $1.15 \mathrm{E}-07$ & $1.17 \mathrm{E}-07$ & $1.15 \mathrm{E}-07$ & $1.15 \mathrm{E}-07$ & & \\
\hline \multirow{4}{*}{$\begin{array}{c}\text { set } 2: \mathrm{pH}=7.0, \\
\mathrm{NaCl}=0.050 \mathrm{~m}, \\
\text { graywacke } \\
270^{\circ} \mathrm{C}\end{array}$} & 0.0 & $1.18 \mathrm{E}-07$ & & & & & \\
\hline & 14.0 & $1.15 \mathrm{E}-07$ & $1.16 \mathrm{E}-07$ & $1.16 \mathrm{E}-07$ & & & \\
\hline & 28.0 & 1.19E-07 & $1.18 \mathrm{E}-07$ & $1.17 \mathrm{E}-07$ & $1.17 \mathrm{E}-07$ & & \\
\hline & 42.0 & $1.21 \mathrm{E}-07$ & $1.18 \mathrm{E}-07$ & 1.19E-07 & $1.18 \mathrm{E}-07$ & & \\
\hline \multirow{4}{*}{$\begin{array}{c}\text { set } 2: \mathrm{pH}=7.0, \\
\mathrm{NaCl}=0.050 \mathrm{~m}, \\
\text { graywacke, } \\
300^{\circ} \mathrm{C}\end{array}$} & 0.0 & $1.18 \mathrm{E}-07$ & & & & & \\
\hline & 14.0 & $1.08 \mathrm{E}-07$ & $1.15 \mathrm{E}-07$ & $1.11 \mathrm{E}-07$ & $1.10 \mathrm{E}-07$ & & \\
\hline & 28.0 & $1.08 \mathrm{E}-07$ & $1.09 \mathrm{E}-07$ & $9.78 \mathrm{E}-08$ & & & \\
\hline & 42.0 & 7.70E-08 & & & & & \\
\hline
\end{tabular}

\section{B.10 Supplementary material Chapter 3, 1-NSA (Set 1 and Set 2)}

Table B.10: 1 -NSA concentration in $\mathrm{mol} \mathrm{kg}^{-1}$ (HPLC).

\begin{tabular}{|c|c|c|c|c|c|c|c|}
\hline & & & repl & $\mathrm{ol} \cdot \mathrm{kg}^{-1}$ & n.d. - & cted & \\
\hline Identifier & time/day & $\# 1$ & $\# 2$ & $\# 3$ & $\# 4$ & $\# 5$ & \#6 \\
\hline \multirow{9}{*}{$\begin{array}{c}\text { set } 1: \mathrm{pH}=7.0 \text {, } \\
\mathrm{NaCl}=0.050 \mathrm{~m}, \\
200^{\circ} \mathrm{C}\end{array}$} & 0.0 & n.d. & & & & & \\
\hline & 0.8 & n.d. & n.d. & n.d. & n.d. & n.d. & n.d. \\
\hline & 1.7 & n.d. & n.d. & n.d. & n.d. & n.d. & n.d. \\
\hline & 2.5 & n.d. & n.d. & n.d. & n.d. & n.d. & n.d. \\
\hline & 3.3 & n.d. & n.d. & n.d. & n.d. & n.d. & n.d. \\
\hline & 4.2 & n.d. & n.d. & n.d. & n.d. & n.d. & n.d. \\
\hline & 27.9 & n.d. & n.d. & n.d. & n.d. & n.d. & n.d. \\
\hline & 56.9 & n.d. & n.d. & n.d. & n.d. & n.d. & n.d. \\
\hline & 88.9 & n.d. & n.d. & n.d. & n.d. & n.d. & n.d. \\
\hline
\end{tabular}


replicates $/ \mathrm{mol}^{\circ} \mathrm{kg}^{-1} \quad$ n.d. - not detected

\begin{tabular}{|c|c|c|c|c|c|c|c|}
\hline Identifier & time/day & $\# 1$ & $\# 2$ & $\# \mathbf{3}$ & $\# 4$ & $\# 5$ & $\# 6$ \\
\hline \multirow{5}{*}{$\begin{array}{l}\text { set } 1: \mathrm{pH}=7.0 \\
\mathrm{NaCl}=0.050 \mathrm{~m}, \\
\quad 225^{\circ} \mathrm{C}\end{array}$} & 0.8 & n.d. & n.d. & n.d. & n.d. & n.d. & n.d. \\
\hline & 20.0 & n.d. & n.d. & n.d. & n.d. & n.d. & n.d. \\
\hline & 27.9 & n.d. & n.d. & n.d. & n.d. & n.d. & n.d. \\
\hline & 38.7 & n.d. & n.d. & n.d. & n.d. & n.d. & n.d. \\
\hline & 45.0 & n.d. & n.d. & n.d. & n.d. & n.d. & \\
\hline \multirow{9}{*}{$\begin{array}{c}\text { set } 1: \mathrm{pH}=7.0 \\
\mathrm{NaCl}=0.050 \mathrm{~m} \\
250^{\circ} \mathrm{C}\end{array}$} & 0.0 & n.d. & & & & & \\
\hline & 0.8 & $1.64 \mathrm{E}-09$ & $1.76 \mathrm{E}-09$ & 9.35E-09 & 7.71E-09 & $3.25 \mathrm{E}-09$ & 5.80E-09 \\
\hline & 2.5 & 4.11E-09 & 6.01E-09 & 7.52E-09 & 4.42E-09 & $6.85 \mathrm{E}-09$ & $4.02 \mathrm{E}-09$ \\
\hline & 3.3 & $6.88 \mathrm{E}-09$ & 3.01E-09 & 5.13E-09 & 4.20E-09 & 5.69E-09 & 3.83E-09 \\
\hline & 4.2 & $5.76 \mathrm{E}-09$ & $5.46 \mathrm{E}-09$ & 8.87E-09 & 7.16E-09 & $6.82 \mathrm{E}-09$ & 7.61E-09 \\
\hline & 5.8 & $8.56 \mathrm{E}-09$ & 5.33E-09 & $8.50 \mathrm{E}-09$ & 5.29E-09 & $8.65 \mathrm{E}-09$ & 7.48E-09 \\
\hline & 27.9 & $1.53 \mathrm{E}-08$ & 9.91E-09 & $1.18 \mathrm{E}-08$ & $1.46 \mathrm{E}-08$ & $1.29 \mathrm{E}-08$ & $1.23 \mathrm{E}-08$ \\
\hline & 56.9 & $1.88 \mathrm{E}-08$ & $1.73 \mathrm{E}-08$ & $1.56 \mathrm{E}-08$ & $1.81 \mathrm{E}-08$ & $1.75 \mathrm{E}-08$ & $1.72 \mathrm{E}-08$ \\
\hline & 88.9 & $1.82 \mathrm{E}-08$ & $1.75 \mathrm{E}-08$ & $1.89 \mathrm{E}-08$ & & & \\
\hline \multirow{8}{*}{$\begin{array}{c}\text { set } 1: \mathrm{pH}=7.0 \\
\mathrm{NaCl}=0.050 \mathrm{~m} \\
270^{\circ} \mathrm{C}\end{array}$} & 0.0 & n.d. & & & & & \\
\hline & 0.8 & 5.39E-09 & 3.34E-09 & 5.24E-09 & 6.39E-09 & 5.94E-09 & 7.79E-09 \\
\hline & 1.7 & 3.79E-09 & 8.07E-09 & 7.50E-09 & 6.19E-09 & $9.88 \mathrm{E}-09$ & 8.54E-09 \\
\hline & 6.6 & $1.55 \mathrm{E}-08$ & $1.70 \mathrm{E}-08$ & $1.42 \mathrm{E}-08$ & $1.38 \mathrm{E}-08$ & $1.75 \mathrm{E}-08$ & \\
\hline & 13.6 & $1.81 \mathrm{E}-08$ & $1.88 \mathrm{E}-08$ & & & & \\
\hline & 21.1 & $1.84 \mathrm{E}-08$ & $1.93 \mathrm{E}-08$ & $1.89 \mathrm{E}-08$ & & & \\
\hline & 28.0 & & & & & & \\
\hline & 42.0 & & & & & & \\
\hline \multirow{10}{*}{$\begin{array}{c}\text { set } 1: \mathrm{pH}=7.0 \\
\mathrm{NaCl}=0.050 \mathrm{~m}, \\
300^{\circ} \mathrm{C}\end{array}$} & 0.0 & n.d. & & & & & \\
\hline & 0.8 & $1.73 \mathrm{E}-08$ & $1.51 \mathrm{E}-08$ & $1.78 \mathrm{E}-08$ & 3.36E-08 & $1.90 \mathrm{E}-08$ & $1.81 \mathrm{E}-08$ \\
\hline & 1.7 & $2.62 \mathrm{E}-08$ & $2.00 \mathrm{E}-08$ & $2.31 \mathrm{E}-08$ & $1.43 \mathrm{E}-08$ & $2.08 \mathrm{E}-08$ & $1.66 \mathrm{E}-08$ \\
\hline & 2.5 & 2.06E-08 & 1.89E-08 & 2.07E-08 & $1.84 \mathrm{E}-08$ & $1.94 \mathrm{E}-08$ & $1.96 \mathrm{E}-08$ \\
\hline & 3.3 & $1.55 \mathrm{E}-08$ & $2.37 \mathrm{E}-08$ & $2.05 \mathrm{E}-08$ & $1.70 \mathrm{E}-08$ & $1.92 \mathrm{E}-08$ & \\
\hline & 4.2 & 8.97E-09 & $2.10 \mathrm{E}-08$ & $5.65 \mathrm{E}-09$ & $2.00 \mathrm{E}-08$ & $1.28 \mathrm{E}-08$ & $1.28 \mathrm{E}-08$ \\
\hline & 14.0 & n.d. & & & & & \\
\hline & 41.0 & n.d. & & & & & \\
\hline & 56.0 & n.d. & & & & & \\
\hline & 84.0 & n.d. & & & & & \\
\hline \multirow{5}{*}{$\begin{array}{l}\text { set } 1: \mathrm{pH}=7.0 \\
\mathrm{NaCl}=0.050 \mathrm{~m} \\
\quad 330^{\circ} \mathrm{C}\end{array}$} & 0.0 & n.d. & & & & & \\
\hline & 0.8 & $1.57 \mathrm{E}-08$ & $1.99 \mathrm{E}-08$ & $1.72 \mathrm{E}-08$ & $2.47 \mathrm{E}-08$ & $1.94 \mathrm{E}-08$ & \\
\hline & 1.7 & $9.00 \mathrm{E}-09$ & 2.87E-09 & 3.31E-09 & $9.12 \mathrm{E}-09$ & $6.08 \mathrm{E}-09$ & \\
\hline & 6.6 & n.d. & n.d. & n.d. & n.d. & & \\
\hline & 13.6 & n.d. & n.d. & $5.83 \mathrm{E}-10$ & $1.94 \mathrm{E}-10$ & & \\
\hline \multirow{4}{*}{$\begin{array}{c}\text { set } 2: \mathrm{pH}=7.0, \\
\mathrm{NaCl}=0.050 \mathrm{~m}, \\
\text { graywacke, } \\
250^{\circ} \mathrm{C}\end{array}$} & 0.0 & n.d. & & & & & \\
\hline & 14.0 & 2.24E-09 & 2.79E-09 & 3.38E-09 & $3.38 \mathrm{E}-09$ & & \\
\hline & 28.0 & 4.83E-09 & 4.83E-09 & 3.38E-09 & 3.38E-09 & & \\
\hline & 42.0 & 5.31E-09 & 4.83E-09 & $3.86 \mathrm{E}-09$ & $6.76 \mathrm{E}-09$ & & \\
\hline \multirow{5}{*}{$\begin{array}{c}\text { set } 2: \mathrm{pH}=7.0, \\
\mathrm{NaCl}=0.050 \mathrm{~m}, \\
\text { graywacke, } \\
270^{\circ} \mathrm{C}\end{array}$} & 0.0 & n.d. & & & & & \\
\hline & 14.0 & $6.76 \mathrm{E}-09$ & 8.20E-09 & 7.24E-09 & 7.72E-09 & & \\
\hline & 28.0 & $1.21 \mathrm{E}-08$ & 8.20E-09 & $1.21 \mathrm{E}-08$ & 8.69E-09 & & \\
\hline & 42.0 & $1.54 \mathrm{E}-08$ & 1.79E-08 & $1.40 \mathrm{E}-08$ & $1.59 \mathrm{E}-08$ & & \\
\hline & 0.0 & n.d. & & & & & \\
\hline
\end{tabular}




\begin{tabular}{|c|c|c|c|c|c|c|c|}
\hline & & & \multicolumn{2}{|c|}{ replicates/mol· $\mathbf{k g}^{-1}$} & \multicolumn{2}{|c|}{ n.d. - not detected } & \multirow[b]{2}{*}{ \#6 } \\
\hline Identifier & time/day & $\# 1$ & $\# 2$ & \#3 & \#4 & \#5 & \\
\hline \multirow{3}{*}{$\begin{array}{l}\text { set 2: } \mathrm{pH}=7.0, \\
\mathrm{NaCl}=0.050 \mathrm{~m}, \\
\text { graywacke, } \\
300^{\circ} \mathrm{C}\end{array}$} & 14.0 & $3.21 \mathrm{E}-08$ & $3.04 \mathrm{E}-08$ & $3.10 \mathrm{E}-08$ & 3.32E-08 & & \\
\hline & 28.0 & 4.29E-08 & $4.05 \mathrm{E}-08$ & $3.73 \mathrm{E}-08$ & & & \\
\hline & 42.0 & 4.34E-09 & & & & & \\
\hline
\end{tabular}

\section{B.11 Supplementary material Chapter 3, 2-NSA (Set 1 and Set 2)}

Table B.11: 2-NSA concentration in $\mathrm{mol} \mathrm{kg}^{-1}$ (HPLC).

\begin{tabular}{|c|c|c|c|c|c|c|c|}
\hline & & & replica & $\mathrm{mol} \cdot \mathrm{kg}^{-1}$ & n.d. - n & detected & \\
\hline Identifier & time/day & $\# 1$ & $\# 2$ & $\# \mathbf{3}$ & $\# 4$ & $\# 5$ & \#6 \\
\hline \multirow{9}{*}{$\begin{array}{c}\text { set } 1: \mathrm{pH}=7.0, \\
\mathrm{NaCl}=0.050 \mathrm{~m}, \\
200^{\circ} \mathrm{C}\end{array}$} & 0.0 & $1.18 \mathrm{E}-07$ & & & & & \\
\hline & 0.8 & $1.16 \mathrm{E}-07$ & $1.16 \mathrm{E}-07$ & $1.14 \mathrm{E}-07$ & $1.19 \mathrm{E}-07$ & $1.19 \mathrm{E}-07$ & $1.13 \mathrm{E}-07$ \\
\hline & 1.7 & $1.14 \mathrm{E}-07$ & $1.16 \mathrm{E}-07$ & $1.19 \mathrm{E}-07$ & $1.12 \mathrm{E}-07$ & $1.19 \mathrm{E}-07$ & $1.16 \mathrm{E}-07$ \\
\hline & 2.5 & $1.19 \mathrm{E}-07$ & $1.19 \mathrm{E}-07$ & $8.60 \mathrm{E}-08$ & $1.17 \mathrm{E}-07$ & $1.19 \mathrm{E}-07$ & $1.18 \mathrm{E}-07$ \\
\hline & 3.3 & $1.21 \mathrm{E}-07$ & $1.15 \mathrm{E}-07$ & $1.13 \mathrm{E}-07$ & $1.19 \mathrm{E}-07$ & $1.15 \mathrm{E}-07$ & $1.21 \mathrm{E}-07$ \\
\hline & 4.2 & $1.13 \mathrm{E}-07$ & $1.22 \mathrm{E}-07$ & $1.17 \mathrm{E}-07$ & $1.25 \mathrm{E}-07$ & $1.18 \mathrm{E}-07$ & $1.20 \mathrm{E}-07$ \\
\hline & 27.9 & $1.20 \mathrm{E}-07$ & $1.20 \mathrm{E}-07$ & $1.20 \mathrm{E}-07$ & $1.23 \mathrm{E}-07$ & $1.23 \mathrm{E}-07$ & $1.19 \mathrm{E}-07$ \\
\hline & 56.9 & $1.22 \mathrm{E}-07$ & $1.19 \mathrm{E}-07$ & $1.18 \mathrm{E}-07$ & $1.23 \mathrm{E}-07$ & $1.20 \mathrm{E}-07$ & $1.20 \mathrm{E}-07$ \\
\hline & 88.9 & $1.17 \mathrm{E}-07$ & $1.23 \mathrm{E}-07$ & $1.22 \mathrm{E}-07$ & $1.16 \mathrm{E}-07$ & $1.24 \mathrm{E}-07$ & $1.17 \mathrm{E}-07$ \\
\hline \multirow{6}{*}{$\begin{array}{c}\text { set } 1: \mathrm{pH}=7.0 \text {, } \\
\mathrm{NaCl}=0.050 \mathrm{~m}, \\
225^{\circ} \mathrm{C}\end{array}$} & 0.0 & $1.29 \mathrm{E}-07$ & $1.30 \mathrm{E}-07$ & $1.27 \mathrm{E}-07$ & $1.30 \mathrm{E}-07$ & $1.22 \mathrm{E}-07$ & $1.21 \mathrm{E}-07$ \\
\hline & 0.8 & $1.25 \mathrm{E}-07$ & $1.35 \mathrm{E}-07$ & $1.33 \mathrm{E}-07$ & $1.31 \mathrm{E}-07$ & $1.30 \mathrm{E}-07$ & $1.27 \mathrm{E}-07$ \\
\hline & 20.0 & $1.27 \mathrm{E}-07$ & $1.29 \mathrm{E}-07$ & $1.26 \mathrm{E}-07$ & $1.28 \mathrm{E}-07$ & $1.32 \mathrm{E}-07$ & $1.30 \mathrm{E}-07$ \\
\hline & 27.9 & $1.29 \mathrm{E}-07$ & $1.27 \mathrm{E}-07$ & $1.26 \mathrm{E}-07$ & $1.27 \mathrm{E}-07$ & $1.30 \mathrm{E}-07$ & $1.32 \mathrm{E}-07$ \\
\hline & 38.7 & $1.29 \mathrm{E}-07$ & $1.34 \mathrm{E}-07$ & $1.26 \mathrm{E}-07$ & $1.30 \mathrm{E}-07$ & & \\
\hline & 45.0 & $1.27 \mathrm{E}-07$ & $1.33 \mathrm{E}-07$ & $1.23 \mathrm{E}-07$ & $1.29 \mathrm{E}-07$ & & \\
\hline \multirow{9}{*}{$\begin{array}{c}\text { set } 1: \mathrm{pH}=7.0 \\
\mathrm{NaCl}=0.050 \mathrm{~m}, \\
250^{\circ} \mathrm{C}\end{array}$} & 0.0 & $1.18 \mathrm{E}-07$ & & & & & \\
\hline & 0.8 & $1.17 \mathrm{E}-07$ & $1.20 \mathrm{E}-07$ & $1.23 \mathrm{E}-07$ & $1.26 \mathrm{E}-07$ & $1.17 \mathrm{E}-07$ & $1.13 \mathrm{E}-07$ \\
\hline & 2.5 & $1.20 \mathrm{E}-07$ & $1.17 \mathrm{E}-07$ & $1.19 \mathrm{E}-07$ & $1.18 \mathrm{E}-07$ & $1.18 \mathrm{E}-07$ & $1.19 \mathrm{E}-07$ \\
\hline & 3.3 & $1.20 \mathrm{E}-07$ & $1.17 \mathrm{E}-07$ & $1.19 \mathrm{E}-07$ & $1.16 \mathrm{E}-07$ & $1.19 \mathrm{E}-07$ & $1.19 \mathrm{E}-07$ \\
\hline & 4.2 & $1.19 \mathrm{E}-07$ & $1.16 \mathrm{E}-07$ & $1.15 \mathrm{E}-07$ & $1.18 \mathrm{E}-07$ & $1.16 \mathrm{E}-07$ & $1.15 \mathrm{E}-07$ \\
\hline & 5.8 & $1.19 \mathrm{E}-07$ & $1.15 \mathrm{E}-07$ & $1.19 \mathrm{E}-07$ & $1.15 \mathrm{E}-07$ & $1.12 \mathrm{E}-07$ & $1.17 \mathrm{E}-07$ \\
\hline & 27.9 & $1.34 \mathrm{E}-07$ & $1.06 \mathrm{E}-07$ & $1.19 \mathrm{E}-07$ & $1.26 \mathrm{E}-07$ & $1.21 \mathrm{E}-07$ & $1.20 \mathrm{E}-07$ \\
\hline & 56.9 & $1.27 \mathrm{E}-07$ & $1.26 \mathrm{E}-07$ & $1.26 \mathrm{E}-07$ & $1.28 \mathrm{E}-07$ & $1.28 \mathrm{E}-07$ & \\
\hline & 88.9 & $1.27 \mathrm{E}-07$ & $1.31 \mathrm{E}-07$ & $1.29 \mathrm{E}-07$ & & & \\
\hline \multirow{8}{*}{$\begin{array}{c}\text { set } 1: \mathrm{pH}=7.0, \\
\mathrm{NaCl}=0.050 \mathrm{~m}, \\
270^{\circ} \mathrm{C}\end{array}$} & 0.0 & $1.19 \mathrm{E}-07$ & & & & & \\
\hline & 0.8 & $1.08 \mathrm{E}-07$ & $1.13 \mathrm{E}-07$ & $1.13 \mathrm{E}-07$ & $1.08 \mathrm{E}-07$ & $1.13 \mathrm{E}-07$ & \\
\hline & 1.7 & $1.17 \mathrm{E}-07$ & $1.12 \mathrm{E}-07$ & $1.12 \mathrm{E}-07$ & $1.12 \mathrm{E}-07$ & $1.09 \mathrm{E}-07$ & \\
\hline & 6.6 & $1.25 \mathrm{E}-07$ & $1.23 \mathrm{E}-07$ & $1.16 \mathrm{E}-07$ & $1.12 \mathrm{E}-07$ & $1.32 \mathrm{E}-07$ & $1.42 \mathrm{E}-07$ \\
\hline & 13.6 & $1.25 \mathrm{E}-07$ & $1.28 \mathrm{E}-07$ & & & & \\
\hline & 21.1 & $1.27 \mathrm{E}-07$ & $1.35 \mathrm{E}-07$ & $1.31 \mathrm{E}-07$ & & & \\
\hline & 14.0 & $1.32 \mathrm{E}-07$ & $1.35 \mathrm{E}-07$ & & & & \\
\hline & 28.0 & $1.32 \mathrm{E}-07$ & $1.38 \mathrm{E}-07$ & & & & \\
\hline
\end{tabular}


replicates $/ \mathbf{m o l} \cdot \mathbf{k g}^{-1}$

n.d. - not detected

\begin{tabular}{|c|c|c|c|c|c|c|c|}
\hline Identifier & time/day & $\# 1$ & $\# 2$ & $\# \mathbf{3}$ & $\# 4$ & $\# 5$ & $\# 6$ \\
\hline & 42.0 & $1.38 \mathrm{E}-07$ & $1.44 \mathrm{E}-07$ & & & & \\
\hline \multirow{5}{*}{$\begin{array}{c}\text { set } 1: \mathrm{pH}=7.0 \\
\mathrm{NaCl}=0.050 \mathrm{~m} \\
300^{\circ} \mathrm{C}\end{array}$} & 0.0 & 1.19E-07 & 1.19E-07 & $1.18 \mathrm{E}-07$ & $1.15 \mathrm{E}-07$ & $1.16 \mathrm{E}-07$ & $1.15 \mathrm{E}-07$ \\
\hline & 14.0 & $7.40 \mathrm{E}-08$ & 7.66E-08 & 7.23E-08 & 7.44E-08 & $8.73 \mathrm{E}-08$ & $6.40 \mathrm{E}-08$ \\
\hline & 27.0 & 7.29E-08 & 8.70E-08 & 1.19E-07 & 7.94E-08 & $8.68 \mathrm{E}-08$ & \\
\hline & 42.0 & $6.47 \mathrm{E}-08$ & $6.96 \mathrm{E}-08$ & 8.10E-08 & 7.10E-08 & 7.97E-08 & $8.70 \mathrm{E}-08$ \\
\hline & 70.0 & $6.96 \mathrm{E}-08$ & $6.22 \mathrm{E}-08$ & 7.82E-08 & & & \\
\hline \multirow{5}{*}{$\begin{array}{c}\text { set } 1: \mathrm{pH}=7.0 \\
\mathrm{NaCl}=0.050 \mathrm{~m} \\
330^{\circ} \mathrm{C}\end{array}$} & 0.0 & $1.16 \mathrm{E}-07$ & & & & & \\
\hline & 0.8 & $1.57 \mathrm{E}-07$ & $1.56 \mathrm{E}-07$ & $1.84 \mathrm{E}-07$ & $1.57 \mathrm{E}-07$ & $1.63 \mathrm{E}-07$ & \\
\hline & 1.7 & $1.69 \mathrm{E}-07$ & $1.71 \mathrm{E}-07$ & $1.58 \mathrm{E}-07$ & $1.56 \mathrm{E}-07$ & & \\
\hline & 6.6 & $1.46 \mathrm{E}-07$ & $1.63 \mathrm{E}-07$ & $1.53 \mathrm{E}-07$ & $1.56 \mathrm{E}-07$ & & \\
\hline & 13.6 & $1.68 \mathrm{E}-07$ & $1.57 \mathrm{E}-07$ & $1.63 \mathrm{E}-07$ & $1.62 \mathrm{E}-07$ & & \\
\hline \multirow{4}{*}{$\begin{array}{c}\text { set } 2: \mathrm{pH}=7.0, \\
\mathrm{NaCl}=0.050 \mathrm{~m}, \\
\text { graywacke, } \\
250^{\circ} \mathrm{C}\end{array}$} & 0.0 & $1.28 \mathrm{E}-07$ & & & & & \\
\hline & 14.0 & $1.50 \mathrm{E}-07$ & $1.36 \mathrm{E}-07$ & $1.33 \mathrm{E}-07$ & $1.43 \mathrm{E}-07$ & & \\
\hline & 28.0 & $1.32 \mathrm{E}-07$ & $1.31 \mathrm{E}-07$ & $1.31 \mathrm{E}-07$ & $1.33 \mathrm{E}-07$ & & \\
\hline & 42.0 & $1.33 \mathrm{E}-07$ & $1.40 \mathrm{E}-07$ & $1.31 \mathrm{E}-07$ & $1.36 \mathrm{E}-07$ & & \\
\hline \multirow{4}{*}{$\begin{array}{c}\text { set } 2: \mathrm{pH}=7.0, \\
\mathrm{NaCl}=0.050 \mathrm{~m}, \\
\text { graywacke } \\
270^{\circ} \mathrm{C}\end{array}$} & 0.0 & $1.28 \mathrm{E}-07$ & & & & & \\
\hline & 14.0 & $1.35 \mathrm{E}-07$ & $1.35 \mathrm{E}-07$ & $1.33 \mathrm{E}-07$ & $1.50 \mathrm{E}-07$ & & \\
\hline & 28.0 & $1.50 \mathrm{E}-07$ & $1.35 \mathrm{E}-07$ & $1.44 \mathrm{E}-07$ & $1.35 \mathrm{E}-07$ & & \\
\hline & 42.0 & $1.40 \mathrm{E}-07$ & $1.61 \mathrm{E}-07$ & $1.57 \mathrm{E}-07$ & $1.47 \mathrm{E}-07$ & & \\
\hline \multirow{4}{*}{$\begin{array}{c}\text { set } 2: \mathrm{pH}=7.0, \\
\mathrm{NaCl}=0.050 \mathrm{~m}, \\
\text { graywacke } \\
300^{\circ} \mathrm{C}\end{array}$} & 0.0 & $1.28 \mathrm{E}-07$ & & & & & \\
\hline & 14.0 & $1.61 \mathrm{E}-07$ & $1.50 \mathrm{E}-07$ & $1.61 \mathrm{E}-07$ & $1.44 \mathrm{E}-07$ & & \\
\hline & 28.0 & $1.71 \mathrm{E}-07$ & $1.66 \mathrm{E}-07$ & $1.78 \mathrm{E}-07$ & & & \\
\hline & 42.0 & $2.45 \mathrm{E}-07$ & & & & & \\
\hline
\end{tabular}




\section{B.12 Supplementary material Chapter 4, greywacke experiment}

Table B.12: Full ICP and HPLC data for Chapter 4, greywacke experiment.

\begin{tabular}{|c|c|c|c|c|c|c|c|c|c|c|c|c|c|c|c|}
\hline & & & & & $\mathrm{mol} / \mathrm{kg}$ & $\mathrm{mol} / \mathrm{kg}$ & $\mathrm{mol} / \mathrm{kg}$ & $\mathrm{mg} / \mathrm{kg}$ & $\mathrm{mol} / \mathrm{kg}$ & $\mathrm{mol} / \mathrm{kg}$ & $\mathrm{mol} / \mathrm{kg}$ & $\mathrm{mol} / \mathrm{kg}$ & $\mathrm{mol} / \mathrm{kg}$ & $\mathrm{mol} / \mathrm{kg}$ & $\mathrm{mol} / \mathrm{kg}$ \\
\hline sample & $\begin{array}{l}\text { time } \\
\text { (day) }\end{array}$ & $\begin{array}{c}\text { pressure } \\
\text { (bar) }\end{array}$ & $\begin{array}{c}\text { Temperature } \\
\left({ }^{\circ} \mathbf{C}\right)\end{array}$ & $\begin{array}{c}\mathbf{p H} \\
25^{\circ} \mathrm{C} \\
\end{array}$ & $\mathrm{SiO}_{2}$ & $\mathrm{Cl}^{-}$ & $\mathrm{SO}_{4}{ }^{2}-$ & $\mathbf{H}_{2} \mathbf{S}$ & $\mathbf{N a}^{+}$ & 2,6-NDS & 1,5-NDS & 2,7-NDS & 1,6-NDS & 1-NSA & 2-NSA \\
\hline blank & 0.0 & - & 25.0 & 7.00 & $2.16 \mathrm{E}-05$ & 0.00 & 0.00 & 0.00 & $0.00 \mathrm{E}+00$ & $3.77 \mathrm{E}-08$ & $3.81 \mathrm{E}-08$ & $3.67 \mathrm{E}-08$ & $3.67 \mathrm{E}-08$ & $0.00 \mathrm{E}+00$ & $7.70 \mathrm{E}-10$ \\
\hline 1 & 0.9 & 18.4 & 25.0 & 7.32 & $2.03 \mathrm{E}-04$ & 0.00 & 0.00 & 0.00 & $2.68 \mathrm{E}-04$ & 3.91E-08 & $3.97 \mathrm{E}-08$ & $3.74 \mathrm{E}-08$ & $3.63 \mathrm{E}-08$ & $0.00 \mathrm{E}+00$ & $7.70 \mathrm{E}-10$ \\
\hline 2 & 1.9 & 18.3 & 25.0 & 7.42 & $1.85 \mathrm{E}-04$ & 0.00 & 0.00 & 0.00 & $8.56 \mathrm{E}-05$ & $3.74 \mathrm{E}-08$ & $3.76 \mathrm{E}-08$ & $3.58 \mathrm{E}-08$ & $3.47 \mathrm{E}-08$ & $0.00 \mathrm{E}+00$ & $1.12 \mathrm{E}-09$ \\
\hline 3 & 2.9 & 18.1 & 25.0 & 7.30 & $1.39 \mathrm{E}-04$ & 0.00 & 0.00 & 0.00 & $0.00 \mathrm{E}+00$ & $3.69 \mathrm{E}-08$ & $3.73 \mathrm{E}-08$ & $3.53 \mathrm{E}-08$ & $3.71 \mathrm{E}-08$ & $0.00 \mathrm{E}+00$ & $1.06 \mathrm{E}-09$ \\
\hline 4 & 3.8 & 18.0 & 25.0 & 7.37 & $1.13 \mathrm{E}-04$ & 0.00 & 0.00 & 0.00 & $0.00 \mathrm{E}+00$ & 3.73E-08 & $3.78 \mathrm{E}-08$ & $3.56 \mathrm{E}-08$ & $6.35 \mathrm{E}-08$ & $0.00 \mathrm{E}+00$ & 2.97E-09 \\
\hline 5 & 4.8 & 17.9 & 100.0 & 7.15 & $9.22 \mathrm{E}-04$ & 0.00 & 0.00 & 0.03 & $1.54 \mathrm{E}-04$ & $3.65 \mathrm{E}-08$ & $3.70 \mathrm{E}-08$ & $3.50 \mathrm{E}-08$ & $3.70 \mathrm{E}-08$ & $2.12 \mathrm{E}-10$ & $1.87 \mathrm{E}-09$ \\
\hline 6 & 5.8 & 18.0 & 100.0 & 7.15 & $1.31 \mathrm{E}-03$ & 0.00 & 0.00 & 0.00 & $2.07 \mathrm{E}-04$ & $3.71 \mathrm{E}-08$ & $3.74 \mathrm{E}-08$ & $3.56 \mathrm{E}-08$ & $3.44 \mathrm{E}-08$ & $0.00 \mathrm{E}+00$ & $1.31 \mathrm{E}-09$ \\
\hline 7 & 6.8 & 18.0 & 100.0 & 7.24 & $1.09 \mathrm{E}-03$ & 0.00 & 0.00 & 0.00 & $1.14 \mathrm{E}-04$ & $3.73 \mathrm{E}-08$ & $3.75 \mathrm{E}-08$ & $3.58 \mathrm{E}-08$ & $3.47 \mathrm{E}-08$ & $5.01 \mathrm{E}-10$ & 2.01E-09 \\
\hline 8 & 7.7 & 18.0 & 100.0 & 7.54 & $9.42 \mathrm{E}-04$ & 0.00 & 0.00 & 0.03 & 8.97E-05 & $3.70 \mathrm{E}-08$ & $3.72 \mathrm{E}-08$ & $3.54 \mathrm{E}-08$ & $3.42 \mathrm{E}-08$ & $0.00 \mathrm{E}+00$ & $2.49 \mathrm{E}-09$ \\
\hline 9 & 8.7 & 18.0 & 100.0 & 7.93 & 8.70E-04 & 0.00 & 0.00 & 0.01 & $8.47 \mathrm{E}-05$ & $3.74 \mathrm{E}-08$ & $3.78 \mathrm{E}-08$ & $3.59 \mathrm{E}-08$ & $3.73 \mathrm{E}-08$ & $0.00 \mathrm{E}+00$ & $1.20 \mathrm{E}-09$ \\
\hline 10 & 9.8 & 18.0 & 100.0 & 7.72 & 8.53E-04 & 0.00 & 0.00 & 0.00 & 7.87E-05 & 3.72E-08 & $3.76 \mathrm{E}-08$ & $3.58 \mathrm{E}-08$ & $3.47 \mathrm{E}-08$ & $1.76 \mathrm{E}-09$ & $2.88 \mathrm{E}-09$ \\
\hline 11 & 10.7 & 18.0 & 100.0 & 8.37 & 8.47E-04 & 0.00 & 0.00 & 0.00 & $9.16 \mathrm{E}-05$ & 3.72E-08 & $3.76 \mathrm{E}-08$ & $3.57 \mathrm{E}-08$ & $3.43 \mathrm{E}-08$ & $0.00 \mathrm{E}+00$ & $1.00 \mathrm{E}-09$ \\
\hline 12 & 11.7 & 18.0 & 100.0 & 8.53 & $8.73 \mathrm{E}-04$ & 0.00 & 0.00 & 0.00 & 7.57E-05 & $3.69 \mathrm{E}-08$ & $3.74 \mathrm{E}-08$ & $3.54 \mathrm{E}-08$ & $3.42 \mathrm{E}-08$ & $0.00 \mathrm{E}+00$ & $1.44 \mathrm{E}-09$ \\
\hline 13 & 12.9 & 18.0 & 100.0 & 8.54 & 8.99E-04 & 0.00 & 0.00 & 0.16 & 7.61E-05 & 3.67E-08 & $3.72 \mathrm{E}-08$ & $3.54 \mathrm{E}-08$ & $3.43 \mathrm{E}-08$ & $8.14 \mathrm{E}-10$ & 5.67E-09 \\
\hline 14 & 13.7 & 17.9 & 100.0 & 8.65 & $8.02 \mathrm{E}-04$ & 0.00 & 0.00 & 0.08 & $7.76 \mathrm{E}-05$ & $3.67 \mathrm{E}-08$ & $3.72 \mathrm{E}-08$ & $3.53 \mathrm{E}-08$ & 3.39E-08 & $0.00 \mathrm{E}+00$ & $1.31 \mathrm{E}-09$ \\
\hline 15 & 14.7 & 17.8 & 150.0 & 7.61 & $2.56 \mathrm{E}-03$ & 0.00 & 0.00 & 0.08 & $2.32 \mathrm{E}-04$ & $3.65 \mathrm{E}-08$ & 3.70E-08 & $3.52 \mathrm{E}-08$ & $3.42 \mathrm{E}-08$ & $0.00 \mathrm{E}+00$ & $5.00 \mathrm{E}-09$ \\
\hline 16 & 15.7 & 17.8 & 150.0 & 7.33 & $3.12 \mathrm{E}-03$ & 0.00 & 0.00 & 0.13 & 4.84E-04 & 3.82E-08 & 3.87E-08 & $3.66 \mathrm{E}-08$ & $3.66 \mathrm{E}-08$ & $0.00 \mathrm{E}+00$ & $1.66 \mathrm{E}-09$ \\
\hline 17 & 16.7 & 27.5 & 150.0 & 7.47 & $2.13 \mathrm{E}-03$ & 0.00 & 0.00 & 0.09 & $4.27 \mathrm{E}-04$ & 3.69E-08 & $3.73 \mathrm{E}-08$ & $3.54 \mathrm{E}-08$ & $3.42 \mathrm{E}-08$ & $1.42 \mathrm{E}-10$ & $1.43 \mathrm{E}-09$ \\
\hline 18 & 17.8 & 30.6 & 150.0 & 8.21 & $1.89 \mathrm{E}-03$ & 0.00 & 0.00 & 0.06 & $3.25 \mathrm{E}-04$ & $3.66 \mathrm{E}-08$ & $3.72 \mathrm{E}-08$ & $3.53 \mathrm{E}-08$ & $3.41 \mathrm{E}-08$ & $6.58 \mathrm{E}-11$ & $2.25 \mathrm{E}-09$ \\
\hline 19 & 18.8 & 30.6 & 150.0 & 8.24 & $1.80 \mathrm{E}-03$ & 0.00 & 0.00 & 0.07 & 3.09E-04 & 3.67E-08 & 3.73E-08 & $3.53 \mathrm{E}-08$ & $3.40 \mathrm{E}-08$ & $0.00 \mathrm{E}+00$ & 3.95E-09 \\
\hline 20 & 19.9 & 30.5 & 150.0 & 8.20 & $1.78 \mathrm{E}-03$ & 0.00 & 0.00 & 0.15 & $3.02 \mathrm{E}-04$ & $3.71 \mathrm{E}-08$ & $3.73 \mathrm{E}-08$ & $3.56 \mathrm{E}-08$ & $3.59 \mathrm{E}-08$ & $0.00 \mathrm{E}+00$ & $1.55 \mathrm{E}-09$ \\
\hline 22 & 20.8 & 30.5 & 150.0 & 8.54 & $1.74 \mathrm{E}-03$ & 0.00 & 0.00 & 0.14 & 2.69E-04 & $3.60 \mathrm{E}-08$ & 3.63E-08 & $3.46 \mathrm{E}-08$ & $3.32 \mathrm{E}-08$ & $0.00 \mathrm{E}+00$ & $2.78 \mathrm{E}-09$ \\
\hline 23 & 21.7 & 30.5 & 150.0 & 8.45 & $1.81 \mathrm{E}-03$ & 0.00 & 0.00 & 0.15 & $2.98 \mathrm{E}-04$ & 3.61E-08 & 3.65E-08 & $3.46 \mathrm{E}-08$ & $3.75 \mathrm{E}-08$ & $0.00 \mathrm{E}+00$ & $2.55 \mathrm{E}-09$ \\
\hline 23 & 22.7 & 30.5 & 150.0 & 8.50 & $1.80 \mathrm{E}-03$ & 0.00 & 0.00 & 0.06 & $2.92 \mathrm{E}-04$ & $3.58 \mathrm{E}-08$ & $3.58 \mathrm{E}-08$ & $3.44 \mathrm{E}-08$ & $3.25 \mathrm{E}-08$ & $0.00 \mathrm{E}+00$ & $3.51 \mathrm{E}-09$ \\
\hline 24 & 23.7 & 30.5 & 150.0 & 8.78 & $1.79 \mathrm{E}-03$ & 0.00 & 0.00 & 0.00 & $2.88 \mathrm{E}-04$ & $3.65 \mathrm{E}-08$ & $3.69 \mathrm{E}-08$ & $3.51 \mathrm{E}-08$ & $3.42 \mathrm{E}-08$ & $0.00 \mathrm{E}+00$ & $1.71 \mathrm{E}-09$ \\
\hline 25 & 24.8 & 30.5 & 150.0 & 8.39 & $1.78 \mathrm{E}-03$ & 0.00 & 0.00 & 0.11 & $2.77 \mathrm{E}-04$ & 3.71E-08 & $3.75 \mathrm{E}-08$ & $3.56 \mathrm{E}-08$ & $3.43 \mathrm{E}-08$ & $0.00 \mathrm{E}+00$ & 1.99E-09 \\
\hline 26 & 25.9 & 30.5 & 150.0 & 8.63 & $1.78 \mathrm{E}-03$ & 0.00 & 0.00 & 0.18 & $2.78 \mathrm{E}-04$ & $3.55 \mathrm{E}-08$ & $3.59 \mathrm{E}-08$ & $3.42 \mathrm{E}-08$ & $3.26 \mathrm{E}-08$ & $0.00 \mathrm{E}+00$ & $1.45 \mathrm{E}-09$ \\
\hline 27 & 26.8 & 30.4 & 150.0 & 8.59 & $1.74 \mathrm{E}-03$ & 0.00 & 0.00 & 0.10 & $2.75 \mathrm{E}-04$ & $3.54 \mathrm{E}-08$ & $3.59 \mathrm{E}-08$ & $3.41 \mathrm{E}-08$ & $3.83 \mathrm{E}-08$ & $0.00 \mathrm{E}+00$ & $1.64 \mathrm{E}-09$ \\
\hline 28 & 27.8 & 30.4 & 150.0 & 8.63 & $1.73 \mathrm{E}-03$ & 0.00 & 0.00 & 0.11 & $2.72 \mathrm{E}-04$ & 3.54E-08 & 3.59E-08 & $3.41 \mathrm{E}-08$ & $3.26 \mathrm{E}-08$ & $0.00 \mathrm{E}+00$ & $1.28 \mathrm{E}-09$ \\
\hline 29 & 29.0 & 32.9 & 200.0 & 5.64 & $2.00 \mathrm{E}-04$ & 0.00 & 0.00 & 0.49 & $7.00 \mathrm{E}-05$ & $9.20 \mathrm{E}-09$ & 8.67E-09 & $9.71 \mathrm{E}-09$ & 8.13E-09 & $1.19 \mathrm{E}-09$ & $1.10 \mathrm{E}-09$ \\
\hline 30 & 29.8 & 30.0 & 200.0 & 5.11 & $5.73 \mathrm{E}-05$ & 0.00 & 0.00 & 0.18 & $1.54 \mathrm{E}-05$ & 7.37E-09 & $6.76 \mathrm{E}-09$ & 7.43E-09 & $6.49 \mathrm{E}-09$ & 1.12E-09 & $1.32 \mathrm{E}-09$ \\
\hline 31 & 30.8 & 29.9 & 200.0 & 5.77 & $1.41 \mathrm{E}-04$ & 0.00 & 0.00 & 0.09 & $1.53 \mathrm{E}-04$ & $1.40 \mathrm{E}-08$ & $1.03 \mathrm{E}-08$ & $1.47 \mathrm{E}-08$ & $1.10 \mathrm{E}-08$ & $6.88 \mathrm{E}-09$ & $1.21 \mathrm{E}-08$ \\
\hline
\end{tabular}




\begin{tabular}{|c|c|c|c|c|c|c|c|c|c|c|c|c|c|c|c|}
\hline & & & & & $\mathrm{mol} / \mathrm{kg}$ & $\mathrm{mol} / \mathrm{kg}$ & $\mathrm{mol} / \mathrm{kg}$ & $\mathrm{mg} / \mathrm{kg}$ & $\mathrm{mol} / \mathrm{kg}$ & $\mathrm{mol} / \mathrm{kg}$ & $\mathrm{mol} / \mathrm{kg}$ & $\mathrm{mol} / \mathrm{kg}$ & $\mathrm{mol} / \mathrm{kg}$ & $\mathrm{mol} / \mathrm{kg}$ & $\mathrm{mol} / \mathrm{kg}$ \\
\hline sample & $\begin{array}{l}\text { time } \\
\text { (day) }\end{array}$ & $\begin{array}{l}\text { pressure } \\
\text { (bar) }\end{array}$ & $\begin{array}{c}\text { Temperature } \\
\left({ }^{\circ} \mathrm{C}\right)\end{array}$ & $\begin{array}{c}\mathrm{pH} \\
25^{\circ} \mathrm{C}\end{array}$ & $\mathrm{SiO}_{2}$ & $\mathrm{Cl}^{-}$ & $\mathrm{SO}_{4}{ }^{2-}$ & $\mathbf{H}_{2} \mathrm{~S}$ & $\mathbf{N a}^{+}$ & 2,6-NDS & 1,5-NDS & 2,7-NDS & 1,6-NDS & 1-NSA & 2-NSA \\
\hline 32 & 31.7 & 36.7 & 200.0 & 8.60 & $7.41 \mathrm{E}-03$ & 0.00 & 0.00 & 0.33 & $8.06 \mathrm{E}-04$ & $4.22 \mathrm{E}-08$ & $4.11 \mathrm{E}-08$ & 3.99E-08 & $3.98 \mathrm{E}-08$ & $1.75 \mathrm{E}-09$ & $4.48 \mathrm{E}-09$ \\
\hline 33 & 32.8 & 36.6 & 200.0 & 7.68 & $7.12 \mathrm{E}-03$ & 0.00 & 0.00 & 0.18 & $5.22 \mathrm{E}-04$ & $3.50 \mathrm{E}-08$ & $3.48 \mathrm{E}-08$ & $3.34 \mathrm{E}-08$ & $3.34 \mathrm{E}-08$ & $6.01 \mathrm{E}-10$ & $1.45 \mathrm{E}-09$ \\
\hline 34 & 33.8 & 36.5 & 200.0 & 7.30 & $5.38 \mathrm{E}-03$ & 0.00 & 0.00 & 0.18 & 4.63E-04 & $3.86 \mathrm{E}-08$ & $3.80 \mathrm{E}-08$ & $3.66 \mathrm{E}-08$ & $3.66 \mathrm{E}-08$ & $1.18 \mathrm{E}-09$ & $2.96 \mathrm{E}-09$ \\
\hline 35 & 35.7 & 36.9 & 200.0 & 7.31 & $5.10 \mathrm{E}-03$ & 0.00 & 0.00 & 0.15 & 5.34E-04 & 5.03E-08 & $5.12 \mathrm{E}-08$ & 4.79E-08 & $4.88 \mathrm{E}-08$ & $0.00 \mathrm{E}+00$ & $1.39 \mathrm{E}-09$ \\
\hline 36 & 36.7 & 37.0 & 200.0 & 8.15 & $4.49 \mathrm{E}-03$ & 0.00 & 0.00 & 0.18 & $3.75 \mathrm{E}-04$ & $4.87 \mathrm{E}-08$ & $4.96 \mathrm{E}-08$ & $4.63 \mathrm{E}-08$ & $4.70 \mathrm{E}-08$ & $0.00 \mathrm{E}+00$ & $1.19 \mathrm{E}-09$ \\
\hline 37 & 37.7 & 37.0 & 200.0 & 8.19 & $4.65 \mathrm{E}-03$ & 0.00 & 0.00 & 0.11 & $3.97 \mathrm{E}-04$ & 4.82E-08 & 4.92E-08 & $4.59 \mathrm{E}-08$ & 4.64E-08 & $0.00 \mathrm{E}+00$ & $9.11 \mathrm{E}-10$ \\
\hline 38 & 38.7 & 37.0 & 200.0 & 8.27 & $4.69 \mathrm{E}-03$ & 0.00 & 0.00 & 0.14 & $3.92 \mathrm{E}-04$ & 4.79E-08 & $4.87 \mathrm{E}-08$ & $4.55 \mathrm{E}-08$ & 4.62E-08 & $0.00 \mathrm{E}+00$ & $1.04 \mathrm{E}-09$ \\
\hline 38 & 39.7 & 36.9 & 200.0 & 8.26 & $4.65 \mathrm{E}-03$ & 0.00 & 0.00 & 0.11 & $3.98 \mathrm{E}-04$ & $4.77 \mathrm{E}-08$ & $4.85 \mathrm{E}-08$ & $4.54 \mathrm{E}-08$ & $4.59 \mathrm{E}-08$ & $0.00 \mathrm{E}+00$ & $1.88 \mathrm{E}-09$ \\
\hline 39 & 40.8 & 36.9 & 200.0 & 8.30 & $4.69 \mathrm{E}-03$ & 0.00 & 0.00 & 0.11 & $4.11 \mathrm{E}-04$ & $4.81 \mathrm{E}-08$ & $4.89 \mathrm{E}-08$ & $4.57 \mathrm{E}-08$ & $4.65 \mathrm{E}-08$ & $0.00 \mathrm{E}+00$ & $1.19 \mathrm{E}-09$ \\
\hline 40 & 41.8 & 36.9 & 200.0 & 8.33 & $4.70 \mathrm{E}-03$ & 0.00 & 0.00 & 0.14 & $4.07 \mathrm{E}-04$ & 4.76E-08 & $4.86 \mathrm{E}-08$ & $4.53 \mathrm{E}-08$ & 4.62E-08 & 7.93E-10 & 3.09E-09 \\
\hline 41 & 42.7 & 45.4 & 200.0 & 8.30 & $4.58 \mathrm{E}-03$ & 0.00 & 0.00 & 0.15 & $3.91 \mathrm{E}-04$ & $4.71 \mathrm{E}-08$ & $4.75 \mathrm{E}-08$ & $4.47 \mathrm{E}-08$ & $5.19 \mathrm{E}-08$ & $2.26 \mathrm{E}-10$ & $2.59 \mathrm{E}-09$ \\
\hline 42 & 43.8 & 99.5 & 250.0 & 6.40 & $6.85 \mathrm{E}-03$ & 0.00 & 0.00 & 0.32 & $4.91 \mathrm{E}-04$ & $4.80 \mathrm{E}-08$ & $4.89 \mathrm{E}-08$ & $4.56 \mathrm{E}-08$ & $4.62 \mathrm{E}-08$ & $0.00 \mathrm{E}+00$ & $1.57 \mathrm{E}-09$ \\
\hline 43 & 44.8 & 99.6 & 250.0 & 6.34 & $7.98 \mathrm{E}-03$ & 0.00 & 0.00 & 0.39 & $6.02 \mathrm{E}-04$ & $4.78 \mathrm{E}-08$ & $4.85 \mathrm{E}-08$ & $4.54 \mathrm{E}-08$ & $4.59 \mathrm{E}-08$ & $0.00 \mathrm{E}+00$ & $1.74 \mathrm{E}-09$ \\
\hline 44 & 45.7 & 99.6 & 250.0 & 6.56 & $7.98 \mathrm{E}-03$ & 0.00 & 0.00 & 0.46 & $5.93 \mathrm{E}-04$ & $4.74 \mathrm{E}-08$ & 4.83E-08 & $4.51 \mathrm{E}-08$ & $4.56 \mathrm{E}-08$ & $0.00 \mathrm{E}+00$ & $1.16 \mathrm{E}-09$ \\
\hline 45 & 46.9 & 99.6 & 250.0 & 6.80 & $8.03 \mathrm{E}-03$ & 0.00 & 0.00 & 0.53 & $6.12 \mathrm{E}-04$ & 4.73E-08 & 4.83E-08 & 4.48E-08 & 4.52E-08 & $0.00 \mathrm{E}+00$ & $1.15 \mathrm{E}-09$ \\
\hline 46 & 47.8 & 99.5 & 250.0 & 7.02 & 7.91E-03 & 0.00 & 0.00 & 0.34 & $5.91 \mathrm{E}-04$ & $4.73 \mathrm{E}-08$ & $4.80 \mathrm{E}-08$ & 4.49E-08 & $4.56 \mathrm{E}-08$ & $0.00 \mathrm{E}+00$ & $1.21 \mathrm{E}-09$ \\
\hline 47 & 48.7 & 99.5 & 250.0 & 7.20 & $7.93 \mathrm{E}-03$ & 0.00 & 0.00 & 0.56 & $5.90 \mathrm{E}-04$ & $4.71 \mathrm{E}-08$ & $4.80 \mathrm{E}-08$ & $4.47 \mathrm{E}-08$ & $4.52 \mathrm{E}-08$ & $0.00 \mathrm{E}+00$ & $1.08 \mathrm{E}-09$ \\
\hline 48 & 49.7 & 99.5 & 250.0 & 7.38 & 8.09E-03 & 0.00 & 0.00 & 0.59 & $6.05 \mathrm{E}-04$ & 4.69E-08 & 4.76E-08 & 4.47E-08 & 4.52E-08 & $0.00 \mathrm{E}+00$ & $1.23 \mathrm{E}-09$ \\
\hline 49 & 50.8 & 99.5 & 250.0 & 7.73 & $7.71 \mathrm{E}-03$ & 0.00 & 0.00 & 0.46 & $6.21 \mathrm{E}-04$ & 4.68E-08 & $4.76 \mathrm{E}-08$ & $4.45 \mathrm{E}-08$ & $4.51 \mathrm{E}-08$ & $0.00 \mathrm{E}+00$ & $1.72 \mathrm{E}-09$ \\
\hline 50 & 51.8 & 99.5 & 250.0 & 7.77 & 8.17E-03 & 0.00 & 0.00 & 0.62 & $6.22 \mathrm{E}-04$ & $4.68 \mathrm{E}-08$ & 4.75E-08 & $4.45 \mathrm{E}-08$ & $4.50 \mathrm{E}-08$ & $0.00 \mathrm{E}+00$ & $1.65 \mathrm{E}-09$ \\
\hline 51 & 52.7 & 99.5 & 250.0 & 7.94 & $8.16 \mathrm{E}-03$ & 0.00 & 0.00 & 0.86 & $6.27 \mathrm{E}-04$ & $4.70 \mathrm{E}-08$ & $4.77 \mathrm{E}-08$ & $4.47 \mathrm{E}-08$ & $4.56 \mathrm{E}-08$ & $0.00 \mathrm{E}+00$ & $1.59 \mathrm{E}-09$ \\
\hline 52 & 53.7 & 99.7 & 250.0 & 8.03 & $8.26 \mathrm{E}-03$ & 0.00 & 0.00 & 0.77 & $6.36 \mathrm{E}-04$ & $4.70 \mathrm{E}-08$ & 4.77E-08 & $4.47 \mathrm{E}-08$ & $4.53 \mathrm{E}-08$ & $0.00 \mathrm{E}+00$ & $1.41 \mathrm{E}-09$ \\
\hline 53 & 54.9 & 99.7 & 250.0 & 7.38 & 7.49E-03 & 0.00 & 0.00 & 1.68 & 7.23E-04 & $4.58 \mathrm{E}-08$ & 4.66E-08 & 4.37E-08 & $4.41 \mathrm{E}-08$ & $0.00 \mathrm{E}+00$ & $1.66 \mathrm{E}-09$ \\
\hline 54 & 55.7 & 99.4 & 250.0 & 7.87 & $8.18 \mathrm{E}-03$ & 0.00 & 0.00 & 2.16 & $6.47 \mathrm{E}-04$ & $1.12 \mathrm{E}-08$ & $1.16 \mathrm{E}-08$ & $1.06 \mathrm{E}-08$ & $1.06 \mathrm{E}-08$ & $5.54 \mathrm{E}-10$ & $6.20 \mathrm{E}-09$ \\
\hline 55 & 56.7 & 130.8 & 300.0 & 5.37 & $2.00 \mathrm{E}-03$ & 0.00 & 0.00 & 4.59 & $1.53 \mathrm{E}-04$ & $3.39 \mathrm{E}-11$ & $0.00 \mathrm{E}+00$ & $0.00 \mathrm{E}+00$ & $0.00 \mathrm{E}+00$ & $0.00 \mathrm{E}+00$ & $3.06 \mathrm{E}-09$ \\
\hline 56 & 57.8 & 138.4 & 300.0 & 4.57 & $5.51 \mathrm{E}-05$ & 0.00 & 0.00 & 4.33 & $9.44 \mathrm{E}-06$ & $0.00 \mathrm{E}+00$ & $0.00 \mathrm{E}+00$ & $0.00 \mathrm{E}+00$ & $0.00 \mathrm{E}+00$ & $1.98 \mathrm{E}-09$ & $3.26 \mathrm{E}-08$ \\
\hline 57 & 58.7 & 138.4 & 300.0 & 4.55 & $4.89 \mathrm{E}-05$ & 0.00 & 0.00 & 4.17 & $9.57 \mathrm{E}-06$ & $1.48 \mathrm{E}-11$ & $0.00 \mathrm{E}+00$ & $0.00 \mathrm{E}+00$ & $0.00 \mathrm{E}+00$ & 2.21E-09 & $2.68 \mathrm{E}-08$ \\
\hline 58 & 59.8 & 138.9 & 300.0 & 4.86 & $7.54 \mathrm{E}-05$ & 0.00 & 0.00 & 4.08 & $3.09 \mathrm{E}-06$ & $5.29 \mathrm{E}-09$ & $5.13 \mathrm{E}-09$ & $5.03 \mathrm{E}-09$ & $4.90 \mathrm{E}-09$ & $1.55 \mathrm{E}-08$ & $1.56 \mathrm{E}-07$ \\
\hline 59 & 60.8 & 207.5 & 300.0 & 5.70 & $1.55 \mathrm{E}-03$ & 0.00 & 0.00 & 6.92 & $3.63 \mathrm{E}-04$ & $0.00 \mathrm{E}+00$ & $0.00 \mathrm{E}+00$ & $0.00 \mathrm{E}+00$ & $0.00 \mathrm{E}+00$ & $1.90 \mathrm{E}-08$ & $3.57 \mathrm{E}-08$ \\
\hline 60 & 61.9 & 207.3 & 300.0 & 4.98 & $6.15 \mathrm{E}-04$ & 0.00 & 0.00 & 3.29 & $6.22 \mathrm{E}-06$ & $0.00 \mathrm{E}+00$ & $0.00 \mathrm{E}+00$ & $0.00 \mathrm{E}+00$ & $0.00 \mathrm{E}+00$ & 9.91E-09 & $1.95 \mathrm{E}-08$ \\
\hline 61 & 62.8 & 207.3 & 300.0 & 5.08 & $4.57 \mathrm{E}-04$ & 0.00 & 0.00 & 3.36 & $1.52 \mathrm{E}-06$ & $0.00 \mathrm{E}+00$ & $0.00 \mathrm{E}+00$ & $0.00 \mathrm{E}+00$ & $0.00 \mathrm{E}+00$ & $2.70 \mathrm{E}-10$ & $5.49 \mathrm{E}-10$ \\
\hline 62 & 63.7 & 207.1 & 300.0 & 5.15 & $9.67 \mathrm{E}-05$ & 0.00 & 0.00 & 4.08 & $5.61 \mathrm{E}-06$ & $1.21 \mathrm{E}-08$ & 7.02E-09 & $1.69 \mathrm{E}-08$ & $1.00 \mathrm{E}-08$ & $1.43 \mathrm{E}-08$ & $2.41 \mathrm{E}-08$ \\
\hline 63 & 64.7 & 207.2 & 300.0 & 7.41 & $2.30 \mathrm{E}-03$ & 0.00 & 0.00 & 3.28 & $1.32 \mathrm{E}-03$ & 2.04E-08 & $1.23 \mathrm{E}-08$ & $2.43 \mathrm{E}-08$ & 1.49E-08 & $1.30 \mathrm{E}-08$ & $1.93 \mathrm{E}-08$ \\
\hline 64 & 65.7 & 207.2 & 300.0 & 7.16 & $2.94 \mathrm{E}-03$ & 0.00 & 0.00 & 3.91 & $1.26 \mathrm{E}-03$ & $2.28 \mathrm{E}-08$ & $1.48 \mathrm{E}-08$ & $2.84 \mathrm{E}-08$ & $1.77 \mathrm{E}-08$ & $1.55 \mathrm{E}-08$ & $3.17 \mathrm{E}-08$ \\
\hline 65 & 66.7 & 207.2 & 300.0 & 6.93 & $2.28 \mathrm{E}-03$ & 0.00 & 0.00 & 3.90 & $9.35 \mathrm{E}-04$ & $1.76 \mathrm{E}-08$ & $1.10 \mathrm{E}-08$ & $2.35 \mathrm{E}-08$ & $1.30 \mathrm{E}-08$ & $1.25 \mathrm{E}-08$ & $2.91 \mathrm{E}-08$ \\
\hline 66 & 67.8 & 207.2 & 300.0 & 6.74 & $1.96 \mathrm{E}-03$ & 0.00 & 0.00 & 9.12 & $6.70 \mathrm{E}-04$ & $1.50 \mathrm{E}-08$ & $1.05 \mathrm{E}-08$ & $1.58 \mathrm{E}-08$ & $1.23 \mathrm{E}-08$ & 6.84E-09 & $8.60 \mathrm{E}-09$ \\
\hline
\end{tabular}




\begin{tabular}{|c|c|c|c|c|c|c|c|c|c|c|c|c|c|c|c|}
\hline & & & & & $\mathrm{mol} / \mathrm{kg}$ & $\mathrm{mol} / \mathrm{kg}$ & $\mathrm{mol} / \mathrm{kg}$ & $\mathrm{mg} / \mathrm{kg}$ & $\mathrm{mol} / \mathrm{kg}$ & $\mathrm{mol} / \mathrm{kg}$ & $\mathrm{mol} / \mathrm{kg}$ & $\mathrm{mol} / \mathrm{kg}$ & $\mathrm{mol} / \mathrm{kg}$ & $\mathrm{mol} / \mathrm{kg}$ & $\mathrm{mol} / \mathrm{kg}$ \\
\hline sample & $\begin{array}{l}\text { time } \\
\text { (day) }\end{array}$ & $\begin{array}{c}\text { pressure } \\
\text { (bar) }\end{array}$ & $\begin{array}{c}\text { Temperature } \\
\left({ }^{\circ} \mathbf{C}\right)\end{array}$ & $\begin{array}{c}\mathbf{p H} \\
25^{\circ} \mathrm{C}\end{array}$ & $\mathrm{SiO}_{2}$ & $\mathrm{Cl}^{-}$ & $\mathrm{SO}_{4}{ }^{2-}$ & $\mathbf{H}_{2} \mathbf{S}$ & $\mathbf{N a}^{+}$ & 2,6-NDS & 1,5-NDS & 2,7-NDS & 1,6-NDS & 1-NSA & 2-NSA \\
\hline 67 & 68.8 & 207.2 & 300 & 6.37 & $1.40 \mathrm{E}-03$ & 0.00 & 0.00 & 2.21 & $4.45 \mathrm{E}-04$ & $4.51 \mathrm{E}-09$ & $1.74 \mathrm{E}-09$ & $8.27 \mathrm{E}-09$ & $2.66 \mathrm{E}-09$ & $7.33 \mathrm{E}-09$ & $3.57 \mathrm{E}-08$ \\
\hline 68 & 69.8 & 207.2 & 300 & 5.88 & $4.85 \mathrm{E}-04$ & 0.00 & 0.00 & 2.76 & $2.08 \mathrm{E}-04$ & $6.03 \mathrm{E}-09$ & $6.19 \mathrm{E}-09$ & $6.98 \mathrm{E}-09$ & 7.95E-09 & $1.13 \mathrm{E}-08$ & $1.94 \mathrm{E}-08$ \\
\hline 69 & 70.8 & 207.3 & 300 & 8.80 & $3.62 \mathrm{E}-03$ & 0.00 & 0.00 & 1.15 & $9.93 \mathrm{E}-04$ & $5.40 \mathrm{E}-09$ & 4.60E-09 & $5.58 \mathrm{E}-09$ & 4.82E-09 & 8.53E-09 & $1.06 \mathrm{E}-08$ \\
\hline 70 & 71.7 & 207.3 & 300 & 6.28 & $6.44 \mathrm{E}-04$ & 0.00 & 0.00 & 0.91 & $2.31 \mathrm{E}-04$ & $1.01 \mathrm{E}-10$ & $0.00 \mathrm{E}+00$ & 2.79E-10 & $1.20 \mathrm{E}-10$ & $6.15 \mathrm{E}-09$ & 9.54E-09 \\
\hline 71 & 72.8 & 207.3 & 300 & 6.51 & $1.57 \mathrm{E}-03$ & 0.00 & 0.00 & 1.53 & $3.68 \mathrm{E}-04$ & $6.16 \mathrm{E}-09$ & $6.49 \mathrm{E}-09$ & $1.73 \mathrm{E}-08$ & $4.92 \mathrm{E}-08$ & $2.25 \mathrm{E}-08$ & $1.63 \mathrm{E}-07$ \\
\hline 72 & 73.7 & 207.2 & 300 & 5.77 & $6.57 \mathrm{E}-04$ & 0.00 & 0.00 & 0.61 & $6.91 \mathrm{E}-05$ & $2.12 \mathrm{E}-10$ & $1.70 \mathrm{E}-10$ & $5.10 \mathrm{E}-10$ & $9.23 \mathrm{E}-10$ & 9.08E-09 & $3.36 \mathrm{E}-08$ \\
\hline 73 & 74.7 & 207.2 & 300 & 5.40 & $1.47 \mathrm{E}-04$ & 0.00 & 0.00 & 0.33 & $2.76 \mathrm{E}-05$ & $4.38 \mathrm{E}-11$ & $3.61 \mathrm{E}-11$ & $2.00 \mathrm{E}-10$ & $3.60 \mathrm{E}-10$ & $1.75 \mathrm{E}-09$ & $5.71 \mathrm{E}-09$ \\
\hline 74 & 75.8 & 207.1 & 300 & 5.32 & $2.41 \mathrm{E}-04$ & 0.00 & 0.00 & 0.44 & $2.41 \mathrm{E}-05$ & $0.00 \mathrm{E}+00$ & $0.00 \mathrm{E}+00$ & $0.00 \mathrm{E}+00$ & $0.00 \mathrm{E}+00$ & $3.31 \mathrm{E}-09$ & $1.19 \mathrm{E}-08$ \\
\hline 75 & 76.8 & 207.2 & 300 & 5.26 & $3.28 \mathrm{E}-04$ & 0.00 & 0.00 & 0.33 & $2.60 \mathrm{E}-05$ & $0.00 \mathrm{E}+00$ & $0.00 \mathrm{E}+00$ & $0.00 \mathrm{E}+00$ & $0.00 \mathrm{E}+00$ & 3.44E-09 & $1.00 \mathrm{E}-08$ \\
\hline 76 & 77.7 & 207.1 & 300 & 5.17 & $1.99 \mathrm{E}-04$ & 0.00 & 0.00 & 0.03 & $2.41 \mathrm{E}-05$ & $0.00 \mathrm{E}+00$ & $0.00 \mathrm{E}+00$ & $0.00 \mathrm{E}+00$ & $0.00 \mathrm{E}+00$ & $3.00 \mathrm{E}-09$ & 8.31E-09 \\
\hline 77 & 78.8 & 214.9 & 350 & 6.12 & $2.65 \mathrm{E}-03$ & 0.00 & 0.00 & 2.37 & $3.69 \mathrm{E}-04$ & $3.77 \mathrm{E}-11$ & $0.00 \mathrm{E}+00$ & $7.75 \mathrm{E}-11$ & $4.01 \mathrm{E}-11$ & $3.07 \mathrm{E}-09$ & $1.24 \mathrm{E}-08$ \\
\hline 78 & 79.7 & 242.4 & 350 & 5.34 & $1.86 \mathrm{E}-03$ & 0.00 & 0.00 & 2.33 & $1.99 \mathrm{E}-05$ & $3.66 \mathrm{E}-10$ & $2.51 \mathrm{E}-10$ & 7.32E-10 & $1.95 \mathrm{E}-09$ & $7.26 \mathrm{E}-10$ & $2.05 \mathrm{E}-08$ \\
\hline 79 & 80.7 & 242.3 & 350 & 5.55 & $2.21 \mathrm{E}-03$ & 0.00 & 0.00 & 0.82 & $5.41 \mathrm{E}-05$ & 5.04E-09 & 4.18E-09 & $1.09 \mathrm{E}-08$ & 3.10E-08 & $1.00 \mathrm{E}-08$ & $1.05 \mathrm{E}-07$ \\
\hline 80 & 81.8 & 242.4 & 350 & 5.78 & 2.33E-03 & 0.00 & 0.00 & 0.79 & $8.88 \mathrm{E}-05$ & $0.00 \mathrm{E}+00$ & $0.00 \mathrm{E}+00$ & $0.00 \mathrm{E}+00$ & $0.00 \mathrm{E}+00$ & $0.00 \mathrm{E}+00$ & $1.39 \mathrm{E}-08$ \\
\hline 81 & 82.8 & 242.4 & 350 & 5.65 & $1.89 \mathrm{E}-03$ & 0.00 & 0.00 & 0.52 & $1.03 \mathrm{E}-05$ & $0.00 \mathrm{E}+00$ & $0.00 \mathrm{E}+00$ & $0.00 \mathrm{E}+00$ & $0.00 \mathrm{E}+00$ & $0.00 \mathrm{E}+00$ & $1.40 \mathrm{E}-08$ \\
\hline 82 & 83.8 & 242.3 & 350 & 5.91 & $2.46 \mathrm{E}-03$ & 0.00 & 0.00 & 1.25 & 8.92E-05 & $0.00 \mathrm{E}+00$ & $0.00 \mathrm{E}+00$ & $0.00 \mathrm{E}+00$ & $0.00 \mathrm{E}+00$ & $0.00 \mathrm{E}+00$ & $1.34 \mathrm{E}-08$ \\
\hline 83 & 84.7 & 242.4 & 350 & 5.52 & $2.02 \mathrm{E}-03$ & 0.00 & 0.00 & 1.26 & $3.25 \mathrm{E}-05$ & $0.00 \mathrm{E}+00$ & $0.00 \mathrm{E}+00$ & $1.23 \mathrm{E}-09$ & $0.00 \mathrm{E}+00$ & $0.00 \mathrm{E}+00$ & $1.45 \mathrm{E}-08$ \\
\hline 84 & 85.7 & 242.3 & 350 & 5.87 & $2.44 \mathrm{E}-03$ & 0.00 & 0.00 & 0.99 & 8.02E-05 & $0.00 \mathrm{E}+00$ & $0.00 \mathrm{E}+00$ & $0.00 \mathrm{E}+00$ & $0.00 \mathrm{E}+00$ & $0.00 \mathrm{E}+00$ & $1.49 \mathrm{E}-08$ \\
\hline 85 & 86.7 & 242.3 & 350 & 5.91 & $2.24 \mathrm{E}-03$ & 0.00 & 0.00 & 0.73 & $5.48 \mathrm{E}-05$ & $0.00 \mathrm{E}+00$ & $0.00 \mathrm{E}+00$ & $0.00 \mathrm{E}+00$ & $0.00 \mathrm{E}+00$ & $0.00 \mathrm{E}+00$ & $1.56 \mathrm{E}-08$ \\
\hline 86 & 87.7 & 242.4 & 350 & 5.55 & $1.92 \mathrm{E}-03$ & 0.00 & 0.00 & 0.62 & $4.15 \mathrm{E}-05$ & $0.00 \mathrm{E}+00$ & $0.00 \mathrm{E}+00$ & $0.00 \mathrm{E}+00$ & $0.00 \mathrm{E}+00$ & $0.00 \mathrm{E}+00$ & $1.74 \mathrm{E}-08$ \\
\hline 87 & 88.8 & 242.3 & 350 & 5.67 & $2.16 \mathrm{E}-03$ & 0.00 & 0.00 & 0.53 & $4.78 \mathrm{E}-05$ & $0.00 \mathrm{E}+00$ & $0.00 \mathrm{E}+00$ & $0.00 \mathrm{E}+00$ & $0.00 \mathrm{E}+00$ & $0.00 \mathrm{E}+00$ & $2.52 \mathrm{E}-08$ \\
\hline 88 & 89.9 & 261.5 & 350 & 6.61 & $4.55 \mathrm{E}-03$ & 0.00 & 0.00 & 1.06 & $1.72 \mathrm{E}-04$ & $0.00 \mathrm{E}+00$ & $0.00 \mathrm{E}+00$ & $0.00 \mathrm{E}+00$ & $0.00 \mathrm{E}+00$ & $0.00 \mathrm{E}+00$ & $2.61 \mathrm{E}-08$ \\
\hline 89 & 90.7 & 274.6 & 350 & 7.22 & 7.09E-03 & 0.00 & 0.00 & 1.40 & $3.01 \mathrm{E}-04$ & $1.49 \mathrm{E}-09$ & $1.32 \mathrm{E}-09$ & $3.90 \mathrm{E}-09$ & $1.22 \mathrm{E}-08$ & $4.12 \mathrm{E}-09$ & $7.18 \mathrm{E}-08$ \\
\hline 90 & 91.7 & 413.7 & 400 & 5.53 & $9.02 \mathrm{E}-03$ & 0.00 & 0.00 & 6.70 & $3.94 \mathrm{E}-04$ & $6.44 \mathrm{E}-11$ & $0.00 \mathrm{E}+00$ & $8.89 \mathrm{E}-11$ & $0.00 \mathrm{E}+00$ & $2.46 \mathrm{E}-10$ & $9.45 \mathrm{E}-09$ \\
\hline 91 & 92.7 & 414.9 & 400 & 6.11 & $8.41 \mathrm{E}-03$ & 0.00 & 0.00 & 1.77 & $1.80 \mathrm{E}-04$ & $0.00 \mathrm{E}+00$ & $0.00 \mathrm{E}+00$ & $0.00 \mathrm{E}+00$ & $0.00 \mathrm{E}+00$ & $0.00 \mathrm{E}+00$ & $4.50 \mathrm{E}-10$ \\
\hline 92 & 93.7 & 414.9 & 400 & 6.03 & $7.60 \mathrm{E}-03$ & 0.00 & 0.00 & 0.00 & $1.07 \mathrm{E}-04$ & $0.00 \mathrm{E}+00$ & $0.00 \mathrm{E}+00$ & $3.60 \mathrm{E}-11$ & $8.09 \mathrm{E}-11$ & $0.00 \mathrm{E}+00$ & $1.68 \mathrm{E}-09$ \\
\hline 93 & 94.8 & 414.9 & 400 & 6.31 & $7.40 \mathrm{E}-03$ & 0.00 & 0.00 & 0.71 & $8.47 \mathrm{E}-05$ & $0.00 \mathrm{E}+00$ & $0.00 \mathrm{E}+00$ & $0.00 \mathrm{E}+00$ & $0.00 \mathrm{E}+00$ & $0.00 \mathrm{E}+00$ & $6.10 \mathrm{E}-10$ \\
\hline 94 & 95.9 & 414.9 & 400 & 6.01 & 7.57E-03 & 0.00 & 0.00 & 0.74 & $1.07 \mathrm{E}-04$ & $0.00 \mathrm{E}+00$ & $0.00 \mathrm{E}+00$ & $0.00 \mathrm{E}+00$ & $0.00 \mathrm{E}+00$ & $0.00 \mathrm{E}+00$ & $4.87 \mathrm{E}-10$ \\
\hline
\end{tabular}




\section{B.13 Supplementary material Chapter 4, pumice experiment}

Table B.13: Full ICP and HPLC data for Chapter 4, pumice experiment.

\begin{tabular}{|c|c|c|c|c|c|c|c|c|c|c|c|c|c|c|c|}
\hline & & & & & $\mathrm{mol} / \mathrm{kg}$ & $\mathrm{mol} / \mathrm{kg}$ & $\mathrm{mol} / \mathrm{kg}$ & $\mathrm{mg} / \mathrm{kg}$ & $\mathrm{mol} / \mathrm{kg}$ & $\mathrm{mol} / \mathrm{kg}$ & $\mathrm{mol} / \mathrm{kg}$ & $\mathrm{mol} / \mathrm{kg}$ & $\mathrm{mol} / \mathrm{kg}$ & $\mathrm{mol} / \mathrm{kg}$ & $\mathrm{mol} / \mathrm{kg}$ \\
\hline sample & $\begin{array}{l}\text { time } \\
(\text { day })\end{array}$ & $\begin{array}{c}\text { pressure } \\
\text { (bar) }\end{array}$ & $\begin{array}{c}\text { Temperature } \\
\left({ }^{\circ} \mathbf{C}\right)\end{array}$ & $\begin{array}{c}\text { pH } \\
25^{\circ} \mathrm{C}\end{array}$ & $\mathrm{SiO}_{2}$ & $\mathrm{Cl}^{-}$ & $\mathrm{SO}_{4}{ }^{2}-$ & $\mathbf{H}_{2} \mathbf{S}$ & $\mathbf{N a}^{+}$ & 2,6-NDS & 1,5-NDS & 2,7-NDS & 1,6-NDS & 1-NSA & 2-NSA \\
\hline blank & 0.0 & - & 25.0 & 7.00 & $1.69 \mathrm{E}-04$ & $1.75 \mathrm{E}-05$ & $2.39 \mathrm{E}-05$ & 0.00 & $4.00 \mathrm{E}-05$ & $6.71 \mathrm{E}-08$ & $7.12 \mathrm{E}-08$ & $7.06 \mathrm{E}-08$ & $6.75 \mathrm{E}-08$ & $0.00 \mathrm{E}+00$ & $0.00 \mathrm{E}+00$ \\
\hline 1 & 0.8 & 18.4 & 25.0 & 6.75 & $9.07 \mathrm{E}-05$ & $1.66 \mathrm{E}-04$ & $1.87 \mathrm{E}-05$ & 0.00 & $0.00 \mathrm{E}+00$ & $6.67 \mathrm{E}-08$ & $6.99 \mathrm{E}-08$ & $7.15 \mathrm{E}-08$ & $6.84 \mathrm{E}-08$ & $0.00 \mathrm{E}+00$ & $0.00 \mathrm{E}+00$ \\
\hline 2 & 1.9 & 18.3 & 25.0 & 7.34 & $6.54 \mathrm{E}-05$ & $1.95 \mathrm{E}-05$ & 4.58E-06 & 0.01 & $0.00 \mathrm{E}+00$ & $6.87 \mathrm{E}-08$ & 7.06E-08 & 7.18E-08 & $6.90 \mathrm{E}-08$ & $0.00 \mathrm{E}+00$ & $0.00 \mathrm{E}+00$ \\
\hline 3 & 2.9 & 18.1 & 25.0 & 7.03 & $6.24 \mathrm{E}-05$ & $1.64 \mathrm{E}-05$ & $2.60 \mathrm{E}-06$ & 0.00 & $0.00 \mathrm{E}+00$ & $6.72 \mathrm{E}-08$ & 7.01E-08 & 7.13E-08 & $6.80 \mathrm{E}-08$ & $0.00 \mathrm{E}+00$ & $0.00 \mathrm{E}+00$ \\
\hline 4 & 3.8 & 18.0 & 25.0 & 7.07 & $5.48 \mathrm{E}-05$ & $9.31 \mathrm{E}-06$ & $1.98 \mathrm{E}-06$ & 0.00 & $0.00 \mathrm{E}+00$ & $6.70 \mathrm{E}-08$ & $6.98 \mathrm{E}-08$ & 7.08E-08 & $6.77 \mathrm{E}-08$ & $0.00 \mathrm{E}+00$ & $0.00 \mathrm{E}+00$ \\
\hline 5 & 5.0 & 17.9 & 100.0 & 7.06 & $1.29 \mathrm{E}-03$ & 7.90E-06 & $1.77 \mathrm{E}-06$ & 0.00 & 4.05E-05 & $6.49 \mathrm{E}-08$ & $6.76 \mathrm{E}-08$ & $6.86 \mathrm{E}-08$ & $6.60 \mathrm{E}-08$ & $0.00 \mathrm{E}+00$ & $0.00 \mathrm{E}+00$ \\
\hline 6 & 5.8 & 18.0 & 100.0 & 8.02 & $2.41 \mathrm{E}-03$ & $3.38 \mathrm{E}-05$ & $1.25 \mathrm{E}-05$ & 0.01 & $0.00 \mathrm{E}+00$ & $6.18 \mathrm{E}-08$ & $6.46 \mathrm{E}-08$ & $6.51 \mathrm{E}-08$ & $6.29 \mathrm{E}-08$ & $0.00 \mathrm{E}+00$ & $0.00 \mathrm{E}+00$ \\
\hline 7 & 6.9 & 18.0 & 100.0 & 6.94 & $2.14 \mathrm{E}-03$ & $1.58 \mathrm{E}-05$ & 4.37E-06 & 0.08 & $0.00 \mathrm{E}+00$ & $6.15 \mathrm{E}-08$ & $6.45 \mathrm{E}-08$ & $6.47 \mathrm{E}-08$ & $6.25 \mathrm{E}-08$ & $0.00 \mathrm{E}+00$ & $0.00 \mathrm{E}+00$ \\
\hline 8 & 7.9 & 18.0 & 100.0 & 8.40 & $2.10 \mathrm{E}-03$ & $1.27 \mathrm{E}-05$ & $3.23 \mathrm{E}-06$ & 0.02 & $1.61 \mathrm{E}-05$ & $6.16 \mathrm{E}-08$ & $6.45 \mathrm{E}-08$ & $6.46 \mathrm{E}-08$ & $6.27 \mathrm{E}-08$ & $0.00 \mathrm{E}+00$ & $0.00 \mathrm{E}+00$ \\
\hline 9 & 8.9 & 18.0 & 100.0 & 8.49 & $2.08 \mathrm{E}-03$ & $1.04 \mathrm{E}-05$ & 4.27E-06 & 0.00 & $0.00 \mathrm{E}+00$ & $6.14 \mathrm{E}-08$ & $6.43 \mathrm{E}-08$ & $6.45 \mathrm{E}-08$ & $6.20 \mathrm{E}-08$ & $0.00 \mathrm{E}+00$ & $0.00 \mathrm{E}+00$ \\
\hline 10 & 9.9 & 18.0 & 100.0 & 8.42 & $2.06 \mathrm{E}-03$ & $9.31 \mathrm{E}-06$ & 4.27E-06 & 0.04 & 3.09E-04 & $6.13 \mathrm{E}-08$ & 6.39E-08 & $6.41 \mathrm{E}-08$ & $6.17 \mathrm{E}-08$ & $0.00 \mathrm{E}+00$ & $0.00 \mathrm{E}+00$ \\
\hline 11 & 10.8 & 18.0 & 100.0 & 8.54 & $2.08 \mathrm{E}-03$ & $1.10 \mathrm{E}-05$ & $3.44 \mathrm{E}-06$ & 0.32 & $3.15 \mathrm{E}-04$ & $6.12 \mathrm{E}-08$ & 6.39E-08 & $6.39 \mathrm{E}-08$ & $6.17 \mathrm{E}-08$ & $0.00 \mathrm{E}+00$ & $0.00 \mathrm{E}+00$ \\
\hline 12 & 11.8 & 18.0 & 100.0 & 8.44 & $2.17 \mathrm{E}-03$ & $9.87 \mathrm{E}-06$ & 3.33E-06 & 0.01 & $2.53 \mathrm{E}-04$ & $6.05 \mathrm{E}-08$ & $6.34 \mathrm{E}-08$ & 6.32E-08 & $6.13 \mathrm{E}-08$ & $0.00 \mathrm{E}+00$ & $0.00 \mathrm{E}+00$ \\
\hline 13 & 12.9 & 18.0 & 100.0 & 8.51 & $2.06 \mathrm{E}-03$ & $9.59 \mathrm{E}-06$ & $3.64 \mathrm{E}-06$ & 0.02 & $3.78 \mathrm{E}-05$ & $6.03 \mathrm{E}-08$ & 6.33E-08 & $6.29 \mathrm{E}-08$ & $6.09 \mathrm{E}-08$ & $0.00 \mathrm{E}+00$ & $0.00 \mathrm{E}+00$ \\
\hline 14 & 13.9 & 17.9 & 100.0 & 8.47 & $2.04 \mathrm{E}-03$ & $1.10 \mathrm{E}-05$ & $3.85 \mathrm{E}-06$ & 0.01 & 8.70E-06 & $6.00 \mathrm{E}-08$ & $6.28 \mathrm{E}-08$ & $6.24 \mathrm{E}-08$ & $6.09 \mathrm{E}-08$ & $0.00 \mathrm{E}+00$ & $0.00 \mathrm{E}+00$ \\
\hline 15 & 14.9 & 17.8 & 150.0 & 8.52 & $5.22 \mathrm{E}-03$ & $1.16 \mathrm{E}-05$ & $4.16 \mathrm{E}-06$ & 0.00 & $5.94 \mathrm{E}-04$ & $5.81 \mathrm{E}-08$ & $6.09 \mathrm{E}-08$ & $6.05 \mathrm{E}-08$ & $5.90 \mathrm{E}-08$ & $0.00 \mathrm{E}+00$ & $0.00 \mathrm{E}+00$ \\
\hline 16 & 15.8 & 17.8 & 152.0 & 8.28 & 7.03E-03 & $2.12 \mathrm{E}-05$ & $6.04 \mathrm{E}-06$ & 0.02 & $1.41 \mathrm{E}-03$ & $5.39 \mathrm{E}-08$ & 5.72E-08 & $5.58 \mathrm{E}-08$ & $5.46 \mathrm{E}-08$ & $0.00 \mathrm{E}+00$ & $0.00 \mathrm{E}+00$ \\
\hline 17 & 16.9 & 27.5 & 151.0 & 8.95 & $6.80 \mathrm{E}-03$ & $2.17 \mathrm{E}-05$ & $6.14 \mathrm{E}-06$ & 0.01 & $1.54 \mathrm{E}-03$ & $5.65 \mathrm{E}-08$ & 5.92E-08 & $5.85 \mathrm{E}-08$ & $5.70 \mathrm{E}-08$ & $0.00 \mathrm{E}+00$ & $0.00 \mathrm{E}+00$ \\
\hline 18 & 17.9 & 30.6 & 150.0 & 9.30 & $6.89 \mathrm{E}-03$ & 2.09E-05 & $5.93 \mathrm{E}-06$ & 0.10 & $1.53 \mathrm{E}-03$ & 5.91E-08 & $6.20 \mathrm{E}-08$ & $6.08 \mathrm{E}-08$ & $5.95 \mathrm{E}-08$ & $0.00 \mathrm{E}+00$ & $0.00 \mathrm{E}+00$ \\
\hline 19 & 18.9 & 30.6 & 150.0 & 9.29 & $6.84 \mathrm{E}-03$ & $1.95 \mathrm{E}-05$ & $6.04 \mathrm{E}-06$ & 0.01 & $1.49 \mathrm{E}-03$ & $6.15 \mathrm{E}-08$ & $6.47 \mathrm{E}-08$ & 6.32E-08 & $6.24 \mathrm{E}-08$ & $0.00 \mathrm{E}+00$ & $0.00 \mathrm{E}+00$ \\
\hline 20 & 19.9 & 30.5 & 150.0 & 9.33 & $6.92 \mathrm{E}-03$ & $2.23 \mathrm{E}-05$ & $6.04 \mathrm{E}-06$ & 0.01 & $1.51 \mathrm{E}-03$ & $6.07 \mathrm{E}-08$ & $6.38 \mathrm{E}-08$ & $6.21 \mathrm{E}-08$ & $6.13 \mathrm{E}-08$ & $0.00 \mathrm{E}+00$ & $0.00 \mathrm{E}+00$ \\
\hline 22 & 20.9 & 30.5 & 150.0 & 9.32 & $6.92 \mathrm{E}-03$ & $1.97 \mathrm{E}-05$ & $5.62 \mathrm{E}-06$ & 0.05 & $1.49 \mathrm{E}-03$ & $6.02 \mathrm{E}-08$ & $6.33 \mathrm{E}-08$ & $6.16 \mathrm{E}-08$ & $6.11 \mathrm{E}-08$ & $0.00 \mathrm{E}+00$ & $0.00 \mathrm{E}+00$ \\
\hline 23 & 21.9 & 30.5 & 150.0 & 9.23 & $7.35 \mathrm{E}-03$ & $2.14 \mathrm{E}-05$ & $6.14 \mathrm{E}-06$ & 0.00 & $1.17 \mathrm{E}-03$ & 5.93E-08 & $6.25 \mathrm{E}-08$ & $6.05 \mathrm{E}-08$ & $6.03 \mathrm{E}-08$ & $0.00 \mathrm{E}+00$ & $0.00 \mathrm{E}+00$ \\
\hline 23 & 22.9 & 30.5 & 150.0 & 9.29 & $6.77 \mathrm{E}-03$ & $1.92 \mathrm{E}-05$ & $6.04 \mathrm{E}-06$ & 0.00 & $1.27 \mathrm{E}-03$ & $5.94 \mathrm{E}-08$ & $6.26 \mathrm{E}-08$ & $6.05 \mathrm{E}-08$ & $6.02 \mathrm{E}-08$ & $0.00 \mathrm{E}+00$ & $0.00 \mathrm{E}+00$ \\
\hline 24 & 23.9 & 30.5 & 150.0 & 9.29 & $6.79 \mathrm{E}-03$ & $2.06 \mathrm{E}-05$ & $7.50 \mathrm{E}-06$ & 0.00 & $1.34 \mathrm{E}-03$ & $5.97 \mathrm{E}-08$ & $6.29 \mathrm{E}-08$ & $6.06 \mathrm{E}-08$ & $6.08 \mathrm{E}-08$ & $0.00 \mathrm{E}+00$ & $0.00 \mathrm{E}+00$ \\
\hline
\end{tabular}




\begin{tabular}{|c|c|c|c|c|c|c|c|c|c|c|c|c|c|c|c|}
\hline & & & & & $\mathrm{mol} / \mathrm{kg}$ & $\mathrm{mol} / \mathrm{kg}$ & $\mathrm{mol} / \mathrm{kg}$ & $\mathrm{mg} / \mathrm{kg}$ & $\mathrm{mol} / \mathrm{kg}$ & $\mathrm{mol} / \mathrm{kg}$ & $\mathrm{mol} / \mathrm{kg}$ & $\mathrm{mol} / \mathrm{kg}$ & $\mathrm{mol} / \mathrm{kg}$ & $\mathrm{mol} / \mathrm{kg}$ & $\mathrm{mol} / \mathrm{kg}$ \\
\hline sample & $\begin{array}{c}\text { time } \\
\text { (day) }\end{array}$ & $\begin{array}{c}\text { pressure } \\
\text { (bar) }\end{array}$ & $\begin{array}{c}\text { Temperature } \\
\left({ }^{\circ} \mathbf{C}\right)\end{array}$ & $\begin{array}{c}\mathbf{p H} \\
25^{\circ} \mathrm{C}\end{array}$ & $\mathrm{SiO}_{2}$ & $\mathrm{Cl}^{-}$ & $\mathrm{SO}_{4}{ }^{2-}$ & $\mathbf{H}_{2} \mathrm{~S}$ & $\mathbf{N a}^{+}$ & 2,6-NDS & 1,5-NDS & 2,7-NDS & 1,6-NDS & 1-NSA & 2-NSA \\
\hline 25 & 24.8 & 30.5 & 204.0 & 9.28 & $6.87 \mathrm{E}-03$ & 2.03E-05 & $6.66 \mathrm{E}-06$ & 0.00 & $2.00 \mathrm{E}-03$ & 7.22E-08 & 7.33E-08 & 7.40E-08 & 7.13E-08 & $0.00 \mathrm{E}+00$ & $1.21 \mathrm{E}-09$ \\
\hline 26 & 25.9 & 30.5 & 200.0 & 9.48 & $1.46 \mathrm{E}-02$ & 3.67E-05 & 8.54E-06 & 0.00 & $2.88 \mathrm{E}-03$ & $6.72 \mathrm{E}-08$ & $6.77 \mathrm{E}-08$ & $6.86 \mathrm{E}-08$ & $6.60 \mathrm{E}-08$ & $0.00 \mathrm{E}+00$ & $1.93 \mathrm{E}-09$ \\
\hline 27 & 26.8 & 30.4 & 200.0 & 9.46 & $1.33 \mathrm{E}-02$ & $3.38 \mathrm{E}-05$ & $2.08 \mathrm{E}-05$ & 0.00 & $2.99 \mathrm{E}-03$ & $6.35 \mathrm{E}-08$ & $6.54 \mathrm{E}-08$ & $6.44 \mathrm{E}-08$ & $6.31 \mathrm{E}-08$ & $0.00 \mathrm{E}+00$ & $1.01 \mathrm{E}-09$ \\
\hline 28 & 27.9 & 30.4 & 200.0 & 9.66 & $1.28 \mathrm{E}-02$ & $3.95 \mathrm{E}-05$ & $1.04 \mathrm{E}-05$ & 0.00 & $3.05 \mathrm{E}-03$ & $6.48 \mathrm{E}-08$ & $6.66 \mathrm{E}-08$ & $6.59 \mathrm{E}-08$ & $6.45 \mathrm{E}-08$ & $0.00 \mathrm{E}+00$ & $3.86 \mathrm{E}-10$ \\
\hline 29 & 28.8 & 32.9 & 200.0 & 9.68 & $1.18 \mathrm{E}-02$ & $3.67 \mathrm{E}-05$ & $9.47 \mathrm{E}-06$ & 0.00 & $2.84 \mathrm{E}-03$ & $6.38 \mathrm{E}-08$ & $6.55 \mathrm{E}-08$ & $6.47 \mathrm{E}-08$ & $6.38 \mathrm{E}-08$ & $0.00 \mathrm{E}+00$ & $7.24 \mathrm{E}-10$ \\
\hline 30 & 29.9 & 30.0 & 200.0 & 9.65 & $1.02 \mathrm{E}-02$ & $6.77 \mathrm{E}-05$ & $1.02 \mathrm{E}-05$ & 0.00 & $2.55 \mathrm{E}-03$ & $6.41 \mathrm{E}-08$ & $6.57 \mathrm{E}-08$ & $6.49 \mathrm{E}-08$ & $6.44 \mathrm{E}-08$ & $0.00 \mathrm{E}+00$ & $7.72 \mathrm{E}-10$ \\
\hline 31 & 30.8 & 29.9 & 200.0 & 9.65 & $1.05 \mathrm{E}-02$ & $3.95 \mathrm{E}-05$ & $1.02 \mathrm{E}-05$ & 0.00 & $2.32 \mathrm{E}-03$ & $6.54 \mathrm{E}-08$ & $6.71 \mathrm{E}-08$ & $6.62 \mathrm{E}-08$ & $6.56 \mathrm{E}-08$ & $0.00 \mathrm{E}+00$ & $7.72 \mathrm{E}-10$ \\
\hline 32 & 31.8 & 36.7 & 200.0 & 9.59 & $1.06 \mathrm{E}-02$ & 3.67E-05 & $1.15 \mathrm{E}-05$ & 0.00 & $2.38 \mathrm{E}-03$ & $6.56 \mathrm{E}-08$ & $6.71 \mathrm{E}-08$ & $6.65 \mathrm{E}-08$ & $6.60 \mathrm{E}-08$ & $0.00 \mathrm{E}+00$ & $9.17 \mathrm{E}-10$ \\
\hline 33 & 32.9 & 36.6 & 200.0 & 9.62 & $1.05 \mathrm{E}-02$ & $3.95 \mathrm{E}-05$ & $1.04 \mathrm{E}-05$ & 0.00 & $2.34 \mathrm{E}-03$ & $6.68 \mathrm{E}-08$ & 6.84E-08 & $6.76 \mathrm{E}-08$ & $6.71 \mathrm{E}-08$ & $0.00 \mathrm{E}+00$ & 4.73E-09 \\
\hline 34 & 34.9 & 36.5 & 200.0 & 9.59 & $1.02 \mathrm{E}-02$ & 4.23E-05 & $6.87 \mathrm{E}-06$ & 0.06 & $2.39 \mathrm{E}-03$ & $5.57 \mathrm{E}-08$ & $5.81 \mathrm{E}-08$ & $6.03 \mathrm{E}-08$ & 5.72E-08 & $0.00 \mathrm{E}+00$ & $2.03 \mathrm{E}-09$ \\
\hline 35 & 35.9 & 36.9 & 250.0 & 9.59 & $1.05 \mathrm{E}-02$ & $6.49 \mathrm{E}-05$ & $5.00 \mathrm{E}-06$ & 0.01 & $2.68 \mathrm{E}-03$ & $5.84 \mathrm{E}-08$ & $5.93 \mathrm{E}-08$ & $6.26 \mathrm{E}-08$ & 5.83E-08 & $3.38 \mathrm{E}-10$ & $3.47 \mathrm{E}-09$ \\
\hline 36 & 36.9 & 37.0 & 250.0 & 9.52 & $7.70 \mathrm{E}-03$ & $1.18 \mathrm{E}-04$ & 5.31E-05 & 0.00 & 2.63E-03 & $6.09 \mathrm{E}-08$ & $6.16 \mathrm{E}-08$ & $6.57 \mathrm{E}-08$ & $6.14 \mathrm{E}-08$ & $6.76 \mathrm{E}-10$ & $5.26 \mathrm{E}-09$ \\
\hline 37 & 37.9 & 37.0 & 250.0 & 9.44 & $8.28 \mathrm{E}-03$ & 1.92E-04 & $2.81 \mathrm{E}-06$ & 0.01 & $2.73 \mathrm{E}-03$ & 6.14E-08 & 6.19E-08 & 6.92E-08 & $6.31 \mathrm{E}-08$ & $1.11 \mathrm{E}-09$ & $1.18 \mathrm{E}-08$ \\
\hline 38 & 38.9 & 37.0 & 250.0 & 9.35 & $8.51 \mathrm{E}-03$ & 3.07E-04 & $6.25 \mathrm{E}-05$ & 0.01 & $2.51 \mathrm{E}-03$ & $5.84 \mathrm{E}-08$ & $5.78 \mathrm{E}-08$ & $6.40 \mathrm{E}-08$ & 5.92E-08 & 7.24E-10 & $3.28 \mathrm{E}-09$ \\
\hline 38 & 39.9 & 36.9 & 250.0 & 9.40 & $8.56 \mathrm{E}-03$ & 4.20E-04 & $1.06 \mathrm{E}-04$ & 0.01 & $2.42 \mathrm{E}-03$ & 5.61E-08 & $5.50 \mathrm{E}-08$ & $6.23 \mathrm{E}-08$ & 5.71E-08 & 1.11E-09 & $4.78 \mathrm{E}-09$ \\
\hline 39 & 41.0 & 36.9 & 250.0 & 9.37 & 8.94E-03 & 4.82E-04 & 7.29E-07 & 0.01 & $2.27 \mathrm{E}-03$ & 5.51E-08 & 5.35E-08 & $6.15 \mathrm{E}-08$ & $5.55 \mathrm{E}-08$ & $8.69 \mathrm{E}-10$ & 4.44E-09 \\
\hline 40 & 41.9 & 36.9 & 250.0 & 9.40 & $8.12 \mathrm{E}-03$ & $4.82 \mathrm{E}-04$ & 7.29E-07 & 0.01 & $1.90 \mathrm{E}-03$ & $4.86 \mathrm{E}-08$ & 4.74E-08 & $5.45 \mathrm{E}-08$ & 4.90E-08 & $9.65 \mathrm{E}-10$ & $3.33 \mathrm{E}-09$ \\
\hline 41 & 42.9 & 45.4 & 250.0 & 9.38 & $1.93 \mathrm{E}-02$ & $3.05 \mathrm{E}-04$ & $2.91 \mathrm{E}-06$ & 0.01 & $2.66 \mathrm{E}-03$ & $5.40 \mathrm{E}-08$ & $5.50 \mathrm{E}-08$ & $5.78 \mathrm{E}-08$ & $5.44 \mathrm{E}-08$ & $4.83 \mathrm{E}-10$ & $2.32 \mathrm{E}-09$ \\
\hline 42 & 44.1 & 99.5 & 250.0 & 9.33 & $1.85 \mathrm{E}-02$ & $4.51 \mathrm{E}-04$ & $1.35 \mathrm{E}-06$ & 0.01 & $2.61 \mathrm{E}-03$ & $3.33 \mathrm{E}-08$ & $3.41 \mathrm{E}-08$ & $3.43 \mathrm{E}-08$ & $3.08 \mathrm{E}-08$ & $1.45 \mathrm{E}-10$ & $7.24 \mathrm{E}-10$ \\
\hline 43 & 44.7 & 99.6 & 250.0 & 9.30 & $1.82 \mathrm{E}-02$ & 4.12E-04 & 8.33E-07 & 0.01 & $2.68 \mathrm{E}-03$ & $4.56 \mathrm{E}-08$ & $4.50 \mathrm{E}-08$ & $4.77 \mathrm{E}-08$ & 4.32E-08 & $1.45 \mathrm{E}-10$ & $1.45 \mathrm{E}-09$ \\
\hline 44 & 46.0 & 99.6 & 250.0 & 9.27 & $1.84 \mathrm{E}-02$ & $3.70 \mathrm{E}-04$ & $1.15 \mathrm{E}-06$ & 0.00 & $2.46 \mathrm{E}-03$ & $5.00 \mathrm{E}-08$ & 4.99E-08 & $5.22 \mathrm{E}-08$ & 4.93E-08 & $3.38 \mathrm{E}-10$ & $4.25 \mathrm{E}-09$ \\
\hline 45 & 47.0 & 99.6 & 250.0 & 9.38 & $1.82 \mathrm{E}-02$ & 3.33E-04 & $1.25 \mathrm{E}-06$ & 0.03 & $2.34 \mathrm{E}-03$ & 4.97E-08 & 5.02E-08 & 5.09E-08 & 4.89E-08 & $0.00 \mathrm{E}+00$ & $1.11 \mathrm{E}-09$ \\
\hline 46 & 47.9 & 99.5 & 279.0 & 9.33 & $1.75 \mathrm{E}-02$ & $5.42 \mathrm{E}-04$ & 2.19E-06 & 0.00 & $1.66 \mathrm{E}-03$ & 4.86E-08 & 4.77E-08 & 4.99E-08 & 4.70E-08 & $4.83 \mathrm{E}-10$ & $1.16 \mathrm{E}-09$ \\
\hline 47 & 49.0 & 99.5 & 300.0 & 9.01 & $1.86 \mathrm{E}-02$ & 7.90E-04 & $2.08 \mathrm{E}-06$ & 0.01 & $1.65 \mathrm{E}-03$ & 4.84E-08 & 4.33E-08 & $5.26 \mathrm{E}-08$ & 4.57E-08 & $4.83 \mathrm{E}-10$ & $1.74 \mathrm{E}-09$ \\
\hline 48 & 49.6 & 99.5 & 300.0 & 8.77 & $2.11 \mathrm{E}-02$ & 4.15E-04 & $2.71 \mathrm{E}-06$ & 0.00 & $1.39 \mathrm{E}-03$ & 4.64E-08 & $4.00 \mathrm{E}-08$ & $5.08 \mathrm{E}-08$ & $4.50 \mathrm{E}-08$ & $1.21 \mathrm{E}-09$ & $1.11 \mathrm{E}-08$ \\
\hline 49 & 51.0 & 99.5 & 300.0 & 8.84 & $2.21 \mathrm{E}-02$ & $2.57 \mathrm{E}-04$ & 2.19E-06 & 0.05 & $1.07 \mathrm{E}-03$ & 4.52E-08 & 3.92E-08 & 4.88E-08 & 4.20E-08 & $4.34 \mathrm{E}-10$ & $2.03 \mathrm{E}-09$ \\
\hline 50 & 51.9 & 99.5 & 300.0 & 8.94 & $2.31 \mathrm{E}-02$ & $1.61 \mathrm{E}-04$ & $1.98 \mathrm{E}-06$ & 0.07 & $1.12 \mathrm{E}-03$ & 4.45E-08 & $3.88 \mathrm{E}-08$ & $4.82 \mathrm{E}-08$ & 4.19E-08 & 4.34E-10 & $1.88 \mathrm{E}-09$ \\
\hline 51 & 53.0 & 99.5 & 300.0 & 8.92 & $2.41 \mathrm{E}-02$ & $1.18 \mathrm{E}-04$ & 2.19E-06 & 0.06 & $1.05 \mathrm{E}-03$ & 4.41E-08 & $3.89 \mathrm{E}-08$ & $4.72 \mathrm{E}-08$ & 4.07E-08 & $3.86 \mathrm{E}-10$ & $1.54 \mathrm{E}-09$ \\
\hline 52 & 53.9 & 99.7 & 300.0 & 9.05 & $2.51 \mathrm{E}-02$ & $9.59 \mathrm{E}-05$ & 2.19E-06 & 0.06 & $9.61 \mathrm{E}-04$ & $4.47 \mathrm{E}-08$ & $3.93 \mathrm{E}-08$ & 4.76E-08 & 4.15E-08 & $4.83 \mathrm{E}-10$ & $1.88 \mathrm{E}-09$ \\
\hline
\end{tabular}




\begin{tabular}{|c|c|c|c|c|c|c|c|c|c|c|c|c|c|c|c|}
\hline & & & & & $\mathrm{mol} / \mathrm{kg}$ & $\mathrm{mol} / \mathrm{kg}$ & $\mathrm{mol} / \mathrm{kg}$ & $\mathrm{mg} / \mathrm{kg}$ & $\mathrm{mol} / \mathrm{kg}$ & $\mathrm{mol} / \mathrm{kg}$ & $\mathrm{mol} / \mathrm{kg}$ & $\mathrm{mol} / \mathrm{kg}$ & $\mathrm{mol} / \mathrm{kg}$ & $\mathrm{mol} / \mathrm{kg}$ & $\mathrm{mol} / \mathrm{kg}$ \\
\hline sample & $\begin{array}{l}\text { time } \\
\text { (day) }\end{array}$ & $\begin{array}{c}\text { pressure } \\
\text { (bar) }\end{array}$ & $\begin{array}{c}\text { Temperature } \\
\left({ }^{\circ} \mathbf{C}\right)\end{array}$ & $\begin{array}{c}\mathrm{pH} \\
25^{\circ} \mathrm{C}\end{array}$ & $\mathrm{SiO}_{2}$ & $\mathrm{Cl}^{-}$ & $\mathrm{SO}_{4}{ }^{2-}$ & $\mathrm{H}_{2} \mathrm{~S}$ & $\mathbf{N a}^{+}$ & 2,6-NDS & 1,5-NDS & 2,7-NDS & 1,6-NDS & 1-NSA & 2-NSA \\
\hline 53 & 54.9 & 99.7 & 300.0 & 9.02 & $1.90 \mathrm{E}-02$ & $8.46 \mathrm{E}-05$ & $3.12 \mathrm{E}-06$ & 0.03 & $1.12 \mathrm{E}-03$ & 4.51E-08 & 4.00E-08 & $4.81 \mathrm{E}-08$ & 4.20E-08 & $4.83 \mathrm{E}-10$ & $1.50 \mathrm{E}-09$ \\
\hline 54 & 55.9 & 99.4 & 300.0 & 9.06 & $1.86 \mathrm{E}-02$ & 7.33E-05 & $1.77 \mathrm{E}-06$ & 0.04 & $1.05 \mathrm{E}-03$ & 4.52E-08 & 4.05E-08 & 4.84E-08 & 4.22E-08 & $3.86 \mathrm{E}-10$ & $1.50 \mathrm{E}-09$ \\
\hline 55 & 56.6 & 130.8 & 300.0 & 9.03 & $1.86 \mathrm{E}-02$ & $6.49 \mathrm{E}-05$ & 2.29E-06 & 0.06 & $1.12 \mathrm{E}-03$ & 4.13E-08 & $3.66 \mathrm{E}-08$ & 4.35E-08 & $3.78 \mathrm{E}-08$ & $5.31 \mathrm{E}-10$ & $1.64 \mathrm{E}-09$ \\
\hline 56 & 58.0 & 138.4 & 350.0 & 9.06 & $1.98 \mathrm{E}-02$ & 2.31E-04 & $5.21 \mathrm{E}-06$ & 0.06 & $6.44 \mathrm{E}-04$ & $3.05 \mathrm{E}-08$ & $2.11 \mathrm{E}-08$ & $3.55 \mathrm{E}-08$ & $2.57 \mathrm{E}-08$ & 2.99E-09 & 3.23E-09 \\
\hline 57 & 59.0 & 138.4 & 350.0 & 8.50 & $2.10 \mathrm{E}-02$ & 2.09E-04 & $3.44 \mathrm{E}-06$ & 0.05 & 5.30E-04 & $1.22 \mathrm{E}-08$ & 4.95E-09 & $1.58 \mathrm{E}-08$ & $1.05 \mathrm{E}-08$ & 2.80E-09 & $6.18 \mathrm{E}-09$ \\
\hline 58 & 59.8 & 138.9 & 350.0 & 8.02 & $2.10 \mathrm{E}-02$ & $1.44 \mathrm{E}-04$ & 2.91E-06 & 0.07 & $5.29 \mathrm{E}-04$ & $1.03 \mathrm{E}-08$ & $4.26 \mathrm{E}-09$ & $1.27 \mathrm{E}-08$ & 8.37E-09 & 1.79E-09 & 2.61E-09 \\
\hline 59 & 60.8 & 207.5 & 350.0 & 8.09 & 2.19E-02 & $1.04 \mathrm{E}-04$ & 2.91E-06 & 0.03 & $6.02 \mathrm{E}-04$ & $1.07 \mathrm{E}-08$ & 4.81E-09 & $1.34 \mathrm{E}-08$ & 9.19E-09 & $1.59 \mathrm{E}-09$ & 2.99E-09 \\
\hline 60 & 62.0 & 207.3 & 350.0 & 8.15 & $2.21 \mathrm{E}-02$ & 7.90E-05 & $2.71 \mathrm{E}-06$ & 0.05 & $5.92 \mathrm{E}-04$ & $1.08 \mathrm{E}-08$ & $4.88 \mathrm{E}-09$ & 1.49E-08 & $1.08 \mathrm{E}-08$ & $2.46 \mathrm{E}-09$ & $1.37 \mathrm{E}-08$ \\
\hline 61 & 63.2 & 207.3 & 350.0 & 8.41 & $2.20 \mathrm{E}-02$ & $6.49 \mathrm{E}-05$ & $3.44 \mathrm{E}-06$ & 0.07 & $5.84 \mathrm{E}-04$ & $1.07 \mathrm{E}-08$ & $5.02 \mathrm{E}-09$ & $1.35 \mathrm{E}-08$ & $9.19 \mathrm{E}-09$ & $1.83 \mathrm{E}-09$ & $2.85 \mathrm{E}-09$ \\
\hline 62 & 64.0 & 207.1 & 350.0 & 8.40 & $2.14 \mathrm{E}-02$ & 5.92E-05 & $3.33 \mathrm{E}-06$ & 0.06 & $5.22 \mathrm{E}-04$ & $1.00 \mathrm{E}-08$ & 4.95E-09 & $1.34 \mathrm{E}-08$ & 8.85E-09 & 2.08E-09 & $2.70 \mathrm{E}-09$ \\
\hline 63 & 64.9 & 207.2 & 350.0 & 8.36 & $2.16 \mathrm{E}-02$ & $9.87 \mathrm{E}-04$ & $4.58 \mathrm{E}-06$ & 0.04 & $5.07 \mathrm{E}-04$ & $1.22 \mathrm{E}-08$ & $5.65 \mathrm{E}-09$ & $1.56 \mathrm{E}-08$ & $1.08 \mathrm{E}-08$ & $1.98 \mathrm{E}-09$ & 3.09E-09 \\
\hline 64 & 65.9 & 207.2 & 350.0 & 8.36 & $2.24 \mathrm{E}-02$ & $1.66 \mathrm{E}-04$ & 4.37E-06 & 0.06 & $6.84 \mathrm{E}-04$ & $1.09 \mathrm{E}-08$ & $5.23 \mathrm{E}-09$ & $1.35 \mathrm{E}-08$ & $9.46 \mathrm{E}-09$ & $1.98 \mathrm{E}-09$ & $3.14 \mathrm{E}-09$ \\
\hline 65 & 66.8 & 207.2 & 350.0 & 8.35 & $2.25 \mathrm{E}-02$ & 2.91E-04 & $5.21 \mathrm{E}-06$ & 0.04 & $8.16 \mathrm{E}-04$ & 8.33E-09 & 4.53E-09 & $1.03 \mathrm{E}-08$ & 7.21E-09 & 1.64E-09 & $2.46 \mathrm{E}-09$ \\
\hline 66 & 67.9 & 207.2 & 350.0 & 8.26 & $2.28 \mathrm{E}-02$ & $2.34 \mathrm{E}-04$ & $6.35 \mathrm{E}-06$ & 0.05 & 7.51E-04 & 7.65E-09 & 4.26E-09 & 9.73E-09 & $6.46 \mathrm{E}-09$ & 1.40E-09 & $2.08 \mathrm{E}-09$ \\
\hline 67 & 68.9 & 207.2 & 400 & 8.34 & $2.53 \mathrm{E}-02$ & $1.44 \mathrm{E}-04$ & 8.95E-06 & 0.01 & 8.00E-04 & $6.63 \mathrm{E}-09$ & $1.46 \mathrm{E}-09$ & 7.63E-09 & 3.06E-09 & 2.80E-09 & $1.22 \mathrm{E}-08$ \\
\hline 68 & 70.0 & 207.2 & 400 & 8.19 & $2.73 \mathrm{E}-02$ & $1.04 \mathrm{E}-05$ & 4.79E-06 & 0.12 & $5.17 \mathrm{E}-04$ & 2.91E-09 & $0.00 \mathrm{E}+00$ & 2.13E-09 & $0.00 \mathrm{E}+00$ & $3.81 \mathrm{E}-09$ & $3.54 \mathrm{E}-08$ \\
\hline 69 & 70.9 & 207.3 & 400 & 7.72 & $2.94 \mathrm{E}-02$ & 4.80E-06 & $1.67 \mathrm{E}-06$ & 0.02 & 4.92E-04 & $1.02 \mathrm{E}-09$ & $0.00 \mathrm{E}+00$ & $5.67 \mathrm{E}-10$ & $0.00 \mathrm{E}+00$ & 8.73E-09 & 7.35E-08 \\
\hline 70 & 71.7 & 207.3 & 400 & 7.62 & $2.99 \mathrm{E}-02$ & $2.82 \mathrm{E}-06$ & $1.35 \mathrm{E}-06$ & 0.01 & $4.08 \mathrm{E}-04$ & $0.00 \mathrm{E}+00$ & $0.00 \mathrm{E}+00$ & $0.00 \mathrm{E}+00$ & $0.00 \mathrm{E}+00$ & $9.31 \mathrm{E}-09$ & 7.48E-08 \\
\hline 71 & 73.0 & 207.3 & 400 & 7.54 & 2.99E-02 & $1.97 \mathrm{E}-06$ & $1.15 \mathrm{E}-06$ & 0.02 & $4.86 \mathrm{E}-04$ & $0.00 \mathrm{E}+00$ & $0.00 \mathrm{E}+00$ & $0.00 \mathrm{E}+00$ & $0.00 \mathrm{E}+00$ & $1.04 \mathrm{E}-08$ & 7.83E-08 \\
\hline
\end{tabular}




\section{B.14 Supplementary material Chapter 4, quartz experiment}

Table B.14: Full ICP and HPLC data for Chapter 4, quartz experiment.

\begin{tabular}{|c|c|c|c|c|c|c|c|c|c|c|c|c|c|}
\hline & & & & & $\mathrm{mol} / \mathrm{kg}$ & $\mathrm{mg} / \mathrm{kg}$ & $\mathrm{mg} / \mathrm{kg}$ & $\mathrm{mol} / \mathrm{kg}$ & $\mathrm{mol} / \mathrm{kg}$ & $\mathrm{mol} / \mathrm{kg}$ & $\mathrm{mol} / \mathrm{kg}$ & $\mathrm{mol} / \mathrm{kg}$ & $\mathrm{mol} / \mathrm{kg}$ \\
\hline sample & $\begin{array}{l}\text { time } \\
\text { (day) }\end{array}$ & $\begin{array}{c}\text { pressure } \\
\text { (bar) }\end{array}$ & $\begin{array}{c}\text { Temperature } \\
\left({ }^{\circ} \mathbf{C}\right)\end{array}$ & $\begin{array}{c}\text { pH } \\
25^{\circ} \mathrm{C}\end{array}$ & $\mathrm{SiO}_{2}$ & $\mathrm{Cl}^{-}$ & $\mathrm{SO}_{4}{ }^{2}-$ & 2,6-NDS & 1,5-NDS & 2,7-NDS & 1,6-NDS & 1-NSA & 2-NSA \\
\hline blank & 0.0 & - & 20.0 & 7.05 & $9.49 \mathrm{E}-06$ & 0 & 0 & 4.42E-08 & $3.84 \mathrm{E}-08$ & $3.57 \mathrm{E}-08$ & $3.48 \mathrm{E}-08$ & $0.00 \mathrm{E}+00$ & $1.67 \mathrm{E}-09$ \\
\hline 1 & 1.0 & 210.0 & 20.0 & 7.05 & $7.96 \mathrm{E}-05$ & 0.51 & 0.25 & 4.47E-08 & $3.93 \mathrm{E}-08$ & 3.63E-08 & $3.52 \mathrm{E}-08$ & $0.00 \mathrm{E}+00$ & $1.51 \mathrm{E}-09$ \\
\hline 2 & 2.0 & 210.0 & 20.0 & 7.26 & $6.87 \mathrm{E}-05$ & - & - & 4.42E-08 & $3.84 \mathrm{E}-08$ & 3.57E-08 & $3.48 \mathrm{E}-08$ & $0.00 \mathrm{E}+00$ & $1.67 \mathrm{E}-09$ \\
\hline 3 & 3.0 & 210.0 & 22.0 & 6.82 & $6.41 \mathrm{E}-05$ & - & - & 4.36E-08 & $3.81 \mathrm{E}-08$ & $3.53 \mathrm{E}-08$ & 3.44E-08 & $0.00 \mathrm{E}+00$ & $1.90 \mathrm{E}-09$ \\
\hline 4 & 4.0 & 210.0 & 22.0 & 7.09 & $5.76 \mathrm{E}-05$ & - & 0.48 & 4.27E-08 & 3.69E-08 & $3.47 \mathrm{E}-08$ & 3.34E-08 & $0.00 \mathrm{E}+00$ & 3.81E-09 \\
\hline 5 & 5.0 & 210.0 & 22.0 & 6.78 & 5.43E-05 & 0.25 & - & $4.20 \mathrm{E}-08$ & 3.68E-08 & $3.41 \mathrm{E}-08$ & 3.30E-08 & $0.00 \mathrm{E}+00$ & 7.60E-10 \\
\hline 6 & 6.0 & 210.0 & 22.0 & 6.97 & $5.39 \mathrm{E}-05$ & - & - & 4.19E-08 & 3.63E-08 & $3.40 \mathrm{E}-08$ & 3.26E-08 & $0.00 \mathrm{E}+00$ & $1.53 \mathrm{E}-09$ \\
\hline 7 & 7.0 & 210.0 & 22.0 & 6.62 & 4.09E-05 & - & - & 4.06E-08 & $3.51 \mathrm{E}-08$ & $3.30 \mathrm{E}-08$ & 3.13E-08 & $0.00 \mathrm{E}+00$ & $9.74 \mathrm{E}-10$ \\
\hline 8 & 8.0 & 210.0 & 100.0 & 6.96 & $1.15 \mathrm{E}-03$ & - & - & 3.82E-08 & 3.31E-08 & $3.13 \mathrm{E}-08$ & $3.11 \mathrm{E}-08$ & $0.00 \mathrm{E}+00$ & 3.14E-09 \\
\hline 9 & 9.0 & 210.0 & 100.0 & 6.40 & $5.24 \mathrm{E}-04$ & - & 1.1 & $3.83 \mathrm{E}-08$ & $3.29 \mathrm{E}-08$ & 3.12E-08 & 3.02E-08 & $0.00 \mathrm{E}+00$ & $0.00 \mathrm{E}+00$ \\
\hline 10 & 10.0 & 210.0 & 99.0 & 6.54 & 3.02E-04 & 0.13 & - & $3.59 \mathrm{E}-08$ & $3.13 \mathrm{E}-08$ & $2.91 \mathrm{E}-08$ & 2.77E-08 & $0.00 \mathrm{E}+00$ & $1.51 \mathrm{E}-09$ \\
\hline 11 & 11.0 & 210.0 & 99.0 & 6.65 & $2.21 \mathrm{E}-04$ & - & - & $3.44 \mathrm{E}-08$ & 2.87E-08 & 2.79E-08 & 2.63E-08 & $1.58 \mathrm{E}-09$ & $1.91 \mathrm{E}-09$ \\
\hline 12 & 12.0 & 210.0 & 99.0 & 6.72 & $1.55 \mathrm{E}-04$ & - & - & 3.42E-08 & $2.96 \mathrm{E}-08$ & 2.77E-08 & 2.59E-08 & $0.00 \mathrm{E}+00$ & 1.49E-09 \\
\hline 14 & 14.0 & 210.0 & 99.0 & 6.84 & 1.05E-04 & - & 1.4 & 3.30E-08 & $2.88 \mathrm{E}-08$ & 2.69E-08 & 2.57E-08 & $0.00 \mathrm{E}+00$ & $1.75 \mathrm{E}-09$ \\
\hline 15 & 15.0 & 210.0 & 149.0 & 6.69 & 4.55E-04 & - & - & 3.15E-08 & $2.75 \mathrm{E}-08$ & $2.57 \mathrm{E}-08$ & 2.44E-08 & $0.00 \mathrm{E}+00$ & 6.91E-10 \\
\hline 16 & 16.0 & 210.0 & 150.0 & 6.61 & 7.84E-04 & - & - & 3.09E-08 & 2.75E-08 & $2.52 \mathrm{E}-08$ & $2.44 \mathrm{E}-08$ & $0.00 \mathrm{E}+00$ & $9.72 \mathrm{E}-10$ \\
\hline 17 & 17.0 & 210.0 & 150.0 & 6.60 & $8.53 \mathrm{E}-04$ & - & - & 2.94E-08 & 2.62E-08 & $2.41 \mathrm{E}-08$ & 2.34E-08 & $0.00 \mathrm{E}+00$ & $1.20 \mathrm{E}-09$ \\
\hline 18 & 18.0 & 210.0 & 150.0 & 6.60 & $8.70 \mathrm{E}-04$ & - & - & $2.80 \mathrm{E}-08$ & 2.52E-08 & $2.44 \mathrm{E}-08$ & 2.23E-08 & $0.00 \mathrm{E}+00$ & $1.68 \mathrm{E}-09$ \\
\hline 19 & 19.0 & 210.0 & 150.0 & 6.45 & $9.05 \mathrm{E}-04$ & - & 1.7 & $2.76 \mathrm{E}-08$ & $2.51 \mathrm{E}-08$ & $2.25 \mathrm{E}-08$ & 2.19E-08 & $0.00 \mathrm{E}+00$ & $8.12 \mathrm{E}-10$ \\
\hline 20 & 20.0 & 210.0 & 150.0 & 6.58 & $9.02 \mathrm{E}-04$ & 0.05 & - & $2.82 \mathrm{E}-08$ & 2.53E-08 & $2.31 \mathrm{E}-08$ & 2.22E-08 & $0.00 \mathrm{E}+00$ & 3.35E-10 \\
\hline 22 & 21.0 & 210.0 & 150.0 & 6.38 & $8.75 \mathrm{E}-04$ & - & 1.7 & $2.77 \mathrm{E}-08$ & $2.47 \mathrm{E}-08$ & $2.26 \mathrm{E}-08$ & $2.15 \mathrm{E}-08$ & $0.00 \mathrm{E}+00$ & $5.47 \mathrm{E}-10$ \\
\hline 23 & 22.0 & 210.0 & 200.0 & 6.58 & $2.34 \mathrm{E}-03$ & 0.17 & - & $2.73 \mathrm{E}-08$ & $2.39 \mathrm{E}-08$ & $2.23 \mathrm{E}-08$ & $2.12 \mathrm{E}-08$ & $0.00 \mathrm{E}+00$ & 1.04E-09 \\
\hline 23 & 23.0 & 210.0 & 200.0 & 6.31 & $3.77 \mathrm{E}-03$ & - & - & $2.98 \mathrm{E}-08$ & $2.51 \mathrm{E}-08$ & $2.44 \mathrm{E}-08$ & $2.26 \mathrm{E}-08$ & 1.10E-09 & $1.54 \mathrm{E}-09$ \\
\hline 24 & 24.0 & 210.0 & 200.0 & 5.85 & $4.08 \mathrm{E}-03$ & - & 1.7 & $2.96 \mathrm{E}-08$ & $2.45 \mathrm{E}-08$ & $2.44 \mathrm{E}-08$ & 2.27E-08 & $0.00 \mathrm{E}+00$ & 1.39E-09 \\
\hline
\end{tabular}




\begin{tabular}{|c|c|c|c|c|c|c|c|c|c|c|c|c|c|}
\hline & & & & & $\mathrm{mol} / \mathrm{kg}$ & $\mathrm{mg} / \mathrm{kg}$ & $\mathrm{mg} / \mathrm{kg}$ & $\mathrm{mol} / \mathrm{kg}$ & $\mathrm{mol} / \mathrm{kg}$ & $\mathrm{mol} / \mathrm{kg}$ & $\mathrm{mol} / \mathrm{kg}$ & $\mathrm{mol} / \mathrm{kg}$ & $\mathrm{mol} / \mathrm{kg}$ \\
\hline sample & $\begin{array}{l}\text { time } \\
\text { (day) }\end{array}$ & $\begin{array}{c}\text { pressure } \\
\text { (bar) }\end{array}$ & $\begin{array}{c}\text { Temperature } \\
\left({ }^{\circ} \mathbf{C}\right)\end{array}$ & $\begin{array}{c}\mathbf{p H} \\
25^{\circ} \mathrm{C}\end{array}$ & $\mathrm{SiO}_{2}$ & $\mathrm{Cl}^{-}$ & $\mathrm{SO}_{4}{ }^{2-}$ & 2,6-NDS & 1,5-NDS & 2,7-NDS & 1,6-NDS & 1-NSA & 2-NSA \\
\hline 25 & 25.0 & 210.0 & 200.0 & 5.83 & $2.99 \mathrm{E}-03$ & 0.08 & - & $2.89 \mathrm{E}-08$ & $2.28 \mathrm{E}-08$ & 2.39E-08 & $2.17 \mathrm{E}-08$ & 3.27E-09 & $5.00 \mathrm{E}-09$ \\
\hline 26 & 26.0 & 210.0 & 200.0 & 5.91 & 3.94E-03 & - & - & 2.93E-08 & 2.37E-08 & $2.41 \mathrm{E}-08$ & $2.18 \mathrm{E}-08$ & $2.15 \mathrm{E}-09$ & 2.09E-09 \\
\hline 27 & 27.0 & 210.0 & 199.0 & 5.66 & 4.16E-03 & - & - & $2.80 \mathrm{E}-08$ & 2.30E-08 & 2.32E-08 & $2.12 \mathrm{E}-08$ & $1.17 \mathrm{E}-09$ & $1.32 \mathrm{E}-09$ \\
\hline 28 & 28.0 & 240.0 & 201.0 & 6.00 & 3.95E-03 & - & - & $2.76 \mathrm{E}-08$ & 2.27E-08 & $2.27 \mathrm{E}-08$ & $2.08 \mathrm{E}-08$ & $1.22 \mathrm{E}-09$ & $1.13 \mathrm{E}-09$ \\
\hline 29 & 29.0 & 240.0 & 200.0 & 5.66 & $4.26 \mathrm{E}-03$ & - & 1.3 & $2.72 \mathrm{E}-08$ & $2.19 \mathrm{E}-08$ & 2.24E-08 & $2.02 \mathrm{E}-08$ & $9.39 \mathrm{E}-10$ & $1.14 \mathrm{E}-09$ \\
\hline 31 & 31.0 & 240.0 & 250.0 & 6.08 & $9.65 \mathrm{E}-03$ & - & - & $2.15 \mathrm{E}-08$ & 8.36E-09 & $1.91 \mathrm{E}-08$ & $1.18 \mathrm{E}-08$ & 9.55E-09 & $2.30 \mathrm{E}-08$ \\
\hline 32 & 32.0 & 240.0 & 250.0 & 5.86 & $8.18 \mathrm{E}-03$ & - & - & $1.52 \mathrm{E}-08$ & 3.91E-09 & $1.47 \mathrm{E}-08$ & 7.49E-09 & $8.69 \mathrm{E}-09$ & $2.41 \mathrm{E}-08$ \\
\hline 33 & 33.0 & 240.0 & 250.0 & 5.72 & $8.14 \mathrm{E}-03$ & - & - & $1.58 \mathrm{E}-08$ & 4.32E-09 & $1.51 \mathrm{E}-08$ & 7.78E-09 & 7.92E-09 & 2.23E-08 \\
\hline 34 & 34.0 & 240.0 & 250.0 & 5.71 & $8.19 \mathrm{E}-03$ & - & 1.2 & 1.60E-08 & 4.55E-09 & $1.72 \mathrm{E}-08$ & 8.04E-09 & $8.42 \mathrm{E}-09$ & $2.31 \mathrm{E}-08$ \\
\hline 35 & 35.0 & 240.0 & 250.0 & 5.72 & $8.22 \mathrm{E}-03$ & 0.26 & - & $1.60 \mathrm{E}-08$ & 4.26E-09 & $1.55 \mathrm{E}-08$ & 7.86E-09 & 8.01E-09 & $2.68 \mathrm{E}-08$ \\
\hline 36 & 36.0 & 240.0 & 300.0 & 5.74 & 7.12E-03 & - & - & 4.41E-09 & $8.90 \mathrm{E}-10$ & 5.07E-09 & 2.00E-09 & 3.46E-09 & $1.73 \mathrm{E}-08$ \\
\hline 37 & 37.0 & 240.0 & 300.0 & 5.82 & 3.63E-03 & - & 0.76 & 4.53E-09 & 1.99E-09 & 4.92E-09 & 2.39E-09 & 4.21E-09 & $2.04 \mathrm{E}-08$ \\
\hline 38 & 39.0 & 240.0 & 300.0 & 5.73 & $2.46 \mathrm{E}-04$ & - & 0.57 & $3.21 \mathrm{E}-08$ & 8.44E-09 & $2.75 \mathrm{E}-08$ & 1.42E-08 & 2.89E-08 & 4.04E-08 \\
\hline 39 & 40.0 & 240.0 & 300.0 & 5.37 & $9.01 \mathrm{E}-03$ & 0.23 & - & $3.08 \mathrm{E}-08$ & $1.38 \mathrm{E}-10$ & $2.69 \mathrm{E}-08$ & $6.71 \mathrm{E}-09$ & 4.18E-08 & $7.58 \mathrm{E}-08$ \\
\hline 40 & 41.0 & 240.0 & 300.0 & 5.50 & $1.45 \mathrm{E}-02$ & - & - & 3.53E-08 & 2.19E-09 & 3.05E-08 & $1.43 \mathrm{E}-08$ & 4.09E-08 & 4.54E-08 \\
\hline 41 & 42.0 & 240.0 & 300.0 & 5.36 & $1.46 \mathrm{E}-02$ & - & - & 3.84E-08 & 3.30E-09 & 3.32E-08 & $1.70 \mathrm{E}-08$ & 4.27E-08 & 3.94E-08 \\
\hline 42 & 43.0 & 240.0 & 300.0 & 5.43 & $1.35 \mathrm{E}-02$ & - & - & $3.83 \mathrm{E}-08$ & $4.20 \mathrm{E}-09$ & $3.29 \mathrm{E}-08$ & $1.74 \mathrm{E}-08$ & 4.50E-08 & 3.37E-08 \\
\hline 43 & 44.0 & 240.0 & 300.0 & 5.35 & $1.28 \mathrm{E}-02$ & - & - & $3.80 \mathrm{E}-08$ & 4.93E-09 & $3.28 \mathrm{E}-08$ & $1.82 \mathrm{E}-08$ & 4.06E-08 & $3.16 \mathrm{E}-08$ \\
\hline 44 & 45.0 & 240.0 & 300.0 & 5.54 & $1.18 \mathrm{E}-02$ & - & 0.53 & 3.78E-08 & $5.36 \mathrm{E}-09$ & 3.23E-08 & 1.79E-08 & 3.94E-08 & 8.49E-08 \\
\hline 45 & 46.0 & 311.0 & 350.0 & 5.71 & $1.17 \mathrm{E}-02$ & 0.32 & - & 4.76E-09 & $0.00 \mathrm{E}+00$ & $4.21 \mathrm{E}-09$ & $1.01 \mathrm{E}-09$ & 8.47E-09 & $1.01 \mathrm{E}-07$ \\
\hline 46 & 47.0 & 311.0 & 350.0 & 5.64 & $9.67 \mathrm{E}-03$ & - & - & $6.06 \mathrm{E}-10$ & $0.00 \mathrm{E}+00$ & $3.86 \mathrm{E}-10$ & $0.00 \mathrm{E}+00$ & $1.59 \mathrm{E}-08$ & $1.05 \mathrm{E}-07$ \\
\hline 47 & 48.0 & 311.0 & 350.0 & 5.24 & $1.03 \mathrm{E}-02$ & - & - & $6.05 \mathrm{E}-10$ & $0.00 \mathrm{E}+00$ & $6.81 \mathrm{E}-10$ & $0.00 \mathrm{E}+00$ & 2.09E-09 & $9.36 \mathrm{E}-08$ \\
\hline 48 & 49.0 & 311.0 & 350.0 & 5.31 & $1.29 \mathrm{E}-02$ & - & - & $6.84 \mathrm{E}-10$ & $0.00 \mathrm{E}+00$ & $6.87 \mathrm{E}-10$ & $0.00 \mathrm{E}+00$ & 2.62E-09 & 9.09E-08 \\
\hline 49 & 50.0 & 311.0 & 350.0 & 5.25 & $4.46 \mathrm{E}-03$ & - & - & $7.36 \mathrm{E}-10$ & $0.00 \mathrm{E}+00$ & $6.49 \mathrm{E}-10$ & $0.00 \mathrm{E}+00$ & 2.64E-09 & $9.68 \mathrm{E}-08$ \\
\hline 50 & 51.0 & 311.0 & 350.0 & 5.28 & 8.33E-03 & 0.05 & 0.7 & 7.77E-10 & $0.00 \mathrm{E}+00$ & $6.33 \mathrm{E}-10$ & $0.00 \mathrm{E}+00$ & $2.52 \mathrm{E}-09$ & 8.35E-08 \\
\hline 51 & 52.0 & 311.0 & 350.0 & 5.01 & $8.30 \mathrm{E}-03$ & - & - & $9.64 \mathrm{E}-10$ & $0.00 \mathrm{E}+00$ & $7.66 \mathrm{E}-10$ & $0.00 \mathrm{E}+00$ & $3.15 \mathrm{E}-09$ & $9.68 \mathrm{E}-08$ \\
\hline
\end{tabular}




\begin{tabular}{|c|c|c|c|c|c|c|c|c|c|c|c|c|c|}
\hline & & & & & $\mathrm{mol} / \mathrm{kg}$ & $\mathrm{mg} / \mathrm{kg}$ & $\mathrm{mg} / \mathrm{kg}$ & $\mathrm{mol} / \mathrm{kg}$ & $\mathrm{mol} / \mathrm{kg}$ & $\mathrm{mol} / \mathrm{kg}$ & $\mathrm{mol} / \mathrm{kg}$ & $\mathrm{mol} / \mathrm{kg}$ & $\mathrm{mol} / \mathrm{kg}$ \\
\hline sample & $\begin{array}{l}\text { time } \\
\text { (day) }\end{array}$ & $\begin{array}{c}\text { pressure } \\
\text { (bar) }\end{array}$ & $\begin{array}{c}\text { Temperature } \\
\left({ }^{\circ} \mathbf{C}\right)\end{array}$ & $\begin{array}{c}\mathbf{p H} \\
25^{\circ} \mathrm{C}\end{array}$ & $\mathrm{SiO}_{2}$ & $\mathrm{Cl}^{-}$ & $\mathrm{SO}_{4}{ }^{2-}$ & 2,6-NDS & 1,5-NDS & 2,7-NDS & 1,6-NDS & 1-NSA & 2-NSA \\
\hline 53 & 54.0 & 311.0 & 350.0 & 5.11 & $8.34 \mathrm{E}-03$ & - & - & $1.96 \mathrm{E}-09$ & $0.00 \mathrm{E}+00$ & $1.61 \mathrm{E}-09$ & $0.00 \mathrm{E}+00$ & 4.49E-09 & $4.63 \mathrm{E}-08$ \\
\hline 54 & 55.0 & 311.0 & 350.0 & 5.51 & $8.31 \mathrm{E}-03$ & - & - & $1.40 \mathrm{E}-08$ & $0.00 \mathrm{E}+00$ & $1.13 \mathrm{E}-08$ & $7.61 \mathrm{E}-10$ & 2.19E-08 & $3.26 \mathrm{E}-08$ \\
\hline 55 & 56.0 & 311.0 & 350.0 & 5.00 & $8.31 \mathrm{E}-03$ & 0.09 & 0.44 & $6.93 \mathrm{E}-10$ & $0.00 \mathrm{E}+00$ & $6.23 \mathrm{E}-10$ & $0.00 \mathrm{E}+00$ & 4.72E-09 & $3.61 \mathrm{E}-08$ \\
\hline 56 & 57.0 & 311.0 & 350.0 & 5.00 & $8.31 \mathrm{E}-03$ & - & - & $0.00 \mathrm{E}+00$ & $0.00 \mathrm{E}+00$ & $0.00 \mathrm{E}+00$ & $0.00 \mathrm{E}+00$ & $0.00 \mathrm{E}+00$ & $3.61 \mathrm{E}-08$ \\
\hline 57 & 58.0 & 311.0 & 350.0 & 5.05 & 8.36E-03 & - & - & $0.00 \mathrm{E}+00$ & $0.00 \mathrm{E}+00$ & $0.00 \mathrm{E}+00$ & $0.00 \mathrm{E}+00$ & $0.00 \mathrm{E}+00$ & $3.78 \mathrm{E}-08$ \\
\hline 59 & 60.0 & 311.0 & 350.0 & 5.36 & $2.00 \mathrm{E}-02$ & - & - & $0.00 \mathrm{E}+00$ & $0.00 \mathrm{E}+00$ & $0.00 \mathrm{E}+00$ & $0.00 \mathrm{E}+00$ & $0.00 \mathrm{E}+00$ & 3.99E-08 \\
\hline 60 & 61.0 & 414.0 & 400.0 & 4.93 & $1.23 \mathrm{E}-02$ & - & - & $0.00 \mathrm{E}+00$ & $0.00 \mathrm{E}+00$ & $0.00 \mathrm{E}+00$ & $0.00 \mathrm{E}+00$ & $0.00 \mathrm{E}+00$ & $4.08 \mathrm{E}-08$ \\
\hline 61 & 62.0 & 414.0 & 400.0 & 5.03 & $1.27 \mathrm{E}-02$ & 0.9 & 0.3 & $0.00 \mathrm{E}+00$ & $0.00 \mathrm{E}+00$ & $0.00 \mathrm{E}+00$ & $0.00 \mathrm{E}+00$ & $0.00 \mathrm{E}+00$ & $3.87 \mathrm{E}-08$ \\
\hline
\end{tabular}


Table B.15a: Full HPLC data for Chapter 6, 1,6-NDS decomposition.

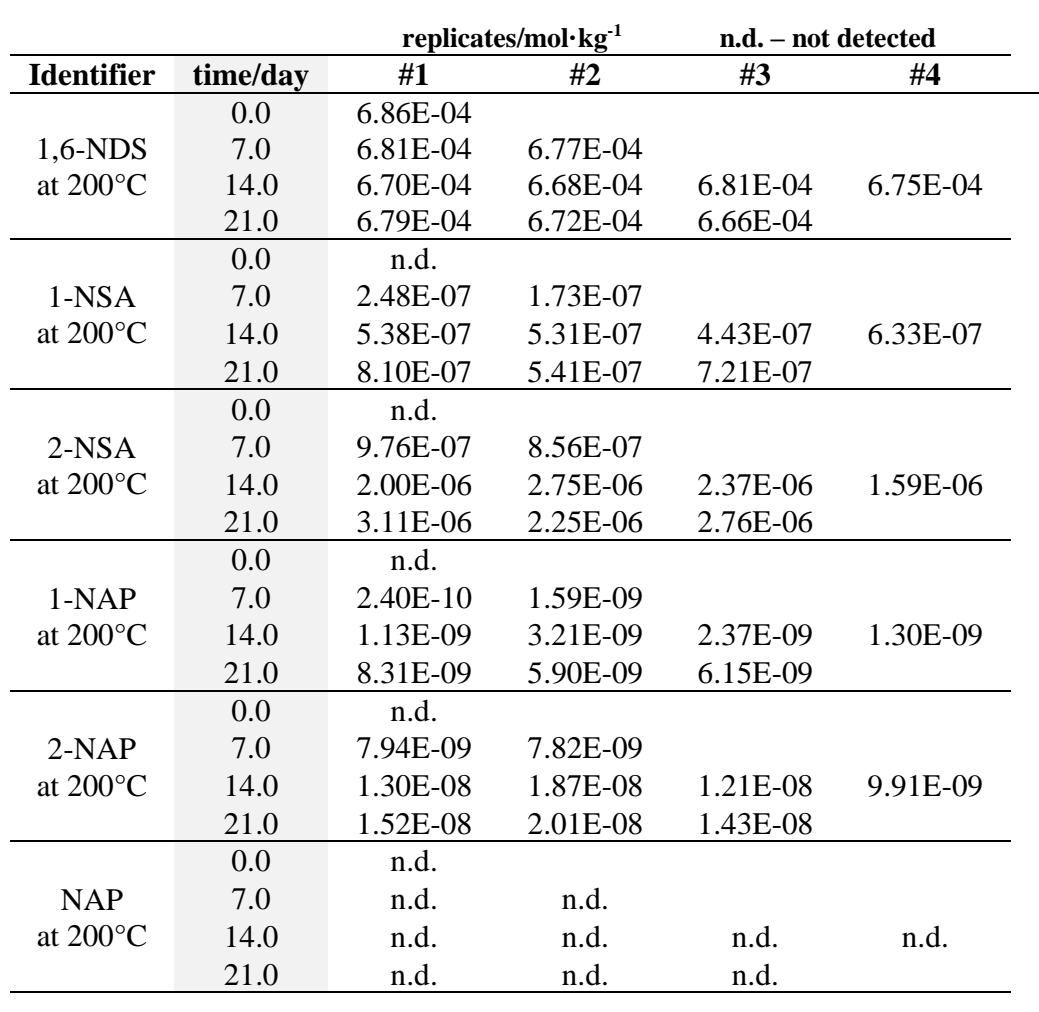

\begin{tabular}{|c|c|c|c|c|}
\hline Identifier & time/daw & repis & 8 & detected \\
\hline \multirow{4}{*}{$\begin{array}{l}\text { 1,6-NDS } \\
\text { at } 250^{\circ} \mathrm{C}\end{array}$} & 0.0 & $6.86 \mathrm{E}-04$ & & \\
\hline & 7.0 & 6.61E-04 & 6.46E-04 & \\
\hline & 14.0 & $5.80 \mathrm{E}-04$ & $5.71 \mathrm{E}-04$ & $5.71 \mathrm{E}-04$ \\
\hline & 21.0 & $4.04 \mathrm{E}-04$ & $3.47 \mathrm{E}-04$ & $2.73 \mathrm{E}-04$ \\
\hline \multirow{4}{*}{$\begin{array}{c}\text { 1-NSA } \\
\text { at } 250^{\circ} \mathrm{C}\end{array}$} & 0.0 & n.d. & & \\
\hline & 7.0 & $2.50 \mathrm{E}-07$ & $3.12 \mathrm{E}-07$ & \\
\hline & 14.0 & 4.67E-07 & 4.02E-07 & $5.30 \mathrm{E}-07$ \\
\hline & 21.0 & $6.93 \mathrm{E}-07$ & $6.36 \mathrm{E}-07$ & $5.49 \mathrm{E}-07$ \\
\hline \multirow{4}{*}{$\begin{array}{c}\text { 2-NSA } \\
\text { at } 250^{\circ} \mathrm{C}\end{array}$} & 0.0 & n.d. & & \\
\hline & 7.0 & $3.37 \mathrm{E}-05$ & 3.57E-05 & \\
\hline & 14.0 & $1.14 \mathrm{E}-04$ & $1.36 \mathrm{E}-04$ & $1.37 \mathrm{E}-04$ \\
\hline & 21.0 & 2.62E-04 & $2.35 \mathrm{E}-04$ & 2.00E-04 \\
\hline \multirow{4}{*}{$\begin{array}{c}\text { 1-NAP } \\
\text { at } 250^{\circ} \mathrm{C}\end{array}$} & 0.0 & & & \\
\hline & 7.0 & $9.23 \mathrm{E}-09$ & $9.02 \mathrm{E}-09$ & \\
\hline & 14.0 & $1.20 \mathrm{E}-08$ & $1.34 \mathrm{E}-08$ & $1.48 \mathrm{E}-08$ \\
\hline & 21.0 & $3.27 \mathrm{E}-07$ & 2.36E-07 & $3.93 \mathrm{E}-07$ \\
\hline \multirow{4}{*}{$\begin{array}{l}\text { 2-NAP } \\
\text { at } 250^{\circ} \mathrm{C}\end{array}$} & 0.0 & n.d. & & \\
\hline & 7.0 & $2.77 \mathrm{E}-07$ & $6.94 \mathrm{E}-08$ & \\
\hline & 14.0 & 2.08E-07 & 2.78E-07 & $2.08 \mathrm{E}-07$ \\
\hline & 21.0 & $1.18 \mathrm{E}-06$ & $9.02 \mathrm{E}-07$ & \\
\hline \multirow{4}{*}{$\begin{array}{c}\text { NAP } \\
\text { at } 250^{\circ} \mathrm{C}\end{array}$} & 0.0 & & & \\
\hline & 7.0 & $2.34 \mathrm{E}$ & $7.80 \mathrm{E}-08$ & \\
\hline & 14.0 & $1.25 \mathrm{E}-06$ & $1.64 \mathrm{E}-06$ & $1.64 \mathrm{E}-06$ \\
\hline & 21.0 & $3.98 \mathrm{E}-06$ & 4.34E- 06 & $5.54 \mathrm{E}-06$ \\
\hline
\end{tabular}

Table B.15b: Full HPLC data for Chapter 6, 1,5-NDS decomposition.

\begin{tabular}{|c|c|c|c|c|}
\hline \multirow{6}{*}{$\begin{array}{l}\text { Identifier } \\
1,5-\mathrm{NDS} \\
\text { at } 200^{\circ} \mathrm{C}\end{array}$} & \multirow{2}{*}{ time/day } & \multicolumn{2}{|c|}{ replicates $/ \mathbf{m o l}^{\prime} \cdot \mathrm{kg}^{-1}$} & \multirow{2}{*}{$\frac{. \text { d. }- \text { not detecte }}{\# 3}$} \\
\hline & & & $\# 2$ & \\
\hline & 0.0 & $6.84 \mathrm{E}-04$ & & \\
\hline & 7.0 & $6.84 \mathrm{E}-04$ & $6.72 \mathrm{E}-04$ & $6.72 \mathrm{E}-04$ \\
\hline & 14.0 & $6.59 \mathrm{E}-04$ & $6.59 \mathrm{E}-04$ & $6.68 \mathrm{E}-04$ \\
\hline & 21.0 & $6.43 \mathrm{E}-04$ & $6.35 \mathrm{E}-04$ & \\
\hline $1-\mathrm{NSA}$ & 0.0 & n.d. & & \\
\hline at $200^{\circ} \mathrm{C}$ & 7.0 & $1.41 \mathrm{E}-05$ & $1.41 \mathrm{E}-05$ & $2.73 \mathrm{E}-06$ \\
\hline & 14.0 & 3.35E-05 & $2.53 \mathrm{E}-05$ & $1.42 \mathrm{E}-05$ \\
\hline & 21.0 & $5.27 \mathrm{E}-05$ & $6.87 \mathrm{E}-05$ & \\
\hline 2-NSA & 0.0 & n.d. & & \\
\hline at $200^{\circ} \mathrm{C}$ & 7.0 & n.d. & n.d. & n.d. \\
\hline & 14.0 & n.d. & n.d. & n.d. \\
\hline & 21.0 & n.d. & n.d. & \\
\hline 1-NAP & 0.0 & n.d. & & \\
\hline at $200^{\circ} \mathrm{C}$ & 7.0 & 3.97E-07 & $4.60 \mathrm{E}-07$ & $5.13 \mathrm{E}-07$ \\
\hline & 14.0 & 8.93E-07 & $9.18 \mathrm{E}-07$ & $1.21 \mathrm{E}-06$ \\
\hline & 21.0 & $3.22 \mathrm{E}-06$ & $2.27 \mathrm{E}-06$ & \\
\hline & 0.0 & & & \\
\hline at $200^{\circ} \mathrm{C}$ & 7.0 & $1.39 \mathrm{E}-09$ & $1.39 \mathrm{E}-09$ & \\
\hline & 14.0 & 2.08E-09 & $6.94 \mathrm{E}-10$ & $4.16 \mathrm{E}-09$ \\
\hline & 21.0 & $3.47 \mathrm{E}-09$ & $3.47 \mathrm{E}-09$ & \\
\hline & 0.0 & - & & \\
\hline at $200^{\circ} \mathrm{C}$ & 7.0 & $8.58 \mathrm{E}-09$ & $1.17 \mathrm{E}-08$ & $2.60 \mathrm{E}-08$ \\
\hline & 14.0 & 3.33E-08 & 2.03E-08 & $3.02 \mathrm{E}-08$ \\
\hline & 21.0 & 4.42E-08 & 4.26E-08 & \\
\hline
\end{tabular}

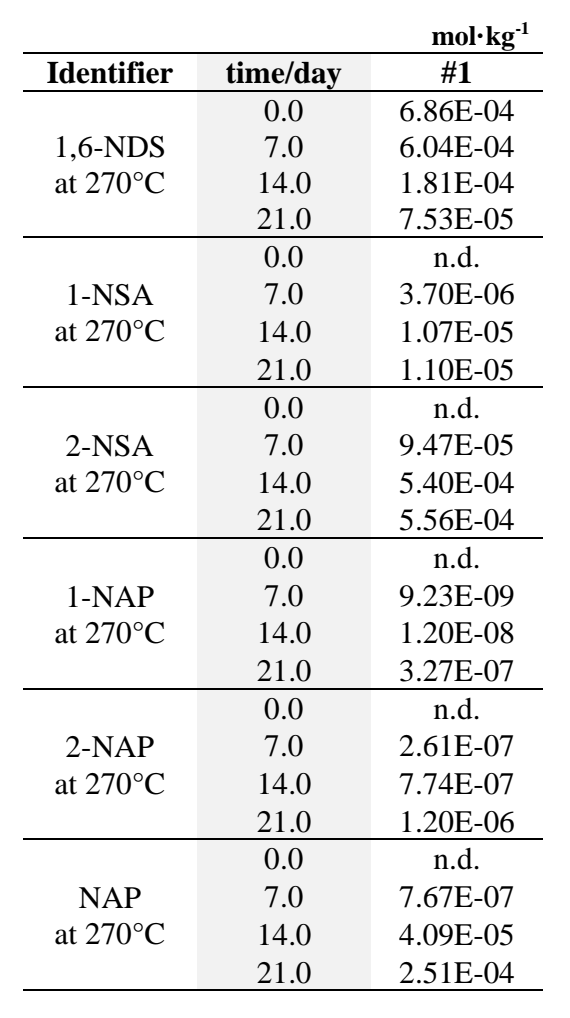

\begin{tabular}{|c|c|c|c|c|}
\hline \multirow{2}{*}{ Identifier } & \multirow[b]{2}{*}{ time/day } & \multicolumn{3}{|c|}{$\begin{array}{lll}\text { replicates } / \mathbf{m o l} \cdot \mathrm{kg}^{-1} & \text { n.d. }- \text { not detected }\end{array}$} \\
\hline & & & $\# 2$ & \multirow{5}{*}{$1.08 \mathrm{E}-06$} \\
\hline \multirow{4}{*}{$\begin{array}{l}\text { 1,6-NDS } \\
\text { at } 300^{\circ} \mathrm{C}\end{array}$} & 0.0 & $6.86 \mathrm{E}-04$ & & \\
\hline & 7.0 & $5.50 \mathrm{E}-05$ & $2.52 \mathrm{E}-05$ & \\
\hline & 14.0 & $3.49 \mathrm{E}-08$ & $3.49 \mathrm{E}-08$ & \\
\hline & 21.0 & $3.49 \mathrm{E}-09$ & $3.49 \mathrm{E}-09$ & \\
\hline \multirow{4}{*}{$\begin{array}{c}1-\mathrm{NSA} \\
\text { at } 300^{\circ} \mathrm{C}\end{array}$} & 0.0 & & & \multirow{4}{*}{$3.91 \mathrm{E}-06$} \\
\hline & 7.0 & $4.58 \mathrm{E}-06$ & $1.02 \mathrm{E}-05$ & \\
\hline & 14.0 & $1.45 \mathrm{E}-05$ & $1.08 \mathrm{E}-05$ & \\
\hline & 21.0 & $5.07 \mathrm{E}-06$ & $8.93 \mathrm{E}-06$ & \\
\hline \multirow{4}{*}{$\begin{array}{c}\text { 2-NSA } \\
\text { at } 300^{\circ} \mathrm{C}\end{array}$} & 0.0 & n.d. & & \multirow{4}{*}{$4.39 \mathrm{E}-04$} \\
\hline & 7.0 & $4.59 \mathrm{E}-04$ & $4.08 \mathrm{E}-04$ & \\
\hline & 14.0 & $5.71 \mathrm{E}-04$ & $5.23 \mathrm{E}-04$ & \\
\hline & 21.0 & $6.34 \mathrm{E}-05$ & $8.44 \mathrm{E}-05$ & \\
\hline \multirow{4}{*}{$\begin{array}{l}\text { 1-NAP } \\
\text { at } 300^{\circ} \mathrm{C}\end{array}$} & 0.0 & n.d. & & \multirow{4}{*}{$\begin{array}{l}2.76 \mathrm{E}-09 \\
4.44 \mathrm{E}-08 \\
7.48 \mathrm{E}-07\end{array}$} \\
\hline & 7.0 & $5.90 \mathrm{E}-09$ & $1.46 \mathrm{E}-09$ & \\
\hline & 14.0 & $8.39 \mathrm{E}-08$ & $1.79 \mathrm{E}-07$ & \\
\hline & 21.0 & $5.54 \mathrm{E}-07$ & $8.39 \mathrm{E}-07$ & \\
\hline \multirow{4}{*}{$\begin{array}{l}\text { 2-NAP } \\
\text { at } 300^{\circ} \mathrm{C}\end{array}$} & 0.0 & & & \multirow{4}{*}{$1.91 \mathrm{E}-06$} \\
\hline & 7.0 & $7.63 \mathrm{E}-07$ & $1.29 \mathrm{E}-06$ & \\
\hline & 14.0 & $2.43 \mathrm{E}-06$ & $1.80 \mathrm{E}-06$ & \\
\hline & 21.0 & $3.53 \mathrm{E}-06$ & $2.57 \mathrm{E}-06$ & \\
\hline \multirow{4}{*}{$\begin{array}{c}\text { NAP } \\
\text { at } 300^{\circ} \mathrm{C}\end{array}$} & 0.0 & n.d. & & \multirow{4}{*}{$1.77 \mathrm{E}-04$} \\
\hline & 7.0 & $1.71 \mathrm{E}-04$ & $1.50 \mathrm{E}-04$ & \\
\hline & 14.0 & $2.05 \mathrm{E}-04$ & $2.08 \mathrm{E}-04$ & \\
\hline & 21.0 & $2.30 \mathrm{E}-04$ & $2.78 \mathrm{E}-04$ & \\
\hline
\end{tabular}

\begin{tabular}{|c|c|c|c|}
\hline & \multicolumn{2}{|c|}{ replicates $/ \mathrm{mol}^{-\mathrm{kg}^{-1}}$} & \multirow{2}{*}{$\frac{\text { n.d. }- \text { not detected }}{\# 2}$} \\
\hline Identifier & time/day & $\# 1$ & \\
\hline \multirow{4}{*}{$\begin{array}{l}1,5-\mathrm{NDS} \\
\text { at } 300^{\circ} \mathrm{C}\end{array}$} & 0.0 & $6.84 \mathrm{E}-04$ & \\
\hline & 7.0 & $2.42 \mathrm{E}-05$ & \\
\hline & 14.0 & $8.55 \mathrm{E}-07$ & \\
\hline & 21.0 & $1.07 \mathrm{E}-09$ & $9.41 \mathrm{E}-10$ \\
\hline \multirow{4}{*}{$\begin{array}{l}\text { 1-NSA } \\
\text { at } 300^{\circ} \mathrm{C}\end{array}$} & 0.0 & n.d. & \\
\hline & 7.0 & n.d. & \\
\hline & 14.0 & n.d. & \\
\hline & 21.0 & n.d. & n.d. \\
\hline \multirow{4}{*}{$\begin{array}{l}\text { 2-NSA } \\
\text { at } 300^{\circ} \mathrm{C}\end{array}$} & 0.0 & n.d. & \\
\hline & 7.0 & n.d. & \\
\hline & 14.0 & n.d. & \\
\hline & 21.0 & n.d. & n.d. \\
\hline \multirow{4}{*}{$\begin{array}{l}\text { 1-NAP } \\
\text { at } 300^{\circ} \mathrm{C}\end{array}$} & 0.0 & n.d. & \\
\hline & 7.0 & $3.31 \mathrm{E}-06$ & \\
\hline & 14.0 & $3.91 \mathrm{E}-06$ & \\
\hline & 21.0 & 3.91E-06 & $3.53 \mathrm{E}-06$ \\
\hline \multirow{4}{*}{$\begin{array}{l}\text { 2-NAP } \\
\text { at } 300^{\circ} \mathrm{C}\end{array}$} & 0.0 & & \\
\hline & 7.0 & $2.75 \mathrm{E}-07$ & \\
\hline & 14.0 & $4.79 \mathrm{E}-07$ & \\
\hline & 21.0 & $5.97 \mathrm{E}-08$ & $6.80 \mathrm{E}-08$ \\
\hline \multirow{4}{*}{$\begin{array}{l}\text { NAP } \\
\text { at } 300^{\circ} \mathrm{C}\end{array}$} & 0.0 & n.d. & \\
\hline & 7.0 & $2.14 \mathrm{E}-04$ & \\
\hline & 14.0 & $2.16 \mathrm{E}-04$ & \\
\hline & 21.0 & 2.13E-04 & $2.17 \mathrm{E}-04$ \\
\hline
\end{tabular}




\section{B.16 Supplementary material to Chapter 7}

B.16 Supplementary material Chapter 7, adsorption experiments
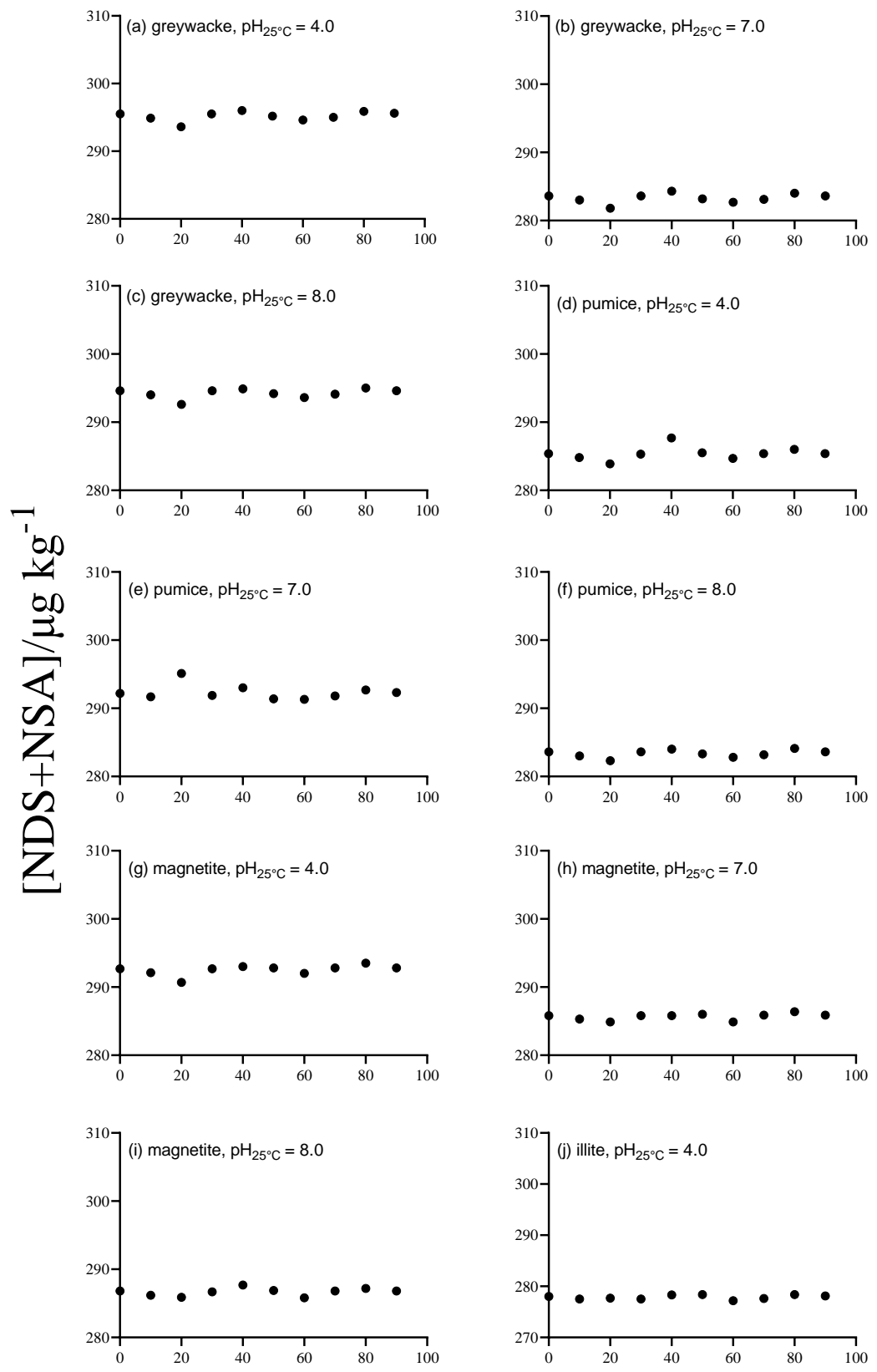

time/minute

Figure B.16a: Batch adsorption experimental results. Total concentration of naphthalene disulfonates and naphthalene sulfonates $\left(\mu \mathrm{g} \mathrm{kg}^{-1}\right)$ after time (minutes) in presence of different solid substrate. 

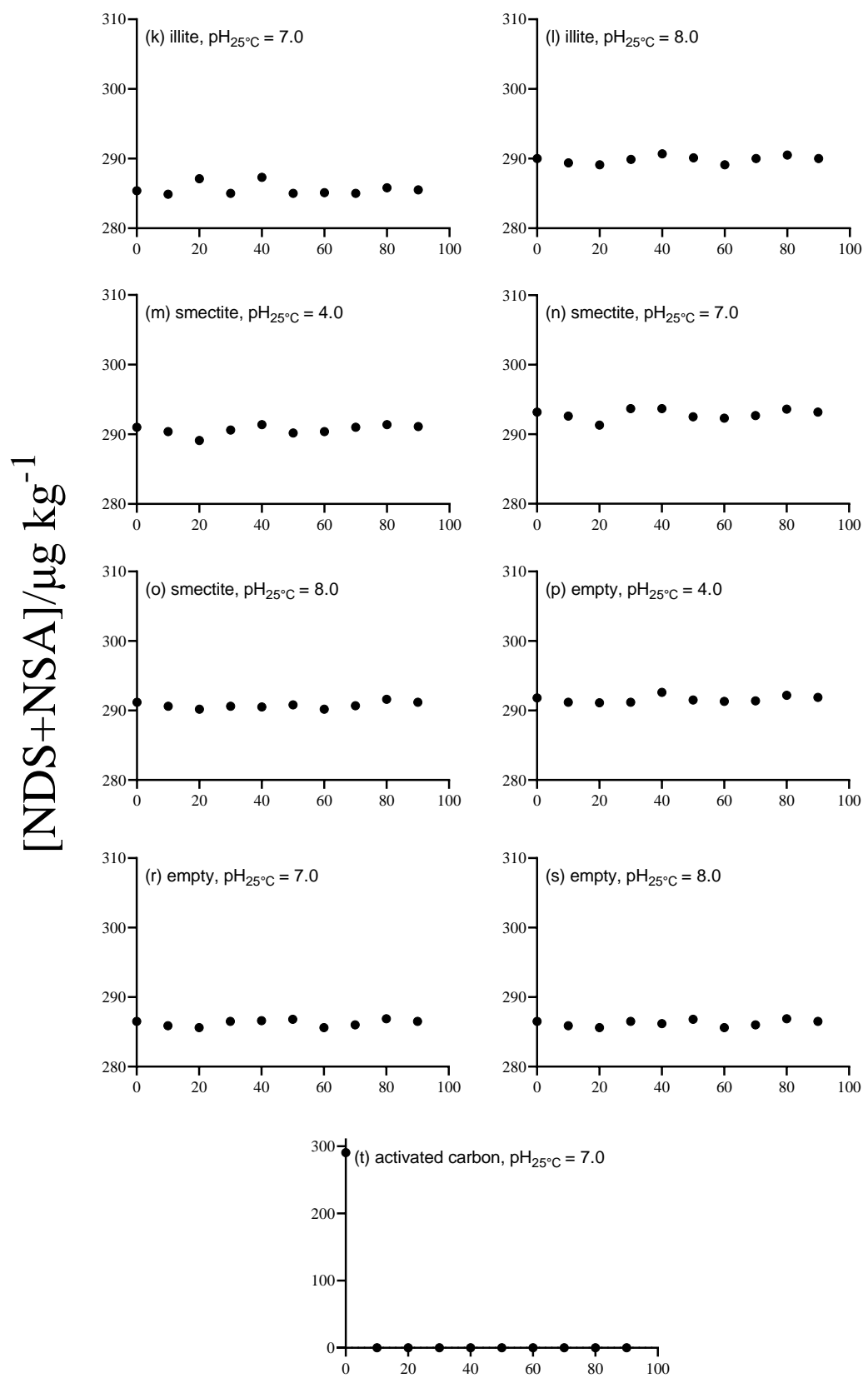

time/minute

Figure B.16b: Batch adsorption experimental results. Total concentration of naphthalene disulfonates and naphthalene sulfonates $\left(\mu \mathrm{g} \mathrm{kg}^{-1}\right)$ after time (minutes) in presence of different solid substrate. 